University of Louisville

ThinkIR: The University of Louisville's Institutional Repository

Electronic Theses and Dissertations

$5-2010$

\title{
Vincent van Gogh, a formal and psychological analysis of the final years at Arles, Saint-Remy and Auvers.
}

Sue Ann Grey 1943-

University of Louisville

Follow this and additional works at: https://ir.library.louisville.edu/etd

\section{Recommended Citation}

Grey, Sue Ann 1943-, "Vincent van Gogh, a formal and psychological analysis of the final years at Arles, Saint-Remy and Auvers." (2010). Electronic Theses and Dissertations. Paper 531.

https://doi.org/10.18297/etd/531

This Doctoral Dissertation is brought to you for free and open access by ThinkIR: The University of Louisville's Institutional Repository. It has been accepted for inclusion in Electronic Theses and Dissertations by an authorized administrator of ThinkIR: The University of Louisville's Institutional Repository. This title appears here courtesy of the author, who has retained all other copyrights. For more information, please contact thinkir@louisville.edu. 


\title{
VINCENT VAN GOGH, A FORMAL AND PSYCHOLOGICAL ANALYSIS OF THE FINAL YEARS AT ARLES, SAINT-REMY AND AUVERS
}

\author{
By \\ Sue Ann Grey \\ B.S., University of Maryland, 1965 \\ M.S., University of Maryland, 1972 \\ C.A.S., Johns Hopkins University, 1976 \\ E.F.M., University of the South, Sewanee \\ M.A., University of Louisville, 1993
}

\begin{abstract}
A Dissertation
Presented to the Faculty of the

Graduate School of the University of Louisville

in partial Fulfillment of the Requirements

for the Degree of
\end{abstract}

Doctor of Philosophy

Department of Art History
University of Louisville
Louisville, Kentucky

May 2010 
Copyright 2010 by Sue Ann Grey, ATR-BC, LPAT

All rights reserved 
Vincent van Gogh, A Formal and Psychological Analysis of the Final Years at Arles, Saint-Rémy and Auvers

\section{By}

Sue Ann Grey

B.S., University of Maryland, 1965

M.S., University of Maryland, 1972

C.A.S., Johns Hopkins University, 1976

E.F.M., University of the South, Sewanee

M.A., University of Louisville, 1993

A Dissertation Approved on

March 12, 2010

By the Following Reading Committee:

Dissertation Director 


\section{DEDICATION}

This dissertation is dedicated to my parents, William and Grace Grey, who taught me many life values, and who always expected nothing but my very best in every situation. They passed away while I was working on the dissertation and it grieves me that they were not able to be here to see this accomplishment. They would have been very proud.

This paper is dedicated to the first day of the rest of my life and to what the future holds:

to more time to concentrate on my own music and art,

to the achieving of greater simplicity, to the completion of an era of life, to the new beginning that lies before me, and to the wisdom to discern what is to fill that future. 


\section{ACKNOWLEDGMENTS}

The completion of any major project, such as this dissertation, depends upon the help and support of many people. There are so many people to whom I need to say, "I couldn't have done it without you. First of all, I thank my husband, Jack Edward Reece, for his constant patience, support, and encouragement through this long and difficult process, for the many times that he helped with computer applications and printing the text, with meals, laundry and various household tasks. I appreciate my daughter, Laura Lucia Grey-Reece Burkhead, for assisting me with the computer on many occasions, especially for help with formatting. Kudos to Kathy Krug for her superb editorial assistance and advice about the use of ellipses, comprehensive commas, and the like. Thanks to my friends Jean and Yolande Oostens-Wittimer for Sunday tea, friendship and support and Yolande’s advice to make it a topic close to my heart, a "Violon d' Ingres." I am indebted to the many friends and family who believe in me.

I appreciate my dissertation advisor Dr. Kloner so very much. He was always kind, patient, and helpful throughout this arduous ordeal, but he was also relentless in the pursuit of excellence, always pushing me to improve and make the text better. I am also grateful to the members of my dissertation committee for their assistance, Dr. Benjamin Hufbauer, Dr. Dario Covi, Dr. Sandra Graves, and Professor James Grubola. 
And lastly, and perhaps rather unexpectedly, thanks to Larry the Cable Guy for his unforgettable phrase, “Git ‘er done!” that became a rallying cry and a point of encouragement until finally "I got 'er did!” 


\section{ABSTRACT \\ Vincent van Gogh, A Formal and Psychological \\ Analysis of the Final Years at Arles, Saint-Remy and Auvers \\ Sue Ann Grey}

March 12, 2010

This dissertation is an intensive analysis of the artworks and letters of Vincent van Gogh focusing on the final three years of his life from February 1888 to July 1890 at Arles, Saint-Rémy, and Auvers. The author is both an art historian and an art therapist, so this is an interdisciplinary dissertation.

Chapter one, the introduction, provides the theoretical background for this paper, discussing the words and images of Vincent van Gogh, and setting forth the thesis statement: The thesis statement of this dissertation is that variations in the psychological state of Vincent van Gogh are discernable be psychoanalytical analysis of the words in his Letters in conjunction with observation of the way the formal elements of art are consciously manipulated by the artist in the service of artistic expression or unconsciously manipulated by the mental state of the artist.

Chapter two sets the stage for the remainder of the paper discussing the time from March 1886 to February 1888, when Vincent lived with his brother Theo in Paris. The purpose of chapter two is to show that although Vincent's personality was difficult and he 
had trouble getting along with people; this was prior to the onset of his major mental pathology. The art works from Paris provide a baseline for comparison to the artworks after his major pathology began. Chapters three through seven discuss Arles, Saint-Rémy, and Auvers.

Chapter eight reveals the expected tendencies of this pilot study in which the author has created a Formal Elements Rating Scale. The charts and graphs are in the appendix. Chapter nine sets forth the summary and conclusions. 
TABLE OF CONTENTS

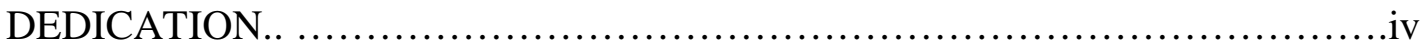

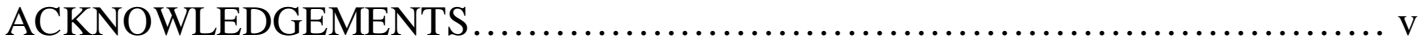

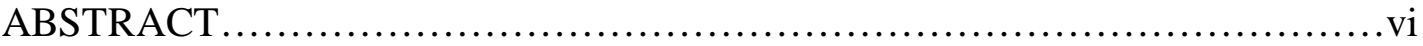

LIST OF FIGURES.

\section{CHAPTER}

I. INTRODUCTION: The Words and Images of Vincent van Gogh.....1

II. FROM PARIS TO ARLES, March1886 to February1888..............

Wheatfield with a Lark.

Lemons, Pears, Apples, Grapes and an Orange.

Portrait of Père Tanguy.

Selected Self-Portraits from the Intermediate Period in Paris

Self-Portrait, Paris, 1886

Self-Portrait, Paris, 1887

Self-Portrait, Paris, 1887 (in pale tones).

Self-Portrait with Gray Felt Hat, Paris, 1887.

Self-Portrait (in a straw hat)....

The Decision to Move to the South of France.

III. ARLES, PART ONE: VAN GOGH'S JAPAN, February 1888

to mid-July1888.

Snowy Landscape with Arles in the Background.

Thinking about Japan.

The Painter on the Road to Tarasçon.

An Association of Artists.

Flowering Trees and Possible Mania

Pink Peach Trees (Souvenir de Mauve).

The Langlois Bridge. ....

From Flowering Orchards to Irises.

View of Arles with Irises

Depression Tinged with Yellow Hope.

Discussion of Health Concerns....

Further Discussion of the Yellow House and Health Concerns.

Still-Life with Blue Enamel Coffeepot.

The Painter of the Future

Painting Portraits.

Existential Malaise.

The Issue of Paul Gauguin. 
Vincent's Visit to Saintes-Maries.

Fishing Boats on the Beach at Saintes-Maries-de-la-Mer.

Work Ethic.

A Return to Portraiture.

Portrait of a Zouave.

Further Discussion of Paul Gauguin.

Dissatisfactions....

More Existential Remarks

IV. ARLES, PART TWO: WAITING FOR GAUGUIN, Mid-July 1888 to October 20, 1888 .

Sheer Work and Concentration.

Money Trouble and Mistral.

The Stars Make Me Dream. ...

Working Headlong and Getting Older.

Financial, Physical, and Mental Concerns.

Winds of Change in the World of Art....

Advice about Self-care.

La Mousmé.

Loneliness and Longing for Companionship....

Existential Musings.

Portrait of Joseph Roulin.

Existential Concerns

A Self-Critique.

Portrait of Eugene Boch, also known as The Poet

The Importance of Creating.

Conscious and Subconscious Concerns

Financial Concerns and Matters of Health.

Discussion of Sexuality....

Concerns about Living Expenses.

Problems with Obtaining Models.

A Notable Madman or an Insignificant One...

Portrait of Patience Escalier.

The Sower (after Millet)....

A Response from Gauguin.

Sunflowers.

Still-Life: Vase with Sunflowers

Materials and Techniques.

Difficulties with Models.

Concerns, Annoyances, and Anger....

The Night Café. 
Decorating the Yellow House.

Studies and a Few Finished Pictures.

Concerns about Gauguin.

A Period of Intense Work

Existential Musings, Japan, and Work

Temperament, Companionship, and Love.

All Work and No Play....

Portrait of Milliet

Autumn Mania.

In Search of Eternal Truths.

Plans for Next Year's Painting.

Theological Thoughts and Religious Ideas. ...

Narcissism or Altruism.

Starry Night on the Rhône.

The Café Terrace at Night...

The Yellow House.

Religious Discussion

Visceral Artistic Creation.

A Possible Colony of Artists.

Preparing the House for Gauguin.

Looking Forward with Hope.

Precarious Status of Finances and Health.

Self-Portrait (as a Bonze).

A Sincerity of Expression though Rash and Clumsy....

Self-Portrait with Straw Hat and Pipe.

Financial Concerns.

My Work is Your Work.

A Lot of Expenses and a Lot of Work

The Tarasçon Diligence.

Van Gogh's Bedroom.

A New School of Colorists Built on Co-dependency.

Still Waiting for Gauguin....

V. ARLES, PART THREE, FROM COMPANIONSHIP TO

CONFINEMENT, October 20, 1888, to May 8,1888.

More Versions of The Sower.

The Sower (October 1888)

The Sower (November 1888)....

Self-Determined Goals and Deadlines.

L'Arlésienne.

An Exchange of Ideas Between van Gogh and Gauguin. 
Les Alyscamps.

The Red Vineyard.

Learning to Work from the Imagination.

The Two Chairs. ...

Van Gogh's Chair....

Gauguin's Chair.....

Terribly Electric Arguments.

The Incident of the Ear

Chronology of the Incident of the Ear.

Going Home to the Yellow House....

Minimizing His Difficulties.

Theo's Engagement and Vincent's Possible Eviction.

Returning to Health and Returning to Work.

Counting the Cost....

In the Asylum.

Self-Portrait with Bandaged Ear and Pipe.

Portrait of Dr. Félix Rey....

Matters of Conscience.

Vincent, a Doctor?

La Berceuse.

Staying in Arles and Starting Over.

Exemplary Couples

His Life Passed Before His Eyes.

Working to Make a Comforting Impression.

Concerns about His Future.

The Same, Yesterday, Today, and Always

Enthusiasm, Madness, or Prophecy....

Again Hospitalized.

Home Again, Home Again. .

Back in the Hospital. .

Not Fit to be at Liberty...

Not Properly Speaking a Madman....

A Visit from Signac.

Mental Anguish and Disastrous Reality....

A Certain Undercurrent of Vague Sadness

A Certain Malaise.

An Exchange of Letters with Paul Signac

An Urgent Request for Supplies.

A Turning Point....

Vincent Continued to Decompensate.

Escapist Ideas 
May Day, Mayday

Concerns about Expenses. ...

Considering Enlistment....

A Glimmer of Hope.

VI. SAINT-RÉMY, May 1889-May 1890

Periods of Crisis

An Intensity of Focus

Racing the Clock....

Flowers at Saint-Rémy

Irises (1889)

Working with a Calm and Steady Enthusiasm.

Irises (Amsterdam Still-Life)

Irises (Metropolitan Still-Life).

Roses.

Pink Roses in a Vase.

On the Verge of Recognition

The Prisoner's Round.

Cypresses and Olive Trees at Saint-Rémy....

Calm and Sensible Brushstrokes and Chaotic and Crazy Ones

The Starry Night.

Self-Portraits at Saint-Rémy....

Self-Portrait (Saint-Rémy \# 1)

Self-Portrait (Saint-Rémy \# 2)

Self-Portrait (Saint-Rémy \# 3)

Self-Portrait (Saint-Rémy \# 4)

VII. PARIS AND AUVERS, May 21-July 29, 1890

Leaving Saint-Rémy and Visiting Paris.

Going to Auvers.

The First Two Drawings from Auvers

Paintings of Two Country Houses in Auvers

The Church at Auvers.

Dr. Gachet.

Portrait of Dr. Gachet

Suffering and Illness.

A Visit from Theo, Jo, and the Baby

A Still-Life from Auvers

L'Arlesienne.

Dissociation.

Combinations and Permutations. 
Portrait of Marguerite Gachet

Wheatfields as a Pendant to the Portrait of Marguerite Gachet............ Bank of the Ôise at Auvers.

Practicalities

Wheatfield Under Clouded Sky and Crows Over the Wheatfield... Crows Over the Wheatfield.

The Calm before the Storm.....

VIII. FORMAL ELEMENTS IN THE ART OF VINCENT VAN GOGH.... IX. SUMMARY AND CONCLUSIONS.

BIBLIOGRAPHY

APPENDICES

CURRICULUM VITAE 


\section{LIST OF FIGURES \\ ARTWORKS BY VINCENT VAN GOGH}

\section{FIGURE}

\section{PAGE}

1. Wheatfield with a Lark, 1887. 27

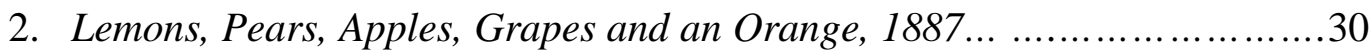

3. Portrait of Pere Tanguy, 1887-88......................................... 33

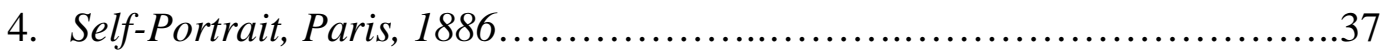

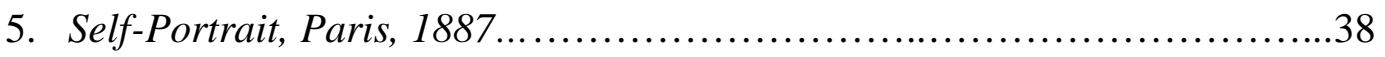

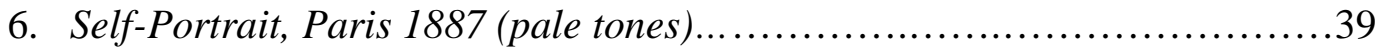

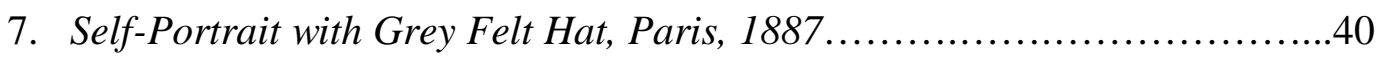

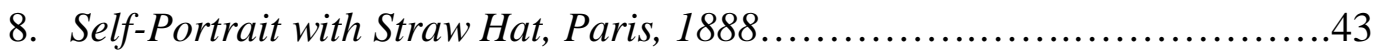

9. Snowy Landscape with Arles in the Background............................47

10. The Painter on the Road to Tarascon.....................................50

11. Pink Peach Trees (Souvenir de Mauve)...................................56

12. The Langlois Bridge .............................................58

13. View of Arles with Irises.............................................60

14. Still-Life with Blue Enamel Coffeepot..................................68

15. Fishing Boats on the Beach at Saintes-Maries-de-la-Mer..................76

16. Portrait of a Zouave................................................79

17. La Mousmé...........................................................96 


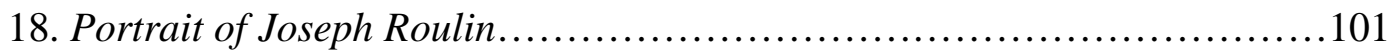

19. Portrait of Eugene Boch, also known as The Poet..........................108

20. Portrait of Patience Escalier..........................................115

21. The Sower (after Millet) .................................................. 118

22. Still-Life: Vase with Sunflowers.......................................122

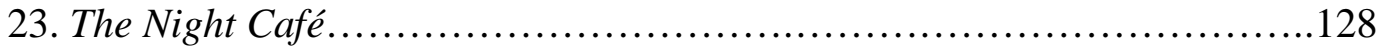

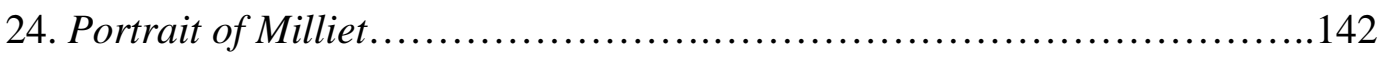

25. Starry Night on the Rhône.............................................148

26. The Café Terrace at Night.............................................150

27. The Yellow House ......................................................153

28. Self-Portrait (as a Bonze) .............................................162

29. Self-Portrait with Straw Hat and Pipe....................................166

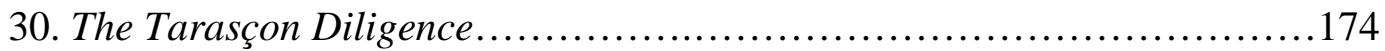

31. Van Gogh's Bedroom..............................................176

32. The Sower (October 1888) ...........................................182

33. The Sower (November 1888)........................................183

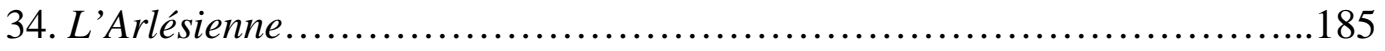

35. Les Alyscamps...................................................... 189

36. The Red Vineyard...................................................190

37. Van Gogh's Chair...................................................195

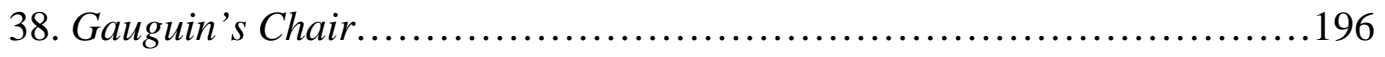

39. Self-Portrait with Bandaged Ear and Pipe..............................206

40. Portrait of Dr. Félix Rey.............................................208 


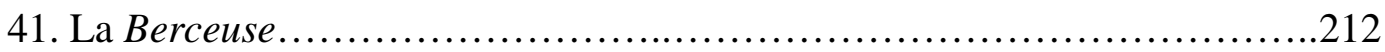

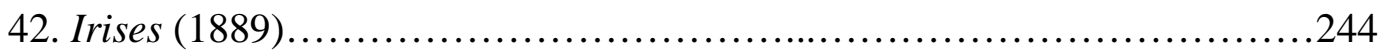

43. Irises (Amsterdam Still-Life) .....................................246

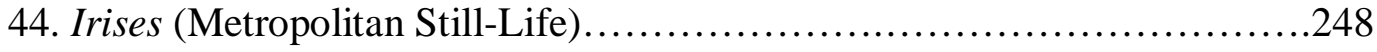

45. Pink Roses in a Vase..............................................251

46. The Prisoner's Round..............................................255

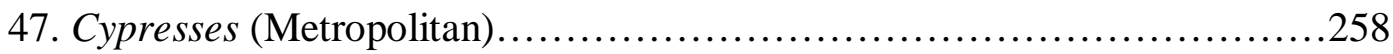

48.The Starry Night..................................................268

49. Self-Portrait (Saint-Rémy \# 1) ....................................273

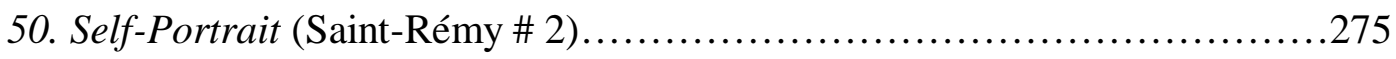

51. Self-Portrait (Saint-Rémy \# 3).......................................278

52. Self-Portrait (Saint-Rémy \# 4).....................................280

53. Cottages with Thatched Roofs.......................................287

54. Old Vineyard with Peasant Woman.......................................288

55. The House of Père Pilon.............................................290

56. Village Street and Stairs with Figures............................... 292

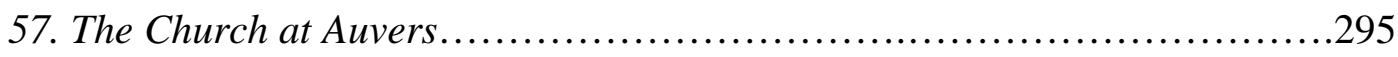

58. Portrait of Dr. Gachet............................................ 300

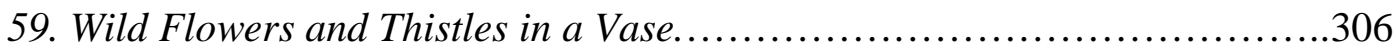

60. Marguerite Gachet at the Piano....................................... 310

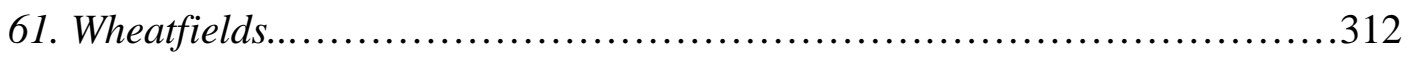

62. Bank of the Ôise at Auvers........................................... 313

63. Wheatfield Under Clouded Sky.......................................317 


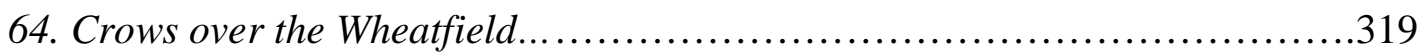




\section{CHAPTER I}

\section{INTRODUCTION}

\section{The Words and Images of Vincent van Gogh}

Words and images form our perceptions of the world around us. Words and images are a conjoined pair of opposites, like day and night or male and female. The concept that reality is made up of pairs of opposites that complete and fulfill each other is the worldview that was proposed by psychologist Carl Jung, and it is the theoretical framework for this dissertation. Not only in his art and words, but also within the personality of Vincent van Gogh, the union of opposites is apparent, and that has led this author to the conclusion that Vincent van Gogh suffered from what today would be diagnosed as Bipolar Disorder exacerbated by Borderline Personality Disorder. The thesis statement of this dissertation is that variations in the psychological state of Vincent van Gogh are discernible by psychoanalytical analysis of the words of his Letters, in conjunction with observation of the way the formal elements of art are consciously manipulated by the artist in the service of artistic expression or even unconsciously manipulated by the mental state of the artist.

There are several categories of Bipolar Disorder, but the primary feature is a recurrent cyclical pattern of mood that changes in polarity from depression to mania. The diagnostic criteria for Bipolar Disorder specify that the mood symptoms cause clinically significant distress or impairment in social, occupational, or other areas of functioning (Reid and Wise, 1995, 165). It is also specified that the mood symptoms are not better 
as a drug of abuse or a medication, and are not due to a general medical condition (ibid.). While Vincent did have substance abuse issues and several medical problems, this author asserts that a mental health diagnosis better explains his symptoms.

Turco (1998, 158-159), an author who is also a psychiatrist, has identified a cyclical pattern of crises around the time of Christmas in the life of Vincent van Gogh as follows:

Christmas 1874 - Van Gogh was extremely despondent regarding Ursula’s rejection; Christmas 1875 - Van Gogh left Goupil’s to go home, without notice, at the busiest time; Christmas 1876 - Van Gogh's father called him back from England where he failed to hold down two jobs;

Christmas 1877 - Van Gogh was a theological student in Amsterdam and was miserable; Christmas 1878 - Van Gogh was a struggling evangelist in the Borinage; Christmas 1879 - Van Gogh was a vagabond, estranged from his family; Christmas 1880 - Van Gogh was an art student in Brussels and ignored the holiday; Christmas 1881 - Van Gogh left his Etten home on Christmas day after a violent quarrel with his father;

Christmas 1882 - Van Gogh was in the Hague with a prostitute and he had just quarreled with his friend Mauve;

Christmas 1883 - Van Gogh returned to his parent's home at Neunen, fearing that he was having a nervous breakdown;

Christmas 1884 - Van Gogh spent the day with his parents in Neunen and commented, "I was never more gloomy;"

Christmas 1885 - Van Gogh wandered around the outskirts of Antwerp in despair and considered returning to the Borinage; 
Christmas 1886 - not recorded;

Christmas 1887 - Van Gogh had a crisis, confusion and a psychotic episode at SaintRémy;

Christmas 1888 - Van Gogh was at Arles, and cut off part of his ear;

Christmas 1889 - Van Gogh was at Saint-Rémy; He anticipated and experienced his longest attack.

Based on this strongly cyclical pattern, Turco asserts the diagnosis of Bipolar Disorder.

Vincent had a difficult personality that fits the diagnostic criteria for Borderline Personality Disorder which are a pervasive pattern of instability of interpersonal relationships, self-image, and affect, and marked impulsivity beginning by early adulthood and present in a variety of contexts, as indicated by five or more of the following diagnostic criteria:

(1) frantic efforts to avoid real or imagined abandonment

(2) a pattern of unstable and intense interpersonal relationships characterized by alternating between extremes of idealization and devaluation

(3) identity disturbance: markedly and persistently unstable self-image or sense of self

(4) impulsivity in at least two areas that are potentially self-damaging (e.g., spending, sex, substance abuse, reckless driving, binge eating)

(5) recurrent suicidal behavior, gestures, or threats, or self-mutilating behavior

(6) affective instability due to a marked reactivity of mood (e.g., intense episodic dysphoria, irritability, or anxiety) usually lasting a few hours and only rarely more than a few days 
(7) chronic feelings of emptiness

(8) inappropriate, intense anger or difficulty controlling anger (e.g., frequent displays of temper, constant anger, recurrent physical fights)

(9) transient, stress-related paranoid ideation or severe dissociative symptoms (ibid., 287-288).

Throughout this dissertation, this author will identify bipolar and borderline characteristics as expressed in the lifestyle, letters and art of Vincent van Gogh. This theoretical mindset will be supported by the analysis of his words as written in his letters and by the observation and discussion of the changes in the formal elements of art in the artwork of Vincent van Gogh during the last three years of his life. Support for this author's viewpoint will be given with examples from a wide variety of disciplines including art history, art therapy, psychology, physics, and theology. In addition to degrees in art history and art therapy, I have completed a four year-certificate program in theology from the University of the South - Sewanee.

This interdisciplinary dissertation combines art history and art therapy in an intensive psychological and psychoanalytical analysis of the words and images of the artist Vincent van Gogh from the last three years of his life with the focus on primary sources. The three-volume set of The Complete Letters of Vincent van Gogh has been used throughout this dissertation, and the abbreviation LT with a number refers to a letter in one of those volumes. In the artwork the attention has been placed on paintings. Vincent van Gogh was a prolific author of both words and images. His words have been preserved in his The Complete Letters of Vincent van Gogh, which is described as one of the world's greatest pieces of confessional literature (Leon, 2000). The letters of 
Vincent van Gogh in conjunction with his art work provide a unique opportunity to study the words and images of a single artist. Vincent's letters and art constitute a framework of primary sources that can be used for a psychological analysis of the juxtaposition of visual and verbal. I believe that image and word are co-equal opposites that are complementary to each other and that truth is found in the mutual and combined interpretation of word and image with each informing the other. I further believe that the formal elements of art are the constants in artistic expression.

The methodology of this author has been to carefully glean the letters of Vincent van Gogh from the last three years of his life in order to discern the psychiatrically relevant passages. The written words of Vincent van Gogh, in lieu of the words spoken in therapy by a patient, have been studied in conjunction with the artwork. The author is a practicing and board certified professional art psychotherapist and a certified hypnotherapist, thus qualified to draw these conclusions.

Vincent van Gogh’s time in Paris, from March 1886 to February 1888, is included in this dissertation in order to provide baseline data from a time when his mental pathology is in a premorbid state. It is expected that as Vincent van Gogh becomes more emotionally and psychiatrically unstable there will be more extreme variations in the expression of the formal elements in his artwork, i.e. things will swing more wildly out of control.

This author sees word and image as a binary pair of conjoined opposites that complement and balance each other. Within the artwork of Vincent van Gogh the union of opposites abounds, as in the complementary color schemes that he so often chose and in conjunctions of opposite images such as the sower and the reaper. As Sarup (1993, 
44) points out, structure always presumes a center. Throughout this paper conjoined opposites and the concepts of the center and balance will consistently be pointed out.

The idea of the center and balance is herein interpreted as the force that causes the formal elements to cohere in the artwork of Vincent van Gogh. Colin Wilson, writing in From Atlantis to the Sphinx: Recovering the Lost Wisdom of the Ancient World (1999, 327), said that two forces ... may remain forever in equilibrium if nothing alters the balance. Wilson discussed The Law of Three, an idea from the Sankhya philosophy of India, which states that all creation involves a ‘third force’ (1999, 312). The third force creates the push that acts upon the counterpoised dualities in order for the deadlock to be broken so that change can happen. This author will observe mental instability as the third force in the life work of the artist Vincent van Gogh.

This author has produced a Formal Elements Rating Scale (FERS) as a tool to demonstrate conjoined opposites in the artwork of Vincent van Gogh and to show the importance of the center and of balance. In this Formal Elements Rating Scale a score of 3 represents the balanced center position on a Likert scale arranged from 1 to 5 . The elements on the scale are ordered on a continuum from less (1) to more (5) or from reductive (1) to complex (5). The scoring does not imply that a five is better than a one, or vice-versa. The FERS is a tool used to spread formal elements on a continuum. A blank copy of the Formal Elements Rating Scale is included as Appendix 1.

A Formal Elements Guide was created with statements ranking from one to five for each quality to be analyzed. A copy of the Formal Elements Guide is included as Appendix 2. When assigning rankings to the various formal elements and principles of design, the viewer needs to refer to the Formal Elements Guide. Expected tendencies 
were proposed to go with the Formal Elements Rating Scale. The expected tendencies for the Formal Elements Rating Scale are found in Appendix 3. The Formal Elements Rating Scales scored by the author comprise Appendix 4.

The idea of a Formal Elements Rating Scale (FERS) was derived from the Formal Elements Art Therapy Scale (FEATS) created by art therapy researchers Linda Gantt and Carmello Tabone (1998). The purpose of the FEATS was to study whether certain formal elements of art can be tied to specific psychological manifestations and therefore be used for diagnostic purposes. The FEATS is always used to analyze a particular subject, a drawing called the PPAT ("Draw a Person Picking an Apple from a Tree"). The persons who are asked to draw the PPAT are often psychiatric patients and are usually not professional artists. At the time of this writing the FEATS is an ongoing research study. The FEATS and this author's formal elements analysis will be discussed more fully in chapter 8.

Erle Loran (1947) searched for an understanding of the few basic principles that can be regarded as constants in the entire history of pictorial creation regardless of era or style. The visual elements and principles of design provide the foundation for all graphic art expression, and thus are treated as constants in the discussion of formal elements by the author of this dissertation. Each of the constants is positioned with a center point and a continuum on which they can be thought of in a binary way. The concept of the third force, the mental instability of Vincent van Gogh, will be considered throughout this dissertation and discussed in the summary and conclusions.

In order to analyze the art of Vincent van Gogh, the formal elements to be included had to be identified. This researcher first selected a working list of the visual 
elements and principles of design from Living with Art by Rita Gilbert (1995). The visual elements as defined by Gilbert are Line; Shape and Mass; Light, Value, and Color; Texture; Space; and Time and Motion. The principles of design as defined by Gilbert are Unity and Variety; Balance; Emphasis and Focal Point; Proportion and Scale; and Rhythm. Then this author revised the selected formal elements in order to make them more relevant to this particular research project (see Appendix 1). For example, the concepts of Line Quality and Freedom of Expression are interpreted in accordance with the concepts of art historian Heinreich Wölfflin, who described linear style as having outline play a central part, and that the components of the composition are well defined in themselves with sharp boundaries an essential constitutive element (Barasch, 1990).

The concept of centric and eccentric was added to the list of formal elements after consultation of the book by Rudolph Arnheim, The Power of the Center (1988). Centric and eccentric have to do with whether the design is primarily based on a circular pattern with internal vectors that radiate outward, or on a grid design (square or rectangular) and responding to external vectors. It is expected that the qualities of centric and eccentric may relate to internal or external locus of control. In discussing these formal elements, the centrist position is considered to be a circle and a grid pattern, a combination of both, a squaring of the circle. According to Jung, the circle is a symbol of the psyche, while the square (and often the rectangle) is a symbol of earthbound matter, of the body and reality (Jung, 1964). In most modern art, the connection between these two primary forms is either nonexistent, or loose and casual, and this separation is another symbolic expression of the psychic state of twentieth- 
century man, that his soul has lost its roots and he is threatened by dissociation (Jung, 1964). Nevertheless the forms of the circle and square occur frequently in art, and Jung interpreted this as an uninterrupted psychic urge to bring into consciousness the basic factors of life that they symbolize.

The circle form (or sphere) has occurred consistently in art since the earliest images were drawn. The circle has been explained in various ways, as a symbol of the self, of the totality of the psyche in all of its aspects, and of wholeness. Circles may take many forms, such as the lotus of creation in the stories of both Brahma and Buddha, the rose windows in medieval cathedrals, mandalas, and the ground plans of cities or buildings, to name just a few. The squaring of the circle is a mystery in that it is considered to be mathematically insoluble. One of the symbols created about A.D. 1000 by alchemists was a true mandala, the quadratura circuli (the squaring of the circle), whereby they sought to express a wholeness of man encompassing matter and spirit (Jung, 1964). Until Carolingian times, the equilateral or Greek cross was the usual form of the Christian cross and thus the mandala was implied. During medieval times, the center of the cross became raised; symbolic of elevation into the spiritual sphere, and the result was the Latin cross with stake and crossbeam (Jung, 1964).

Word and image are a conjoined pair of opposites like male and female, and they need to be kept in balance. But which came first, the visual or the verbal? John Berger (1977) reported that seeing comes before words. But Kristeva (1987) takes this dialogue back even further, to the primeval ground of being; to the ancient, mobile, unstable receptacle prior to the One (God); and she discusses prelinguistic and infralinguistic emotional traces, the semiotic, as prior even to language and images. 
Are word and image in conflict or in harmony with one another? Leonard Schlain (1998) wrote about the conflict between word and image, and like Berger, Schlain asserted the primacy of the image. The Greek philosopher, Sophocles said that nothing vast enters the life of mortals without a curse. Another way of saying this is that within each solution lie the seeds of the next problem. The invention of writing was a quantum leap of progress, but with the blessing that it brought there may also be a curse. Schlain hypothesized that when a critical mass of people within a society acquire literacy, especially alphabet literacy, left hemispheric modes of thought are reinforced at the expense of right hemispheric ones, and this manifests as a decline in the status of images, women's rights, and goddess worship.

Schlain proposed that a holistic, simultaneous, synthetic, and concrete view of the world are the essential characteristics of a feminine outlook; and that linear, sequential, reductionist, and abstract thinking define the masculine. Even though these qualities represent opposite perceptual modes, every individual is generously endowed with all the features of both. The semantics of this are difficult because on the surface of it, concrete thinking patterns would seem to go along with the masculine qualities of linear, sequential, and reductionist. Even though images are changeable and have the ability to morph and change both appearance and meaning, Schlain is considering an image to be a concrete manifestation of the mind, similar to a "freeze frame" picture. The capacity for abstract thought, on the other hand, allows language to be understood without recourse to the use of images, and thus is considered to cohere with the masculine qualities of linear, sequential, and reductionist. 
The work of Jacques Lacan, The Language of the Self: The Function of Language in Psychoanalysis, parallels the ideas of Schlain. A follower of Sigmund Freud, Lacan (1968) referred to the unconscious as a language, the discourse of the other. Lacan's view was that if the unconscious exists, as Freud described it, it functions linguistically. The Lacanian view of psychoanalysis is that it is a talking cure based upon the spoken truth of the client and that the truth (the logos of the individual) emerges in language. The problem with this is that people can be very deceptive with words, even deceiving themselves, and people are typically less skilled with art, thus in their images a truer look at unconscious and subconscious process is provided. According to Sarup, $(1993,123)$ Kristeva believes that Lacan concentrates too heavily or exclusively on verbal language at the expense of other models of signification. This author finds herself in agreement with Kristeva, and as an art therapist is dedicated to the truth as presented not only by words, but also by images and feelings. The works of Julia Kristeva are a touchstone to which this author returns again and again.

Speech and language are abstract and depend upon the left brain's ability to process information without the use of images (Schlain, 1998). The mind arranges words as image substitutes in much the same way that children assemble building blocks, thus creating thoughts that allow us to ponder abstract concepts without conjuring images for these words (Schlain, 1998).

But what of the right brain and images? There is an equally valid and perhaps more primitive way of communicating that is not based upon the language of words, instead it is built upon pictures and images. Some language systems, such as early Egyptian, were pictographic as well as ideographic. Dreams and art usually 
communicate more by way of images than by words. In dreaming Freud identified three functions, condensation, displacement, and the transformation of thoughts into visual images (Freud, 1953). Condensation happens when in the dream state the connections between two or more sets of impressions are worked out and combined together using primary psychic process. Displacement is the psychological method of transferring meanings, symbols, and psychical intensity to various other elements in a dream. Dream-condensation and dream-displacement are factors that determine the form assumed by dreams. In Freud's Interpretation of Dreams, first published in 1900, he called dreams the royal road to the unconscious. It has been said that a picture is worth a thousand words. Communication by images, whether in dreams, art or other forms of images, is not primarily intellectual, but is intuitive and may be contemplative and mystical.

Jean Piaget believed that symbols represent mental images of things that may be absent or present, and they may range from known to unknown (Piaget, 1962). When the image is of an unknown or not fully realized expression, it is the best approximation available to the psyche at that time to represent the unknown aspect (Lusebrink, 1990). Freud (1953) said that a symbol could be an object, image, or act representing in disguised form a latent thought or a repressed desire of which the individual is unconscious. According to Jung, a true symbol represents and expresses an intuitive idea or it has a meaning that cannot yet be expressed in any other or better way. The meaning of a symbol may be much deeper and more profound than the visual image alone. Deciphering meaning in words and art is a difficult task that is shared by many persons from art historians to art therapists and even by casual observers of art. The task 
of the observer is to unravel the meaning of the symbols presented not only in words but also in art. Both the words and the images function as chora, that is to say they function as receptacles for meaning which may be expressed as semiotic or symbolic (Kristeva, 1980). Semiotic is primitive, pre-Oedipal mental content and may be chaotic like the subconscious or the personal unconscious, while the symbolic is more organized and understandable in an orderly way using archetypes and the collective unconscious. Modern day psychotherapy stands on the shoulders of the work of Sigmund Freud. Carl Jung, a student of Freud, broke with Freud over the importance of mental imagery. Freud posited the personal unconscious, while Jung enlarged the concept to include the collective unconscious and archetypes. Lacan took the concepts of Freud and expanded them with careful analysis of the role of language in psychotherapy and consideration of the Symbolic, the Imaginary, and the Real (Lacan, 1968). In Lacan's discussion of the Symbolic and the Imaginary, he is referring to word only, and does not mention art and images. Lacan was always concerned with the status of human discourse in analysis. Lacan broke with the American-style psychoanalysis over behavioralism, feeling that it was unfaithful to the psychoanalysis inspired by Freud (Lacan, 1968). In speaking of the Empty Word and the Full Word, Lacan said, "Whether it sees itself as an instrument of healing, of formation, or of exploration in depth, psychoanalysis has only a single intermediary: the patient's word” (Lacan, 1968, 9). The difficulty with this statement from Lacan is that no credence is given to the importance of the image, and it is my contention that image is as important as word. Indeed, image forms another way of expression for the psychotherapy patient. This 
author would like to assert that image is more important than word, but that would violate the principle of balance and maintaining the position of the center.

Reality may be understood in a binary way by seeing complementary pairs of opposites as bound together, balancing and completing each other. This method of comprehending reality resembles the ancient Taoist circle symbol of integration and symmetry, the Yin-Yang. Kristeva (1987) discusses the Taoist triad as yang, space between, and yin. The work of Jung was based on an understanding of the I Ching, the so-called "Book of Changes" which is held in common in the two main branches of Chinese philosophy - Taoism and Confucianism (Jung, 1964). The I Ching put forward the hypothesis of the oneness of man and the surrounding cosmos, and of the complementary pairs of opposites Yin and Yang (Jung, 1964). Jung posited the concepts that there is both a personal unconscious and the greater collective unconscious and that the world is a unity composed of the interlocked and balanced pairs of opposites, light and dark, day and night, summer and winter, word and image, semiotic and symbolic, and so forth. Each concept is made complete in union with its opposite or the shadow of its opposite. The unfolding of creation is the process of a continuous struggle between opposite poles: light and dark, give and take, up and down, right and left, life and death (Cooper, 1997). A theological way of expressing this same truth is found in the saying, "as above, so below;" this is another way of asserting the correspondences of opposites with the understanding that this world is a reflection of, and is in symbiotic relationship with, other realms of reality (Cooper, 1997, 36). There is a belief that everything we do stirs up a corresponding energy in other realms of reality (Cooper, 1997). Modern physics expresses this reality in "chaos theory," and the 
butterfly effect. The universe unfolds from moment to moment as a function of all the variables leading up to that moment, and all things are interdependent; what we do, say, and even think affects every other thing (Cooper, 1997). This view, like the Jungian conception of the world, is based on the complementarity of opposites and maintaining balance is of the utmost importance.

Balance, the concept of the center, and an axis about which all else revolves, is inherent in the Jungian world view and is expressed perhaps best of all in W. B. Yeats' poem The Second Coming :

Turning and turning in the widening gyre

The falcon cannot hear the falconer;

Things fall apart; the centre [italics added] cannot hold;

Mere anarchy is loosed upon the world,

The blood-dimmed tide is loosed, and everywhere

The ceremony of innocence is drowned;

The best lack all conviction, while the worst

Are full of passionate intensity.

Surely some revelation is at hand;

Surely the Second Coming is at hand.

The Second Coming! Hardly are those words out

When a vast image out of Spiritus Mundi

Troubles my sight: somewhere in the sands of the desert

A shape with lion body and the head of a man,

A gaze blank and pitiless as the sun,

Is moving its slow thighs, while all about it

Reel shadows of the indignant desert birds.

The darkness drops again; but now I know

That twenty centuries of stony sleep

Were vexed to nightmare by a rocking cradle, And what rough beast, its hour come round at last, Slouches towards Bethlehem to be born.

$$
\text { W. B. Yeats }
$$

The poem The Second Coming by William Butler Yeats opens with a concrete statement about a falcon flying in increasing circles or spirals (gyres) and proceeds to more abstract language prophesying the falcon as a harbinger of a revelation, of a 
Second Coming. But this Second Coming suggests a man-made monster and evil rather than good and the orthodox belief of the Second Coming of Christ. One interpretation might be that Christianity has failed to sustain mankind and that an ominous larger principle is about to replace it (Bloom, 1954). The Sphinx, a shape with lion body and the face of a man, could be construed to represent paganism which was kept in check by the birth of Christ, but which never really died. Bloom explained that as soon as Christianity breaks down, permitting mere anarchy to be loosed upon the world, there can be no restraining of this monstrous symbol of seeming evil, since evil can be subjugated only by good. This author proposes another possible interpretation: that after mankind achieved verbal literacy expressed in the ability to write, image (pre-verbal) has historically been subjugated to word (verbal). The very language of Christianity is of the Word (the Logos). Indeed, in the words of many languages and cultures of various times and places, God has been revealed. The Gospel of John says, "In the beginning was the Word, and the Word was with God and the Word was God.” Kristeva (1987) both quoted and paraphrased the previous phrase with the quote from 1 John 4:8, "God is love," and named her book In the Beginning was Love. Really, in the beginning, before the Word, there were emotional traces (affects and feelings), the preverbal, and images. For centuries, perhaps millennia, word and image have warred with each other and at times found an uneasy truce. Word and image need each other, and each completes the other. Word and image need to be kept in balance, as equals bound together in unity like the Yin-Yang. At this time in history, the union of the opposites, word and image are being united by way of computer technology and the world is truly being changed thereby. 
The focus maintained throughout this study has been on primary sources, most importantly the paintings of Vincent van Gogh and his words in the The Complete Letters of Vincent van Gogh. A great many of the articles and books perused are not referred to in this dissertation. "Why read commentaries written on commentaries, maps re-drawn from the original? Find the mystery in the original! Read between the lines, and you will be surprised at what you will find” (Hays, 1986, 42). References that were directly relevant to the position of the author and the points that were being made are quoted herein. As Vincent van Gogh said in LT 556, "I have nevertheless pushed what I was working on as far as I could in my great desire to be able to show him something new, and not to be subjected to his influence (for he will certainly influence me, I hope) ... I can indubitably show him my own individuality.” Vincent was, of course, speaking of Gauguin. It has been the sincere effort of this author to present something new and original in this dissertation by studying the conjoined opposites of word and image and the concept of the center in the literary and artistic works of Vincent van Gogh.

In this study at hand, it is now time to turn our attention to the words and images of Vincent van Gogh during his time in Paris from March 1886 to February 1888. 


\section{CHAPTER II \\ FROM PARIS TO ARLES}

March 1886 - February 1888

Vincent van Gogh arrived quite unexpectedly in Paris from Antwerp in March of 1886 and from the station sent a hastily scribbled note to his brother Theo van Gogh. This is an example of the impulsivity that shows up again and again in the personality of Vincent van Gogh, and may also indicate an attempt to avoid abandonment in his reaching out to Theo. Both impulsivity and attempts to avoid abandonment are features of Borderline personality disorder, and there seems to be quite a bit of co-dependency in the relationship between Vincent and his brother Theo, with Theo being the enabler. True to form, his brother took Vincent in even though Theo had wanted him to wait until June when a larger apartment could be acquired in order to better accommodate the necessary living conditions. Vincent stayed with Theo in his apartment at the Rue de Laval and in June moved with him to the Montmartre section of Paris at 54 Rue Lepic.

Insight into the situation of the van Gogh brothers in Paris is provided by some excerpts from letters written between March 1886 and February 1887 by Andreas Bongers to his parents in Amsterdam. Bongers would become Vincent and Theo’s brother-in-law when Jo and Theo got married. Bongers pointed out certain personality traits, stating that Vincent was accusatory and blaming. Bongers said that Vincent was making life rather a burden to Theo, and reproaching him with all kinds of things of 
which he was quite innocent. And in an even more pointed way Bongers remarked, "It now appears that Theo's brother has come to stay. ... I think I told you last summer what a queer life this brother has led. This man hasn't the slightest notion of social conditions. He is always quarreling with everybody. Consequently Theo has a lot of trouble getting along with him” (Complete Letters, v.2, 523-524). In spite of this, by August 27, 1886, Bongers had decided to have his dinners at van Gogh's and stated that he appreciated the refinement of Theo's mind and that his company was always entertaining, "We always have subjects enough to discuss, the three of us." The comments in Bonger's letter indicate anger, affective instability and interpersonal difficulties that support my viewpoint that Vincent may already have had Borderline personality disorder. Kernberg $(1985,3)$ prefers the terminology borderline personality organization because he believes that the personality structure of these patients occupy a borderline area between neurosis and psychosis. Kernberg (ibid.) believes that they have a specific and stable personality organization, but that it is pathological, and that it is permanent, not a transitory state fluctuating between neurosis and psychosis. During his time in Paris, Vincent van Gogh was reasonably stable, and the more serious psychiatric incidents that required hospitalization had not yet begun.

At this time there is a shift in the use of the formal element of color. Vincent began to use brighter colors and he started to mention his happy desire to move to the South of France. In LT 459a, of uncertain dating, written to an English painter named Levens, he stated, "In spring - say February or even sooner I may be going to the South of France, the land of blue tones and gay colors.” In this same letter he discussed his painterly ideas about color by describing an energy that he felt in "a sincere personal 
feeling of color in nature," and said that lacking money for models, he had "made a series of color studies in painting, simply flowers, red poppies, blue cornflowers and myosotys, white and rose roses, yellow chrysanthemums- seeking oppositions of blue with orange, red and green, yellow and violet seeking les tons rompus et neutres to harmonize brutal extremes, trying to render intense colour and not a grey harmony.” This attempt to harmonize brutal extremes (through conjoined opposites in color) could be a visual expression of the Bipolar union of opposites and it could also indicate a tendency toward psychosis since the use of dramatic oppositions of color is a characteristic in the artwork of bipolar and schizophrenic patients.

The application of complementary color schemes in Vincent van Gogh’s oeuvre was a coloristic theme that emerged and re-emerged. It was as if he strived intuitively in his painting to express through color harmonies and symbolic means the conjoined pairs of opposites that compose life. This concept would not be clearly written until the early 1900's in the work of psychologist Carl Jung, although symbolically it had been expressed in the ancient symbol for balance, the Yin-Yang. The way that Carl Jung expressed this was, "Nothing can exist without its opposite; the two were one in the beginning and will be one again in the end. How else could it have occurred to man to divide the cosmos, on the analogy of day and night, summer and winter, into a bright day-world and a dark night-world peopled with fabulous monsters, unless he had the prototype of such a division in himself, in the polarity between the conscious and knowable and the invisible and unknowable unconscious?” (Jung, 1970)

The Kristevan concept of the semiotic, specifically the term chora, is related to and borrowed from the ideas of Plato, and it means the mother and receptacle of all 
things (Kristeva, 1980, 6-7). Kristeva's chora is a concept similar to Freud's

unconscious. Carl Jung’s theories took these ideas another step forward positing the collective unconscious with order and symbolic structures coming out of it. The chora is chthonic, the ground of all being, the swirling miasma of formless and unformed out of which the symbolic may emerge.

Opposing qualities are evident in Jung's discussion of the mother archetype, the Great Mother, containing both positive and negative aspects, capable of being both creator and destroyer. The feminine archetype is often associated with things and places standing for fertility and fruitfulness, such as plowed fields, gardens, rocks, caves, trees, springs, and vessel-shaped flowers such as roses (Jung, 1970). These kinds of images became more frequent in the artwork of Vincent van Gogh in Arles, Saint-Rémy and Auvers. The relationship of Vincent van Gogh with his own mother seems to have been lacking in warm affection. He described it as being stunted like a tender plant growing up in a chilly draft. The many images that subjectively represent the feminine may have come subconsciously from his longing for relationship with otherness, beginning with his mother and continuing in his unfortunate experiences with love.

There had been a series of disappointments and a pattern of poor judgments in his desired love relationships. Vincent seemed uniquely unaware of how others perceived and responded to him. He seemed to only note his own self-absorbed actions and reactions. Vincent's first rejection had been in 1873 when he was in England and he declared his love for Ursula Loyer, the daughter of his landlady. Ursula said that she was already secretly engaged. Bonafoux $(1992,19)$ stated that Vincent became disappointed, bewildered and distraught, and that during the winter of 1874-75, Vincent 
experienced long weeks of depression. In August of 1881, Vincent declared his love for his recently widowed cousin, Kee Vos-Stricker and he was strongly rejected when the still grieving woman declared, “No, never, never.” This must have reiterated his previous rejection, and his response was to relentlessly pursue her. This was considered by his family to be an inappropriate and tactless response on his part. When he was informed that Kee's no was final, he was furious and after following her to her home in Amsterdam, he held his hand in the flame of an oil lamp, resulting in a burn. His reaction to the second rejection was more violent than the first and his anger turned to self-abusive behavior. His next attempt at love was in December 1881 when he attempted to reform a prostitute, Clasina Maria Hoornik, whom he called Sien. She was thirty-two years old, pregnant, an alcoholic, and had syphilis (Bonafoux, 1992). He wanted to marry her, but his attempts to reform her were unsuccessful. She was unfaithful to him and became pregnant again. Vincent was hospitalized with a venereal disease. Despite this he returned to her. This relationship distressed his family and threatened to completely undo his relationship with them. He finally could put up with her infidelity no more and left her on September 11, 1883 (ibid.). These three thwarted loves show indicators of borderline personality disorder: frantic attempts to avoid abandonment ( especially with Kee), a pattern of unstable and intense personal relationships, impulsivity, self-mutilating behavior, affective instability including depression, chronic feelings of emptiness, and difficulty controlling anger. It is also typical that people with bipolar disorder have difficulty in maintaining interpersonal relationships. 
Vincent said in LT 459a that he felt "nowhere so much myself a stranger as in my family and country.” Julia Kristeva has written about the 'stranger', the outsider and the notion of strangeness within the self - a person’s own deep sense of being (Sarup, p.122). Each of these concepts is relevant to Vincent van Gogh, who called himself, a stranger on the earth (Lubin, 1972; Dobrin, 1975) .

During the summer of 1887, while Theo vacationed in Holland, Vincent wrote to him in letters 461 and 462. He spoke about personal and financial concerns, and asked him to send more money. The overarching tone of LT 462 is depressed, with the second sentence of the letter saying, "It depresses me to think that even when it's a success, painting never pays back what it costs.” Vincent continued in this tone, bemoaning a loss of confidence that the family would always prosper, and discussing Theo's plans to marry. There seemed to be more than a little of sour grapes as Vincent continued, "As for me - I feel I am losing the desire for marriage and children, and now and then, it saddens me that I should be feeling like that at thirty-five, just when it should be the opposite. And sometimes I have a grudge against this rotten painting. It was Richepin who said somewhere: ‘The love of art makes one lose real love.' I think that is terribly true, but on the other hand real love makes you disgusted with art.” Kristeva would classify this neurotic portion of van Gogh's discourse as the semiotic, i.e. primitive emotional content of a depressive nature, breaking through the symbolic order.

Seeming old before his time, Vincent continued in LT 462, “And at times I already feel old and broken, and yet still enough of a lover not to be a real enthusiast for painting. One must have ambition in order to succeed, and ambition seems to me 
absurd. I don’t know what will come of it; above all I should like to be less of a burden to you - and that is not impossible in the future - for I hope to make such progress that you will be able to show my stuff boldly without compromising yourself.” In this last statement, Vincent tinged his depressive statements with a sense of hopefulness that to an extent raised the tone of the letter to a more positive note. Then he continued by describing what was to become his grand dream, "And then I will take myself off somewhere down south, to get away from the sight of so many painters that disgust me as men” (LT 462).

From the period when Vincent van Gogh was in Paris before he went to Arles, several paintings have been selected to discuss, including the landscape Wheatfield with a Lark; a still-life, Lemons, Pears, Apples, Grapes, and an Orange; Portrait of Père Tanguy; and several self-portraits. These paintings have been chosen for comparison with selected works from Arles, Saint-Rémy and Auvers. Wheatfield with a Lark is comparable in subject matter with Crows over the Wheatfield from the Auvers period, but the emotional tone and the use of the formal elements are quite different between the two paintings. And the still life Lemons, Pears, Apples, Grapes, and an Orange compares in tonality with the "high yellow note" that Vincent van Gogh achieved at Arles.

\section{Wheatfield with a Lark}

The painting Wheatfield with a Lark has an elemental quality as it is divided into two approximately equal horizontal bands of earth and sky. The element of fire may be implied by the subject of wheat, even though the concept connecting wheat and fire may not have been completely defined and expressed in the thinking of Vincent van 
Gogh at this time. However, it had been apparent in the van Gogh oeuvre from at least 1881 when he had copied The Sower (after Millet). Wheat and fire were clearly connected in Vincent van Gogh's thought, and by the time he was in Arles he stated that humanity was the wheat that the sower would reap. After the wheat is reaped, it is processed and then cast into the fire [baked] so as to make bread.

The foreground of Wheatfield with a Lark is composed of stubble in the lowest register. The low vantage point of the perspective requires the viewer to adopt a stance of looking up. The practicality of this choice of perspective may have been deliberate to avoid the encroachments of civilization such as industrial smokestacks and urban vestiges in the background of this painting. A lyrical freedom in the return to nature is expressed in Wheatfield with a Lark. So masterfully is the paint applied that one is drawn into the reality of this pastoral scene and the viewer could forget that this is a painting, a signifier, rather than that which is signified. The application of the paint provides a flecked texture that is at one with the shorter stubble, the wheat gently swaying in the breeze, and the lark flying in the sky above. In Wheatfield with a Lark, art and the artifice that is painting have become fully identified with and expressed as one with nature. Signifier and signified come close to being one and the same.

The color harmonies chosen by Vincent van Gogh in Wheatfield with a Lark began with a ground primed with pale beige. The foreground of stubble displays golden and ochre tones with touches of lavender and some darker brushstrokes that provide highlights and dramatic contrast. The directionality of the stubble leads the eye directly into the field of standing wheat where there are green stalks and a few bright red poppies among the grain. The wheat continues to lead the viewer's eye upward to the 
vast sky that is inhabited by a single lark. The bird implies a deeper perspective by its placement in the sky.

Duality is evident in Kristeva's semiotic and symbolic, in Freud's conscious and unconscious, in Jung's personal and collective unconscious, and in Lacan's concept of language operating on dual planes. Language can be material, i.e. literal and used for ordinary communication, but it can also be poetic language and transparent, where the word is forgotten for the sake of the object or concept that is designated. Art also can have this kind of transparency where one can almost forget that it is paint on canvas, and that which is signified is presented with incredible clarity of purpose. Van Gogh’s Wheatfield with a Lark has the quality of Kristeva's poetic language expressed in paint.

(See Figure 1 on the next page). 


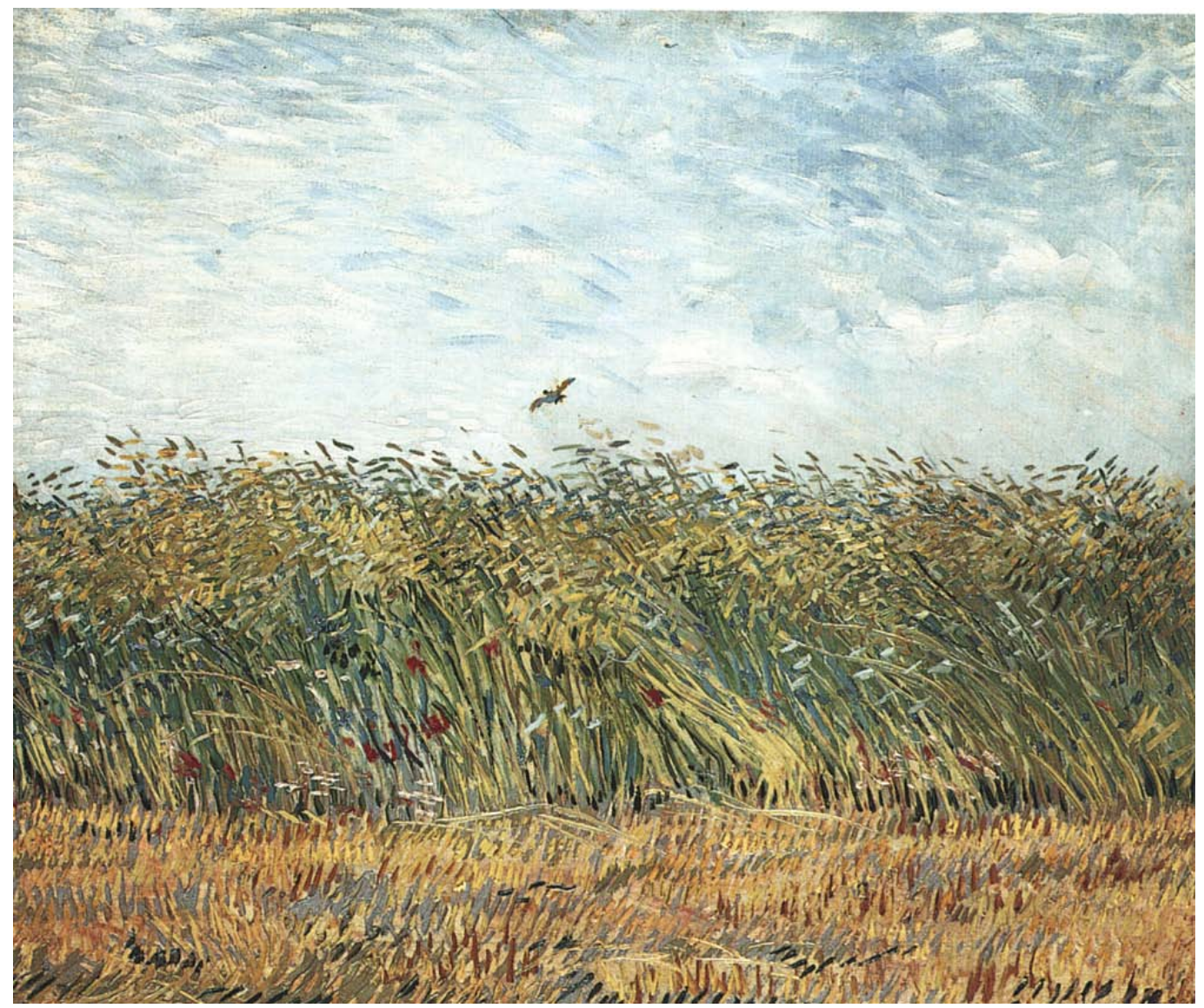

Figure 1. Wheatfield with a Lark, 1887

McQuillian, M. (1989) Van Gogh. Thames and Hudson, Ltd: New York, N.Y., p. 160.

Wheatfield with a Lark may be compared with one of Vincent van Gogh’s last paintings, Crows over the Wheatfield, from July 1890. While the two paintings have similar content, the emotive tone is totally different, from the freedom and liberation of Wheatfield with a Lark to the oppressive qualities of the composition and subject of Crows over the Wheatfield.

The symbolism is different between a lark and crows. The lark is a songbird with pleasant connotations. The small bird could allude to the concept that less is more 
and small is beautiful. The lark may further signify that self-realization lies more in humility, gentleness, and subtleness than in other overt qualities. The lark may allow one to glimpse the beauty of God. Crows are members of the corvine family of birds and are closely related to ravens. Crows are capable of "mobbing," which means that they will gather in large groups and may actually attack en masse. Considering the numbers and placement of the birds in Crows over the Wheatfield, they may actually represent a mob. It is possible that Vincent van Gogh might have felt attacked and overwhelmed by their sheer numbers and oppressive sense of presence.

Crows are a strikingly black color and black is the color of night and of the womb of creation, a maternal color. The crow was a common symbol in medieval alchemy, representing the nigredo, the initial state of substance, unformed, but full of potential (Andrews, 1999). This chthonic reality is the womb of creation, the mother of all possibilities, the semiotic of which Kristeva speaks. Crows are a reminder that out of the black darkness of night, the new day is born. Out of the darkness of the maternal womb comes new life, and for Christian believers, out of the darkness of the grave and death comes new life.

\section{Lemons, Pears, Apples, Grapes, and an Orange}

The monochromatic still-life, Lemons, Pears, Apples, Grapes, and an Orange, from the autumn of 1887, is completely formed by the manipulation and draftsmanship of color. The painted surface is dazzling in its range of tones of yellows. The subject is brought to the surface of the canvas and there is little if any recession of space in the composition. The material subject of the painting, fruit, is unified by the illusion of light to produce a strikingly simplified expression of the color yellow. While there are some 
flecks of red, pink, blue, and turquoise, they are subsumed into the overarching persona of yellow that is the essence of this painting. In this still-life of ripened fruit, the yellow tones may stand for the sun’s energy. At Arles and Saint-Rémy, van Gogh often included in his compositions the sun, a symbol of the element of fire. His sunflowers at Arles are customarily interpreted as symbols of the sun's energy.

Lemons, Pears, Apples, Grapes, and an Orange is a powerful chromatic composition in which the graphic constructions of the still-life of fruit fill a luminous space. With variegated yellows, each figuration of fruit is bathed in a luminous light. Van Gogh's yellow seems to be an expression of Kristevan jouissance especially when compared to the earlier dark tonality of his paintings like The Potato Eaters. Lemons, Pears, Apples, Grapes, and an Orange presents a glimpse of van Gogh's future preoccupation with yellow at Arles and seems like a precursor of the jouissance of that brief time of happiness in Vincent's all too short life.

(See Figure 2 on the next page). 


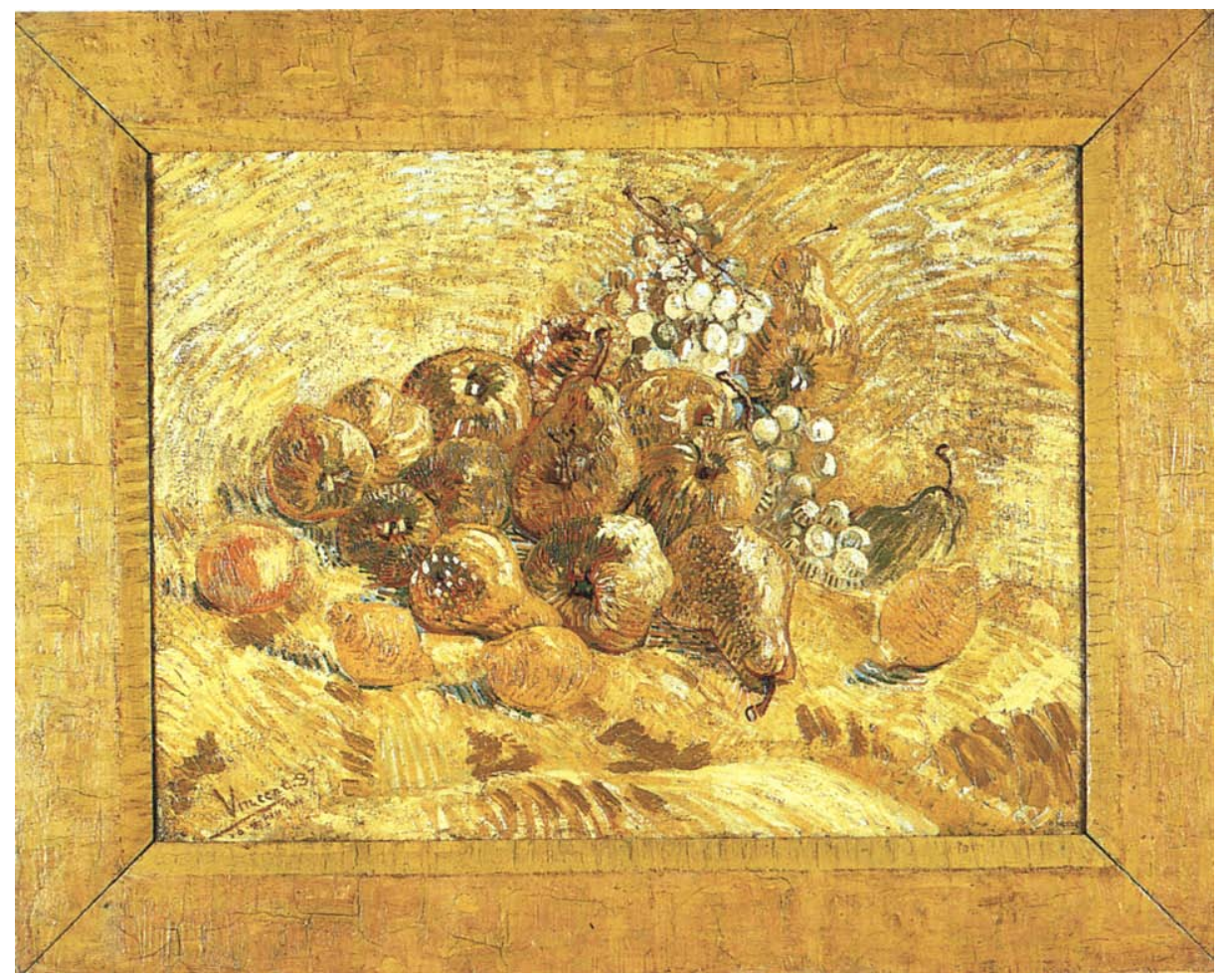

Figure 2. Lemons, Pears, Apples, Grapes, and an Orange, 1887

McQuillian, M. (1989) Van Gogh. Thames and Hudson, Ltd:

New York, N.Y., p. 162.

\section{Portrait of Père Tanguy}

During the winter months, when Vincent was in Paris, he was largely confined indoors. His artistic response to this was that he painted several still-lifes, landscapes, self-portraits, and portraits such as the Portrait of Père Tanguy.

Tanguy was the owner of a paint shop where Vincent purchased supplies during his time in Paris. Tanguy had a reputation for being frugal, declaring that a man who lived on more than fifty centimes a day was a rogue, and Vincent, accustomed to living on the cheap during much of his life, was readily welcomed by Tanguy (Bonafoux, 
1992). Sometimes Tanguy would sell paintings for a few francs or take paintings in trade for art supplies, and his art materials were reasonably priced.

The Portrait of Père Tanguy straightforwardly presented the image of the sitter in front of a background of Japanese prints. Tanguy, with his hands clasped over his belly, is sitting solidly while wearing a blue jacket, brown pants, and a hat with an upturned brim. The stated subject of the portrait is rendered in the broken brush strokes of impressionism. But, equally as bold as the portrait, and perhaps even more expressive is the background. The viewer is led to question, is this a portrait or a showcase for the background of Japanese prints? Van Gogh had first referred to Japanese prints and Japonisme in his letters from Antwerp, but according to McQuillen (1989), he only began to work out his own orientalism in the second half of 1887 .

At Tanguy's van Gogh met some of the artists that worked in the studio of Cormon - Emile Bernard, Louis Anquetin, John Russell, and Henri de ToulouseLautrec - and Vincent joined them beginning in April (McQuillen, 1989). The famous studio of Cormon was a favorite gathering place for artists and students of art alike. Vincent, who found Theo's small apartment too confining, went to Cormon's studio where he could draw from live models in the morning and practice from plaster casts in the afternoon. But Vincent did not find what he was looking for there and after four months he withdrew from Cormon’s studio.

In art, the product of the artist may be perceived as a narration. The origin of narration is an experience of emptiness, the blank page or the blank canvas. The existential emptiness is then filled by the creative essence and choices of the self as impinged upon by the environment and others in the environment. Kristeva (1980, 74), 
in her discussion of the narrative, says that in the act of narrating, the narration addresses an other. This is the I-Thou relationship. The artist and the viewer are in an IThou relationship, and the viewer, the one addressed by the narrative is the other. A variation of "I think therefore I am" is rephrased as "I speak and you hear me, therefore we are.” Art may also be understood as a dialogue of the I-Thou, and the existential statement may be paraphrased as; "I create and you observe my creation, therefore we are.”

In the portrait of Père Tanguy there seems to be more than one I-Thou relationship involved. There is, of course, the relationship between the artist and the viewer, but there is also a strong sense of relationship between Père Tanguy and the viewer as well as between him and the artist. The portrait seems to speak on a variety of dialectical levels.

(See Figure 3 on the next page). 


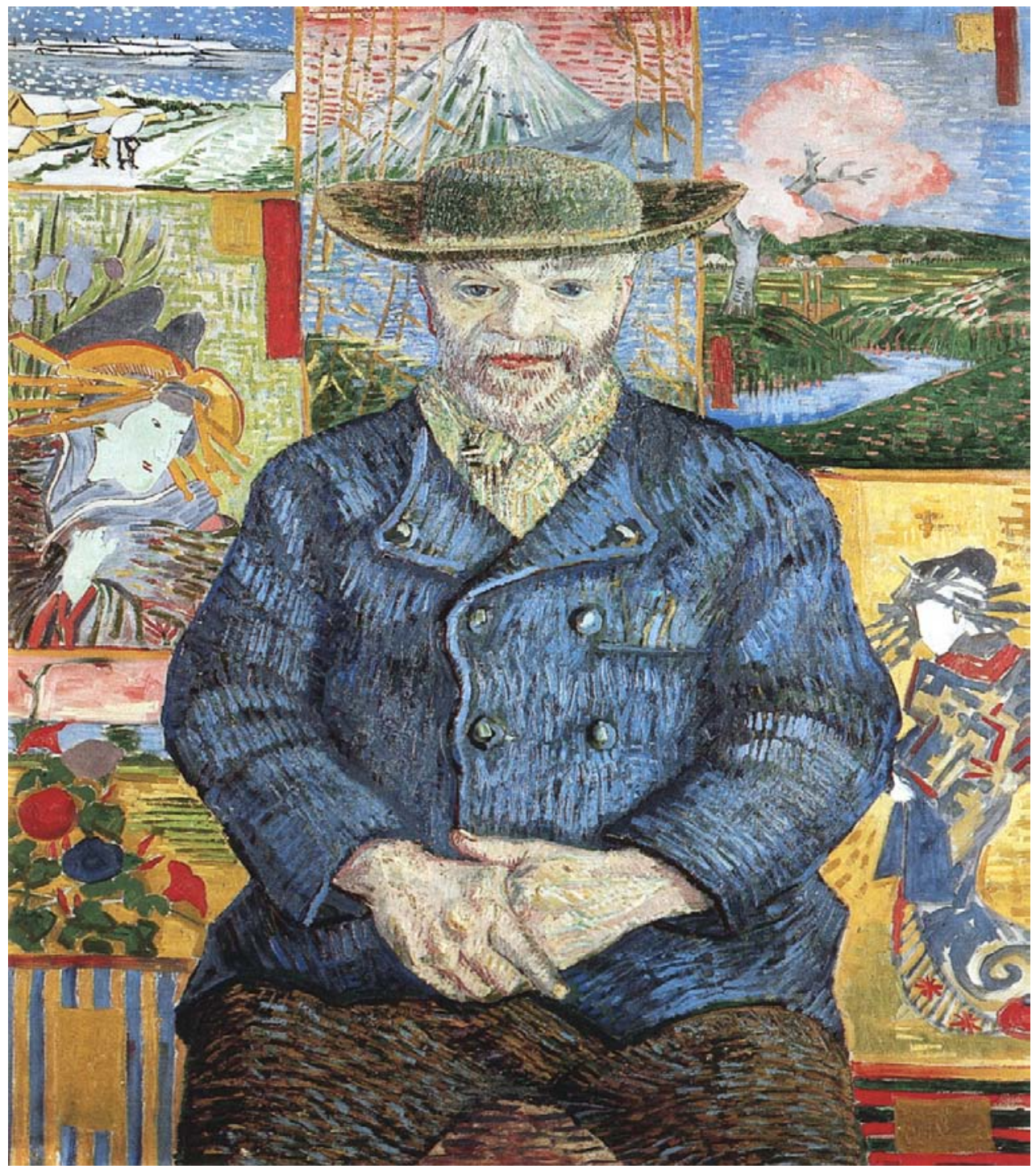

Figure 3. Portrait of Père Tanguy, 1887-88

McQuillian, M. (1989) Van Gogh. Thames and Hudson, Ltd:

New York, N.Y., p. 101.

Selected Self-Portraits from Vincent's Time in Paris

When money was scarce or models were not available, Vincent van Gogh, like many artists, turned to the most easily and readily available model, himself. According to Ronald Pickvance in Van Gogh in Arles (1984), van Gogh painted some thirty-seven 
self-portraits, with all of them concentrated during the last five years of his life. At least twenty-four self-portraits were done while he was in Paris for two years between March 1886 and February 1888 and only five were done in Arles. The self-portraits done in Paris and many of his still-life subjects were explorations of color theory and brushstroke.

The self-portraits of Vincent van Gogh provide an opportunity to examine the Kristevan preoccupation with the subject and a heterogeneous signifying process. Kristeva describes the speaking subject as belonging to both the semiotic chora and to the symbolic device, thus accounting for the duality of the eventual split nature. The discourse of the split subject includes two types of signifying processes, the semiotic and the symbolic. Kristeva emphasizes the interdependence and the polarity of the semiotic and signifying modalities. Kristeva speaks of the subject in process (en procès), i.e. on trial (1984, ix). Kristeva's concept is that the subject is always in process, and the identity is ever becoming, never become, questioned and questionable, always on trial. This concept of en procès is similar to the ideas of process theologians. The self-portraits from Vincent van Gogh’s time in Paris seem to be where Vincent tries on various personas in his process of self-discovery and becoming.

\section{Self-Portrait, Paris, 1886}

This self-portrait places Vincent van Gogh squarely in the tradition of the great Dutch portrait painters such as Rembrandt. The dark tonality and lack of experimentation with brushstrokes and color belie his Northern heritage. The face, modeled in color and light, emerges from the dark neutral background, which in the 
Kristevan sense shows meaning emerging from the chora. The black coat and white shirt give a further dignity to his symbolic presentation of himself as a gentleman. Self-Portrait, Paris, 1887

Vincent van Gogh demonstrated an increasing familiarity with the techniques of the impressionists in this self-portrait by stippled technique applied throughout the background and the coat that he is wearing. While the tonality of the palette remains dark, chthonic, and semiotic, symbolic meaning emerges by the way the broken brush strokes of the impressionists compose the entire painting. The background has blue and orange stippling, and the coat appears tweed-like with dots and dashes of black, brown, and orange. Brush strokes in the face, hair, and beard are becoming increasingly bolder and more evident with little or no attempt to smooth and blend the tones and brush strokes.

\section{Self-Portrait, Paris, 1887 (in pale tones)}

The ghostly appearance this self-portrait is created by the pale hues chosen and by the way that the body dissolves into the background on the left side of the painting. With eyes appearing sunken and the overall effect of haggardness, there is a disturbing lack of solidity in this self-representation. The face shape is implied in the bluish-grey field created by loose brushstrokes of primarily white, gray, and blue color. The semiotic seems to break through as the self-image barely emerges from the miasma of the background. The color emphasis in this self-portrait is the bright red mustache and beard and the red in the hair. It is as if the entire self-representation is thrown together with a few loose, splotchy brushstrokes and it could just as quickly dissolve into nothingness. This painting lacks existential solidity. 
Self-Portrait with Gray Felt Hat, Paris, 1887

Painted during his last months in Paris in the winter of 1887/88, Self-Portrait with Gray Felt Hat defined him as a bourgeois in a felt hat and a jacket with decoratively trimmed lapels. The apparel depicted in this self-portrait symbolically presented him as a gentleman. It was one of only a few self-portraits in which he represented his social class, although there were several self-portraits that showed his identification with his profession by presenting him in artist's attire or showing him at the easel. In Self-Portrait with a Gray Felt Hat prominent striations of paint organize the modulation of planes, spreading outwards over the face like the fur growth on an animal, contouring the upwardly curving hat-brim, and encircling the head with a background halo (McQuillen, 1989).

Self-Portrait with Gray Felt Hat, Paris, 1887, retains the same pale palette as the Self-Portrait, Paris, 1887 (in pale tones), but meaning and symbolism emerge from the semiotic with the figure more solid, the skin tones more believable and the presentation of van Gogh as a gentleman. The eyes are composed of an unearthly paleness and of the same tone as the background color giving them an icon-like quality. These disturbing iconic eyes are like openings that the viewer can look into and through and they are like holes through which the artist can look out. In these eyes, the I-Thou, the known and unknown see each other and meet on the ground of unknowing. These eyes seem to reveal an identity crisis, a Vincent who peers into himself, and does not know who he is. 


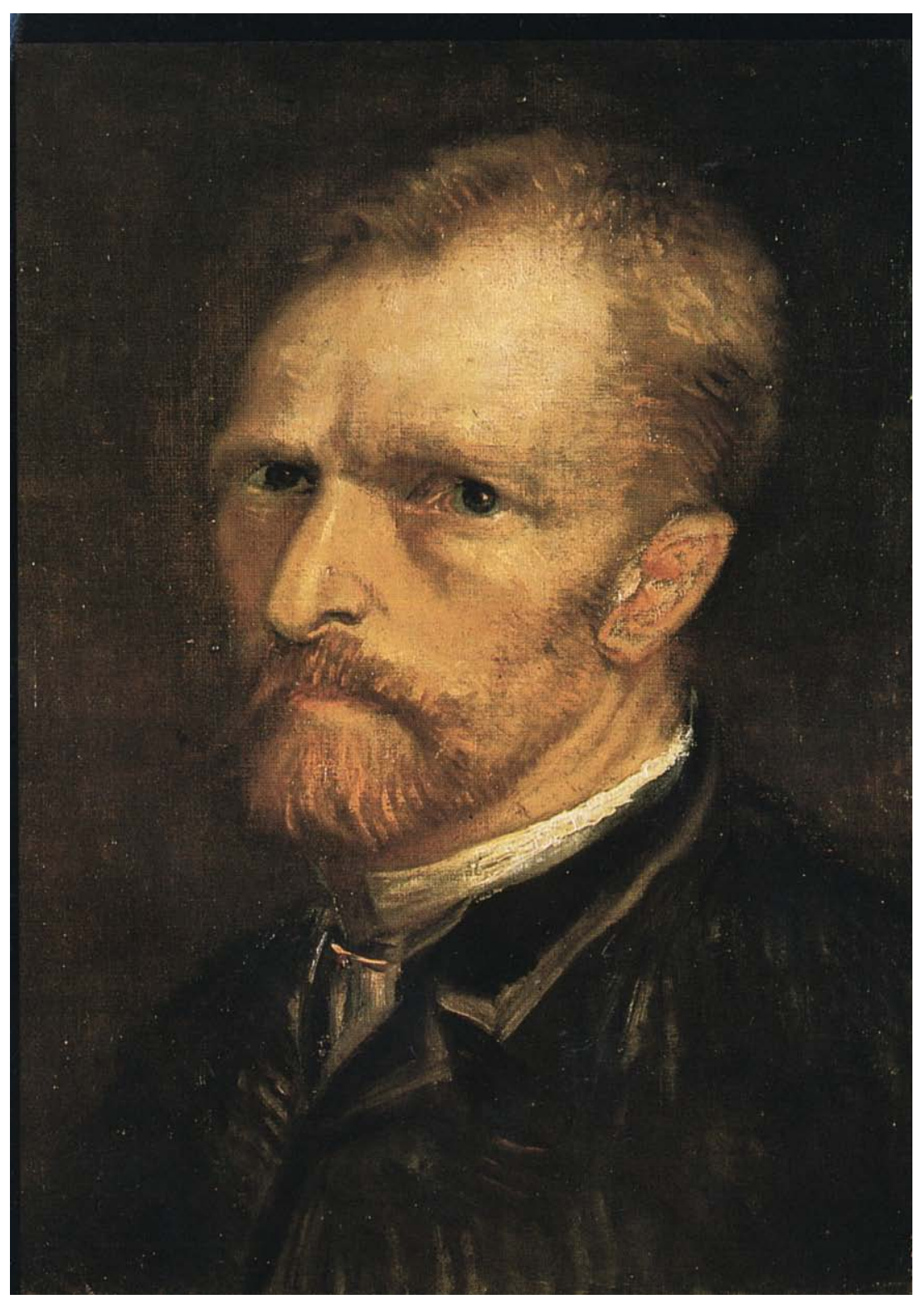

Figure 4. Self-Portrait, Paris, 1886

Bonafoux, P. (1992) Van Gogh: The Passionate Eye.

Harry N. Abrams, Inc: New York, N.Y., p. 2. 


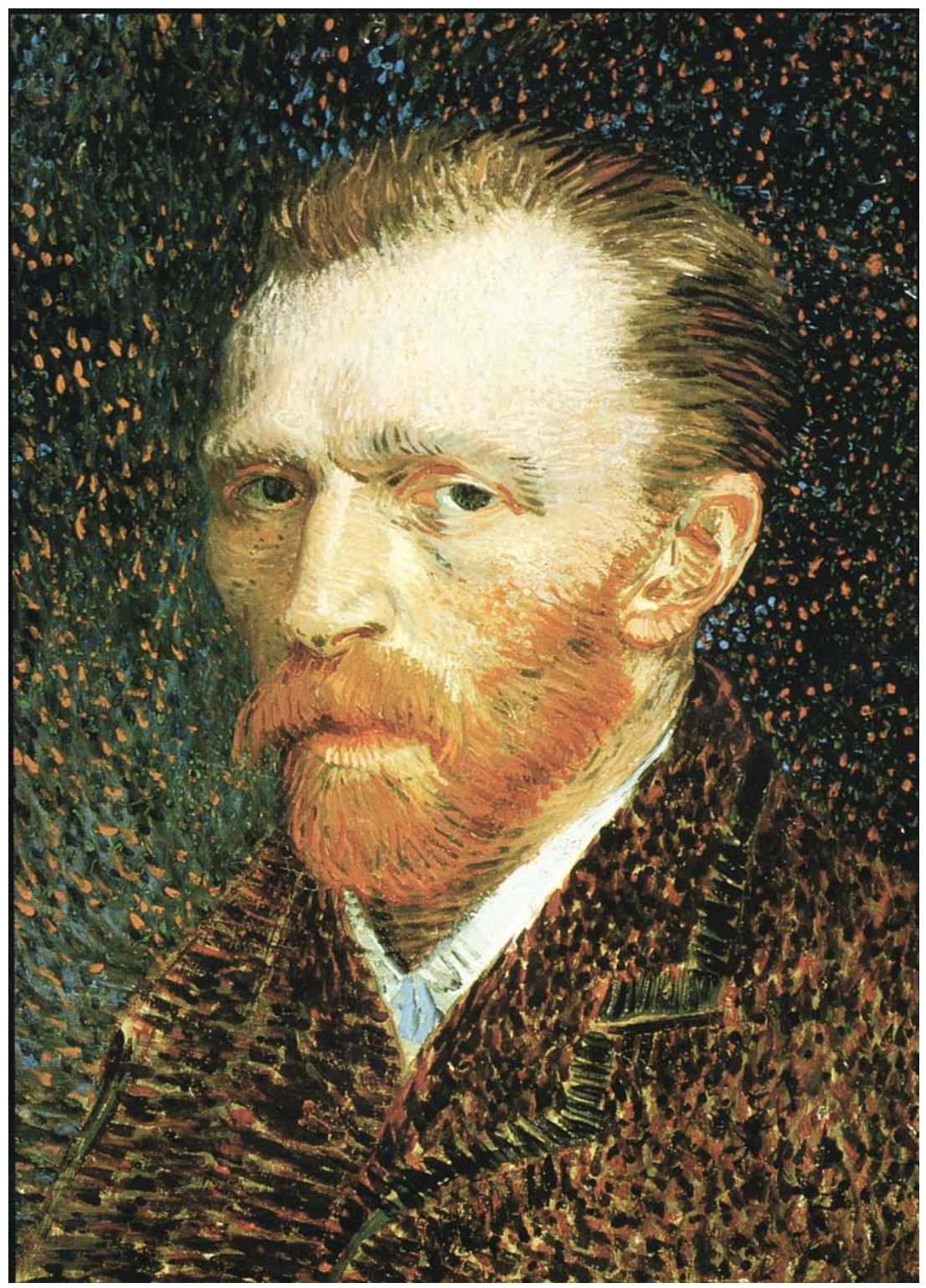

Figure 5. Self-Portrait, Paris, 1887

Bonafoux, P. (1992) Van Gogh: The Passionate Eye.

Harry N. Abrams, Inc: New York, N.Y., p. 3. 


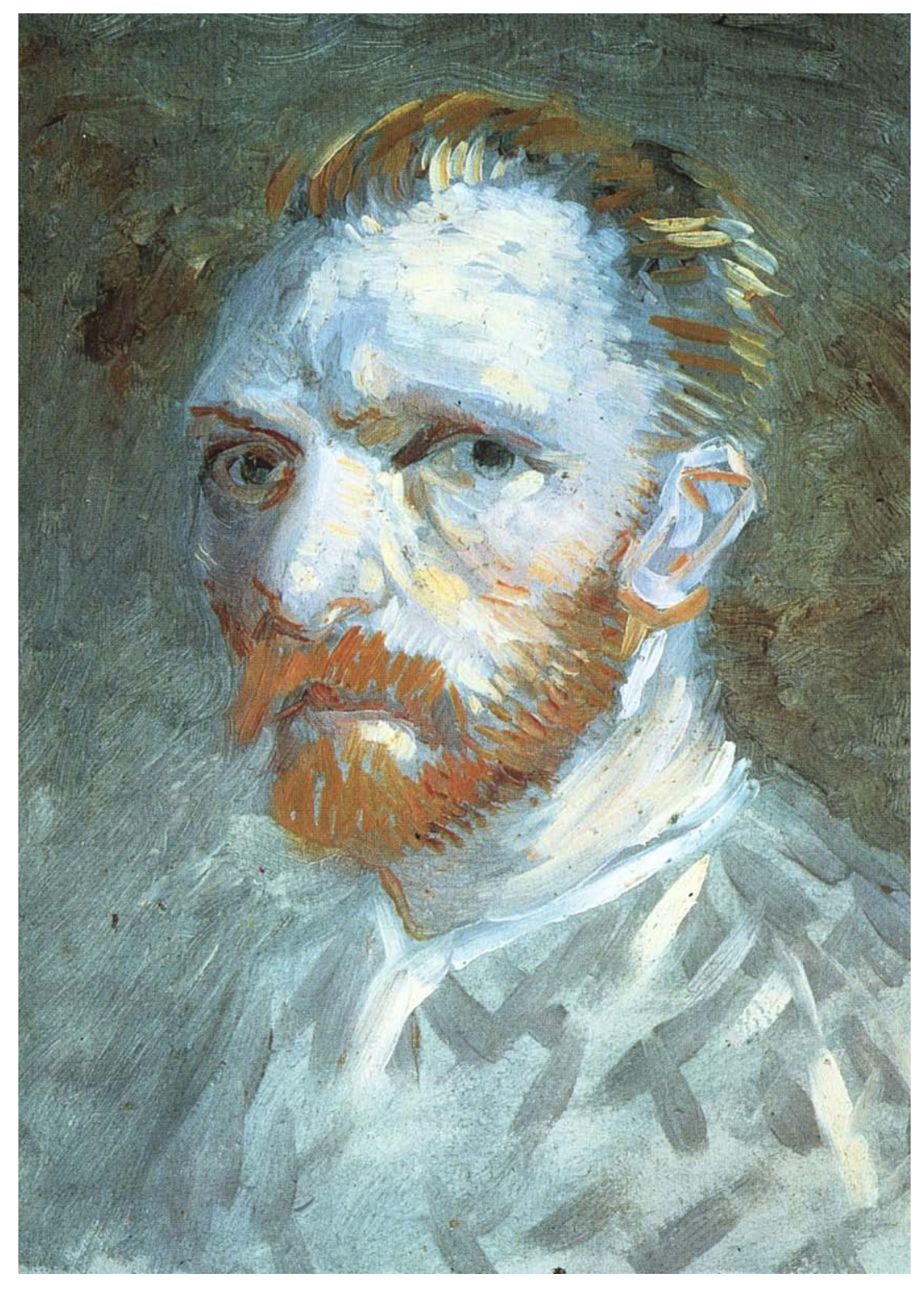

Figure 6. Self-Portrait, Paris, 1887 (in pale tones)

Bonafoux, P. (1992) Van Gogh: The Passionate Eye.

Harry N. Abrams, Inc: New York, N.Y., p.4. 


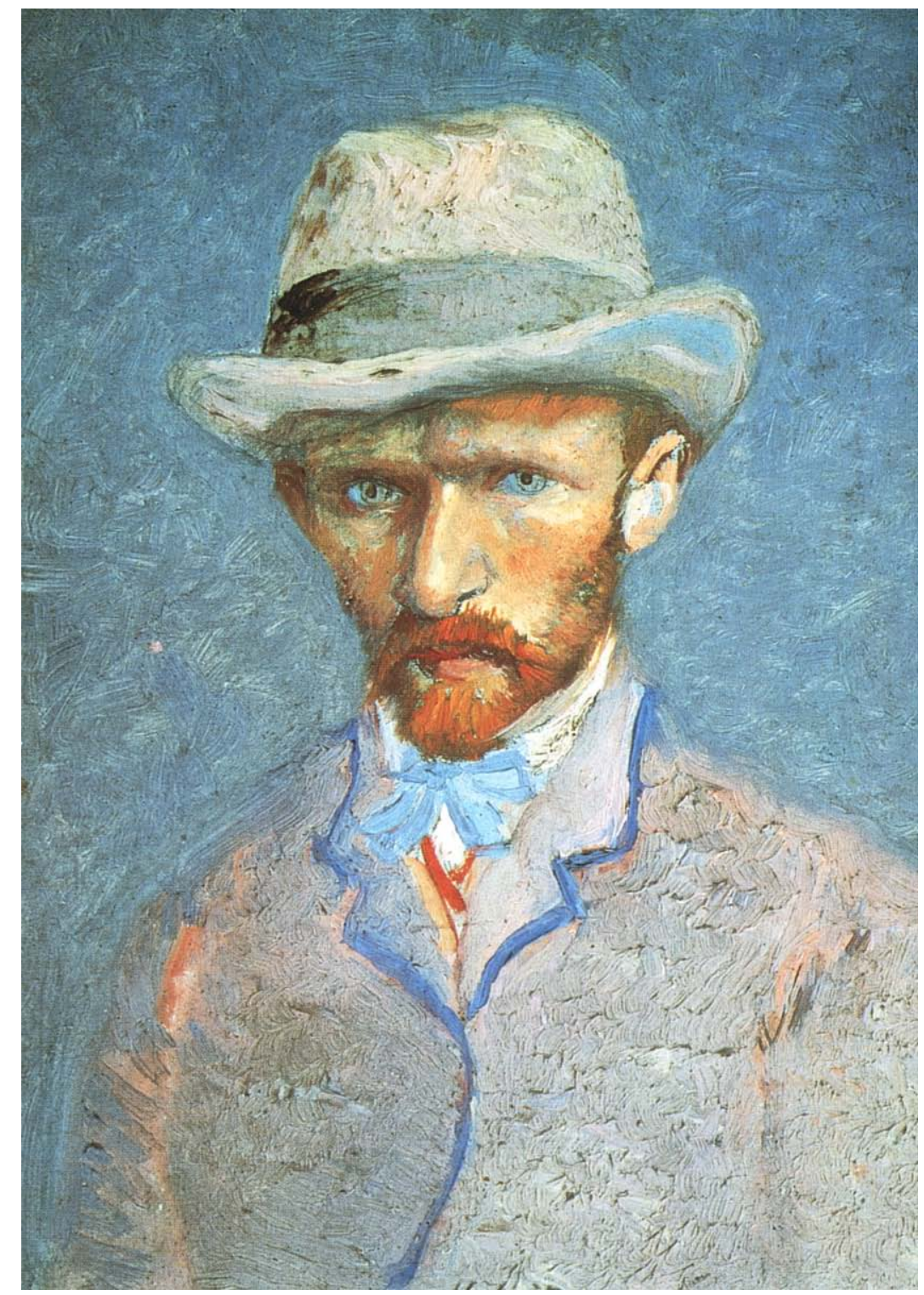

Figure 7. Self-Portrait with Grey Felt Hat, Paris, 1887

Bonafoux, P. (1992) Van Gogh: The Passionate Eye.

Harry N. Abrams, Inc: New York, N.Y., p.5. 
Self-Portrait (in a straw hat)

In Self-Portrait (in a straw hat) it appears that Vincent is consciously experimenting with impressionistic brushstrokes and colors. The broken brush strokes give a semiotic appearance to the background and the treatment of the face. By the use of textural techniques of hatching, stippling, and small comma-like strokes, the face in the painting is made to emerge from the background. The strokes barely hang together, making the image seem loosely constructed and somewhat insubstantial. The color combination of the yellow straw hat paired with a blue jacket is striking, but not quite the complementary combination that he so often preferred. For that, the use of yellow and violet or orange and blue would have been needed. There appear to have been two sources of light as there is a disparity in the placement of the shadows. Pickvance (1984) noted that there is a horizontal shadow under the brim of the hat that could have been due to natural sunlight and there is a vertical shadow on the side of the face that could have come from studio light.

Van Gogh painted himself in a straw hat on seven different occasions with none of the paintings being dated and none mentioned in his letters (Pickvance, 1984). The straw hat was an indicator of summer as well as a challenge of technique. The brim of the hat swirls around the head of the wearer. In later paintings, Vincent would make the halo effect even more pronounced. The straw hat was also a tribute of sorts from Vincent to an artist named Monticelli whom Van Gogh greatly admired. It has been said that imitation is the sincerest form of flattery. In a letter to his sister Wilhelmina (indicated by a W), Vincent wrote that it was his "firm intention to go saunter in the Cannebière [the fashionable street in Marseilles] ... dressed exactly like him, 
Monticelli, as I have seen his portrait, with an enormous yellow hat, black velvet jacket, white trousers, yellow

gloves, a bamboo cane, and with a grand southern air” (W 8). This outfit certainly

sounds like the attire of a dandy. It is as if Vincent wanted to try on a different persona.

This seems to bespeak a certain instability in Vincent's self-image. The wide variances of personal representations in Vincent's self-portraits seem to indicate an unstable selfimage which is a characteristic feature of borderline personality disorder, and they also sugge st the disparities of Bipolar disorder.

(See Figure 8 on the next page). 


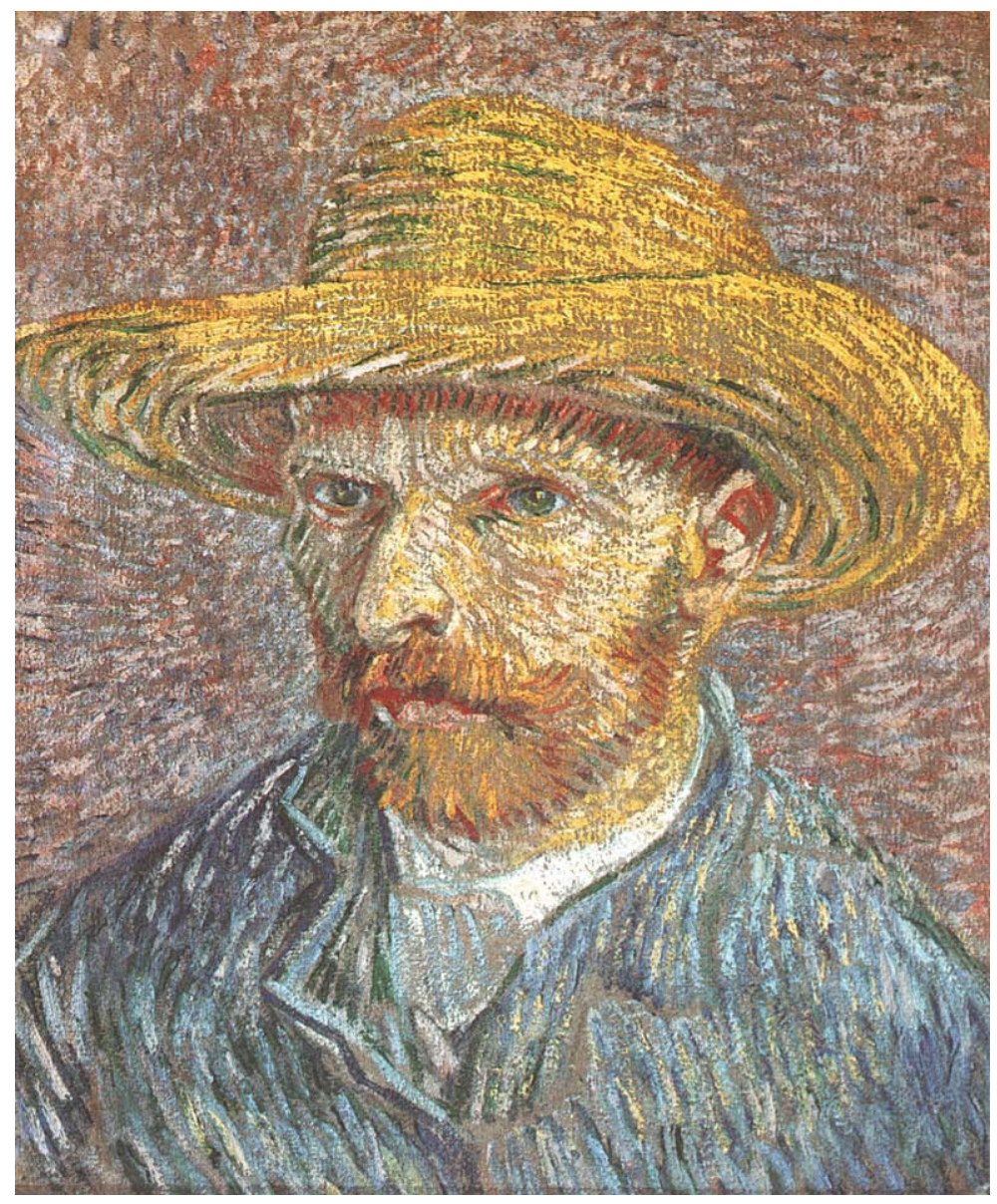

Figure 8. Self-Portrait, 1888 (in a Straw Hat)

Pickvance, R. (1984) Van Gogh in Arles. Metropolitan

Museum of Art: New York, N.Y., p.34.

The Decision to Move to the South of France

Paris had been a kind of training ground for Vincent van Gogh, a place where he learned to give up the dark tones of his earlier style of painting. In Paris he hobnobbed with many artists among whom were Toulouse-Lautrec, Anquetin, Emile Bernard, Monet, Renoir, Manet, Degas, Seurat, Signac, and Gauguin (Meier-Graefe, 1987). In Paris, Vincent van Gogh learned the nuances of impressionism. He painted flowers in 
gay tones rather than brown and dusty potatoes and Dutch wooden clogs. In Paris, Vincent van Gogh joined the studio of the painter Cormon so that he could meet the other students and because Theo's little flat was not large enough for him to paint there.

Winter was a difficult time for Vincent. There was a strong pattern of disturbances around the time of Christmas. He may also have struggled with Seasonal Affective Disorder, in which depressive episodes are attributed to not coping well with winter and decreased amounts of sunlight. Julius Meier-Graefe (1987) said that the winter was always Vincent's worst time, because he could not let off steam in the open air and had to swallow his temper, which was very indigestible. Through his art, however, Vincent could release some of the tension from his mind and spirit. Vincent struggled with some of the new ideas in painting, such as the dot system of pointillism that Seurat espoused. But in the long run, Vincent needed a greater freedom of expression, a faster and looser brushwork, a more impassioned style. Vincent van Gogh had to find his own way, his own unique odyssey, and that meant moving to the South of France. 


\section{CHAPTER III}

\section{ARLES, PART 1: VAN GOGH'S JAPAN}

\section{February 1888 to Mid-July 1888}

Just as he had arrived suddenly and unexpectedly in Paris, after a year and a half of living with Theo, Vincent van Gogh made an impulsive and hasty departure from Paris for the South of France. It was as if all at once he could no longer stand living in Paris. He hated the cold climate and disparaged the people in the city. He wanted to go far away to a warmer clime. He wanted open country where he could feel at home among the peasants. He decided to go to the South of France where it was warm. Arles became the grand dream of Vincent van Gogh, the place where he wanted to found a community of painters.

Theo accompanied his brother to the train station and saw him off. They had considered Marseilles as a destination, but Arles was selected rather than Marseilles in the belief that it would be cheaper to live there. Vincent would continue to receive an allowance from his brother.

After a train journey of sixteen hours, Vincent arrived in Arles on February 20, 1888. To his surprise, the "sunny" South of France, to which he was so looking forward, was covered in snow. Despite this, Vincent found beauty and hope in the wintry scene saying, "And the landscapes in the snow, with the summits white against a sky as luminous as the snow, were just like the winter landscapes that the Japanese have painted” (Bonafoux, 1992). It was snowing when he arrived at Arles and by the 
next morning, February 21, some twelve inches of snow had fallen. Vincent's artistic response was to paint snowscapes. By Saturday, February 25, most of the earlier snow was gone, but a new snowfall of four inches accumulated. Vincent wrote LT 464 telling Theo that a "landscape in the snow was one of three paintings that he had completed.” Snowy Landscape with Arles in the Background was one of the earliest paintings done in Arles.

Snowy Landscape with Arles in the Background

The scene has a planar arrangement organized primarily in a horizontal composition. The city of Arles appears on the horizon with a soft blue sky above it. The foreground occupies about $3 / 4$ of the pictorial space. The eye is led into the scene by the diagonal placement of an unusual wooden construction in the foreground which may be a hunting blind for bird hunting. Between the foreground construction and the city on the horizon, there is a large snow-covered plain with blue shadows. There is plant life in the picture, appearing to be some rushes, dry stubble, two bare trees, one evergreen, and what may be a clump of oak trees in the background with some brownish-yellow foliage. A bright touch of red on the roof of the building near these trees provides a visual accent and adds color to the picture. Human habitation is implied by the hunting blind and the town in the background. In Snowy Landscape with Arles in the Background, there are symbols of human habitation, but no actual persons. The vast expanse of the picture is given to a large, open, desolate snowcovered plain.

When Vincent van Gogh went to Arles, he must have had a sense of estrangement similar to that of Julia Kristeva when she visited China in 1974. Kristeva discussed a feeling of total estrangement from the crowd who met her delegation there. She 
described knowing on two levels, first, that the crowd of Chinese had a sense of solidarity and knew they belonged to a community, and second, she knew that she would never be in common with them. This is an example of in-group and out-group. Vincent traveled alone to Arles and felt so much an outsider that he even imagined that he was going to Japan. He was out-grouped for most of his life, seldom if ever feeling that he fit in.

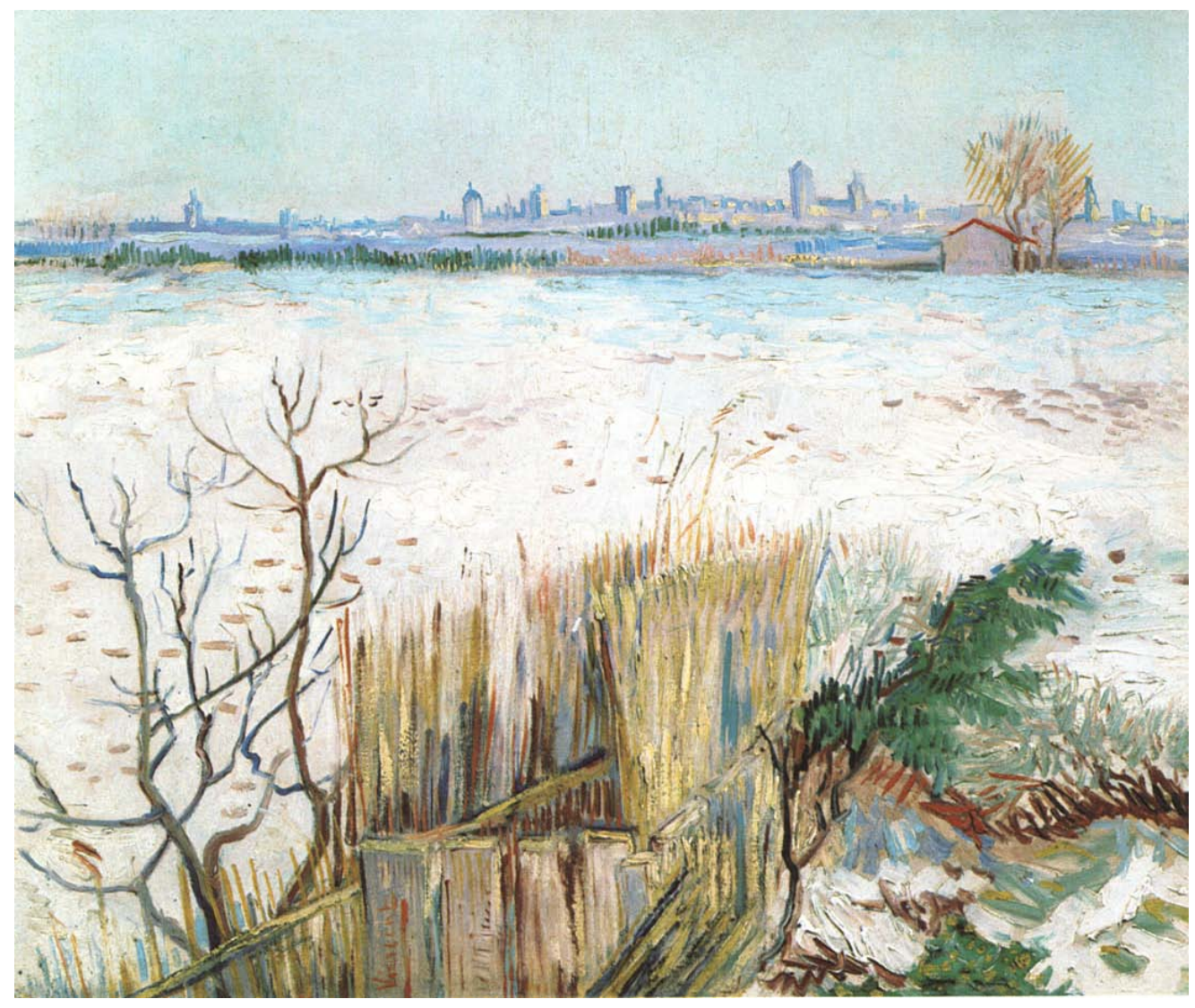

Figure 9. Snowy Landscape with Arles in the Background Pickvance, R. (1984) Van Gogh in Arles. Metropolitan Museum of Art, New York: N.Y., p. 43 
Thinking about Japan

While on the train to Arles, with thought patterns that seem irrational, Vincent had considered himself as on the way to Japan - southern France became for him in his mind "his Japan." He again mentioned this unusual thought in LT 469; writing to Theo, Vincent said, “But, old boy, you know, I feel as though I were in Japan - I say no more than that, and mind, I haven’t seen anything in its usual splendor yet.” The first self-portrait that Vincent painted in Arles was The Painter on the Road to Tarasçon; however, it was in the second one, Self-Portrait (as a Bonze), that he orientalized his features (Pickvance, 1984).

\section{The Painter on the Road to Tarasçon}

This unusual painting was likely done in June 1888 and was destroyed in World War II. It is also referred to as The Artist on the Road to Tarasçon. The theme displayed represents the artist as a journeyman, a workman who carries his supplies with him and travels on foot in order to paint on site. The painter walking to Tarasçon was laden with his easel, paint box, and canvas, a walking stick, as well as perhaps a folding chair, an umbrella, and whatever foodstuffs he might require for the day. Painting is not generally considered physical work, but the image of this painter carrying his materials belies that concept. And working outdoors, standing or sitting for many hours in the sun, the artist might be bothered by any number of inconveniences, among them weather and natural effects like wind, rain, dust; tormenting insects like flies, wasps, and mosquitoes; and the nuisance of passersby and unwelcome observers. Vincent van Gogh was an artist who worked hard, but at this time in Arles he also enjoyed what he did. 
Painter on the Road to Tarasçon communicates jouissance and affirms freedom as the painter jauntily strides along. Jouissance, a Kristevan concept, as discussed in Revolution in Poetic Language (p.3), stands against a society that extols material goods and profit. This painting seems more symbolic than semiotic; there is an innocence of expression that is free, as if unaware of, or unconcerned with society. This painting could be interpreted as standing on the original ground of innocence before the dualistic split into symbolic or semiotic. The Painter on the Road to Tarasçon, as a textual presence, is poetic language visually expressed by paint on canvas. The psychological forces that brought this work into production were Vincent van Gogh’s existential desire for self-expression and self-identification. This painting is an "I am” statement, "I am an artist.” The joy (jouissance) and freedom shine through saying, "This is who I am; This is what I am.”

Painter on the Road to Tarasçon is notable for the sense of both foreshadowing and shadow. Painter on the Road to Tarasçon foreshadows the coming tendency toward abstraction and modernism with its strong verticals and horizontals. The two large tree trunks that flank the painter provide powerful vertical presences, and smaller trees punctuate the skyline with little repeated vertical accents. Horizontals are noted in the roadside, the near and far edges of the fields, and the tops of the mountain range. The semiotic seems to ominously seek to break out by way of the large and dark shadow that is cast by the painter. The shadow side of Vincent's personality was expressed in traits such as his fits of temper, obsessive qualities, personal excesses, and the like. But as an artistic presence in the history of art, few artists have cast as large a shadow as Vincent van Gogh and it looms large even today. 


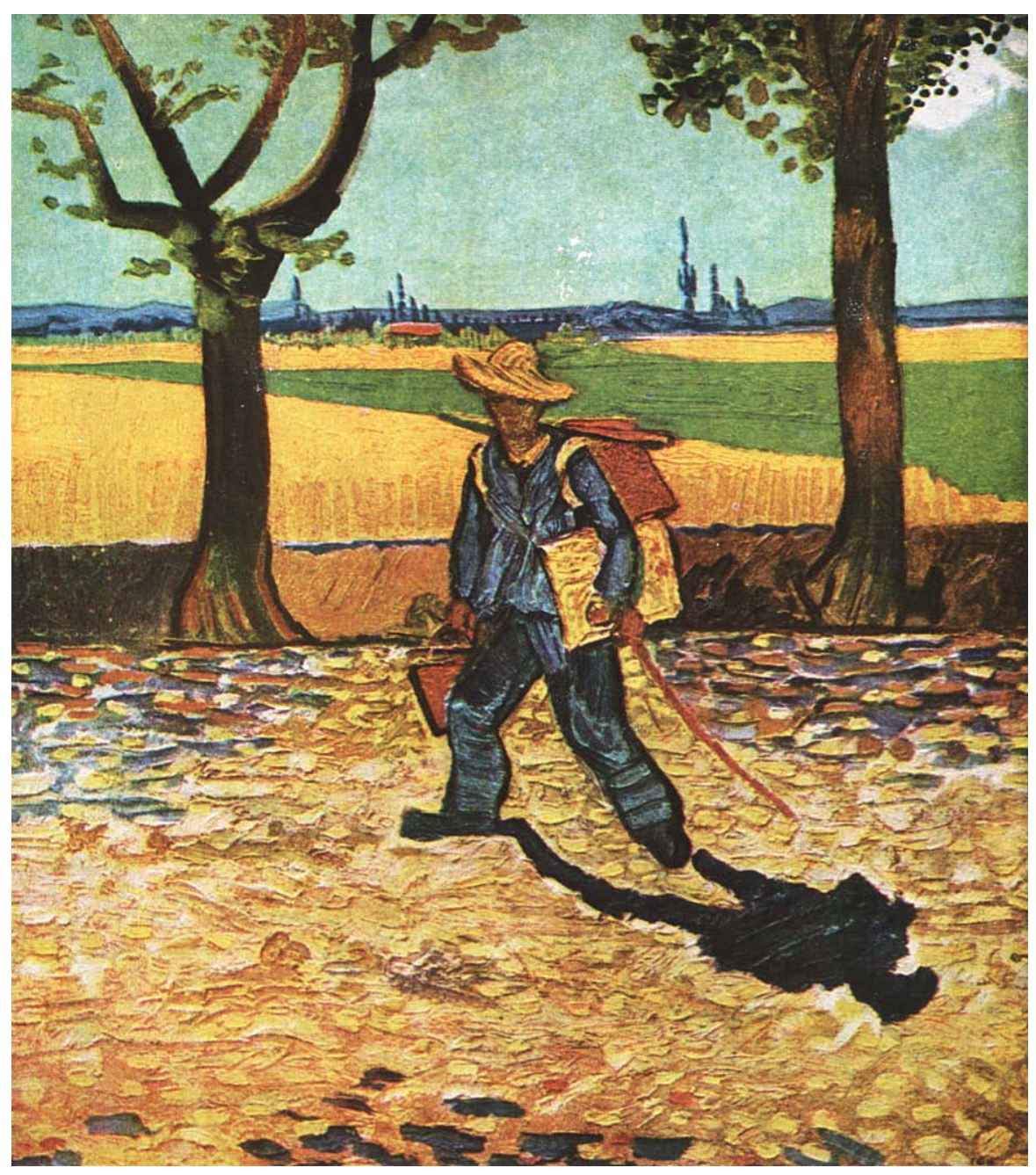

Figure 10. The Painter on the Road to Tarasçon

Huyghe, R. (undated) Van Gogh. Flammarion: Italy, p. 45

\section{An Association of Artists}

The concept of a painter's colony in the South of France is the idea to which

Vincent returned again and again. In his first letter to Theo after he arrived in Arles,

Vincent wrote on February 21, 1888, “It seems to me almost impossible to work in

Paris unless one has some place of retreat where one can recuperate and get one's 
tranquility and poise back. Without that, one would get hopelessly stultified” (LT 463). “That's why - even although I'm vexed that just now expenses are heavy and the pictures worthless - that's why I don't despair of the future success of this idea of a long sojourn in the Midi” (LT 469). Vincent had several ideas about creating a profitable venue for the paintings of the impressionists, but he recognized Theo's difficult position of possibly getting caught in a conflict of interests with the firm for which he worked by selling artworks, “... and you yourself get your own income from the Boussod Valadon people, I do not want to do anything against that firm” (LT 465). And since Vincent derived his income from Theo, he realized the importance of not threatening Theo's livelihood. Theo was unable to interest the firm in the works of the impressionists in which he and his brother so firmly believed, "I firmly believe in the ultimate victory, but will the artists themselves gain any advantage from it, and will they see less troubled days?” (LT 467).Vincent suggested having an agent, Tersteeg, to specialize in the works of the impressionists, and if Tersteeg did not respond as they hoped, "we shall not say a word against him, but we will manage to convey that we do not deserve to be treated as if we were dead” (LT 467). Vincent's idea was for the artists to join together and put in capital in the form of their pictures which would then be displayed and sold. Vincent identified Monet, Sisley, Renoir, and Pissarro, whose work was shown by Theo on the Boulevard Montmartre, as The Painters of the Grand Boulevard, and he called himself and Bernard, Anquetin, Gauguin, and ToulouseLautrec, who used to exhibit in the restaurant on the Boulevard Clichy, The Painters of the Petit Boulevard. It was Vincent’s hope that the reputation of all the impressionists could be advantaged by such a deal, "I am continually thinking about this association 
of artists, and the plan has developed further in my mind; but Tersteeg must be in it, a lot depends on that” (LT 468).

Flowering Trees and Possible Mania

With the advent of springtime, the flowering trees became Vincent's favorite subject and a sense of urgency entered his letters to Theo, "I should have liked to write you at leisure, but must do it in great haste” (LT 472). In a similar manner Vincent continued in LT 473, "I'm up to my ears in work, for the trees are in blossom and I want to paint a Provençal orchard of outstanding gaiety. It is very difficult to write collectedly. Yesterday I wrote a letter which I tore up later.” After reporting that he could not write the kind of letter that he wanted to, Vincent said that his work absorbed him completely. The end of LT 473 is missing; perhaps it was left incomplete, or hastily completed, or it may have been sent without a closing greeting. The sense of working frantically continued in the next letter, \# 474, when Vincent said that he was "in a continual fever of work.” His painting was like an obsession to him.

All this frantic attention to work, the impulsivity, and lack of self-care sounds very much like Vincent was having a manic episode. The essential feature of a manic episode includes a distinct period of elated, expansive, or irritable mood lasting at least a week or of any duration if hospitalization is required (Reid and Wise, 1995). Additional symptoms, such as grandiosity, decreased need for sleep, talkativeness, flight of ideas, distractibility, increase of activity, and involvement in risky activity, are present during a manic episode, and result in marked dysfunction in several areas of life, i.e. work, social activities, and/or relationships with others.

Paintings and studies of the orchards and blooming trees completely consumed him at this time. Van Gogh's paintings of orchards in blossom were begun in late 
March, and in less than a month he reported that he had completed ten paintings of orchards (Pickvance, 1984). It was his hope that the paintings of flowering trees and orchards might be popular and saleable in Holland and that the numerous studies might be appropriate for exchanges with other artists. In LT 477 Vincent described six canvases of orchards and said that he hoped to complete three more to make a series of nine. He planned to continue on with the decoration scheme of orchards in bloom and enlarge it with another similar series the following spring. In his letter he enclosed a sketch showing how he planned to place the vertical pear tree between two horizontal canvases.

\section{Pink Peach Trees (Souvenir de Mauve)}

While Vincent was enthralled with painting the blossoming trees during his first spring in Arles, he came in one afternoon to find a letter from his sister, Wilhelmina. It informed him that his relative Mauve had died. Anton Mauve had been his first art teacher and the first person to put a paintbrush into his hands. In an immediate emotional response, Vincent wrote "Souvenir of Mauve” on the landscape painting of blossoming peach trees that he had just completed. He said that Mauve's death was a terrible blow to him. In LT 474, Vincent wrote “you will see that the pink peach trees were painted with a sort of passion," and with the same sort of passion that painted the flowering trees, the dedication was inscribed. Souvenir de Mauve features a centrally placed and symmetrical presentation of a flowering tree in the foreground with another peach tree in such close proximity that some branches of the second tree are intertwined through the bifurcated branches of the first. The two trees almost appear as one, except that the separate trunks serve to distinguish one from the other. The blossoms are composed of splotches, blobs, and streaks of pink and white applied with 
an impasto technique. The sky is blue with ample white clouds. The scene has the appearance of early spring with snow on the ground. Boundaries and enclosure are indicated by the fence on two sides of the orchard. An enclosing fence often made of cane and a line of cypresses were common features of Provençal orchards and they served the function of protection from the mistral. Enclosure, confinement, and restricted views characterize the 1888 series of blossoming orchards (Pickvance, 1984).

There seem to be several evidences of possible mania both in his words and actions during the time that Vincent was painting the flowering orchards. He mentioned an orchard in bloom in LT 474, likely the painting called The White Orchard, with "plum trees, yellowish-white with thousands of black branches.” Mania may be indicated in the excessiveness of this description "thousands of black branches.” In LT 475 Vincent sent Theo a request for a large order of paints and supplies and said that he had spent more on paints, canvas, etc., than on himself. He went on to say that he didn’t have a cent left at the moment. This impulsive overspending could be another symptom of mania. His method of working was described in a letter to Emile Bernard on April 9, 1888, “At the moment I am absorbed in the blooming fruit trees, pink peach trees, yellow-white pear trees. My brushstroke has no system at all. I hit the canvas with irregular touches of the brush, which I leave as they are. Patches of thickly laid-on color, spots of canvas left uncovered, here and there portions that are left absolutely unfinished, repetitions, savageries; in short I am inclined to think that the result is so disquieting and irritating as to be a godsend to those people who have fixed, preconceived ideas about technique.” The freneticism of this technique by Vincent van Gogh could also fit the category of mania. 
Dialectical development is noted in the process from creation to inscription to completed work in Pink Peach Trees (Souvenir de Mauve). Kristeva discusses both Marx's and Hegel's dialectics which are different one from the other. Marx points out the contradiction inherent in all things causing a cleavage, a struggle between the two elements of the contradiction, elimination of the weaker element and that within the victorious one, there is a contradiction (Kristeva, 1980, 14). Hegel posits thesis, antithesis and finally synthesis.

In Pink Peach Trees (Souvenir de Mauve), there is Marxian contradiction in the gaiety of the flowering tree and Vincent's mood when painting it as contrasted with his abrupt mood swing when informed of his cousin's death. In considering the Hegelian system and van Gogh's Pink Peach Trees (Souvenir de Mauve), the thesis is the painting of a landscape, a scene of a flowering tree. The antithesis is learning of the death of his cousin and first art teacher Mauve. This catastrophe caused an emotional response which Vincent synthesized by dedicating this most recent painting to his cousin’s memory. Artistically van Gogh took Pink Peach Trees (Souvenir de Mauve) from a nature scene to a dedicatory piece (in memory of) by way of a "shifter" which was his emotional response. Kristeva $(1980,288)$ states that a true "catastrophe" in language goes from one enunciative space into another and Vincent's response to the death of Mauve expressed in an artistic way seems to fit this definition.

(See Figure 11 on the next page). 


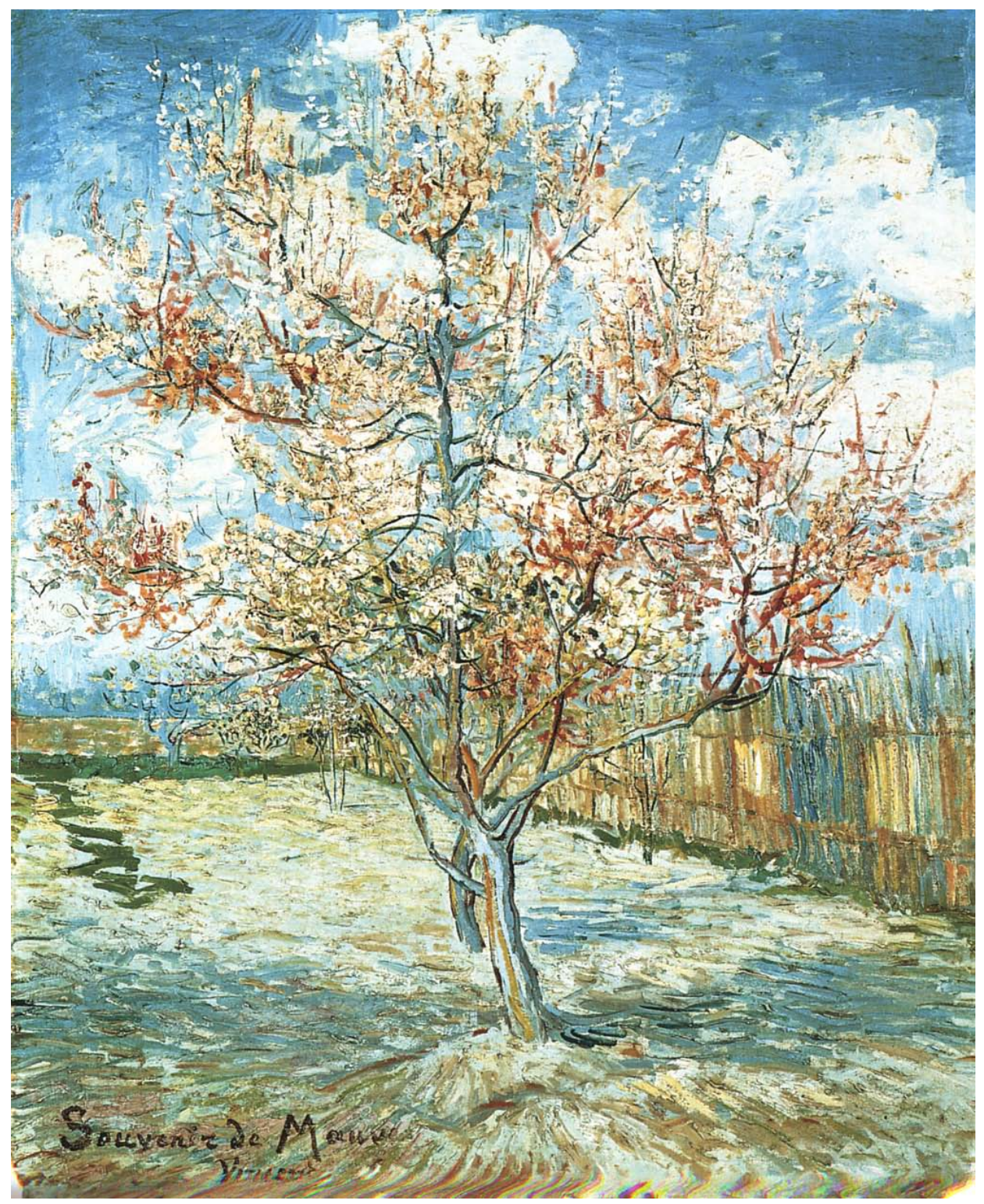

Figure 11. Pink Peach Trees (Souvenir de Mauve)

McQuillen, M. (1989) Van Gogh. Thames and Hudson: New York, N.Y., p.59

\section{The Langlois Bridge}

There are several variations of the nomenclature of this painting. Vincent called this bridge the Pont "Langlais," but it was more correctly called Pont Langlois, after the name of the bridge keeper. Yet the even more correct name would be the Pont 
de Reginelle (or Reginal). This drawbridge was located on the south side of Arles over the Bouc Canal, and according to Pickvance (1984) it was painted between May 10 and 20. Vincent had done several drawings of this subject before he did the painting The Langlois Bridge. In LT 473, written in early April, Vincent described one of his drawbridge pictures as “an odd thing, not like what I generally do.” Pickvance (1984) considered this an unusual statement believing that van Gogh painted these drawbridges because they reminded him of his native Holland. Therefore Pickvance would classify this picture as one of van Gogh's reminiscences of the North.

The observer immediately notices the beautiful asymmetrical balance of the composition. The focal point of the painting, the boldly dark image of an Arlésienne with a parasol on the bridge, is placed slightly to the right of center and is balanced by a similarly colored farmer in a carriage and two cypress trees on the left side of the picture. By choosing a slightly asymmetrical composition, Vincent made the composition much more visually interesting than a central placement would have been.

The Langlois Bridge seems to be a reasonably straightforward narration showing a landscape scene, but even Vincent himself noted that it was different from the things that he normally did. Kristeva $(1980,15)$ used the term "ideology" stating that it is usually transmitted on a preconscious level since it is usually taken for granted, considered as “natural," hence neither repressed (unconscious) nor intentionally propounded (conscious). Louis Althusser defined ideology as a system of representations (images, myths, ideas, or concepts) with specific historical context and functioning within a given society and related to the culture (ibid.). The Langlois Bridge and Pickvance's classification of it as a reminiscence of Vincent's native 
Holland seem to fit the Kristevan and Althussian concepts of an ideological representation. The thing that is different about it is that it blends a scene from France and an unconscious memory of Holland.

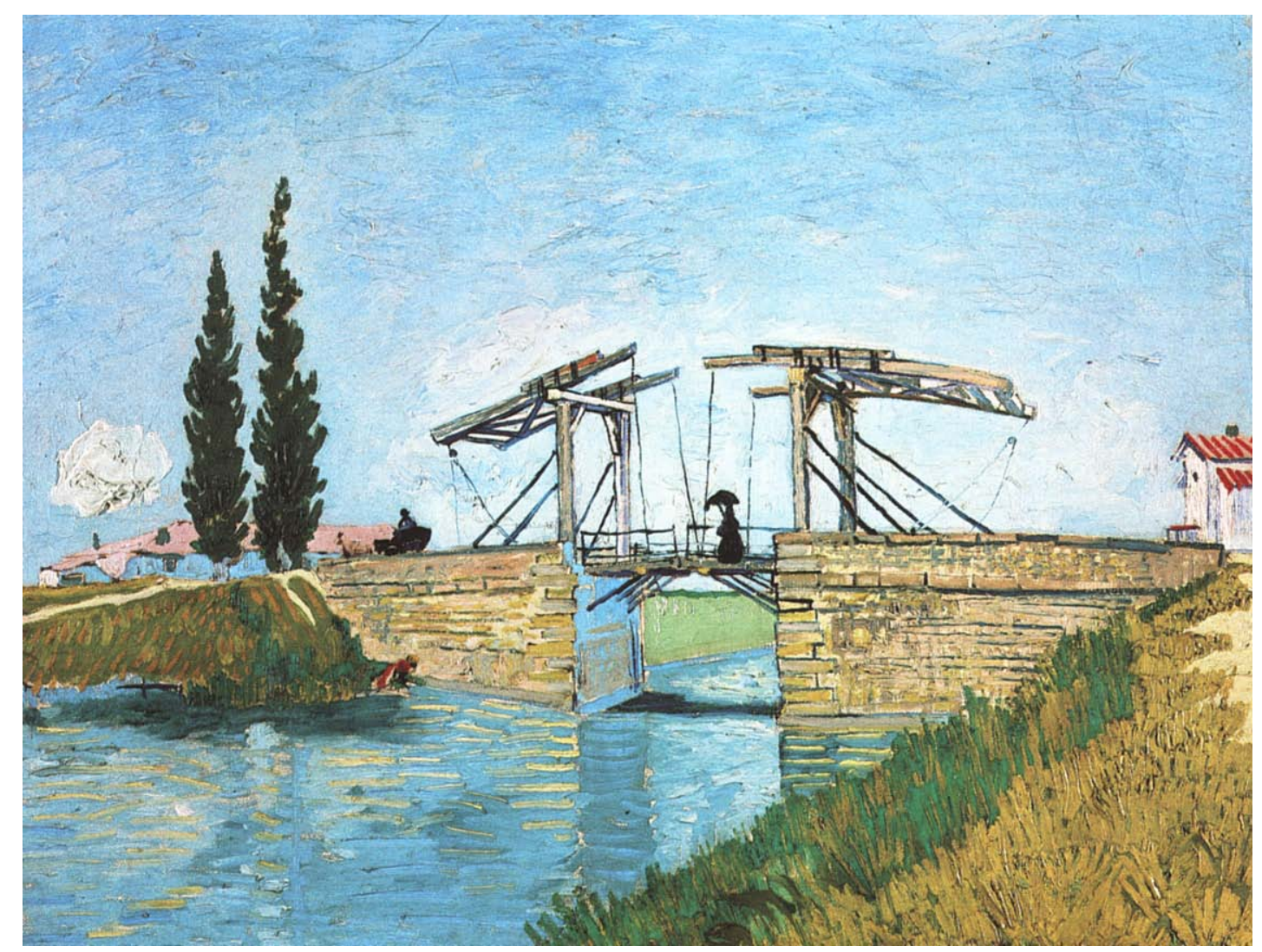

Figure 12. The Langlois Bridge

Pickvance, R. (1984) Van Gogh in Arles.

Metropolitan Museum of Art: New York, N.Y., p. 74.

From Flowering Orchards to Irises

The paintings of the flowering orchards were likely finished by April 20 and were followed by a series of drawings. Several things were happening in Vincent van Gogh’s personal life, his dispute with Carrel, moving to a different hotel, and renting 
the yellow house. But by May 12 he had written to Theo that he had two new studies including a view of Arles.

View of Arles with Irises

Irises were a theme that occurred and recurred in the work of Vincent van Gogh. In the spring of 1888, a view of Arles with irises in the foreground was painted. Several bands of foliage cut diagonally across the canvas back to the view of Arles on the horizon line. First there is an area with ochre and white flowers, then the row of irises bordered by a grassy place created by vertical green and yellow brushstrokes, and finally a band of a yellow tone that appears to be a taller unmowed field. A row of trees, sentinel-like, occupies a midpoint in the field, and it both enhances and partially obscures the view of Arles.

As in Snowy Landscape with Arles in the Background, View of Arles with Irises presents a landscape with signs of human habitation, but with no actual people included in the composition. This could be interpreted as indicative of negativity, i.e. Vincent feeling solitary, out-grouped, and not in solidarity with the people of Arles. Negativity is inscribed in arche-writing as a constitutive absence: the "absence of the other, irreducible absence within the presence of the trace” (Kristeva 1984, 141). Many of Vincent's paintings have the absence of the other, but with traces of human habitation. This negativity occurs frequently enough that this author would consider this a salient feature of the artwork of Vincent van Gogh.

(See Figure 13 on the next page). 


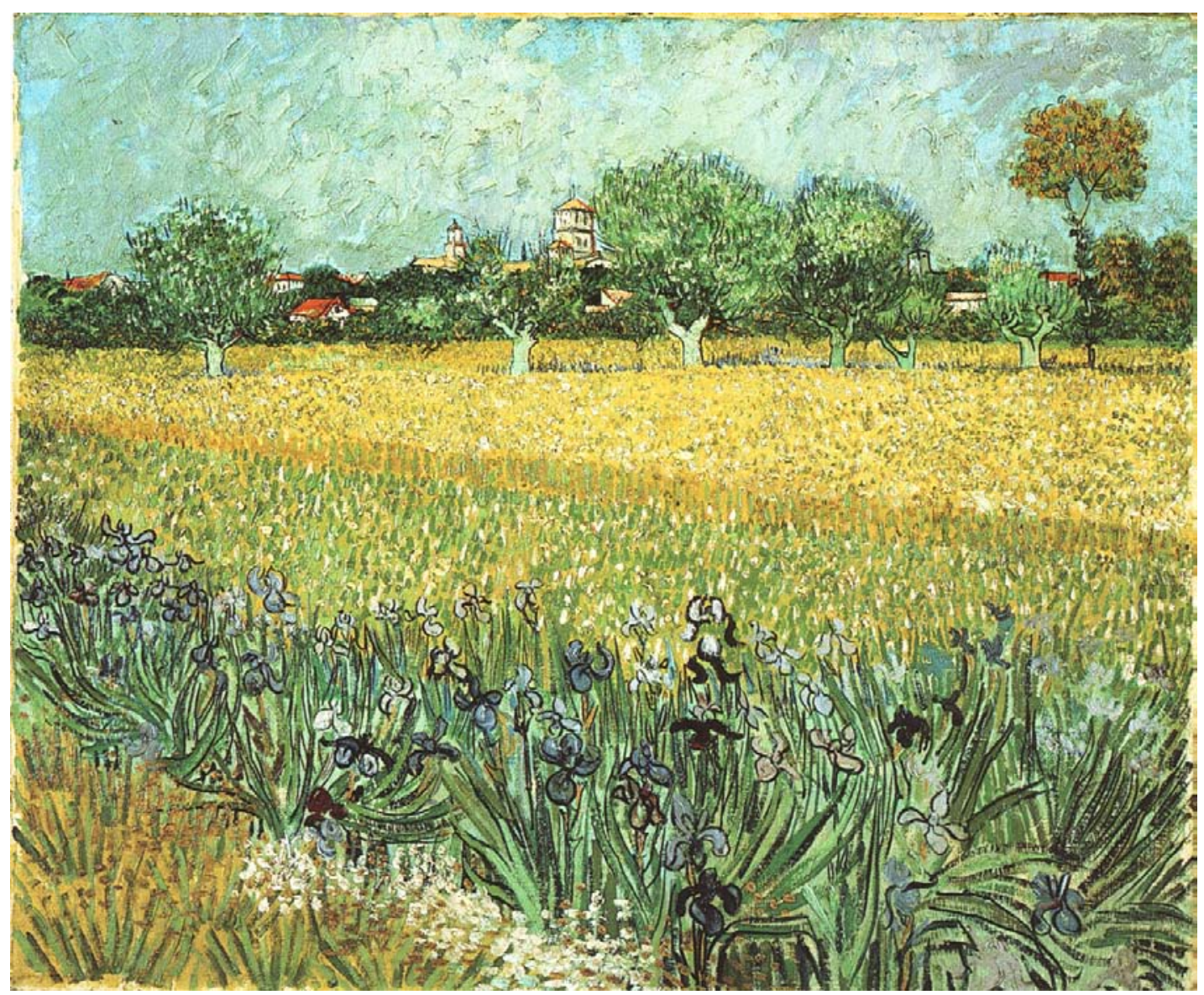

Figure 13. View of Arles with Irises

Pickvance, R. (1984) Van Gogh in Arles.

Metropolitan Museum of Art, New York: N.Y., p.73

\section{Depression Tinged with Yellow Hope}

By May a dark, ominous, and depressive tone has made its way into Vincent's letters, but it is tinged with yellow hope. In May 1888, LT 480, Vincent said, “I don’t see the whole future black, but I do see it bristling with difficulties and sometimes I ask myself if they won't be too much for me. But this is mostly in moments of physical weakness, and last week I had such a fierce toothache that much against my will I had to waste time.” In this same letter, Vincent sent a sketch of the house he had 
rented; it would become known as the yellow house: "Well, today I've taken the right wing of this complex, which contains 4 rooms, or rather two with cabinets. It is painted yellow outside, whitewashed inside, on the sunny side. I have taken it for 15 francs a month.” Vincent was happy to have the possibility of living on his own away from innkeepers, "I hope I have landed on my feet this time, you know - yellow outside, white inside, with all the sun, so that I shall see my canvases in a bright interior - the floor is red brick; outside, the garden of the square, of which you will find two more drawings. I think I can promise you that the drawings will get better and better” (LT 580).

Even though Vincent van Gogh rented the unfurnished yellow house at 2 Place Lamartine in early May 1888, he did not sleep there until in mid-September. He made improvements by having it painted inside and out in early June after he returned from his trip to Saintes-Maries. During the summer months he used it as a studio where he worked with live models and as a gallery where he hung his paintings. The yellow house was not actually furnished until after September 8 when his brother sent him 300 francs, part of Theo's inheritance from their Uncle Vincent.

Renting the yellow house represented many things to Vincent van Gogh. It meant that at last he would be free from the innkeepers that had been so disagreeable to him. Even though it was a rented property, he could feel a sense of having a home, of belonging and security. And beyond this, he perceived it as a possession to be shared. He hoped that Paul Gauguin would join him and become the head of a studio in the South at the yellow house. 


\section{Discussion of Health Concerns}

Vincent complained about his health in LT 480, “ All the same, I am better than I was in Paris, and if my stomach has become terribly weak, it’s a trouble I picked up there and most likely due to the bad wine, which I drank too much of. The wine is just as bad here, but I drink very little of it. And so it comes about that by eating hardly any solid food and hardly drinking, I am pretty weak, but my blood is getting healthier instead of getting poisoned.” A few lines later in this same long letter, he blamed his poor health on not being able to get what he asked for, saying that he could not get even the simplest food requests like baked potato, rice, or macaroni, and that he longed for some good strong soup. In LT 481, Vincent recognized that he had been unhealthy when he left Paris, saying, "I was certainly going the right way for a stroke when I left Paris. I paid for it nicely afterward! When I stopped drinking, when I stopped smoking so much, when I began to think again instead of trying not to think - Good Lord, the depression and prostration of it! Work in these magnificent natural surroundings has restored my morale, but even now some efforts are too much for me: my strength fails me." Vincent described what he felt was "the healthy way to live, to be sensible and look after ourselves. Cold water, fresh air, simple good food, decent clothes, a decent bed and no women.”

\section{Further Discussion of the Yellow House and Health Concerns}

Vincent again turned his attention to furnishing the yellow house at 2 Place Lamartine, and recognized that if he could sleep there, it would save 300 francs a year (LT 481). He began to shop for furniture. At first he suggested that it would take "a cool thousand francs" to set him up, and thought he would need to spend 100 francs per month on food and 100 francs a month on the house. He felt sure that at the end of 
a year he would have a decent establishment and his health to show for it. But Vincent had difficulty in obtaining a bed, and in LT 482 he suggested that for the summer he might get a rug and a mattress and make a bed on the studio floor. The economics of the situation soon took precedence and Vincent reported that he could save 30 francs at the hotel and pay 15 for rent therefore realizing a net savings. He also suggested that it might be wise to put off repairs and further furnishing of the yellow house. In LT 483, Vincent realized that there might have been a delay in Theo receiving his most recent letters, so he reiterated, "I have taken a studio, an entire four room house at 180 francs a year. Now the thing is to go and sleep there. I am going to buy a mat and a mattress and blanket today.” But Vincent encountered difficulties in trying to extricate himself from his arrangement with the hotel; he believed that he owed them 40 francs, but the hotel held out that he owed 67.40. They impounded his belongings and he said that he would have it out with them before the magistrate. He felt swindled and angry. He decried cultural prejudice, saying that he felt taken advantage of as a foreigner even though he was making his home there and not just traveling for pleasure. The problem was that his bill had been calculated at a higher per diem rate that had been in effect when he was sick and had asked for better wine. On May 10, in LT 485, Vincent reported that he paid the bill provisionally so that he could regain possession of his belongings and that "the exorbitant bill will be submitted to the magistrate." He bought supplies to make coffee and soup at home, two chairs and a table, and had only 15 francs left. He wrote and asked Theo to send him more money. The conflict with the innkeeper was resolved by the time of LT 487. After meeting with the justice of the peace, a compromise was reached. Vincent got 12 francs back and the innkeeper was reprimanded for keeping his luggage because he did not refuse 
to pay, rather it was a dispute over the amount. Vincent received an apology from the innkeeper and felt justified that his reputation was not blackened. In retrospect he felt that perhaps he should have asked for more by making a claim also for damages.

This is one of several instances when Vincent was aware of the differences between him and other people. During his earlier religious period he had given a sermon entitled "I am a Stranger on the Earth.” Vincent both felt and sensed his cultural differences in the dispute with the innkeeper. The notion of différence and différance from the French verb différer contains two meanings, to be different and to defer (Sarup, p. 44). Difference would again be an issue in his dispute with the people of Arles who became afraid of him and signed a petition against him after the famous incident of the ear. In his relationship with Paul Gauguin, the other meaning of the French différer is apparent. Vincent deferred to Gauguin as to technique and asked him to be the head of the planned Studio of the South.

In letters 488 and 489 Vincent discussed his health and that of Theo. He reported feeling much better after moving away from the inn where he had previously stayed, "It was mainly their bad food which kept me down, and their wine, which was regular poison” (LT 488). In LT 489 Vincent commiserated with Theo and expressed concerns about his brother's health. Vincent responded compassionately to the description of his brother's feelings of dazedness and lassitude as well as his recent visit to a doctor and compared Theo's symptoms to his own of the previous winter in Paris. Vincent reported of himself, "I am completely well, but it is having pure air and warmth that makes it all possible ... If only you could have one year of life in the country and with nature just now, it would make Gruby’s cure much easier. I expect 
he will make you promise to have nothing to do with women except in the case of necessity, but anyhow as little as possible” (LT 489).

Vincent once again reported his existence as tinged with sadness in what reads almost like a self-diagnosis. "Now as for me, I am doing very well down here, but it is because I have my work here, and nature, and if I didn't have that, I should grow melancholy. If work had any attraction for you where you are, and if the impressionists were getting on, it would be a very good thing. For loneliness, worries, difficulties, the unsatisfied need for kindness and sympathy - that is what is hard to bear, the mental suffering of sadness or disappointment undermines us more than dissipation - us, I say, who find ourselves the happy possessors of disordered hearts" (LT 489). Seasonal Affective Disorder is a depressive emotional response to winter weather and the shorter number of daylight hours during winter days. In a description that sounds like Seasonal Affective Disorder (SAD), Vincent suggested that the illness might have been a reaction to the very harsh and long winter that had just passed, "Get as much of the spring air as possible, go to bed very early, because you must have sleep, and as for food, plenty of fresh vegetables, and no bad wine or bad alcohol. And very little of women, and lots of patience."

In this reflective frame of mind, Vincent recognized that he was beginning to sound old and he touched on the idea of his own sense of death and mortality, as he said in LT 489, "I do not feel so much need of distraction, I am less harassed by my passions, and I can work more calmly, I could be alone without getting bored. I have come through rather older in the way I look at things, but no sadder." He spoke of a "homesick longing for the truly ideal life that can never come true. ... One does not rebel against things, nor is one resigned to them; one's ill because of them, and one 
does not get better, and it's hard to be precise about the cure.” Vincent expressed, “As for us who are not, I am inclined to believe, nearly so close to death, we nevertheless feel that this thing is greater than we are, and that its life is of longer duration than ours. ...We do not feel we are dying, but we do feel the truth that we are of small account, and that we are paying a hard price to be a link in the chain of artists, in health, in youth, in liberty, none of which we enjoy...”(LT 489).

Vincent noted similarities in character between the subjects that he saw in the South of France and those that he remembered from Holland, but the difference was the color. "There is that sulphur-yellow everywhere the sun lights” (LT 488). After the orchards finished blooming, he found not as many flowers as he had expected, rather he noted the green and blue in the landscapes. He reported. "Now the appearance of things has changed and become much harsher ..., I have seen very few roses here, though there are some, among them the big red roses called Rose de Provençe” (LT 488). In the absence of other subjects at this time, two still-lifes were done, a tabletop setting with a blue enamel coffeepot and a majolica pot with wild flowers.

\section{Still-Life with Blue Enamel Coffeepot}

The still-life of the blue enamel coffeepot was sketched and described in LT 489, “A blue enamel coffeepot, a cup (on the left), royal blue and gold, a milk jug in squares of pale blue and white, a cup - on the right - of white with a blue and orange pattern, on an earthen tray of grayish yellow, a jug in earthenware or majolica, blue with a pattern in reds, greens and browns, and lastly 2 oranges and three lemons; the table is covered with a blue cloth, the background is greenish-yellow, so that there are six different blues and four or five yellows and oranges.” Vincent thought highly of this still-life; in LT 497 he said, "The last canvas absolutely kills the others; it is only a 
still-life, with coffeepots and cups and plates in blue and yellow; it is something quite apart. It must be because of the drawing." In the control and serene economy of means, this painting is a worthy successor of the Dutch still-life tradition. Being very Dutch in character, this painting fits the category that Pickvance described as a reminiscence of the North.

It is apparent from Vincent's own self-assessment of the still-life with a blue enamel coffeepot that he admired and esteemed the work that he had done on this painting. He also recognized value and worth in several other paintings that he did during this time period. Vincent advised Theo to retain for himself the pink orchard on coarse canvas, the white orchard painted lengthways, and the bridge, in the belief that these three paintings would appreciate in value.

Still-Life with Blue Enamel Coffeepot seems similar to The Langlois Bridge in that it manifests the Kristevan concept of "ideology" and it may be also a reminiscence of the North. The Kristevan idea of "bounded,” means closed or with boundaries, but does not imply a connotation of something being lacking. (Kristeva, 1980, 13) StillLife with Blue Enamel Coffeepot seems bounded by the thin red line surrounding the composition that has each object perfectly placed and needing neither anything else added, nor anything taken away.

(See Figure 14 on the next page). 


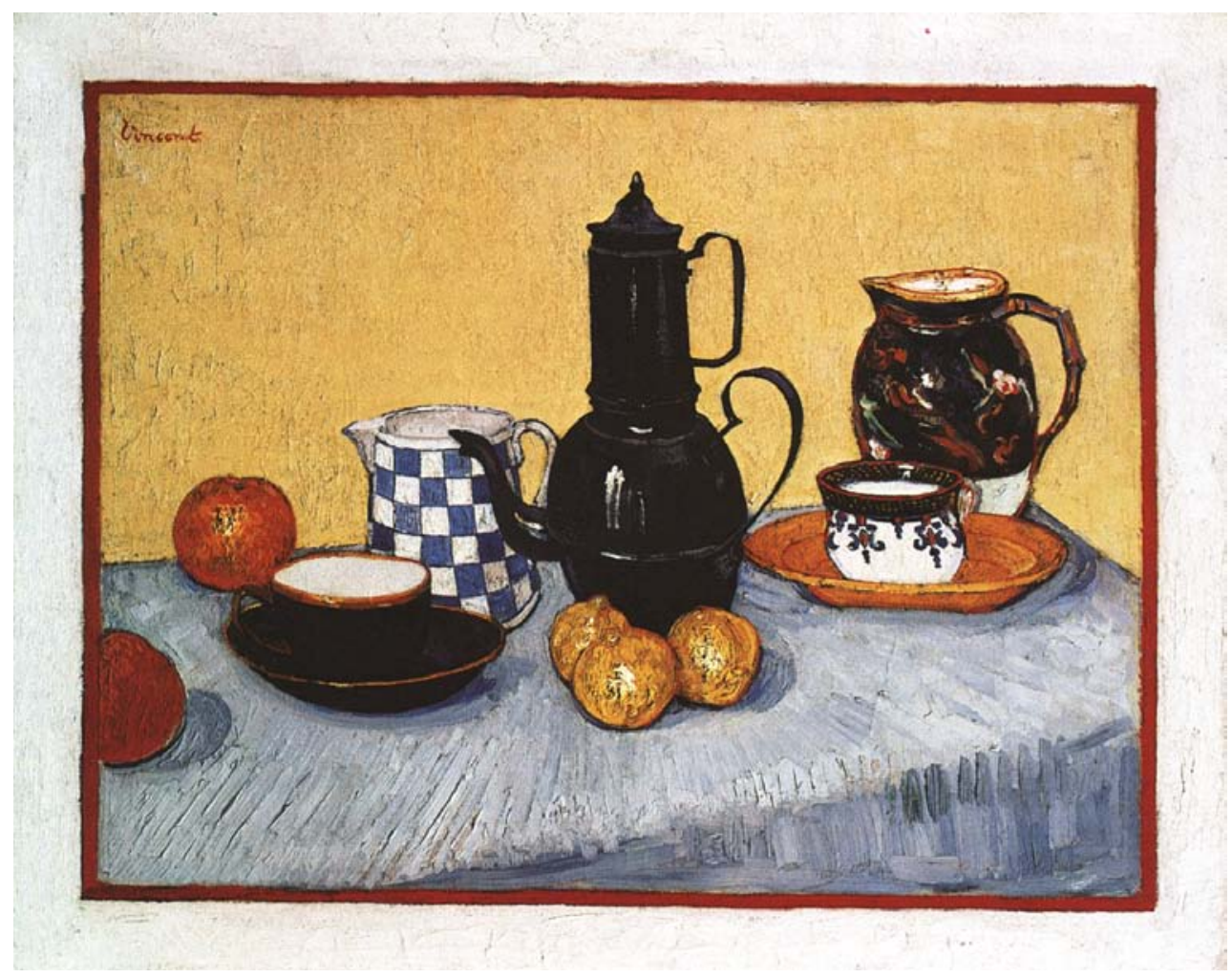

Figure 14. Still-Life with Blue Enamel Coffeepot

Pickvance, R. (1984) Van Gogh in Arles.

Metropolitan Museum of Art, New York: N.Y., p.75

The Painter of the Future

Vincent van Gogh believed that the painter of the future was coming, but that it would be someone other than himself. He referred to this “Bel Ami of the Midi, ... whom I feel to be coming, though I know it isn’t myself ... to paint the beautiful people and things here lightheartedly. As for me, I shall go on working and here and there among my work there will be things which will last ... But the painter of the future will be a colorist such as has never existed ... this painter who is to come - I can’t imagine him living in little cafés, working away with a lot of false teeth, and going to Zouaves’ brothels, as I do” (LT 482). 


\section{Painting Portraits}

Once Vincent became established in his studio in the yellow house, he felt that he could then turn his attention to the idea of painting portraits. "Now as for portraits, I'm pretty sure they'd take the bait. But first before I start along that line, I want my nerves steadier, and also to be settled in so that I could have people in my studio” (LT 481).

The Kristevan concept of ideology is apparent in Vincent's selection and presentation of models for portraits. Each portrait seems to demonstrate not only a person, but also a citizen and a role in society, for instance postman, doctor, mother, soldier. The portraits of Vincent van Gogh rise above the simply personal to the level of the presentation of archetypal images in society.

\section{Existential Malaise}

Vincent spoke with an existential malaise in LT 491 when he compared the creation of the world with an artist's study gone bad: "I feel more and more that we must not judge of God from this world, it's just a study that didn't come off. What can you do with a study that has gone wrong? - If you are fond of the artist, you do not find much to criticize - you hold your tongue. But you have a right to ask for something better. We should have to see other works by the same hand though; this world was evidently slapped together in a hurry on one of his bad days, when the artist didn’t know what he was doing or didn’t have his wits about him. All the same, according to what the legend says, this good old God took a terrible lot of trouble over this world study of his. I am inclined to think that the legend is right, but then the study is ruined in so many ways. It is only a master who can make such a blunder, and perhaps that is the best consolation we can have out of it, since in that case we have a 
right to hope that we'll see the same creative hand get even with itself. And this life of ours, so much criticized, and for such good and even exalted reasons, we must not take it for anything but what it is, and go on hoping that in some other life we'll see something better than this.”

Vincent acknowledged the drain that he must be upon his brother Theo and his resources. This concern, along with Theo's health and the possibility that he might be asked to do a lot of traveling for his work, was mentioned in LT 492, "These people's proposal to send you on short journeys across the water is terribly upsetting to you. And I accuse myself of upsetting you too - with my continual need of money.” Theo was apparently uncomplaining and it appears that he always came through. Vincent must have seemed demanding and constantly in need. This letter (\# 492) is somewhat rare in that Vincent is so empathetic and spent so much of his time discussing Theo's needs. Often Vincent seemed much more narcissistic, self-preoccupied, and selfconcerned; rarely was he as other-centered as this. Vincent advised Theo to take a year of leave to regain his health, and he offered to go with him if the company would pay his way. In advising Theo to regain his health before taking on any new work, Vincent suggested that he steep himself in nature and the world of artists as his way of finding healing.

Continuing in this existential frame of mind, Vincent discussed the Moslem concept of death, "My dear fellow, the Moslem idea that death comes only when it must - but that is a question - for my part I think that we have no proof of any direct management from above in this matter. On the contrary, I think there is proof that good hygiene not only prolongs life, but above all can make it more serene, a clearer stream; whereas bad hygiene not only muddies the current of life, but in addition the 
absolute lack of it may put an end to life before its time” (LT 492). Vincent also discussed the improvement of his own health saying, "As for me, I am feeling decidedly better, and my digestion has improved tremendously during the past month. Some days I still suffer from unaccountable, involuntary fits of excitement or else utter sluggishness, but that will pass as I get calmer.” This statement sounds like a description of bipolar cycling also known as manic-depressive disorder.

There is a postscript to LT 492 in which Vincent continued his rather gloomy discussion about death and he again expressed concern about Theo's health. "You understand so well that 'to prepare oneself for death,' the Christian idea (happily for him, Christ himself, it seems to me, had no trace of it, loving as he did people and things here below to an unreasonable extent, at least according to the folk who can only see him as a little cracked) - if you understand that to prepare oneself for death is idle - let it go for what it is worth - can't you see that similarly self-sacrifice, living for other people, is a mistake if it involves suicide, for in that case you actually turn your friends into murderers” (LT 492). The tone of regret in these remarks is made even sharper by the comment, "People matter more than things, and the more trouble I take over pictures, the more pictures in themselves leave me cold. The reason why I try to make them is to be among artists. You understand, it would make me wretched to be forcing you to make money. Rather, let's be together whatever happens ... But don't kill yourself now, either for me or for anybody else” (LT 492). There seems to be more than a little co-dependency in the relationship between Theo and Vincent with Theo in the role of the enabler. In this letter (\# 492) Vincent made mention that he could see Theo getting married. That marriage could be perceived as a threat to the codependent relationship and it might be upsetting to Vincent. 
The Issue of Paul Gauguin

Vincent addressed the issue of Paul Gauguin in LT 493. Paul Gauguin had written to Theo in a letter dated May 22, 1888, and asked for help. He had been living on credit at the inn at Pont-Aven for two months. Vincent was very concerned about any potential financial arrangement. He realized that Theo could not support both of them: “You can’t send him what will keep him going in Brittany and me what keeps me going in Provençe” (LT 493). But Vincent thought that if Gauguin would join him in Provençe that his living allowance could be sufficient for them both. He was counting on the fact that Gauguin was a sailor and that he could cook. Vincent expected that they would economize by eating at home. He recognized that they would need to buy two beds and two mattresses. Vincent suggested a sum of 250 francs a month for their allowance. For that Theo would get Vincent's work and a Gauguin painting each month. This idea brought Vincent van Gogh one step closer to his cherished dream of a painter's colony in the South of France.

Attached to LT 494 was a draft of a letter to Paul Gauguin suggesting the agreement of sharing an allowance from Theo, in return for which he would have a place to live, the companionship of Vincent van Gogh, and so forth. Vincent said “And it would seem to me that if I could find another painter inclined to work in the South, and who, like myself, would be sufficiently absorbed in his work to be able to resign himself to living like a monk who goes to the brothel once a fortnight - who for the rest is tied up in his work, and not very willing to waste his time, it might be a good job. Being all alone, I am suffering under this isolation” (LT 494a).

Vincent continued to be concerned about his brother's health and his own part in being a burden to him. "Traveling beats you up, and above all it disturbs the brain 
more than can be good for you. Anyway, I feel that I am to blame for it, and tell myself that it is my need for money that is driving you to it” (LT 495). Vincent realized that adding on the support of Paul Gauguin would increase the financial stress on Theo: “... but in addition to the hotel and traveling expenses, there is the doctor's bill, so it will be pretty steep” (LT 495). Despite these financial concerns, Vincent pressed forward with plans to incorporate Gauguin into his scheme to establish a painter's colony in the South of France. But then a few letters later in LT 498, Vincent reconsidered about including Gauguin and said, “And in the business with Gauguin too, perhaps. Let's wait and see. I thought that he was on the rocks, and there I was with money, and this boy who does better work than I do with none; so I said, He ought to have half of mine, and let him, if he likes ... and the only question left for me is simply this: if I looked for a comrade to work with, would it be a good thing, would it be to my brother's advantage and mine, and would the other fellow lose by it, or would he gain?”

\section{Vincent's Visit to Saintes-Maries}

Vincent mentioned his desire to visit the Mediterranean on several occasions, but it was not until May 30 that he was able to visit the village of Saintes-Maries. The name of the town alluded to local folklore of the arrival of the three Biblical Marys in A.D.45 to convert Provençe to Christianity and the annual celebration on May 24 and 25 (McQuillen, 1989). The belief was that the three Marys, Mary Cleopas, sister of the Virgin Mary; Mary Salome, mother of the apostles James the Greater and John the Evangelist, known as the Sons of Thunder; and Mary Magdalene, landed in 45 A.D. along with Martha, Lazarus and Maximin (Pickvance, 1984). Relics of the first two 
Marys and the remains of their servant Saint Sarah have been preserved in the church at Saintes-Maries.

Vincent left Arles by diligence, a horse-drawn carriage, at 7 A.M. Wednesday, May 30, and after crossing the grassy plain of the Carmargue, arrived in SaintesMaries at midday; he stayed until the afternoon of Sunday, June 3 (Pickvance, 1984). Vincent had planned to visit Saintes-Maries earlier, but had to delay because of financial obligations, i.e. he had to pay for having the doors and windows of the yellow house repainted, as well as for rent and art supplies. LT 499 was written from Saintes-Maries. Vincent seemed to reminisce about his native Holland while on holiday at Saintes-Maries. He remembered his uncle who had been a sailor. He described the shoreline, saying, "The shore here is sandy, neither cliffs nor rocks - like Holland without the dunes, and bluer” (LT 499). And he found the houses that he included in his drawings to be similar to the ones on the heaths and peat bogs in Drenthe.

\section{Fishing Boats on the Beach at Saintes-Maries-de-la-Mer}

While at Saintes-Maries, Vincent made several drawings which he used as a guide to paint the size 30 canvas immediately upon his return to Arles. A variety of artistic techniques were used in the creation of Fishing Boats on the Beach; the little boats are painted in a flat way using spectrum hues and a cloissonist technique. The sand is built up by use of dots while the sea and sky are made by flowing brushstrokes. The resulting canvas could be described as very painterly.

Vincent van Gogh had anticipated this trip to Saintes-Maries-de-la-Mer from the time he moved to Arles in February of 1888 until May when he was able to make the journey. Fishing Boats on the Beach at Saintes-Maries-de-la-Mer was certainly 
produced as a happy reminiscence in the life of Vincent van Gogh. Kristeva's idea of jouissance seems to be expressed in the light color tones and flowing brushstrokes of the sky and waves. The recession of the repeated motif of sailboats from the beach to the horizon punctuates the background space in a visual metaphor that seems musical, like the ringing of a bell, at first louder and then quieter and quieter. This painting is like Kristeva's poetic language, an otherness of language from ordinary communication, where the author imparts rhythm consciously or not in a transrational manner. The resulting artwork, Fishing Boats on the Beach at Saintes-Maries-de-laMer, is a lyrical and lovely painting that seems both poetic and musical. But an underlying sadness may be alluded to by the partially buried little box in the sand, possibly an unconsciously produced reminder of the little coffin that held his deceased older brother and namesake back in Holland.

(See Figure 15 on the next page). 


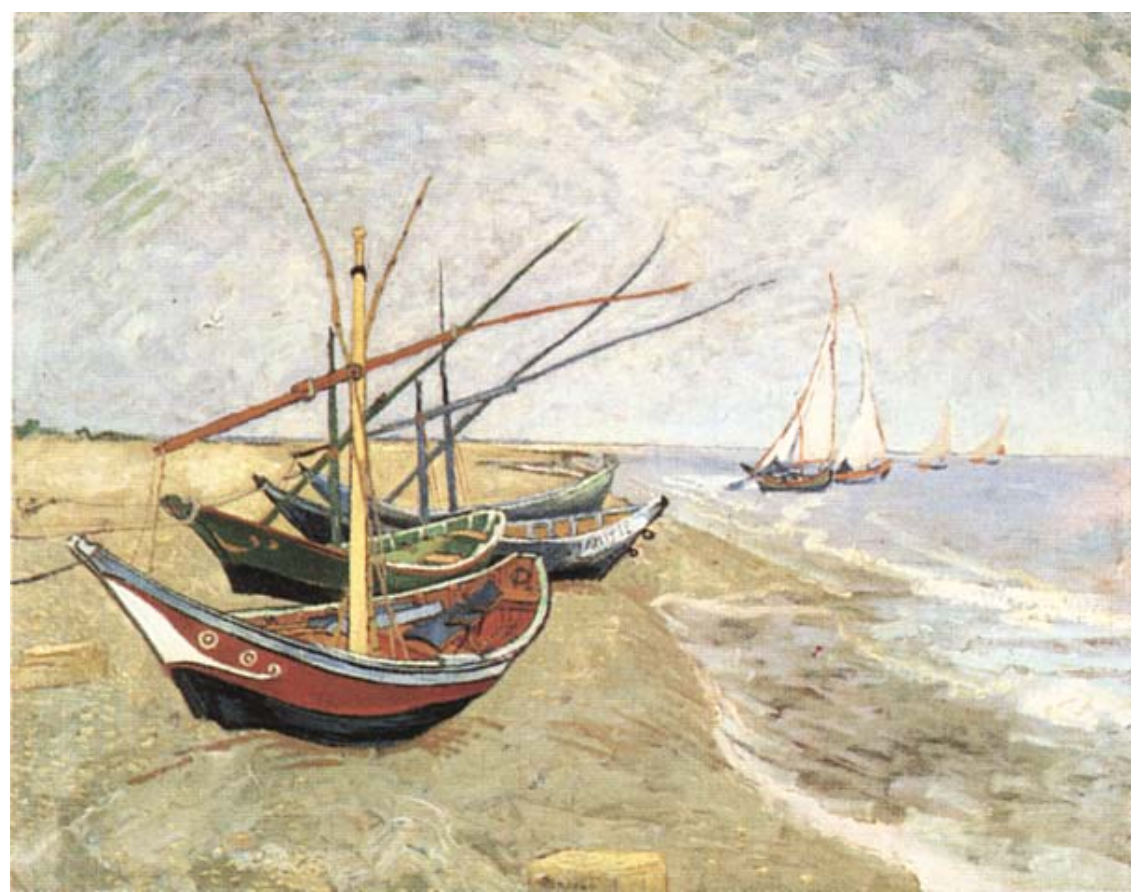

Figure 15. Fishing Boats on the Beach at Saintes-Maries-de-la-Mer Bonafoux, P. (1987) Van Gogh: The Passionate Eye.

Harry N. Abrams, Inc.: New York, N.Y., p. 90

\section{Work Ethic}

Vincent van Gogh was an artist with a strong work ethic. "And the days when I bring home a study I say to myself - If it was like this every day, we might be able to get on; but the days when you come back empty-handed, and eat and sleep and spend money all the same, you don't think much of yourself, and you feel like a fool and a shirker and a good-for-nothing” (LT 498). He worked hard despite a seeming inability to achieve any sales of pictures or any profits from his profession.

In LT 499, Vincent returned to his strange idea that the South of France was for him like Japan. "About this staying on in the South, even if it is more expensive, consider: we like Japanese painting, we have felt its influence, all the impressionists 
have that in common; then why not go to Japan, that is to say to the equivalent of Japan, the South? ... I wish you could spend some time here, you would feel it after a while, one's sight changes: you see things with an eye more Japanese, you feel color differently. The Japanese draw quickly, very quickly, like a lightning flash, because their nerves are finer, their feeling simpler” (LT 499). Vincent felt that he would be able to set his individuality free simply by remaining in the South of France and continuing his work there. "What Pissarro says is true, you must boldly exaggerate the effects of either harmony or discord which colors produce. It is the same as in drawing - accurate drawing, accurate color is perhaps not the essential thing to aim at, because the reflection of reality in a mirror, if it could be caught, color and all, would not be a picture at all, no more than a photograph” ( LT 500).

In LT 501, Vincent said that he had been working hard for a week, painting in the cornfields in the harsh sun. He mentioned studies of cornfields, landscapes, and a sketch of a sower, and "over all a yellow sky with a yellow sun." The importance of color was emphasized when Vincent wrote, "You can tell from this simple mentioning of the tones that it's a composition in which color plays a very important part.

The importance of the image of the sower is evident in Vincent's discussion of LT 501. He said that the sketch of the sower tormented him and he wondered if he should "attack it seriously and make a tremendous picture of it. My Lord, I do want to. I keep asking myself if I have enough vigor to carry it out. ... I have been longing to do a sower for such a long time, but the things I've wanted for a long time never come off. And so I'm almost afraid of it. And yet after Millet and Lhermitte, what remains to be done - is a sower, in color and large sized.” The idea of completing a large and excellent rendition of a sower kept returning to Vincent. 


\begin{abstract}
A Return to Portraiture
Vincent returned his attention to portraiture when he found a model, a Zouave, “a boy with a small face, a bull neck, and the eye of a tiger.” He described the portrait as, “a savage combination of incongruous tones, not easy to manage” and continued on to say, “all the same I'd like always to be working on vulgar, even loud portraits like this” (LT 501).

Portrait of a Zouave
\end{abstract}

Vincent described the colors used in the Portrait of a Zouave, “... in a blue uniform, the blue of enamel saucepans, with braids of a faded reddish-orange, and two stars on his breast, an ordinary blue, and very hard to do. That bronzed feline head of his with the reddish cap, against a green door and the orange bricks of a wall. So it's a savage combination of incongruous tones, not easy to manage” (LT 501).

Portrait of a Zouave illustrates the Kristevan concept of ideology. The Zouave was a military personage in his society, and as such he represented a specific cultural subgroup and a specific historical time. Additionally, this painting may be used to identify cultural reactions to the military in its own time period and henceforth whenever viewed from a current perspective. Therefore, Portrait of a Zouave can serve not only as a window onto its own time period, but also onto all future times.

Portrait of a Zouave, as it is composed and painted, shows both of the Kristevan concepts of boundedness and splitting. The head of the Zouave is strongly bounded by the green area surrounding it. Splitting and opposition are apparent in the strong red and green and in a contrast of hard and soft. An implication of strength is given in the unyielding hardness of the brick wall, but the belly of the Zouave under his blue cumberbund appears large and soft. The face of the Zouave seems strong and rugged, 
but the costume seems excessively ornate. These elements of contradiction struggle with each other in the artistic representation which is Portrait of a Zouave.

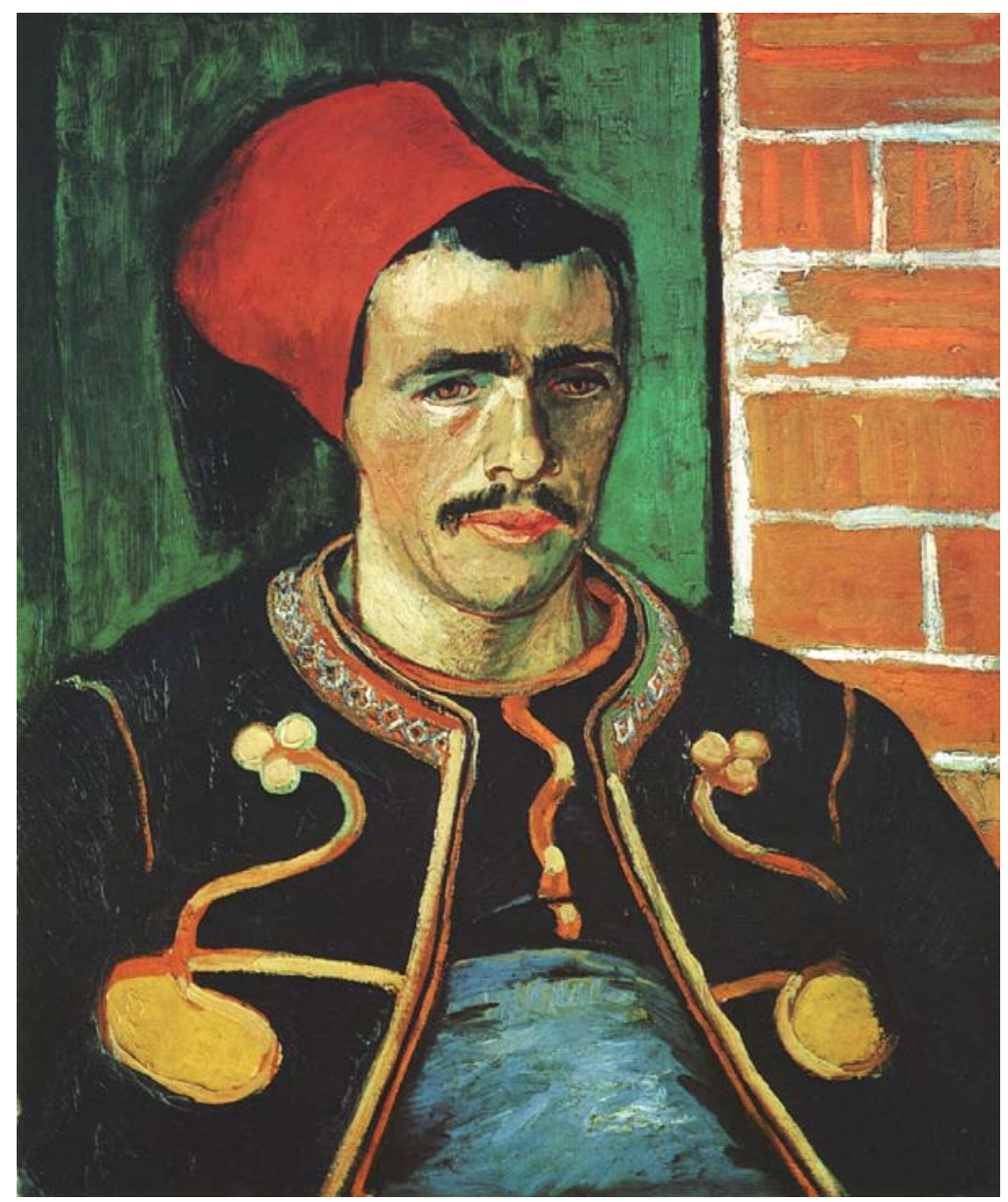

Figure 16. Portrait of a Zouave

Pickvance, R. (1984) Van Gogh in Arles.

Metropolitan Museum of Art, New York: N.Y., p.107

\section{Further Discussion of Paul Gauguin}

Before closing LT 501, Vincent returned to speculation about Paul Gauguin and whether or not he might join him in Arles. Vincent said that he did not want to persuade him or cramp Gauguin’s individuality by any association that they might have. Despite the expression of these sentiments, it was clear that he very much 
wanted Paul Gauguin to join him. The level of Vincent's concern with Paul Gaugu in seems at times obsessive. Kristeva $(1980,14)$ discussed the concept of drive (pulsion) which is sometimes qualified with instinctual and is similar to Frued's Trieb. Vincent van Gogh seemed compulsive and driven (in the Kristevan sense) as to his thoughts and concerns about Paul Gauguin. Borderline personality traits are apparent; these include concerns about abandonment, instability of interpersonal relationships and marked mood shifts.

Near the end of June, or the beginning of July 1888, Vincent wrote LT 501a to Russell and said of Gauguin, "he [Vincent] wished he was in the same place with him [Gauguin], or he [Gauguin] were here with me [Vincent].” Of his work, Vincent said that he was spending his time painting and drawing landscapes or rather studies of color. He had suggested that he and Russell make an exchange of art works and invited Russell to select one of the studies that he was sending to Paris. Vincent described the Sower, "Am working at the Sower: the great field all violet, the sky and sun very yellow, it is a hard subject to treat” (LT 501a).

\section{Dissatisfactions}

In LT 502 to Theo, Vincent said, "I am very dissatisfied with what I have been doing lately, because it is very ugly. But all the same, figure is interesting me more than landscape." He had apparently continued with his interest in drawing the Zouave and mentioned that he was sending a drawing of the Zouave to his brother. Vincent thought that Russell might want to make an exchange of art works with him for the head of the Zouave, even though he himself considered it very ugly. Vincent seemed at the time of writing this letter (\# 502) to be in somewhat of a mood; he complained of his profession, "What often vexes me is that painting is like having a bad mistress 
who spends and spends and it's never enough, and I tell myself that even if a tolerable study comes out of it from time to time, it would have been much cheaper to buy it from somebody else. The other thing, the hope of doing better, is rather a fata morgana too. But there is no quick remedy for all this, unless sometime or other you can join hands with a good worker, and produce more together." He complained of his surroundings there in the South of France, saying, "I see nothing here of the Southern gaiety ... but on the contrary, all kinds of insipid airs and graces, a sordid carelessness. But the country is beautiful in spite of it.” This letter, \# 502, has an overarching tone of moroseness, and he may have felt some homesickness, "Here, except for an intenser coloring, it reminds one of Holland: everything is flat, only one thinks of the Holland of Ruysdael or Hobbems or Ostade than of Holland as it is.” Before closing this gloomy letter, he shared one more piece of bad news, saying that he had shared four or five new studies with Scottish connoisseur of art, McKnight and his friend, and that they looked at them "in frosty silence." Vincent was apparently so out of sorts that he even sent the letter to the wrong address. In LT 503 he indicated that he had sent the letter to 54 Rue de Laval rather than 54 Rue Lepic and that it had been returned to him opened. He bemoaned the likelihood that the postal clerks had "edified themselves" by reading his mail.

The concept of painting a large sower in color stayed with Vincent. He compared the colorful Christ in the Boat by Delacroix and the gray Sower by Millet. He wanted to take the idea of the subject of the sower from Millet and idea of color from Delacroix and make them his own by doing a large colorful painting of the sower. He discussed the idea of using the simultaneous contrast of the complementary colors of yellow and violet, but he recognized the technical difficulties of 
accomplishing this. He clearly wanted his version of the sower to be a masterpiece, saying, "There is certainly a picture of this kind to be painted of this splendid subject, and I hope it will be done someday, either by me or by someone else” (LT 503). Vincent discussed the differences of his rendition and the symbolic importance of the use of color, "the sower ... is done completely differently. The sky is yellow and green, the ground violet and orange.”

LT 504 has a rather lengthy discussion of the need for supplies and discussion of the prices for canvas and paints. After that, Vincent became introspective about discussing his work and said, "I must warn you that everyone will think that I work too fast. Don't you believe a word of it. Is it not emotion, the sincerity of one's feeling for nature, that draws us, and if the emotions are sometimes so strong that one works without knowing one works, when sometimes the strokes come with a continuity and a coherence like words in a speech or letter, then one must remember that it has not always been so, and that in time to come there will again be hard days, empty of inspiration. So one must strike while the iron is hot, and put the forged bars on one side.” This statement has in it the sense of Kristeva's concepts of drive and pulsion, that Vincent felt compulsively driven to create. There is also the connotation of mania, psychogenic fugue, or self-hypnosis. In a manic state the work is done very fast. The continuity and coherence of the brush strokes that Vincent mentioned has the implication of psychogenic fugue. In self-hypnosis, the artist is so focused on the work that all else seems to vanish away from consciousness and the work seems to happen without the sense of the passage of time. Mania, psychogenic fugue and self-hypnosis all have the sense of intently focused work that seems to take on a life of its own and operates rather more through the artist than by the artist. In these profound creative 
states the maker and the product are one, outside of awareness of self and poised in eternity in the dance of creation. The ancients considered work like this to be under the control of the muse.

Vincent was still thinking of the idea of an association of artists and of working with Gauguin. He felt that two or even three artists joined together might live almost as inexpensively as he did alone. The other artists would put in at least some of their work as their collateral and this arrangement would add to Theo's stock of canvases. But Vincent expressed concern about his health, "If Gauguin won’t come to work with me, then I have no other means than my work to set against my expenses. The prospect is only moderately alarming. If my health does not betray me, I shall polish off my canvases, and there will be some that will do among them” (LT 504). Vincent planned to complete 50 studies that he would value at 200 francs each. In this way he felt that he would be earning the money that his brother Theo sent him. He reported that he had 30 completed studies, but that he did not value all of them at 200 francs.

A disagreement with Tanguy came about when he tried to charge the artists a storage fee for their pictures that were in his possession. Vincent was already upset about the poor quality of some of Tanguy's paints and his prices. Vincent said, "Believe me, you have the Tanguy woman to deal with, and if not, and if he himself is behaving like this, then he is playing me false. Tanguy still has a study of mine which he himself expected to sell. At the most I owe him that, but I do not owe him a penny in money” (LT 505). Vincent cautioned his brother to pay Tanguy nothing, for to do so would be to acknowledge a debt that he strongly denied owing. It was Vincent's contention that he did not owe Tanguy any money, because of an agreement that the 
sale of a picture would cover the expenses and that he still was in possession of a saleable study done by Vincent van Gogh.

Vincent used the term “poisonous” to describe Mme Tanguy in LT 505, and in LT 506 he said that she was "more dangerous in the civilized world they go about in than the poor souls bitten by mad dogs who live in the Pasteur Institute. And old Tanguy would be right a hundred times over if he killed his lady ... but he won’t do it. ... And for this reason old Tanguy has more in common - in resignation and long suffering anyhow - with the ancient Christians, martyrs and slaves than with the present-day rotters of Paris.”

\section{More Existential Remarks}

The succession of the seasons and the variety of colors that they provided was inspirational to Vincent and seemed to give him a reason to work and a reason to be. "The wheatfields have been a reason for working, just like the orchards in bloom. And I only just have time to get ready for the next campaign, that of the vineyards. ... The orchards meant pink and white; the wheatfields yellow; and the marines blue. Perhaps now I will look around for a bit of greens. There's the autumn, and that will give the whole scale of the lyre” (LT 504). Vincent van Gogh was in tune with the complementarities of the seasons and the ways that they complete each other in order to create wholeness.

There are several existential remarks in Vincent’s rather lengthy letter, \# 506: "It certainly is a strange phenomenon that all artists, poets, musicians, painters, are unfortunate in material things - the happy ones as well... That brings up again the eternal question: Is the whole of life visible to us, or isn't it rather that this side of death we see only one hemisphere? Painters - to take them alone, dead and buried 
speak to the next generation or to several succeeding generations through their work. Is that all, or is there more to come? Perhaps death is not the hardest thing in a painter's life. For my own part, I declare I know nothing whatever about it, but looking at the stars always makes me dream, as simply as I dream over the black dots representing towns and villages on a map. Why I ask myself, shouldn't the shining dots of the sky be as accessible as the black dots on the map of France? Just as we take the train to get to Tarasçon or Rouen, we take death to reach a star. One thing undoubtedly true in this reasoning is that we cannot get to a star while we are alive, any more than we can take the train when we are dead. So to me it seems possible that cholera, gravel, tuberculosis and cancer are the celestial means of locomotion, just as steamboats, buses and railways are the terrestrial means. To die quietly of old age would be to go there on foot.” 


\section{CHAPTER IV}

\section{ARLES, PART 2: WAITING FOR GAUGUIN}

\section{Mid-July 1888 to October 20, 1888}

Vincent had become engrossed in his plan for a studio of the South and that he would be joined by Paul Gauguin in the Yellow House. Theo had written to Vincent that Gauguin agreed to their plan and Vincent responded to that news from Theo in LT 507, "Your letter brings great news, namely that Gauguin agrees to our plan. Certainly the best thing would be for him to come rushing here at once. Instead of getting out of a mess, he will probably get into one if he goes to Paris first.” Vincent went on to say that he was enthusiastic about painting in the South, but equally so about the North, and was willing to move to Brittany where the expenses might be less even despite the winter weather that he did not like. Vincent said that he could move to the North because his health was better than it had been six months ago.

\section{Sheer Work and Concentration}

Vincent described a method of working that involved completing all the essential work of a painting in a single long sitting with as little change as possible in the retouching. But this intense method of working took its toll upon him. Vincent said, “after a spell like that, I assure you my head is so tired that if that kind of work keeps recurring, as it has done since this harvest began, I become hopelessly absent-minded and incapable of heaps of ordinary things ... when I come back to myself from the mental labor of balancing the six essential colors, red - blue - yellow - orange - lilac - 
green. Sheer work and calculation, with one's mind strained to the utmost, like an actor on the stage with a difficult part, with a hundred things to think of at once. ... After that, the only thing to bring ease and distraction, in my case and other people's too, is to stun oneself with a lot of drinking or heavy smoking” (LT 507). This statement indicates substance abuse and racing thought patterns indicative of mania. Vincent denied that he would maintain a feverish condition artificially, but that he was "in the midst of a complicated calculation which results in a quick succession of canvases quickly executed but calculated long beforehand. So now, when anyone says that such and such is done too quickly, you can reply that they have looked at it too quickly” (LT 507). This same hasty tone continued in the next letter, "Work engrosses me so much that I cannot manage to write letters” (LT 508).

Usually Vincent van Gogh seemed to have been a rather solitary figure, totally occupied with his work, but in LT 508 he described intense feelings of loneliness, "When I came here I hoped it would be possible to make some connection with art lovers here, but up to the present I haven’t made the least progress in people's affection. ... Often whole days pass without my speaking to anyone, except to ask for dinner or coffee. And it has been like that from the beginning. But up to now the loneliness has not worried me much because I have found the brighter sun and its effect on nature so absorbing.”

\section{Money Trouble and Mistral}

In LT 508 Vincent complained that he was seeing the bottom of his purse after he paid his rent. Expenses for living, food and lodging, and expenditures for his art seemed to take all of his allowance. He continued with his concerns about money in LT 
509, saying that he could not help with money as they were entering the combination with Gauguin, but it was his hope that some of his pen and ink drawings of the Crau and of the banks of the Rhone would sell. The difficulties that he endured doing these drawings was described: "Not everyone would have the patience to get themselves devoured by mosquitoes and to struggle against the nagging malice of this constant mistral, not to mention that I have spent whole days outside with a little bread and milk, since it was too far to go back to town every once in a while” (LT 509). Vincent reported that he had walked there "with a painter, and he said 'there is something that would be boring to paint.' Yet I went fully fifty times to Mont Major to look at this flat landscape, and was I wrong? I went for a walk there with someone else who was not a painter, and when I said to him, 'Look, to me that is as beautiful and as infinite as the sea,' - and he knows the sea." Vincent then wrote, 'For my part, I like this better than the sea, because it is no less infinite, and yet you feel that it is inhabited'” (LT 509). Vincent complained of "this damn wind" and how it inhibited his work by making the easel shake all the time. But he said that the wind did not bother him when he was drawing. Vincent, like many artists, seemed to have an ability to hyper-focus when he was creating art.

Letter 510 dealt almost completely with financial concerns. Vincent apparently sent 50 francs back to Theo to assist in settling an account on Japanese prints with a dealer named Bing. He discussed the importance of Japanese prints to his own work as well as to the impressionists in general, saying "In a way all my work is founded on Japanese art” (LT 510). Vincent also included a suggestion of how he would reply to old Tanguy’s “absurd” bill, saying that he would draw up a bill as follows: 
Portrait of Tanguy 50

Portrait of Mme. Tanguy 50

Portrait of Mme. Tanguy's friend 50

Money Tanguy has made on paints 50

Friendship, etc. 50

Some failed dreams and schemes were also mentioned in this same letter: that he had wished to have a showroom of his own at a café when he was in Paris, but that fell through; that the exhibition of prints that he had had at the Tambourin was a disaster; that the second exhibition at the Boulevard de Clichy had some advantages, i.e. Bernard sold his first picture there, Anquetin sold a study, and Vincent made an exchange with Gauguin; other than that it was not very successful. Vincent suggested that he and Gauguin might have a similar exhibit at Marseilles, but he was not sure that there would be any greater success than in Paris.

The business with Bing concerning Japanese prints occupied Vincent as he wrote LT 511. He was positive of the speculative value of the Japanese prints and felt sure that they would increase greatly in value. Vincent advised Theo not to sell the prints, but to even select and buy more, "If I was not caught and absorbed in my work, how I should love to sell the whole pile. There isn’t much to be made out of it. That's why no one takes it up. Nevertheless, in a few years all these prints will become very rare, and will bring higher prices. That's why we must not undervalue the small advantage we have now in rummaging through thousands of them to make our choice... So please hang on to the stock and do not get rid of any fine prints -for that matter it would pay us better to get more” (LT 511). If Theo did sell any, Vincent advised that he should sort them in order to retain the ones that they liked the most. Vincent was sure of the enduring quality of Japanese art, "But to wind up our 
connection with Bing, oh never! Japanese art is a thing like the Primitives, like the Greeks, like our old Dutchmen, Rembrandt, Potter, Hals, Van der Meer, Ostade, Ruysdael. They never pass away” (LT 511).

\section{The Stars Make Me Dream}

Before closing LT 511, which was written on a Sunday, Vincent returned to a philosophical discussion of his existential thoughts and beliefs, “let's don't forget that this earth is a planet too, and consequently a star, or celestial orb. And if all the other stars were the same!!! That would not be much fun; nothing for it but to begin all over again. But in life, for which one needs time, it would not be so bad to live more than one life. And it is rather attractive to think of the Greeks, the old Dutch masters, and the Japanese continuing their glorious school on other orbs” (LT 511). This discussion prefigures his painting of The Starry Night.

\section{Working Headlong and Getting Older}

An interesting statement as to his method of working was revealed in LT 512. Vincent reported that Theo’s letter came when he was “still dazed with the sun and the strain of wrestling with a rather big canvas.” A few sentences later in this same letter an introspective statement is made, “And I truly can’t tell if I shall ever paint pictures that are peaceful and quietly worked out, for it seems to me it will always be headlong.” This headlong quality of working is typical of both the impulsivity of Borderline Personality Disorder and the manic phase of Bipolar Disorder. Kay Redfield Jamison (1993) is a Professor of Psychiatry at Johns Hopkins University, and she kept her own diagnosis of Bipolar Disorder secret for as long as she could, fearing for both her employment and her reputation. Writing with firsthand knowledge, Jamison (ibid.) asks 
this question, "Who would not want an illness that has among its symptoms elevated and expansive mood, inflated self-esteem, abundance of energy, less need for sleep. Intensified sexuality, and - most germane to our argument here - 'sharpened and unusually creative thinking' and 'increased productivity?' ” Jamison includes Vincent van Gogh in her extensive list of poets, writers, both classical and nonclassical composers and musicians, and artists that she considers to have been Bipolar.

The existential tone continued like a thread that Vincent picked up again and again to weave into his letters. Vincent mentioned several times in LT 513 that he was getting older, “But our carcasses are no longer young ... The painter’s fingers of mine are growing supple, even though the carcass is going to pieces. ... I am getting older than you, and my ambition is to be less of a burden to you. And, if no actual obelisk of too pyramidal a catastrophe occurs, and there's no rain of frogs in the meantime, I hope to achieve it sometime. ... What's wrong - basically is that we are getting older, and must behave accordingly.”

\section{Financial, Physical and Mental Concerns}

Financial concerns and Vincent's own assessment of his mental status are also addressed in LT 513: "All it has cost me is a carcass pretty well destroyed and wits pretty well crazed, and only to lead the same life I might and should lead if I were a philanthropist. All it has cost you is, say, 15,000 francs, which you have advanced to me. ... If I reminded you just now of what painting costs us, it is only to tell ourselves that we have gone too far to turn back, that's all I harp on. For material existence aside, what else shall I ever need? My dear brother, if I were not broke and crazy with this blasted painting, what a dealer I'd make just for the impressionists. But there, I am 
broke.” Despite his unfortunate financial situation at this time, Vincent soothed himself with a reminder that a canvas that he painted was worth more than a blank canvas and that he felt that he could say of himself that he was at the height of his powers and talent, even if he was not at the height of his finances, "My concentration becomes more intense, my hand more sure. That is why I almost dare to swear to you that my painting will improve” (LT 513).

Vincent used the terms "crazy" and "cracked" several times to describe his mental state: "If I were to think of and dwell on disastrous possibilities, I could do nothing. I throw myself headlong into my work and come up again with my studies; if the storm within gets too loud, I take a glass too much to stun myself. Cracked, of course; when you look at what one ought to be. But in the old days I used to feel less of a painter, now painting is becoming a distraction for me, like rabbit hunting for the cracked-brained: they do it to distract themselves. ... After the crisis which I went through when coming down here, I can make no plans or anything; I am decidedly better now, but hope, the desire to succeed is gone, and I work because I must, so as not to suffer too much mentally, so as to distract my mind” (LT 513). In this last statement Vincent van Gogh alluded to the healing power of art and the value of art as personal therapy. He also mentions again the use of alcohol. Persons with Bipolar disorder often attempt to self-medicate and control their symptoms by the use of alcohol or other substances.

Theo apparently responded to Vincent’s comments about getting old with depressive statements of his own, because in LT 514 Vincent replied to Theo, "Now you talk of the emptiness you feel everywhere, it is just the very thing I feel myself.” It 
is apparent, though, in spite of this overarching tone of sadness, that Vincent van Gogh had a sense of his own importance in the great stream of art history, and he also acknowledged Theo's contributions, “Considering, if you like, the time in which we live a great and true renaissance of art, the worm-eaten official tradition still alive but really impotent and inactive, the new painters isolated, poor, treated like madmen, and because of this treatment actually becoming so, at least as far as their social life is concerned: Then remember that you are doing exactly the same work as these primitive painters, since you provide them with money and sell their canvases for them, which enables them to produce others. If a painter ruins his character by working hard at painting, a thing which leaves him useless for many other things, for family life, etc., etc., if therefore he paints not only with colors, but with self-denial and selfrenunciation and with a broken heart - as far as you are concerned, your own work is not only no better paid than his, but it costs you exactly what the painter's costs him, this sacrifice of the individuality, half-voluntary, half accidental. That is to say that if you paint indirectly, you are more productive than I am, for instance. The more irrevocably you become a dealer, the more you become an artist” (LT 514). Vincent seems to be discussing the mood swings between mania and depression that are the hallmark of Bipolar disorder.

Winds of Change in the World of Art

Vincent van Gogh was aware that the winds of change were blowing through the art world of his time and he believed that they were in the midst of a new kind of renaissance of art. "The more I am spent, ill, a broken pitcher, by so much more I am an artist - a creative artist - in this great renaissance of art of which we speak. These things 
are surely so, but this eternally living art, and this renaissance, this green shoot springing from the roots of the old felled trunk, these are such abstract things that a kind of melancholy remains in us when we think that one could have created life at less cost than creating art” (LT 514). Vincent's self-prescribed remedy for the depression that he describes is not to depend upon art, but to depend upon himself, "the only way to get back my confidence and peace of mind is to improve my work" (LT 514).

Advice about Self-care

Vincent van Gogh, who was not exemplary in taking care of himself, gave Theo advice about personal care, hygiene, and other remedies. Vincent remembered the advice that his former Doctor (Gruby) had given him, and he passed this advice on to his brother: "Take care of your health, above all take baths if Gruby recommends it, for in the four years by which I am older than you, you will see how necessary comparatively good health is for being able to work. Now for us who work with our brains, our one and only hope of not breaking down too soon is this artificial eking-out by an up-to-date hygienic regimen rigorously applied, as much as we can stand. Because I for one do not do everything I ought. And a bit of cheerfulness is better than all the other remedies” (LT 514). Vincent stated that both he and his pictures had become haggard looking, comparing himself to Hugo van der Goes in the picture by Emil Wauters, “Only, having got my whole beard carefully shaved off, I think that I am as much like the very placid priest in the same picture as like the mad painter so intelligently portrayed therein (LT 514). This sounds like the self-portrait (as a Bonze), and the description includes within it two very different personality types (placid priest and mad painter), both of which Vincent perceived within himself. Kristeva (1980, 
126) has a concept of an organic identity that unites similar persons, things, etc., but within the personality of Vincent van Gogh, there seems to have been what this author is calling organic disparity as evidenced by instability of self-image, which is a diagnostic criterion for both Bipolar and Borderline Personality Disorder.

\section{La Mousmé}

A portrait, La Mousmé, is mentioned, in LT 514. Vincent said that he had read Madame Chrysantheme and that it explained what a mousmé is, "a mousmé is a Japanese girl - Provençal in this case - 12 to 14 years old.” Vincent said that he now had two portraits, The Zouave and La Mousmé. He gave his description of La Mousmé, "The portrait of the girl is against a background of white strongly tinged with malachite green, her bodice is striped blood red and violet, the skirt is royal blue, with large yellow-orange dots. The mat flesh tones are yellowish-gray; the hair tinged with violet; the eyebrows and the eyelashes are black; the eyes, orange and Prussian blue. A branch of oleander in her fingers, for the two hands are showing."

This portrait, La Mousmé, shows both Kristeva’s concept of an organic identity and organic disparity. As an example of organic identity, La Mousmé, is representative of young girls of her age group. Like many of Vincent’s portrait models, she is a citizen of Arles (France) and nationality is a way of classifying by organic identity. But Vincent blurs this national identity by giving a Japanese connotation to the portrait, $\mathrm{La}$ Mousmé, as well as to his Self-Portrait (as a Bonze). Vincent's fascination with things Japanese and his tendency to give a Japanese interpretation to some of his paintings from the South of France, shows organic disparity expressed in his art. While Vincent made a conscious artistic choice to orientalize his paintings, it seems that the 
subconscious motive behind this choice is an organic disparity in the personality and mental processes of Vincent van Gogh.

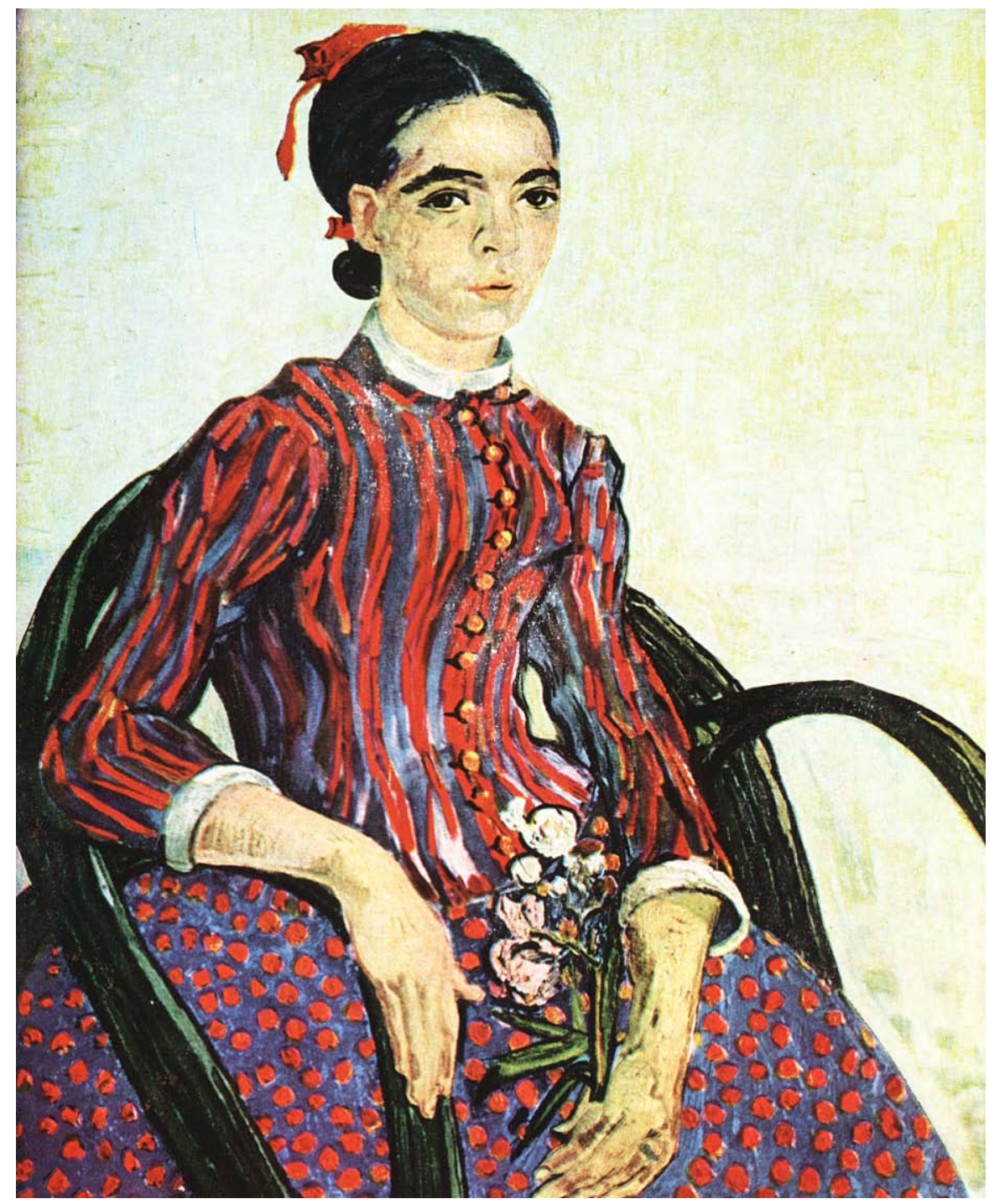

Figure 17. La Mousmé

Huyghe, R. (undated) Van Gogh. Flammarion: Italy, p. 46

\section{Loneliness and Longing for Companionship}

Loneliness seemed to be taking its toll on Vincent van Gogh, “it would make a tremendous difference to me if Gauguin were here, for now the days go by without my 
speaking a word to anyone. ... If you are alone in this country too long, you get stupid, and though not yet - still this winter - I may become sterile because of this. Now if he came, there would be no danger of this, because there would be no lack of ideas" (LT 515). The voluminous amount of correspondence primarily with his brother, but also with other people, seems have been a substitute behavior for personal contact and close personal relationships during much of the life of Vincent van Gogh. Having been fearlessly and fiercely independent in his life up to now, except for brief times of female companionship, it seems that now he longed for a compatriot to work with. This observation is in line with a concept of Jungian psychology that there will be reversals in personal qualities during the second half of life. That which you were not in the first half of life, you will become during the second half. This is not true in every small detail of a life; but in some overarching way, according to Carl Jung, there will be a change. A reversal of the previously solitary and independent Vincent van Gogh was that now he longed for companionship.

\section{Existential Musings}

In early August, 1888, Vincent received the news that his uncle had died, and this returned Vincent to musing about existential concepts; "How short life is and how like smoke. Which is no reason for despising the living, on the contrary. So we are right to care more for the artists than for the pictures” (LT 516). Vincent, having taken the words of his sister to heart, repeated them to his brother in LT 516: "As our sister said, from the moment people are gone, you remember only their good moments and their good qualities. But the great thing is to try to see these while they are still with us. It would be so simple and would account so much for the terrible things in life, which 
now amaze and wound us so, if life had yet another hemisphere, invisible it is true, but where one lands when one dies. To those who make this interesting and solemn journey, our best wishes and sympathy.” This verbalization seems to describe the Jungian concept of the collective unconscious, and it seems to relate to the union of pairs of opposites like life and death, visible and invisible, spirit and matter. The Yin-Yang image, symbol of the Tao, pictorially expresses these same concepts. Here in LT 516 Vincent used the words of his sister as well as his own words to express this dualistic concept of Jungian psychology, in other instances, the organic disparity in his words and images express it.

LT 517 found Vincent wrestling with whether or not to rent the yellow house for another six months. He had not yet heard from Paul Gauguin. He was late with his rent and the landlord suggested that he could find another tenant. This seemed to annoy Vincent because he had done some repairs and improved the property. He had spent his money on models for his painting. His new model was the postman and he was doing two portraits of the same model. He mentioned how deeply satisfying it was to him to work on portraits, "There is no better or shorter way of improving your work than doing figures. And I always feel confident when I am doing portraits, knowing that this work has much more depth - it isn't the right word perhaps, but it is what makes me cultivate whatever is best and deepest in me” (LT 517).

Vincent continued with similar sentiments in LT 518, still discussing his uncle’s death, "The best way to cope with death is to accept the illustrious departed, whatever he was, as being the best man in the best of all possible worlds, where everything is for the best.” As to himself, Vincent said, “And meanwhile I am in my own hide, and my 
hide caught in the wheels of the Fine Arts, like wheat between the millstones.” This image of being the wheat was connected to concepts of life and death and was expressed in Vincent's fascination with images of the sower and the reaper, who represent the beginning and the ending of all that is.

In discussing his work, Vincent said that the haggard look of some of his studies was because he had to fight against the mistral, and because of the fierce wind, he said it was hard to be the master of his stroke. Vincent van Gogh was absolutely dedicated to the idea of plein air painting and of being on site when doing studies from nature.

When he was confined indoors, still-lifes and portraits became Vincent's subjects. His most recent portrait work had been two versions of the postman, a half length with the hands and a life size head. He said that the postman had posed very well, and would not accept payment for posing, but that it cost more eating and drinking with him than normal payment would have been. There was another privilege as well, as the postman's wife had just recently had a baby, and Vincent expected to paint a portrait of the baby in the near future. An additional subject that Vincent mentioned was a “café de nuit,” an interior scene of the café where he ate in the evenings.

The Portrait of Joseph Roulin is yet another example of Kristeva's concept of organic identity. Roulin, a French citizen, a civil servant (postman), and a patriot, also exemplifies Kristevan idéologie (ideology). The uniform and demeanor of the postman are a sign system created by the signifying practice (pratique signifiante) that establishes the identity of the subject within a social framework (Kristeva, 1980, 18). This portrait, like many of van Gogh's portraits, is an example of a type and is presented in a grand manner rather than simply an individual personification. 


\section{Portrait of Joseph Roulin}

The first portrait that Vincent van Gogh painted of the postman Joseph Roulin was begun near the end of July and finished August 6 according to LT 516, 517, and 518. Vincent complained that Roulin posed stiffly, "I do not know if I can paint the postman as I feel him. ... I once watched him sing the 'Marseillaise,' and I thought I was watching '89, not next year, but the one ninety-nine years ago” (LT 520). When he wrote to Theo and his sister Wil, Vincent discussed the patriotism of Joseph Roulin, his character, appearance and opinions, but he did little to describe the portrait painting (Pickvance, Arles, 152). However, in writing to his artist friend, Emile Bernard, (letters indicated by the letter B and a number), Vincent described the colors in Portrait of

Joseph Roulin, “A Socratic type, none the less Socratic for being somewhat addicted to liquor and having a high color as a result. ... A blue, nearly white background on the white canvas, all the broken tones in the face - yellows, greens, violets, pinks, reds. The uniform Prussian blue with yellow adornments” (B 14). Roulin is somewhat awkwardly posed in the same chair that was used in La Mousmé, with his arm resting even more awkwardly on the nearby diagonally placed table. There seems to be a spatial contradiction by the diagonal placement of the line where the floor and wall meet. It does not result in a right angle for the corner behind Roulin.

(See Figure 18 on the next page). 


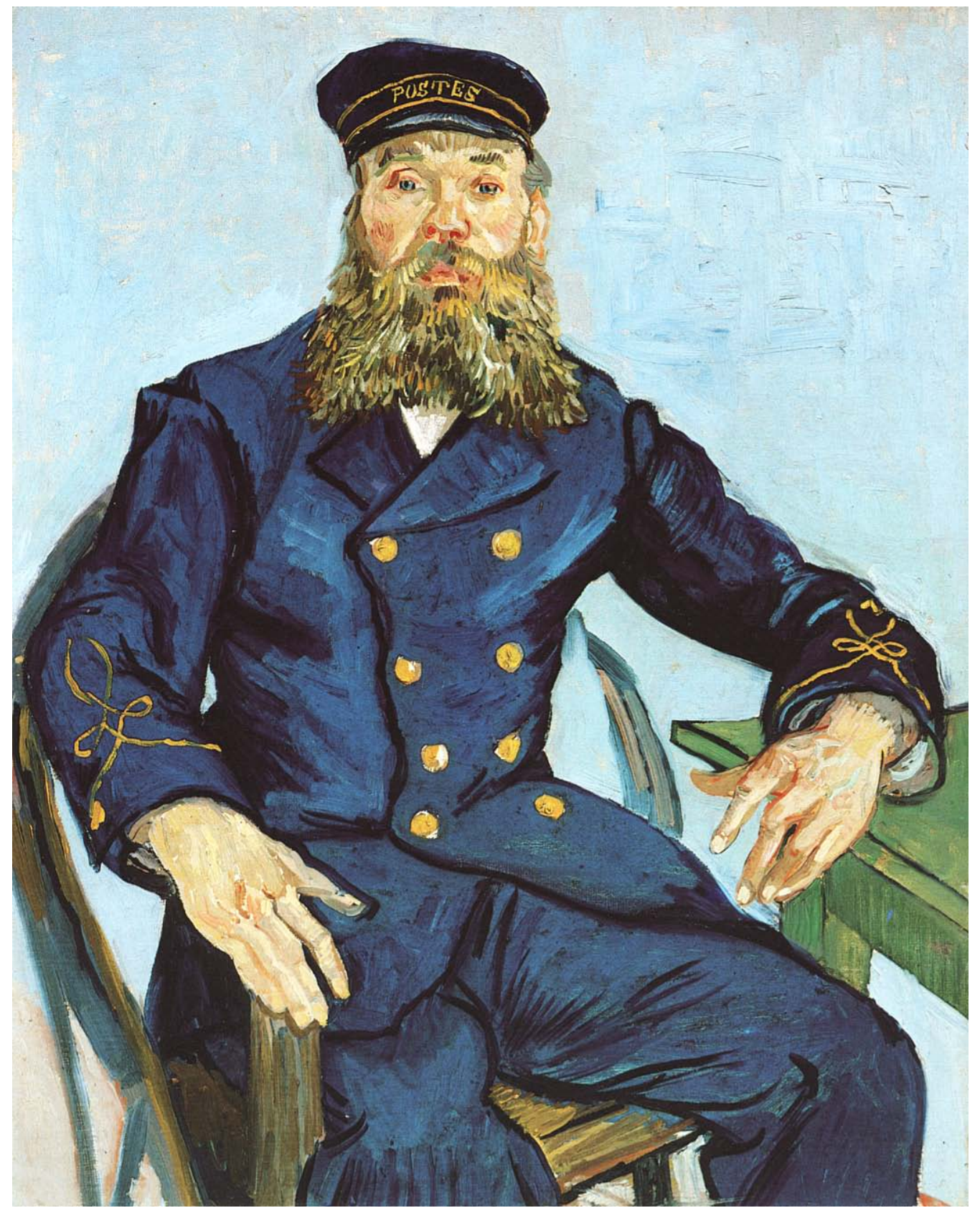

Figure 18. Portrait of Joseph Roulin

Pickvance, R. (1984) Van Gogh in Arles.

Metropolitan Museum of Art: New York, N.Y. p. 153. 


\section{Existential Concerns}

The death of his uncle seemed to set Vincent van Gogh to pondering and musing about the concept of an afterlife. The death of a loved one often brings up concern about one’s own mortality. Vincent was aware of his aloneness and being away from family and native land, but he felt that he was doing pretty well without them. "I always feel I am a traveler, going somewhere and to some destination. If I tell myself that the somewhere and the destination do not exist, that seems to me very reasonable and likely enough" (LT 518). At the end of his career Vincent wondered if he would find that "not only the Arts but everything else were only dreams, that one was nothing at all oneself. If we are as flimsy as that, so much the better for us, for then there is nothing to be said against the unlimited possibility of future existence” (LT 518). Vincent mentioned two proofs that made him feel a sense of belief in the afterlife. Vincent reported that he had looked upon the face of a deceased one and had seen a calm, peaceful, or grave expression unlike the expression while still alive. His second example was the experience of looking into the eyes of a child in the cradle and seeing the infinite there. "In short, I know nothing, nothing about it, but it is just this feeling of not knowing that makes the real life that we are actually living now like a one-way journey on a train. You go fast, but cannot distinguish any object very clearly, and above all you do not see the engine” (LT 518).

Vincent van Gogh’s unusual statement about a train seems to allude in a precognitive way to Einstein's special theory of relativity which would be published in 1905 in the German Annalen der Physik. Einstein’s special theory of relativity dealt with space, time, and light, which are also formal elements in art. Light is often 
considered in conjunction with color and value, and time and motion are usually placed together. According to the old concepts of physics, i.e. Newtonian physics, space, time, and light were all considered to be rigid and constant. Space was believed to be absolute, flat, homogeneous, inert, and everywhere the same (Schlain, Art and Physics, 1991). Newton also believed that time was an absolute quantity, an ever-constant, irresistible river that flowed in only one direction, with a given unit of time such as a minute being everywhere the same. In the early nineteenth century the speed of light was calculated by Augustin Fresnel to be 186,000 miles per second (ibid.). Einstein’s special theory of relativity turned everything upside down; he declared that only the speed of light was constant, and that space and time were relative. For example, if a train were moving away from a clock tower at precisely the speed of light, the time on the clock tower would appear not to change, but obviously there would be a passage of time. Time slows as one approaches the speed of light and the present moment expands from a narrow sliver until it encompasses both the past and the future; furthermore at lightspeed, time ceases to change because it contains all change (ibid.). According to the special theory of relativity, traveling at high relativistic speeds creates bizarre distortions in the shape of ordinary objects, and rigid forms change their appearance when viewed at speeds that approach the speed of light. Therefore space is interactive with the volume, shape, and size of objects within it and can deform objects according to the observer's relative speed. Within works of art, the visual elements of space, time, and light are manipulated according to the will of the artist, i.e. they are relativistic in art as well as in physics. 
Vincent mentioned that both his uncle and his father believed in the afterlife, but that they became angry if it was questioned or discussed deeply. Of his mother he said, "If the kind old mother of a family, with her rather limited ideas, and tortured by the Christian system, is to be immortal as she believes, and seriously too ... why should a consumptive or neurotic cab horse with vast ideas like Delacroix and de Goncourt, be any less immortal” (LT 518)? He disregarded the idea of the artist living on through his works by asking, "But is that all?” And he questioned the doctors who "will tell us that not only Moses, Mahomet, Christ, Luther, Bunyan and others were mad, but Frans Hals, Rembrandt, Delacroix too, and also all the dear narrow-minded old women like our mother. Ah - that's a serious matter - one might ask these doctors: Where then are the sane people” (LT 518)? This is an interesting question in that psychology can define the abnormal, but it is more difficult to be able to state what is normal. It is typically a treatment criterion to ask, is this manifestation of the personality perceived as interfering with daily functioning? If the answer is yes, then it is clinically significant, i.e. not normal.

\section{A Self-Critique}

A self-critique of his work is given by Vincent van Gogh in LT 519. He had just sent three big drawings of gardens to Theo, a cottage garden, the little garden of a bathing establishment with sunflowers, and a horizontal treatment of a garden. He considered the cottage garden to be the best. He said that he regretted not painting more flowers while living in the South of France. He mentioned painting a Harvest, a Garden, and the Sower as well as two marine sketches after painted studies. His painted studies he felt lacked clearness of touch. 
Vincent considered whether or not Gauguin would be able to join him and thought about the possibility that he might need to be the one to move if Gauguin could not afford to relocate. He mentioned how much he enjoyed the weather, the sunshine and the colors of nature in the South of France. He said, "I am feeling very, very well these days. In the long run I think I shall come to belong to the country altogether” (LT 519).

Vincent mentioned wanting to paint "a poor old peasant, whose features bear a very strong resemblance to Father, only he is coarser, bordering on a caricature” (LT 519). Vincent was experiencing transference between the peasant and his father. Transference is the technical term that describes the exchange of feelings about one person to another person, and it may be rational or irrational, conscious or unconscious. But the old peasant, if he sat for the portrait, wanted to keep the picture, and Vincent objected to having to paint two copies. This is unusual because he often painted two copies or versions, as he had done with the portrait of the postman. In this same letter he mentioned that he had done another portrait of the Zouave.

\section{Portrait of Eugene Boch, also known as The Poet}

Vincent described the Belgian artist Eugene-Guillaume Boch: "He is a young man whose appearance I like very much, a face like a razor blade, green eyes, and a touch of distinction” (LT 505). By August 11, Vincent clearly described his conception of the painting that he wanted to do of Boch: "I should like to paint the portrait of an artist friend, a man who dreams great dreams, who works as the nightingale sings, because it is his nature. He'll be a blonde man. I want to put my appreciation, the love I have for him, into the picture. So I paint him as he is, as faithfully as I can, to begin 
with. But the picture is not yet finished. To finish it I am now going to be the arbitrary colorist. I exaggerate the fairness of the hair, I even get to orange tones, chromes and pale citron yellow. Behind the head, instead of painting the ordinary wall of the mean room, I paint infinity, a plain background of the richest, intensest blue that I can contrive, and by this simple combination of the bright head against the rich blue background, I get a mysterious effect, like a star in the depths of an azure sky” (LT 520). Finally on September 2, 1888, Boch sat for van Gogh, "Well, thanks to him I at last have a first sketch of that picture which I have dreamed of for so long - the poet. He posed for me. His fine head with that keen gaze stands out in my portrait against a starry sky of deep ultramarine, for clothes, a short yellow coat, a collar of unbleached linen, and a striped tie. He gave me two sittings in one day” (LT 531). When Vincent attempted to recreate the study as a canvas, he felt that the color was right, but the form was not, and in his dissatisfaction, he destroyed the canvas. The study is the copy that remains.

Vincent referred to Eugene Boch as the Belgian. Boch was an aspiring artist who was learning impressionistic techniques. The idea was discussed that Boch might go to the Borinage and set up a sort of post in the coal mines where he could draw and paint. Living in the Borinage had been a step in the artistic development of Vincent van Gogh and it seems as if he is mentoring Boch to follow in his own footsteps. There was even the idea of Boch establishing a post among the coal mines so that there would be a colony of artists in the South of France and one in the North and the artists could travel between these locations. 
Boch represents the type, i.e. organic identity, that is the poet and a person of artistic sensibilities. By setting the portrait against a night sky with stars, the transcendence of the poetic type is conceptually united with other similar thinkers in all time and space. Kristeva's Revolution in Poetic Language $(1984,1)$ refers to the profound change that began to take place in the literary representation of the nineteenth century post-Symbolist avant-garde. This change affected not only literature, but also philosophy and history, and the creation of new bodies of knowledge in linguistics and psychoanalysis came into being (ibid.). The author of this dissertation wishes to remind the reader that these revolutionary changes were powerfully expressed in the artistic representations that mark the beginnings of modernism in this same time period. The revolution that Kristeva recognized has consequences that are still working themselves out and being evaluated in our own time.

(See Figure 19 on the next page). 


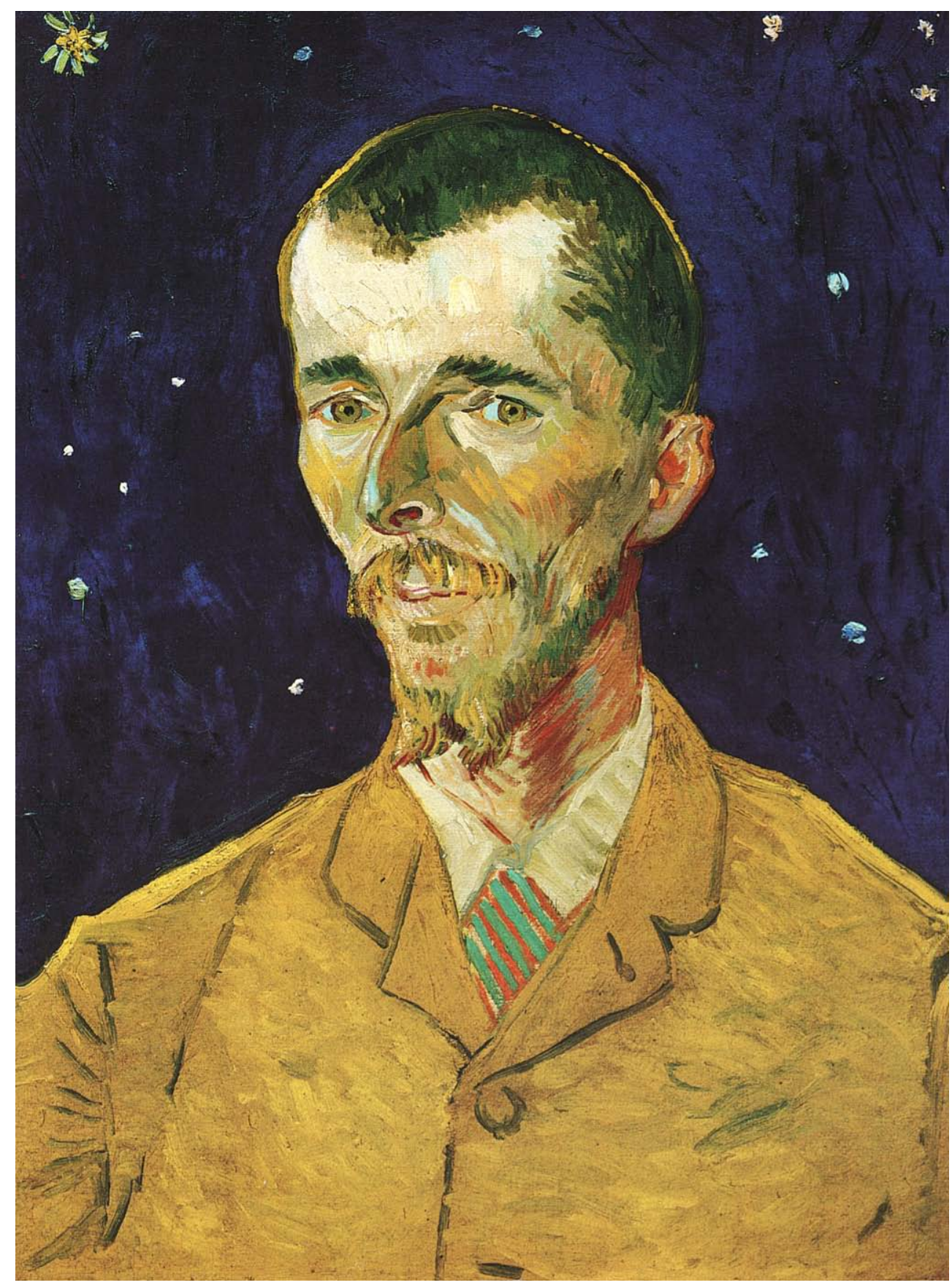

Figure19. Portrait of Eugene Boch, also known as The Poet

Pickvance, R. (1984) Van Gogh in Arles.

Metropolitan Museum of Art: New York, N.Y. p. 168 
The Importance of Creating

Vincent said, “Oh, my dear brother, sometimes I know so well what I want. I can very well do without God both in my life and in my painting, but I cannot, ill as I am, do without something which is greater than I, which is my life - the power to create. And if, frustrated in the physical power, a man tries to create thoughts instead of children, he is still part of humanity. And in a picture I want something comforting, as music is comforting. I want to paint men and women with that something of the eternal which the halo used to symbolize, and which we seek to convey by the actual radiance and vibration of our coloring” (LT 531).

Vincent thought so highly of his new paintings, the study of the poet and the peasant's head, that he had oak frames made for them. He hung the framed study of The Poet in his bedroom along with the Portrait of Milliet (Pickvance, Arles, 169).

\section{Conscious and Subconscious Concerns}

On a conscious level, two things constantly preoccupied Vincent, firstly material and financial concerns, and secondly the study of color. On a subconscious level, Vincent van Gogh seemed to have been consistently working out the organic disparity of his personality by the expression of the union of opposites and the complementarity of opposites in his artwork. In speaking of color, Vincent said, "I am always in hope of making a discovery there, to express the love of two lovers by a wedding of two complementary colors, their mingling and their opposition, the mysterious vibrations of kindred tones. To express the thought of a brow by the radiance of a light tone against a somber background. To express hope by some star, the eagerness of a soul by a sunset 
radiance. Certainly there is no delusive realism in that, but isn't it something that actually exists?” (LT 531).

Financial Concerns and Matters of Health

Financial concerns were prominently discussed in LT 520. Vincent said, “The needs of painting are like those of a wasteful mistress, you can do nothing without money, and you never have enough of it. That's why painting ought to be done at the public expense, instead of the artists being overburdened with it.”

Matters of health were discussed in LT 521, "I am happier to feel my old strength returning than I ever thought I could be. I owe this largely to the people at the restaurant where I have my meals at the moment, who really are extraordinary. Certainly I have to pay for it, but it is something you don’t find in Paris, really getting something to eat for your money. ... What Gruby says about doing without women and eating well is true, for if your very brain and marrow are going into your work, it is pretty sensible not to exhaust yourself more than you must in love-making. But it is easier to put into practice in the country than in Paris.”

\section{Discussion of Sexuality}

There seems to be an abrupt switch from LT 521 to LT 522, where Vincent discussed sexuality in a totally different way. In LT 522 he asked, "Why should it be forbidden to handle these subjects, unhealthy and overexcited sexual organs seek sensual delights such as da Vinci's. Not I, who have hardly seen anything but the kind of women at 2 francs, originally intended for the Zouaves. But the people who have leisure for love-making, they want the da Vinci mysteries. I realize these loves are not for everyone's understanding. But from the point of view of what is allowed, one could 
write books treating worse aberrations of perversion than Lesbianism, just as it would be permissible to write medical documents on this sort of story, surgical disquisitions. At all events, law and justice apart, a pretty woman is a living marvel whereas the pictures by da Vinci and Correggio only exist for other reasons.” This discussion seems curious in the light of Vincent's increasingly obsessive thoughts of being joined by Paul Gauguin in the South of France. It is possible this might be a reaction formation on the part of Vincent van Gogh. A reaction formation is a Freudian defense mechanism in the service of the ego in which an impulse or behavior is converted into its opposite (Ryckman, 57). In this instance van Gogh might be discussing lesbianism as a reaction formation to his perhaps latent homoerotic attraction to Gauguin. Psychically speaking, the reaction formation is yet another expression of the Yin-Yang or union of opposites that appears in so many guises in Vincent van Gogh. In this instance the opposites are female and male homosexuality.

\section{Concerns about Living Expenses}

LT 522 continued with discussion of Gauguin; Vincent was concerned that there was no definite calculation of expenses either for Gauguin joining him in Provence, or for Pont-Aven if Vincent was to move there. In a postscript to LT 522, Vincent indicated his decision not to move to Pont-Aven, "but he writes nothing about any means of finding a studio of our own, or about what it would cost to furnish it. And I can’t help feeling there's something queer about it.”

Theo had received a legacy from his uncle who died, and in LT 523 Vincent responded thankfully because Theo had set aside part of his uncle's legacy to carry out Vincent's plan to establish a colony of painters in the South of France or to work with 
Gauguin. Vincent requested an advance of 300 francs so that he could buy two decent beds complete at 100 francs each and 100 francs for other furniture. Then he figured that he could live at the yellow house and save the 1 franc per night that he paid the innkeeper. And he would be prepared if Gauguin did come to live there. His concern was to find the place where he could live the most economically.

\section{Problems with Obtaining Models}

The continual problem with obtaining models was frustrating to Vincent van Gogh. He said, "If I painted prettily like Bouguereau, people would not be ashamed to let themselves be painted, but I think that I have lost models because they thought they were "badly done” (LT 524). He also commented in LT 524 that he had told Gauguin in his last letter "if we painted like Bouguereau we could hope to make money by it, but that the public will never change, and it likes only easy, pretty things. With a more austere talent, you cannot count on profit from your work; most of the people intelligent enough to like and understand impressionist pictures are and will remain too poor to buy them.” He indicated that he intended to write to Gauguin to inquire what he paid for models.

There is a roughness in the technique of Vincent van Gogh, a masculine quality in his painting that seems to suit portraits of men better than portraits of women. "It is a gloomy enough prospect to have to say to myself that perhaps the painting I am doing will never be of any value whatever. If it was worth what it cost to do, I could say, 'I never bothered my head about money’” (LT 524). It was at this time and in this same letter that Vincent said, "I had begun to sign canvases, but I soon stopped, because it seemed too foolish. On one marine there is an excessively red signature, because I 
wanted a red note in the green.” Here he seems to be speaking of Fishing Boats at Saintes-Maries-sur-Mer. Both his words and his action of ceasing to sign his artwork, seem to bespeak a loss of self-confidence and a low self-esteem at this time in his life.

\section{A Notable Madman or an Insignificant One}

In LT 525, of August 15, 1888, Vincent said that he was sending pictures to Theo by Second Lieutenant Milliet, but he had chosen to retain the big portrait of the postman Joseph Roulin. He reported that "the head which I included was done at a single sitting." Vincent said, "that's what I'm good at, doing a fellow roughly in one sitting." Vincent indicated that what he felt he did well was painting quickly, in a somewhat rough manner, and the subject matter that he preferred was tramps, "I'd always do it, drink with the first comer, paint him ... on the spot” (LT 525). Vincent suggested that he would like to do a hundred such pictures and that among them there would be some good ones.

Pictures of menial laborers and of the underprivileged of society emerged and re-emerged throughout the oeuvre of Vincent van Gogh as a consistent theme. "What I gained by it [i.e. paint hundreds of pictures of tramps] as an artist, should I lose that as a man? If I had the faith to do it, I'd be a notable madman; now I am an insignificant one, but you see I am not sufficiently ambitious for the fame to set the match to the powder. I would rather wait for the next generation...Y You are a good enough judge of painting to see and understand what I may have of originality, and also to see the uselessness of presenting what I am doing to the modern public, because the others surpass me in clearness of touch. That is more the fault of wind and circumstance, compared to what I could do without the mistral and without the fatal conditions of vanished youth and 
comparative poverty. For my part I am in no way set on changing my condition, and I count myself only too happy to be able to go on as I do” (LT 525).

\section{Portrait of Patience Escalier}

Portrait of Patience Escalier, a peasant of the Camargue, was painted in clear brilliant tones described by Vincent: "I imagine the man I have to paint, terrible in the furnace of the height of harvest time, as surrounded by the whole Midi. Hence the orange colors flashing like lightning, vivid as red-hot iron, and hence the luminous tones of old gold in the shadows” (LT 520). In a postscript to LT 529, Vincent mentioned that the old peasant was presented against a vivid orange background that is not a red sunset, but that may give the suggestion of one. His postscript to LT 522 said that the picture of the old peasant's head was as strange in color as The Sower, but he disparaged both works calling The Sower a failure and the peasant even more so.

Portrait of Patience Escalier shows a peasant or a worker of the fields, thus demonstrating a type, an organic identity (Kristeva, 1980, 126). Bold colors chosen by van Gogh operate as a signifying practice (pratique signifiante), (ibid., 18) showing the powerful forces of nature that the sitter must reckon with in his line of work.

Vincent suggested another of his odd juxtapositions, that the roughness of the peasant's portrait might be effectively displayed beside a de Lautrec painting that Theo had. Vincent thought "that sun-steeped, sunburned quality tanned and air-swept, would show up still more effectively beside all that face powder and elegance” (LT 520). This is yet another example of the sense of complementarity of opposites, of one thing completing another by its opposition, yet another expression of the Yin-Yang in the work of Vincent van Gogh. 


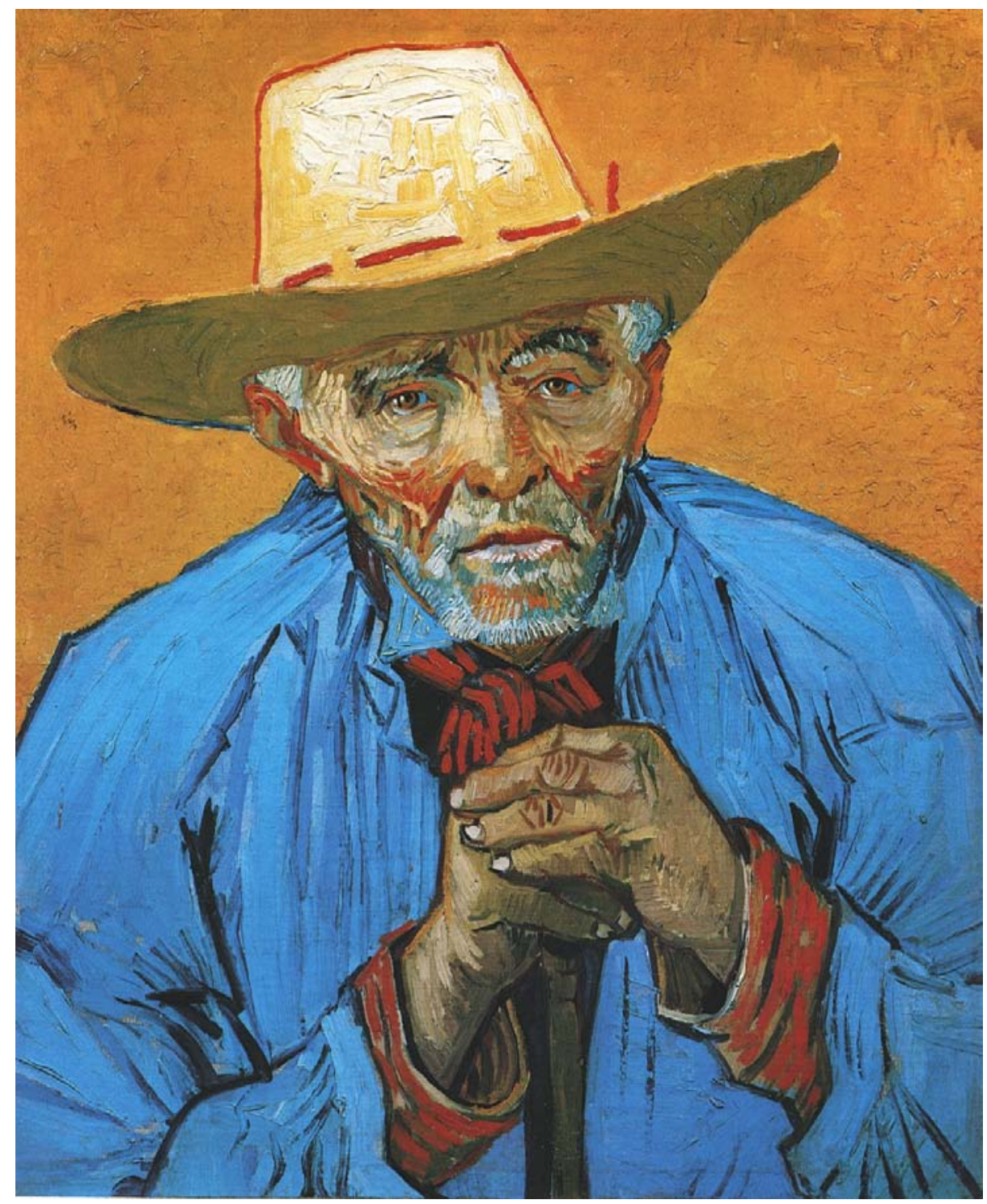

Figure 20. Portrait of Patience Escalier

Pickvance, R. (1984) Van Gogh in Arles.

Metropolitan Museum of Art: New York, N.Y. p. 165

The Sower (after Millet)

The idea of painting an image of the sower occurred and reoccurred in the thoughts of Vincent van Gogh, perhaps to the extent that it could be classified as an 
obsession. This was a mental obsession about which Vincent van Gogh had insight and it resulted in his compulsion to paint a sower. The iconic image of the sower was emotion-charged and had symbolism relating to pantheism, sun worship and life forces. Writing to Theo on about June 21, 1888, Vincent said of The Sower, “It's a composition in which color plays a very important part. And the sketch, such as it is - a size 25 canvas - torments me, making me wonder if I shouldn’t attack it seriously and make a tremendous picture of it. My Lord, I do want to. But I keep asking myself if I have vigor enough to carry it out. Such as it is, I am putting the sketch to one side, hardly daring to think about it. I have been longing to do a sower for such a long time, but the things I've wanted for a long time never come off. And so I am almost afraid of it. And yet, after Millet ... what still remains to be done is - a sower, in color and large-sized” (LT 501).

At first Vincent considered The Sower to be a sketch, an esquisse, and he thought that he might later make a large picture, a tableau, from it. That first sketch was finished about June 18, but then Vincent worked and reworked the image in the studio, making changes in color, figure, and composition. The final result is a studio painting expressing a language of color symbolism. The simultaneous contrast of complementary colors was exploited as a visual technique by adding yellow to the violet field and touches of violet to the yellow sky. Brushstrokes powerfully radiate out from the centrally placed sun on the high horizon line. Blue and orange brushstrokes add further structural denseness to the field, but at the same time the colors give a transient effect. In the shimmering field, the sower almost appears to be walking on water. It is a metaphor that life is like playing ball on running water, meaning that 
everything is constantly changing, one must be always adapting, and life needs to be lived mindfully and carefully (or the water will sweep you away). In a very real, though perhaps unconscious way, Vincent van Gogh has powerfully expressed the seemingly contradictory concept of the permanence of transitoriness in the image of The Sower who appears as if walking on water.

The concept of the sower was in "process" (en procès), in the Kristevan sense $(1980,17)$. This conveys the idea that the subject is in continued forward motion and will be accompanied by transformations (three more versions of the sower will emerge). As Vincent continued to work out the theme of the sower, a level of obsessions and compulsions is noted and the process was "unsettling" as to its place within the semiotic or symbolic disposition (ibid., 17).

Even though Vincent apparently considered The Sower to be a failed art work, he signed it and sent it to Theo in mid-August 1888. But on September 10 he wrote to Theo, "The idea of The Sower continues to haunt me all the time” (Pickvance, 1984). Vincent van Gogh continued to wrestle with the subject of the Sower and produced three more paintings of the subject in October and November.

(See Figure 21 on the next page). 


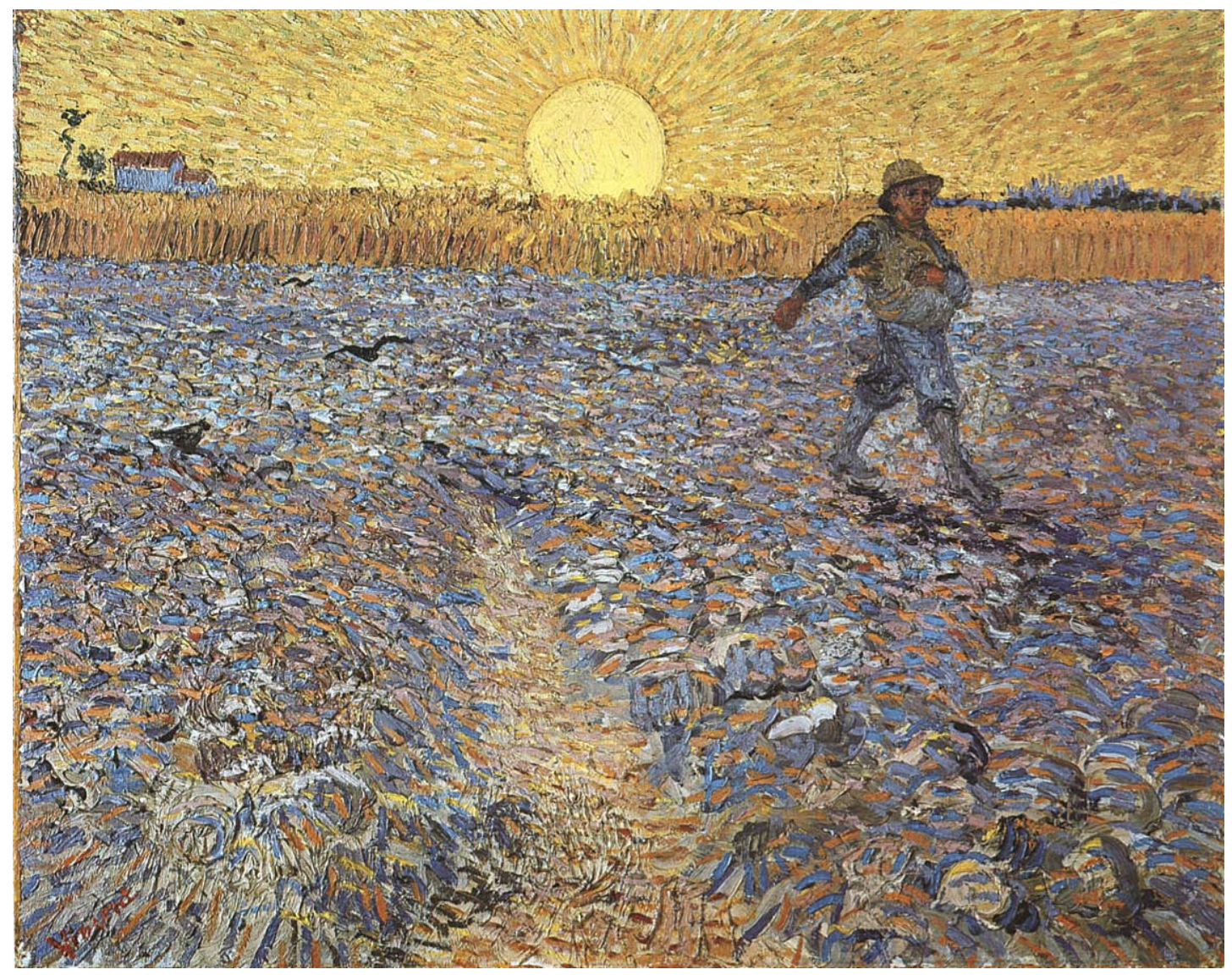

Figure 21. The Sower (after Millet)

Pickvance, R. (1984) Van Gogh in Arles.

Metropolitan Museum of Art: New York, N.Y. p. 103

\section{A Response from Gauguin}

A sense of great joy infused LT 526 because Vincent van Gogh had heard from Gauguin that he was “quite ready to come South” as soon as the opportunity arose. Vincent's response was to paint panels of sunflowers to decorate the yellow house. "I am hard at it, painting with the enthusiasm of a Marseillais eating bouillabaisse, which won't surprise you when you know that what I'm at is the painting of some big sunflowers” (LT 526). Vincent reported that he had three canvases that he was working 
on, "Nothing but big flowers." He planned to complete a dozen panels of sunflowers that would be a symphony in blue and yellow, and he also mentioned a "study of dusty thistles, with an innumerable swarm of white and yellow butterflies.”

Jouissance was van Gogh’s response to hearing from Gauguin that he would be coming to the South of France. Kristeva (1980, 15-16) used the term jouissance in the sense of total joy or ecstacy, including spiritual, physical, and conceptual, as well as sexual. Lacan's (ibid.) concept of jouissance was given sexual modifiers that limit its interpretation, ( jouissance sexuelle and jouissance phallique), but Kristeva used the term plaisir to cover specifically sensual or sexual pleasure. Van Gogh’s jouissance was expressed in his subject matter of sunflowers, in his color choices, in the size and number of his paintings, and in the speed with which he produced them. Jouissance, carried to an extreme and rampantly expressed, could express as mania in the work of Vincent van Gogh.

\section{Sunflowers}

Vincent described the three pictures of sunflowers that he was working on; "first, three huge flowers in a green vase, with a light background, a size 15 canvas; second, three flowers, one gone to seed, having lost its petals and one a bud against a royal-blue background, size 25 canvas; third, twelve flowers and buds in a yellow vase (size 30 canvas). The last one is therefore light on light, and I hope it will be the best” (LT 526).

By the time of LT 528, Vincent reported, "I am now on the fourth picture of sunflowers. The fourth one is a bunch of 14 flowers, against a yellow background, like a still life of quinces and lemons that I did some time ago. Only as it is much bigger, it 
gives a rather singular effect, and I think that this one is painted with more simplicity than the quinces and lemons.” This fourth painting, Still-Life: Vase with Sunflowers, is the picture selected for discussion. Sunf lowers became Vincent's emblem and he painted ten versions of Sunflowers (Bonafoux, 1992).

\section{Still-Life: Vase with Sunflowers}

It is a coloristic motif in the oeuvre of Vincent van Gogh to place in close proximity colors which in theory clash, and it is this very quality of clashing that establishes the emotional tone of this picture (Dawe, 1976). Still-Life: Vase with Sunflowers has a delicate clash established by the thin blue lines that establish the table edge, the lower section of the vase and the signature. Dawe asserted that this simple element of clash set up a subtle resonance of vibration throughout the picture and created pictorial vitality. Except for the small area of blue clash, the picture is painted in very harmonious shades of yellow, orange, and green. In another picture of sunflowers, the clash was much more bold, "One of the decorations of sunflowers on a royal blue ground has a 'halo,' that is to say each object is surrounded by a glow of the complementary color of the background against which it stands out” (LT 528). The clashing colors may be a subconscious expression of the clash of Vincent's difficult personality with other persons and in society, a visual cue as to his mental health issues of Borderline personality disorder and Bipolar.

In Arles Vincent often painted in a color called "the high yellow note.” A fascination with yellow is mentioned in LT 522, "There is a sun, a light that for want of a better word I can only call yellow, pale sulphur yellow, pale golden citron. How lovely yellow is!” In LT 520 Vincent had described the weather in this way, 
"Unfortunately, along with the good god sun three quarters of the time there is the devil's mistral." Yellow represented the energy and color of the sun, but as the ancient Egyptians had realized so well the energy of the sun can be both creator and destroyer. The Egyptian lionness-headed Sekhmet personified the fierce, destructive heat of the sun. Too much sun, unremitting heat and energy, can burn up the harvest rather than facilitating its growth. Vincent van Gogh lived and worked with a Sekhmet-like expression of intensity. The relationship between Vincent van Gogh and Paul Gauguin was charged with this same Sekhmet-like intensity and eventually the excessive amount of energy burned itself out and that relationship ended badly.

(See Figure 22 on the next page). 


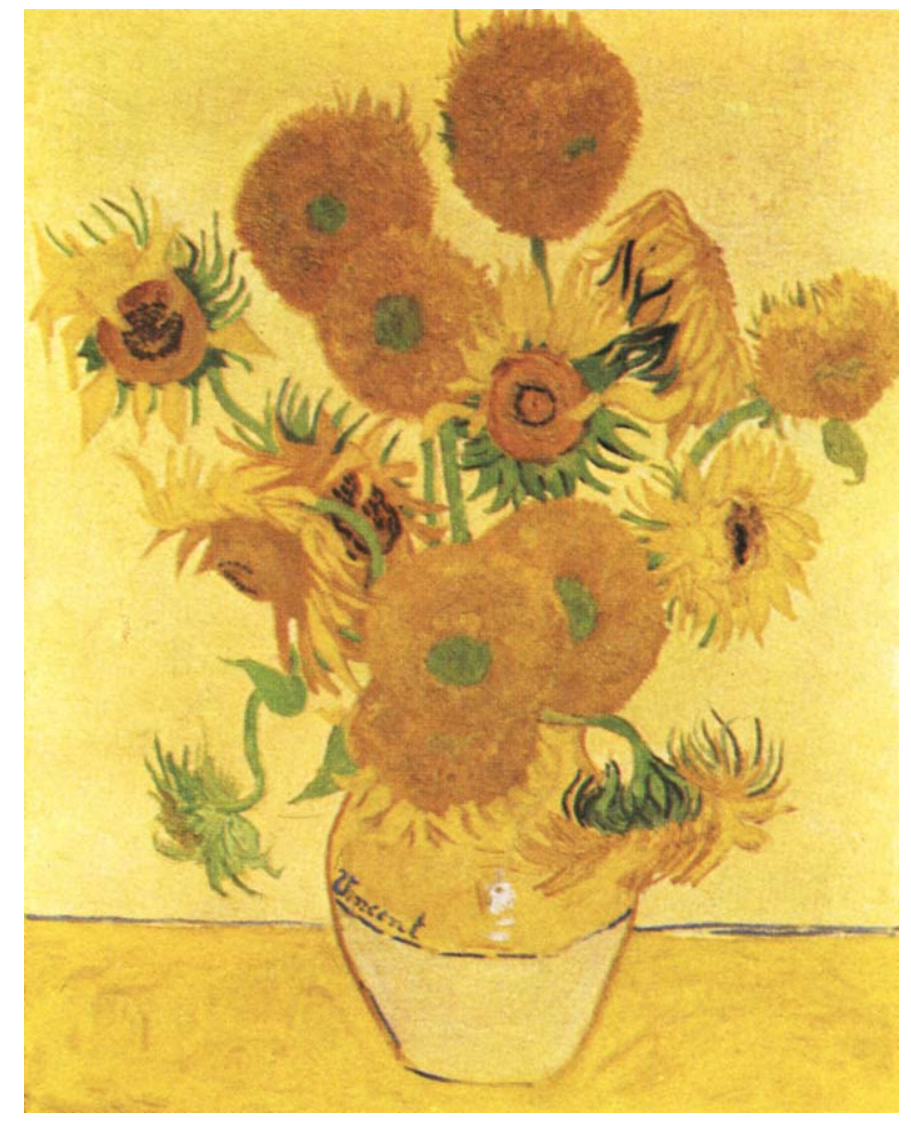

Figure 22. Still-Life: Vase with Sunflowers

Dawe, F. (1977) Understanding Vincent van Gogh.

Trewin Copplestone Publishing Ltd.: London, p. 8.

\section{Materials and Technique}

There was a considerable amount of discussion of materials and technique in LT 527, of the non-necessity of having very finely ground pigments since he "did not object to the canvas having a rough look.” This he felt might have the advantages of being easier to prepare, costing less, and being fresher and more lasting. Vincent reported that he wanted to achieve simplicity of technique and he admired and aspired to paint in a solid impasto. He was "trying to find a special brushwork without stippling 
or anything else, nothing but the varied stroke.” In LT 528 Vincent continued to discuss technique, “As for stippling and making halos and other things, I think they are real discoveries, but we must already see to it that this technique does not become a universal dogma any more than any other. That is another reason why Seurat's Grande Jatte, the landscapes with broad stippling by Signac and Anquetin's boat will become in time even more personal and even more original.”

\section{Difficulties with Models}

“Difficulties with models continue with exactly the same tenacity as the mistral here. It is not cheering”; this is the postscript to LT 529. He reported that he had two models for the week, “an Arlésienne and the old peasant.” He was concerned that the Arlésienne might not return because the last time she had posed she requested payment in full and he gave it to her even though the work was not finished. Vincent reported that he had not seen her since. He also mentioned two still-life subjects, a bunch of flowers and an old pair of shoes.

Vincent reported that he had lots of ideas for his work, but then he sounded quite depressed, “But what's the use? Sometimes I feel too feeble to fight against existing circumstances, and I should have to be cleverer and richer and younger to win. Fortunately for me, I do not hanker after victory any more, and all that I seek in painting is a way to make life bearable” (LT 529). This rapid mood swing from excitement to depression is typical of bipolar disorder. Vincent reported that he wanted to do as many figure studies as possible and that if he made himself master of the figure, that he felt it would make his work seem deeper. 
On September 1, 1888, Vincent wrote to Theo thanking him for the money that had enabled him to pay his rent. The landlord also requested a commitment as to whether he was planning to keep the house; he had to renew the agreement or cancel it in advance. Vincent agreed to extend the lease either on a month by month basis or by not longer than three months. In that way if Gauguin came and did not like the house, they would not be saddled with a long lease. Vincent was concerned about whether Gauguin would accept the isolation of that area of the country, and he continued to be distressed about his problems with models. The depressed tone continued in LT 530, "I feel that even so late in the day I could be a very different painter if I were capable of getting my own way with the models, but I also feel the possibility of going to seed and of seeing the day of one's capacity for artistic creation pass, just as a man loses his virility in the course of his life. That is inevitable, and naturally in this as in the other, the one thing to do is to be of good heart and strike while the iron is hot. And I often get downhearted. ... My life is disturbed and restless, but then if I make a change and move about much, I shall perhaps only make things worse.” Vincent's comments point out his propensity for depression.

\section{Concerns, Annoyances, and Anger}

Vincent had concerns about the cost of paints and said, “Often now I hesitate before planning a picture because of what the colors would cost us. You see all the same this is rather a pity, for the simple reason that we may have the power to work today, but we do not know if it will hold out till tomorrow. All the same, far from losing my physical strength, I am regaining it, and my stomach is especially stronger” (LT 530). 
Much of LT 532 was spent in discussing Vincent's feelings of annoyance or anger that Paul Gauguin still had not joined him in the South of France: "I think that Gauguin doesn't care a damn about it, because it isn't going to be done at once, and I for my part, seeing that Gauguin has managed to muddle along by himself for six months, am ceasing to believe in the urgent necessity of helping him. So let's be prudent. If it does not suit him here, he may be forever reproaching me with, 'Why did you bring me to this rotten country?’ And I don’t want any of that. Naturally we can still remain friends with Gauguin, but I see only too clearly that his mind is elsewhere. So I say, let's behave as if he were not there; then if he comes, so much the better - if he doesn't, so much the worse. ... As for Gauguin, perhaps he is letting himself drift with the current, not thinking of the future. And perhaps he thinks that I shall always be here and that he has our word. But it is not too late to withdraw, and really I am strongly tempted to do so, because failing him, I should naturally think of another partnership, whereas at present we are bound.” The feelings of depression, anger and annoyance that van Gogh indicated are symptomatic of borderline personality disorder.

It was a great concern to Vincent that there was so much being spent with the innkeepers for lodgings and that he did not have a home to call his own. "How I'd like to settle down and have a home” (LT 533)! His lack of furniture hampered him. He had inquired of the postman whose portrait he painted and learned that to get a good bed that would last and be substantial, it would cost 150 francs rather than the 100 that he had originally estimated. Vincent wanted "a home of my own, which frees the mind from the dismal feeling of being a homeless wanderer. That is nothing when you are an adventurer of twenty, but it is bad when you have turned thirty-five” (LT 533). The 
opposite of all that a home represented to Vincent van Gogh was exemplified in The Night Café.

The emotional tone of The Night Café is dark, ominous and terrible, the opposite of jouissance. There is the sense of the "bounded" (Kristeva, 1980, 13-14), that Vincent knows the horrible end result of being in a place such as The Night Café. Kristeva's lieu, or place, is a hypothetical place even though constrained by actual forces or presences. The Night Café was an actual place that Vincent made hypothetical by giving it an archetypal treatment by the forces and presences apparent in the color choices, by the artistic rendering, and by his discussion in his letters.

\section{The Night Café}

On September 8, 1888, Vincent wrote LT 533, saying that he had decided to paint The Night Café by staying up three nights to do so and sleeping through the days. Vincent described the picture as one of the "ugliest" that he had done. "I have tried to express the terrible passions of humanity by means of red and green. The room is blood red and dark yellow with a green billiard table in the middle; there are four citronyellow lamps with a glow of orange and green. Everywhere there is clash and contrast of the most disparate reds and greens in the figures of little sleeping hooligans, in the empty, dreary room, in violet and blue. The blood-red and the yellow-green of the billiard table, for instance, contrast with the soft tender Louis XV green of the counter, on which there is a pink nosegay. The white coat of the landlord, awake in a corner of that furnace, turns citron-yellow or a pale luminous green” (LT 533). The Night Café was again discussed in LT 534, "In my picture of The Night Café I have tried to express the idea that the café is a place where one can ruin oneself, go mad or commit a crime. 
So I have tried to express, as it were, the powers of darkness in a low public house, by soft Louis XV green and malachite, contrasting with yellow-green and harsh bluegreens, all this in an atmosphere like a devil's furnace, of pale sulphur.” The clash and contrast, the intensity of his negativity, and the method of working that Vincent described are expressive of bipolar.

Stylistically Vincent saw The Night Café carrying on in the manner of The Sower, as did the head of the old peasant and of the poet also. "It is color not locally true from the point of view of the delusive realist, but color suggesting some emotion of an ardent temperament” (LT 533). He compared the effect that he was trying to achieve to that of Delacroix’s “Bark of Christ” a violent and inspired sketch, a critic said of it, I did not know that one could be so terrible with a little blue and green.” Hokusai's The Wave has a similar effect, the waves are like claws and the ship is caught in them. When Vincent van Gogh painted night scenes like The Night Café, The Café Terrace at Night, and Starry Night over the Rhône at Night, he was trying to achieve powerful sensations similar to those of Delacroix or Hokusai.

(See Figure 23 on the next page). 


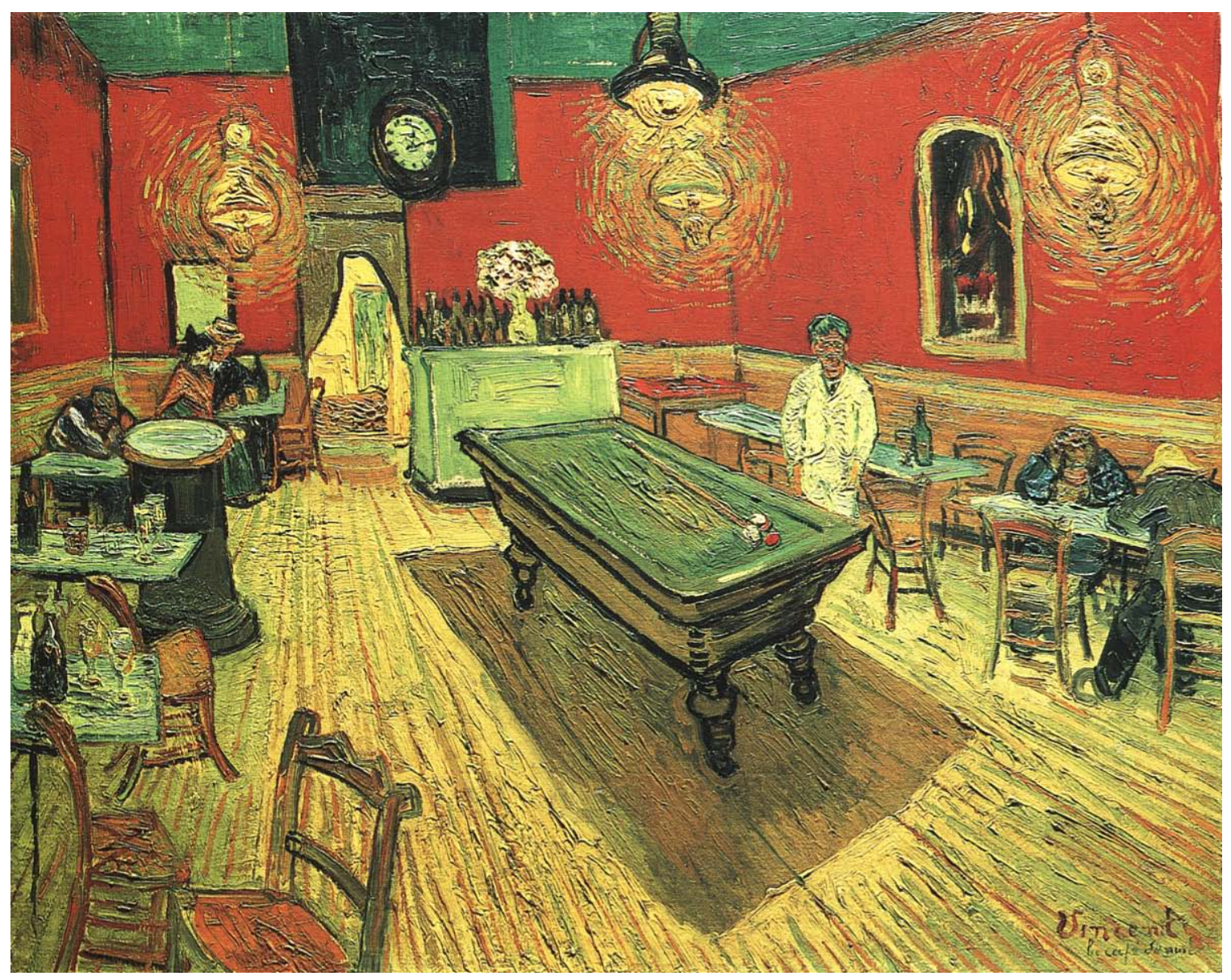

Figure 23. The Night Café

Stein, S. (1986) Van Gogh: A Retrospective.

Hugh Lauter Levin Associates, Inc.: China, p. 183.

\section{Decorating the Yellow House}

Vincent's plans for the decoration of the yellow house filled LT 534. He was busy with furnishing and decorating. He bought two beds, bedclothes for one of them, and two mattresses, 12 chairs, a mirror, and some small necessities. He planned to be ready to live there within a week and he could be ready for a guest at any time. "For a visitor there will be the prettier room upstairs, which I shall try to make as much as 
possible like the boudoir of a really artistic woman.” This author questions, would Paul Gauguin really feel comfortable and at home in a "tiny boudoir with its pretty bed and everything else dainty?” Gauguin seemed to be a man’s man, yet Vincent prepared for him a room that would seem more appropriate for a female lover. What is one to make of this discussion? There seem to be psychosexual issues implied and homoerotic tendencies on the part of Vincent van Gogh. Perhaps Vincent was so unable to accept his own feelings toward Paul Gauguin that he transformed them into affection toward a female which he expressed by decorating the guest bedroom in a feminine manner. The Freudian defense mechanisms of transference and reaction formation seem to be operating here. The dainty bedroom could also represent Vincent's sublimated desires for the otherness of the feminine which was absent in his life. The optimism about Gauguin coming to Arles was reflected in Vincent's use of images with more positive connotations in his pictures, sunflowers, the sun, strolling couples, sowers and the like. Nagera (1967, 91-130) stated that there was a blurring of homosexual and heterosexual desires and that the homoerotic sexual element, conscious or unconscious, contained all the extremes of a passionate romance. It is possible that Vincent psychologically transformed Gauguin to the opposite sex as a defense against his own fears of assuming a feminine stance in his relationship to Paul Gauguin. Gauguin both attracted and intimidated van Gogh, and Vincent's attitudes ran the spectrum from overidealization to bitter recriminations and dark suspicions. This pattern of human relationships is typical of borderline personality disorder.

The relationship between Vincent van Gogh and his father was a difficult one, and was strained at many times in Vincent's lifetime. Nagera (63) points out that there 
are many old conflicts between Vincent van Gogh and his father. Nagera gives a traditionally Freudian analysis stating that the previous idealization of his father, conscious or unconscious, (even to the point of Vincent previously seeking to be like him by being a preacher) was coming to an end and transforming itself into a sort of negative idealization. Vincent seems to have split his ambivalent feelings toward his father so that his father became the recipient of most of his negative feelings and hostility and Theo became a father substitute and the recipient of Vincent's positive feelings. At other times in the pattern of relationship between van Gogh and Gauguin, it was as if Vincent became the naughty child and Gauguin was ascribed the role of the father figure. This cast a dark cloud over the relationship between van Gogh and Gauguin from the outset, especially given Vincent's persistent inability to relate to anyone in a positive manner for any length of time, most notably someone in authority over him. This difficulty in human relations is indicative of both borderline personality disorder and bipolar disorder. The relationship between Vincent van Gogh and Paul Gauguin was convoluted with many psychological twists and turns.

Vincent described the decoration of his own bedroom, “Then there will be my own bedroom, which I want extremely simple, but with large, solid furniture, the bed chairs and table all in white deal. Downstairs will be the studio, and another room, a studio too, but at the same time a kitchen. Someday or other you shall have a picture of the little house itself in bright sunshine, or else with the window lit up, and a starry sky. Henceforth you can feel that you have your country house in Arles. ... The room you will have then, or Gauguin if he comes, will have white walls with a decoration of great yellow sunflowers. In the morning, when you open the window, you see the green of the 
gardens and the rising sun, and the road into town. But you will see these great pictures of the sunflowers, 12 or 14 to the bunch, crammed into this tiny boudoir with its pretty bed and everything else dainty. It will not be commonplace. And in the studio, the red tiles of the floor, the walls and ceiling white, rustic chairs, white deal table, and I hope a decoration of portraits.” (LT 534)

Vincent continued to describe his decorating scheme for the yellow house, "I want to make it really an artist's house - not precious, on the contrary nothing precious, but everything from the chairs to the pictures having character. About the beds, I have bought country beds, big double ones instead of iron ones. That gives an appearance of solidity, durability and quiet, and if it takes a little more bedding, so much the worse, but it must have character." He planned to paint his own bed, "there will be three subjects on it. Perhaps a nude woman, I haven't yet decided, or perhaps a child in a cradle, I don’t know, but I shall take my time over it.” He indicated that he intended to buy something for the house each month. On September 17, 1888, Vincent wrote to Theo in LT 537 that he planned to go to live in the yellow house on the morrow.

\section{Studies and a Few Finished Pictures}

Vincent indicated in LT 534 that he considered only The Sower and The Night Café to be attempts at finished pictures, all else he apparently considered studies. LT 535 contained continued discussion of these themes, "The idea of the sower continues to haunt me all the time. Exaggerated studies like The Sower and like this Night Café usually seem to me atrociously ugly and bad." He also mentioned a third study - "a landscape with a factory, and a huge sun in a red sky above red roofs, a day with a wicked mistral when nature seems to be in a fury. 


\section{Concerns about Gauguin}

The end of LT 535 is missing, but 535a is included, a letter for Gauguin. Vincent was surprised to learn what a large family Paul Gauguin had and felt that those responsibilities might preclude his ability to relocate to the South. Vincent was willing to move to the North in order to implement the artistic partnership. Vincent sought to clarify the proposed arrangement in this letter so that there would not be misunderstanding, "that we ourselves are too short of money to be able to risk anything but living together and sharing the monthly money.” There were concerns about other expenses that Gauguin had accumulated and might expect Vincent and Theo to pay, “traveling expenses, the debt at the inn, his doctor's bill ... and a debt of 300 francs. In short, it would not be very prudent to hold out expectations beyond our means, and to enter into greater obligations than we could fulfill.” On September 11, Vincent had received a letter from Gauguin and wrote to Theo that it was "just a cry of distress. 'I am getting deeper into debt every day.”” Health matters were mentioned, “But his stomach is all wrong, and when one has a stomach-ache and indigestion, one has no will power. Now I myself have nothing wrong with my stomach at the moment, consequently my brain is freer and, I hope, clearer.”

LT 535 is filled with discussion of uncertainty about Gauguin’s plans, but Vincent also said, "Ideas for my work are coming to me in swarms, so that though I'm alone, I have no time to think or feel. I go on painting like a steam engine. I think there will hardly ever be a standstill again.” Talk like this gives the impression of an episode of mania, and the unfinished letter might be an indication of the flight of ideas connected with a manic episode. 
Jamison (2004) points out that journal articles and psychology textbooks devote much more space to "negative" emotions such as depression and anxiety than they do to "positive" ones such as joy and happiness, and that exuberance is hardly studied at all. While mania is psychopathology, and destructive, there are positive qualities of high energy, exuberance, increased sexual desire and rapid, creative, expansive thinking associated with its milder forms ( $\mathrm{ibid}$.). In bipolar cycling there is an optimal highenergy period before the mania becomes full-blown, and people like it because it feels good. For this reason, people are often resistant to taking medicines to control bipolar and often attempt rather to self-medicate by the use of substances such as alcohol and drugs.

Jamison (2004) discussed brain imaging studies that have been conducted at the University of Iowa, showing subjects emotionally pleasant pictures, unpleasant pictures, and neutral pictures. The unpleasant pictures provoked activation in the primitive, subcortical parts of the brain conceptualized by scientists as an ancient danger recognition system. Pleasant pictures, on the other hand, activated a phylogenetically much younger part of the brain, the prefrontal cortex. The researchers concluded that the sensing of danger (triggered by the unpleasant pictures) is a relatively quick and simple response system, but that the processing of the positive (triggered by the pleasant pictures) requires a more sophisticated level of processing in the brain. It is important to note that nature has taken care to create a capacity for delight and prolonged enthusiasm in a relatively recent (evolutionally speaking), but vital brain system. Jamison points out that there are positive rewards of appreciation of the auspicious, and she enumerates them as: the generation of alternative solutions to menace and hazard, the fostering of 
resilience and social bonds, and the rewarding of successful behavior with and infusion of pleasure. The process of painting is a pleasurable action, as is the appreciation of viewing completed artworks whether one’s own or the product of another artist.

\section{A Period of Intense Work}

Several art works are discussed in LT 537, "a square size 30 canvas, a corner of a garden with a weeping tree, grass, round clipped cedar shrubs and an oleander bush.” Vincent discussed the colors and paint techniques, "with a citron sky over everything, and also the colors have the richness and intensity of autumn. And besides it is in even heavier paint than the other one, plain and thick." Vincent had already sent a study of the same subject to Theo. "The second represents the outside of a café, with the terrace lit up by a big gas lamp in the blue night, and a corner of a starry blue sky, The Café Terrace at Night." The third picture this week is a portrait of myself, almost colorless, in gray tones against a background of pale malachite.” The portrait he painted by looking in a mirror, "I purposely bought a mirror good enough to enable me to work from my own image in default of a model. ... The problem of painting night scenes and effects on the spot and actually by night interests me enormously. This week I have done absolutely nothing but paint and sleep and have my meals.” (LT 537)

$$
\text { Existential Musings, Japan and Work }
$$

A thread of existential musings ran consistently through the letters of Vincent van Gogh and it resurfaced in LT 538 where he said, "If what one is doing looks out upon the infinite, and if one sees that one's work has its raison d'être and continuance in the future, then one works with more serenity.” Vincent also returned to his thoughts about Japan and he said, "If there were less mistral, this place would really be as lovely 
as Japan, and it would lend itself as well to art.” The idea of Japan was a mental construct of Vincent van Gogh representing to him an allegedly perfect place. Vincent considered Japan like an utopia, a place of extreme artistic and actual beauty.

Existential thoughts, ideas of Japan as a perfect place, and concerns about any financial arrangement with Paul Gauguin made up the majority of the content of LT 538. Vincent continued to express concerns to Theo about any arrangement with Paul Gauguin, reminding him that they "must be very clear and very firm in any understanding with Gauguin, because of the need to avoid any misunderstanding.” The suggestion had been made to pay Gauguin 150 francs a month in exchange for a picture each month. "In principle, and in theory, I am for an association of artists who guarantee each other's work and living, but in principle and in theory I am equally against attempts to destroy old established businesses ... let's guarantee a living among ourselves, live like a family, like brothers and friends, and this even if it should not succeed - I would like to be in this, but I will never have anything to do with an attack on other dealers." LT 538a contained continued discussion of Gauguin and whether or not he would join Vincent in Arles. Vincent's work ethic again surfaced and he said, "it is my bounden duty to work on indefatigably,” and he felt that he must continue on alone if Gauguin should chose not to come.

The tone of LT 539 sounds busy and hyper. As of the time he wrote this letter, he had already written to Theo, had taken a canvas out to paint in the garden and completed it, obtained a new blank canvas, went out again to paint, and now wrote to Theo again. "Because I have never had such a chance, nature here being so extraordinarily beautiful. Everywhere and over the vault of heaven is a marvelous blue, 
and the sun sheds a radiance of pale sulphur, and it is soft and as lovely as the combination of heavenly blues and yellows in a Van der Meer of Delft. I cannot paint it as beautifully as that, but it absorbs me so much that I let myself go, never thinking of a single rule.” Vincent enumerated his work in Arles thus far mentioning three pictures of gardens opposite the house, two cafés, the sunflowers, the portraits of Bock and of himself, the red sun over the factory, the men unloading sand, the old mill, and other studies. He said, "But my paints, my canvas and my purse are all completely exhausted today. The last picture, done with the last tubes of paint on the last canvas, of a garden, green of course, is painted with pure green, nothing but Prussian blue and chrome yellow. ... This afternoon I had a select public - four or five hooligans and a dozen street arabs, who were especially interested in seeing the paint come out of the tubes” (LT 539). This sounds as if he is painting directly from the tubes onto the canvas, perhaps not even using a brush at all, and it is known that this is a method that he sometimes employed. This method of painting, at once more direct and immediate, could be yet another indication of mania.

Temperament, Companionship and Love

Vincent discussed an emotional malaise that he was feeling and compared himself to his friend Bernard. He described Bernard, saying, "Basically Bernard has so much temperament! He is sometimes foolish and vicious, but I certainly have no right to reproach him with that, because I myself know the same disorder of the nerves only too well.” Vincent seemed to be rattling on and jumping from one idea to another (flight of ideas is another indicator of mania), “And it gives you ambitions for the autumn, enthusiasm that makes the time pass without your feeling it. Beware of the morning 
after the night before and the winter mistrals. ... I am so happy in the house and in my work that I even dare to think that this happiness will not always be limited to one, but that you will have a share in it and good luck to go with it.” Then suddenly Vincent began to speak of erotic love in this curious statement: "there is a Venus of Arles just as there is a Venus of Lesbos, and one still feels the youth of it in spite of all” (LT 539). Just as abruptly he changed the subject back to his work, “Tomorrow I am going to draw, until the paints come. But I have deliberately arrived at the point where I will not draw a picture with charcoal. That's no use, you must attack drawing with the color itself in order to draw well.” Vincent said that he saw the relationship between color and music and that in impressionism he saw the resurrection of Eugene Delacroix. "That is why I myself remain among the impressionists, because it professes nothing, and binds you to nothing, and as one of the comrades I need not declare my formula” (LT 539). Some critics said that his pictures were unfinished. Sometimes his thoughts were unfinished in his letters as he jumped from subject to subject. This quality of unfinishedness is yet another indicator of manic thought processes.

Concerns about continuing to furnish the yellow house were in the forefront of LT 540. Vincent reported that he had bought a dressing table for his room and that his room was complete, but that he still needed another dressing table and a chest of drawers for the other bedroom, and for downstairs, a big frying pan and a cupboard. “You cannot think what peace of mind it gives me, I am so set on making an artist's home, but one for practical use, and not the ordinary studio full of knick-knacks. ... But the room where I shall put up anybody who comes this way will be like a boudoir, and when it is finished, you will see that it will not be a haphazard production, but a 
deliberate creation.” He reported that the house brought him a sense of tranquility. He mentioned that he had just completed a self-portrait in his own ashen coloring, having "taken a terrific amount of trouble to get the combination of ashen and gray-pink tones.” He said that he would have liked to have painted portraits of his own family. He had scraped off for the second time a study of Christ with the angel in the Garden of Olives. He said, “I cannot or rather I will not paint any more without models; but I have the thing in my head with the colors, a starry night, the figure of Christ in blue, all the strongest blues, and the angel blended citron-yellow. And every shade of violet, from a blood-red purple to ashen, in the landscape.” This twice scraping off and repainting seems to indicate a manic quality in the impatience and discontent with his work, and the intention to use every shade of violet might also indicate a manic quality in the excessiveness and overabundance of his thought processes. Vincent stated his belief in impressionism, "This art that we are working in, we feel it has a long future before it. ..” (LT 540)

\section{All Work and No Play}

Another scene of the garden is described in LT 541, and it is suggested as a pendant to the size 30 canvas of the same spot, only from a totally different angle and in different greens under a sky of pale citron. Vincent described a clipped round bush of cedar or cypress amid grass: "The row of bushes in the background are all oleanders, raving mad; the blasted things are flowering so riotously they may well catch locomotor ataxia. They are loaded with fresh flowers, and quantities of faded flowers as well, and their green is continually renewing itself in fresh, strong shoots, apparently inexhaustibly. A funereal cypress is standing over them, and some small figures are 
sauntering along a pink path.” The previous statement contains concepts of oppositions in fresh flowers and faded flowers, ideas of renewal and death, and of lunacy (chaos) as well as peaceful sauntering (order). Vincent reported that he had painted that spot three times. He said that now the line was simple and the paint was laid on thick. "Today again from seven o'clock in the morning till six in the evening I worked without stirring except to take some food a step or two away. That is why the work is getting on fast. ... I have a lover’s insight or a lover's blindness for work just now. Because these colors about me are all new to me, and give me an extraordinary exaltation. I have no thought of fatigue, I shall do another picture this very night, and I shall bring it off. ... I can’t help it, I feel my brain is lucid, and I want as far as possible to make sure of enough pictures to hold my own when the others are making a great show for the year '89. I still have a kind of concentrated power, which only asks to spend itself in work.” This method of working described in LT 541 sounds like Vincent van Gogh was in a manic phase or a period of extreme hyperactivity.

\section{Portrait of Milliet}

Vincent made the acquaintance of Paul-Eugene Milliet before mid-June, 1888, and they became friends. Milliet was a second lieutenant in the third regiment of the Zouaves, a body of light infantry in the French army composed originally of Algerians (Pickvance, 1984). Milliet was enough of a friend that when he was going on leave to the North of France, that he took thirty-six rolled canvases and delivered them to Theo on August 17; and on his return trip he picked up some Japanese prints, nineteenthcentury lithographs, and illustrated periodicals and brought them to Vincent. During most of his life Vincent van Gogh was a loner and seemed to have formed few 
friendships, but his friendship with Milliet seems to have been an exception to Vincent’s typical solitariness.

Milliet had more than a little interest in learning to draw, and Vincent spent some time in giving him art lessons. Vincent had considerable interest in obtaining a copy of Cassagne’s book, $A B C D$ du dessin, so that he could use it for instructional purposes (LT 502). Van Gogh wrote to Bernard about June 18, "I am acquainted with a second lieutenant of the Zouaves here, called Milliet. I give him drawing lessons - with my perspective frame - and he is beginning to make drawings; by God, I've seen worse! He is zealously intent upon learning” (B 7). But by mid-August in LT 522, Vincent indicated, "this valiant warrior has given up the art of drawing, into the mysteries of which I endeavored to initiate him, but it was for a plausible reason, namely that he had unexpectedly to take an examination."

By September Vincent was working on a portrait of Milliet, but he complained that he did not pose well, that he could not keep still when posing, because he had a nervous motion of the legs. Vincent said that Milliet was "a good-looking boy, very unconcerned, and easy-going in his behavior, and he would suit me damned well for the picture of a lover” (LT 541a).

Vincent described Milliet's portrait in LT 543 to Theo on September 29, "I now have [finished] his portrait with red cap on emerald green ground, and in the background the arms of his regiment, the crescent and a five-pointed star.” Vincent reported that he was doing his studies with a single coat of impasto. Portrait of Milliet was composed with less divided touch and more blending in the tones than other works by Vincent van Gogh that more fully exploited impressionistic techniques. The portrait 
seems largely straightforward, but the symbolic is expressed in the uniform and by the star and crescent that are the coat of arms of the regiment. The decorative elements of the uniform are painted with restraint rather than exuberance. The background is not interpreted as sky. Portrait of Milliet was left unsigned and is considered a study, but van Gogh esteemed it highly enough to frame it in oak and hang it in his bedroom (LT 543).

The Portrait of Milliet is a straightforward presentation of the sitter, but it also represents a type, the military officer, a lieutenant in the Zouave forces. In Portrait of Milliet, the humanistic is presented, but there is also the sociological sense of the society with the attendant ideological overtones of the culture. (Kristeva, 1980, 15).

(See Figure 24 on the next page). 


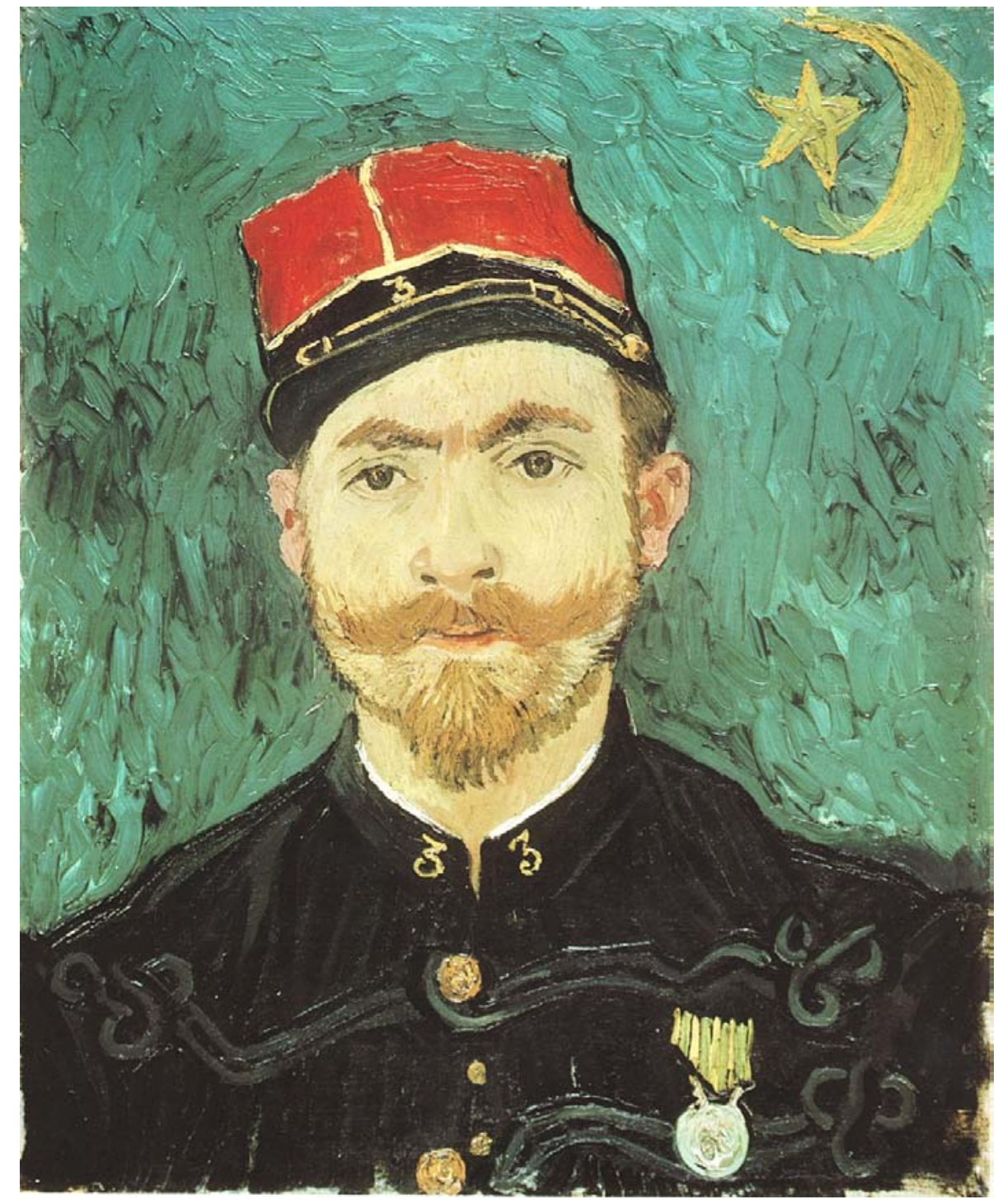

Figure 24. Portrait of Milliet

Pickvance, R. (1984) Van Gogh in Arles.

Metropolitan Museum of Art: New York, N.Y. p. 173

Autumn Mania

Vincent wrote in LT 541a that "autumn has manifested itself in rain and bad weather." He went on to describe aP size 30 canvas of a plowed field, "A blue sky with white clouds. An immense expanse of ground of an ashy lilac. Innumerable furrows and 
clods. A horizon of blue hills and green bushes with [illegible].” Note the incomplete sentences in LT 541a and the seeming mania of the way he is working, "As long as autumn lasts, I shall not have hands, canvas and colors enough to paint the beautiful things I see. ... I must work like a team of mules as long as autumn lasts if I want to recover what our furniture has cost.” He discussed the order of paints to see him through the autumn, "It is the minimum that I shall need during autumn and the falling of the leaves, which certainly will be marvelous and which lasts only one week.” By the time that Vincent wrote LT 542 the autumn weather had turned to mud and rain. He reported his plan to draw a lot during the winter. "If only I could manage to draw figures from memory, I should always have something to do ... but in my opinion that figure will never come up to the figure painted from the model.”

\section{In Search of Eternal Truths}

Religious discussion took up part of LT 542 where Vincent wrote, “There must be a book by Tolstoi about religion. I think it is called My Religion, it must be very fine. In it he is trying to find, so I understand from this article, what remains eternally true in the religion of Christ, and what religions have in common. It appears that he does not admit of the resurrection of the body, nor even of the soul, but says like the nihilists, that after death there is nothing more, yet though the man dies, and dies thoroughly, humanity, living humanity, abides. Anyway, not having read the book itself, I can’t say what his concept is, but I think that his religion cannot be a cruel one which would increase our sufferings, but that on the contrary, it must be very comforting, and would inspire serenity and energy and courage to live and many other things.” Vincent then turned his thoughts to the upcoming winter season, "I think I shall end up not feeling 
lonesome in the house, and that during the bad days in the winter, for instance, and the long evenings, I shall find some occupation that will take all my attention. ... I'd certainly like company, but if I haven’t got it, I shall not be unhappy because of it” (LT 542). Then, as they so often did, Vincent's thoughts returned to financial matters: "For my part I think that it is absolutely my duty to try to make money by my work, and so I see my work before me very clearly. ... I want to produce, to produce a lot and with the utmost energy.” He longed to live in a time when money would not be necessary in order to live. Vincent expressed his faith in his work as he said "whether the pictures take a long time to be appreciated or not, they will find a collector someday” (LT 542).

\section{Plans for Next Year's Painting}

Going on in LT 542, Vincent looked forward to the next year's painting and said, "I think that next year you are going to see the same subjects all over again, orchards, and harvest, but with a different coloring, and above all a change in workmanship." Vincent described himself as being like a spider waiting for flies in a web, and that he could be content and settled and wait for a good picture from time to time.

Theological Thoughts and Religious Ideas

Vincent again picked up a theological train of thought and discussed religious ideas that he had gained from Tolstoi, that whatever happened in the way of violent revolution, there would also be a private and secret revolution in men, from which a new religion would be born, or rather something altogether new, which would have no name, but which would have the same effect of comforting, of making life possible, which the Christian religion used to have. He said, "In the end we shall have had 
enough of cynicism and skepticism and humbug, and we shall want to live more musically.” What is it about music that appealed to Vincent? Music has a symmetry and controlled exuberance with a certain timing and beats and the rise and fall of expression. This analogy to music could indicate his desire to express of the extremes of his bipolar personality but with the control of an imposed order and symmetry. Art, music and creative expression allow for expression of personality extremes in a safe way. In this same letter, and perhaps speaking from the depressive side of his personality, Vincent gave a pessimistic view of the future, stating that he felt disasters were bound to strike the modern world and civilization like terrible lightning, through a revolution or a war, or the bankruptcy of worm-eaten states.

Vincent combined his religious thoughts with his concepts about Japan in LT 542. He felt that the man who was undoubtedly wise, philosophic, and intelligent would take a lesson from the Japanese and contemplate a single blade of grass. "But this blade of grass leads him to draw every plant and then the seasons, the wide aspects of the countryside, then animals, then the human figure. And that all would lead one back to nature in spite of education and convention." Vincent said, "I envy the Japanese the extreme clearness which everything has in their work. It is never tedious, and never seems to be done too hurriedly. Their stroke is as simple as breathing and they do a figure in a few sure strokes with the same ease as if it were as simple as buttoning your coat.” Vincent aspired to learn to do a figure in a few strokes. These qualities of simplicity and clarity in Japanese art appealed to Vincent likely because they are the foil to the excessiveness and clutter in his bipolar thought processes. In this he showed the desire for the balance of otherness in his personality, the tao of the yin-yang. Due to his 
interest in Japanese prints and in things Japanese, Vincent would have been aware of the concept of the yin-yang and may have either consciously or unconsciously sought to express it in his artwork.

\section{Narcissism or Altruism}

Vincent usually tended to be self-centered and narcissistic with his concern most often for himself, but in LT 543 he showed concern for his brother. The pain in Theo's leg had returned and Vincent felt that if he could live in the South where the weather was better, that he would make a quicker recovery citing "sun and fine weather and a blue sky as the most efficacious cure. ... The weather here remains fine, and if it was always like this, it would be better than the painters’ paradise, it would be absolute Japan.” This statement again reveals his mental construct that Japan represented perfection to him.

Two sketches were included with LT 543; both were of size 30 canvases, The Starry Sky, also known as Starry Night on the Rhône, and The Yellow House. The first one he described as “the starry sky actually painted at night under a gas jet.” The second sketch was "the house and its surroundings in sulphur-colored sunshine, under a sky of pure cobalt.”

\section{Starry Night on the Rhône}

Vincent described the colors of Starry Night on the Rhône in LT 543, “The sky is greenish-blue, the water royal blue, the ground mauve. The town is blue and violet, the gas is yellow and the reflections are russet-gold down to greenish-bronze. On the blue-green expanse of sky the Great Bear sparkles green and pink, its discreet pallor 
contrasts with the harsh gold of the gas. Two colorful little figures of lovers in the foreground."

Starry Night on the Rhône is also called The Starry Sky in order to distinguish it from the famous and perhaps more well-known painting called The Starry Night from the Saint-Rémy period of Vincent van Gogh. Starry Night on the Rhône features a wide expanse of sky filled with many stars, a town spread out on the bank of the Rhône River and a couple walking in the foreground. The depiction of a couple could be interpreted as wish-fulfillment by Vincent van Gogh and could indicate his longing for closeness and companionship. Lights of the town are indicated by areas of yellow paint, and they are reflected luminously in the broad expanse of water. Water and sky are painted in dark rich shades of blue and in the foreground a lighter blue was used for the nearer bank of the river.

Starry Night on the Rhône speaks dialectically on a variety of levels. Society and human habitation is represented by the town in the background and the lights reflected in the water. An existential sense of the Other (autre, Autre) (Kristeva, 1980, 17) is apparent by the stars, lights in the sky. Nature as an "Other” is shown in stars, sky, and water. A tender personal human connection is implied by the couple in the foreground. Vincent's paintings seldom expressed affection like this in quite so overt a manner. He was often out-grouped and seems to have largely lacked warm human affection in the relationships in his life.

(See Figure 25 on the next page). 


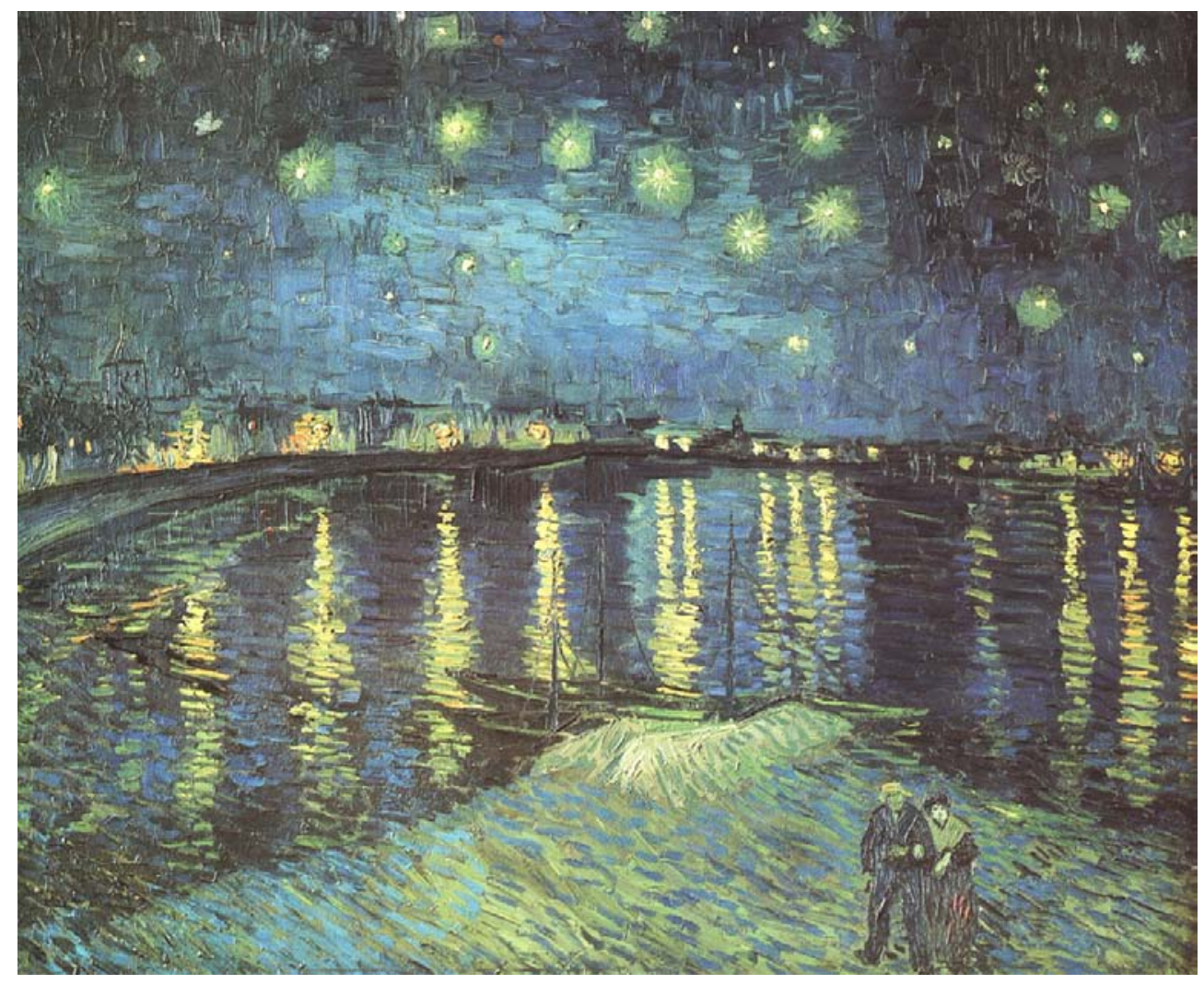

Figure 25. Starry Night on the Rhône

Stein, S. (1986) Van Gogh: A Retrospective.

Hugh Lauter Levin Associates, Inc.: China, p. 189

\section{The Café Terrace at Night}

The Café Terrace at Night was another painting that focused on night effects.

When Vincent painted The Café Terrace at Night he was at the height of his all too brief ten-year artistic career which would be ended by his suicide in just two short years. In The Café Terrace at Night the contrast of artificial light from the gaslights with natural light from the stars is another one of Vincent's juxtapositions of opposites, i.e. the harsh glare of artificial light and the soft natural glow of the eternal stars. The circular shapes of the stars, glowing with a particular intensity as yellow swirls of paint 
in the deep blue twilight are visually repeated in the circular yellowish forms of the tables. Dawe (1976) interpreted the uppermost circles as symbolizing light from heaven that van Gogh particularly longed to reach.

But the greater message of The Café Terrace seems to be about loneliness and social distance. In The Café Terrace, as in The Night Café, the area of human habitation is placed in the middle ground. In both of these paintings the emptiness in the foreground space makes the observer aware of perceived social distance, and the generalized facial features emphasize the lack of personal contact. The perceived sense of alienation from other people is further emphasized by the clash of the colors chosen by the artist van Gogh. The large blue door jamb on the left side of The Café Terrace and the blue of the night sky set up a strong contrast with the bright yellow in the mid ground. The clang of this blue and yellow contrast points out a strong visual expression of conflict and helps to reveal van Gogh's sense of alienation from other people.

On the surface, The Café Terrace at Night seems to have a lot of human interaction, but it is all at a distance and the author (auteur) of the artwork seems vaguely detached from the people in the picture. Kristeva's concept of the auteur $(1980,13)$ relates to the full conscious control of the writing process and "authority" over what has been written. Vincent exercised conscious control and authority over the subject matter, but the unbidden subconscious manifested itself in the sense of social distance and in the isolation and detachment that are apparent when the viewer "reads between the lines." In this the "semiotic disposition" of the auteur becomes apparent and reveals the dialectical conflict with le symbolique (ibid. 18). 


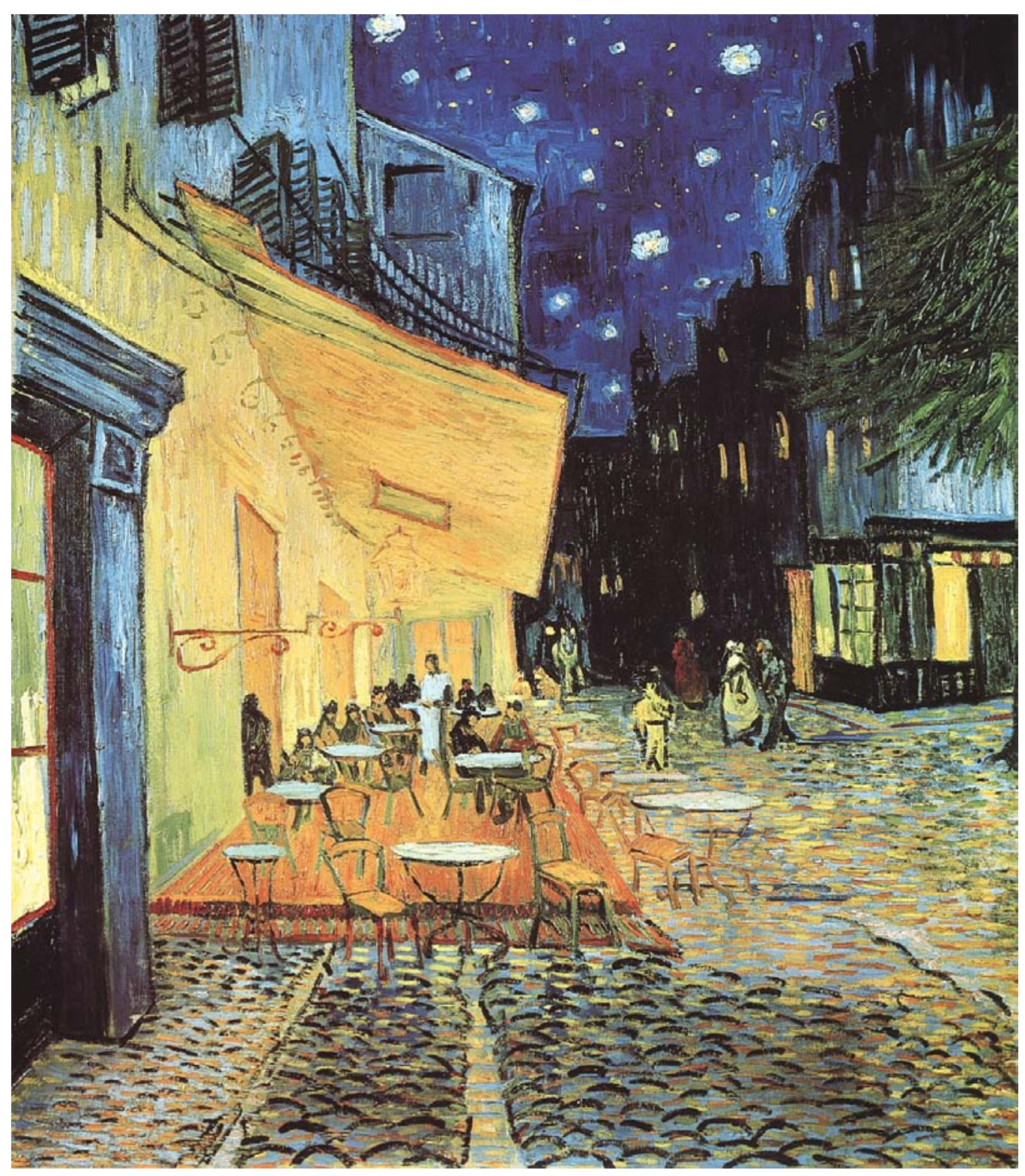

Figure 26. The Café Terrace at Night

Stein, S. (1986) Van Gogh: A Retrospective.

Hugh Lauter Levin Associates, Inc.: China, p. 184 


\section{The Yellow House}

Unfortunately, the yellow house no longer survives as an architectural landmark. It is preserved only in pictures. The house was badly damaged by the Allied bombing in June 1944, and although it could have been repaired, it was taken down.

The Yellow House, a size 30 canvas, was completed by the end of September 1888. Vincent described the subject as "frightfully difficult," but he seemed to perceive it as a challenge to be conquered. He showed the yellow house and its surroundings in a sunny sulphur-color against the brilliant contrast of a bright cobalt blue sky so dark that it could be taken for a night effect. The windows and door of the yellow house are dark. A train steams past in the background. Several people are shown sitting and walking in the environs of the yellow house. There is a liveliness of human habitation here that had not been apparent in many of the earlier pictures from Arles which were often unpeopled or showing social distance.

The Yellow House is a discursive instance (Kristeva, 1984, 14) of a typology that corresponds to the subjective and socioeconomic typologies in society as a whole. As a discourse this painting indicates Arlésian Vincent van Gogh’s socioeconomic status within it by stating, "I have a house in Arles”, (a rented house, but a house, nonetheless). The painting is an individualized articulation by the artist reflecting upon his sense of "having arrived” as a citizen of his adopted town of Arles. Interpersonal communication is implied by the presence of other people in the picture. This is somewhat unusual in that often Vincent's paintings lack the presence of people. Arlésian society could be interpreted from a Kristevan viewpoint as a closed set and Vincent van Gogh as the outsider entering it, thus decentering the closed set and 
elaborating the dialectic of a process within plural and heterogeneous universes. (ibid.) The internal differentiation is implied by various interpretations such as: 1.Arlésian society without Vincent where the house would be just a house, 2. Arlésian society including van Gogh where the house is symbolic of his presence, 3. Arlésian society as a part of modernity in process as implied by the train in the background, 4. Arlésian society where the people stroll and mingle and engage in pleasant discourse. Of course, many other interpretations are also possible. The Kristevan interpretation rationalizes the signifying process as practiced within the text of Vincent van Gogh's painting The Yellow House.

Vincent wrote about painting The Yellow House, "The subject is frightfully difficult; but that I just why I want to conquer it...And it does me good to do difficult things. That does not prevent me from having a terrible need of - shall I say the word? of religion. Then I go out at night to paint the stars, and I am always dreaming of a picture like this with a group of living figures of our comrades” (LT 543). The van Gogh family in general, and Vincent van Gogh in particular, had dual alliances to art and religion with a history of preachers and religious vocations and with persons strongly involved in the arts, such as art dealers. A duality was also evident in the architecture of the yellow house, and a theme of doubling. The yellow house was half of a paired complex of buildings. This may explain on a subconscious level why the yellow house appealed so much to Vincent van Gogh. Vincent longed to share the yellow house and he had a letter from Gauguin who said that he would come to the South of France as soon as he sold something. 


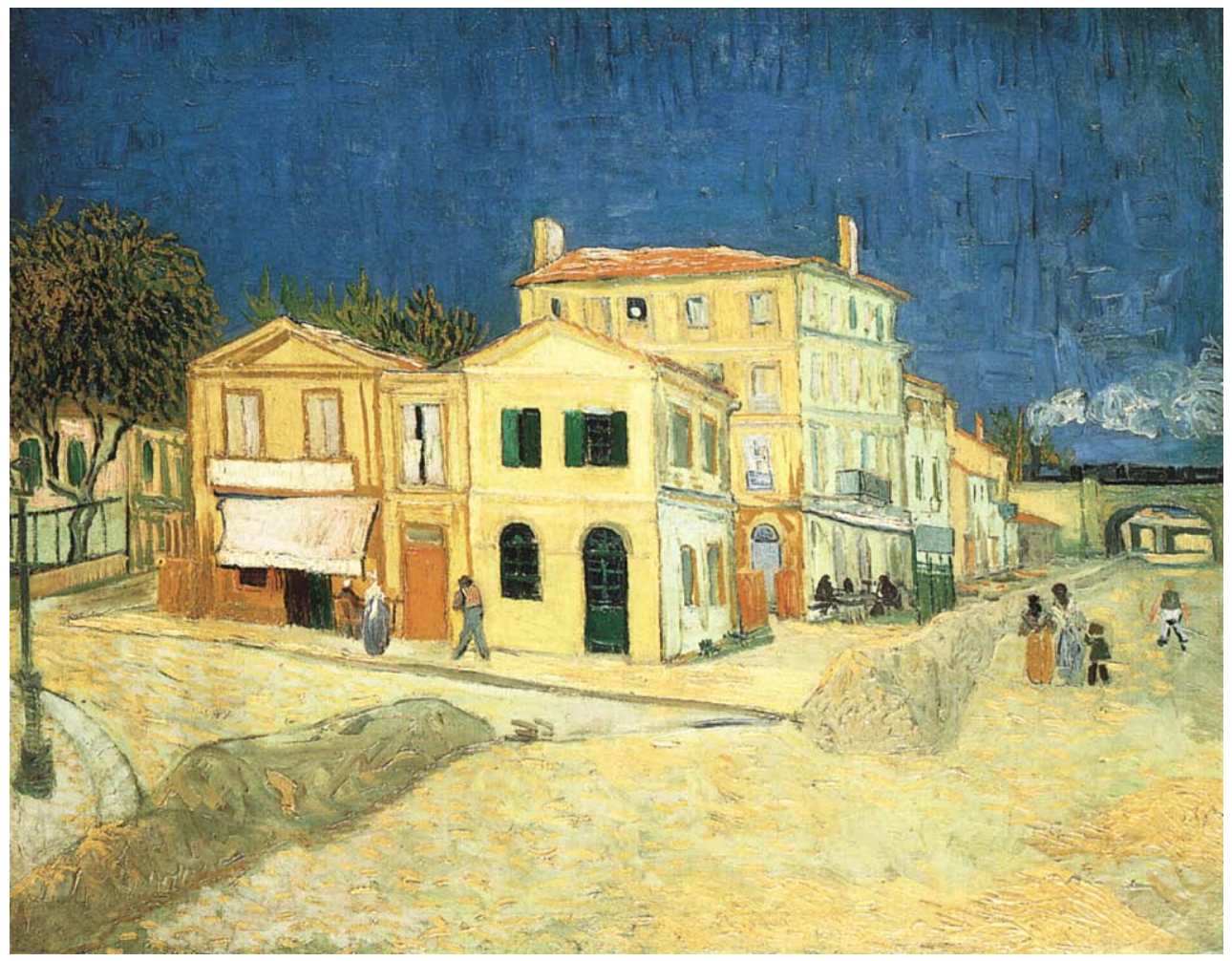

Figure 27. The Yellow House

McQuillen, M. (1989) Van Gogh.

Thames and Hudson: New York, N.Y., p. 170

\section{Religious Discussion}

By the time Vincent van Gogh moved to Arles he had given up on formal religion, but he remained a deeply spiritual man and a religious thinker. The discussion of religion was a theme that emerged and re-emerged throughout the letters of Vincent van Gogh. In LT 543 he returned to the theme of religion by saying, "That Benedictine Father must have been very interesting. What would the religion of the future be according to him? He would probably say, the same as that of the past. Victor Hugo said, God is an eclipsing lighthouse, and in that case we are certainly passing through 
that eclipse now. I only wish that they would succeed in proving something that would tranquilize and comfort us so that we might stop feeling guilty and wretched, and could go on just as we are without losing ourselves in solitude and nothingness, and not have to stop at every step in a panic, or calculate nervously the harm we may unintentionally be doing to other people.” It seems apparent that Vincent van Gogh had both a spiritual malaise and a need to make peace with his inner spiritual self as well as with organized religion.

\section{Visceral Artistic Creation}

Returning to discussion of his art work, Vincent wrote in LT 543, "I should not be surprised if you liked the "Starry Night" and the "Plowed Fields," there is a greater quiet about them than in the other canvases.” He complained of the mistral and how difficult it was to get the brushwork firm and interwoven with feeling, like a piece of music played with emotion. The very visceral experience of artistic creation described here suggests a haptic way of working. Hapticism involves a darkly intuitive, non-visual way of working that includes rhythmic and felt patterns in the designs created. Using their haptic senses even blind people can create art such as painting and sculpture. The bold impasto of Vincent van Gogh created hills and valleys in his painted surfaces; this is a haptic quality. Vincent advised his brother to follow his taste and suggested that good pictures were rare and as difficult as finding a good pearl or diamond. "There are as few good pictures as good diamonds.” He also said, “I have a terrible lucidity at moments, these days when nature is so beautiful, I am not conscious of myself any more, and the picture comes to me as in a dream. I am rather afraid that this will mean a reaction and depression when the bad weather comes, but I will try to avoid it by 
studying this business of drawing figures from memory.” This sounds like Vincent experienced a level of dissociation at times. He also seems to refer to seasonal affective disorder or the bipolar crash into depression after a manic spell. Vincent was aware of the cyclical nature of his mood changes. He continued to be distressed by the lack of models, but reported that he did "landscape and color without fussing about where it will lead me.” He hoped to complete enough pictures that he could have an exhibition by years end if he so chose.

Discussion about religion continued to be interwoven through LT 543, and he was still pondering about what Tolstoi believed, that he seemed to believe neither in the resurrection of the body or the soul nor in heaven, "he attaches great importance to doing what you are doing well, since it is probably all you have. And he [Tolstoi] seems to believe in the equivalent of the resurrection, as the continuance of life in which the progress of humanity, i.e. the man and his work, is almost infallibly continued by humanity in the next generation.” Apparently Tolstoi believed in a peaceful revolution, caused by the need of love and religion which he felt must appear among men as a reaction to skepticism, and to the desperate suffering that makes people despair.

\section{A Possible Colony of Artists}

Along with LT 544 Vincent forwarded to Theo "a very, very remarkable letter from Gauguin.” Vincent said that Gauguin's self-description moved him to the depths of his soul. It now seemed that several artists might move to the South of France. Vincent felt that if there were several artists, that there would need to be "an abbot to keep order, and that would naturally be Gauguin.” This indication that he would immediately demur to Gauguin seems odd since Vincent had the yellow house, the 
financial backing, and the original idea for a colony of artists. This would place Gauguin in charge and put Vincent in a secondary role. It is interesting to look at this in terms of sexual roles; Gauguin would be taking the masculine role and Vincent the feminine. Yet the room that he was preparing for Gauguin, he had described as being like the boudoir of a lady. Gauguin's chair that he painted was fancy (feminine) and had the very prominent phallic looking candle on it, while Vincent's chair was rougher (masculine) and had a pipe on it. A pipe has a combination of male and female elements; the bowl being a receptacle and feminine in nature while the stem is male and phallic. There seem to be some curious sex role reversals going on here, and possible confusion as to sexual orientation.

\section{Preparing the House for Gauguin}

"As for me I want two things, I want to earn back the money that I have already spent, so as to give it to you, and I want Gauguin to have peace and quiet in which to produce, and to be able to breathe freely as an artist.... When I left you at the station to go South, very miserable, almost an invalid and almost a drunkard ...I hadn't the courage to hope. After continued efforts on your part and mine, now at last something is beginning to show on the horizon: Hope” (LT 544). Vincent sent a list of things he wanted to buy before Gauguin came, some more furnishings for the house, but also a goodly supply of paints and canvas, “But you will say - ‘And these paints?’ Well, yes, I am ashamed of it, but I am vain enough to want to make a certain impression on Gauguin with my work, so I cannot help wanting to do as much work as possible alone before he comes. His coming will alter my manner of painting and I shall gain by it, I believe, but all the same I am rather keen on my decorations, which are almost like 
French painted porcelain. And these days are magnificent. All the expenses I have mentioned are only meant to make a good impression on him at the moment he arrives. I would like him to feel it all harmonious, and I wish that we could have managed - you by your money and I with a general effect and the arrangement of things - to have the studio complete, and a setting worthy of the artist Gauguin who is to be its head.” And in addition to the expenses mentioned, Vincent reiterated that Gauguin's fare comes before everything else (LT 544).

Vincent mentioned his study of the vineyards in LT 544, speaking of the "Vines" that he had painted as a companion piece to a painting of the garden. "The 'Vines' that I have just planted are green, purple and yellow, with violet bunches and branches in black and orange. On the horizon are some gray willows, and the winepress a long, long way off, with a red roof, and the lilac silhouette of the distant town. In the vineyard there are little figures of women with red parasols, and other little figures of men working at gathering grapes with their cart. Over it is a blue sky, and the foreground is of gray gravel. This is a pendant to the garden with the clipped bush and the oleanders."

\section{Looking Forward with Hope}

Vincent was looking forward to the colors of autumn: "Day after day it grows richer. And when the leaves start to fall - I do not know if this happens in the beginning of November here the way it does with us - when all the foliage is yellow, it will be amazing among the blue. ... Then a short winter, and after that we shall have got to the orchards in bloom again” (LT 544). 


\section{Precarious Status of Finances and Health}

LT 544a, a letter to Gauguin from Vincent, has been preserved. In it Vincent mentioned discussions that he and Theo had had in Paris, "Often these discussions had to do with the problems that are so very near my brother's heart and mine, i.e. the measures to be taken to safeguard the material existence of painters and to safeguard the means of production (paints, canvases) and to safeguard, in their direct interest, their share in the price which, under the present circumstances, pictures only bring a long time after they leave the artist’s possession” (LT 544a). It is noteworthy to observe the number of times that the word safeguard is used in a single sentence by Vincent van Gogh in this instance. He must have been feeling s sense of vulnerability and a need to compensate for it.

Vincent realized the precariousness of both his mental and physical health before he came to Arles. In a description that sounds like clinical depression, or the depressed phase of bipolar, Vincent said, "when I left Paris, seriously sick at heart and in body, and nearly an alcoholic because of my rising fury at my strength failing me then I shut myself up within myself, without having the courage to hope! Now, however, hope is breaking for me vaguely on the horizon; that hope in intermittent flashes, like a lighthouse, which has sometimes comforted me during my solitary life” (LT 544a). It sounds as if the depression is starting to lift and that his health is returning to a better state.

He discussed the financial problems of the artists and felt that he and Theo had come up with a viable solution to the penury of the artists' life, to start a company of artists who put their paintings in as capital. Vincent wrote in LT 544a, “These days I 
have an extraordinary feverish energy.” After the previous depressive tone, this sounds like the bipolar cycling from depression to mania.

\section{Self-Portrait (as a Bonze)}

Vincent talked about his concept of the South of France as Japan and the orientalized self-portrait in letters over a time period of several months until SelfPortrait (as a Bonze) was completed in September 1888. Writing to his brother Theo in LT 537, 539, and 540, Vincent described this self-portrait as a carefully and painstakingly done study in color. Since he considered it a study, he did not sign it. The additional quality of the orientalizing of his features was mentioned in the letter to his sister Wil, on September 16: "I also made a new portrait of myself, as a study, in which I look like a Japanese” (W 7). To his friend Paul Gauguin he wrote, "I have in the first place aimed at the character of a simple bonze [a Buddhist monk] worshiping the Eternal Buddha” (LT 544a). Vincent van Gogh had said in LT 514 that both he and his pictures had become haggard looking and compared himself to Hugo van der Goes in the picture by Emil Wauters, “Only, having got my whole beard carefully shaved off, I think that I am as much like the very placid priest in the same picture as like the mad painter so intelligently portrayed therein. Only I have made the eyes slightly slanting like the Japanese.” Apparently Vincent shaved his head and beard during the summer of 1888, having written to his sister Wil, "I am wearing neither hair nor beard, the same having been shaved off clean” (W 4). In Self-Portrait (as a Bonze) his hair and beard appear to be starting to grow back in. This self-portrait was completed before he moved into the yellow house on September 16, 1888. 
The color effects of this self-portrait as a Bonze were the visual element of primary concern to Vincent van Gogh. In LT 540 Vincent had said that he had just completed a self-portrait in his known ashen coloring, and that getting the combination of ashen and gray-pink tones had been a lot of trouble. And in LT 544a he described his self-portrait, "I have a portrait of myself, all ash colored. The ashen-gray color that is the result of mixing malachite green with an orange hue on pale malachite ground, all in harmony with the reddish-brown clothes. But as I also exaggerate my personality, I have in the first place aimed at the character of a simple bonze worshiping the Eternal Buddha. It has cost me a lot of trouble, yet I shall have to do it all over again if I want to succeed in expressing what I mean.” Continuing on in LT 545, Vincent said of this selfportrait, "It is all ashen gray against pale malachite (no yellow). The clothes are this brown coat with a blue border, but I have exaggerated the brown into purple, and the width of the blue borders.”

The head is modeled in light colors painted in a thick impasto against the light background with hardly any shadows. The pale green background swirls subtly around Vincent's head in this self-portrait. The concentric strokes curve around the head and become slightly darker near the edges of the canvas. This visual effect that has intimations of a halo provides a type of glowing aura around his head. A rather otherworldly effect is created by the simplification of the background and by the use of unnatural color effects. The “whites” of Vincent's eyes are painted pale green and seem to give off an eerie inner illumination, and the matching of the hue with that of the background suggests a transparency through the eyes to this spiritual malachite green ether (McQuillen, 1989). These swirling brush strokes around the head are an artistic 
device that will continue to be used by Vincent van Gogh and will become an even more pronounced halo in future art works.

Kristeva's $(1980,19)$ idea of the unary subject (sujet unaire) can be related to the self-portraits of Vincent van Gogh. The unary subject is related to traditional concepts of consciousness where the self is seen as a homogeneous, consistent whole (ibid.). The problem is that the great variety within the van Gogh self-portraits seems to show a constantly changing persona. In this self-portrait, Self-Portrait (as a Bonze), Vincent changed his appearance to seem more like a Japanese person. Self-Portrait (as a Bonze) is like a momentary stasis in the changing persona of Vincent van Gogh.

Gauguin and van Gogh exchanged self-portraits as a token of their friendship. On October 4, 1888, immediately upon receiving Gauguin's self-portrait, Vincent sent his own self-portrait with orientalized features inscribed á mon ami Paul Gauguin.

(See Figure 28 on the next page). 


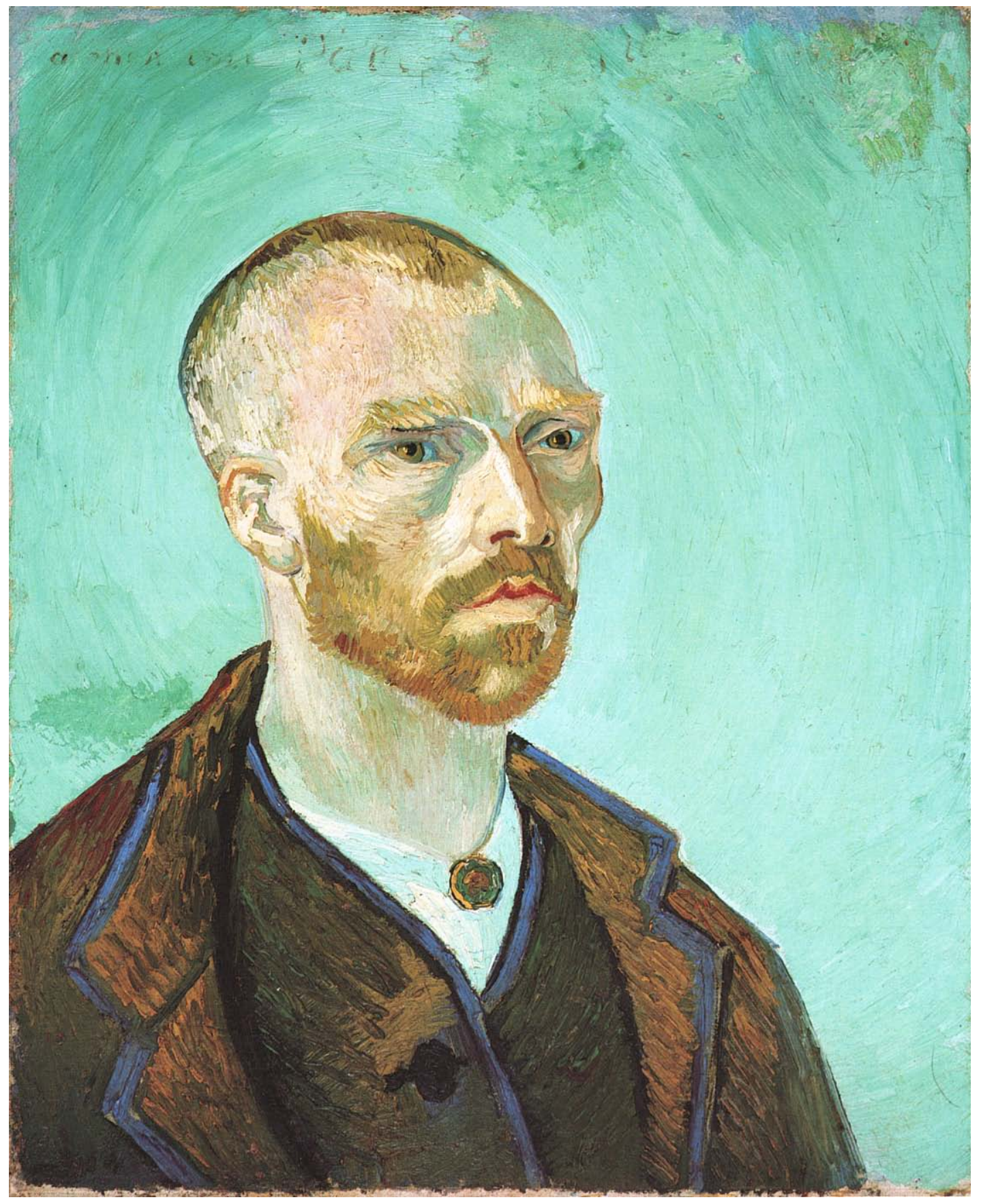

Figure 28. Self-Portrait (as a Bonze)

Pickvance, R. (1984) Van Gogh in Arles.

Metropolitan Museum of Art: New York, N.Y. p. 170 


\section{A Sincerity of Expression though Rash and Clumsy}

Vincent wrote to Gauguin, "I always think my artistic conceptions extremely ordinary when compared to yours. ... I have always had the coarse lusts of a beast. I forget everything in favor of the external beauty of things, which I cannot reproduce, for in my pictures I render it as something ugly and coarse, whereas nature seems perfect to me. However, at present the élan of my bony carcass is such that it goes straight for its goal. The result of this is a sincerity, perhaps original at times, in what I feel, if only the subject can lend something to my rash and clumsy execution” (LT 544a). Vincent continued to express his confidence in the style of impressionism: "The part of the country where I live has already seen the cult of Venus - in Greece essentially artistic and after that the poets and artists of the Renaissance. Where such things could flourish, impressionism will too.” Vincent bravely spoke on in LT 544a written to Gauguin, "However clumsy this attempt may be, yet it is possible you will see in it that I was thinking of you with a very strong emotion while preparing your studio. Let's be full of courage with regard to the success of our enterprise, and you must go on considering this your home, for I am very much inclined to believe that it will last long ... I am a great advocate of the system of exchanges among artists, because I see that it used to be of considerable importance in the lives of Japanese painters.”

In LT 545 to Theo, Vincent discussed the self-portraits of Gauguin and Bernard as well as his own. He described the Gauguin as "remarkable ... more studied, carried further.” Gauguin’s portrait gave Vincent the impression of “representing a prisoner. Not a shadow of gaiety. Absolutely nothing of the flesh, but one can confidently put that down to his determination to make a melancholy effect, the flesh in the shadows 
has gone a dismal blue. ... Gauguin looks ill and tormented in his portrait!!” Vincent also said that he very much liked Bernard’s self-portrait. "It is just the inner vision of a painter, a few abrupt tones, a few dark lines, but it has the distinction of a real, real Manet.” He noted that in the background of the Gauguin self-portrait, there was included a small version of the Bernard self-portrait, and vice versa, one of Gauguin in the self-portrait of Bernard. He said that placing his self-portrait and Gauguin's side by side, he found his to be “as grave, but less despairing.” Vincent felt that Gauguin’s portrait was “Too dark, too sad.” Vincent said that “Once more, one must not do flesh with Prussian blue. Because then it ceases to be flesh; it becomes wood.” Vincent felt that he would assist Gauguin in coloristic effects. Vincent said that he felt sure that his own self-portrait (as a Bonze) held its own. Vincent showed a very different self-image from Self-Portrait (as a Bonze) when he painted Self-Portrait with Straw Hat and Pipe, which is also from the Arles period.

\section{Self-Portrait with Straw Hat and Pipe}

In Self-Portrait with Straw Hat and Pipe the artist showed himself as a rustic, bearded person like a Provençal peasant or fisherman. The hat on Vincent's head with the down-turned brim is like a fisherman's headgear. Throughout his life Vincent van Gogh identified with the poor people of society. Vincent van Gogh experimented with various roles as well as with artistic techniques in his self-portraits. The Paris selfportraits and many of van Gogh’s still-life subjects were exploratory exercises in color theory and brushstroke (Pickvance, 1984). Experimentation continued on into the Arles self-portraits. Self-Portrait with Straw Hat and Pipe shows a simple man formed by a simple artistic technique. The bust-length figure is shown against a very light 
background that is largely unenhanced by brushstrokes or coloristic modeling. There is an economy of means in that the subject is created by a few well-placed brush strokes. With straightforward brush work, the figure is effectively and minimalistically modeled from a few colors, blue, yellow, a bit of reddish-brown and some touches of black for emphasis.

The subject matter of Self-Portrait with Straw Hat and Pipe is similar to SelfPortrait (in a Straw Hat) both from the Arles period. The straw hat functions like a sign system that signifies summer and identifies the speaking subject within a specific social framework (Kristeva, 1980, 18). The countervailing of the sign system questions the subject in process and challenges the identified social framework; therefore it coincides with times of abrupt changes, renewal, or revolution in society. While Vincent might have painted himself in a straw hat as conscious identification with a social class and a specific locale, it also may have unconsciously signified profound change in his persona and cultural milieu.

(See Figure 29 on the next page). 


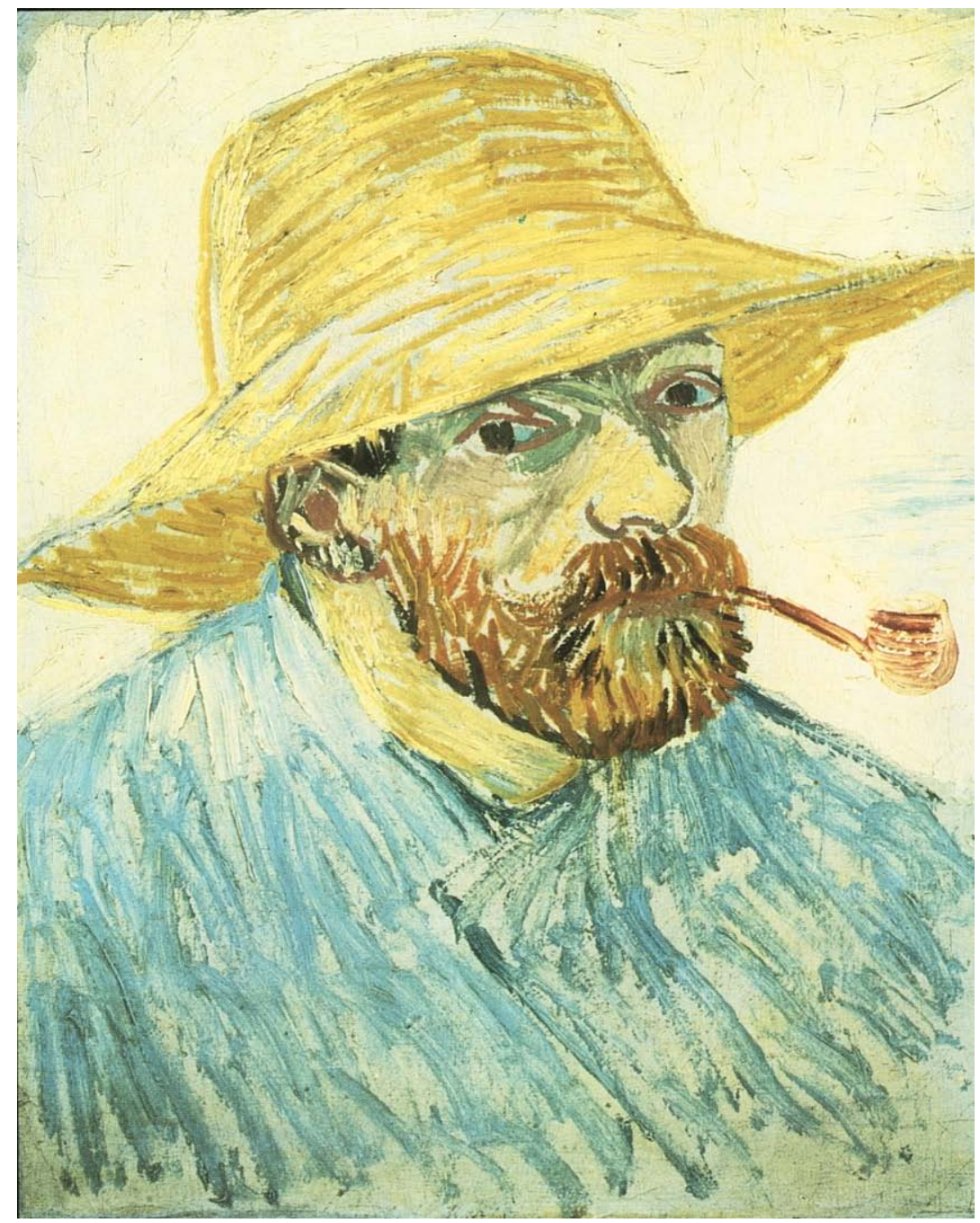

Figure. 29. Self-Portrait with Straw Hat and Pipe

Bonafoux, P. (1992) Van Gogh: The Passionate Eye.

Harry N. Abrams: New York, N.Y., p.6

\section{Financial Concerns}

Vincent felt that his plan for the colony of artists was coming to fruition, and he perceived that this placed a financial responsibility upon him, so he wrote to Theo, “And I see clearly that the duty laid upon me is to do everything I can to lessen our poverty. ... So then I believe that it is your duty and mine to demand comparative 
wealth, just because we have very great artists to keep alive” (LT 546). This letter written in October mentioned that Vincent had overspent on art supplies and did not have enough money for living expenses from Thursday thru Monday noon, so he had essentially fasted for four days: "These four days I have lived mainly on 23 cups of coffee, with bread which I still have to pay for ... Because I was wild to see my pictures in frames, and I had ordered too many for my budget, seeing that the month's rent and the charwoman also had to be paid.” This impulsive overspending and his own description of his decision as "wild" seems to be yet another indicator of the mania of bipolar personality disorder.

Vincent recognized the pressure that this work must put on his brother, but he also thought "that if you saw the studies, you would say I was right to work at white heat as long as it was fine.” Vincent worked furiously when the weather was good, but the mistral would interrupt his work, and he seems to be anticipating the bipolar crash into depression after a manic period of work. He expected another spell of magnificent weather and magnificent effects and that he would make in another spurt of work; "I am so much taken up with the work that I cannot come to a dead stop. Don't worry, the bad weather will make me stop only too soon, like today, yesterday, and the day before yesterday too.”

Vincent mentioned that he had completed some big studies of autumn effects, reporting, "We must not push the studies, which are more trouble to do but are less pleasing to the eye than the pictures, which are the result and fruit of them, and which one paints as in a dream, without so much agony.” Speaking of Gauguin, "He must eat and go for walks with me in lovely surroundings, pick up a nice girl now and then, see 
the house as it is and as we shall make it, and altogether enjoy himself. He has lived cheaply, yes, but he has got so ill by doing it that he can see no difference between a gay color and a dismal one.”

Obsessive and perhaps compulsive thought patterns are revealed in LT 547 when Vincent said, "My whole mind, like yours, is set on Gauguin now. And like you, I hope that he will come right away.” A Kristevian interpretation would be that van Gogh's semiotic processes are going too far in the direction of fascism (in that the disruptive semiotic processes are being rechannelled into both a narcissistic love relation with the charismatic leader Gauguin), and a rigidly hierarchical organization is emerging because of this (that Gauguin would head the colony of painters).

Vincent shared the need for more money. He hoped that they might have a sale of some of his paintings, and identified a Starry Night, Furrows, Poet's Garden, and The Vineyard as romantic landscapes that he considered saleable. Vincent described the importance of having his art materials ready so that he could work when the weather was right, "We have an absolutely merciless mistral, but I must hold myself in readiness, the work is done in short intervals. So that everything must be prepared, and ready for the attack. ... The thing is that you must take advantage of the intervals in the mistral and be ready beforehand. ... The work holds me in its grip, and I am sure I shall not lose by it if I can go on like this, the big canvases are all good. But they are exhausting too” (LT 547).

Vincent requested a timely reception of money, “Only don’t let the next letter come later than Sunday, for it is a close, very close siege these days. But we will hold out, and I feel quite calm amid all the commotions we are passing through. ... Let's be 
sensible, and not forget for a minute that not only for our own sake, but also for the success of this studio, we must get back the money spent during the unproductive years. We shall if we keep calm; besides, it is our due and we have suffered enough for it” LT 548). Vincent suggested that Theo might also show these pictures for potential sale, White Orchard, Pink Orchard and The Harvest with a ruin in the background. Vincent mentioned some difficulties that he was having with his work; he mentioned again that it was a terrible mistral right then, but he wanted to have everything ready to work furiously when the weather cleared up.

Vincent mentioned a portrait of his mother painted from a photo, a size 8 canvas, ashen grey, against a green background, the dress carmine, with the impression of a blonde coloring, and done in thick impasto. In LT 546 Vincent said, "I cannot stand the colorless photograph, and am trying to do one in a harmony of color, as I see her in my memory.” He reported that he was writing home to get a portrait of his father also.

In LT 549 Vincent wrote to Theo that he had had a "rather too complimentary letter” from Gauguin and that he could not come until the end of the month. This time frame made him want to get everything even moreso in readiness for Gauguin to come. Vincent's estimated valuation on the decorations he was making (for the house) was that they would be worth 10,000 francs when they were done. Vincent seemed to think that Gauguin was malingering, but Gauguin said that he was sick and couldn’t come until he was better. Vincent thought that Gauguin should go ahead and come to the South of France and that he would recover sooner in the better weather there. "These days I always have the feeling that I am spending money, but every day too it astonishes me to find how I get it back from the house.” 
Vincent's reply to Gauguin suggested that he come earlier rather than later, and he discussed making lithographs. Vincent was concerned about the expense and felt that he already had enough to do with his painting, but if the lithos were done at night and just for their own benefit, then it might be all right. Gauguin thought that they might publish the lithographs, but Vincent was opposed to this.

\section{My Work Is Your Work}

LT 550 contains a discussion of the collaboration between Vincent van Gogh and his brother Theo, "If I were not so horribly and continually tormented by this uneasiness, I should say that we were getting on, because my work will get better, and my health is much better than in Paris. I see more and more that my work goes infinitely better when I am properly fed and the paints are there, and the studio and all that. ... I wish I could manage to make you really understand that when you give money to artists, you are yourself doing an artist's work, and that I only want my pictures to be of such a quality that you will not be too dissatisfied with your work. ... And what will be done later to reform trade may be just this, that the dealer will join hands with the artist, the one for what one may call the housekeeping side, to provide the studio, food, paint, etc. the other to create.” Vincent had begun to mention in his letters that he felt that they were getting close to selling, but he was concerned about the expense to Theo, “Then when I think of that, I get into a mercenary frenzy. Then I want to earn money so that you will be freer to go where you like and do what you like.” Vincent regretted spending the money on a chest of drawers, but desired to have the house ready for Gauguin. Then, abruptly changing subjects, he discussed night effects with gas lights. This letter seems to reflect flight of ideas and sounds as if Vincent might have been in 
the midst of a manic episode. He may have been responding to the stresses of work and managing finances.

In LT 551, Vincent said that he thought Seurat might also join them and that he would value large pictures like Grande Jatte at 5,000 francs apiece. Vincent's mind seems to be whirling and spinning with numbers and schemes. "Once more that squares exactly with what I was telling you, that I was determined to do 10,000 francs' worth of paintings for the house.” Vincent seems to have obsessively fixed upon achieving the sum that he had in mind. Then just as quickly he began to discuss the turning of the seasons: "The leaves have begun to fall, you can see the trees turning yellow, and the yellow increasing every day. It is at least as beautiful as the orchards in bloom, and as for the work we are doing, I venture to think that far from losing on it, we shall make a profit” (LT 551).

\section{A Lot of Expenses and a Lot of Work}

Vincent wrote, "I have a lot of expenses, and it worries me a good deal sometimes when I realize more and more that painting is a profession carried on most likely by exceedingly poor men, and it costs so much money” (LT 552). He discussed the size 30 canvases of The Tarasçon Diligence, a large pine tree with the figures of two lovers, The Trinquetaille Bridge, and another bridge, “Two canvases in gray and blended tones, and two highly colored ones.” Here is another juxtaposition of opposites, that of colorless and colorful. In LT 552 Vincent enumerated and listed fifteen size 30 canvases that he had done:

2 canvases of sunflowers

3 canvases of the poet's garden

2 canvases of the other garden

1 canvas of the night café 
1 canvas of the Trinquetaille bridge

1 canvas of the railway bridge

1 canvas of the house

1 canvas of the Tarasçon diligence

1 canvas of the starry night

1 canvas of the furrows

1 canvas of the vineyard

All this work was referenced in LT 553 where Vincent said, "I have been and still am nearly half dead from the past week’s work.” He complained of a violent mistral that made it impossible for him to work, "So I am forced to be quiet. I have just slept sixteen hours at a stretch, and it has restored me considerably. And tomorrow I shall have recovered from this queer turn.” He reported that he had worked on five canvases that week, and that "If I had worked more quietly, you can easily see that the mistral would have caught me again.” Sixteen hours of sleep after a long stretch of frenetic works surely sounds like the crash that comes after a manic episode. There is often a switch to depressed mood after the physical and emotional crash.

Further insight into the intensity of Vincent's method of working was given in LT 553b. LT 553b was written to his friend Eugene Boch who had gone to the Borinage. Vincent described his work, reporting that he had seven size 30 canvases in process, describing them and enclosing a sketch of a night effects work. "More than once I have done a size 30 canvas in one day, but then I did not stir from the spot from morning till sunset except to eat a morsel.”

\section{The Tarasçon Diligence}

The Tarasçon Diligence, a size 30 canvas, seems to have been painted in one session. Van Gogh mentioned in his letter that he was completely exhausted after painting "this Tarasçon diligence.” The diligence was a means of transportation, and 
implies the contrast of the opposites of arriving and departing. The diligence is an oldfashioned means of transportation, like a stagecoach. In other pictures van Gogh depicted a modern method of conveyance - a train, for example, in The Yellow House.

The Tarasçon Diligence canvas shows two carriages, one in bright bold colors with contrast of red and green against a yellow wall, and the other was a green and black one. The composition of the painting includes a large area of buff colored foreground, representing sand or gravel, a mid-ground area with the two carriages, and a background of buildings with a patch of blue sky.

The Tarasçon Diligence was mentioned in LT 554 and described as a contrast to the paintings Van Gogh's Bedroom and The Night Café. This is another one of those curious juxtapositions that are a characteristic of the work of Vincent van Gogh, but this is a three-way one. The oppositions and conjunctions of The Tarasçon Diligence with Van Gogh's Bedroom and The Night Café demonstrate one aspect of Hegel's dialectics with thesis, antithesis, and finally synthesis (Kristeva, 1980, 14). What is the connection that he perceived between the painting of his bedroom, the Tarasçon diligence, and the night café? His stated intention in the bedroom painting was that he meant to express "an absolute restfulness" and this is the opposite of the emotional quality of the night café. The diligence was a horse-drawn carriage that would convey someone to a particular destination. A night café was a destination, but he would likely have walked there rather than going by diligence because it was in town. Conceptually there is a conjunction of stillness (the bedroom) with its opposite, motion (the diligence), and a destination to which the motion might bring someone (the café). Visually there are the opposites of an interior (the bedroom), and an exterior (the diligence) and of daytime 
and nighttime. Coloristically there is the dark richness of a night scene, a bright daylight scene (the diligence), and an interior scene by daylight (the bedroom), but with implied darkness by the subject, a bedroom. In this dialectical analysis, connections are discerned between these three pictures.

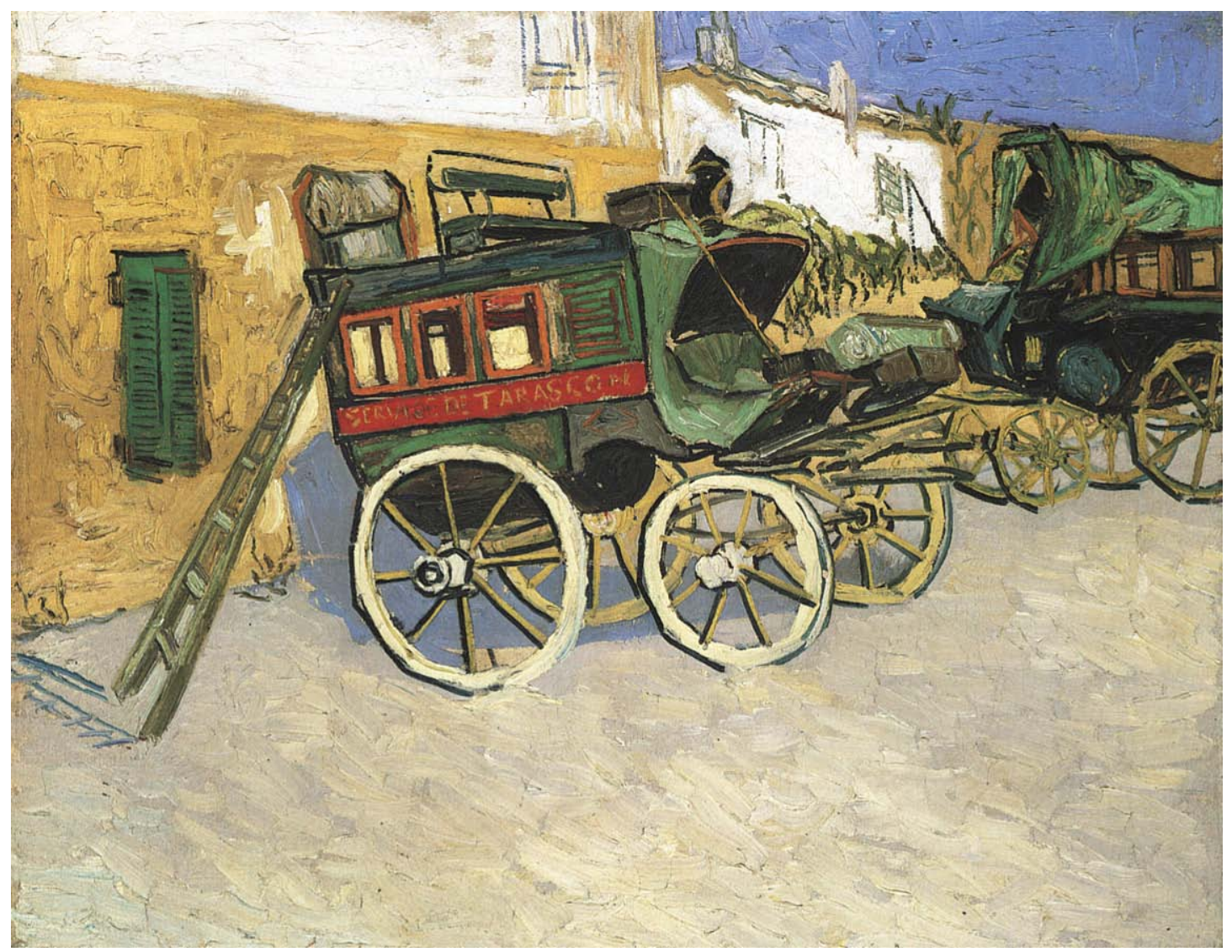

Figure 30. The Tarasçon Diligence

Pickvance, R. (1984) Van Gogh in Arles.

Metropolitan Museum of Art: New York, N.Y. p. 188 


\section{Van Gogh’s Bedroom}

Three versions of the bedroom were done while Vincent was at Arles; the painting discussed here and two sketches that he included in letters. Another painted version was done from memory while he was at Saint-Rémy. The pictures displayed on the walls of the bedroom varied from version to version. The painting selected for discussion here is Van Gogh's Bedroom from the collection of the Rijksmuseum Vincent van Gogh in Amsterdam. Vincent said, “This time it’s just simply my bedroom, only here color is to do everything, and giving by its simplification a grander style to things, is to be suggestive here of rest or of sleep in general” (Pickvance, 1984).

Kristeva $(1980,18)$ uses the archaic word signifiance (signifiance), which is similar in meaning to significance, but not exactly the same. Significance has a connotation of covert rather than ostensible meaning while signifiance through the heterogeneous articulation of semiotic and symbolic dispositions enables a text to signify what representative and communicative speech does not say (ibid.). The representation of Van Gogh's Bedroom was symbolic of the subject (sujet), that is to say of the thinking, speaking, acting, doing, or writing subject, (Kristeva ,1980, 18). This subject is none other than Vincent van Gogh himself. The furnishings of his room are utilitarian, and he had described wanting them to be simple and solid. This can be seen as an expression in paint of Vincent van Gogh’s personality, for he did see himself as a simple man. But a more covert meaning emerges as the solidity of the furnishings are at variance with the lack of restfulness in his bipolar personality. This seems to be a covert artistic depiction of wish fulfillment for greater solidity in his personality. Also, the coverlet of red may foreshadow the blood of his cut ear that will cover that bed at a later time. The more 
covert meaning of Van Gogh's Bedroom continues in the implication of restfulness or sleep as stated by Vincent, and possibly of other activities that he does not mention that might take place there.

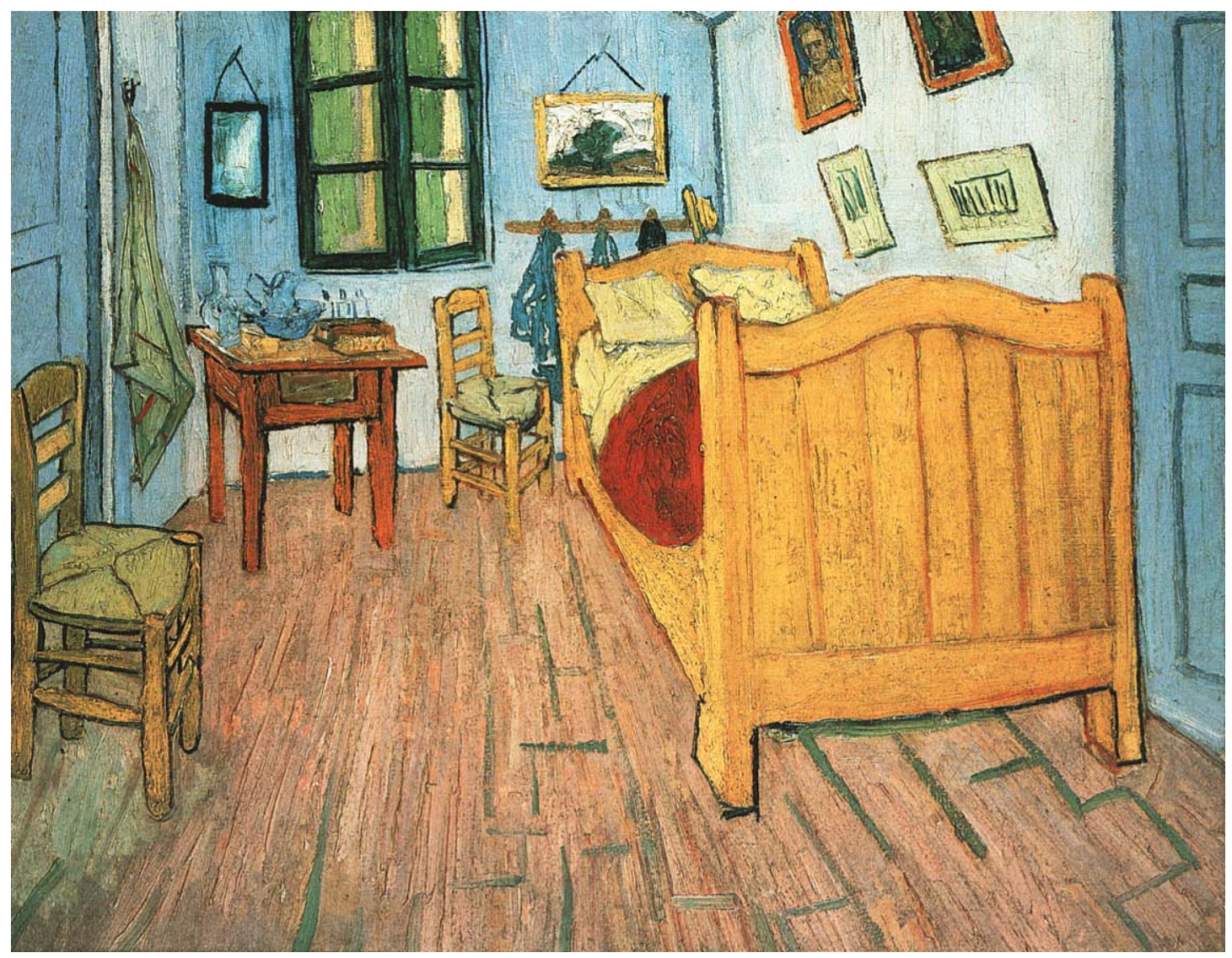

Figure 31. Van Gogh’s Bedroom

Pickvance, R. (1984) Van Gogh in Arles.

Metropolitan Museum of Art: New York, N.Y. p. 190

A New School of Colorists Built on Co-dependency

In LT 555 Vincent van Gogh stated, "I believe that a new school of colorists

will take root in the South, as I see more and more that those in the North rely on their ability with the brush, and the so-called 'picturesque,' rather than on the desire to 
express something by color alone.” This letter has a lengthy postscript including these words that seem to indicate co-dependency, "my dear boy, look here - if you complain of having nothing in your noodle in the way of producing good stuff, just imagine how very much more reason I have for feeling the same depression. I could not even do a stroke of work without you, and we must not go and get excited over what the two of us manage to produce, but just smoke our pipes in peace and not torment ourselves into melancholia because we are not productive separately and with less pain. Certainly I have my own moments when I should dearly like to change and be in business for a bit, and by so doing be able to earn some money myself. But since for the moment we can do nothing to change it, let's accept this fate, that you on your part are condemned always to do business without rest or change, and that I on my part also have a job without rest, wearing enough and exhausting to the brain.”

Vincent described his conception of the painting of his bedroom, "no stippling, no hatching, nothing, only flat colors in harmony. I do not know what I shall undertake next, for my eyes are still tired even yet. And in just such moments after hard work and all the more the harder it is - I feel my own noodle empty too, you know” (LT 555). Vincent felt that the workmanship of the bedroom painting was virile and simple. He debated about his studies as to their quality and artistic merit, “And after all, don't let's meditate on good and bad too deeply - they're always relative. That is exactly the fault of the Dutch to call one thing absolutely good and another absolutely bad. Nothing in the world is as hard and fast as that” (LT 555). These statements both recognize and to a certain extent deny a judgmental duality. 


\section{Still Waiting for Gauguin}

Vincent had the gas installed in the studio and kitchen at a cost of 25 francs. He expected Gauguin any day and said that he desperately needed another 50 francs. "I am not ill, but without the slightest doubt I'd get ill if I did not eat plenty of food and if I did not stop painting for a few days. As a matter of fact, I am again pretty nearly reduced to the madness of Hugo van der Goes in Emil Wauters's picture. And if it were not that I have almost a double nature, that of a monk and that of a painter, as it were I should have been reduced, and that long ago, completely and utterly, to the aforesaid condition. Yet even then I do not think that my madness could take the form of persecution mania, since when in a state of excitement my feelings lead me rather to the contemplation of eternity, and eternal life. But in any case I must beware of my nerves” (LT 556). In this preceding statement Vincent mentions his own awareness of the duality of his personality and his awareness for the need of self-care. He stated that he had decided not to paint for three days, but to rest. With LT 556, Vincent included a sketch of his most recent canvas, "a row of green cypresses against a pink sky with a crescent moon in pale citron. An indefinite foreground, sand and some thistles. Two lovers, the man in pale blue with a yellow hat, the woman with a pink bodice and a black skirt.” He said that it was the fourth canvas of The Poet's Garden, which was the scheme for Gauguin’s room.

At long last the long advent of waiting for Paul Gauguin was ended. Paul Gauguin arrived in Arles on October 20, 1888. 


\section{CHAPTER V}

\section{ARLES, PART 3: FROM COMPANIONSHIP TO CONFINEMENT}

\section{October 20, 1888, to May 8, 1889}

“Gauguin arrived in good health,” Vincent to Theo on October 20, 1888 (LT 557). Speaking of Gauguin, Vincent said, "He is very interesting as a man, and I have every confidence that we shall do loads of things with him. He will probably produce a great deal here, and I hope perhaps I shall too.” The Kristevan concept of jouissance is apparent in Vincent’s excitement about Gauguin’s arrival. Jouissance includes total conceptual, physical, spiritual and sexual happiness. Gauguin was the signifier relating to the meaning of jouissance $=$ j'ouis sens $=$ I heard meaning (Kristeva, 1980, 16). The meaning in Gauguin's arrival was for Vincent a step toward his dream of a colony of painters, a compatriot and companion, and a hope of greater financial success. There is a bipolar quality in the jouissance combined with Vincent's grumbling and complaining.

Vincent makes reference to Theo that he hoped "the burden would be a little less heavy for you, and I even hope, much less heavy. I myself realize the necessity of producing even to the extent of being mentally crushed and physically drained by it, just because after all I have no other means of ever getting back what we have spent. I cannot help it that my pictures do not sell. Nevertheless the time will come when people will see that they are worth more than the price of the paint and my own living, very 
meager after all, that is put into them. I have no other desire nor any other interest as to money or finance, than primarily to have no debts ... the pains of producing pictures will have taken my whole life from me, and it will seem to me then that I have not lived" (LT 557). About his pictures, Vincent said, "It is agonizing to me that there is no demand for them now, because you suffer for it, but as far as I am concerned - if only you were not too worried by my bringing nothing in - it would pretty much be all the same to me.” Vincent had figured that living expenses of 2,000 francs a year for a person who lived 50 years would amount to a lifetime total of 100,000 francs. He was therefore trying to produce 1,000 pictures valued at 100 francs apiece in order to pay his way.

The prospect of Gauguin’s arrival distracted Vincent, "For a while I had a feeling that I was going to be ill, but Gauguin's arrival has so taken my mind off it that I'm sure it will pass. I must not neglect my food for a time, and that is all, absolutely all there is to it." Vincent had every confidence that someday he would turn a profit, "I believe that the time will come when I too shall sell, but I am so far behind with you, and while I go on spending, I bring nothing in. Sometimes the thought of it saddens me" (LT 557). On the other hand, Theo had sold a picture for Gauguin, and that income had made it possible for him to make the trip to Arles.

Vincent became even more concerned with financial matters after Gauguin joined him in Arles. In LT 558, he said they would each need 150 francs per month. In return for the monthly sum, Gauguin would provide one picture a month and as previously agreed, all of Vincent's work would belong to Theo. Vincent felt that two could live as cheaply as one. Vincent believed that his own work "would mature 
quietly, like wine in the cellar.” In a postscript to LT 558, Vincent said, “I do not yet know what Gauguin thinks of my decorations in general, I only know that there are already some studies which he really likes, like the Sower, the Sunflowers and the Bedroom.” The image of the sower seemed to constantly inhabit Vincent's thoughts.

\section{More Versions of The Sower}

Of the several versions of the sower theme that Vincent van Gogh produced, four were done in 1888. One has previously been discussed in this paper. Three more versions of the sower were soon completed, one in October, 1888, and two in November, 1888.

\section{The Sower (October 1888)}

During Gauguin’s first week in Arles, between Wednesday, October 24, and Sunday, October 28, Vincent made two landscape paintings, a sower and its intended companion piece, Trunk of an Old Yew Tree. Vincent said that his "new study of a sower had a flat landscape and that the figure was small and vague.” Even though this was a happy time in the life of Vincent van Gogh, the image and the painting seem quite restrained. It is as if he may have felt self-conscious and threatened that his work would not measure up to that of Gauguin. This is the kind of response that a narcissist might have had when there was a threat to his ego. Vincent had already stated in LT 498 to Theo that he felt Gauguin painted better than he did.

(See Figure 32 on the next page). 


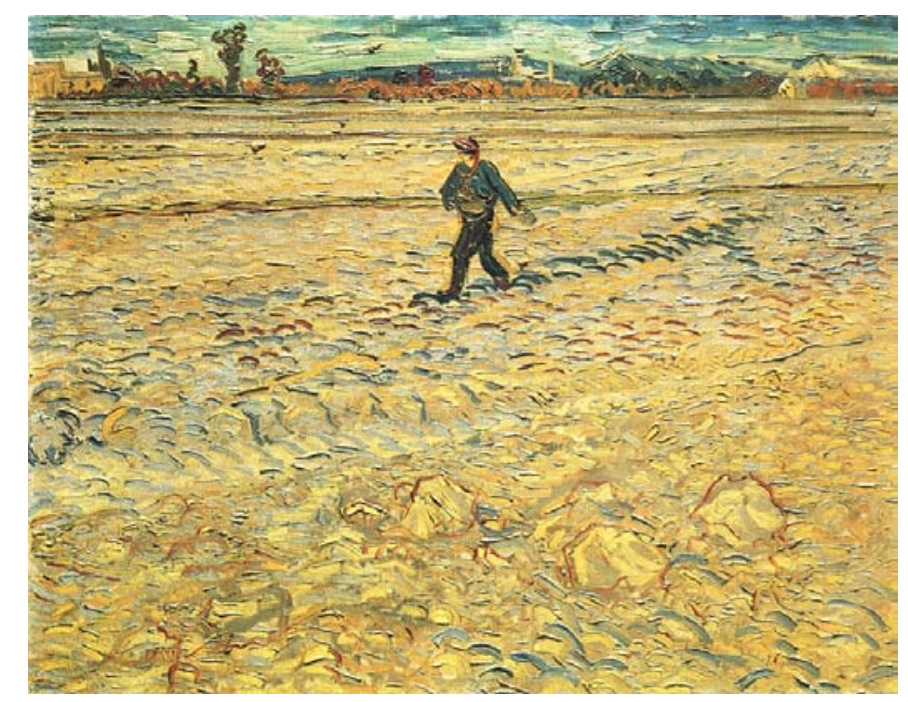

Figure 32. The Sower (October, 1888)

Pickvance, R. (1984) Van Gogh in Arles.

Metropolitan Museum of Art: New York, N.Y., p. 196.

The subject of the sower was an emerging and changing image, in "process" (en procès) as previously discussed. An intertextual analysis of the sower images shows the evolution of the subject. In The Sower (after Millet), Vincent's indebtedness to Millet is evident by the similarity to the piece that was his source and inspiration. The Sower (October, 1888) begins to move toward a more personal representation, but this still seems to be a tentative exploration of the image. It is in Figure 33, The Sower (November, 1888) that Vincent makes the image truly his own.

\section{The Sower (November 1888)}

In November, Vincent returned yet again to the theme of the sower and completed two more versions, virtually the same except for size. The smaller one (12 5/8 x 15 3/4 inches) was a pochade, an oil study, in preparation for the larger (28 7/8 x 36 
1/4 inches) painting (Pickvance, 1984). Around the end of October, Vincent sent Theo verbal and visual sketches of the new sower, "An immense citron-yellow disk for the sun. A green-yellow sky with pink clouds. The field violet, the sower and the tree Prussian blue. Size 30 canvas” (LT 558a). Compositionally, this Sower, completed in November, combines the images of the October companion pieces, the open field from the Sower and the Trunk of an Old Yew Tree. The old tree trunk with some amputated branches cuts boldly across the picture space in a diagonal manner. Lubin (1972, 4-17) discussed van Gogh's use of tree symbolism at length, and the truncated branches likely represent areas of Vincent's life, hopes and dreams that he felt were cut off. Vincent signed his name on the trunk of the tree. Pickvance noted that this is the only picture that van Gogh signed during Gauguin’s stay at Arles. The size 30 November sower was a masterful conclusion to van Gogh's series of sower pictures.

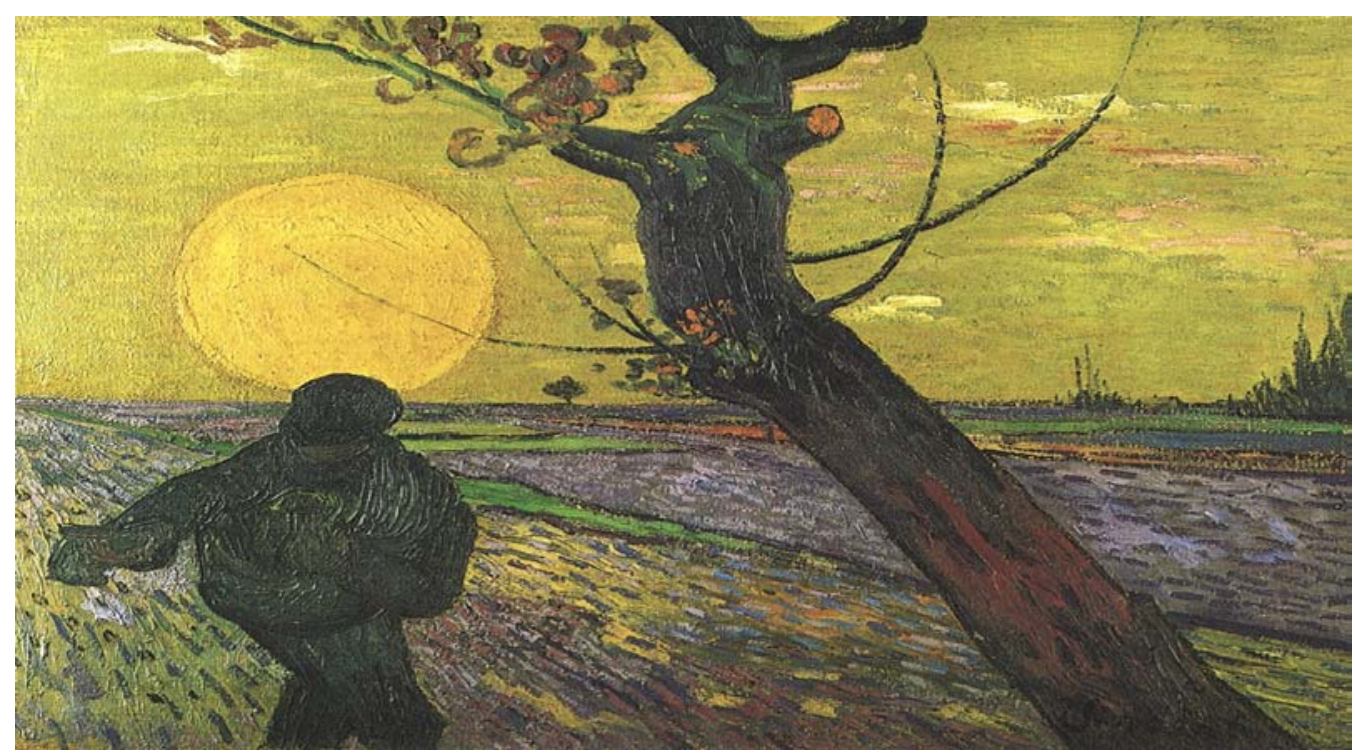

Figure 33. The Sower (November 1888)

Pickvance, R. (1984) Van Gogh in Arles.

Metropolitan Museum of Art: New York, N.Y., p. 219 


\section{Self-Determined Goals and Deadlines}

Vincent wanted to postpone exhibiting until he had thirty size 30 canvases and then he wanted them shown quietly at Theo’s apartment “only once to our friends.” This seems strange given his stated desire to sell his work and be a financial success. Perhaps this is a way to avoid threat to his ego, a decompensation to avoid disappointment if his work was not well received or did not sell. Pickvance (1984) believed that Vincent was attempting to produce thirty size 30 canvases for the Paris World’s Fair of 1889.

\section{L’Arlésienne}

Vincent reported triumphantly that he had "an Arlésienne at last, a figure (size 30 canvas) slashed on in an hour, background pale citron, the face gray, the clothes black, black, black, with perfectly raw Prussian blue. She is leaning on a green table and seated in an armchair of orange wood” (LT 559). This appears to be the same armchair used for the painting of Gauguin's Chair. Vincent's model was Mme Ginoux, the innkeeper of the night café.

L'Arlésienne is a representation of a type, a female citizen of Arles, and thus is an example of Kristeva’s $(1980,15)$ ideology (idéologie). Kristeva’s $(1980,16)$ concept of mechanistic materialism moving in a linear, non-reversible fashion and apparent in cause and effect, is discernible as Vincent was very aware that Gauguin had painted his version of an Arlésienne. There was possibly more than a little jealousy involved leading Vincent to paint his version of L'Arlésienne. This type of cause and effect determinism is sometimes called vulgar Marxism. 


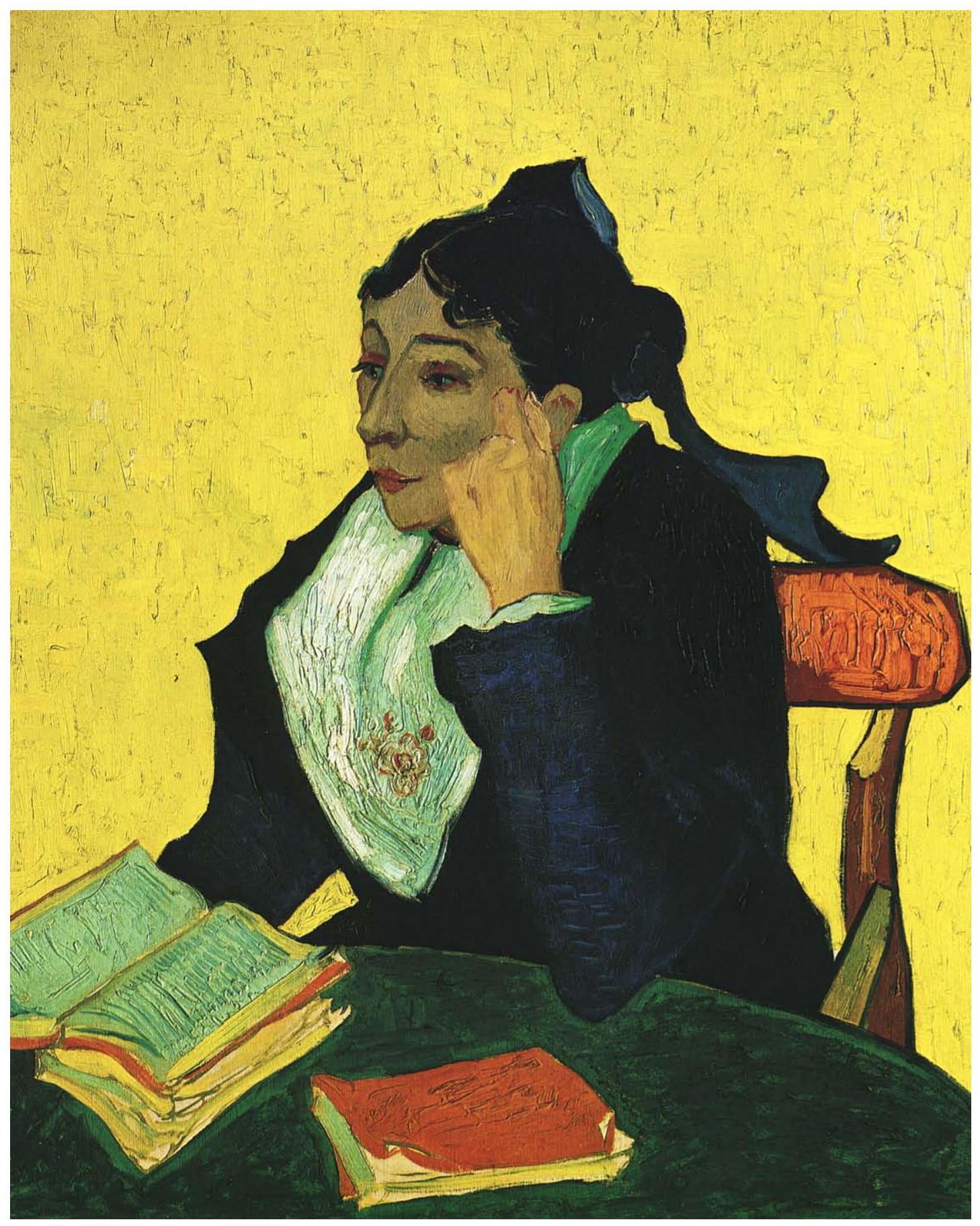

Figure 34. L’Arlésienne

Pickvance, R. (1984) Van Gogh in Arles.

Metropolitan Museum of Art: New York, N.Y., p. 209 
An Exchange of Ideas between van Gogh and Gauguin

"My brain is still feeling tired and dried up, but this week I am feeling better than during the previous fortnight” (LT 559). In a discussion of the tropics, Vincent said that he might go there if he were younger, but for now, "the little yellow house here in Arles will remain a way station between Africa, the Tropics, and the people of the North.”

In LT 559 Vincent mentioned that Gauguin was painting some women in a vineyard, completely from memory, and a picture of the same night café that he had painted. Vincent, preferring to paint on site, reported that he had done two canvases of the falling leaves and a vineyard all purple and yellow (non-local color). Painting from memory or painting from life would become a source of argument between Gauguin and van Gogh. But a new method of painting was opened up for Vincent by starting to paint from memory and he began to move toward greater abstraction in his work.

Gauguin had bought some things for the house - a chest of drawers, some utensils, 20 meters of canvas - and Vincent was very concerned that they pay him back, “Only you must not forget to return to Gauguin, either at the end of the year or in March, the money he may have spent, for instance, on sheets and other things that are to remain in the studio.”

Continuing in LT 559, Vincent gave an insight into their everyday life, saying, "Gauguin and I will have our dinner at home today, and we feel as sure that it will turn out well and that it will prove to be better or cheaper.” Vincent also discussed color in the tropical countries, "Then in those brighter countries, with a stronger sun, the direct 
shadow as well as the shadow cast by objects and figures becomes quite different, and is so full of color that one is tempted simply to leave it out. That happens even here.”

\section{Les Alyscamps}

Vincent mentioned painting "tree trunks lined up like pillars along an avenue lined with Roman tombs and a carpet of fallen leaves. And in the avenue little black figures of lovers.” This is surely one of three versions of Les Alyscamps that Vincent discussed in a letter to Emile Bernard that was probably written November 2 (Pickvance, 1984). Vincent also discussed a second canvas of the same avenue with "an old fellow and a woman as fat and round as a ball,” and he mentioned seeing a red vineyard.

Arnheim (1988) discussed centricity and eccentricity, an analysis of composition viewed as dynamic interaction of visual forces. This centric-eccentric interaction is yet another example of a conjoined pair of opposites. There is a psychological aspect to the analysis of centric-eccentric systems of composition that is relevant to the twofold task of human beings, the spread of action from the generating core of the self and the interaction with other such centers in the social field (Arnheim, 1988). Centricity and eccentricity have to do with whether internal or external forces are predominant, and this is similar to the concept of internal locus of control versus external locus of control. The task of balancing the demands of the inner self and the powers and needs of outer entities is relevant both in life and in artistic composition. Vincent van Gogh was constantly in conflict with others because of his inability to balance his own internal needs with the external needs of others. Borderline personality disorder is characterized by this type of interpersonal conflict. 
Centric composition is that in which a system is free to spread its energy in space, and it sends out its circular vectors evenly all around, like snowflakes, planets, and stars, i.e. the rays emanating from a source of light. The second system, eccentric composition, happens when the original center responds to the presence of another center and instead of radial vectors, a system of parallel verticals and/or horizontals is seen. The domination of the grid-like eccentric system is seen in rows or groups like choruses of columns or trees or groups of people (Arnheim, 1988). Les Alyscamps with its parallel tree trunks is an example of the eccentric style.

Les Alyscamps seems to have two distinctly different aspects, a street with benches, sarcophagi and a couple walking; and a grid arrangement of tree trunks. The synthesis of these two aspects is achieved by the superimposition of tree trunks on the scene. The splitting of a single whole and the cognition of its contradictory parts is the theory of dialectics as explained by Lenin (Kristeva, 1980, 14). Hegel saw this process as thesis, antithesis, and finally synthesis (ibid.). The Marxist view sees contradiction inherent in all things, resulting in a cleavage, a struggle between the two elements of the contradiction, elimination of the weaker element, and contradiction apparent in the victorious element (Kristeva, 1980, 14). Les Alyscamps seems to depict synthesis of the dialectical parts (Leninist and Hegelian, rather than Marxist).

(See Figure 35 on the next page). 


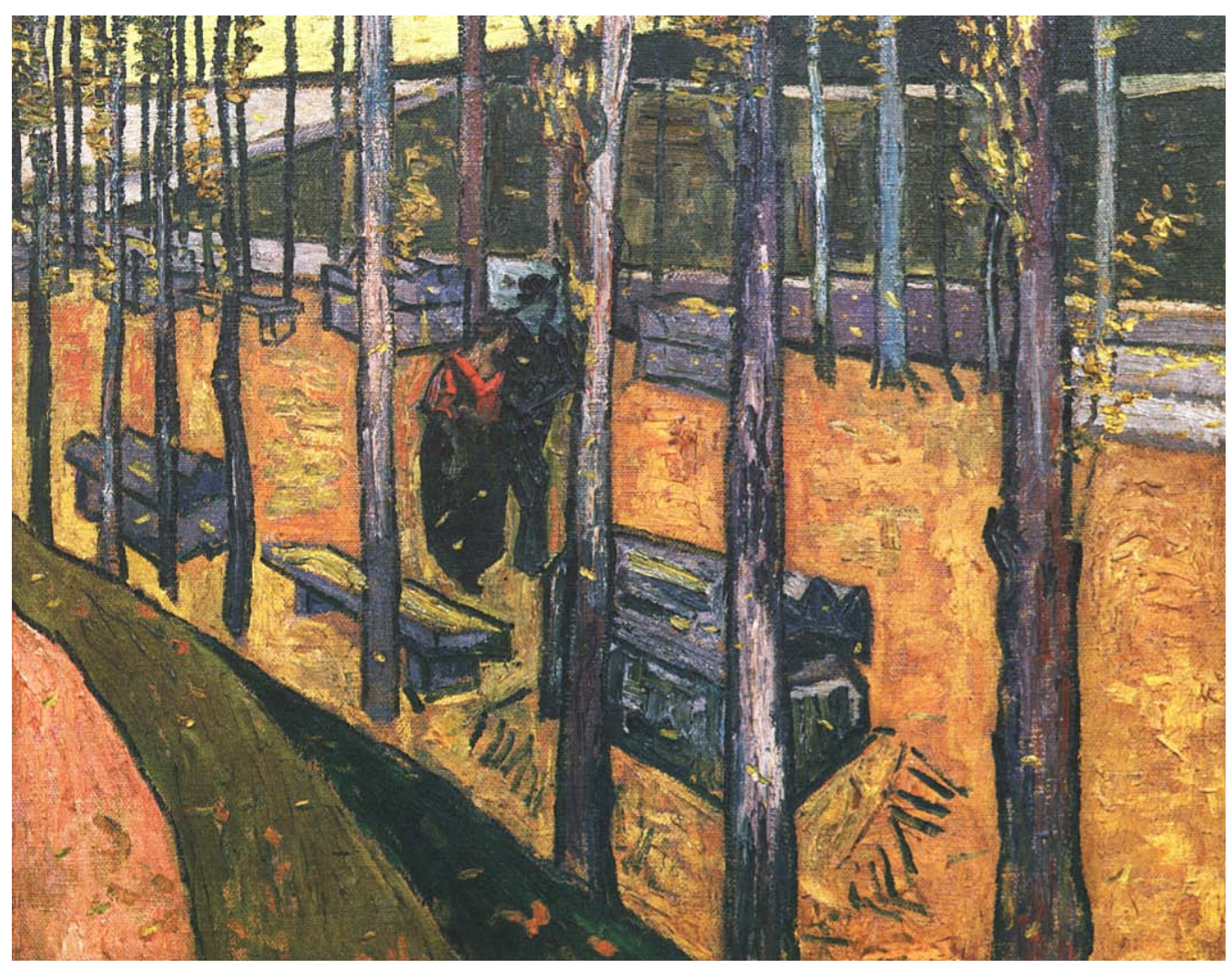

Figure 35. Les Alyscamps

Pickvance, R. (1984) Van Gogh in Arles.

Metropolitan Museum of Art: New York, N.Y., p. 199

The Red Vineyard

The colors of a sunset that Vincent saw during an evening walk were the inspiration for the brilliant coloration of The Red Vineyard. Although it is commonly thought to be the only painting that Vincent sold during his lifetime, Pickvance believed that Anna Boch might have acquired The Red Vineyard after van Gogh’s death. The sister of Eugene Boch, Anna purchased a painting from the exhibition of Les Vingt in Brussels in February, 1889, and that painting might have been The Red Vineyard. But The Red Vineyard is mentioned in Vincent's letter of May 2, 1889, as one of the 
canvases that he was sending to Theo that he considered worthy of putting on stretchers (LT 589).

Kristeva’s $(1980,15)$ concept of intertextuality (intertextualité) has to do not with the influence of one writer upon another, or the sources of a work, rather it has to do with the components of a textual system and the transposition of one or more systems of signs into another. In the artistic textual system, the visual elements are the components and signs. Color is the foremost visual element in The Red Vineyard. The color is nonlocal, highly expressive, and is a new articulation of the enunciative and denotative position of the artist. Vincent van Gogh transposed the use of abstract, imagined color upon an otherwise traditional landscape.

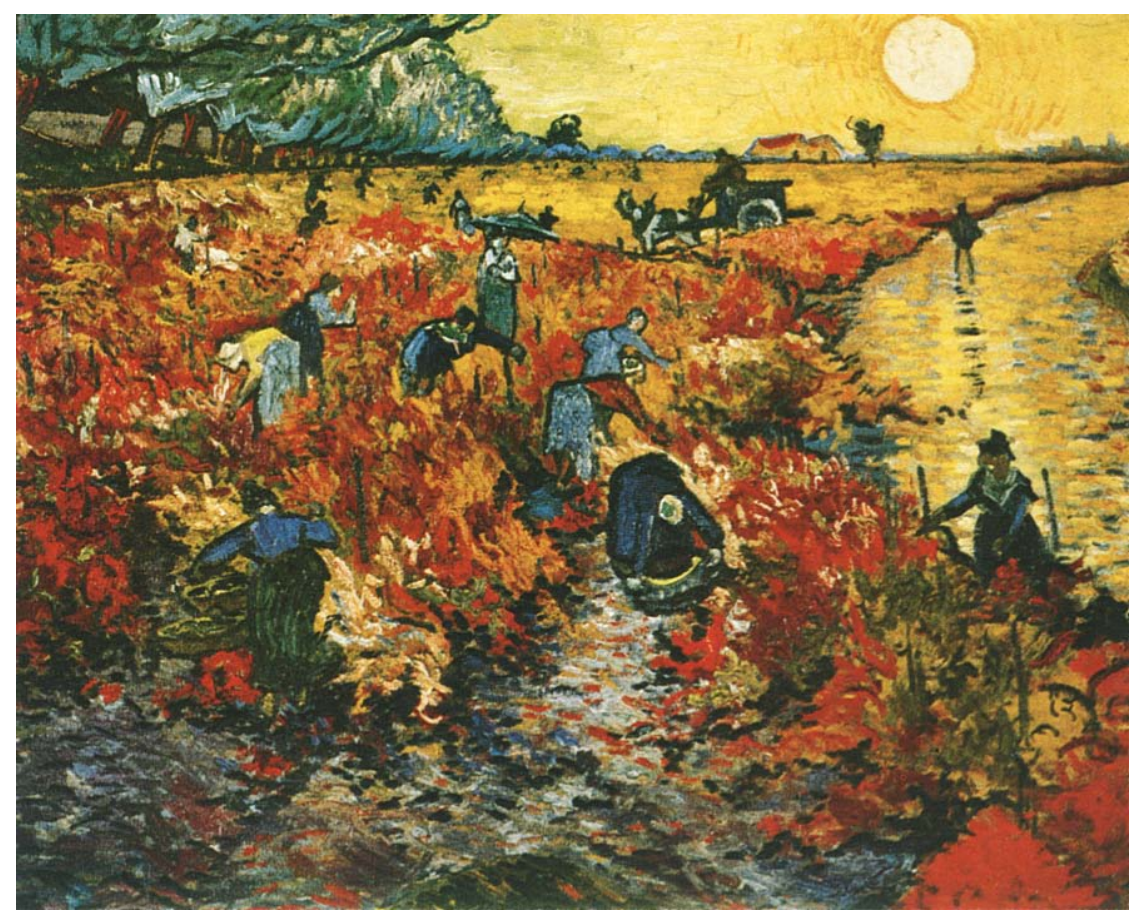

Figure 36. The Red Vineyard

Pickvance, R. (1984) Van Gogh in Arles.

Metropolitan Museum of Art: New York, N.Y., p. 207 
Learning to Work from the Imagination

By November of 1888, Vincent van Gogh and Paul Gauguin had settled into a winter regimen as reported in LT 560: "Our days pass in working, working all the time, in the evening we are dead beat and go off to the café, and after that, early to bed. Such is our life ... Of course it's winter here with us too, though it's still very fine from time to time. But I do not dislike trying to work from imagination, since that allows me to stay in. It does not worry me to work in the heat of a stove, but cold does not suit me, as you know.”

Portraiture, a discipline that lends itself to indoor work, was possible on inclement days. Vincent reported having painted portraits of the postman's whole family. He was hopeful of selling portraits. He reminded Theo that "You always told me to work more for quality than quantity” (LT 560). Gauguin's propensity for work dovetailed nicely with Vincent’s own work ethic, and he wrote in LT 560, “Gauguin works a lot. ... I think that we shall end up spending our evenings drawing and writing, there is more work than we can manage.” Vincent reported that Gauguin was "very successful with the Arlésiennes. ... He is married but he doesn't look it very much” (LT 560). The criticism apparent in this comment may mark the beginning of a rift in the relationship between Vincent van Gogh and Paul Gauguin.

LT 561 contained quite a lengthy discussion of Vincent's concerns about exhibiting his pictures. He was not anxious to do so. Learning to work from memory challenged him and he said, "I am going to set myself to work from memory often, and the canvases from memory are always less awkward, and have a more artistic look than studies from nature, especially when one works in mistral weather. ...We are having 
wind and rain here, and I am very glad not to be alone. I work from memory on bad days, and that I would not do if I were alone.” Speaking of Gauguin, Vincent said, "He is very interesting as a friend, I must tell you that he knows how to cook perfectly; I think I shall learn from him, it is very convenient.”

Vincent said that Gauguin was "working on a very original nude woman in the hay with some pigs. It promises to be very fine and of great distinction” (LT 562). Vincent mentioned two canvases of his own, "a memory of the garden at Etten with cabbages, cypresses, dahlias, and figures, then a Woman reading a novel in a library, like in the Lecture Française, a woman all in Green.” Vincent said that Gauguin gave him the courage to imagine things, and that he had noticed that things from the imagination take on a more mysterious character. This same train of thought was picked up in LT 563, "Gauguin, in spite of himself and in spite of me, has more or less proved to me that it is time I was varying my work a little. I am beginning to compose from memory and all my studies will still be useful for that sort of work, recalling to me the things I have seen.”

By December when Vincent wrote LT 563, he reported that Gauguin was beginning to get over the disorder of the liver or the stomach which had been tormenting him. Vincent now stated that he preferred for Theo not to sell his canvases: "If you asked me what would please me, it’s just this one thing, that you keep in the apartment for yourself whatever you like out of my work, and sell none of it now. ... What then does selling matter, unless we are absolutely pressed for money?” This is a reversal of his previous concerns to sell in order to gain income. 
Vincent discussed his earlier disagreement with his previous employer, who was also Theo’s current employer, Boussod Valadon and Co., saying, “But as far as I'm concerned, I still carry that old grudge.” Part of his concern that Theo not sell was to avoid Theo doing business outside the firm that he worked for, so that he would avoid any possible conflict of interest. Theo could exhibit and if anyone was interested in buying they could apply directly to Vincent.

Having Gauguin’s companionship was encouraging to Vincent and he said, “It does me a tremendous amount of good to have such intelligent company as Gauguin’s, and to see him work.” Vincent's work was done quickly, but he stated that he was indifferent to the criticism that he worked too quickly. He reported that his last two studies "were odd enough, Size 30 canvases, a wooden rush-bottomed chair all yellow on red tiles against a wall, (daytime). Then Gauguin's armchair, red and green night effect, walls and floor red and green again, on the seat two novels and a candle, on thin canvas with a thick impasto.”

\section{The Two Chairs}

The paintings of Van Gogh's Chair and Gauguin's Chair are pendants meant to be displayed together. They are also opposites representing day and night, coarse and refined. Van Gogh did few still-life paintings while Gauguin was in Arles, but the two paintings of the chairs are considered by Pickvance (1984) to be monumental still-lifes.

Kristeva’s $(1980,15)$ idea of intertextuality (intertextualité) is shown in Vincent's transmutation of implied portraiture into still-lifes. The chair paintings Van Gogh's Chair and Gauguin's Chair express the personality of the unpictured sitter transposed to the presence of the chair. The Hegelian concept of negativity (négativité) is apparent in 
the absence of van Gogh and Gauguin from the pictures. And Kristeva's other, Other (autre, Autre), is expressed in the opposite qualities of the personalities of the two artists as expressed in the differences (différence) of symbolic retention by way of the two chairs.

\section{Van Gogh's Chair}

Shown in natural daylight, Vincent's chair, plain and simple, is sitting sturdily on the red tile floor. His presence is implied by the pipe and tobacco lying on the seat. The stem and bowl of the pipe have a hermaphroditic quality in the conjunction of opposites implied by the pipe. Masculine is represented by the phallic pipe stem and feminine by the hollow receptacle of the bowl of the pipe. A box with sprouting onions shown in the background could be interpreted as an indication of new growth and new ideas springing to life. Two shades of blue comprise the background walls.

(See Figure 37 on the next page.) 


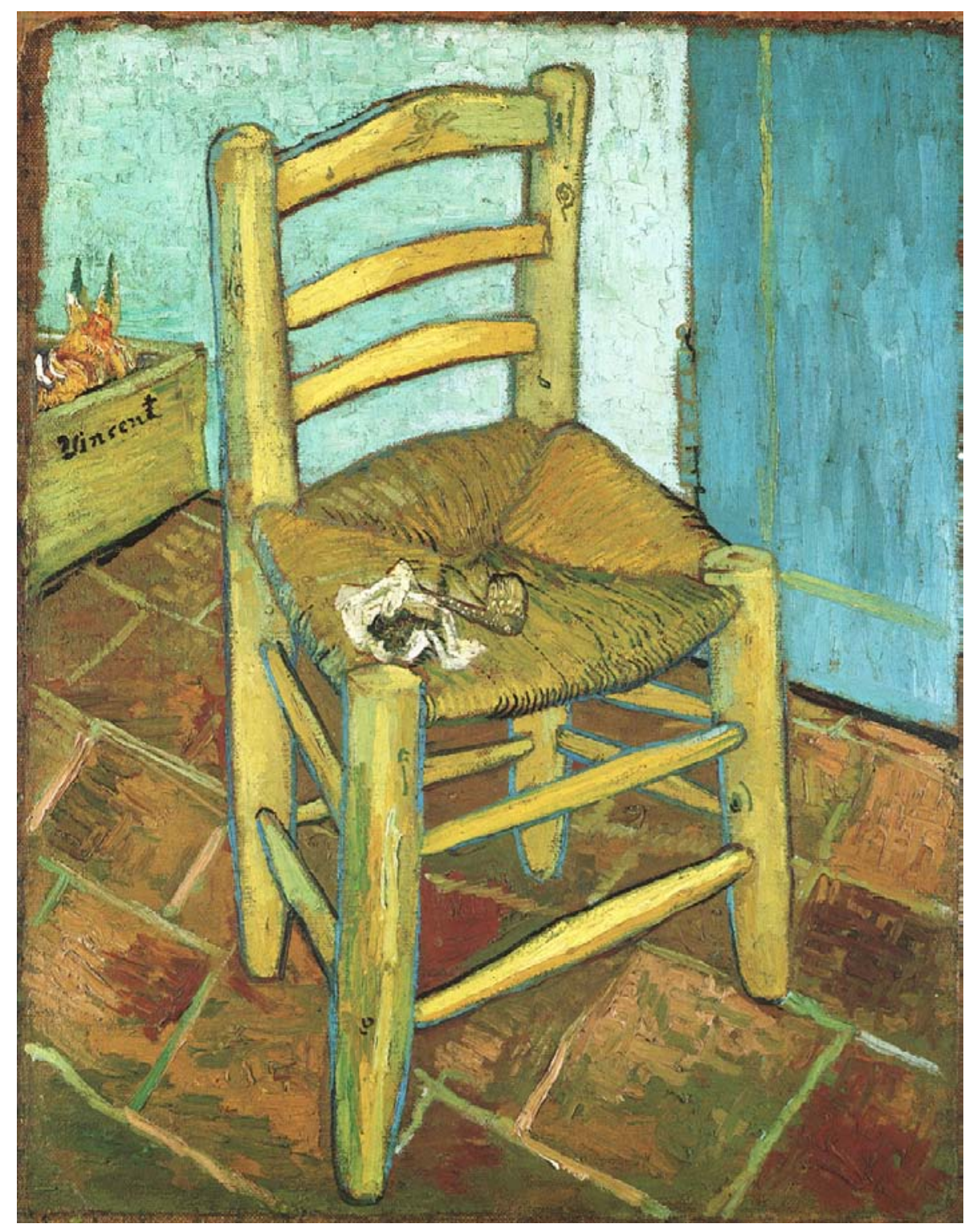

Figure 37. Van Gogh's Chair

Pickvance, R. (1984) Van Gogh in Arles.

Metropolitan Museum of Art: New York, N.Y., p. 234 


\section{Gauguin's Chair}

Gauguin's armchair is pictured in a night effect by artificial light. The chair is largely curvilinear and is much more fancy and refined than Vincent's chair. Gauguin's presence is implied by two books and a lighted candle sitting on the seat of the chair. The candle is an extremely phallic image and it could be interpreted as visually expressing homoerotic feelings that Vincent might have had for Gauguin. If indeed Vincent had those types of feelings, they seem to have been largely sublimated, but they may have been expressed in the obsession that he seemed to have about Gauguin and in their arguments that he described as very electric.

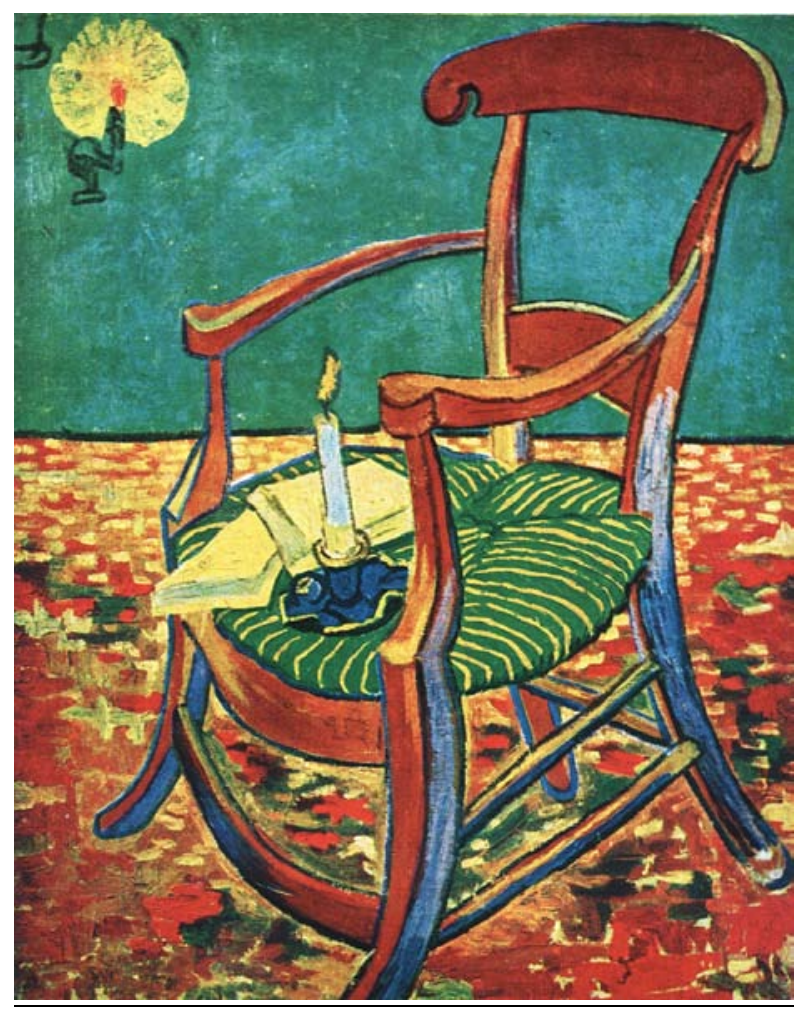

Figure 38. Gauguin’s Chair

Pickvance, R. (1984) Van Gogh in Arles.

Metropolitan Museum of Art: New York, N.Y., p. 57 


\section{Terribly Electric Arguments}

"Our arguments are terribly electric, sometimes we come out of them with our heads as exhausted as a used electric battery;” apparently they argued about art, artists, and art techniques: “Gauguin and I talked a lot about Delacroix and Rembrandt” (LT 564). These electric arguments sound like lover's quarrels. The Sekhmet-like intensity in the personality of Vincent van Gogh seemed to be transforming into an even more destructive quality that the Egyptians personified as Set (or Seth). Set, the Egyptian god of thunder and lightning, was believed to control the forces of destruction and the power of storms (Seton-Williams, 1988). Set, described in the Chester Beatty Papyrus, The Judging of Horus and Set, as he who "shall thunder in the sky and be feared," represented the firestorm of the cosmos, the relentlessness of thunder (Jacq, 1995; Peters, 2000). Energy like a firestorm and relentlessness were qualities that were evident in the personality of Vincent van Gogh and these are the very qualities of bipolar and borderline disorders.

Despite the arguments between Paul Gauguin and Vincent van Gogh, there seemed to be physical healing taking place at Arles. Vincent reported, "Gauguin was saying to me this morning when I asked him how he felt, that he felt his old self coming back, which gave me enormous pleasure. When I came here myself last winter, tired out and almost dazed in mind, before being able to recover, I had some inner suffering too" (LT 564).

The Incident of the Ear

"I think myself that Gauguin was a little out of sorts with the good town of Arles, the little yellow house where we work, and especially with me. As a matter of 
fact, there are bound to be grave difficulties to overcome here too, for him as well as for me. But these difficulties are more within ourselves than outside. Altogether I think that he will definitely go, or else definitely stay. I told him to think it over and make his calculations all over again before doing anything. Gauguin is very powerful, strongly creative, but just because of that he must have peace” (LT 565).

Gauguin had written to Theo that Vincent and he could not go on living together because of incompatability of temper. Then they made up after the quarrel and Gauguin wrote another letter, saying that the first had been like a bad dream. The next day after this letter, December 24, Gauguin sent a telegram asking Theo to come to Arles. Vincent had been in a state of terrible excitement. Although it is commonly believed that the artist Vincent van Gogh cut off his ear, actually he only cut off a piece of his ear. He cut off the lobe of his ear and took it as a present to a woman in a brothel.

Christmas is a time of expectations and hopefulness, a time when emotions run high and disappointments happen easily. Christmas was also a time when Vincent had a strong history of "incidents.” Gauguin and van Gogh had walked in the park, and after a disagreement they visited the Mère Chose where Vincent was particularly fond of one small brunette there (Meier-Graefe, 1987). Vincent was called Fou-roux by the girls who lived there, Fou-roux, Crazy-Red or Mad-Red; and Gauguin was called Montezuma. Julius Meier-Graefe said that the little brunette stroked Vincent's ears and said that since he did not have five francs to give her that he might at least honor her with one of his large lop-ears for a Christmas present. In Vincent's heightened emotional state, this seems to have acted like a post-hypnotic suggestion and Vincent soon carried it out. When a person's emotions are running high the critical factor may 
be short-circuited, i.e. the critical factor is like a safety valve built into the thought process. It is the critical factor that causes one to think better of doing unwise behavior. There is also another quality in the incident of the ear that might seem to indicate that Vincent had possibly inadvertently been hypnotized: he referred to Gauguin as Master and behaved subserviently toward him. Vincent came running toward Gauguin with a knife in his hand. Meier-Graefe reported that Gauguin said severely, "Vincent!” and that Vincent dropped his head and said, "Yes, Master.” He returned to the Yellow House while Gauguin chose to sleep at an inn that evening. During the evening, Vincent cut off a piece of his ear, wrapped it up and took the bloody packet to his little brunette who fainted upon opening it. Madame Chose called the police.

There had been a violent scene but Roulin the postman managed to get him home and the police had intervened. Gauguin sent a wire to Theo in Paris. Theo came and stayed over Christmas saying, "poor fighter and poor, poor sufferer." When Theo left to go back to Paris, apparently Gauguin went with him.

Chronology of the Incident of the Ear

Helpful insights can be gained by observing the course of Vincent's hospitalization and recovery. Pickvance (1984) established a chronology of the incident of the ear and it is summarized here:

Monday, December 24 - Vincent was discovered in his bed by the police, "giving almost no sign of life.” He was admitted to the hospital in Arles, the Hôtel Dieu, and he was attended there by Dr. Félix Rey. Theo arrived in Arles in response to Gauguin’s telegram. Theo is probably the one who sought out the Reverend Frederick Salles, the pastor of the Reformed Protestant Church. 
Tuesday, December 25 - Van Gogh’s condition was considered critical.

Wednesday, December 26 - Theo returned to Paris and almost certainly was accompanied by Paul Gauguin. Theo wrote to his fiancéé, Johanna Bonger, "If it must be that he dies, so be it, but my heart breaks when I think of it.”

Thursday, December 27 - Mme Roulin visited Vincent in the hospital, but after this he had a serious attack and was put in an isolated room.

Friday, December 28 - Joseph Roulin tried to visit Vincent but was not permitted to see him. Vincent would not eat and he was refusing to talk to anyone. There was a possibility that Vincent would be transferred to a mental hospital in Aix. Monday, December 31 - Reverend Salles wrote to Theo that Vincent was calm and behaving normally, but that he was amazed and indignant that he was being deprived of his liberty and that Theo had not written. There was concern that Vincent's indignant state might escalate to another attack.

Wednesday, January 2 - Vincent wrote to Theo stating that he was hoping soon to return to the yellow house. Dr. Rey added a reassuring note to the letter, "I am firmly convinced that he will be himself again in a few days” (LT 567).

Thursday, January 3 - Roulin wrote to Theo saying that Vincent was recovered and that he could move freely about the hospital. Roulin said that they had walked together for more than an hour and that he perceived Vincent to be in "a very healthy state of mind." Friday, January 4 - Roulin wrote again to Theo proclaiming that Vincent was completely recovered. He was able to take Vincent on a four-hour outing away from the hospital and they visited the yellow house. While at the yellow house, Vincent wrote two notes in pencil, one to Theo and one to Paul Gauguin. 
Monday, January 7 - Vincent left the hospital and went home. Dr. Rey and two colleagues visited Vincent at the yellow house. Vincent wrote a reassuring three-page letter to his mother and sister Wil and one to Theo in which he mentioned his intent to return to his work of painting on the morrow by doing one or two still-lifes.

\section{Going Home to the Yellow House}

When Vincent was able to come home after his fifteen-day hospitalization, he found everything prepared for his homecoming. The charwoman and his friend Roulin had taken care of the little yellow house and had put everything in order. Vincent wanted to get back to work immediately and he apparently looked forward to a productive future, as he had said in his letter to Theo written on January 4, "When I get out, I shall be able to go my own little way here again, and soon the fine weather will be coming and I shall start again on the orchards in bloom.” Vincent regretted that Theo's journey had not been during a more beautiful time of year. He reminded Theo that they owed Gauguin money that he spent on furniture and that he would send Gauguin's pictures when he was ready. On the back of the page of this same January $4^{\text {th }}$ letter, also written in pencil and addressed to "My dear friend Gauguin”, Vincent expressed his "very deep and sincere friendship." He said that he had often thought of Gauguin when he was in the hospital, even at the height of fever and comparative weakness and he wondered had Theo’s trip really been necessary? At the time LT 566 was written Theo was already engaged to Johanna Bonger.

On January 2, 1889, Vincent had written to Theo (LT 567) while he was in the office of Dr. Rey, the house surgeon. Vincent would stay at the hospital a few more days and then, "I think I can return to the house very quietly." He asked about his 
friend Gauguin, “Have I scared him? In short, why doesn't he give me any sign of life? He must have left with you." Dr. Rey added a brief note on the back of the page to reassure Theo. Dr. Rey said that "the overexcitement had been only temporary" and that he was convinced that Vincent would "be himself again in a few days."

\section{Minimizing His Difficulties}

Vincent minimized the recent difficulties by saying, "I do so regret that you had all that trouble for such a trifle. Forgive me, who am after all probably the primary cause of it all. I did not foresee that it would be important enough for you to be told of it” (LT 568). He said that Dr. Rey had come with two friends to visit him and look at his paintings. Vincent recognized that Gauguin's leaving was probably a permanent decision and suggested that the amount for monthly expenses might be reduced to 150 francs as it had been before and said that he thought, "now I shall see calmer days here than in the past year." Vincent continued to suggest a covert secrecy about his paintings, "Only I think that we must still keep quiet with regard to my own painting. If you want any pictures, certainly I can send you some already, but when my peace of mind comes back to me, I hope to do different things” (ibid.) Vincent realized that his difficulties had caused a delay in Theo's relationship with the Bongers and he regretted this. He inquired about Gauguin.

LT 569 was written the evening of the same day that he wrote LT 567. He recognized that there had been several days when he could not write. He had written to his mother and sister with the intention of "setting their minds at rest" about his recent hospitalization. "Just tell them on your part that I have been a bit beat, the way I used to be in the past, when I had that venereal trouble in the Hague, and that I got myself 
looked after in the hospital. Only that is not worth mentioning since I have completely recovered...” He hoped that his family would not "get into a stew about it." He reported his plans to get back into the habit of painting again on the next day by doing a couple of still-lifes. He planned to make a gift to Dr. Rey of an engraving of The Anatomy Lesson for his study. "I assure you that some days at the hospital were very interesting, and perhaps it is from the sick that one learns how to live. I hope that I have just had simply an artist's fit, and then a lot of fever after very considerable loss of blood, as an artery was severed; but my appetite came back at once, my digestion is all right and my blood recovers from day to day, and in the same way serenity returns to my brain day by day. So please quite deliberately forget your unhappy journey and my illness.”

Written in Dutch on January 7, 1889, LT 569a was addressed to "Dear Mother and Sister" to tell them that in December he had been indisposed, "But at the same time I can inform you that I have completely recovered, and am at work again, and everything is normal." Vincent sought to minimize and normalize what had happened to him.

\section{Theo’s Engagement and Vincent’s Possible Eviction}

On January 9, Vincent had received a letter from Johanna informing him of her engagement to Theo. In LT 570 Vincent returned congratulations to her and also wrote them to Theo. He included news of his recovery, saying that he had returned to the hospital for a dressing change and had walked for one and a half hours with Dr. Rey. In Dr. Rey, Vincent found a friend who was interested in learning about art, but Vincent advised him to be a collector rather than to be an artist himself. 
It had become known to Vincent that during his absence, the owner of the house made an arrangement with a tobacconist to turn Vincent out and give the tobacconist the house. Vincent took exception to the planned eviction, and it made him angry because he had made a number of improvements to the yellow house at his own expense.

\section{Returning to Health and Returning to Work}

In LT 570 Vincent analyzed his condition by saying, "Physically I am well, the wound is healing very well and the great loss of blood is being made up, because I eat and digest well. What is to be feared most is insomnia, and the doctor has not spoken about it to me, nor have I spoken of it to him either. But I am fighting it myself. I fight this insomnia by a very, very strong dose of camphor in my pillow and mattress, and if ever you can't sleep, I recommend this to you. I was very much afraid of sleeping alone in the house, and I have been afraid I should not be able to sleep. But that is quite over and I dare to think that it will not reappear. My suffering from this in the hospital was frightful.” Vincent's comments about being afraid to sleep in the yellow house reveal a certain level of paranoia. And in a rather curious comment, Vincent said that previously he had been powerless to paint the women of Arles as anything but poisonous, but that so far it had only been the work of a sick man. He intended to return to his work and spoke of beginning again.

\section{Counting the Cost}

LT 571 of January 17 was a very long letter with a detailed accounting of finances, including additional expenses incurred by his hospitalization. This had caused Vincent to expend his month's allotment of money by the $8^{\text {th }}$ of the month. He borrowed 5 francs, but from the $10^{\text {th }}$ to the $17^{\text {th }}$ he observed a strict fast, and he realized 
that he could not recover under such conditions. He said that he felt "weak and rather uneasy and frightened.” Vincent bemoaned "my pictures are valueless, it is true they cost me an extraordinary amount, perhaps even in blood and brains at times.”

Vincent reported that since the hospitalization, he had finished three studies and the portrait of Dr. Rey which he gave to him as a keepsake. Vincent recounted that Dr. Rey had told him, "that being very impressionable was enough to account for the attack that I had, and that I was really only anemic, but that I really must feed myself up.” Vincent had just kept a rigorous fast for a week due to lack of funds, and he inquired of Dr. Rey, "whether he had seen many madmen in similar circumstances fairly quiet and able to work; if not, would he then be good enough to remember occasionally that for the moment I am not yet mad.”

In the Asylum

When Paul Signac visited Arles in the spring of 1889, Vincent van Gogh was already in that town's asylum. On the day that Signac visited, Vincent was described as “quite sane,” and the house physician gave Signac permission to take Vincent out of the asylum. They visited Vincent's studio and talked of many things like painting, literature, and socialism. There had been a terrible spell of mistral and Vincent became upset. After this he wanted to drink about a quart of essence of turpentine from the bottle standing on the table in the room. He needed to return to the asylum. Signac reported, "He had the famous bandage around his head and wore his fur hat."

\section{Self-Portrait with Bandaged Ear and Pipe}

In Self-Portrait with Bandaged Ear and Pipe, the author (auteur) of the painting, Vincent van Gogh, narrates the aftermath of the self-imposed injury to his ear. It is clear 
that he is the subject (sujet), the thinking, speaking, acting, doing, or writing agent (Kristeva, 1980, 19). Kristeva does not use the term sujet to denote the topic or theme of a work. This self-portrait is yet another indication of Vincent as a subject in process, rather than a unary subject.

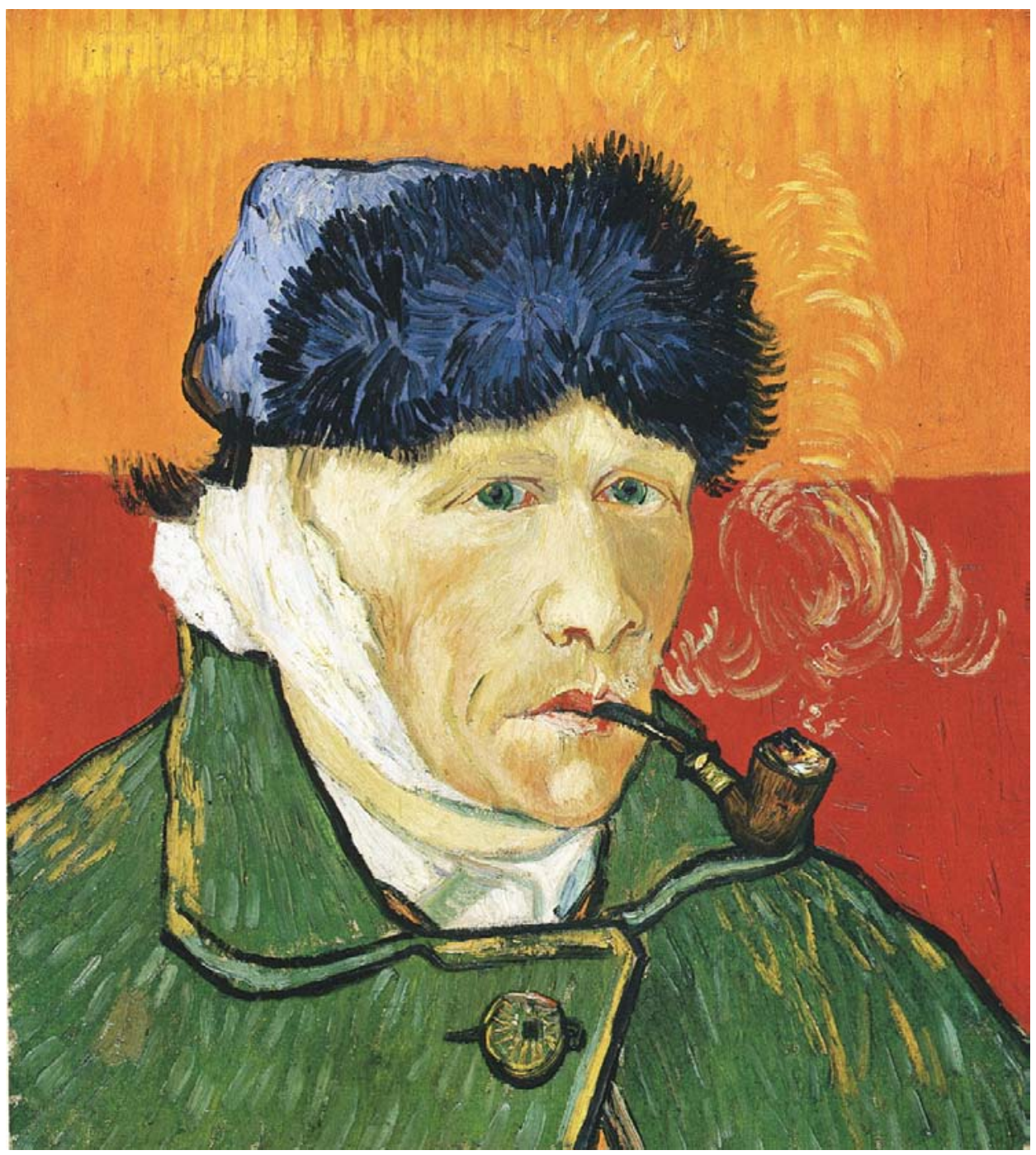

Figure 39. Self-Portrait with Bandaged Ear and Pipe

Pickvance, R. (1984) Van Gogh in Arles.

Metropolitan Museum of Art: New York, N.Y., p. 244 


\section{Portrait of Dr. Félix Rey}

Vincent painted Dr. Rey’s portrait and gave it to him as a gift. Dr. Rey had taken care of him in the hospital at Arles from December 24, 1888, to January 7, 1889, and Vincent wanted to show his gratitude in his own way. It was reported in Kunst and Kunstler that the doctor thought it so lacking in beauty that he put it in the garret. It is said that there it took the place of a broken windowpane, serving the purpose of keeping out the drafts. Pickvance (1984) stated that the picture was so disliked by the doctor's mother that it was used to stop a gap in a hen house.

Dr. Rey is depicted wearing a blue suit jacket trimmed with red buttons and piping. The outline of the right side of the face has been noticeably altered, resulting in a reshaping of the face to a narrower presentation. An unnaturalness is also noted in the hairline.

The portrait of Dr. Rey is characterized by a very decorative paisley-like patterned green background with yellow ochre swirls, red dots and ovoid black strokes. Patterned backgrounds were later also used in the portrait of Joseph Roulin and the one of Madame Roulin in La Berceuse. Pickvance (1984) described the patterned background as less floral than musical.

(See Figure 40 on the next page). 


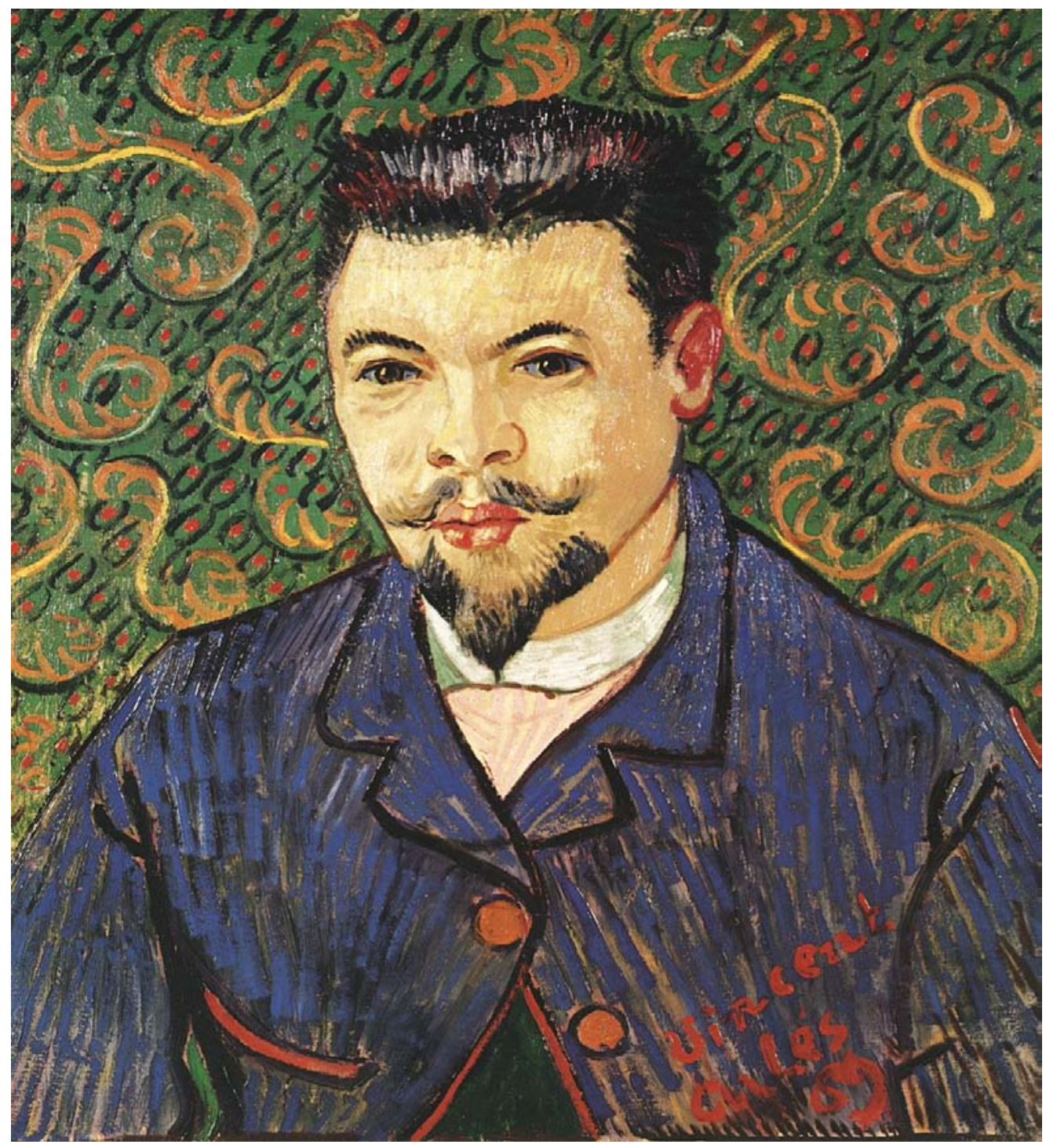

Figure 40. Portrait of Dr. Félix Rey

Pickvance, R. (1984) Van Gogh in Arles.

Metropolitan Museum of Art: New York, N.Y., p. 243

\section{Matters of Conscience}

Speaking of Gauguin, Vincent said, "On various occasions I have seen him do things which you and I would not let ourselves do, because we have consciences that 
feel differently about these things. I have heard one or two things said of him, but having seen him at very, very close quarters, I think that he is carried away by his imagination, perhaps by pride, but ... practically irresponsible” (LT 571). There was a dispute about paintings, Gauguin had made off with two of Vincent's sunflower paintings and was claiming another one. He had left some studies. Vincent would have preferred to have his paintings back and would exchange with Gauguin "his little Martinique canvas, and his self-portrait sent me from Brittany, at the same time giving me back both my portrait and the two sunflower canvases which he has taken with him to Paris” (LT 571).

\section{Vincent, a Doctor?}

Vincent stated that he regretted not being a doctor. In a description that possibly sounds like a migraine headache, Vincent wrote, “After my illness my eyes have naturally been very sensitive” (LT 571). He referenced the paintings of the two chairs, and wrote that he was still working on the one of his own chair. He said, "I have tried for an effect of light by means of clear color.” He also reflected on the future of impressionism and felt that "It seems to me impossible, or at least pretty improbable, that impressionism will organize and steady itself now.” He thought that there would be no union of artists, and that as an artistic movement impressionism would break up.

Vincent had received a postcard from A. H. Koning while he was in the hospital and he replied in LT 571a describing his recent illness, "I received your postcard in the hospital at Arles, where I had been quartered following an attack of something the matter with my brains, or otherwise fever ... that is to say whether I am mad or not, or whether I have been mad, and am still mad, in some imagination of a purely sculptural 
nature. And if not, whether I was already mad before that time; or whether I am so at present, or shall be so in the hereafter.” These very convoluted statements seem confused and confusing, but in this same letter he described the painting La Berceuse as “our lullaby or the woman rocking the cradle” (LT 571a).

\section{La Berceuse}

La Berceuse was begun before his hospitalization in December, 1888, and completed afterward in late January, 1889. Vincent had concerns about the unfinished portrait of Mme Roulin fearing that she might not want to pose with her husband away. Roulin had taken a position in Marseilles with a slight raise in pay, but his family was not yet able to join him there. The Roulins wanted to be together as a family, but circumstances prevented them.

Vincent described La Berceuse as an impressionist arrangement of colors and said that he had never invented anything better. "It is a woman in a green dress (the bust olive green and the skirt pale malachite green). The hair is quite orange and is in plaits. The complexion is chrome yellow, worked up with some naturally broken tones for the purpose of modeling. The hands holding the rope of the cradle, the same. At the bottom, the background is vermilion (simply representing a tiled floor or else a stone floor). The wall is covered with wallpaper, which of course I have calculated in conformity with the rest of the colors. This wallpaper is bluish-green with pink dahlias spotted with orange and ultramarine ...Whether I really sang a lullaby in colors is something I leave to the critics” (LT 571a). These colors seem very bold, whereas a lullaby would likely be soft, pale and quiet. 
La Berceuse showed motherhood at an archetypal and symbolic level. The concept of the mother, as indicated by Vincent in paint, is transmitted on a preconscious level, neither repressed (unconscious), nor intentionally propounded (conscious) (Kristeva, 1980, 15). The idea of mother was taken for granted and considered as natural. And as Vincent had stated, his intention was to paint "a lullaby in color." The maternal type shown is a generously built woman, but her facial expression does not seem to have the same softness as her body. This may indicate some transference from Vincent's feelings about his mother. Vincent had described the relationship with his own mother as similar to growing up in a chilly draft.

(See Figure 41 on the next page). 


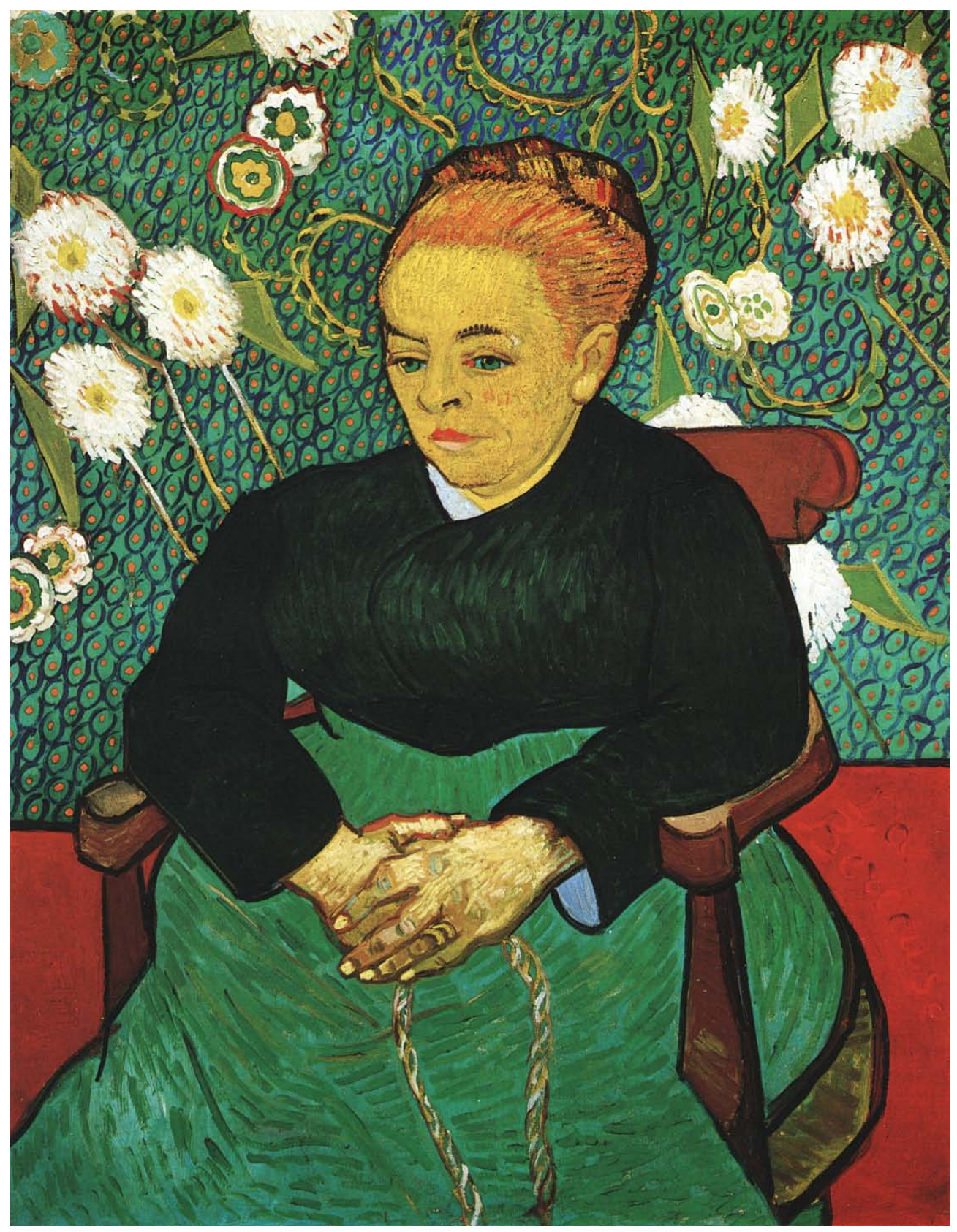

Figure 41. La Berceuse

Pickvance, R. (1984) Van Gogh in Arles.

Metropolitan Museum of Art: New York, N.Y., p. 247 
Staying in Arles and Starting Over

On January 19, 1889, Vincent complained of the cold, in LT 572, and said that Dr. Rey would prescribe quinine wine. In a lengthy postscript he said "In the future I shall always need a doctor from time to time," therefore staying in Arles where the doctor already knew him would be an advantage. He also mentioned the possibility of Gauguin returning to Arles and that they could begin again together.

On January 23, Vincent was considering the legacy of his art work. He reported that his concern was to get back what his training as a painter had cost, neither more nor less. He also said that he had a right to earn his daily bread. He valued his sunflower paintings at 500 francs each, equivalent to a Monticelli bunch of flowers. He felt that it was not everyone who could do those golden flower tones, that it needed "the whole and entire force and concentration of a single individual. ... You know that the peony is Jeannin’s, the hollyhock belongs to Quost, but the sunflower is mine in a way” (LT 573). Vincent also said, "When I saw my canvases again after my illness, the one that seemed the best to me was the bedroom” (LT 573).

\section{Exemplary Couples}

Roulin was much more the family man than Gauguin, who had left his family to go to the South Seas and to Arles. Of Gauguin, Vincent said, "But up to the last days I saw one thing only, that he was working with his mind divided between his desire to go to Paris to carry out his plans, and his life in Arles” (LT 573). He said that Roulin and his wife were an exemplary couple, and that his parents had been an exemplary couple despite what he might have thought about them on other points. Vincent encouraged 
Theo to proceed with his marriage and stated that he was glad he would not be lonely anymore.

\section{His Life Passed before His Eyes}

During the time when Vincent was indisposed with the incident of the ear, he seemed to have had a life review, as sometimes happens with those who are close to death. "During my illness I saw again every room in the house at Zundert, every path, every plant in the garden, the views of the fields outside, the neighbors, the graveyard, the church, our kitchen garden at the back - down to a magpie’s nest in a tall acacia in the graveyard. I say no more about it, since I had better not try to go over all that passed through my head then” (LT 573).

Vincent was surprised and pleased with his recovery. In LT 574 written on January 28, 1889, he said, "It astonishes me already when I compare my condition today with what it was a month ago. Before that I knew well enough that one could fracture one's legs and arms and recover afterward, but I did not know that you could fracture the brain in your head and recover from that too.”

\section{Working to Make a Comforting Impression}

Vincent discussed winter, his least favorite season in LT 574, "Since it is still winter, look here, let me go quietly on with my work; if it is that of a madman, well, so much the worse. I can’t help it. However, the unbearable hallucinations have ceased, and are now getting reduced to a simple nightmare, in consequence of my taking bromide of potassium, I think. ...And once again, either shut me up in a madhouse right away - I shan’t oppose it, for I may be deceiving myself - or else let me work with all my strength, while taking the precautions I speak of. If I am not mad, the time will 
come when I shall send you what I promised you from the beginning. Now perhaps the pictures are alas bound to be dispersed, but when you for one see the whole that is in my mind, I dare hope it will make a comforting impression on you.” The great importance of this statement is that it reveals why he was reluctant to sell. He wanted the entire legacy of his artistic endeavors to be displayed together. He hoped to someday see a series of his canvases in a window display. "You will perhaps understand that what would reassure me in some fashion as to my illness and the possibility of a relapse would be to see that Gauguin and I had not exhausted our brains for nothing, but that some good canvases have come out of it” (LT 574).

Vincent reported doing two copies of the sunflower paintings that had been in Gauguin’s room, “absolutely identical replicas of them” and a copy of La Berceuse also. He imagined La Berceuse hanging in the cabin of an Icelandic fishing boat and thought that the sailors "would feel the old sense of being rocked come over them and remember their own lullabies” (LT 573). He also described an interesting concept of displaying the canvases of La Berceuse between the sunflowers thus forming torches or candelabra beside them.

\section{Concerns about His Future}

Theo’s planned marriage seemed to make Vincent feel somewhat insecure as to his future, "I only ask the position of a painting employee, at least as long as there is enough to pay one” (LT 574). He was concerned about the possibility of being institutionalized, "If it is not absolutely necessary to shut me up in a cell, then I am still good at paying, at least in goods, what I am considered to owe” (LT 574). In his consideration of various possible futures, Vincent van Gogh apparently even considered 
the possibility of going to the tropics, but he said that he was too old to go there and “[especially if I have a papier maché ear put on] too jerry built to go there.” In a very philosophical statement, Vincent van Gogh said, "We are nothing but links in a chain” (LT 574). Vincent was concerned with his artistic legacy, his place in the history of art. Since Vincent did not have children, his art works were his children that he passed on to the world.

“Old Gauguin and I understand each other basically, and if we are a bit mad, what of it? Aren't we also thoroughly artists enough to contradict suspicions on that score by what we say with the brush? Perhaps someday everyone will have neurosis, St. Vitus’ dance, or something else. But doesn’t the antidote exist? In Delacroix, in Berlioz, and Wagner? And really, as for the artist's madness of all the rest of us, I do not say that I especially am not infected through and through, but I say and will maintain that our antidotes and consolations may, with a little good will, be considered ample compensation” (LT 574). Within these statements lies the germ of the idea of the artist as madman, and of creativity and madness as a conjoined pair. There also seems to be a rudimentary understanding of the use of art as therapy.

The Same, Yesterday, Today and Always

Vincent wrote in LT 575, "People are the same, yesterday, today, and always - I saw our friend Roulin again last Monday ... worldly ambition and fame pass away, but the human heart beats the same to this day, in as perfect sympathy with the past of our buried forefathers as with the generation to come.” He showed Roulin two canvases of La Berceuse between four panels of flowers. Vincent had painted La Berceuse three times and he later let Mme Roulin select one on the condition that he could paint 
himself a duplicate of the one that she chose. He described La Berceuse as "an attempt to get all the music of the color here into the painting." He later complained that she had a good eye and selected the best one of the lot.

Vincent described his continuing recovery in LT 575, "From what I am told, I am obviously looking better; inwardly my heart is rather too full of so many feelings and divergent hopes, for I am amazed to be getting better.” He had gotten a letter from Gauguin and had answered it immediately. “I will finish this letter like Gauguin’s, by telling you that there certainly are signs of previous overexcitement in my words, but that is not surprising, since everyone in this good Tarasçon country is a trifle cracked” (LT 575). It is noteworthy that Vincent was self-cognizant enough to recognize his possible mania in his previous overexcitement, but then he immediately sought to minimize it.

\section{Enthusiasm, Madness or Prophecy}

“This so-called good town of Arles is such an odd place that it's with good reason that old Gauguin calls it 'the dirtiest hole in the South"” (LT 576). "I have no illusions about myself any more. I am feeling very well, and I shall do everything the doctor says, but ...When I came out of the hospital with kind old Roulin, who had come to get me, I thought that there had been nothing wrong with me, but afterward I felt that I had been ill. Well, well, there are moments when I am twisted by enthusiasm or madness, or prophecy, like a Greek oracle on the tripod” (LT 576). In spite of this Vincent remarked, “I am feeling so weak.” And he remembered that he had told Dr. Rey that at the "slightest grave symptom" he would either return to his care or place himself under the treatment of the mental specialists in Aix. Vincent asked Theo, "Can 
anything come of it but trouble and suffering if we are not well, either you or I? So completely has our ambition foundered. Then let's work on very quietly, let's take care of ourselves as much as we can and not exhaust ourselves in barren efforts of mutual generosity. You will do your duty and I will do mine, and as far as that goes, we have both already paid in ways other than in words, and at the end of the road we may quietly come together again. But when that delirium of mine upsets everything I dearly loved, I do not accept it as a reality, and I am not going to be a false prophet. Indeed, illness and death hold no terrors for me, but fortunately for us, ambition is not compatible with the profession we follow. But how come you are thinking at the same time of the clauses of your marriage settlement and of the possibility of dying? Wouldn't it be simpler to stab your wife and be done with it” (LT 576).

Vincent's thoughts have taken a morbid and violent turn here and he sounds depressed, but then he counters with "It will all come out right, indeed it will.” He was continuing to stew about the paintings of his that Gauguin had and said that he felt that if Gauguin kept the two sunflower paintings and a copy of La Berceuse that he should give Theo three of his paintings in exchange - "better than average ones." Vincent again mentioned that he wanted to provide Theo with 30 or so serious studies of his own. Vincent said that he "was keeping the house provisionally, since for the sake of my mental recovery I need to feel that I am in my own home.” Sounding very depressed, Vincent said that when people inquired after his health, he replied, "I shall begin by dying in their midst, and that then my malady will be dead." He reported that the neighbors were kind to him and "everyone here is suffering either from fever, or hallucinations, or madness, we understand each other like members of the same 
family." He reported that he "went to see the girl I had gone to when I was out of my wits. They told me there that in this country things like that are not out of the ordinary. She had been upset by it and had fainted but had recovered her calm. And they spoke well of her, too” (LT 576). Vincent realized his precarious mental condition and said, "But as for considering myself as completely sane, we must not do it. People here who have been ill like me have told me the truth. You may be old or young, but there will always be moments when you lose your head. So I do not ask you to say of me that there is nothing wrong with me, or that there never will be” (LT 576).

\section{Again Hospitalized}

In February 1889, Vincent was again hospitalized. He imagined that people wanted to poison him, and exhibited selective mutism, as he did not say a word after coming into the hospital. Dr. Salles, the Protestant clergyman, wrote to Theo asking what was to be done? Theo wired Dr. Rey on February 13 and got the following reply, "Vincent much better, hope getting better, keeping him here. Do not worry now.” Five days later Theo got a letter from Vincent himself.

\section{Home Again, Home Again}

Vincent wrote, "I have been so completely out of sorts mentally that it would have been useless to try to write an answer to your kind letter. Today I have just come home provisionally, I hope for good. I feel quite normal so often, and really I should think that if what I am suffering from is only a disease peculiar to this place, I must wait here quietly till it is over, even if it returns again [and let's say that it won’t]” (LT 577). Vincent said that he would agree to go to Aix for mental treatment, but that he would prefer to stay in Arles and in the care of Dr. Rey. Vincent alluded to the value of art as 
therapy and said that he had "always kept a comparative presence of mind in my work.” He felt that there were certain prejudices in Arles, against him, against Gauguin, and against painting in general. Vincent questioned “why shouldn’t I take things as they come and wait for the upshot here? To what place worse could I go than where I have twice been: in the madhouse” (LT 577)? He felt that neighbors and Dr. Rey had been very kind to him, "Then they know me now at the hospital, and if it comes on again, nothing would be said, and they would know what to do at the hospital. I have no desire at all to be treated by other doctors, nor is there any necessity” (LT 577).

\section{Back in the Hospital}

On February 22, 1889, Vincent reported in LT 578, “I walk a lot to get fresh air. So far I am sleeping and eating at the hospital. Yesterday and today I began to work.” Vincent alluded to cultural differences, "for it is so hard to explain the character of the difficulties one may meet with here, and without habits and ways of thinking in the North or in Paris, it is fatal to stay here long. In this part of the world you have to endure things that are no joke.” He mentioned a generalized panic about an earthquake and he hated the mistral. "I agree with what you say, that if it takes a more serious turn someday, I must do what the doctors say and not oppose it. But that may be neither tomorrow nor the next day. ... Well, well, after all there are so many painters who are cracked in one way or another that little by little I shall be reconciled to it” (LT 578).

Not Fit to Be at Liberty

More than eighty signatures of citizens of Arles had been obtained on a petition to the mayor, “describing me as a man not fit to be at liberty, or something like that,” and Vincent continued, "I write to you in the full possession of my faculties and not as a 
madman, but as the brother you know ... So the commissioner gave the order to shut me up again. Anyhow, Here I am, shut up in a cell all the livelong day, under lock and key and with keepers, without my guilt being proved or even open to proof.” (LT 579) Vincent believed "that the whole accusation will be reduced to nothing.” He admitted, "If I did not restrain my indignation, I should at once be thought a dangerous lunatic ... while I am absolutely calm at the present moment, I may easily relapse into a state of overexcitement on account of fresh mental emotion.” Vincent described it as cowardly that so many people would “join together against one man, and that man ill.” He described his condition, “as far as my mental state is concerned, I am greatly shaken, but I am recovering a sort of calm in spite of everything, so as not to get angry. Besides, humility becomes me after the experience of the repeated attacks. So I am being patient.”

The illness and hospitalizations had created a fallow period in Vincent's artistic production: "here are three months that I haven’t been working” but he felt that he could have worked if they had not "vexed and worried me." He complained that he was even forbidden to smoke, whereas some other patients were allowed to smoke. He became rather philosophical, "to suffer without complaining is the one lesson that has to be learned in this life.” He said that his "work would not permit being reduced to living in hotels again. I must have my own fixed niche ... If I had had peace I would have recovered long ago ... In present-day society we artists are only the broken pitchers.” Vincent's yellow house had been closed by the police, and all of his canvases were under lock and key, guarded by the police and keepers. In a postscript to LT 579, Vincent said, "I am myself rather afraid that, if I were at liberty outside, I should not 
always keep control of myself if I were provoked or insulted, and then they would be able to take advantage of that.” After the petition was signed against him, Vincent stated that he was "quite prepared, for instance, to chuck myself into the water if that would please these good folk once and for all, but that in any case if I had inflicted a wound on myself, I had done nothing of the sort to them.” He said, "I am quite calm now.” Vincent revealed in these statements thoughts of self-harm possibly to the extent of suicide.

\section{Not Properly Speaking a Madman}

M. Salles was looking for an apartment in another area of the town of Arles for Vincent. Vincent said in LT 580, “As far as I can judge, I am not properly speaking a madman. You will see that the canvases I have done in the intervals are steady and not inferior to the others. I miss the work more than it tires me.” Theo had written that one must not let oneself have any illusions about life. Vincent responded, "The thing is to put up with the real facts of your destiny, and then there you are.” Vincent had no respect for the citizens of Arles after what they had done to him and he described them as meddlers. He did not want to be bothered with them, “do not meddle with me when I am busy painting, or eating, or sleeping, or taking a turn at the brothel, since I haven't a wife," he said. In a blaming tone, Vincent said that, "If they should continue, these repeated and unexpected agitations may change a passing and momentary mental disturbance into a chronic disease ... If sooner or later I should really go mad, I think I should not want to stay on here at the hospital, but just now I want to come and go freely" (LT 580). He said he would rather "not to live alone, but I would rather live in a cell forever than sacrifice another life to mine.” Vincent said that if he were a Roman 
Catholic, "I should have the resource of turning monk, but not being precisely that way, as you know, I haven’t that resource.” Perhaps it was the fact that the hospital management was Jesuit that had put him to thinking this way, but then in a seeming change of tone, Vincent said "and meanwhile I am a man after all, so you know I will shift for myself in matters of conscience which concern myself alone” (LT 580).

\section{A Visit from Signac}

On March 24, 1889, artist friend Paul Signac visited Vincent van Gogh and they were able to go to the yellow house. The police had locked it and destroyed the lock so that it could not be opened, but Signac and van Gogh found a way to get in. Vincent gave Signac a still-life as a keepsake. Vincent was pleased to report that Signac "was not frightened by my painting... and he thought 'that I looked healthy'” (LT 581). The doctor's assessment of Vincent's health, given in this same letter was “M. Rey says that instead of eating enough and at regular times, I kept myself going on coffee and alcohol. I admit all that, but all the same it is true that to attain the high yellow note that I attained last summer, I really had to be pretty well keyed up.”

Vincent realized that he might relapse and felt that the opposition of the citizens of Arles, and the involvement of the police and the mayor might cause this. Vincent was feeling the effects of stress from these various quarters and stress could cause relapse or worsening of his situation. Vincent asked, “Am I to suffer imprisonment or the madhouse?” He was resigned to the possibility and recognized that other artists, authors, and creators before him had had the same fate. But he said, "this is a thing above the mere question of illness and health.” He felt that his case was parallel to 
theirs and he quoted a line from a Dutch poem, "I am attached to the earth by more than earthly ties.”

Vincent seemed to be spiraling downward into despair, "what I have experienced in the midst of much suffering - above all - in my so-called mental illness,” and he also spoke of his work and profession disparagingly: “Unfortunately I have a handicraft which I do not know well enough to express myself as I should like” (LT 581). This statement prefaced his request for more paints and looking forward to the blooming orchards, he hoped to resume his work again: "Oh, if only nothing had happened to mess up my life. I am thinking of frankly accepting my role of madman ... But there it is, I do not feel that altogether I have strength enough for such a part. ...However intense my feelings may be, or whatever power of expression I may acquire at an age when physical passions have lessened, I could never build an imposing structure on such a moldy, shattered past.” He recognized that it was not a good time to make changes, “since you are getting married and I am getting too old.” (LT 581)

Paul Signac wrote to Theo in LT 581a, and reported that he found Vincent in perfect health both physically and mentally. He had seen Vincent's pictures and described them, "many of which are very good, and all of which are very curious." Signac relayed Dr. Rey’s assessment of Vincent’s prognosis to Theo by saying, “Dr. Rey is of the opinion that, if he should lead a very methodical life, eating and drinking normally and at regular hours, there would be every chance that the terrible crises would not repeat themselves at all.” Dr. Rey felt that the municipality would pay for Vincent's expenses because it was at the administration's request that he was kept in the 
asylum. Dr. Rey thought it would be best for Vincent to return to Paris, and failing that, he would likely have to move because the neighbors were hostile to him.

\section{Mental Anguish and Disastrous Reality}

In an increasingly catastrophic tone, Vincent wrote to Theo on March 29 in LT 582, “These last three months do seem so strange to me. Sometimes moods of indescribable mental anguish, sometimes moments when the veil of time and the fatality of circumstances seemed to be torn apart for an instant. Certainly you are right after all, damn well right - even allowing for hope, the thing to do is to accept the probably disastrous reality. I am hoping once again to throw myself wholly into my work, in which I’ve fallen behind.” Vincent pondered on an epitaph that he had read, “Thebe, daughter of Thelhui, priestess of Osiris, who never complained of anyone.” He related this statement to Paul Gauguin and to a perfect eternity. The qualities that he related to Thebe were reasonableness, patience, and serenity, and he realized that he did not personify those qualities. He spoke of the spirit of "the real South" as a place where those qualities might be found. And he said, "That is the happiness, the serenity, I am invoking for you and your wife on the occasion of your marriage, so that you may have this 'real South' within your soul.” The author finds this statement a bit strange, for a year before he would have wished them "absolute Japan” in their soul rather than "real South.”

\section{A Certain Undercurrent of Vague Sadness}

The occasion of Theo's marriage in the beginning of April, 1889, caused Vincent to recognize and comment on his social ineptitude. Vincent wrote LT 583 to Theo saying, "It is a sort of nervous affliction of mine that on festive occasions I 
generally have difficulty in formulating good wishes, but you must not conclude from this that I wish you happiness less earnestly than anyone else, as you well know.”

A group of circumstances was taking on a threatening configuration. Theo's marriage was vaguely perceived as a threat to Vincent's livelihood because in taking on a wife, would he still be able to support his brother? Both Rev. Salles and Dr. Rey had advised that Vincent must move away from the yellow house by Easter. Vincent described himself, saying, "I am well just now, except for a certain undercurrent of vague sadness difficult to define - but anyway - I have rather gained than lost in physical strength, and I am working. Just now I have on the easel an orchard of peach trees beside a road with the Alpine foothills in the background” (LT 583).

\section{A Certain Malaise}

Vincent commented on a sort of malaise that Roulin had noted about Arles "business not too good, resources exhausted, people discouraged ... and growing illnatured from being out of work - if anybody can still make a joke or do some work, down they come on him” (LT 583). In spite of this, Vincent still had hope, “And now, my dear boy, I believe that soon I shall not be ill enough to have to stay shut up. Except for that, I am beginning to get used to it, and if I had to stay in an asylum for good, I should resign myself to it and I think I could find subjects for painting there as well.” In Roulin, Vincent had found a true friend. He described Roulin as "a man who is neither embittered, nor sad, nor perfect, nor happy, nor always irreproachably just. But such a good soul and so wise and so full of feeling and so trustful.” There is almost a tone of forgiveness in Vincent’s statement, "I tell you I have no right to complain of anything 
whatever in Arles when I think of some things I have seen there which I shall never be able to forget” (LT 583).

\section{An Exchange of Letters with Paul Signac}

Paul Signac had written to Vincent mentioning that Theo had not responded to his letter. Vincent responded with LT 583b to Signac explaining that Theo probably had not replied to Signac's letter because he was getting married, "when I think of the obsequial pomp of the reception and the lamentable congratulations on the part of the two families ... goodness gracious - mustn’t one pity the poor wretch who is obliged, after having provided himself with the necessary documents, to repair to a locality, where, with a ferocity unequaled by the cruelest cannibals, he is married alive at a slow fire of receptions and the aforesaid funereal pomp.” This is a very depressive attitude.

Vincent said that he was working at the sanatorium and its environs; he included two sketches of orchards in LT 583b and described another work, saying, "The other landscape is nearly all green with a little lilac and gray - on a rainy day ... Since your visit my head has just about returned to its normal state, and for the time being I desire nothing better than that this will last. Above all it will depend on a very sober way of living.” He stated his intention to stay in Arles for at least a few more months and said that he had rented an apartment of two very small rooms. "But at times it is not easy for me to take up living again, for there remain inner seizures of despair of a pretty large caliber. My God, those anxieties - who can live in the modern world without catching his share of them? The best consolation, if not the best remedy, is to be found in deep friendships, even though they have the disadvantage of anchoring us more firmly in life than would seem desirable in the days of our great sufferings” (LT 583b). 
Paul Signac replied to van Gogh’s letter in LT 584a inviting him to visit in Cassis. Signac asked, “Why don’t you come and make a study or two in this fine country?”

\section{An Urgent Request for Supplies}

Vincent wrote to Theo requesting a large amount of painting supplies and reported "six studies of the spring, two of them big orchards. It is very urgent, because these effects are so short-lived” (LT 584). He reported that he had rented two small rooms from M. Rey, at 6 to 8 francs per month, water included; "It is certainly not expensive but nothing like as nice as the other studio.”

\section{A Turning Point}

The letters of the previous few months manifest an increasing level of depression and a deepening sense of despair. This author finds a turning point in LT 585 of April 21. There is a marked tone of decompensation, and after this time, Vincent no longer wanted to return home or attempt to live on his own. He had become resigned to being institutionalized. Financial concerns were also discussed in LT 585, "I have paid only 25 francs to my landlord, having had to pay three months’ rent in advance for a room which I shan't be living in, but where I have sent my furniture, and having besides had expenses of 10 francs or so for moving, etc. ... Then as my clothes were not in too brilliant a condition and I had to have something new to go out in the street in, I got a suit for 35 francs and spent 4 francs on six pairs of socks.” Vincent also reported that he had settled his bill at the hospital.

LT 585 is quite long and it reveals a turning point, “At the end of the month I should like to go to the hospital in Saint Rémy, or another institution of this kind, of 
which M. Salles has told me.” Vincent made this statement, but didn’t want to discuss it at length, “Talking about it would be mental torture. It will be enough, I hope, if I tell you that I feel quite unable to take a new studio and to stay there alone - here in Arles or elsewhere, for the moment it is all the same; I have tried to make up my mind to begin again, but at the moment it’s not possible.” Vincent's ability to work was returning, but he was afraid of losing his ability to work if he took on the responsibilities of a studio. “And temporarily I wish to remain shut up as much for my own peace of mind as for others."” He was becoming reconciled to his condition, "What comforts me a little is that I am beginning to consider madness as a disease like any other and accept the thing as such, whereas during the crises themselves I thought that everything I imagined was real.” Vincent van Gogh felt that he just could not start over, "Beginning again that painter's life I have been living, isolated in the studio so often, and without any other means of distraction than going to the café or a restaurant with all the neighbors criticizing, etc., I can't face it; going to live with another person, say another artist - difficult, very difficult - it's taking too much responsibility on oneself. I dare not even think about it.” Vincent suggested to try a three-month period, “and I shall do a little painting and drawing without putting such frenzy into it as a year ago.” He acknowledged the sadness involved in all the packing up and moving of his belongings, including mailing canvases to Theo. He had a deep sadness, "but the thing I felt saddest about was that you had given me all these things with such brotherly love, and that for so many years you were always the one who supported me, and then to be obliged to come back and tell you this sorry tale - but it's difficult to express it as I felt it." Vincent realized that his illness was due at least in part to choices that he had made: 
"Meanwhile you do understand that if alcohol has undoubtedly been one of the great causes of my madness, then it came on very slowly and will go away slowly too, assuming it does go, of course. Or the same thing if it comes from smoking." He did not agree with "the frightful superstition of some people on the subject of alcohol, so that they prevail upon themselves never to drink or smoke. We are already ordered not to lie or steal, etc. and not to commit other crimes great or small, and it would become too complicated if it was absolutely indispensable to have nothing but virtues in the society in which we are very undeniably planted; whether it be good or bad.” In this Vincent was recognizing the need for balance between good and evil and the counterpoised opposites that comprise the world.

Vincent said that when he would become settled into his new living arrangement, he would like to be able to go outside in the daytime to draw and paint. He said that the company of other patients was not disagreeable to him, rather that it distracted him; and that ordinary food suited him quite well, but that he did like a little more generous allotment of wine, $1 / 2$ liter rather than the usual $1 / 4$ liter. He did not necessarily require a private room, but would take what was available according to the arrangements of the institution. Vincent spoke with a tone of reconciliation, saying, "After all we must take our share, my boy, of the diseases of our time - in a way it is only fair after all that, having lived some years in comparatively good health, we should have our share sooner or later. As for me, you know well enough that I should not exactly have chosen madness if I had had a choice ... I do not know if I shall write very, very often because not all my days are clear enough for me to write fairly logically.” Vincent felt that his condition was nothing to be too distressed about and that, "I may 
still have some almost normal years before me. It is a disease like any other, and now almost everyone we know among our friends has something the matter with him.” Vincent gave a self-assessment, “My head isn’t steady enough to begin again as before - then the important thing is not to cause any more scenes in public, and naturally, being a little calmer now, I distinctly feel that I was mentally and physically in an unhealthy condition” (LT 585).

\section{Vincent Continued to Decompensate}

LT 586 continued in the same tone of decompensation, "The power of thought is coming back to me gradually, but I am much less able to manage practical things than hitherto. I am absent-minded and could not direct my own life just now ... I feel deeply that this has been at work within me for a very long time already, and that other people, seeing symptoms of mental derangement, have naturally had apprehensions better founded than my unfounded certainty that I was thinking normally, which was not the case. So that has much softened many of the judgments which I have too often passed with more or less presumption on people who nevertheless were wishing me well.” Vincent was aware of the seriousness of the repeated attacks and he felt that he was unable to shift for himself. "I can’t get the idea out of my head, although I have already explained it to you two or three times, that it really is best if I go into an asylum immediately. Things may come out right in the long run” (LT 586). Vincent felt that painting "narrows your ideas about other things because it is hard to work and think about other things as well ... The job is petty thankless and its usefulness is certainly questionable.” It was hard for Vincent to give up on his dream of a colony of painters even though he recognized that it had been "a deplorable and melancholy failure, the 
idea is still true and reasonable.” Vincent had concerns about finances at Saint Rémy because M. Salles had said that "many of the patients were fairly well off and some of them spend a lot of money.”

\section{Escapist Ideas}

On April 28, Theo sent a letter for the director of the asylum to facilitate making the arrangements to transfer Vincent to Saint Rémy. Then in an escapist tone like the earlier idea that if he were Roman Catholic he might become a monk, Vincent began to consider the option of military service. In LT 587 Vincent said, “For myself, I shouldn’t be unhappy or discontented if some time from now I could enlist in the Foreign Legion for five years (they take men up to forty, I think). From the physical point of view my health is better than it used to be, and perhaps being in the army would do me more good than anything else.” Vincent was 36 years old. More escapist ideas were expressed, "Sometimes, just as the waves pound against the sullen, hopeless cliffs, I feel a tempest of desire to embrace something, a woman of the domestic hen type, but after all, we must take this for what it is, the effect of hysterical overexcitement rather than a vision of actual reality.” A further escapist fantasy into nature was mentioned as Vincent discussed the beauty of the olives and the plowed fields, "the rustle of an olive grove has something very secret in it, and immensely old” (LT 587).

$$
\text { May Day, Mayday }
$$

On April 30, Vincent commented that the morrow would be the first of May, May Day, and sent well wishes to Theo in LT 588, "I should so like to be able to pass some physical strength on to you. At the moment I feel that I have more than enough. That doesn't mean that my head is still all that it ought to be.” Vincent was packing and 
was distressed at the state of the yellow house in his absence, "The flood water came to within a few feet of the house, and on top of that, the house itself had no fires in it during my absence, so when I came back, the walls were oozing water and saltpeter.” He found some of the paint flaking off his paintings and some of the studies were damaged by moisture.

\section{Concerns about Expenses}

Vincent was concerned about the expenses at Saint-Rémy and considered whether he could make an arrangement with the asylum like the one he had with Theo. But he wrote to Theo, "I assure you that I know of no asylum where they would be willing to take me in for nothing, even supposing I took on myself all the expenses of my painting and left the whole of my work to the hospital ... If I were without your friendship, they would remorselessly drive me to suicide, and however cowardly I am, I should end by doing it” (LT 588). This suicidal ideation was quickly followed by recognizing that he was incurably mentally ill. The cost at Saint-Rémy would be “100 francs a month during the whole long life of an incurable madman.” He continued to consider military service and thought he could paint in the barracks. "If I cannot work unless under surveillance! And in an institution! - Good Lord, is it worth paying money for that.”

On May 2, 1889, Vincent sent Theo two cases of canvases and said, “There are lots of daubs among them, which you will have to destroy" (LT 589). "Bear in mind that shutting me up in an asylum will be expensive in the long run, though probably less so than taking a house again; besides, the thought of beginning to live alone again is an absolute horror to me.” He continued to consider the possibility that he might enlist in 
the military, “if I knew I'd be accepted, I'd join the Legion. The thing is I have become timid and hesitant since I have been living like a machine.” Despite all of his problems, Vincent still saw his surroundings with the eye of an artist and he mentioned an avenue of pink flowering chestnuts, a little cherry tree in flower, a wisteria plant, and a path in the park splashed with light and shade. But after this brief interlude of distraction by the beauty of nature, Vincent soon returned to his gloomy self-assessment, "I have been 'in a hole' all my life, and my mental condition is not only vague now, but has always been so, so that whatever is done for me, I cannot think things out so as to balance my life. Where I have to follow a rule, as here in the hospital, I feel at peace. And it would be more or less the same thing if I were in the army. Now if I certainly run a great risk here of being refused because they know that I am a madman or an epileptic probably for good” (LT 589). It is important to note here that Vincent recognized that his life was out of balance.

Money continued to be a concern for Vincent: "But the money painting costs crushes me with a feeling of debt and worthlessness, and it would be a good thing if it were possible that this should stop” (LT 589). He made a request that he might stay on indefinitely at the hospital in Arles, even offering to pay 60 francs rather than 45 per month, but they seemed determined that he move. He considered going to live at the night café, where his furniture was stored, but it was next door to the yellow house and he would be in daily contact with the people who had been neighbors, some of whom had fostered the petition to have him incarcerated. In LT 589 Vincent listed for Theo the paintings that he thought would be worth putting on stretchers: "The Night Café, The Green Vineyard, The Red Vineyard, The Bedroom, The Furrows, Ditto, Portrait of 
Bock, Portrait of Laval, Portrait of Gauguin, Portrait of Bernard, Les Alyscamps (Path near the Tombs), Ditto, Garden with big bush of Conifers and Oleanders, Ditto, Cedars and Geraniums, Sunflowers, Scabious, etc., Ditto, Asters and marigolds, etc.”

\section{Considering Enlistment}

Vincent continued to consider enlisting, but in LT 590 of May 3, 1889, he said that a martyr's life was not for him, "If I find trouble or cause it, honestly, I am aghast at it ... Now as a painter I shall never amount to anything important, I am absolutely sure of it. Suppose all were changed, character, education, circumstances, then this or that might have been ... Sometimes I regret I did not simply stick to the Dutch palette with its gray tones, and brush away at landscapes of Montmartre without any fuss.”

Vincent considered Theo's career at Goupil's as a type of enlistment in order to help the family. "And, indeed, you did it with zeal and devotion, for just when Father was somewhat broke with that big family, and everything had to be kept going, and you threw yourself into it body and soul - during my illness I have been thinking of all these old things with a good deal of emotion” (LT 590).

\section{A Glimmer of Hope}

Despite Vincent's sad state, there was a tiny glimmer of a possibility that he might be useful and productive again, "I have a sort of hope that with what on the whole I know of my art, the time will come when I shall produce again, even in the asylum” (LT 590). His personal assessment of the discrepancy between his physical state and his mental state was, “It is amazing how well I am physically, but it isn’t enough to be the basis of any hope for its being the same with me mentally.” He even thought that he might consider another profession than that of painter, saying, "I would willingly, once 
I am a little known there, try to become a hospital orderly little by little, in short, to work at something and have some occupation again - whatever presents itself.”

Physically Vincent felt well and he said, "I should be terribly in need of old Pangloss if in the natural course of things I should happen to turn amorous again. After alcohol and tobacco have so much good or bad - it's rather relative - that they are antiaphrodisiacs ... For virtue and temperance, I'm only too afraid, will again lead me into those parts where the compass is apt to go overboard pretty quickly and where this time I must try to have less passion and more good humor” (LT 590). Vincent's thoughts seem to have taken a philosophical turn again and he said, "Madness is salutary in that one becomes less exclusive ... As an artist you are only a link in a chain” (LT 590).

Once more the idea of military service is broached, “And so, though I am very, very glad to be going to Saint-Rémy, nevertheless it would be really fairer to men like myself to shove them into the Legion.” He felt that he would likely be turned down for military service, although he felt he was in better health than he had been in years and that he was capable of being a soldier. Instead of enlistment, Vincent returned more strongly to his art and said, "thus we shall always keep a sort of passion for impressionism, but I feel that I return more and more to the ideas that I already had before I came to Paris.” Vincent continued to cling to the idea of a colony of painters, saying, "They have lots of room here at the hospital, there would be enough to make studios for a score or so of painters. I really must make up my mind, it is only too true that lots of painters go mad, it is a life that makes you, to say the least, very absentminded. If I throw myself fully into my work again, very good, but I shall always be cracked. If I could enlist for five years, I should recover considerably and be more 
rational and more master of myself "(LT 590). The idea of enlisting was probably a vain hope from the beginning and it was never to come to fruition.

Vincent van Gogh lived in Arles from February 1888 to May 1889 in what is considered by many to be his most creative period. It could be said that Arles was his first great period of artistic production. During a year's time, he painted blossoming trees, a series of sunflowers, and a "starry night." These monumental works and others produced during the Arles period confirmed Vincent's own revolutionary and individualistic concept of the beauty of God. Spirituality may be described as the relationship of a person with that which is other than and perceived as greater than the self. From his much earlier hyper-religious period, when he had lived in England and the Borinage, Vincent van Gogh emerged from rigid religiosity to a spirituality based in the natural world and expressed in the creation of his artwork.

Despite the limited acceptance of Vincent van Gogh’s art by his contemporaries, he has been vindicated as an artist in a society some one hundred years after his own time. Kristeva $(1984,7)$ stated that literature is whatever is called literature in a given society at a given time. In a paraphrase of Kristeva, this author states that art is whatever is called art in a given society at a given time. Vincent believed in himself and his art, and there were those of his contemporaries that recognized his greatness, but his greatest acceptance has come from future generations. 


\section{CHAPTER VI}

\section{SAINT-RÉMY}

May 8, 1889 to May 16, 1890

At Saint-Rémy began the final fifteen months of the life of Vincent van

Gogh. On May 8, 1889, at the request of Theo van Gogh, Pastor Salles took

Vincent to the asylum of Saint Paul-de-Mausole near Saint-Rémy-de-Provençe. Theo had his brother Vincent admitted to the asylum and he paid for an extra room for Vincent to use as a studio (Harmon, 101). In LT 591, his first one from SaintRémy, Vincent seemed accepting of his hospitalization stating, "I wanted to tell you that I think I have done well to come here. First of all by seeing the reality of the life of the various madmen and lunatics in this menagerie, I am losing the vague dread, the fear of the thing. And little by little I can come to look upon madness as a disease like any other. Then the change of surroundings does me good, I think.”

Vincent went on to say that the doctor believed that he had had some sort of epileptic attack. Then he turned his attention to his art, inquiring about the case of pictures that he had sent and discussing his current work - garden scenes of irises and lilacs. Vincent continued on in LT 591 to say the following as his selfassessment of his recovery and prognosis, “The idea of work as a duty is coming back to me very strongly, and I think that all my faculties for work will come back to me fairly quickly.” This statement seems to have overtones of Protestant work ethic and Dutch industriousness, two expectations that would have come 
from his upbringing. His general assessment of functioning was recorded, "Only work often absorbs me so much that I think I shall always remain absent-minded and awkward in shifting for myself for the rest of my life too.” Vincent was aware that he was not "mad" in the same ways as some other patients at Saint-Rémy. His incidents were episodic in nature and this is typical of bipolar disorder. They were like the semiotic breaking through, but interspersed with long periods of lucidity.

\section{Periods of Crisis}

While at Saint-Rémy, Vincent van Gogh had four intermittent periods of crisis. Vincent had had three earlier crises while at Arles; the first was the famous ear incident on December 23, 1888, resulting in a two-week hospitalization; a second crisis had happened on February 4, 1889, and lasted two weeks; and the third hospitalization was from the end of February until April 18, 1889. After moving to the asylum at Saint-Rémy on May 8, 1889, Vincent had his fourth crisis, the first one in his new environs, from early June to mid-August 1889.

Vincent’s fifth crisis was at Saint-Rémy, Christmas 1889 to New Year’s Day. This is the anniversary date of Vincent's crisis in Arles, and fits the repetitive pattern of incidents around Christmas time. The sixth crisis in late January, 1890, lasted about a week. On January 31, a son, Vincent Willem, was born to Theo and Joanna. Even though this child was named for Vincent as an indication of respect and to honor him, this action could have stirred up unpleasant emotional content of himself as a replacement child. There was co-dependency and a strongly symbiotic relationship between Vincent and Theo. Cooper (70) points out that Vincent had a strong fantasy of fusing his life with Theo's, and states that this is perhaps 
sublimated from being the replacement child. Vincent's parents had had two children that they named Vincent Willem. The two brothers were both named Vincent Willem, and both shared the same birth date, March 31, but they were born one year apart. The first Vincent Willem died and as a child the second Vincent Willem daily walked past the little tombstone of his namesake. Theo and Johanna's Vincent Willem could stir up those memories and the new child could be interpreted as another threat to the co-dependent relationship with Theo and to Vincent's narcissism. The seventh crisis was from mid-February to mid-April 1890.

\section{An Intensity of Focus}

Upon arriving at Saint-Rémy, Vincent painted with such an intensity of focus that he seemed to have been oblivious to the screams of other patients (Harmon, 101). Vincent apparently had this ability to hyperfocus and ignore all else but his work, or it could be interpreted as a certain compulsivity in his thought processes. The constant threat of the breakthrough of the semiotic loomed over him, that he might have another attack of madness, of out-of-control behaviors and wild visual and auditory hallucinations, quite possibly bipolar mania with psychotic features. The always-present questions lingered now much more. Would he be able to create? How much longer would he be able to work? He had a sense that the time remaining to him might not be long.

\section{Racing the Clock}

Vincent seemed to feel like he was racing against the clock when in LT 610 he said, "I think M. Peyron is right when he says that I am not strictly speaking 
mad, for my mind is absolutely normal in the intervals and even more so than before. But during the attacks it is terrible - and then I lose consciousness of everything. But that spurs me on to work and to seriousness, like a miner who is always in danger makes haste in what he does.” In this analogy he drew upon his previous experiences with the miners in the Borinage where he went down into the mines with them to work in order to fully experience their reality. Bipolar disorder is characterized by normal intervals between attacks.

Immediately upon his arrival at the asylum of Saint-Rémy, Vincent began painting. LT 591, on or about May 15, 1889, was written the first week of his arrival at the asylum, and Vincent discussed working on "some violet irises and a lilac bush, two subjects taken from the garden.” These motifs were taken from the large area of garden to the south of the men's quarters, the only part of the grounds where Vincent was permitted to work during his first month at the asylum. He did not explain why he selected these particular subjects, but it seems apparent that those were the subjects that were readily available to him. He painted four size 30 canvases, two vertical and two horizontal, each one devoted to one predominant flower or plant - iris, lilac, ivy, rose.

\section{Flowers at Saint-Rémy}

Vincent began his art at Saint-Rémy by painting irises as they appeared in the garden. About a year later, during May 1890, he returned to that same theme, but on his own terms, and shortly before leaving Saint-Rémy, he painted the flowers as an indoor still-life in a deliberately conceived formalistic color exercise (Pickvance, 1986). While at Saint-Rémy, he painted few still-lifes, but during his 
last days there he painted four size 30 still-lifes. Two paintings were of irises and two of roses, each pair with one image upright and one image horizontal.

$\underline{\text { Irises (1889) }}$

Van Gogh’s Irises (1889) from the Saint-Rémy period is like poetic language expressed in art. Kristeva $(1980,5)$ started from the concept of "poetic language” as introduced by the Russian formalists. This poetic language is different from language used for ordinary communication, almost an otherness of language (ibid.). Poetic language and art are similar in that the specific words or the art media are forgotten for the sake of the objects or concepts designated. The creation of the author (in writing or art) becomes transrational by way of "semantic displacements,” i.e. use of sounds and rhythms, or employment of formal elements of art. The observer looks through the words or art media and sees the intended representation.

Irises, classified by Vincent as a study, was among the eleven pictures that Vincent sent to Theo in July 1889. Theo submitted Irises to the Salon des Independents in September 1889. It was incorrectly listed as Etude d'oies (Study of Geese) in the first edition catalogue for the Salon des Independents, Paris, September 1889 (Pickvance, 1986). Pickvance described Irises as a living frieze, a close-up of life-size irises, with each delicately headed flower, each tough and spear-like leaf brilliantly rendered. One critic, Felix Feneon, saw images of battle as he wrote in La Vogue (quoted in Pickvance), “The Irises violently slash their petals to pieces on sword-like leaves.” Pickvance interpreted Irises as an obsessively claustrophobic examination of a fragment of nature that would seem to 
echo Van Gogh’s own decreed confinement at Saint-Rémy; but he also recognized that neither Vincent nor Theo interpreted Irises as emotionally disturbing or psychologically charged. The present author recognizes the close-up view of this painting, but does not consider it to express feelings of distress.

McQuillan (1989) intimates that the white flower is personified. Indeed it is tempting to interpret that single white bloom as a symbolic self-image with narcissistic overtones in that it seems to exert that it is different or better than the many more ordinary irises shown in purple. A somewhat crowded and busy quality is noted in the leaf pattern which is repeated many times, but that makes the one white flower stand out even more. This author sees a brilliantly composed work with a lone white iris standing out in a purity of expression. If a Jungian interpretation is made, then every aspect of the composition refers in some way to the artist who created the image. Jung would see the single white flower as a selfimage of Vincent van Gogh. The leaves that writhe and twist with implied motion could be representative of emotional and mental turmoil that Vincent felt. The field of other irises, shown in purple, could be pictorial expressions of his problems and issues, or they could represent the other people surrounding him in his milieu. It would have been interesting to pose these questions to him, "If these other flowers represented problems or issues in your life, what might they be? If they represented persons, who might they be?” It could be that Vincent would have been able to clearly name and label each purple iris.

(See Figure 42 on the next page). 


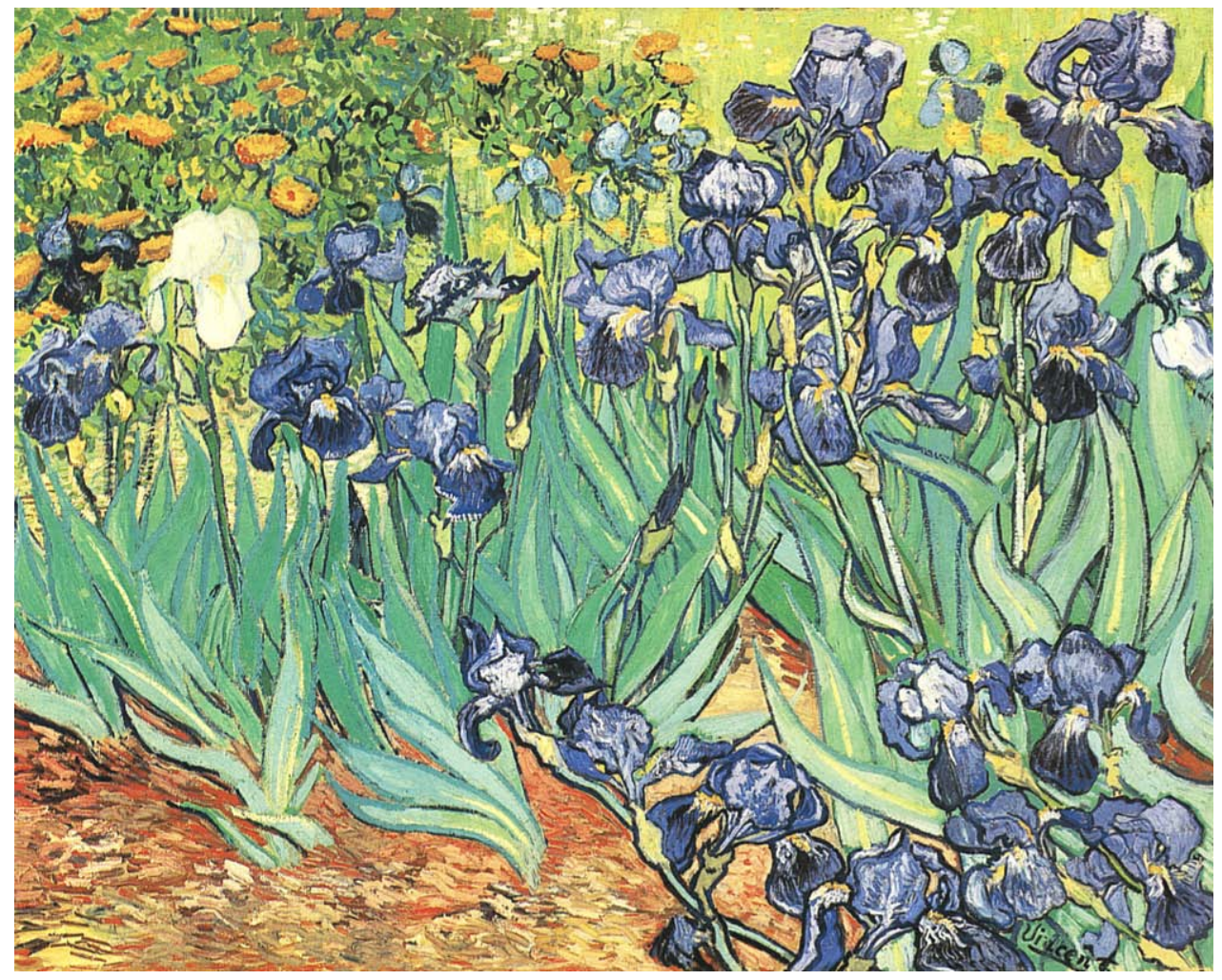

Figure 42. Irises (1889)

Pickvance, R. (1986) Van Gogh in Saint-Rémy and Auvers.

Metropolitan Museum of Art: N.Y.:N.Y. p. 80

Working with a Calm and Steady Enthusiasm

In LT 633 from Saint-Rémy on May 11 or 12, 1890, Vincent wrote to

Theo, “At present all goes well; the whole horrible attack has disappeared like a thunderstorm, and I am working to give a last stroke of the brush here with a calm and steady enthusiasm. I am doing a canvas of roses with a light green background and two canvases representing big branches of violet irises, one lot against a peach background in which the effect is soft and harmonious because of the combination of greens, pinks violets. On the other hand, the other violet bunch, ranging from 
carmine to pure Prussian blue, is painted on a startling citron background, with various yellow tones on the vase and on the stand upon which the vase rests. It presents a tremendously disparate effect where the complementary colors strengthen each other by their juxtaposition." The "whole horrible attack" sounds very much like a bipolar incident.

Irises (Amsterdam Still-Life)

The Irises against a background in which shades of yellow were used is unsigned. It is displayed in Amsterdam at the Riksmuseum in the Vincent Van Gogh Collection. Hereafter it will be referred to as the Irises (Amsterdam StillLife). Vincent discussed color in much the same language that he used in Arles when he was totally absorbed with the idea of using complementary color schemes. In the Amsterdam still-life of a vase of irises there are subtle echoes of one of the Arles Sunflowers in the interplay of yellows, the proportions of the table in relation to the background, and the asymmetrical placement of the vase (Pickvance, 1986). Pickvance reported that Vincent actually painted the flowers, vase, and tabletop before adding the background in and around the established shapes. This was unusual in that it was not his typical way of working, nor is it the way that artists usually create a painting. Generally Vincent van Gogh, like most artists, put in the background color before painting the subject.

The art form of the still-life has the quality of being a bounded (clos) artwork. Kristeva (1980,13-14) uses William Faulkner’s description of how he wrote As I Lay Dying, as an example of a bounded work: "Before I ever put pen to paper and set down the first word, I knew what the last word would be and almost 
where the last period would fall.” A still-life is set up by the artist and has this bounded quality by virtue of the pre-planning, with the artist almost knowing where the last brushstroke will fall. Three still-lifes from the Saint-Rémy period, Irises (Amsterdam Still-Life), Irises (Metropolitan Still-Life), and Pink Roses in a Vase all have this quality that Kristeva calls boundedness.

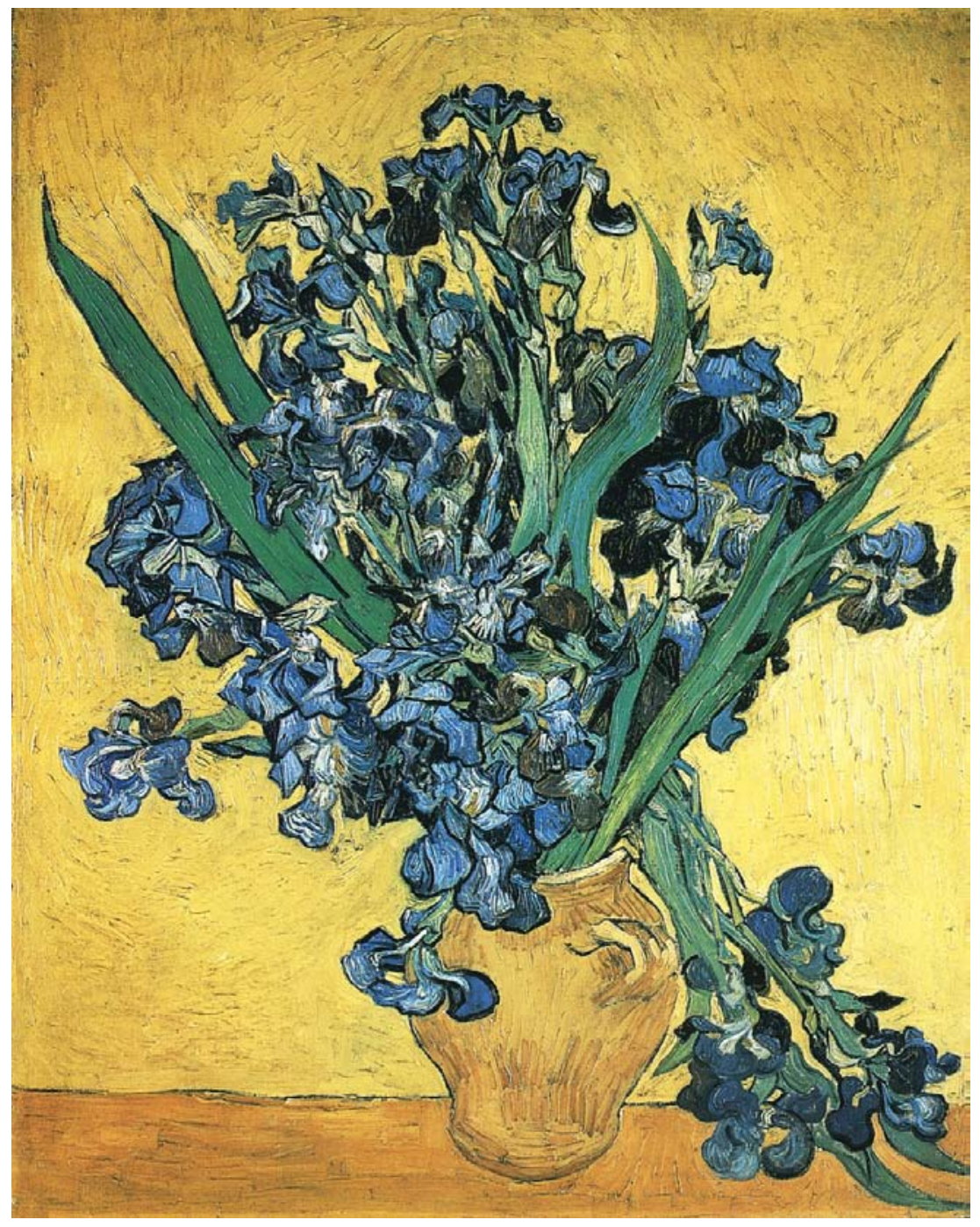

Figure 43. Irises (Amsterdam Still-Life)

Pickvance, R. (1986) Van Gogh in Saint-Rémy and Auvers.

Metropolitan Museum of Art: N.Y.:N.Y. p. 184. 
Irises (Metropolitan Still-Life)

The second still-life of irises from Saint-Rémy was also unsigned.

Displayed in the collection of the Metropolitan Museum of Art in NY, it will hereafter be referred to as Irises (Metropolitan Still-Life). In this painting Vincent sought a soft harmonious peach background as a complementary color contrast to the green, but unfortunately the peach background in the Metropolitan canvas has faded (Pickvance, 1986). The painting of the irises with the peach background is unusual in that the paint surface is thin, even leaving parts of the canvas untouched. Vincent usually painted with a very thick impasto, covering the canvas completely. The untouched portions of this canvas were incorporated into the composition in a dramatic way, as on the handle of the jug. In a letter (W 22) to Wilhelmina, his sister, Vincent confessed, “during the last weeks at Saint-Rémy I worked like a man in frenzy, especially on bunches of flowers.” Pickvance (1986) noted that none of this frenzy is evident in the two completed still-lifes of irises which seem painted with a remarkably serene economy of means. The Irises (Metropolitan Still-Life) presented a distilled purity of statement in which Pickvance saw a presaging of Matisse. "Working like a man in a frenzy” sounds like bipolar mania.

Vincent's theme of irises morphed from the living flowers that he painted when he first moved to Arles and Saint-Rémy to cut blossoms placed in containers in the still-lifes of Irises in 1890. Of these three Saint-Rémy versions of Irises, the first one painted in 1889 showed living plants in bloom in a garden and the other two from 1890 were cut blossoms in containers. The Irises (Amsterdam Still-Life) had some stems bent or broken so that a few blooms drooped to the tabletop. The 
living flowers will bloom again next year, the cut blossoms will die in short order. The Irises (Amsterdam Still-Life) further presages death and decay with the drooping, bent or broken branch. One can see in this a subtle foreshadowing that Vincent's life may not last much longer. That Vincent started and ended with the irises at Saint-Rémy provides an interesting point, a closing of the loop so to speak.

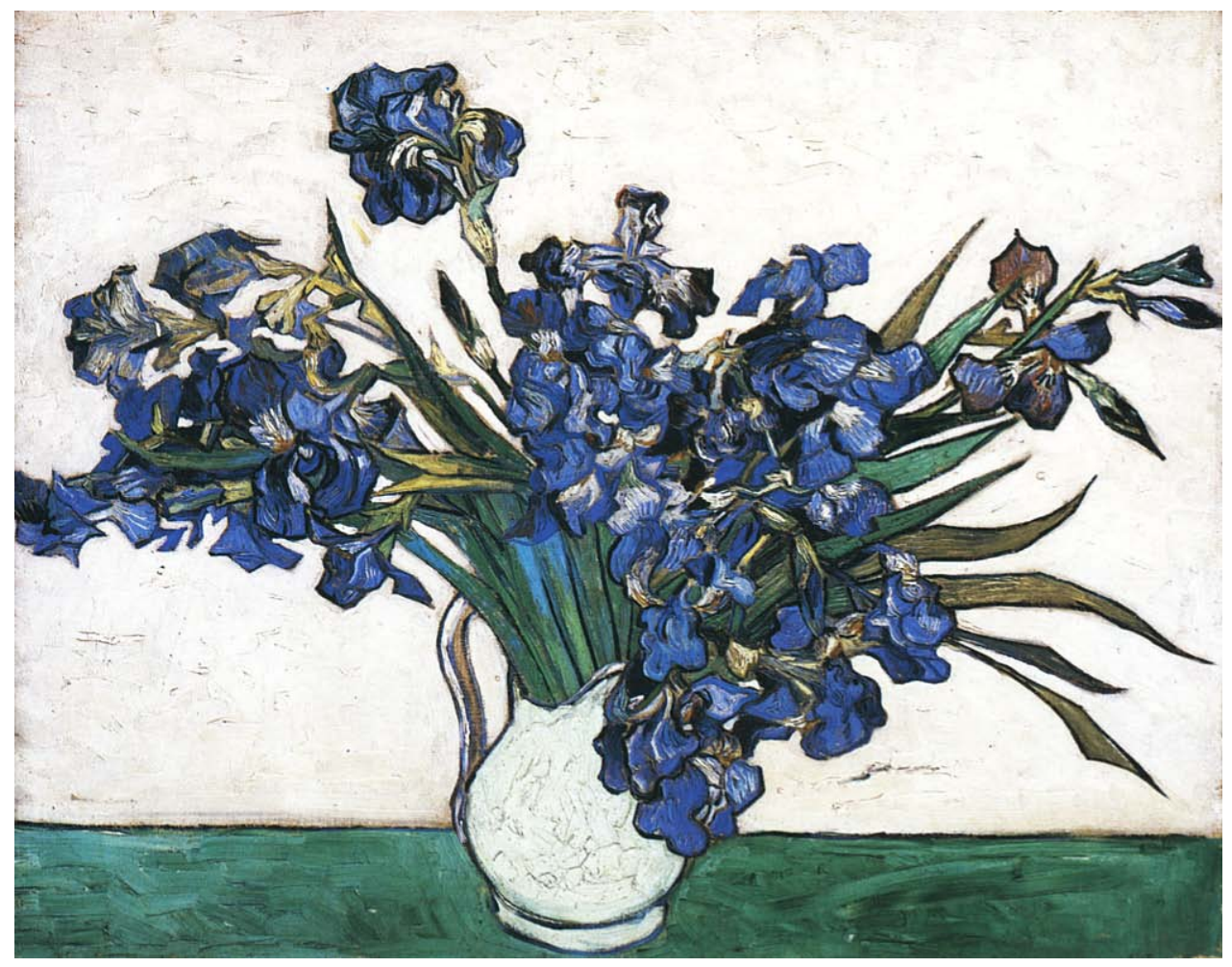

Figure 44. Irises (Metropolitan Still-Life)

Pickvance, R. (1986) Van Gogh in Saint-Rémy and Auvers.

Metropolitan Museum of Art: N.Y.:N.Y. p. 186.

\section{Roses}

In LT 633 of May 11 or 12, 1890, where Vincent van Gogh said that he was busy with two canvases of still-lifes of irises, one horizontal and one vertical, he 
added that he was also working on a "canvas of roses with a light green background.” Indeed it is the same Provençal flowerpot, and at exactly the same angle as in the Amsterdam vertical still-life of irises. According to Pickvance (1986), in both the Amsterdam still-life of Irises and the Roses, the outlines of the pot and tabletop are thin and delicate thus implying a stylistic relationship between the vertical irises and the horizontal roses.

\section{Pink Roses in a Vase}

Vincent’s last letter from Saint-Rémy was written on May 13, 1890, and in it he said, "I have just finished another canvas of pink roses against a yellow-green background in a green vase” (LT 634). This second still-life of roses, Pink Roses in a Vase, in the Walter H. Annenberg collection in California, has thick and bold contours dividing the table and vase from the background wall. Stylistic pairings seem to be implied by the counterpoints of juxtaposed horizontal and vertical placements, complementary color schemes, and putting bold outlines with thin and delicate treatments. This quartet of canvases, two of irises and two of roses, each with one vertical and one horizontal placement, and each with one bold and one delicate treatment, is interpreted by Pickvance as probably Vincent's final Provençal decorative scheme. These pairings of opposites are visually bipolaresque.

Meier-Graefe (1987) saw “a new element” in these final flower-pieces from Saint-Rémy, stating that they were not as violent as the sunflowers in Arles; they were more intellectual in style; they had a general appearance that is lighter and gayer; and they looked almost elegant beside the sunflowers. He continued his interpretation, stating that, the irises and roses represented just irises and roses, but 
the paintings represented them with an intensity that Vincent had not achieved before in subjects such as this. Such intensity of dynamic with normal intervals inbetween is a bipolar quality.

Vincent's general style had now emerged from the particular, as evidenced by the salient feature of the expression of emotion in his artwork. Vincent's style in these flower-pieces did not conceal the humbleness of their origin, but, on the other hand, it represented an individual achievement. The four pictures of flower stilllifes, two of irises and two of roses, were left to dry when Vincent moved away from Saint-Rémy. In LT 633 he said to Theo, “These canvases will take a whole month to dry, but the attendant here will undertake to send them off after my departure.” They eventually arrived in Auvers by June 24, 1890 (Pickvance, 1986).

(See Figure 45 on the next page). 


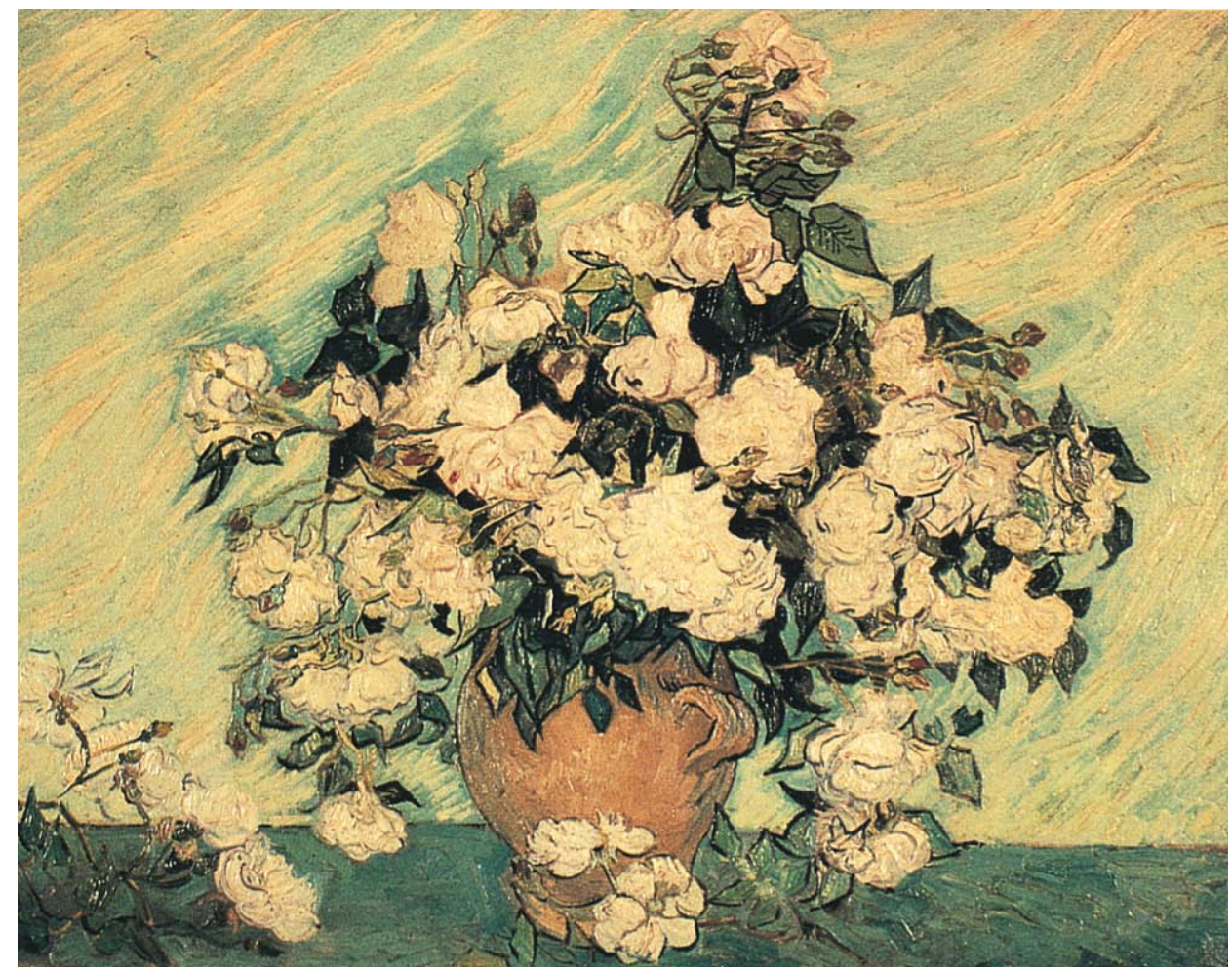

Figure 45. Pink Roses in a Vase

Pickvance, R. (1986) Van Gogh in Saint-Rémy and Auvers.

Metropolitan Museum of Art: N.Y.:N.Y. p. 187.

On the Verge of Recognition

In November 1889, while he was still hospitalized at Saint-Rémy, Vincent van Gogh was invited to exhibit in the Eighth Salon of the Vingtistes in Brussels along with such artists as Cézanne, Toulouse-Lautrec, and Renoir. He had told Theo in LT 590, “As a painter I shall never amount to anything important now,” but on this point he could not have been more wrong. In actuality he was on the verge of attaining considerable recognition and esteem. 
In Theo’s letter to Vincent ( $\mathrm{T}$ 19) of Tuesday, October 22, 1889, he had told of several visitors to his apartment to see Vincent's work. "Two of these visitors were the son of Dutch artist Isaac Israels, Jan Pieter Veth (1864 - 1925), a Dutch painter and writer for The Nieuwe Gids, and the Belgian Neo-Impressionist artist Theodore Van Rysselberghe (1862 - 1926), a member of Les Vingt in Brussels.” Theo also reported, "Rysselberghe has also seen everything there is at Tanguy’s and your pictures seem to interest him quite a lot” (Pickvance, 1986, 49). On Saturday November 16, 1889, Theo wrote to Vincent (T 20), his first letter since October 22. Octave Maus, the secretary of Les Vingt had written to Vincent (but he addressed the letter to Theo), asking Vincent to participate in their forthcoming exhibition in Brussels. Theo also received a letter from Maus repeating the invitation and giving a list of other invited artists including Puvis de Chavannes, Cézanne, Forain, Signac, Lucien Pissarro, Renoir, Sisley and ToulouseLautrec.

On Sunday, November 17, Vincent responded immediately to Theo’s letter with LT 614 and listed the six paintings that he would like to exhibit with Les Vingt:

1. and 2. The two companion pictures of sunflowers.

3. The Ivy, Perpendicular.

4. Orchard in Bloom, with a row of poplars across the canvas, (the one being exhibited by Tanguy)

5. The Red Vineyard

6. Wheat Field at Sunrise, on which he reported he was working at the moment.

The letter from Isaacson to Vincent van Gogh has been lost and van Gogh did not indicate its contents in LT 614; all he said was, "it gave me much pleasure.” In 
Vincent's LT 614 to Theo he may be indicating return to more normal thought processes after a manic episode as he said, "My thoughts begin to link up a little more calmly, but as you will see from it, I do not know if I must continue to paint or let painting alone.” Vincent often made self-deprecating statements that revealed insecurity, but this statement is unusual in that he wavered from his stated purpose of being a painter. Then he proceeded to discuss his recent two-day visit to Arles and described his health as fine. He said he would like to go to Paris in the spring. A copy of Vincent's letter to Isaacson (LT 614a) was attached to Theo’s (LT 614). His letter to Mr. Isaacson was quite long and the end is missing. It contained a lengthy discussion on color theory and coloristic effects. Vincent spoke in a demeaning manner of his work. He discouraged Isaacson from publicizing his work by saying, "As it is possible that in your next article you will put a few words about me, I will repeat my scruples, so that you will not go beyond a few words, because it is absolutely certain that I shall never do important things.” This statement is difficult to understand because of its quality of absolute decompensation. Here on the verge of artistic recognition he completely disparaged his work. It would seem that these new possibilities of fame and recognition would link up with his narcissistic tendencies, but quite the opposite happens. He seemed to have responded with a reaction formation. A reaction formation is a psychological defense mechanism defined by Sigmund Freud as an impulse or behavior that is converted into its opposite (Ryckman, 1985). Rather than accepting the praise and status that seemed to be coming to him, Vincent van Gogh apparently 
rejected and negated it. The opposition inherent in this seems like an architectural personality structure that is similar to bipolar oppositions.

\section{The Prisoner's Round}

On or around Saturday January 25, 1890, Theo sent a roll of papers that included a copy of Gustave Doré's Prisoner's Round. That this image resonated in him is evident since between Tuesday February $4^{\text {th }}$ and Friday February $7^{\text {th }}$, Vincent copied Doré's Prisoner's Round in oil on canvas size 31 1/2 x25 1/4/4 inches. This image seems to connect with his feelings of incarceration even though he had considerable freedom at Saint-Rémy. The "prisoner" in the foreground was established as the center of interest by manipulation of the light source and it appears to be a self-image. This focal point was set apart by the light reddish color of the hair and the outward facing look which goes straight to the observer. If indeed this is a self-image, as it appears, Vincent pointed himself out as special among the mass of humanity taking their exercise by walking round and round. This is a similar interpretation to the lone white iris in the Irises of 1889. This may represent a pattern of symbolic self-images indicative of narcissism by pointing him out as special among the masses (of ordinary humanity or of flowers). This could be a salient feature in the art work of Vincent van Gogh.

As a painting copied from the work of another artist, The Prisoner's Round, is another work from the Saint-Rémy period manifesting the quality that Kristeva describes as boundedness. The Prisoner's Round seems excessively bounded by the walls of the interior exercise room. The quality of boundedness in Vincent's works 
from Saint-Rémy may indicate his response, conscious or unconscious, to the limitations imposed by his stay at the institution.

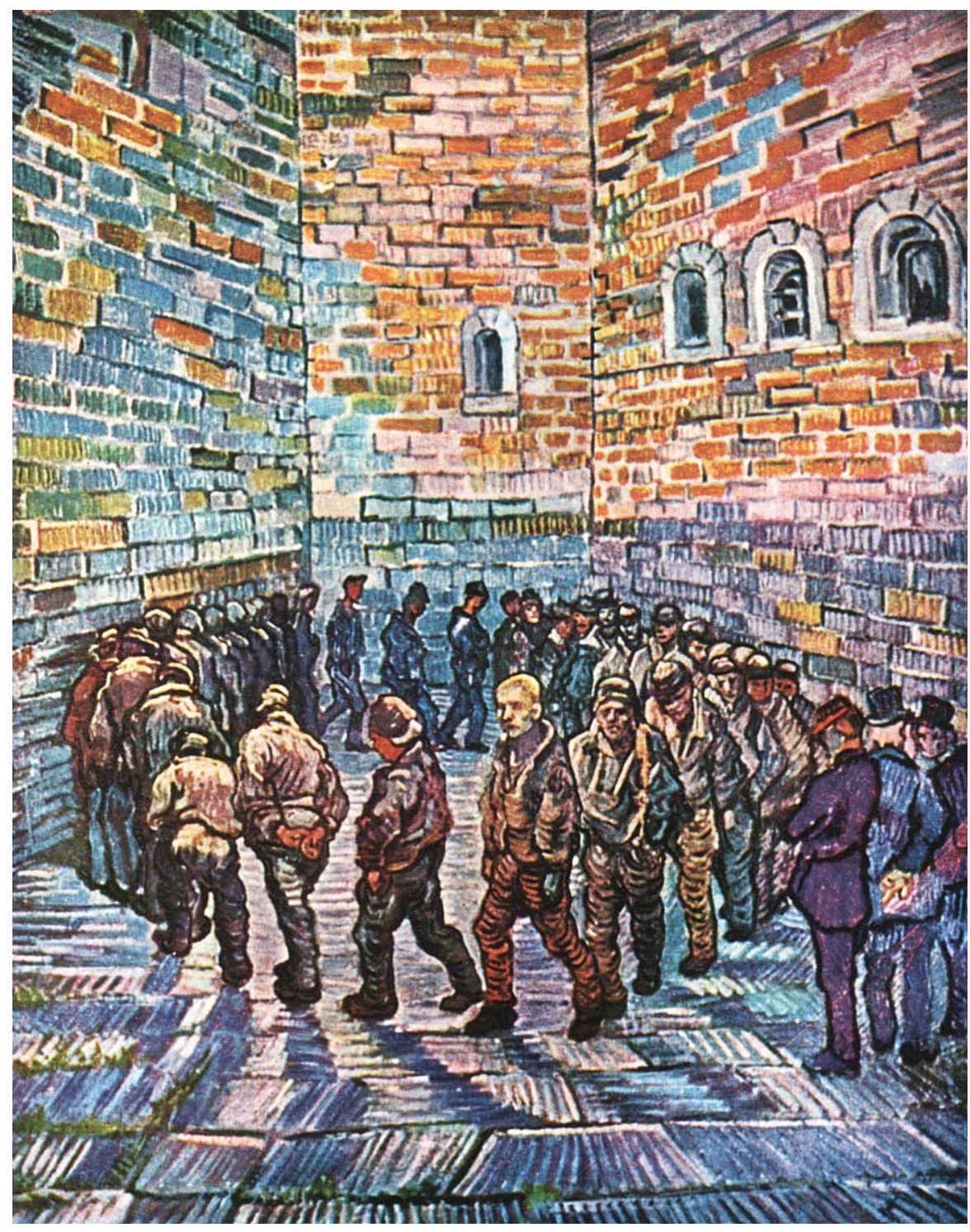

Figure 46. The Prisoner's Round

Huyghe, R.(undated) Van Gogh. Flammarion: Italie, p. 69. 
Cypresses and Olive Trees at Saint-Rémy

In June of 1889, Vincent discovered the cypresses and they enthralled and fascinated him. Grandiose and obsessive thought processes are shown in that Vincent believed that he saw the cypresses as no one else had. LT 596 of June 25, 1889, celebrated the cypress trees by saying, "The cypresses are always occupying my thoughts; I should like to make something of them like the canvases of the sunflowers, because it astonishes me that they have not yet been done as I see them. It is as beautiful in lines and proportions as an Egyptian obelisk. And the green is of so distinguished a quality. It is a splash of black in a sunny landscape, but it is one of the most difficult to hit off exactly that I can imagine. But then you must see them against the blue, in the blue rather...”

Cypress trees and olive orchards became recurrent themes in the art of Vincent van Gogh at Saint-Rémy. It became his quest to truthfully express them in his painting.

The olive trees and olive orchards were a coloristic challenge because of the multiple hues of green in the leaves shading from pale green through silvery grey. The cypresses, on the other hand, were a very dark green-black.

The cypress is traditionally the symbol of death in Mediterranean countries and is frequently found in graveyards. In that death is the ultimate boundary of life as we know it, Kristeva’s concept of boundedness is apparent in Vincent's painting Cypresses (Metropolitan). Vincent described the cypresses as “a splash of black” but did not directly state that he was using them as a death symbol. In wishing to make of the cypress what he had made of the sunflower, he was probably thinking 
of doing a series of five or six paintings as decoration for a room. Possibly he planned to use the cypresses as a foil to the sunflowers that were a symbol of life, consolation and gratitude. Sunflowers and Cypresses in tandem would be similar in concept to his Sower and Reaper and might visually represent the bipolar union of opposites, life and death or beginning and ending. He did not complete a series of cypresses, however, he did complete several canvases that contained cypresses including: Cypresses (Metropolitan), Cypresses (Otterlo), Wheat Field with Cypresses (McQuillen called this Cornfield with Cypresses), Road with Cypresses and a Star, Field with Poppies and The Starry Night.

Vincent said in LT 596 that he had twelve size 30 canvases in progress including "two studies of cypresses of that difficult bottle-green hue. I have worked their foregrounds with thick layers of white lead, which gives firmness to the ground. I think that very often the Monticelli's were prepared like this. On top of that one can then put on other colors. But I do not know if the canvases are strong enough for that sort of work."

Cypresses (Metropolitan) is the image discussed in this dissertation. Two large, dark cypresses dominate the left foreground of the picture. The lowest register of the picture has curvilinear brushstrokes representing flowering grasses. The next area of the picture shows a mountain range in the distant background. The horizon line is low, approximately two-thirds of the way down the side of the picture. The sky is busy with swirls and swoops of paint representing some wisps of clouds and some large puffy clouds. An inverted sickle moon dominates the upper 
right corner of the painting. The overall impression of the picture is a pastoral summer scene.

(See Figure 47 on the next page).

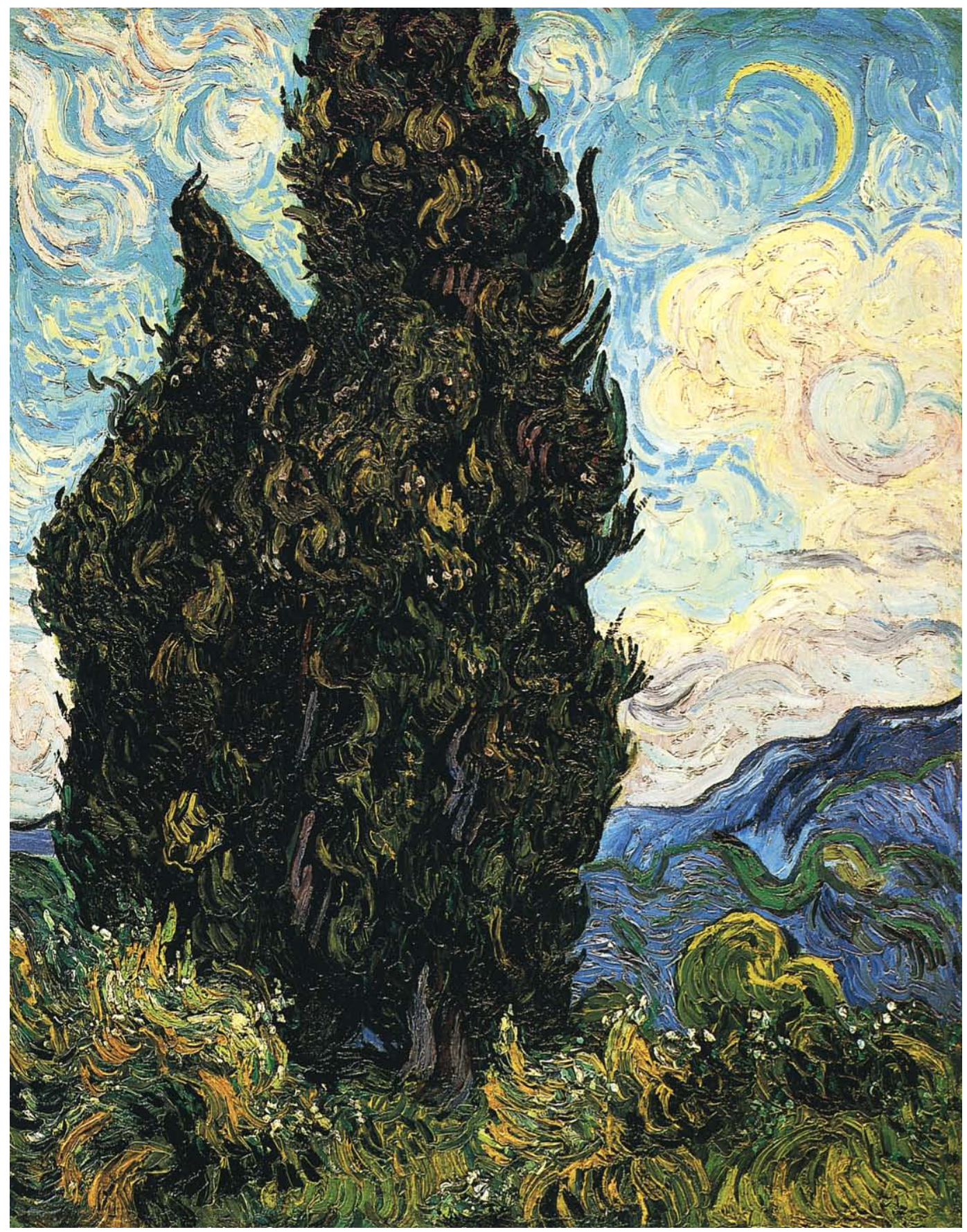


Figure 47. Cypresses (Metropolitan)

Pickvance, R. (1986) Van Gogh in Saint-Rémy and Auvers. Metropolitan Museum of Art: N.Y.:N.Y. p. 109.

Calm and Sensible Brushstrokes and Chaotic and Crazy Ones What was the connection between the calm sensible canvases and the chaotic and crazy ones? Julius Meier-Graefe (1987) believed that Vincent's sensible canvases with orderly compositions and treatment always dated from critical periods. And conversely Meier-Graefe believed that the immensely moving and crazy landscapes from Saint-Rémy, in which every stroke of the brush betrayed his excitement and his emotions, were the products of Vincent's most peaceful moments. Considering Meier-Graefe’s assessment from a psychological perspective, it is certainly possible that this is an apt analysis. When a person is on the verge of a breakdown or semiotic breakthrough, when his life is spinning wildly out of control around him, he may seek to exert control and order upon his environment and within himself through repetition of rote behaviors, such as carefully painting one leaf beside another and another and another. Conversely, when a person is most in charge, he may be most free with his artistic expression, coordinating strongly energetic representations by creating with careless selfabandon and total lack of self-consciousness, because the perceived sense of personal control eliminates fear of the semiotic breakthrough.

The Starry Night 
The Starry Night is an example of powerful masses of color and texture that were organized with profound expressiveness by Vincent van Gogh. Rhythmic swirls undulate actively through the large expanse of sky in The Starry Night and there is a sense of absolute mastery and organization of the artistic medium. This is no crazy and out-of-control painting, rather it is a masterpiece of artistic control and expression. The Starry Night is the canvas that Vincent had always dreamed of painting. Vincent's letters consistently revealed a fascination with twilight, night lights, night skies, and stars. In one of his letters he had said, "Often it seems to me that the night is much more richly colored than the day (Graetz, 1963).

Since an early time in his life, Vincent van Gogh had been fascinated with celestial effects. From Ramsgate, England on May 31, 1876 he had described a star, "the tops of the elm trees, dark against the night sky. Over those roofs, one single star, but a beautiful, large, friendly one.” And from Isleworth, England, on October 7, 1876, Vincent told about sitting before a fireplace, “one’s eyes fixed on a star that sends its rays through the opening in the chimney as if to call me.” A few lines later in the same letter Vincent continued with this classic existential statement, "to think that such is human life: to be born, to work, to love, to grow, and to disappear.”

Writing from Neunen in Holland in June 1885, Vincent had again expressed his yearning toward the sky and described a deeply felt existential connectedness, "and it is a good thing in winter to be deep in the snow, in autumn deep in the yellow leaves, in summer among the ripe corn, in spring amid the grass. It is a good thing to be always with the mowers and the peasant girls, in summer with a big sky 
overhead, in winter by the fireside, and to feel that it always has been and always will be so.” The above passages, from a healthier time in his life, enumerate many of the subjects of his paintings: wintry snowscapes, fields and trees with varying colors to show the seasons, and landscapes peopled with mowers and reapers and peasants.

In Saint-Rémy, Vincent’s attention was again drawn to the morning star. “This morning I saw the country from my window a long time before sunrise with nothing but the morning star" (LT 593). From the window of Vincent's bedroom at Saint-Rémy he could look east and southeast onto an open landscape that culminated in the Alpilles and above that was a vast uninterrupted view of the night sky. This scene became the inspiration for his masterpiece The Starry Night, which has been mysterious since its inception. Vincent, himself, said very little about this painting and why he composed it as he did. About June 18, 1889, Vincent wrote, “At last, I have a landscape with olive trees and also a new study of a starry sky” (LT 595). Both Vincent and Theo said very little about this remarkable painting that has become so famous and valuable.

There are various ways to perceive this painting, The Starry Night. On the simplest level, it is just paint on canvas with clearly discernible brush strokes. When considering the external stimuli for the creation of this painting, it is almost certain that this is not exactly how the night sky appeared. No night sky ever looked like this; stars do not race about in frenzied whirlpools (Gilbert, 12). The viewer is likely to ask, "Why did the artist paint it this way?” Vincent van Gogh was introverted, and introverts see reality in terms of what is going on inside them. The 
patterns in van Gogh’s art work allow a glimpse into his psyche. So, turning to a consideration of internal stimuli, it is known that Vincent van Gogh was a tormented, intense, and mystical man; and some of that torment as well as a kind of ecstasy are built into this painting called The Starry Night (ibid.). People viewing The Starry Night may interpret it in many and varied ways depending upon their perceptions, past experiences and even perhaps their personal biases (ibid.) Gilbert speculated, a cosmologist might think that The Starry Night alludes magnificently to the formation of the universe; a Londoner who experienced the German blitz in World War II might see a bombing raid; someone who has been in a fever or taken drugs might see it as a hallucinatory vision; a person with a certain visual disorder might think this is the way a night sky looks; and the individual who views nature in a scientific way might think that van Gogh was crazy. Each viewer will have his or her own unique ideas and interpretations of this and any other work of art.

The Starry Night is a landscape with a cypress tree, a village with homes and a church, mountains and a night sky. Approximately two thirds of the picture space is sky, and what a sky! Stars swim in swirling whirlpools of light and the sun and moon seem conjoined. A turbulent, swooping, swirling effect dramatically dominates the night sky by forming a prominent Yin-Yang symbol in the center of the painting. This may be a visual representation of the wind, possibly the mistral that blows in Provençe. But there may also be a deeper existential meaning since the Yin-Yang is the symbol of balance and of the unity composed of equal amounts of opposite qualities. Analytical psychology is Jung's unique brand of psychology that emphasizes the complex interplay between oppositional forces within the 
psyche. In nature everything is in balance. While it is true that the world is one, there is an apparent bipolar duality in the balanced pairs of opposites that form the unity. The Yin-Yang may represent male and female, night and day, dark and light, summer and winter, war and peace, order and chaos, spirit and flesh and so on. Each quality informs and completes its bipolar opposite by establishing and maintaining the proper balance between them. In many ways the life of Vincent van Gogh was not a life in balance. For the most part he was unable to establish and sustain meaningful human relationships, i.e. the balance between self and other, even the relationship with Theo was strained at times by the difficult personality of his brother Vincent. When a person's life is not maintained in balance, there may be illness, interpersonal difficulties, and all sorts of problems as there were in the life of Vincent van Gogh. The prominent yin-yang symbol in the sky of The Starry Night may well represent a subconscious yearning for completion through joining and fulfillment in the life of Vincent van Gogh, and the turbulent nature of the representation may symbolize the intensity this yearning. But it is also interesting to speculate about how much of the symbolism of oppositions might have been conscious on the part of Vincent van Gogh as he surely would have been aware of the yin-yang symbolism.

A powerful sense of the ultimate reconciliation of opposites is given in the interlocked clouds and reiterated in the conjoined sun and moon and both images give the same symbolic meaning. Graetz (1963) sees this as the expression of the Yin-Yang symbol, and taking the analysis further, he sees the two lovers in the foreground of the Arles Starry Sky symbolized in The Starry Night by the two 
dynamic clouds, as interfluent as a passionate union, like that of a man and a woman. The composition in the sky is like a love scene on the bed of clouds that extends above the mountains and the agitated motion stresses the sensual nature of the scene (Graetz, 1963). The fulfillment of love is portrayed in The Starry Night. The sun and moon conjoined repeat the message of union, but with a darker interpretation. The moon is somewhat like the death symbol of the sickle, but the ends continue to form a circle. Albert Boime (1984) believed that Vincent began painting the gibbous phase of the moon and then reverted to a more traditional image, while keeping the general configuration through the aureole. The context of the sickle and the waxing and waning of the moon would seem to place the interpretation of this image into the realm of the existential opposites of life and death.

Pickvance (1986) stated that many commentators have concentrated on the complex symbolic imagery in The Starry Night. It has been suggested that it might relate to the creation story in the book of Genesis or to the apocalyptic descriptions of the end times in the book of Revelations (sic) in the Bible. Various possible literary sources for The Starry Night have been suggested including Whitman, Longfellow, Zola, Daudet, Dickens and Carlyle. Different viewers see different things, and interpretations are as varied as the observers.

So what does this viewer see? The eye is immediately drawn to the dark cypress tree that dominates in the foreground and flames upward cutting ominously across the large expanse of sky to nearly touch the top of the picture space. The flame-like area of cypresses may be a pictorial reference to mortality, death and 
even perhaps symbolically to the flames of hell, and this representation could be on either the conscious or unconscious level of the artist Vincent van Gogh.

Cypress trees were often planted in cemeteries and there derives the funereal connection. At the same time, it is an evergreen tree, which the ancient Romans planted around tombs as a symbol of immortality (Boime, 1984). The cypress tree alone, of all the terrestrial elements in The Starry Night, breaks through confinement and shoots into the sky like a projectile to touch the stars (ibid.). Kristeva's idea of poetic language, rather than boundedness, seems to exemplify The Starry Night. Vincent van Gogh may have been expressing in paint, the belief that after death, the spirit breaks free and transcends the bonds of earth. Vincent van Gogh had written in one of his letters, "we take death to reach a star."

The little village sits nestled somewhat peacefully in the valley, sheltered by the mountains in the background, while the sky rolls turbulently above. The several small houses in the village that have a warm yellow glow coming from their windows are contrasted with the church that has dark windows revealing no inner light, no inner warmth. This might express that the church itself needs enlightenment and is searching for light. The unlit bluish-white church seems to express an emptiness and an icy coldness similar to the response that Vincent had sometimes felt from the "church people.” This symbolic visual commentary may refer to Vincent's own troubles with the church, perhaps expressing that he found more of illumination and holiness in the ordinary people and in nature than in the organized church. 
The night sky with stars is the subject of this painting, The Starry Night. The eleven stars vary in size and are surrounded by circular aureoles. The sun and moon are superimposed upon one another. The brush strokes of the artist swoop and swirl combining all of these elements to create the dramatic and mysterious masterpiece that we know as The Starry Night.

Vincent van Gogh had painted an earlier picture with a similar theme. Starry Night over the Rhône, also called The Starry Sky, was a canvas done in September 1888 while he was still at Arles. In painting Starry Night Over the Rhône, van Gogh wanted to demonstrate that night subjects should be done at night, on the spot, rather than during the day in the studio, and that a whole range of colors, not just blue and black were to be found in them, and Pickvance (1986) believed that Vincent was also surely questioning the stated practices of the American artist, James Abbott Mc Neill Whistler (1834-1903) in his Nocturnes.

But when van Gogh painted his new starry night, he did not follow his earlier procedure of plein air painting, rather it was painted from memory and from the sources of some of his earlier canvasses at Saint-Rémy. In his studio several recently painted canvases were drying. From two of them he took elements that he used in The Starry Night. The outline of the Alpilles came from Mountainous Landscape behind the Asylum, and the Wheatfield (now in Prague) gave him the model for the cypress tree. Before The Starry Night could be painted, Vincent had to achieve the courage to paint from imagination rather than reality (Cane, 1983). This very issue, painting from memory, ironically had been the greatest issue of contention in the arguments between Vincent van Gogh and Paul Gauguin, with 
Gauguin speaking out for painting from memory and van Gogh espousing painting from viewed reality. It is no small irony that The Starry Night, considered by many to be the greatest masterpiece of Vincent van Gogh, was primarily a studio work painted mostly from imagination and memory.

Due to the varied sources used in the creation of The Starry Night, it is a type of abstraction with composite procedures and an almost collage-like collection of separate motifs fused into one scene (Pickvance, 1986). The Starry Night is different from the rest of Vincent's work in June 1889 due to its complex and distinctive morphology (ibid.). In the act of painting, the form of the church was changed and the domed church of Saint-Rémy was replaced by the archetypal church from Van Gogh's memory of Brabant (Soth, 1986). Because the little church looks more Dutch than Provençal, Pickvance (1986) refers to The Starry Night as the first of Vincent's memories of the North. It was sent to Theo in the third batch of paintings from Saint-Rémy on September 28, 1889. Theo referred to The Starry Night only as "the village in the moonlight" (T 19). This statement may refer to the van Gogh brothers' shared memory of their past in Holland. Neither Vincent nor Theo said very much about The Starry Night, but certainly much has been said about it since. Describing The Starry Night for the Museum of Modern Art in New York, A. H. Barnes, Jr. wrote, "The Starry Night goes further, it is fundamentally an imaginative invention - the sky, the sunbright moon, the milky way turned to comets, the stars like bursting bombshells - this is the unique and overwhelming vision of a mystic, a man in ecstatic communion with heavenly power” (Cane, 1983). 
In The Starry Night Vincent van Gogh achieved expression of the creative ecstatic

union so earnestly sought by lovers and religious seekers, and longed for by all persons. Art, by its spiritual quality, is not only related to religion, but both of them have in common that they express the very nature of man: the union of matter and spirit (Graetz, 1963). Vincent van Gogh’s artistic expression of the joyful unity of the creative, imaginative process in The Starry Night was strong enough to overpower the existential crises of his birth, life and death. The Starry Night profoundly reveals Vincent van Gogh’s existential victory and courage.

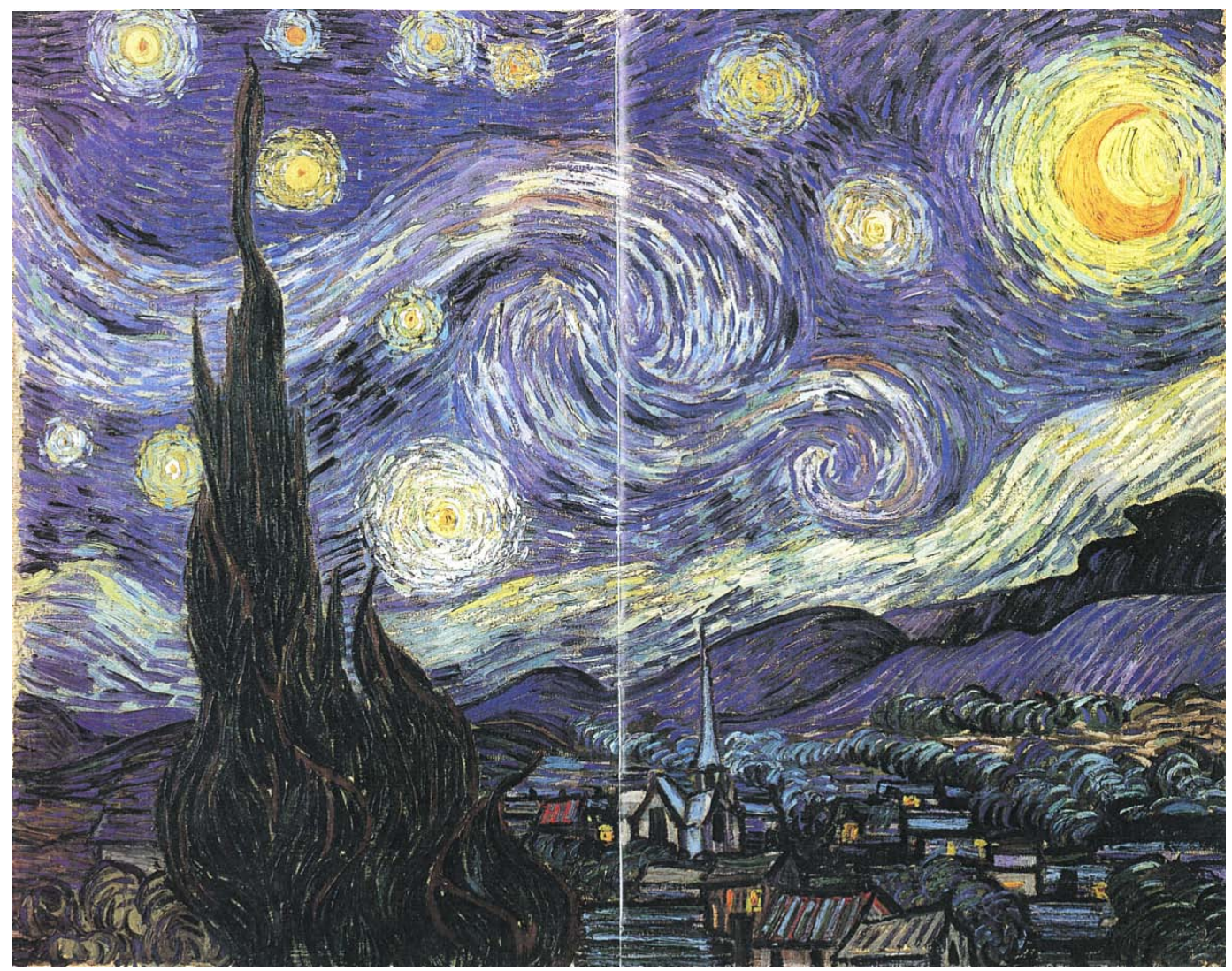

Figure 48. The Starry Night 
Pickvance, R. (1986) Van Gogh in Saint-Rémy and Auvers.

Metropolitan Museum of Art: N.Y.:N.Y. p. 105.

\section{Self-Portraits at Saint-Rémy}

There are four self-portraits of Vincent van Gogh from Saint-Rémy. When he first arrived at Saint-Rémy, Vincent gave no consideration to figure painting, he was too eager to be outdoors and to work on landscape and motifs from nature. Nor was his mood sufficiently introspective for him to think of undertaking a self-portrait (Pickvance, 1986). Pickvance further reported that there were no figure paintings from May to July 1889 and that only one landscape, The Reaper, includes a figure, but it is small and non-dominant. Julius Meier-Graefe (117) reported that the cornfield with the reaper and the cornfield with the sower and the large sun were intended to be displayed together. The sower and the reaper marked the beginning and the ending of life, the Alpha and Omega holding life like bookends.

The Sower and The Reaper seemed to exert a calm assertion of the nature of life. The Sower seemed to symbolically express the hope inherent in new beginnings and could be interpreted to represent eternity. TheReaper put a suggestion of death into Vincent's work. Meier-Graefe (ibid.) reported that Vincent had a terrible fit when he was halfway through with painting the reaper. It was reported that he screamed so violently that people rushed into the field, and that his 
throat was so inflamed with shouting that he could not eat any food for four days. Meier-Graefe speculated that the fit might have been due to his visit to Arles to pack up the pictures that he had left behind in the yellow house and his brief visit with Mme Ginoux. Perhaps his return to the yellow house was too soon, causing powerful semiotic emotions to erupt when he was confronted with the brokenness of his dreams of a studio of the south. Or perhaps he responded subconsciously to the image of the reaper, correctly understanding it as an image of death and perceiving it as a threat to his own mortality.

Vincent van Gogh isolated himself in his room during August and September of 1889. Withdrawal and isolation are typical of the depressive phase of bipolar disorder. Vincent shunned contact with other people and avoided exertion. His concern was not for himself, but for his work, which he knew he might not be able to complete. When he had recovered enough to return to his work, he finished the reaper by working inside behind barred windows (bounded, clos), rather than out in the open. He also completed two portraits of himself during this time.

\section{Self-Portrait (Saint-Rémy \# 1)}

After his five-week breakdown, he returned to his interest in figure painting in late August to September 1889. In LT 604 Vincent said to Theo "They say - and I am very willing to believe it - that it is difficult to know yourself, but it isn’t easy to paint yourself either. So I am working on two portraits of myself at this moment- for want of another model, because it is more than time I did a little figure work. One I began the day I got up. I was thin and pale as a ghost. It is dark 
violet-blue and the head whitish with yellow hair, so it has a color effect. Since then I have begun another one, three-quarter length on a light background.”

The series of four self-portraits from the Saint-Rémy period provide another opportunity to observe the artist as the speaking subject commenting about himself. Kristeva (1980, viii) always questions meaning and the structures of meaning while observing the underlying speaking subject. Post-Freudian rationality takes two stages into account, the conscious and the unconscious (ibid., ix.). In Self-Portrait (Saint-Rémy \# 1) Vincent's conscious presentation of himself is as an artist able to function in his profession despite his recent illness. The use of yellow tones for the sallow complexion and the greenish-yellow shadows in his face bespeak his recent illness in a perhaps unconscious but likely very accurate color choice. The unconscious is not known to lie. The complementarity and opposition of the purplish-indigo background and the yellow tones, place Vincent at odds with his milieu, but the opposite is evident in the largely monochromatic Self-Portrait (Saint-Rémy \# 2).

The first mentioned self-portrait, Self-Portrait (Saint-Rémy \#1), is the one with the dark violet-indigo background from the collection of Mrs. John Hay Whitney. It asserted Vincent van Gogh's identity as a painter. He pictured himself wearing his dark blue artist's smock and holding his palette and brushes. His pale head emerges starkly from the dark violet-blue background that is painted with contoured brushstrokes. The strokes encircle the head creating a boundary that gives an implied sense of a halo. The encircling brushstrokes both incorporated him 
into the dark milieu of the portrait's background and isolated and set him apart from it. He seems to swirl in his own reality.

Pickvance (1986) believed that in the Self-Portrait (Saint-Rémy \# 1) van Gogh was presenting a challenging assertion of his profession as an artist and that he intended to demonstrate to Dr. Peyron that though he was recovering from a serious breakdown he was now quite capable of painting. Vincent was determined to be allowed to resume painting since he believed that would now be safe; i.e. he no longer feared a semiotic breakthrough. He would no longer try to poison himself by eating the paints. Vincent was like a fish out of water if he could not return to his painting. He considered painting to be necessary for his recovery. Vincent van Gogh seemed to have an intuitive grasp of the benefits of art as therapy. He seemed to realize that he could help his mental condition through self-expression in his artwork.

(See Figure 49 on the next page). 


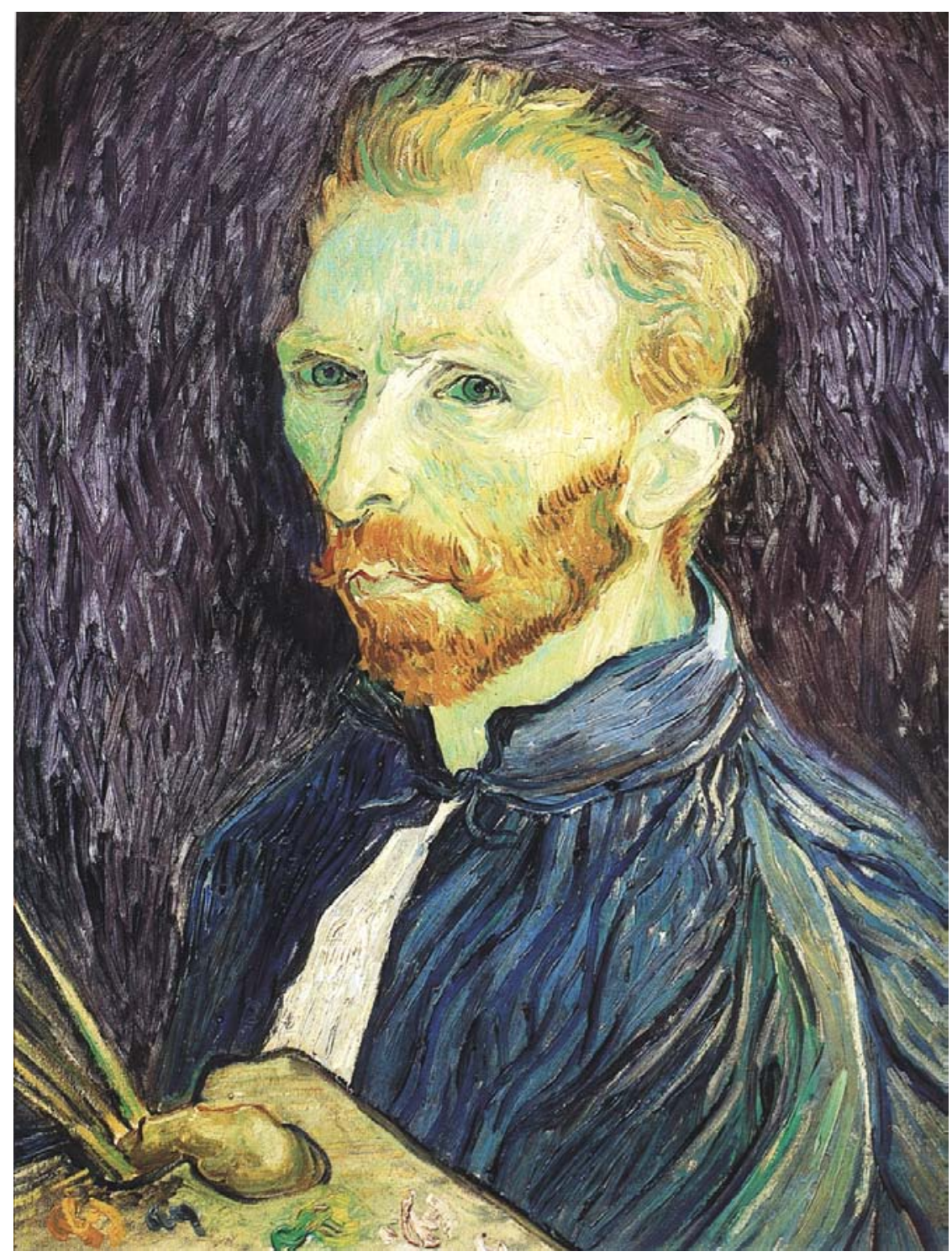

Figure 49. Self-Portrait (Saint-Rémy \# 1)

Pickvance, R. (1986) Van Gogh in Saint-Rémy and Auvers.

Metropolitan Museum of Art: N.Y.:N.Y. p. 122. 


\section{Self-Portrait (Saint-Rémy \# 2)}

In an apparent restructuring of meaning, Vincent uses a primarily monochromatic color choice in Self-Portrait (Saint-Rémy \# 2) and that shows Vincent united with the milieu rather than standing against it. There was very little difference in the blue tonality of the background and the blue coat and vest that he was wearing. Even the pale skin tones and hair had blue shadows. His blue eyes were of the same hue. The red beard and white shirt were the only respite from the pale blueness of this self- portrait. The background was covered with swirls formed by flame-like brushstrokes in the same cool blue tone. A similar style and treatment was used in the background of this Self-Portrait (Saint-Rémy \# 2) and that of The Starry Night.

Vincent's eyes in this pale blue self-portrait revealed a troubled gaze with worried wrinkles on his forehead between his eyebrows. His china blue eyes stare out intently, but seem to reveal a tenuously contained intensity. Vincent van Gogh does not look like a man who is at peace with himself or the world.

(See Figure 50 on the next page). 


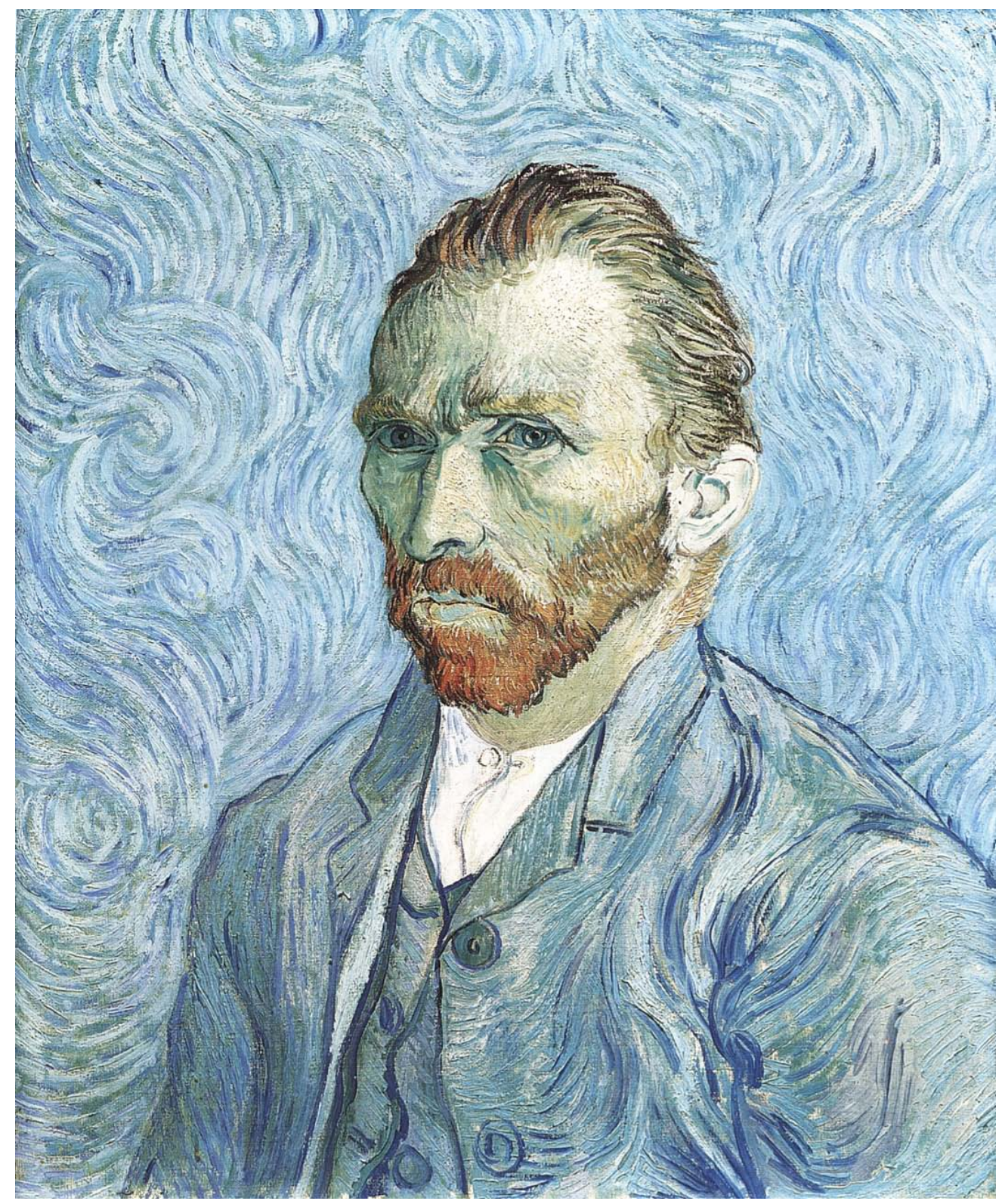

Figure 50. Self-Portrait (Saint-Rémy \# 2)

Pickvance, R. (1986) Van Gogh in Saint-Rémy and Auvers.

Metropolitan Museum of Art: N.Y.:N.Y. p. 123. 


\section{Self-Portrait (Saint-Rémy \# 3)}

Vincent presents himself with an image of healthiness in Self-Portrait (Saint-Rémy \# 3). There is a noticeable ruddiness in his cheeks. But the external vision of health seems to be only skin-deep, and the status of his mental health remains questionable. Kristeva's $(1980,19)$ concept of the unary subject (le sujet unaire) sees the self as a homogeneous, consistent whole, but Vincent's selfportraits have considerable variation in them. He has seemed to experiment with various personas in his self-portraits: artist, gentleman, peasant, a Japanese monk, a dandy, and so forth. Of these various identities, Vincent the artist, and his identification with the poor and down-trodden of society seem to be the most consistent.

Pickvance (1986) stated that van Gogh’s last self-portrait was his third one from the Saint-Rémy period. Vincent intended it to be suitable as a gift for his mother's seventieth birthday on September 10. In LT 604 Vincent told Theo, “I have a great desire to do the 'Reaper' once again for mother. If not I will paint her another picture for her birthday.” By September 19, 1889, he had written to his mother sending her belated congratulations for her birthday and stating, "I intend to send you a picture shortly,” but he did not explain which one. It was not revealed until September 28 in LT 608 that he was planning to send a Reaper and also a “little self-portrait” for his mother and his sister Wil. Then on October 20 he was a bit more forthcoming about this 'little self-portrait,' that would soon be sent to Leiden. He stated, "You will see from the self-portrait...that though I saw Paris and other big cities for many years, I keep looking more or less like a peasant of 
Zundert... and sometimes I imagine I also feel and think like them, only the peasants are of more use in the world” (LT 612). This statement again reaffirmed his feelings of solidarity with the poor, with those who worked the soil, who toiled in coal mines, or who did other menial tasks, but it also revealed a feeling that seems closer to decompensation than to a healthy attitude of humility. Vincent used a self-disparaging tone when he spoke of these poor workers as of more account in the world than he was.

This last self-portrait from Saint-Rémy-de-Provençe had an entirely different tone and presentation than the previously discussed self-portrait on a deep violet-indigo background or the largely monochromatic self-portrait against a light blue background. The Self-Portrait (Saint-Rémy \# 3) may have been intended to reassure his mother, as he wrote to Theo in LT 604, "I am inclined to think that the portrait will tell you better than my letter how I am, and that it will reassure you.” Self-Portrait (Saint-Rémy \# 3) was painted in hues of ochre and flesh-tones against a background formed by short brushstrokes using shades of blue. Gone are the encircling halo and the dramatic flame-like backgrounds; the background is more pragmatic and more straightforward. Pickvance $(1986,130)$ described this as Vincent's most reflective and disturbing self-image. This author does not view this self-image per se as disturbing, nor does Vincent seem to appear like a peasant as he had stated. Vincent chose to present himself as clean-shaven and perhaps as a younger and healthier man than he was. What is disturbing to this author is that the image may be a lie with the physical appearance of health masking his precarious mental condition. 


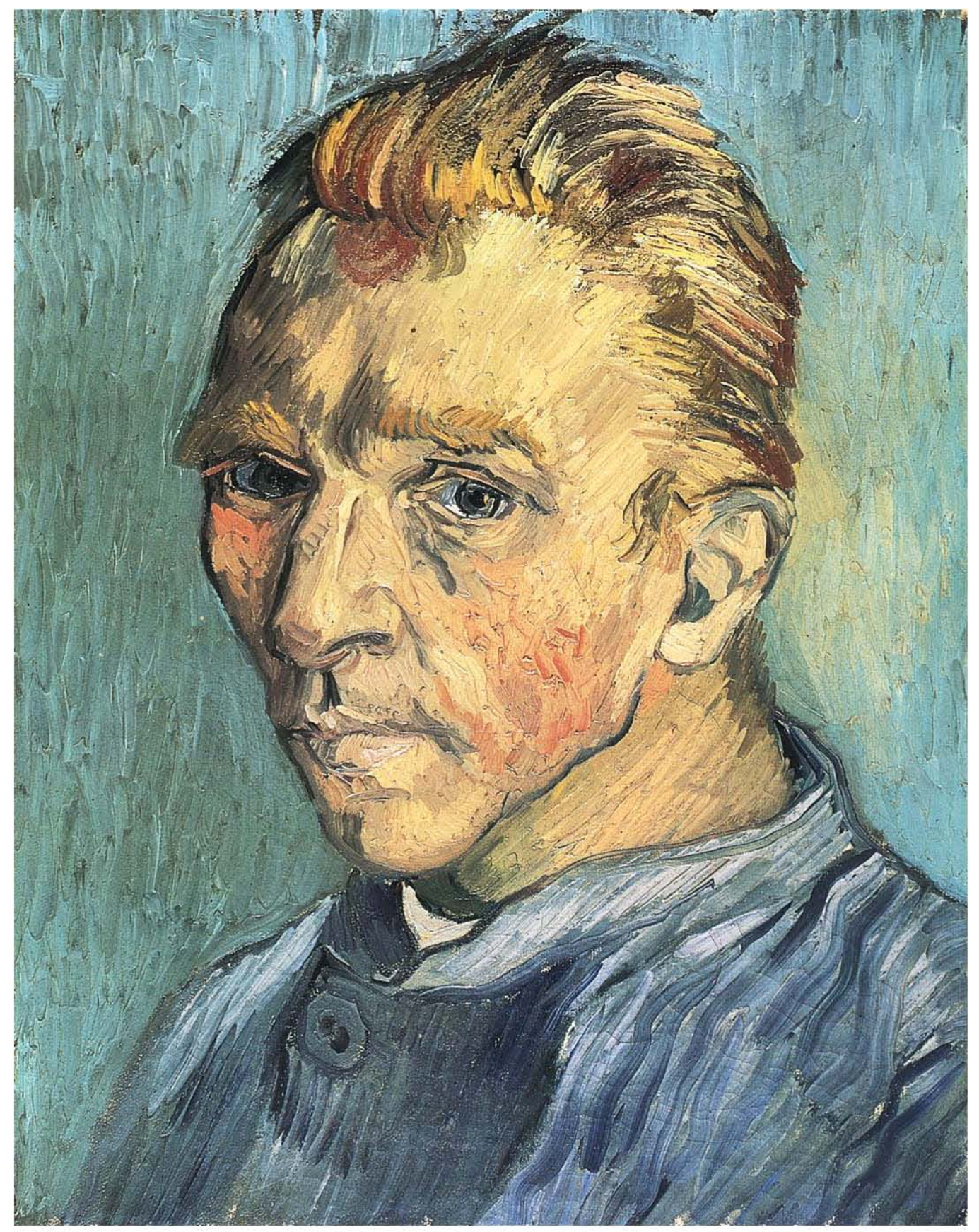

Figure 51. Self-Portrait (Saint-Rémy \# 3)

Pickvance, R. (1986) Van Gogh in Saint-Rémy and Auvers.

Metropolitan Museum of Art: N.Y.:N.Y. p. 131. 
In early December the Self-Portrait (Saint-Rémy \# 3) was sent to Theo along with the painting of his bedroom and five other canvases. Some of these were intended for eventual dispatch to Leiden for his mother and sister. One can only wonder what reaction his mother may have had to this unusual image.

\section{Self-Portrait (Saint-Rémy \# 4)}

Whereas in Self-Portrait (Saint-Rémy \# 3), Vincent seemed robust and healthy, in Self-Portrait (Saint-Rémy \# 4), the opposite seems to be true. SelfPortrait (Saint-Rémy \# 4) seems to present an image of covertness, suspiciousness, perhaps even paranoia in Vincent's gaze. Mental health issues seem to emanate from this self-portrait. The self-portraits of Vincent van Gogh seem to present momentary stases rather than a consistent representation of what Kristeva refers to the unary subject.

Bonafoux (1992) portrayed this self-portrait and stated that it is from Saint-Rémy, but Pickvance does not mention or include it. In Self-Portrait (SaintRémy \# 4),_Vincent van Gogh’s blue eyes look out with a furtive glance (Bonafoux, 1992). The skin tones on the face give a fragmented appearance, and they are streaked and mottled with unhealthy looking shades of bluish-grey. The background is composed of broken brushstrokes that roughly work their way around his head. Although the brushstrokes do tend to encircle the head, instead of giving a halo effect, they seem rather to emanate outward from the head like some sort of visual representation of thought projections. The image seems barely held together by the coarse brushstrokes and the splotchy color blending. Even though the side of his face has a strong black line to create a boundary, the image has the appearance that 
he could easily dematerialize and blend into the ether of the background. Vincent looks as if he might "snap" and lose his carefully contained composure at the least provocation. This is the self-image that this author finds most disturbing.

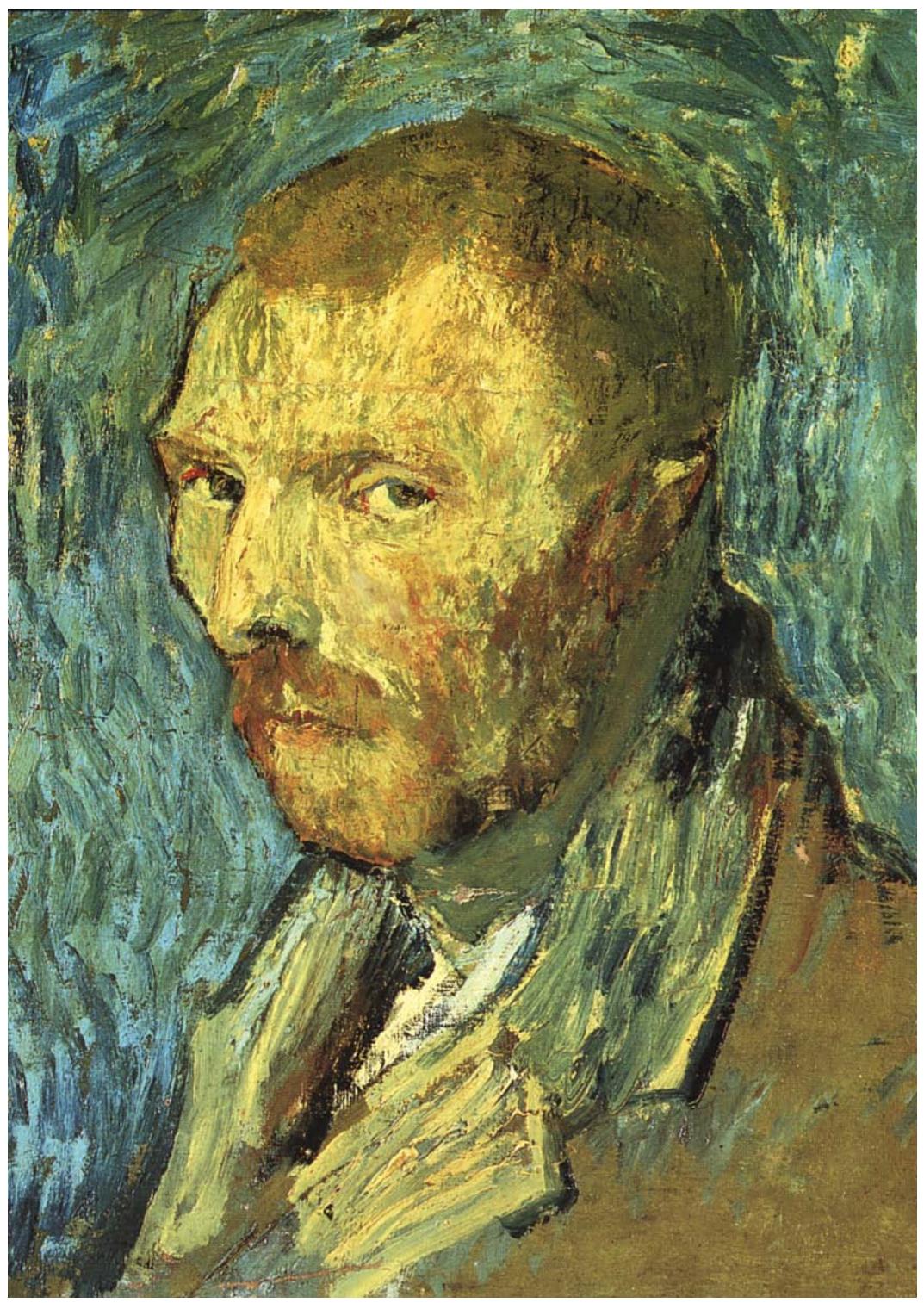

Figure 52. Self-Portrait (Saint-Rémy \# 4)

Bonafoux, P. (1992) Van Gogh, The Passionate Eye.

Harry N. Abrams, Inc.: N.Y., p. 9. 
At Saint-Rémy painting was like a double-edged sword for Vincent van

Gogh. It was his hope that his painting would help to forestall any further attacks. But his painting also was capable of filling him with regret because it confronted him with what he might have been able to accomplish if his health had been better. He said, "I am always filled with remorse, terribly so, when I think of my work that is so little in harmony with what I should have liked to do.”

The personal viewpoint of Vincent van Gogh was coherent with his own unique expression of existentialism. Existentialism is a philosophy that focuses on people’s attempts to make sense of their existence by assigning meaning to it and then taking responsibility for their own actions as they try to live in accordance with their values and principles (Ryckman, 1985). Vincent van Gogh defined himself as an artist and in his work as an artist he found purpose and meaning for his existence. When he found his work to be lacking in any way, he became his own harshest critic and his remorse took on the aspect of existential failure. 


\section{CHAPTER VII}

\section{PARIS AND AUVERS}

\section{May 1890 to July 1890}

Vincent van Gogh's life alternated several times between city and country, with the country serving as a refuge from the city (McQuillen, 121). Towards the end of his time at Saint-Rémy, Vincent began to long for a change of scenery. He revealed the depth of his depressed mood as he wrote, "What am I to say about these last two months? Things didn't go well at all. I am sadder and more wretched than I can say, and I do not know at all where I have got to.” He had felt so sad and down that letters from home went unopened, "Letters from home have come too, which I have not had the courage to read, I feel so melancholy." Vincent bemoaned his bad luck in becoming sick when trying to paint the almond blossoms, "I fell ill at the time I was doing the almond blossoms. If I had been able to go on working, you can judge from it that I would have done others of trees in blossom. Now the trees in blossom are almost over, really I have no luck.”

Vincent longed to leave the asylum. Speaking of Saint-Rémy, he said, "Yes, I must try to get out of here, but where to go? I do not think I could be more shut up and more of a prisoner in the homes where they do not pretend to leave you free, such as at Charenton or Montevergues.” Before the attack in April, Dr. Peyron had believed that Vincent was at last on the road to permanent recovery. Vincent felt that he could no longer stand the asylum of Saint-Paul-de-Mausole at Saint-Rémy, "My surroundings here begin to weigh 
on me more than I can say - my word, I have been patient for more than a year - I need air; I feel overwhelmed with boredom and grief. I am at the end of my patience, my dear brother. I can’t stand anymore - I must make a change, even a desperate one.” He set the deadline of May 15 and Dr. Peyron did not object to this (Bonafoux, 115). Despite his depressed mood and having had three psychotic episodes in the previous six months with two suicide attempts, Vincent van Gogh was discharged as cured from the asylum at Saint-Rémy.

\section{Leaving Saint-Rémy and Visiting Paris}

On May 16, 1890, Vincent van Gogh left Saint-Rémy and was accompanied by a warder as far as Tarasçon; from there he traveled on his own by train to Paris. Theo met him on the platform at the Gâre de Lyon in Paris on May 17. They proceeded at once to 8 Cité Pigalle, where Theo, Johanna and their infant son Vincent Willem lived. The rest of that day was spent in the fourth floor apartment getting acquainted with his brother's wife and his new nephew. Bonafoux (115) reported that Johanna was surprised by the height, robustness, and calm of her brother-in-law. But Paris had not done Theo any good, he looked older than Vincent and he constantly avoided questions about his health (MeierGraefe, 131). It appears that Vincent's physical appearance gave an impression of health, but his mental health status seems to have been anything but robust.

Vincent van Gogh spent three days in Paris before going to Auvers. During that time, he looked over the pictures that were in the apartment and with Theo he visited Tanguy's shop where a number of his pictures were stored. He was concerned about his paintings in storage; that they might ruin in “Tanguy’s bug-infested hole," even though that is the area Theo had rented specifically to store the paintings (Pickvance, 200). The 
brothers also visited the Salon de Champ de Mars, a secessionist group from the Salon, but they did not have enough time to see the Japanese exhibition at the École des Beaux-Arts (Bonafoux, 116). On May 19, Vincent did not want to stay in Paris any longer; in LT 635 he cited "all the noise (in Paris) was not for me.” Theo informed Dr. Gachet of his brother's imminent arrival in Auvers.

\section{Going to Auvers}

On Tuesday May 20, Vincent van Gogh took the train to Auvers-sur-Ôise. Under his arm he had four canvases that he had done while in Saint-Rémy and a letter of introduction from Theo to Dr. Gachet. The four paintings were the Self-Portrait (SaintRémy \# 2), L’Arlésienne, Piéta, and probably Prisoner's Round (Pickvance, 1986, 197). Dr. Gachet particularly admired the self-portrait and sought to have Vincent paint him in the same manner. Vincent said of his self-portrait, "My portrait of myself is done almost exactly the same way, (as the portrait of Dr. Gachet) the blue is a delicate blue of the sky in late afternoon and I am wearing pale lilac.”

At Auvers, Vincent van Gogh was a speaking subject within a social framework which he recognized as a basis for that identity and this established his (pratique signifiante), signifying practice (Kristeva, 1980, 18). He recognized himself as a patient and painted a portrait of his Doctor. He recognized himself as at liberty and painted outdoor and landscape scenes. Possibly an unconscious response to his release from confinement at Saint-Rémy, a sense of externality is immediately apparent in several of the last artworks from his time in Auvers: Wheatfields, Bank of the Ôise at Auvers, Wheatfield Under Clouded Sky, and Crows Over the Wheatfield. In several of the paintings from Auvers (Cottages with Thatched Roofs, Old Vineyard with Peasant 
Woman, Village Street and Stairs with Figures, and The Church at Auvers), there is an undulating quality to lines that should be solid and substantial possibly indicating his declining mental status that ended in suicide.

Lodgings were more costly in Auvers than they had been at Saint-Rémy. Dr. Gachet suggested lodgings at the café-tavern Saint Aubin on the Rue Rémy where board and lodging cost six francs a day (Bonafoux, 116). Thinking this charge to be excessive, Vincent obtained an attic room and board for three-fifty a day with the Ravoux family at Place de la Mairie.

The First Two Drawings from Auvers

Between Vincent van Gogh’s first day in Auvers, May 20, 1890 and May 23, he completed two small (17 3/4 x 21 1/2 inch) pencil, brush, watercolor and gouache drawings, Cottages with Thatched Roofs and Old Vineyard with Peasant Woman. These two drawings from Auvers are unique among the oeuvre of van Gogh, because of their dependence upon generous use of pencil after which fluent brushwork with a blue-violet tonality seems to have been laid on. It appears that the pencil drawing was done on the spot and the color added from memory in the studio. The original pencil composition can still be seen in areas left untouched by the brush and beneath thin areas of the paint. The restriction of his palette to blues and black with some violet tones in the shadows seems unnatural and limiting, but in LT 636 Vincent had said that now he saw "violet hues everywhere.” He may also have been recalling that Gauguin had said, “If you see blue, then chuck on some blue, and don't go telling me that it was a blue rather like this or that, it was blue, wasn’t it?” (LT 607). 
There is an unusual morphology in the form of the cottages when comparing these two drawings, Cottages with Thatched Roofs and Old Vineyard with Peasant Woman that has a backdrop of cottages. There is an unnatural quality in the exaggerated roundedness of the rooftops in Cottages with Thatched Roofs that is not seen in the sharply angular rooftops in Old Vineyard with Peasant Woman. Pickvance $(1986,223)$ sees these rooftops as another of van Gogh's “memories of the North” because these rounded rooflines are not found in Dutch or French thatched cottages, rather they appear only in his Southern adaptations as misremembered Dutch thatched cottages.

Old Vineyard with Peasant Woman continues and takes further the pattern of boldly hatched surface textures and use of linear enhancement that was noted in Cottages with Thatched Roofs. The surface pattern of points and lines dominates and subdues the compositional element of the trellis for the vineyard. A few strong blue lines delineating the trellis establish the horizontal and vertical axes upon which the composition rests and these are echoed in the horizontals and verticals that delineate the cottages in the background. But the predominant elements that draw the eye are the curvilinear dotted foliage of the grapevines and the strongly hatched grasses. The center stage of the composition is busy and intense with visual relief provided only by the sturdy figure of the peasant woman and the solidly drawn houses with their strong vertical and diagonal hatching lines. 


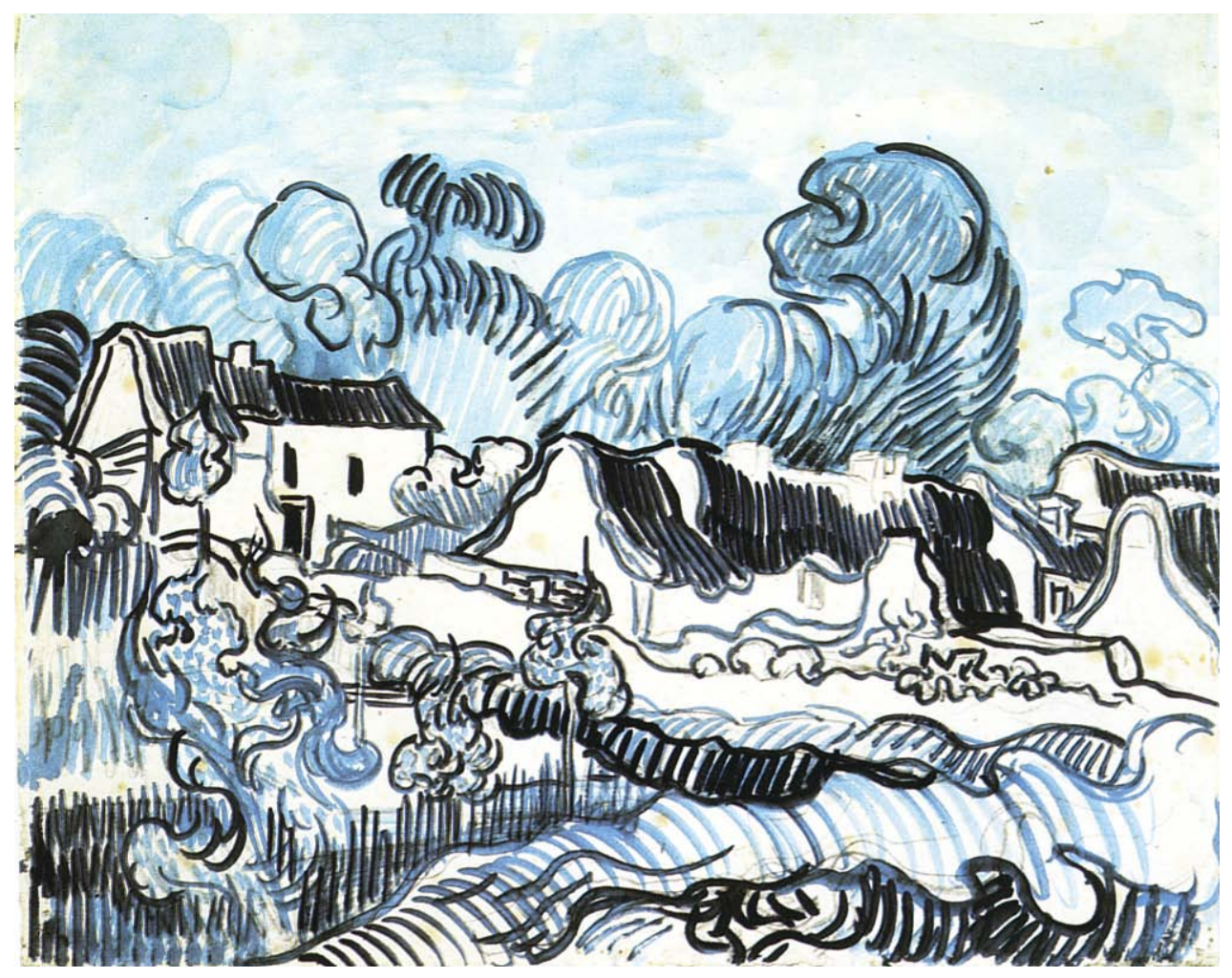

Figure 53. Cottages with Thatched Roofs

Pickvance, R. (1986) Van Gogh in Saint-Rémy and Auvers.

Metropolitan Museum of Art: N.Y, N.Y. p.222 


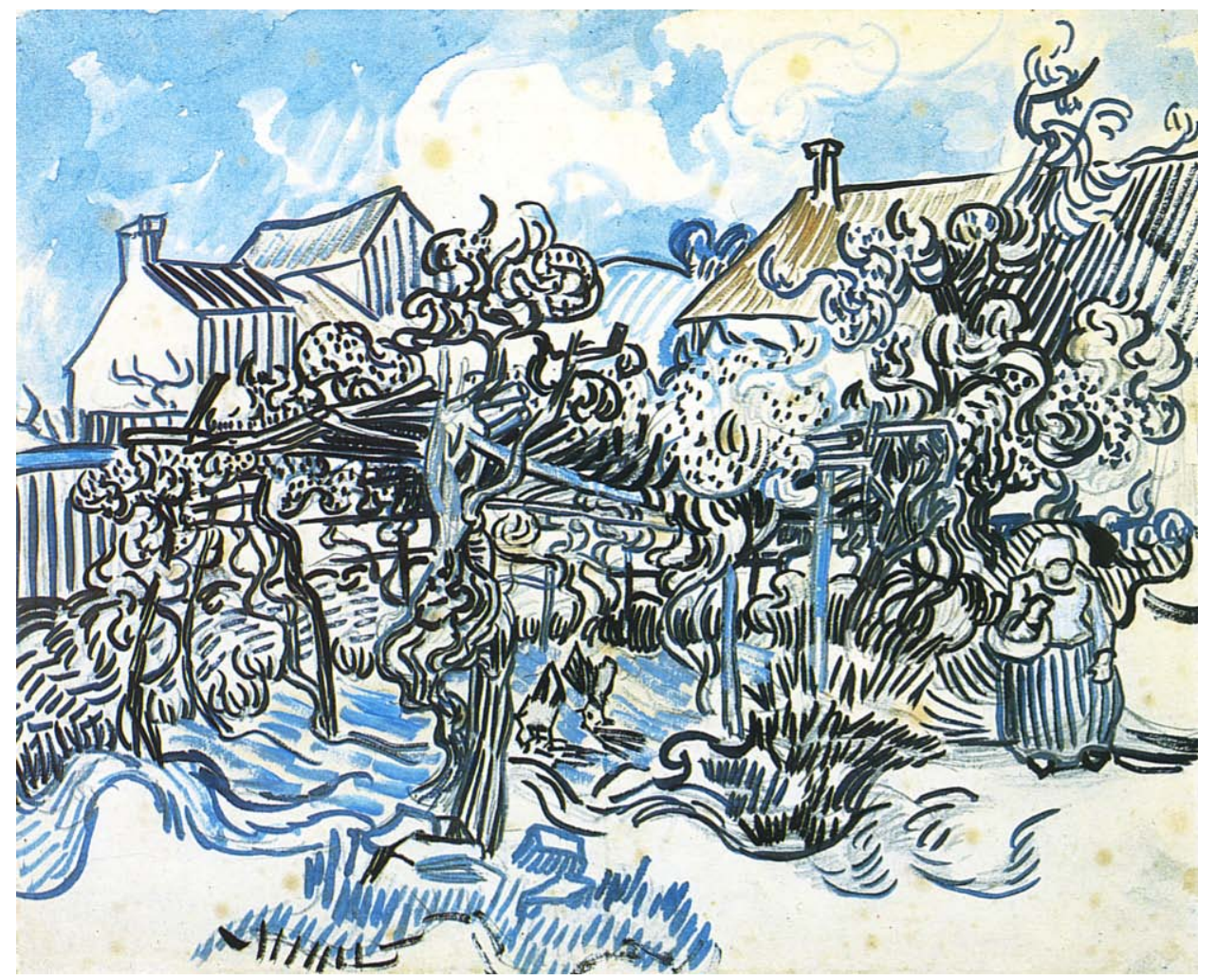

Figure 54. Old Vineyard with Peasant Woman

Pickvance, R. (1986) Van Gogh in Saint-Rémy and Auvers.

Metropolitan Museum of Art: N.Y, N.Y. p.224

These two drawings, Cottages with Thatched Roofs and Old Vineyard with

Peasant Woman, represent something new and different in the oeuvre of Vincent van Gogh. Pickvance compares these to his Saint-Rémy style, by saying "with an emphatic and expressive brush, van Gogh was more apt to generalize, creating swirling, rhythmic patterns, curvilinear and self-willed, coarser and more brutal than the Saint-Rémy style. This viewer observes the increase in unnatural qualities as the most obvious change from his Saint-Rémy style, unnatural coloristic conventions, inaccurate depictions of rooflines, 
and linear configurations that begin to dominate the visual expression. The increase in unnatural qualities may mirror mental decline in the status of Vincent van Gogh at this time. The limited color palette is likely indicative of Vincent's depressed mood when he first moved to Auvers.

\section{Paintings of Two Country Houses in Auvers}

Within days of his arrival at Auvers, Vincent wrote to Theo: "I find the modern villas and the middle-class country houses almost as pretty as the old thatched cottages which are falling into ruin” (LT 636). The House of Père Pilon, one of the modern villas, may have been painted as early as May 24, 1890. The large chestnut tree that partially obscures the view of the house is depicted in flower and is comparable to two other paintings of flowering chestnut trees that were completed by May 23. The dark and turbulent sky, painted with a halo effect, may show the wet and stormy weather of Saturday May 24 and Sunday May 25. These two elements, the flowering chestnut tree and the dark sky have prompted Pickvance to date this picture to between May 23 and 25 1890 (226).

The House of Père Pilon may be characterized by an elegant simplicity. The elements that make up the composition have been simplified and are somewhat abstracted and generalized. Although the view of the receding street draws the eye to the center ground, on the left of the painting, the views of gables seen head-on return the eye to the mid-point. The House of Père Pilon is painted in a quiet, calm and serene manner. House of Père Pilon is one of a pair, along with Village Street and Stairs with Figures, but the line quality varies greatly between the two paintings. House of Père Pilon has primarily straight and angular lines with just an area of curvy lines in the street, 
while the reverse is true of Village Street and Stairs with Figures which has mostly curvilinear lines and sharp angles only in the house in the background. Semiotics, the science of signs, according to Kristeva (1980, 3 \&19), designates that a writer works with and within language, and in like manner an artist works with and within the formal elements. Vincent van Gogh manipulated the formal elements in both conscious and unconscious ways. The conscious manipulation of formal elements is related to the symbolic and deals with artistic decisions about position and judgment. On the other hand, the unconscious is more akin to the semiotic, like automatic writing or production of art.

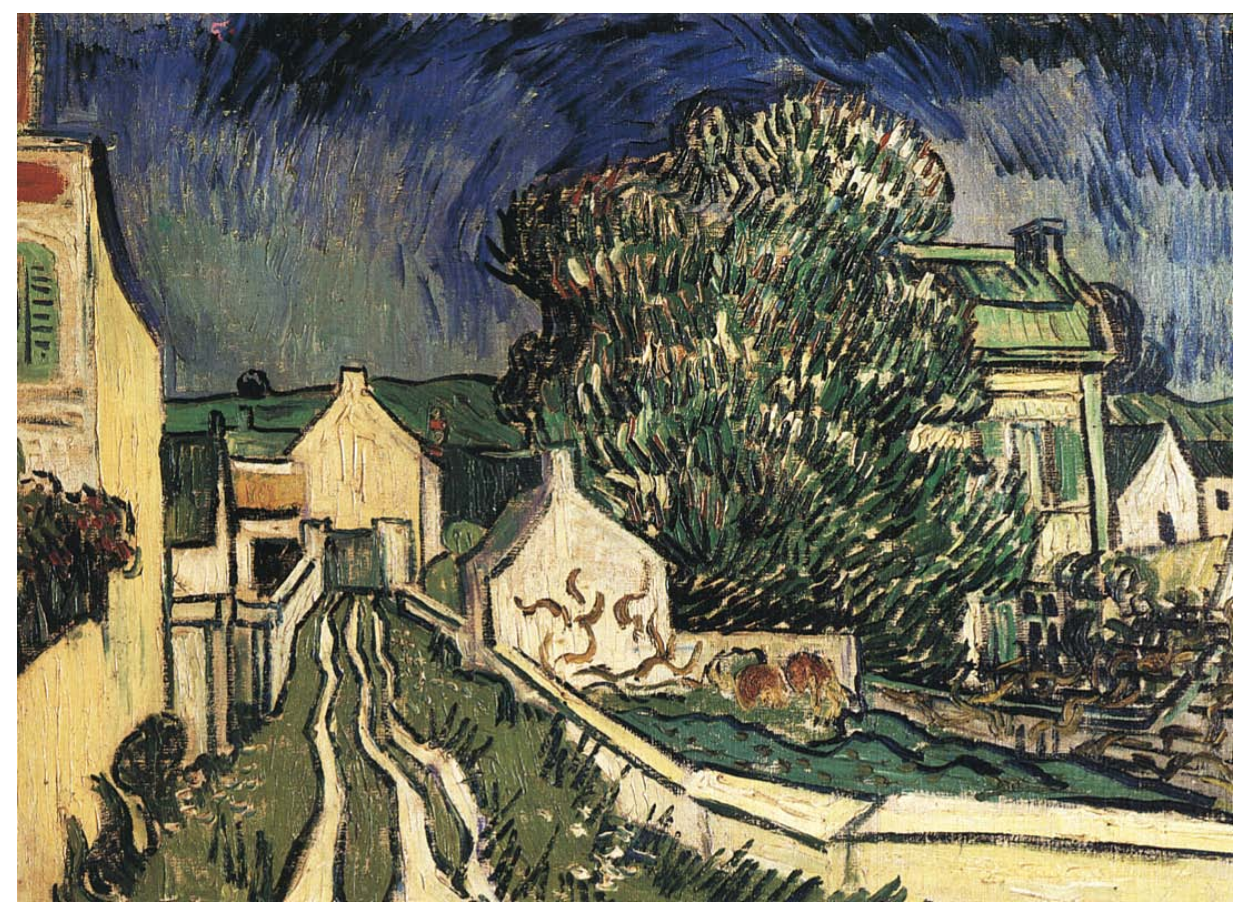

Figure 55. House of Père Pilon

Pickvance, R. (1986) Van Gogh in Saint-Rémy and Auvers.

Metropolitan Museum of Art: N.Y, N.Y. p.227 
Village Street and Stairs with Figures is similar in size and format to The House of Père Pilon and the two may have been intended as a pair even though there are profound differences between them. Village Street and Stairs with Figures is sinuous and wavy, while The House of Père Pilon is angular and geometric. The pairing of sinuous and wavy with angular and geometric is another example of van Gogh's tendency to put bipolar type opposites together. The visual element in common in these two paintings is the cart tracks that snake upward in both pictures, more distant in The House of Père Pilon and up close in Village Street and Stairs with Figures. This is like a free association on one element, or a dream image where one element is consistent, but that it visually changes and emerges. This interpretation of free association and dreamlike images is consistent with the elements of unreality in Village Street and Stairs with Figures. Instability is noted in the curving walls, the wavy, unsteady stairs, and rather strange changes in level shown by a steeply upward perspective and very little sky.

(See Figure 56 on the next page). 


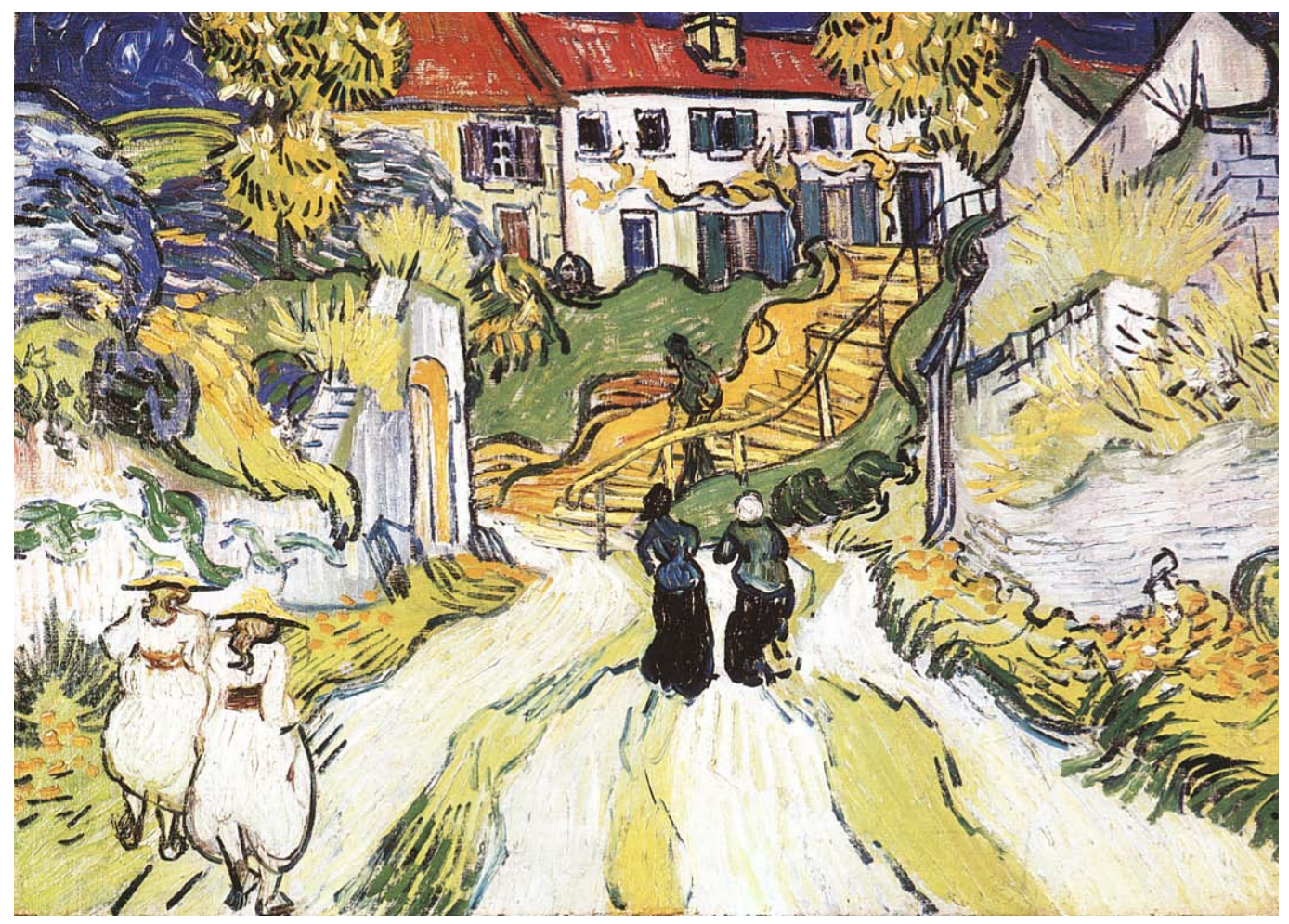

Figure 56. Village Street and Stairs with Figures

Pickvance, R. (1986) Van Gogh in Saint-Rémy and Auvers.

Metropolitan Museum of Art: N.Y, N.Y. p.228

The pairing of The House of Père Pilon and Village Street and Stairs with Figures may be related to the new physics in which light is understood as both a wave and a particle. In 1905 Albert Einstein proposed that light could exist in the form of a particle, that is a small piece of something called a photon, but for over two hundred years, light had been experimentally proven to be a wave (Schlain, 22). Einstein’s premise implied that light had two distinct and seemingly opposing natures, a wave-like aspect and a particle-like aspect. It was not until 1926 that Niels Bohr synthesized the two opposing 
views of light into one, the theory of complementarity. Bohr's theory said that light was not either a wave or a particle, but that it was both a wave and a particle. In scientific experiments, light has appeared both as a wave and a particle. Werner Heisenberg took Bohr's ideas a step further by saying, “The common division of the world into subject and object, inner world and outer world, body and soul, is no longer adequate...” (Schlain, 23). The new physics says that observer and observed are somehow connected and that the inner and subjective world is intimately conjoined with the external of objective facts. These two paintings, The House of Père Pilon and Village Street and Stairs with Figures seem to visually express the previous sentence. The House of Père Pilon with its geometric precision is like light as a particle, like a laser beam, which is a particle focused through space, except for the curiously snakelike cart tracks. Village Street and Stairs with Figures, on the other hand is like light as a wave, where all appears in flux, slip-sliding, curving and unstable except for the solid horizontals of the house in the center background that gives the picture stability. The curving cart tracks are the touchstone that unify the two pictures, along with the theory of complementarity which unifies and locks these two opposites into one complete expression. The thesis of Leonard Schlain's book, Art and Physics, is that art precognitively anticipates science. These two paintings by Vincent van Gogh, The House of Père Pilon and Village Street and Stairs with Figures, may be interpreted as precognitively anticipating the debate of light as a wave and light as a particle. The concept of complementarity suggests a bipolar quality in all of life.

The Church at Auvers

The Church at Auvers was one of the paintings that would be displayed near the coffin at the funeral of Vincent van Gogh. This village church was given monumental 
treatment and painted as though it might be a cathedral, but the inclusion of the figure of a woman walking nearby gave a sense of scale. The tonality of the painting is bold and dark with the building silhouetted against a deep cobalt sky. The partly orange roof against the blue of the sky produced the complementary color scheme that is so often a feature of the artwork of Vincent van Gogh. The roofline looks unstable as it seems to curve with an unnatural looking waviness. Curves are repeated in the path that bifurcates and winds its way around the church. Another conjunction of opposites is observed in the solidity of the building against the instability of the rooflines.

Kristeva speaks of a signifying practice (in modern literature), and she advocates breaking down the barriers that isolate related disciplines from one another. Sound textual analysis has to consider both the subject and the historical context in order to discern meaning. By the time that Vincent painted The Church at Auvers, he had long since moved away from his much earlier hyper-religious phase, and he viewed the church as an institution that was mostly irrelevant to his personal spirituality. Therefore, the question becomes, how does Vincent express his viewpoint toward the church in his painting? The Auvers church building seems isolated, dominating, imposing and rather ominously poised under a threatening Prussian blue sky, and it somehow reminds this author of an owl perched on a branch, a wise, all-seeing, ominous, but largely ignored solitary sentinel. This impression of starkness is moderated by the inclusion of a reddish-orange color on the roof and a lighter foreground that includes a human figure. Despite its seeming solidity, the edifice has a wavery quality and seems not quite substantial due to an unexpected curviness in the rooflines. This ancient and time-honored institution that is the 
church seems to be empty and standing alone, a reminder of its previous importance, but now wobbling and losing its grip in modern society of van Gogh’s time.

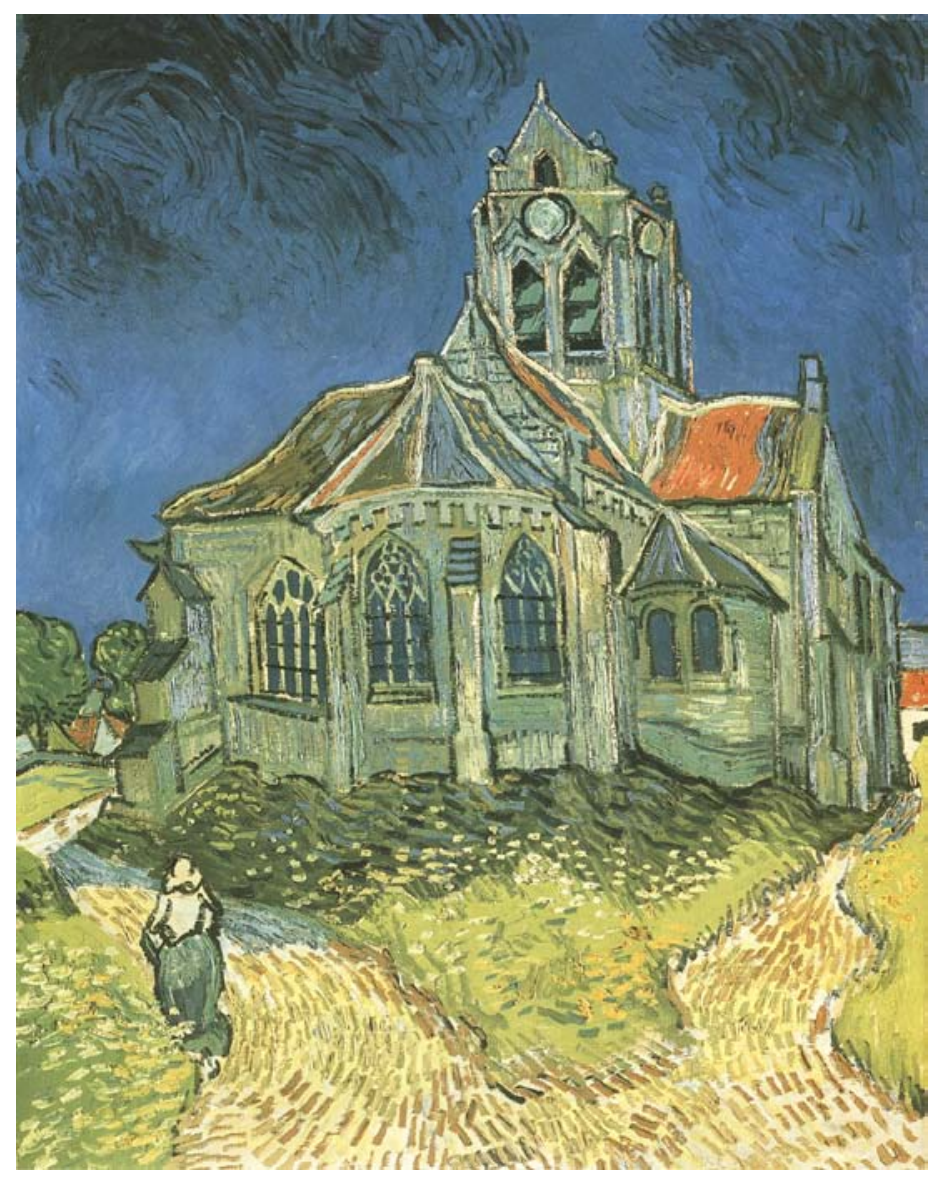

Figure 57. The Church at Auvers

Stein, S. (1986) Van Gogh, A Retrospective.

Hugh Lauter Levin Assoc, Inc.: China. p.323

\section{Dr. Gachet}

Dr. Gachet was an unconventional person, a medic who painted in his spare time and loved art. The doctor had a yellow face with many folds, and life had brought him all kinds of troubles against which he struggled with his unconventionality (Meier-Graefe, 132). Dr. Gachet declared that Vincent suffered from no organic disease, that his troubles 
were nothing but the foibles of an artist, for which no medicine existed (ibid.). This idea fostered the concept of the crazy artist, that creativity and madness were not far apart. That idea has so taken hold of the public psyche that even today there is at least one major annual scholarly conference called Creativity and Madness, Psychological Studies of Art and Artists. This conference is devoted to understanding creative as well as maladaptive responses to life stresses. Kristeva considers art and music as revolutionary poetic responses to the semiotic state, when chaos is converted to order by way of the artistic and creative impulses. When Vincent van Gogh cut off a portion of his ear in Arles, that was a maladaptive response to life stresses, but when he painted Self-Portrait with a Bandaged Ear, his response was creative and transcendent. The Creativity and Madness conference illustrates what we all know to be true, that pain and turmoil do not always result in disability and disease, but can lead to the triumph of the human spirit that we call creativity (Creativity and Madness conference brochure, August, 2003). In his assessment of creativity and madness, Dr. Gachet was wrong; genius was the exact opposite of lunacy and even an ordinary artisan needed a cool brain (Meier-Graefe, 132).

Dr. Gachet had several things going on at the same time, his consultations in Paris, his painting in Auvers, homeopathy and allopathy, literature and angling, boating and the education of his children (Pickvance, 1986, 195). Dr. Gachet was well known for an elixir that he developed for its curative properties. This elixir of Dr. Gachet, a marvelous water that he invented, was reputed to cure all kinds of illnesses, a panacea for both men and beasts, for sprains, cuts, open wounds, etc. and he did not sell it; he gave it away thus making him very popular (ibid.). 
When Vincent van Gogh met Dr. Gachet, his impression was that he was, "rather eccentric, but his experience as a doctor must keep him balanced enough to combat the nervous troubles from which he certainly seems to me to be suffering at least as seriously as I,” and Vincent went on to say, Gachet’s house “is full of black antiques, black, black, black, except for the impressionist pictures (Pickvance, 1986, 197). Even though Dr. Gachet was wrong about genius and lunacy, he was not wrong about the state of Vincent's physical health which appeared to be very satisfactory when he moved to Auvers. Theo’s wife Johanna had noticed that her brother-in-law seemed in good health when he visited them in Paris on the way to Auvers. Vincent van Gogh seemed to have left his disease behind him in the South (Meier-Graefe, 132). However, the evidence of the visual elements in his works from Auvers may bespeak a darker reality.

Portrait of Dr. Gachet

When visiting the home of Dr. Gachet on Sunday, June 1, 1890, almost certainly this is when Vincent began work on the Portrait of Doctor Gachet (Pickvance, 1986, 202). He discussed Dr. Gachet’s portrait when he wrote to Theo on June 3, 1890: “I am working at his portrait, the head with a white cap, very fair, very light, the hands also a light flesh tint, a blue frock coat and a cobalt blue background, leaning on a red table, on which are a yellow book and a foxglove plant with purple flowers” (LT 638). The color composition of the portrait of Dr. Gachet was consciously selected by Vincent van Gogh in order to enhance and express the emotional content of the picture. "What impassions me most much, much more than all the rest of my métier-is the portrait, the modern portrait. I seek it in color, and surely I am not the only one to seek it in this direction. I should like - mind you, far be it from me to say that I shall be able to do it, although this is what I am aiming 
at - I should like to paint portraits which would appear after a century to the people living then as apparitions. By which I mean that I do not endeavor to achieve this by a photographic resemblance, but by means of our impassioned expression - that is to say, using our knowledge of and our modern taste for color as a means of arriving at the expression and the intensification of the character. Thus, the portrait of Dr. Gachet shows you a face the color of an overheated brick, and scorched by the sun, with reddish hair and a white cap, surrounded by rustic scenery with a background of blue hills; his clothes ultramarine - this brings out the face and makes it paler, notwithstanding the fact that it is brick-colored. His hands, the hands of an obstetrician, are paler than the face. Before him, lying on a red garden table, are yellow novels and a foxglove flower of a somber purple hue" (W22).

The foxglove and the two yellow novels lend themselves to a symbolic interpretation. The sprig of foxglove in a glass alludes to Dr. Gachet's profession of practicing homeopathic medicine, in that Digitalis for the treatment of heart disease is derived from foxglove. The two yellow novels, Germinie Lacerteux (1864) and Manette Salomon (1867-68), both by the Goncourt brothers, signify aspects of modernity, one a study of neurosis and the other of the Parisian milieu at mid-century (Pickvance, 1986, 232). Vincent van Gogh’s Portrait of Dr. Gachet exemplifies Kristeva’s symbolique with its specific and symbolic references within the artistic representation.

There is a second and very similar version of the portrait of Dr. Gachet. Pickvance 1986, 233) states that van Gogh did not discuss the second version, but that according to Dr. Gachet's son , it was executed in two sittings on June 6 and 7. In the second portrait of Dr. Gachet, the color areas are flatter and the composition has been simplified. The 
primary differences are that there are no buttons on Gachet's coat, no novels on the table, and there is no glass, the foxglove lies on the table. Some speculation has been leveled at this painting that it may have been a forgery. Gachet made several copies of this painting, as well as others in his collection and he also had copies of the collection painted by his “students" (Bendheim, 345). The original, famous portrait of Dr. Gachet increased from a value of \$58 in 1897 to $\$ 82,500,000$ approximately one hundred years later in 1990 .

Vincent compared the emotional content of the pose thus: "It has the same sentiment as the self-portrait that I brought with me when I left for this place” (LT 638). He also compared the Portrait of Dr. Gachet to L'Arlésienne, recognizing that both paintings are in the traditional pose of melancholia, but while L'Arlésienne is simply retrospective and quiet in tone, Dr. Gachet’s portrait seems despairing and depressed. Writing to his sister Wil, Vincent described the expression of Dr. Gachet in the portrait, "with an expression of melancholy, which would look like a grimace to many who saw the canvas. And yet it is necessary to paint it like this, for otherwise, one could not get an idea of the extent to which, in comparison with the calmness of the old portraits, there is an expression in our modern head, and passion - like a waiting for things as well as a growth. Sad and yet gentle, but clear and intelligent - this is how one ought to paint many portraits” (W23). To Paul Gauguin, writing on June 16, he said that he had painted Gachet with "the heartbroken expression of our time" and that like Gauguin's Christ in the Garden of Olives, "it was not destined to be understood" (LT 643). 


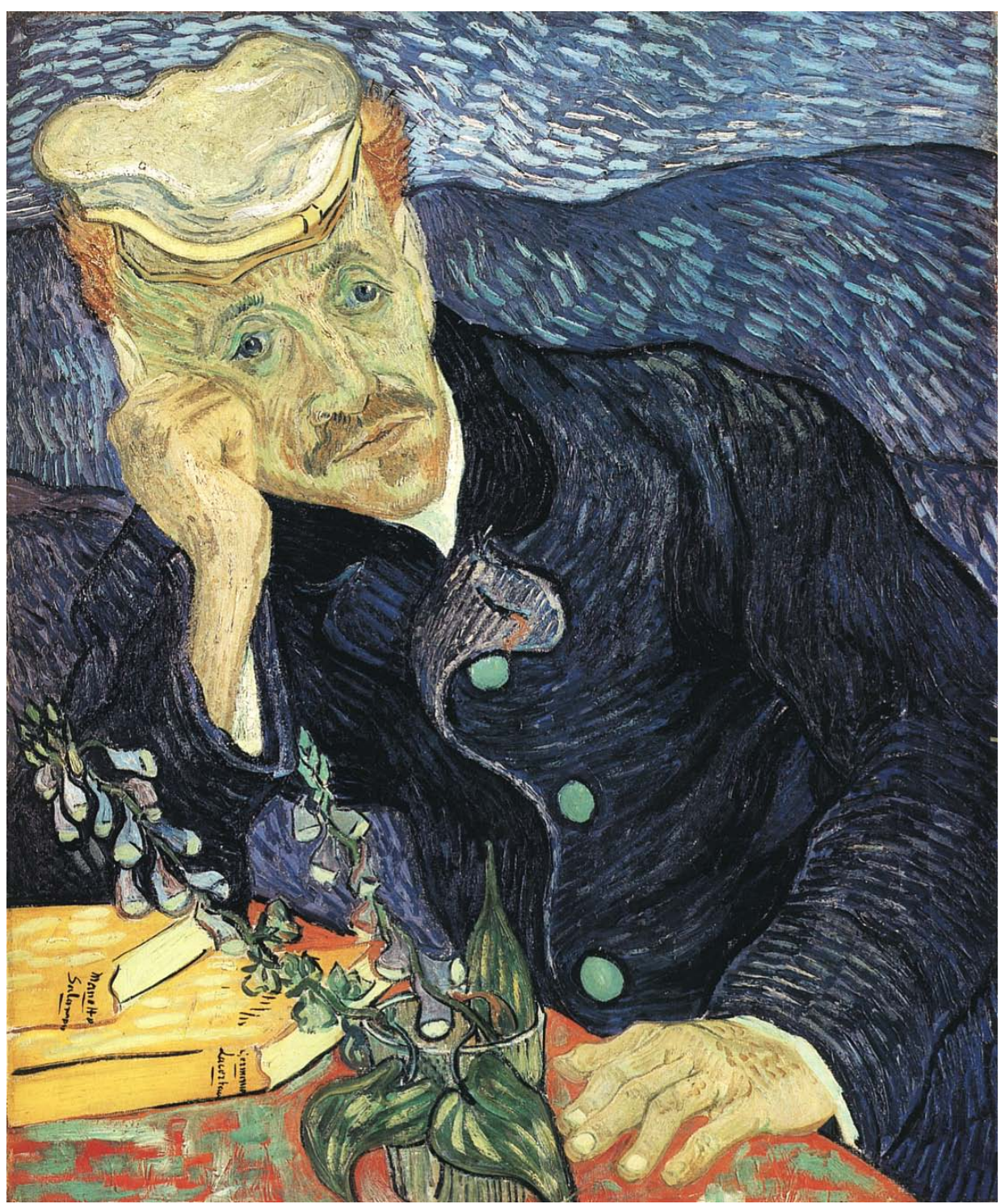

Figure 58. Portrait of Dr. Gachet

Pickvance, R. (1986) Van Gogh in Saint-Rémy and Auvers.

Metropolitan Museum of Art: N.Y, N.Y. p.228

Suffering and Illness

In LT 636 and 637, Vincent discussed his illness. He said "I can do nothing about my disease. I am suffering a little just now- the thing is that after that long seclusion the 
days seem like weeks to me. I felt that in Paris and here too, but serenity will come as my work gets on a bit” (LT 636). Continuing in LT 637 Vincent compared himself to Dr. Gachet saying, "He seems very sensible, but he is as discouraged about his job as a doctor as I am about my painting. Then I told him that I would gladly swap jobs with him. Anyway, I am ready to believe that I shall end up being friends with him. He said to me besides that if the melancholy or anything else became too much for me to bear, he could easily do something to lessen its intensity, and that I must not feel awkward about being frank with him. Well, the moment when I need him may certainly come, however up to now all is well. And it may yet improve, I still think that it is mostly a disease of the South that I have caught and that returning here will be enough to dissipate the whole thing."

One can only speculate as to the type of intervention Dr. Gachet had in mind, for even today treatment for depression is not so easy and it involves a combination of medication and therapy. Both Dr. Gachet and Vincent presented a positive attitude toward the illness and treatment. In LT 638 of June 4, 1890, Vincent further assessed the emotional state of Dr. Gachet saying, "He certainly seems to me as ill and distraught as you or me, and he is older and lost his wife several years ago, but he is very much the doctor, and his profession and faith still sustain him.”

Writing in Dutch to his mother, in LT 639, Vincent discussed his reasons for leaving the South, "I did not intend to return to Paris so soon; I should have stayed in Saint-Rémy another year if I had not attributed my last attack partly to the influence which the illness of others had on me, for which reason I decided it was time to change my surroundings if I wanted to keep my energy, such as it is, and what I have left of common sense." Vincent noted that distractions had "a favorable effect in so far as the symptoms of 
the disease, which are a sort of thermometer, have quite disappeared these days - though as I have learned, one must not count too much on this.” He described Dr. Gachet as very nervous and speculated that he had not improved since his wife's death. Despite the distractions of other patients at Saint-Rémy and his own difficulties with a depressed mood, Vincent said that he had worked from morning till night without stopping during the last two to three weeks that he was in Saint-Rémy, and he continued on to say that he started working right away when he got to Auvers.

A Visit from Theo, Jo, and the Baby

After Theo, Jo and the baby had come to visit Vincent in Auvers, he wrote to them on June 10 with his concern that his furniture still had not arrived. He felt that he must consider it lost, saying that his friends with whom he had left his belongings probably would not put themselves out to send them to him. On that same day, Vincent wrote to the Ginoux asking them to send his belongings and offering to reimburse them all of the expenses that they might incur. He expressed sympathy for the injury that Mme Ginoux had suffered and encouraged that she not be involved with the packing and moving of his belongings. He set a date requesting that they send his things on Saturday and reminded them that he was anxiously awaiting his furniture.

In LT 640a, which was addressed to My dear friends Ginoux, Vincent gave a general assessment of his functioning at Saint-Rémy by saying, “...I had contracted the other patient's disease to such an extent that I could not be cured of mine. The other patient's society had a bad influence on me, and in the end I was absolutely unable to understand it. Then I felt I had better try a change, and for that matter, the pleasure of seeing my brother, his family and my painter friends again has done me a lot of good, and 
I am feeling completely calm and normal. The doctor here says that I ought to throw myself into my work with all my strength, and so distract my mind.” In this same letter, he noted that his work had improved since he stopped drinking, "it is a certain fact that I have done better work than before since I stopped drinking...”

When he was at Auvers, Vincent van Gogh was once again on the verge of recognition during his own lifetime. Continuing on in LT 640a, he mentioned that articles had been written about his pictures, “...Once in a Paris newspaper, and the other time in a newspaper in Brussels...” where he had had an exhibition and also that “...there was an article in a paper of my native country, Holland, and the consequence was that many people went to look at my pictures.” A degree of anxiety was revealed in the responses of Vincent van Gogh to publicity about his painting. "Please ask M. Aurier not to write any more articles on my painting, insist upon this, that to begin, he is mistaken about me, since I am too overwhelmed with grief to be able to face publicity. Making pictures distracts me, but if I hear them spoken of, it pains me more than he knows.” In the postscript of LT629a, Vincent wrote to his mother and sister, “As soon as I heard that my work was having some success, and read the article in question, I feared at once that I should be punished for it; this is how things nearly always go in a painter's life: success is about the worst thing that can happen.” These statements seem to indicate a certain level of paranoia, a fear of success, and perhaps a tendency toward superstition.

An unfinished letter to Paul Gauguin was found among the papers of Vincent van Gogh. From September 1889 through December, a benefactor named de Haan was supposed to have been Gauguin's sole financial support, but Theo wrote to Meyer de Haan on December 13, 1889, “If I hadn’t helped him (i.e. Gauguin) with the necessities these 
last three months, and paid for everything, he would literally have starved, for he hasn't had a penny since September.” (Complete Letters, V.3, 283) Vincent had met de Haan and entertained the possibility of going to Brittany to stay with Gauguin and de Haan.

\section{A Still-Life from Auvers}

When Vincent wrote to Theo on June17, 1890, he discussed several pieces of his artwork. In particular he mentioned the portrait of the Arlésienne that he had painted modeled after the one of the same subject by Gauguin. He discussed two studies that he had in process at the time, "one a bunch of wild plants, thistles, ears of wheat, and sprays of different kinds of leaves - the one almost red, the other bright green, the third turning yellow. He also mentioned a second study, a white house among trees, with a night sky and an orange light in the window and dark greenery and a note of somber pink," and a study that he had done of Daubigny’s house and garden and his plans to do a more important canvas of that subject.

Wild Flowers and Thistles in a Vase is the only documented example of a still life from Vincent's time in Auvers (Pickvance, 240). Because he had run through his supply of canvas, Wild Flowers and Thistles in a Vase was painted on a red-striped linen hand towel as was his first study of Daubigny's garden (ibid.) The precise description of the leaves, "almost red, bright green, turning yellow" leaves little question that this is the painting referred to in LT 642. This is a fairly straightforwardly presented still-life except for one curious feature. There is a strange convergence of black lines that seem irrelevant to the composition, a bold black horizontal that connects to an ear of wheat, and a black inverted $\mathrm{V}$ above the large red flower. They could form the outline of a mountain or the peak of the gable of a house. It is as if another reality began to emerge and did not become 
fully formed. In Wild Flowers and Thistles in a Vase the strangely out of place black composition looks like what Kristeva would call a semiotic breakthrough or the emergence of another reality.

(See Figure 59 on the next page.) 


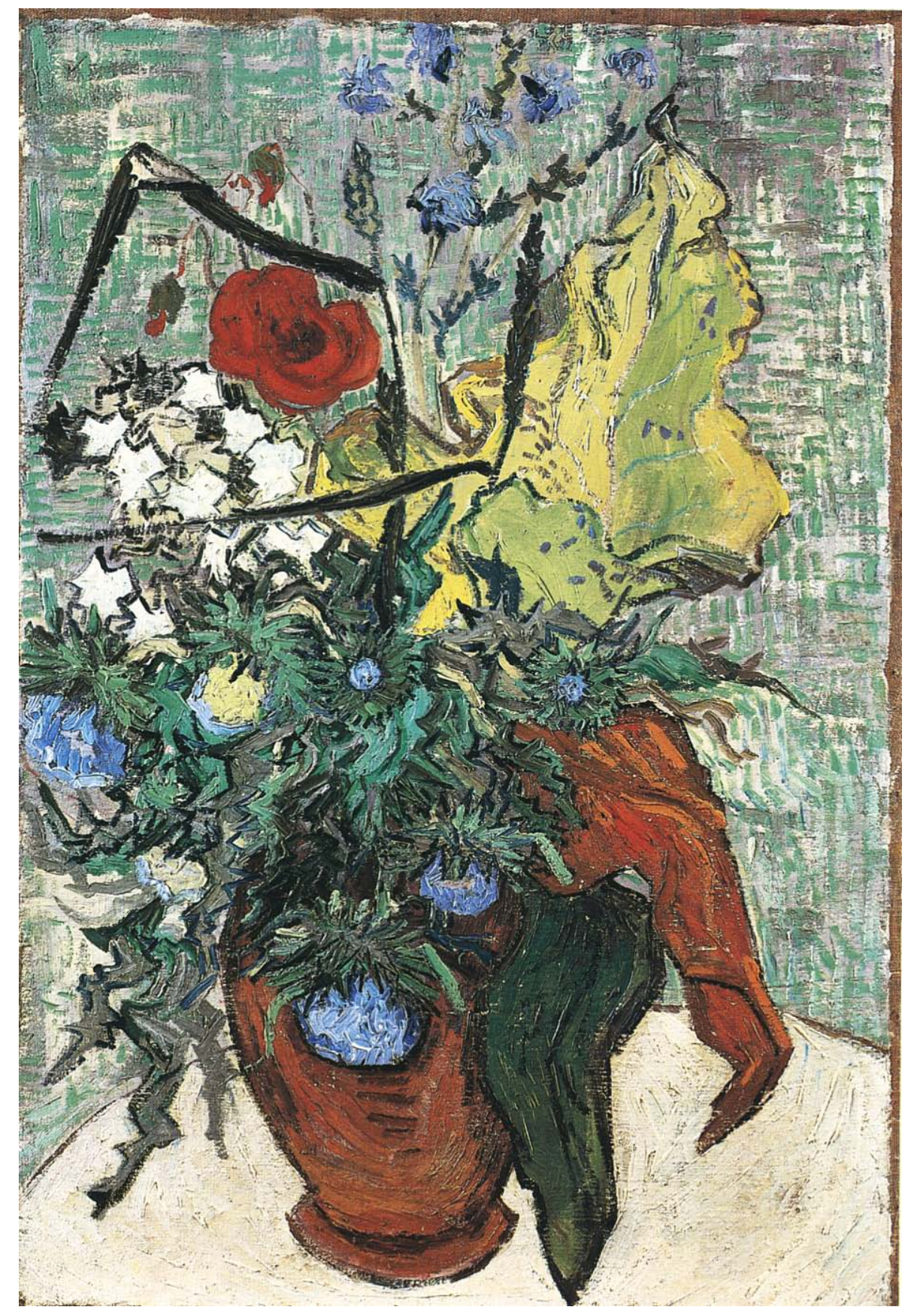

Figure 59. Wild Flowers and Thistles in a Vase

Pickvance, R. (1986) Van Gogh in Saint-Rémy and Auvers.

Metropolitan Museum of Art: N.Y, N.Y. p.241 


\section{L'Arlésienne}

The portrait of L'Arlésienne was based upon Gauguin's drawing of the same. In an unfinished letter to Gauguin, Vincent said "I tried to be religiously faithful to your drawing, while nevertheless taking the liberty of interpreting through the medium of color the sober character and style of the drawing in question.” (LT643) Vincent saw this portrait as a double synthesis, firstly expressing and summing up the qualities of the women of Arles, and secondly as a tangible remembrance of the time that he and Paul Gauguin had spent painting together in Arles. He even suggested a type of joint ownership by saying that it was a work, "belonging to you and me as a summary of our months of work together.” It is apparent that Vincent invested a great deal of time and effort into L'Arlésienne, as he said that he paid for it with another month of illness. He felt that Gauguin would immediately connect emotively and understand the sentiment involved in the painting. Vincent was also concerned about Dr. Gachet’s response to L’Arlésienne. The doctor's response was to immediately recognize that it was the synthesis of a type, and he said, "How difficult it is to be simple" (LT 643). Vincent felt confident that the doctor would let him etch L'Arlésienne, and then it could be published more widely. Vincent indicated that he would like to focus on painting more portraits, and that he would like to place them "against a very vivid yet tranquil background." (ibid.)

\section{Dissociation}

LT 644 of June 24 has a curiously dissociated paragraph where Vincent discussed himself and his work as if an observer, "The Dutchman works quite diligently, but he still has quite a few illusions about the originality of his way of seeing things," then continuing on, he said "...If he has money, then certainly he does well to paint, but if he has to 
intrigue a lot to make sales, I pity him because he does paintings and the others because they buy them at a relatively excessive price. He will get there though, if only he works diligently every day. But alone or with painters who work little, he won't come to much, I think.” (LT 644)

\section{Combinations and Permutations}

There is a holistic quality to the thinking of Vincent van Gogh that seems to be connected to his mysticism. Sometimes he sees combinations that others might find curious. In the artwork of Vincent van Gogh, completions are often achieved by the union of pairs of opposites. This is similar to the balance of the yin-yang symbol. He often considers a horizontal canvas flanked by a vertical one to be a pair. This could be seen as a symbolic expression of the cross, in which completion is found in the combination of a vertical and a horizontal crossbeam. The vertical member of a cross is symbolic of the connection of earth to heaven, man to God, or man to the great unknown. The horizontal crossbeam, on the other hand, bespeaks the connection of human to human and the interconnectedness of persons and things on the earthly plane of existence. The separation of the crossbeams into dismembered horizontal and vertical entities may be symbolic of the way his Christianity had become separated from his life. His mysticism came to find expression in nature and art rather than in organized religion.

Juxtaposition of colors is a further way that Vincent expresses a holistic vision. Color schemes are often consciously chosen complimentary colors that both oppose and complete one another. Vincent perceived and expressed an essential interconnectedness of art and nature, as of portraits paired with landscapes. 
LT 645 contains discussion of the portrait of Marguerite Gachet. Van Gogh saw it as a pendant to a horizontal canvas of wheat, the connection being made in terms of the colors used, "I have noticed that this canvas goes very well with another horizontal one of wheat, as one canvas is vertical and in pink tones, the other pale green and greenishyellow, the complementary of pink; but we are far from the time when people will understand the curious relation between one fragment of nature and another, which all the same explain each other and enhance each other.”

\section{Portrait of Marguerite Gachet}

Vincent van Gogh’s portrait of Marguerite Gachet, Marguerite Gachet at the Piano was painted on or about June 26 or 27 according to LT 645. A complementary color scheme was selected with her dress being of pale pinkish tone and the wall in the background a green with orange dots. Vincent described the carpet as "red with green spots," but the green in the carpet is composed of vertical brushstrokes that are much larger than spots. Similar, but slightly longer brushstrokes were used to model the dress. Marguerite Gachet at the Piano seems to be the straightforward expression of a portrait from van Gogh’s Auvers period. Marguerite Gachet at the Piano shows Vincent's admiration for the sitter and it is representative of Kristeva's symbolic level.

(See Figure 60 on the next page.) 


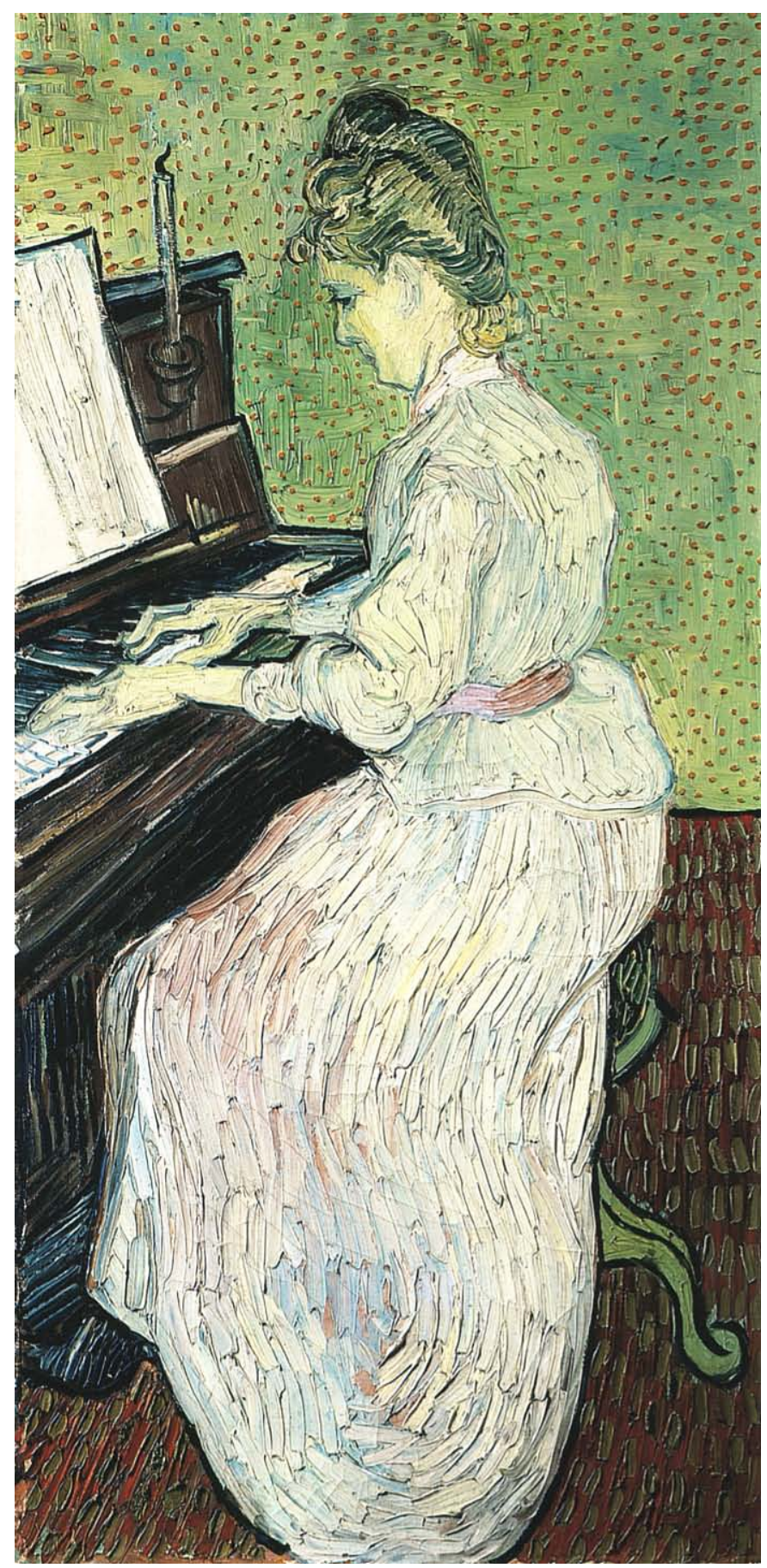

Figure 60. Marguerite Gachet at the Piano

Pickvance, R. (1986) Van Gogh in Saint-Rémy and Auvers.

Metropolitan Museum of Art: N.Y, N.Y. p.266 
Wheatfields as a Pendant to the Portrait of Marguerite Gachet Wheatfields was originally considered as a pendant to Undergrowth with Two Figures, but after completing the portrait Marguerite Gachet at the Piano, Vincent reconsidered his original idea. Perhaps the new idea of pairing Wheatfields with Marguerite Gachet at the Piano seems at first to be a curious notion, but the dark tones in the piano do nicely compliment the dark areas in the Wheatfields. The complementarity of close-up and far away along with indoor and outdoor as an expression of holistic thinking is seen in this pairing. The portrait is a close-up indoor view while the Wheatfields steps back to provide an expansive outside overview. These two paintings further express a holistic view with the semiotic expressed in a landscape scene paired with the symbolic expression in the portrait. And Vincent was fond of pairing paintings one with a vertical and one with a horizontal orientation.

Wheatfields provides an extensive panorama view that unfolds with various fields and areas depicted in coloristic and textural variety. The plain unfolds "as if by sleight of hand” (Pickvance, 259). Texture, brushstrokes and color are used to model the various areas of the wheat fields and a few dark areas of trees on the horizon punctuate the skyline and solidly anchor the concept of this painting. In this pair of paintings, Wheatfields and Marguerite Gachet at the Piano, there is none of the tentativeness and wavery quality that was seen in Cottages with Thatched Roofs and Old Vineyard with Peasant Woman.

(See Figure 61 on the next page.) 


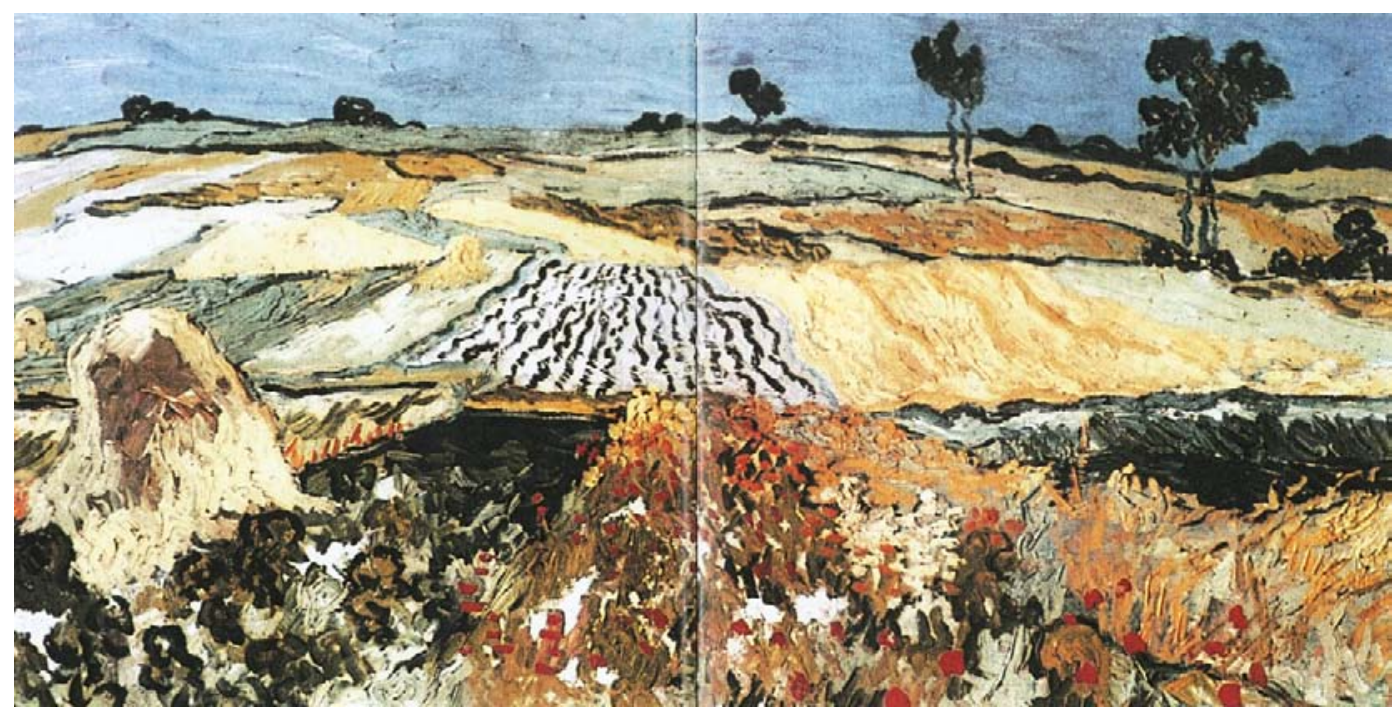

Figure 61. Wheatfields

Pickvance, R. (1986) Van Gogh in Saint-Rémy and Auvers.

Metropolitan Museum of Art: N.Y, N.Y. p.259

\section{Bank of the Ôise at Auvers}

Vincent van Gogh only did one oil painting of the river, Bank of the Ôise at

Auvers, and it dates from July 1890. After a lifelong fascination with peasants and workers this picture is different in that it depicts leisure. One woman is in a boat and the other one is fishing. The lone male figure is standing on the shore in close proximity. This viewer interprets the male figure as a self-image of the artist. Two unusual things are noted by this author concerning the modeling of this male figure. The genital area of the male figure is either painted out or emphasized by horizontal white brush strokes. His finger is pointing to the ground and has the configuration of a gun. In one month's time Vincent van Gogh will be buried in the ground to which he is pointing after ending his life with a self-inflicted gunshot wound. Schlain would interpret this as a precognitive gesture on the part of Vincent van Gogh. Kristeva would see this as a semiotic breakthrough. 


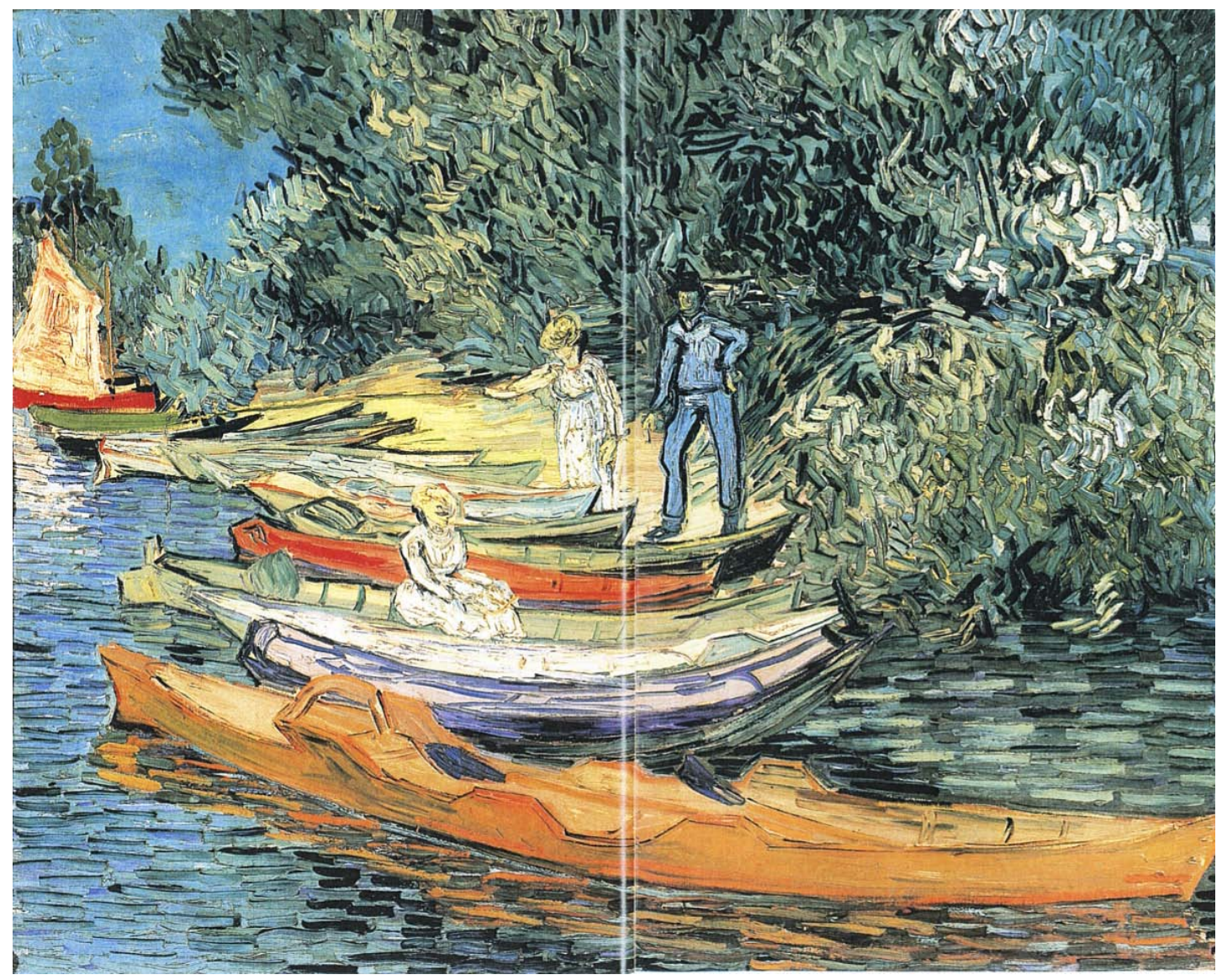

Figure 62. Bank of the Ôise at Auvers

Pickvance, R. (1986) Van Gogh in Saint-Rémy and Auvers.

Metropolitan Museum of Art: N.Y, N.Y. p.24

\section{Practicalities}

In LT 648, Vincent discussed the uncertainty of his financial arrangement with Theo, he hoped that the arrangement remained the same as in Saint-Rémy, 150 francs a month paid in three installments. But the agreement had not been discussed prior to Vincent leaving for Auvers. There was a lot of uncertainty, in that Theo was considering giving up his job and setting out on his own. There was also uncertainty about Vincent's 
caregiver situation, "I think we must not count on Dr. Gachet at all. First of all, he is sicker than I am, I think, or shall we say just as much, so that's that. Now when one blind man leads another blind man, don’t they both fall into the ditch?” Vincent continued with his discussion of his malady and mentioned his last attack at Saint-Rémy, "Certainly my last attack, which was terrible, was in a large measure due to the influence of other patients, and then the prison was crushing me, and old Peyron didn’t pay the slightest attention to it, leaving me to vegetate with the rest, all deeply tainted.” (LT648) A tone of depression crept into the latter part of this letter, "I am trying not to lose my skill. It is the absolute truth, however, that it is difficult to acquire a certain facility in production, and by ceasing to work, I shall lose it more quickly and more easily than the pains it has cost to acquire it. And the prospect grows darker, I see no happy future at all.”

The depressed tone continued in LT 649, “Jo’s letter was really like a gospel to me, a deliverance from the agony which had been caused by the hours I had shared with you which were a bit too difficult and trying for us all. It was no slight thing when we all felt our daily bread was in danger, no slight thing when for reasons other than that we felt our means of subsistence were fragile. Back here, I still felt very sad and continued to feel the storm which threatens you weighing on me too. What was to be done - you see, I generally try to be fairly cheerful, but my life is also threatened at the very root, and my steps are also wavering. I feared - not altogether but yet a little, -that being a burden to you, you felt me to be rather a thing to be dreaded, but Jo's letter proves to me clearly that you understand that for my part I am as much in toil and trouble as you are. There - once back here I set to work again - though the brush almost slipped from my fingers, but knowing exactly what I wanted, I have painted three more big canvases since.” 


\section{Wheatfield Under Clouded Sky and Crows Over the Wheatfield}

Some of the last works of Vincent van Gogh were wheatfields under troubled skies. In these he expressed sadness and extreme loneliness, but also a faith in the healing and restorative forces of nature. An existential malaise and nostalgic recollections are expressed in LT 649, "I often think of the little one. I think it is certainly better to bring up children than to give all of your nervous energy to making pictures, but what then, I am at least I feel - too old to retrace my steps or to desire anything different.” Wheatfield Under the Clouded Sky is considered by Pickvance, (271) to be perhaps van Gogh's most haunting and elemental creation, and he feels that it has often been overlooked because of the excessive concern about Crows Over the Wheatfield. The pictorial schema and composition of Wheatfield Under Clouded Sky is compellingly simple. There is an approximately 1/3, 2/3 division of the pictorial space into horizontal bands of $1 / 3$ fields, $2 / 3$ sky. The modeling of land and sky are accomplished by the shape and direction of the brush strokes. The pure elemental simplicity in Wheatfield Under Clouded Sky expresses an infinite vastness unmarred by any smaller vision that might have included a person, a tree, a building. Only a few small haystacks are suggested in the panorama spread before the viewer. Vincent discussed these two paintings of wheat fields in LT 649 saying, "[Two of them] are vast fields of wheat under troubled skies, and I did not need to go out of my way to try to express sadness and extreme loneliness. I hope you will see them soon- for I hope to bring them to you in Paris as soon as possible, since I almost think that these canvases will tell you what I cannot say in words, the health and restorative forces that I see in the country.” 
In Wheatfield Under Clouded Sky the emptiness of the panorama seems to mirror the emptiness that Vincent van Gogh felt and the lack of human connection. The empty landscape functions as an artistic utterance serving as a springboard and metaphorically proceeding at a suprasegmental level. Kristeva $(1980,37)$ speaks of the univocal correspondence between words or word sequences; while in the next chapter this author will observe and discuss the correspondences between formal elements or formal element sequences in the artworks of Vincent van Gogh.

Observing Wheatfield Under Clouded Sky and Crows Over the Wheatfield causes this author to ask, Can an artist ever be an auteur in the sense that Kristeva used the word, an author with full conscious control of the writing process and authority over what has been written? Art and artistic creation has so much to do with unconscious expression that unknown or unrecognized forces are likely to be at work both in the creation of art and in the writing process to the extent that the creator might better be called a co-creator. Some authors, artists and musicians are aware enough of this co-creation process that they personify the concept of a muse.

(See Figure 63 on the next page). 


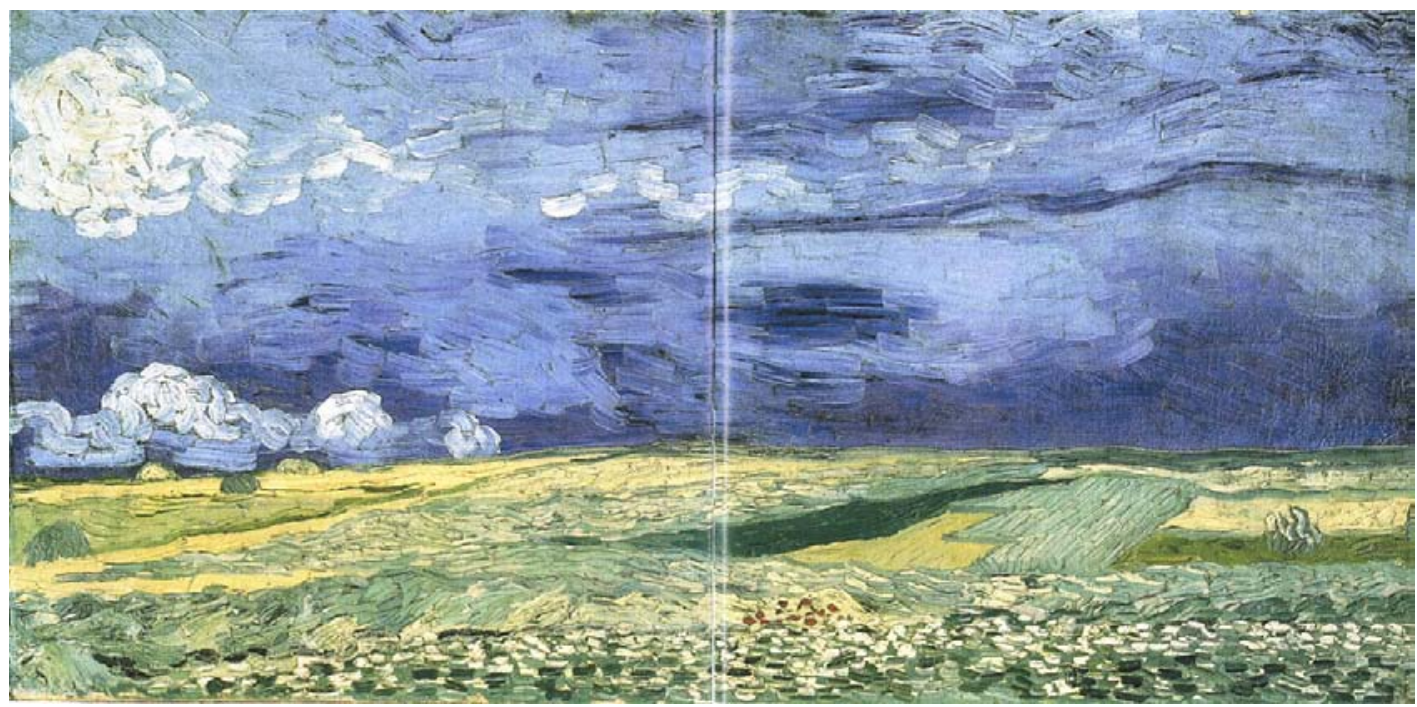

Figure 63. Wheatfield Under Clouded Sky

Pickvance, R. (1986) Van Gogh in Saint-Rémy and Auvers.

Metropolitan Museum of Art: N.Y, N.Y. p.271

\section{Crows Over the Wheatfield}

The emotional tone of Crows Over the Wheatfield is more ominous than

Wheatfield Under Clouded Sky. Taken together these two paintings of wheatfields may be seen as a holistic unity expressing both the bipolar quality of the restorative and destructive forces of nature, evocative of the balance of opposites as pictured in the yinyang symbol. In Biblical revelation, of which Vincent van Gogh would have been well aware, the sentiment expressed in these two paintings of wheatfields is similar in tone to that of chapter 3 of the Book of Ecclesiastes in the Bible: "There is a season for everything, a time for every occupation under heaven: A time for giving birth, a time for dying; a time for planting, a time for uprooting what has been planted. A time for killing, a 
time for healing; a time for knocking down, a time for building. A time for tears, a time for laughter; a time for mourning, a time for dancing. A time for throwing stones away, a time for gathering them up; a time for embracing, a time to refrain from embracing. A time for searching, a time for losing; a time for keeping, a time for throwing away. A time for tearing, a time for sewing; a time for keeping silent, a time for speaking. A time for loving, a time for hating; a time for war, a time for peace (The Jerusalem Bible, 982). Another way of summing up these sentiments is in the statement, "The Lord giveth and the Lord taketh away, Blessed be the name of the Lord.” These biblical sentiments express an existential acceptance of life and of death, as well as of all the other inextricably bound pairs of bipolar opposites that make entire the fabric of existence. What it has taken many words to say can immediately be grasped emotively when the two pictures of wheatfields are viewed together as two parts of a united whole.

There have been many and varied interpretations of Crows Over the Wheafield. It has been interpreted as Christian iconography, from Crucifixion to Last Judgment; as an image of cosmic chaos projected through van Gogh's inner torment; and as a psychic graph of his imminent suicide (Pickvance, ibid.) Much of the discussion of the symbolism and meaning has been linked to the assumption that it was van Gogh's last painting, but Pickvance asserts that this has never been established (275). Nevertheless, it was one of his last paintings, and it was painted sometime during his last 70 days which were spent at Auvers. The dating is questioned because the wheat appears too ripe for the generally accepted dating of July 7 to 10 per his letter of July 10 that references wheatfields under troubled skies. 


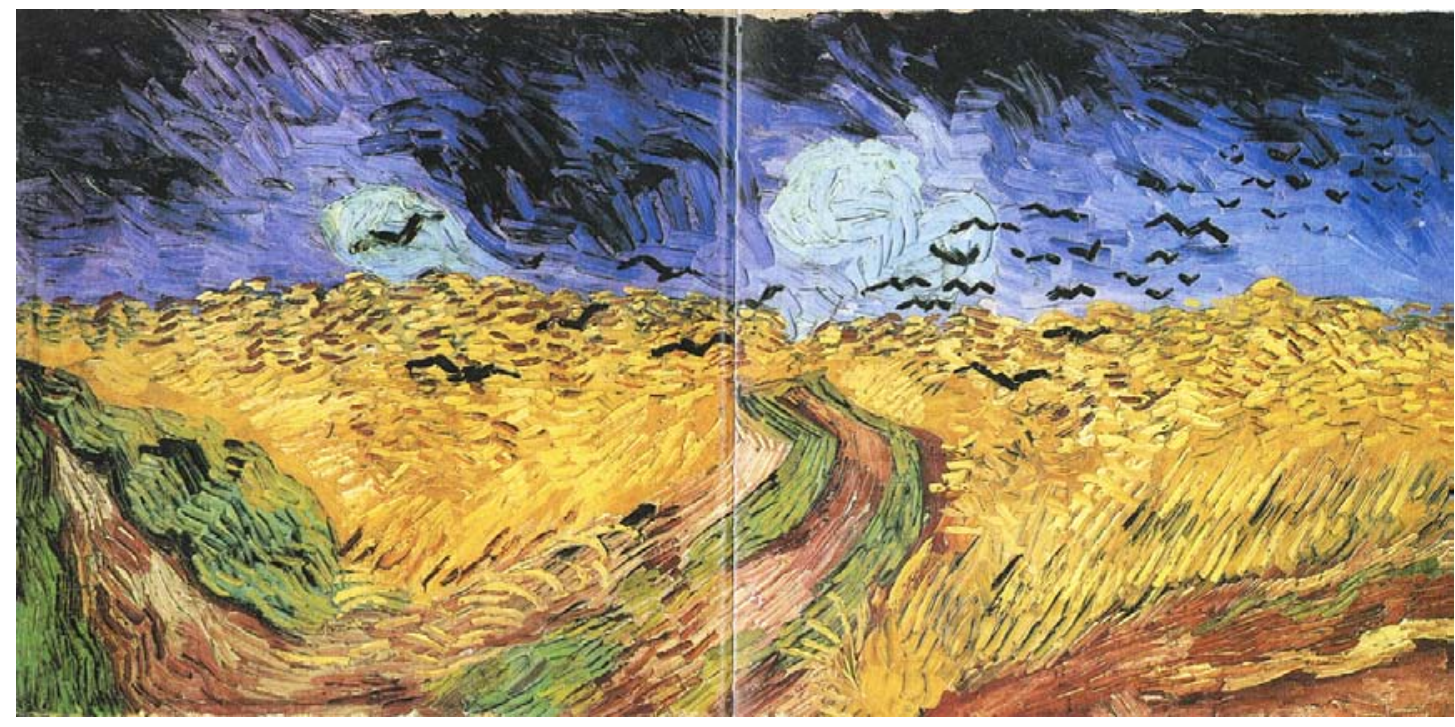

Figure 64. Crows Over the Wheatfield

Pickvance, R. (1986) Van Gogh in Saint-Rémy and Auvers.

Metropolitan Museum of Art: N.Y, N.Y. p.275

Perspective is the visual element that seems most relevant to an analysis of Crows Over the Wheatfield. Like combined opposition of the yin-yang symbol, this picture can be viewed as either extremely claustrophobic and oppressive with the crows flying at the viewer and the paths going nowhere; or the perspective may be reversed and everything is converging away from the viewer. In this reversed view of the perspective, the center path would simply turn into the field and be obscured from the viewer by the wheat and the crows would be flying away. This bipolar quality of convergence and emergence are seen in the one and same image, the beginning and the end seem to be at the same place. What is called the new physics would seem to give valuable insights to what is happening in Crows Over the Wheatfield. In Art \& Physics, Parallel Visions in Space, Time \& Light, by 
Leonard Schlain, he explains that at lightspeed, time ceases to change because it contains all change. The end and the beginning become one and the same, and all that exists is the eternal now. Monet called this instantaneity, the now moment in which the past and future separated by the present lose their meaning and all is swallowed up in the single moment of now (Schlain, 131). Crows Over the Wheatfield, since it can be perceived as emerging or converging, displays this quality called instantaneity. Schlain would say that Vincent van Gogh was precognitively demonstrating through art a scientific concept that had not yet emerged from the collective unconscious into the consciousness of scientists.

The Calm before the Storm

The calm before the storm seemed to be expressed in Vincent's last letter from Auvers to his mother and sister. LT 650 has written at the top in his mother's handwriting, “Very last letter from Auvers.” Vincent said, “For the present, I am feeling much calmer than last year, and really the restlessness in my head has greatly quieted down.” As to the paintings of the wheatfields, Vincent said, "I myself am quite absorbed in the immense plain with wheatfields against the hills, boundless as a sea, delicate yellow, delicate soft green, the delicate violet of a dug-up and weeded piece of soil, checkered at regular intervals with the green of flowering potato plants, everything under a sky of delicate blue, white, pink, violet tones.” Four times in this statement of Vincent van Gogh the word delicate was used. Perhaps in this there is a subtle premonition of his own delicate and precarious connection to the life force at this time. He continued, saying, "I am in a mood of almost too much calmness, in the mood to paint this.” In comparing the wheatfields to the sea, Vincent confronted himself with his own existential smallness against the foil of the enormity of nature. 
On July 23, 1889, Vincent wrote LT 651 to Theo and the depressed tone continued, "Perhaps I'd write you about a lot of things, but to begin with, the desire to do so has completely left me, and then I feel it is useless.” In reference to his painting, Vincent said, “As far as I am concerned, I apply myself to my canvases with all my mind, I am trying to do as well as certain painters whom I have greatly loved and admired. Now I'm back, what I think is that the painters themselves are fighting more and more with their backs to the wall.” He turned his discussion to the hoped-for union between the dealers and the impressionists. He felt that there had been a missed opportunity in that the timeliness for such a union had now passed, that the usefulness was now gone. If such a union were to take place now, he felt that it would founder and be very short-lived. An overarching tone of powerlessness, futility and depression, is expressed, “Although I think that personal initiative remains powerless, and having had the experience of it, should we start again?” (LT 651) He was as a speck of sand is to the beach, as a single point of cosmic awareness is beside the expansiveness of a sea of wheat fields. He was painfully aware of his profound littleness in the vastness of all that is.

The last letter of Vincent van Gogh, LT 652, was found on him on July 29, and he had written, "There are many things I should like to write you about, but I feel it is useless.” Vincent was depressed for Theo and Jo’s situation, "Your reassuring me as to the peacefulness of your household was hardly worth the trouble, I think, having seen the weal and woe of it for myself. And I quite agree with you that rearing a boy on the fourth floor is a hell of a job for you as well as for Jo.” The last sentiments expressed in the last letter of Vincent van Gogh had to do with dead artists and live artists, “... when things are very strained between dealers in pictures of dead artists, and living artists. Well, my own 
work, I am risking my life for it and my reason has half foundered because of it - that's all right - but you are not among the dealers of men as far as I know, and you can still choose your side, I think, acting with humanity, but que veux-tu?” What is the use of it indeed? With the handgun that he carried to scare away crows when he painted, Vincent van Gogh fatally wounded himself on July 27 and died on July 29, 1890. By this final desperate act, Vincent van Gogh placed himself among the rank of the dead artists. Fame, recognition and financial success were achieved after his death, as was the case for so many dead artists. Death, garbed in the robes of a prophet, heralded the posthumous success of Vincent van Gogh. 


\section{CHAPTER VIII}

\section{FORMAL ELEMENTS IN THE ARTWORK OF VINCENT VAN GOGH}

The formal elements of art are the building blocks of all artworks. Each artist creates art by combinations and variations of these compositional components. Furthermore, artists often have habitual ways of using the formal elements that combine into a recognizable pattern that allows the knowledgeable viewer to identify an artist's unique style. In this way an observer may look at an unsigned work of art

and speculate that it is a van Gogh based upon his unique characteristic structure and salient features using the formal elements of art.

As an art historian and an art therapist, this author is particularly interested in the formal elements of art as they relate to indicators of mental illness in artworks. Gantt and Tabone (1998) report a long history of interest in using art for assessment and treatment and that for over one hundred and fifty years various writers have commented on the diagnostic information in the spontaneous drawings of psychiatric patients. There are both spontaneous and directed drawings and two different approaches to interpretation have evolved as a result. Psychologists tend to use a testing approach to look for group principles based on personality characteristics and they stress reliability and validity. Psychoanalysts and art therapists, on the other hand, have sought to understand the individual more thoroughly and have seen the art as a reflection of mood or progress (ibid.). Each of these approaches has drawbacks: 
in the first, more objective method, a sign-based method was used and material was often taken out of context and in the second, more subjective method, scientific rigor was missing. Clearly these approaches must be revised, refined and combined into a more credible system. Analysis involves breaking the whole into component parts for study, but in art this must not be at the expense of the essence of the whole. This dissertation has examined the art of Vincent van Gogh both reductively and holistically. Formal analysis, using the elements of art in a pilot study of the Formal Elements Rating Scale, has been used to accomplish a taking apart or deconstructing of the selected artworks in an objective way, while the essence of the whole was preserved in the more subjective psychological observation and verbal discussion of the artworks in conjunction with the letters of Vincent van Gogh.

The work of Gantt and Tabone (1998) has focused on four psychiatric diagnoses, major depression, schizophrenia, bipolar disorder (manic phase), and cognitive or organic mental disorders including delirium, dementia, amnestic conditions, and their correlation with observable elements in art. Gantt and Tabone stated that the drawings by people with major depression have less color, fewer details, and use less space, i.e they create smaller images, than those of the control group. The findings relating to schizophrenia vary as to whether the incident is an acute flare-up or a chronic episode. The patterns observed in the artwork of patients with acute schizophrenic flare-ups are more illogical and bizarre drawings with unexpected elements along with the use of many and often clashing and unrealistic colors. On the other hand, patients with chronic schizophrenia seem to make pictures that evidence poor problem-solving skills along with fewer details, less realistic 
people, and less color. Bipolar disorder is characterized by a wide range of fluctuation from mildly manic to florid states of mania. Gantt and Tabone stated that as the degree of mania increases, the problem-solving processes get more fantastic and unrealistic and the details get more abundant, but that at the height of mania the pictures seem to have less color, fewer details, less content, and more fluid lines perhaps due to the extreme distractibility of the manic state. The artwork from patients with organic mental disorders varies widely because this group is quite heterogeneous with some disorders being acute and some chronic with a deteriorating course. Organic mental disorders include stroke victims, persons with mental retardation, patients with acute, closed head traumas, as well as a range of degenerative cognitive disorders. In general the drawings from the group with cognitive disorders tend to use only one or two colors to outline forms; usually warm rather than cool colors are chosen; outlines are often broken or sketchy lines with no color filling the forms; and the drawings are likely to have rotation and perseveration.

Gantt and Tabone (1998) used a non-patient control group and discovered that their drawings had an average amount of energy, color, and details, i.e. neither too much nor too little of these variables. Other qualities of the art work of the nonpatient group were recognizable images, coherent compositions, central placement, relative symmetry, pleasing to look at, consistent line quality with rather steady pressure and normal proportions with some suggestion of movement or animation. In this dissertation, the artworks from van Gogh's time in Paris, prior to the onset of his major psychopathology, are intended to function as the control group of paintings for comparison. 
The author of this dissertation has studied the formal elements in the artwork of Vincent van Gogh from 1888 through 1890 by careful observation and verbal discussion from a primarily Jungian psychotherapeutic viewpoint, along with analysis in this pilot study of a Formal Elements Rating Scale. For the purposes of this pilot study, the author enumerated the formal elements into twenty qualities: Line Quality, Expressive Style, Shape and Mass, Realism or Abstraction, Figure Ground Relationship, Value (Light to Dark), Intensity of Color, Variety of Color, Texture, Pattern, Spatial Organization, Spatial Denseness, Illusion of Depth, Time and Motion, Unity and Variety, Emphasis and Focal Point, Proportion, Scale, Rhythm, and Centric or Eccentric, and identified one expected tendency for each formal element.

This author scored the Formal Elements Rating Scales (FERS) by placing the formal elements on a continuum using a five point Likert scale. Scores from 1 to 5 for each formal element were assigned by the author. A lower score of one, or two, indicates less of the element being observed; three is a midpoint indicating a balance, i.e. neither too much nor too little of that element; and a score of four or five indicates more of the formal element. A score of one or two is not less good than a score of four or five. The Formal Elements Rating Scales (FERS) as scored by the author, and the graphs and charts are found in the appendix section of this dissertation.

Several expected tendencies specify near the time of a crisis. This author notes a recurrent pattern of crises around Christmas time in the life of Vincent van Gogh, and especially Christmas 1888 when he was very unstable emotionally and cut off a 
portion of his ear. Figure 39, the Self-Portrait with Bandaged Ear and Pipe, was painted after that event. From that time on there was increasing instability in his mental health status. Throughout the spring of 1889, he was hospitalized several times until in May, he moved to the asylum at Saint-Rémy. He again became unstable near the end of his life at Auvers where he committed suicide.

The focus of this pilot study has been to propose a method of rating the formal elements in artworks. This author recognizes the need for much further research such as replication of this study in order to discern the usefulness of The Formal Elements Rating Scales (FERS). There should be at least two groups to rate the FERS, with demographics to establish a control group, i.e., a group of persons without specialized art knowledge, and a group with specialized art knowledge such as art majors, art historians and art therapists, or perhaps a group for each of these to compare how they rate artworks. There needs to be a suitably large sample and the larger the sample, the greater the statistical validity.

After the list of formal elements to be analyzed was established, this author stated one expected tendency for each formal element at the beginning of this study. It is noted that many other tendencies could be identified. The data was sorted into twenty folders, one for each formal element with 64 scores, one for each artwork. At this point in this dissertation, the author will discuss the expected tendencies and findings for each formal element. The reader is directed to the appendix material in general, and in particular, the graphs for each formal element.

Element 1. Line Quality: a predominance of jagged, diagonal or broken lines in the artwork of Vincent van Gogh is expected to correlate with art works 
done near the time of a crisis. Scores of 1 (and 2) represented jagged, diagonal and broken lines, while scores ranging 4 to 5 were fluid and flowing lines. During the time in Paris there was no mental health crisis, and there were no scores of 1 on line quality. Only two of the eight art works from Paris were scored at a 2 indicating that most, but not all, of the lines were jagged, diagonal or broken. Both of these were self-portraits, Figures 5 and 6. This may indicate some self-esteem issues, body image discrepancies or internal conflict for Vincent van Gogh. The first period in Arles, considered perhaps the happiest time of Vincent's life, had no scores below a 3, and this continued into the second period of Vincent's time in Arles, until Figure 29 which is also a self-portrait. At the beginning of Vincent's third period in Arles, there are two artworks with scores of 2. At Saint-Rémy, although he was an inpatient in the hospital, he had some freedom to roam about the grounds, and he was largely accepting of his situation. There is only one line quality score below the midpoint of 3, and it is a 2 on Figure 52, another self-portrait. At Auvers, there are three paintings with scores of 2; Figure 59, a still-life with some curiously out of place lines; Figure 63, Wheatfield Under Clouded Sky; and Figure 64 Crows Over the Wheatfield, which may have been the painting that he was working on when he shot himself. This author considers that the expected tendency for element 1 is true.

Element 2. Expressive Style: Excessive repetition of graphic elements in the artwork of Vincent van Gogh will correlate with art works done near the time of a crisis. This expected tendency is difficult to assess because it is a characteristic feature of the impressionist style in general and of the specific style of van Gogh to have many repetitive lines, dots and dashes in his artwork. A score of 1 (and 2 to a 
lesser extent) indicated excessive repetition, while a score of 5 indicated a great deal of freedom of expression. There were only three of the sixty-four artworks that scored a 1 and it is interesting to note that all three were self-portraits and two of them had straw hats. Two were from the time in Paris (Figures 5 and 8) and one was from Arles, Figure 29. This author considers the expected tendency for element 2 is neither shown to be true nor false in this pilot study. Further research is recommended on this point.

\section{Element 3. Shape and Mass: The artwork of Vincent van Gogh is expected} to be composed primarily of organic shapes and masses at all times. Scores of 5 (and to a lesser extent 4) represent organic shapes and masses. The highest number of 5's are from Paris and Saint-Rémy; these two periods have no scores below a 3; and the pattern of scores from these two periods is quite similar. There are zero scores of 1 (highly geometric) in all 64 artworks scored by this author, and only eight scores of 2, indicating very little of geometric preponderance in the work of Vincent van Gogh. This author considers that the expected tendency for element 3 is true.

\section{Element 4. Abstraction or Realism: A high degree of abstraction in the} artwork of Vincent van Gogh will correlate with artworks done near the time of a crisis. It is noted that Vincent van Gogh's artwork was primarily realistic, but toward the end of his life there was an increase in abstraction. It is necessary to note that in the last part of the nineteenth century, artistic styles in general were moving toward greater abstraction. Scores of 1 (and 2) indicate abstraction. There are no scores of 1 and only one score of 2 out of the 64 artworks that were analyzed. This author considers that the expected tendency for element 4 is not true. 


\section{Element 5. Figure Ground Relationship: The amount of positive and}

negative space in the artwork of Vincent van Gogh is expected to be balanced at all times. A score of 3 is considered to indicate balance. During the time in Paris, seven out of eight artworks analyzed had scores of 3. This author considers Paris to be a time of relative balance in the life of Vincent van Gogh. While he had some personality problems and interpersonal difficulties, Vincent's time in Paris was reasonably peaceful and it was before the major breakdowns and hospitalizations that would complicate his life after Christmas Eve of 1888. This author scored twenty-one out of sixty-four artworks at a 3 (balanced) as to Figure Ground Relationship. It is noted that prior to the time at Saint-Rémy, only one artwork, Figure 23 (The Night Cafe) had a score of 5 (subject dominant), but the score of 5 became much more prevalent at Saint-Rémy with four artworks scored at 5, and at Auvers with five artworks scored at 5. Out of the sixty-four artworks analyzed there are only two scores of 1 (background dominant), and they are Figure 32 (The Sower, October 1888) and Figure 48 (The Starry Night). The author finds the expected tendency for element 5 to be true.

Element 6. Value (Dark and Light): An unbalanced use of very light or very dark colors, such as a predominance of very light or very dark colors is expected to correlate with depressed mental status. A score of 5 represents light colors and a score of 1 indicates dark colors. There is only one artwork that has a score of 1 (dark) and it is Figure 24, Portrait of Milliet. Conversely there are four artworks that score 5 (light), one from Paris, Figure 2: Lemons, Pears, Apples, Grapes and an Orange, 1887; two from Arles, Figure 21: The Sower (after Millet), and Figure 32: The Sower 
(October 1888); and one from Saint-Rémy, Figure 50: Self-Portrait (Saint-Rémy \#

3). There are thirty-two art works with scores of 3 (balanced, or a combination of light and dark colors). Taking another look at Figure 24, Portrait of Milliet, this author sees a combination of light and dark colors, and if rescoring it at this time, would likely give it a score of 2, rather than 1. It appears that when Vincent worked with dark colors, such as his paintings of night effects, that the darkness was balanced or tempered with use of light colors, often yellow, in the same artwork. While the expected tendency for element 6 may be true for psychiatric patients, or for people in general, in this pilot study of the FERS in relation to the artwork of Vincent van Gogh it does not hold true. The author finds that the expected tendency for element 6 is false.

Element 7. Intensity of Color: A predominant use of low intensity colors is expected to correlate with depressed mental status while a predominance of high intensity color is expected to correlate with an elevated or manic mental status. The score 5 represents pure and saturated colors, while a score of 1 indicates greyed and softened color. It is noted that there were zero scores of 1 in the artworks of Vincent van Gogh that were considered in this pilot study, and on the other hand there were 16 artworks with a score of 5 . This author considers it a salient feature of the artwork of Vincent van Gogh that he tended to use pure and saturated colors, i.e. there is a characteristic boldness in his color choices. It appears by the findings of expected tendencies for elements six and seven that dark and low intensity color choices were not typically the ways that Vincent expressed sadness or depression in his paintings. He was much more prone to use fully intense colors. The first part of 
the expected tendency for element seven (a predominant use of low intensity colors is expected to correlate with depressed mental status) is found to be not true in the artwork of Vincent van Gogh, but it may be true for other artists and for art therapy patients. The second part of the expected tendency for element seven (a predominance of high intensity color is expected to correlate with an elevated or manic mental status) is found to be true. Vincent's work became lighter and brighter at Arles when he was happier. At times it became very intense, and this was referred to as his "high yellow note."

Element 8. Variety of Color: A limited variety of color, monochromatic or primarily monochromatic artworks are expected to correlate with depressed mental status, while polychromy is expected to correlate with elevated or manic mental status. A score of 5 represents polychromatic color usage, while a score of 1 represents monochromatic. It is noteworthy that there are zero scores of 1 on Variety of Color in the 64 artworks studied, and only six scores of 2, three from Paris, Figures 2, 4, and 6, one from Saint-Rémy, Figure 50, and two from Auvers, Figures 53 and 54. Figure 2 is the largely monochromatic still-life, Lemons, Pears, Apples, Grapes and an Orange, 1887, and it is noted that although Vincent restricted himself to a limited color palette of primarily yellows, many shades were used within that color choice. Figure 4 is Self-Portrait, Paris, 1886, and Figure 6 is Self-Portrait, Paris, 1887 (pale tones). Figure 50 is yet another Self-Portrait (Saint-Rémy \# 2). From Auvers, Figure 53 Cottages with Thatched Roofs and Figure 54 Old Vineyard with Peasant Woman, were a pair done with limited media and palette restriction. 
They were painted soon upon Vincent's arrival at Auvers. He may have had limited materials available to him due to just moving.

On the other hand there are nineteen scores of 5 (polychromy). Of the scores of

5, one was from the time of Paris, fifteen were from Arles, one from Saint-Rémy and two from Auvers. This author considers the use of a large variety of colors a salient feature in the artwork of Vincent van Gogh, and he is even more likely to use a large variety of colors when his mood was elevated as at Arles. The first part of the expected tendency for element eight is found to be not true as a limited use of color does not necessarily correlate to depressed times in the artwork of Vincent van Gogh. The second part of the expected tendency for element eight, that polychromy correlates to elevated or manic status is found to be true in the artworks of Vincent van Gogh.

Element 9. Texture: In most instances, an impasto surface and a high score as to texture is expected in the artwork of Vincent van Gogh; a fine textured surface may correlate with exaggerated attempts to establish control and may therefore correlate with times of emotional and mental distress. A score of 5 represents an impasto finish while a 1 indicates a smooth finish. There are 3 artworks that scored very low (1) on Texture: Figure 4, a self-portrait from Paris, and the first two artworks done in Auvers. Self-Portrait, Paris, 1886, has smooth texture and is done in mostly dark tones except for the areas of flesh and the shirt collar. SelfPortrait, Paris, 1886, is painted in Vincent's earlier Northern dark and somber tonality. This author scored it a 2 on Value, Intensity of Color, and Variety of Color. 
As to style, it is pre-Arles, and before his move to the brighter colors and the divided brush strokes of Impressionism.

The first two artworks from Auvers, Cottages with Thatched Roofs and Old Vineyard with Peasant Woman, are different from most of the works studied in this dissertation since they are mixed media drawings with a painted wash. The media of pencil, brush, watercolor and gouache provide little possibility of actual surface texture, but the busyness of the line quality could be interpreted as an implied texture. If Vincent had used oil paints, there would likely have been impasto texture. It may be that his oils were not yet unpacked due to his move. Moving is a stressful time, and this choice of media with the resulting smooth texture could have been an unconscious response on the part of Vincent van Gogh.

Figure 39, Self-Portrait with Bandaged Ear and Pipe, is scored at a 2 on texture, indicating that the surface is mostly smooth and flat. In this instance the smoothness of the texture may indicate exaggerated attempts to establish control as stated in expected tendency 9. The author considers Vincent's Self-Portrait with Bandaged Ear and Pipe a pivotal artwork because it was done after his "incident of the ear" and seems to mark the beginning of his series of hospitalizations and decline into serious mental health issues. Regarding the use of smooth texture, there seem to be too many variables to make a conclusion and further research is needed on the point of smooth textures in the artworks of Vincent van Gogh. It is impossible to consider expected tendency 9 to be affirmed on the basis of these findings.

There are ten artworks with a score of 5 and thirty-one scored at 4 on texture out of a total of 64 artworks studied. There are no scores of 5 from Paris and the first 
period at Arles (Feb. 1888 to Mid-July 1888). It is perhaps a striking finding that except for the two aforementioned drawings (his first two works at Auvers), all artworks analyzed from Auvers had a high score as to impasto texture. Seven works were scored at 4 and three were given the highest score of 5 . Out of his last four artworks, three of them (Wheatfields, Bank of the Ôise at Auvers, and Crows over the Wheatfield) were scored 5 on texture. The other one, (Wheatfield under Clouded Sky) scored nearly as high with a 4 on texture. It appears from these findings that an extreme of texture in either direction, very smooth or very rough, may be an indicator of times of emotional and mental distress. For Vincent van Gogh, rough texture may be an indicator of mental distress and smoothness of texture may represent exaggerated attempts to establish control. This pilot study makes no findings other than in the artwork of Vincent van Gogh, but raises the research question as to the meaning of variations of texture in the artwork of other artists and in the artwork of psychiatric patients. The expected tendency for element 9 is considered worthy of further research.

Element 10. Pattern: A high incidence of surface pattern formed by many repeated motifs in the artwork of Vincent van Gogh is expected to correlate to times of emotional and mental distress. Scores of five indicate highly decorative surfaces with many repeated motifs, while scores of one indicate plain and simple surfaces with no repeated motifs. It is noted that over the time period studied, the scores for surface pattern tend to move toward more scores of four and five, i.e. that Vincent's use of surface pattern increased. There are no scores below three during the first period at Arles and during Vincent's time at Auvers. Moving to Arles was an 
exciting event for Vincent, and excitement is stressful in its own way, although it is not a bad kind of stress. At Auvers, Vincent's life was in decline, and his use of surface pattern in his artworks increased. Throughout the time period studied, Vincent's mental health became more and more unstable and the use of surface pattern increased. The expected tendency for element 10 is found to be true.

\section{Element 11. Spatial Organization (Evenness of Space): Forms are expected}

\section{to be evenly placed within the available space of the artwork of Vincent van}

Gogh at all times. Scores of 5 indicate forms evenly dispersed throughout the space, while scores of 1 indicate irregular dispersion of forms that create an unusual division of space. There are only six scores of 5 throughout the entire study and four are from Vincent's time in Paris, Wheatfield with a Lark and three self-portraits. The other scores of 5 include one from Arles, Painter on the Road to Tarasçon, and one from Saint-Rémy, The Prisoner's Round. It is interesting to note that except for Wheatfield with a Lark, all of the other artworks scoring a 5 are self-portraits, or a type of self-portrait. There are three scores of 1, Portrait of Pere Tanguy from Paris, Les Alyscamps from Arles, and The Starry Night from Saint-Rémy. There are twenty one artworks, out of sixty-four rated, with a score of 3, indicating that forms are organized in the way one might expect, i.e. no unusual division of space by the forms included. The expected tendency for element 11 is found to be not true.

Element 12. Spatial Denseness: The amount of open space in the artwork of Vincent van Gogh is expected to be greater during times of depressed mood.

A score of 5 represents densely packed space, while a score of 1 indicates open space. It is noted that there are no scores of 5 after the first artwork done at Saint-Rémy, 
and that 4 is the predominant score from Vincent's time at Saint-Rémy and Auvers. Throughout the time period and artworks studied in this dissertation, there were only two that scored at a 1; Figure 32, The Sower, (October 1888), and Figure 63, Wheatfield under Clouded Sky. From the dispersion of the scores on Spatial Denseness it appears that Vincent's artworks became much more densely packed during his time at SaintRémy and Auvers. The expected tendency for element 12 is found to be not true and the reverse may be true, that more densely packed artworks may relate to times of emotional distress.

Element 13. Illusion of Depth: Flatness and shallow depth in the artwork of Vincent van Gogh are expected to correlate with times of depressed mood. A score of 5 indicates deep, while a score of 1 represents flat. It is noted that the scores vary widely on this formal element, Illusion of Depth, with only three artworks scoring 3 (balanced): Figure 14, Still-Life with Blue Enamel Coffeepot (during the first period at Arles), Figure 38, Gauguin’s Chair (during the third period at Arles), and Figure 59, Wild Flowers and Thistles in a Vase (Auvers). It is noted that all three of these paintings are still-lifes, with Gauguin's chair being considered a type of still-life. It is also noted that the score of 5 predominates at Auvers, with all but two of the artworks included being scored at 5 . The expected tendency for element 13 is found to be not true and it appears that the opposite is true, i.e. that depth in the artwork of Vincent van Gogh appears to correlate to depressed mood. It is further noted that Figure 39, Self-Portrait with Bandaged Ear and Pipe scores a 1.

Element 14. Time and Motion: A balance between a sense of stillness and a sense of motion is expected at all times in the artwork of Vincent van Gogh. A 
score of 1 indicates no motion and stillness, while a score of 5 indicates in motion. There is a great preponderance of stillness (the score of 1), with forty-four of the sixty-four artworks included in this dissertation being scored at 1. Only eight artworks are scored at a 3, indicating a balance between stillness and motion. The only two artworks scored at 5 are Painter on the Road to Tarasçon and Crows over the Wheatfield. The expected tendency for element 14 is found to be strongly not true.

Element 15. Unity and Variety: The artwork of Vincent van Gogh is expected to be highly unified, coherent and composed of elements that go together at all times. Excessively varied and disordered artworks are not expected at any time regardless of emotional state. Vincent van Gogh was first and foremost an artist, therefore the quality of being unified and coherent (a score of 1) is expected in the artwork at all times. There are thirty-two scores of 1 among the sixtyfour artworks included in this study. There is only one score of 5, and it is Figure 59 Wild Flowers and Thistles in a Vase from Auvers. At Saint-Rémy, the artworks studied were remarkably consistent with the score of 1 , having only two artworks scoring other than a 1: Figure 48, The Starry Night, and Figure 52, Self-Portrait (Saint-Rémy \# 4). The expected tendency for element 15 is considered true.

Element 16. Emphasis and Focal Point: The artwork of Vincent van Gogh is expected to have an element that might be the focal point at all times. The score 5 indicates a definite focal point and 1 indicates no focal point. There is a preponderance of the score 5 with thirty-five artworks scoring 5 . There are only five scores of 1, three from Saint-Rémy and two from Auvers. From the artworks of 
Vincent's time in Paris, there is only one (Figure 2: Lemons, Pears, Apples, Grapes and an Orange, 1887) that did not score a 5. It appears that over time, Vincent became more likely to have artworks with a less definite focal point. More than onehalf of the artworks included in this study had a definite focal point. The expected tendency for element 16 is considered to be true.

\section{Element 17. Proportion: The size relationships between parts in the} artwork of Vincent van Gogh are expected to be in proportion at all times. A score of 5 indicates that the elements are in proportion, while a score of 1 indicates

out of proportion. By far the greatest number of scores is 5 . The score 5 is remarkably constant across the artworks of Vincent van Gogh, indicating that his artworks are mostly in proportion. There are no scores of 1 and only one score of 2 in $L a$ Berceuse. La Berceuse is a portrait of a mother, and it is known that Vincent's relationship with his mother was somewhat troubled. It may be an unconscious response on the part of the artist that the hands are given an out of proportion treatment. The expected tendency for element 17 is true.

Element 18. Scale (Small to Large): Elements in the artwork of Vincent van Gogh are expected to seem normal size with the exception that depictions of persons are expected to seem small in scale at times in the artwork of Vincent van Gogh. The score 5 indicates large in scale; a score of 1 indicates small in scale, and a rating of 3 represents that the elements seem normal in scale, neither large, nor small. The scores of 2 were given to Figure 32: The Sower (October 1888) and Figure 48: The Starry Night. There is only one score of 5 . The only score of 5 was given to a close-up, Figure 16, Portrait of a Zouave. The expected tendency for element 18 is 
partially true in that the score 3 appears the most, however, there were no scores of 1 and not enough scores of 2 to make a determination about the portion of the expected tendency dealing with persons being small in scale.

Element 19. Rhythm: Artworks of Vincent van Gogh that were done near the time of a crisis are expected to pulse and throb with rhythmic movement. The score 5 indicates rhythmic and the score 1 represents static. It is noted that the scores from Paris vary widely from 1 to 5 , and that over time the scores for the artworks of Vincent van Gogh moved more toward 3's, 4's, and 5's, thus indicating greater rhythmic movement in his artworks. His mental health crises were greater toward the end of his life, and the scores for rhythm in his artworks moved toward larger numbers at that time. The expected tendency for element 19 is considered to be true.

Element 20. Centric or Eccentric: It is expected that the composition of Vincent van Gogh will vary between centric and eccentric without correlating to

his mental status. A score of 5 indicates internal vectors (centric), while a score of 1 indicates external vectors (eccentric or gridlike composition). In the artworks from Vincent's time at Paris, 5 is the most frequent score. Then during Vincent's first period at

Arles, there were no 5's, indicating a greater external influence. This may be a response to being in new surroundings and interacting with new people. The second period at Arles seemed to see a shift back toward greater internality and a wide variance of scores, six 5's and four 2's. Toward the end of Vincent's time at Arles and at SaintRémy, the score of 5 becomes remarkably consistent. It is noted that the scores vary the 
most widely from 1's to 5's in the artworks from Auvers. This author speculates that high scores on centricity may relate to internal locus of control, and scores that are strongly eccentric may relate to external locus of control. Further research on this point is suggested. It is noted that what may have been his last painting, Crows over the Wheatfield was scored at a 5. This could indicate internal distress and a strong response on Vincent's part that may have caused his suicide. This author considers the expected tendency for element 20 to be not found either true or false, but in need of further research.

Having carefully reviewed the findings relative to each expected tendency, it is now time to consider the summary and conclusions. The reader is referred to Chapter IX. 


\section{CHAPTER IX SUMMARY AND CONCLUSIONS}

This dissertation is an interdisciplinary pilot study intended to further scholarship in both the disciplines of art history and art therapy. The works of Julia Kristeva have been a touchstone to which this author has returned again and again for insights. Concepts from Kristeva have been defined and applied in the analysis of the artworks of Vincent van Gogh. Kristeva’s discussion of the bipolar oppositions of semiotic and symbolic, as well as many other opposite yet complementary pairs of conjoined opposites have been related to the personality, lifestyle, art and words of Vincent van Gogh.

This author's primary psychoanalytical viewpoint is Jungian, focusing on symbolism and taking note of the conjoined pairs of opposites that create a single, albeit bipolaresque reality in the lifestyle, personality, art and letters of Vincent van Gogh . This study encompasses the final years of the life of Vincent van Gogh from March 1886 (Paris) to July 1890 (Auvers), and that time period has provided an abundance of resources to consider. The focus throughout has been on primary sources, specifically the words of Vincent van Gogh as expressed in his letters and the images of Vincent van Gogh, focusing on paintings. It has been the purposeful intention of this author to avoid further sensationalizing a life which has already been oversensationalized.

Chapter one has presented the theoretical overview of this author. The thesis statement of this dissertation is that variations in the psychological state of Vincent van 
Gogh are discernable by psychoanalytical analysis of the words in his Letters in conjunction with observation of the way that the formal elements of art are consciously manipulated by the artist in the service of artistic expression or even unconsciously manipulated by the mental state of the artist. In his lifestyle and difficult personality, as well as in his words and art, the union of opposites is apparent and that has lead this author to the conclusion that Vincent van Gogh had the mental health issues of Bipolar Disorder exacerbated by Borderline Personality Disorder.

The subjective and psychoanalytical discussion of the words and images of Vincent van Gogh is contained in chapters two through seven. In this subjective analysis, the words of the Letters function like the spoken words of a psychotherapy patient, and the author has discussed the images using art history and art therapy insights. Where the words and images are indicative of psychological manifestations, this has been pointed out by the author and discussed.

Vincent's time at Arles was discussed in chapters three through five. Vincent van Gogh went to Arles with high hopes and great expectations. The warmer climate would be good for him. He did not like cold weather and had a strong history of severe emotional episodes around the time of Christmas. Ironically, there was a large snowfall in the "sunny" South of France when he stepped off the train in Arles. His creative response was to paint several snow scenes. In Arles, Vincent was indeed a stranger in a strange land and as during much of his life he was keenly aware that he did not fit in. At Arles, Vincent continued the experimentation with color theory and brushstrokes that he had begun in Paris. Vincent's grand dream was to establish a studio of the South with a colony of painters. He became obsessed with the idea of Paul Gauguin joining him and finally on October 20, 1888 his dream of a colony of painters, a compatriot and 
companion, and a hope of greater financial success was realized. Despite this optimistic beginning, the relationship between Gauguin and van Gogh seems to have been doomed to failure from the outset. With two such powerful personalities trying to coexist, their arguments were described as terribly electric. Finally Vincent became so mentally unstable that he cut off a portion of his ear just before Christmas 1888. After this incident, Gauguin left Arles for good.

While at Arles, Vincent produced many monumental artworks and his Arlesian portraits in particular were archetypal images that functioned at both the symbolic and creative level. Vincent considered his artworks like children that he and Theo produced and passed on to the world. His concern to produce a magnificent picture of a sower, a powerful image of fecundity, was likely a sublimated desire to spread his seed since it seemed apparent that he would not have offspring of his own.

Chapter six has discussed Vincent’s time at Saint-Rémy. Sunflower paintings had shown optimistic beginnings at Arles, but when Vincent was at Saint-Rémy, a darker, more ominous tone made itself felt. Coloristically, Vincent moved away from the earlier yellows of the period at Arles, and used more greens and blues at Saint-Rémy. In particular a deep indigo blue began to become more prominent in works from SaintRémy and it was increasingly used throughout his time at Auvers. This dark imagery also appeared in the reaper as a foil to the sower(s), and cypresses as a counterpart to the earlier sunflowers. It is as if the color choices and imagery precognitively indicate the approaching death of Vincent van Gogh. As a professional artist, Vincent made conscious and cognitive choices about his colors and imagery, but there also appears to be a level of choices that are being made by the unconscious. Vincent van Gogh would not have been consciously aware of the reasons behind his color and imagery choices other than an 
intuitive sense that they felt right to him. Choices that accord with deep unconscious feelings create a sense of being deeply soul satisfying because they express truth, with a soul resonance like that felt when a full, rich, complete musical chord is sounded at precisely the right time.

Despite a history of depressed mood, manic episodes, psychotic incidents, selfmutilation and suicide attempts, Vincent van Gogh was released from the institution at Saint-Rémy and considered cured. Chapter seven contains the discussion of Vincent's time in Auvers. On his way to Auvers, Vincent stopped for a few days to visit with his brother Theo and his family in Paris, and to proceed from there to Auvers where he would be under the care of Dr. Gachet. At Auvers, Vincent's use of the deep blue color continued and increased and the morphology of his artwork changed. Lines were apt to become more curvilinear and wavery in visual effects such as roofs, cart-tracks and paths and there is an increase in unnatural visual qualities which may mirror decline in the mental health status of Vincent van Gogh at Auvers.

The objective analysis is found in chapter eight and the appendix materials. This formal analysis seeks to demonstrate a primarily Jungian worldview in which reality is composed of the union of pairs of opposites and balance must be maintained. More of one aspect of a formal element means that there will be less of its opposite in order to maintain balance. This author has created a Formal Elements Rating Scale (FERS) to spread the formal elements on a continuum. The FERS is used to assess how the formal elements were expressed in the artwork of Vincent van Gogh and how the scores varied over the time from Paris (March 1886) to Auvers (July 1890). The expected tendency was for the scores of the formal elements to become less balanced and more extreme when close to a crisis and for raw scores to become larger as this time period progressed 
and as Vincent's mental health declined and moved inexorably toward suicide. This tendency is nicely shown in Appendix 8 where a raw score for each artwork was established by adding the scores for each formal element in each artwork. The raw scores were color coded by period with consultation of the MARI color symbolism art therapy research as follows:

Paris - white (March 1886 to February 1888);

Arles - light yellow (February 1888 to mid-July 1888);

Arles - medium yellow (mid-July 1888 to October 20, 1888);

Arles - ochre (October 20, 1888 to May 8, 1889);

Saint-Rémy - green (May 8, 1889 to May 16, 1890); Vincent spent a few days visiting Theo and his family in Paris en route to Auvers

Auvers - blue (May 20,1890 to July 29, 1890)

The reader's attention is directed to Appendix 8 where the raw scores, color coded by period, are displayed. A total of sixty-four artworks were analyzed, so each quadrant of scores had sixteen artworks. The quadrant breakdowns were as follows: Quadrant 4 had raw scores from 73 to 82 with 10 artworks from Saint-Rémy and Auvers ( 3 from Saint-Rémy and 7 from Auvers), 5 from Arles, and 1 from Paris; Quadrant 3 had raw scores from 68 to 72 . It is noted that six artworks scored 68 and the tie scores spanned the break between quadrants 3 and 2 due to one-fourth of the artworks being placed in each quadrant, with sixteen artworks being placed in each quadrant. Three artworks with a tied raw score of 68 were placed in quadrant 3 and three in quadrant 2; Quadrant 3 had 1 score from Auvers, 6 from Saint-Rémy, 9 from Arles and 1 from Paris; Quadrant 2 had scores from 65 to 68 with several ties. There were three scores of 65 and 6 scores of 68 and the tied scores spanned the boundaries of the quadrant. Quadrant 2 with raw scores 
from had no scores from Auvers, 1 from Saint-Rémy, 10 from Arles, and 5 from Paris; Quadrant 1 with the lowest raw scores had 4 scores from Auvers, 1 from Saint-Rémy, 10 from Arles, and 1 from Paris.

In appendix 8, the most dramatic findings are from Saint-Rémy, a time of confinement in a mental institution, and Auvers, a brief few months at liberty, under the care of Dr. Gachet, where the scores clustered nicely in the quadrant of the highest scores, the $4^{\text {th }}$ quadrant. The higher scores in quadrant four show movement toward larger raw scores, i.e. further from the center position and balance, during the last fifteen months of Vincent's life. In the artwork of Vincent van Gogh, higher raw scores on the FERS appear to coordinate with confinement and increasing decline in mental health. As expected there are no particularly significant findings in the distribution of scores from Paris, the first time period studied. The scores from Paris are scattered throughout the findings with at least one score from Paris appearing in each quadrant. The importance of Vincent's time in Paris was that he was exposed to the most advanced art of the time, the revolution of impressionism and post-impressionism. Vincent van Gogh's assimilation of the new techniques and color usage completely changed his artwork from the dark tonalities that characterized his earlier works, and he began to push his art into new directions. It is like Vincent took what he learned and ran with it, becoming an innovator and taking his place among the greatest artists of all times.

So, when all is nearly said and done, the question remains, why another dissertation on Vincent van Gogh? It is because this dissertation is different, new, and original. This author has kept foremost the intention to remain objective and avoid further sensationalism. This pilot study is intended to provide a springboard for further research. It has created at least as many and perhaps more questions than it has answered. It is 
noted that in rating the FERS, the scores for the self-portraits were often skewed to the extremes, either very low or very high. The self-portraits seem to indicate body image discrepancies, possible self-esteem issues, and internal conflict. A study focusing on the self-portraits could be very revealing.

Is the FERS a tool that can be useful for other art historians and art therapists? Can the FERS be used to help diagnose psychological manifestations in artwork? So, what is the heuristic value of this dissertation? The FERS needs to be further tested with enough raters to determine whether it has statistical validity or not. The FERS instrument itself may be found to need revisions and fine tuning. Raters may need to be demographically grouped as persons with a significant amount of art knowledge, such as artists and art majors, and those who are relatively less sophisticated about art. It is the sincere desire of this researcher that such further research will be done. 


\section{REFERENCES}

Andrews, Ted. (1999). The Animal-Wise Tarot. Jackson, TN: Dragonhawk Publishing.

Arnheim, Rudolf. (1988) The Power of the Center, A Study of Composition in the Visual Arts (the new version). Berkley, CA: University of California Press.

Barasch, Moshe. (1985). Theories of Art: From Plato to Winckelmann. New York, NY: New York University Press.

Barasch, Moshe. (1990) Modern Theories of Art, 1, From Winckelmann to Baudelaire. New York, NY: University Press.

Barnes \& Noble Van Gogh 2004 Calendar. New York, NY: Barnes \& Noble.

Bendheim, Fred. Lancet. "The Compassion of Dr. Gachet,” 07/24/99. V.354, \# 9175, 345.

Berger, John. (1977). Ways of Seeing. London, England: British Broadcasting Corporation and Penguin Books.

Bloom, Edward A. (1954) The University of Kansas City Review, Vol. XXI, No. 2, Winter, 'Yeats's Second Coming': An Experiment in Analysis. pp.103-10.

Boime, Albert (1984). “Van Gogh’s Starry Night: A History of Matter and a Matter of History.” Arts Magazine: 59 (4), 86-103.

Bonafoux, Pascal. (1992). Van Gogh: The Passionate Eye. New York, NY: Harry N. Abrams, Inc.

Braumann, Max. (1928). from Kunst und Kunstler (Art and Artists), "With friends of Van Gogh’s in Arles” from an article, “Memories of Travels” (1926, p. 451).

Cane, Florence (1983). The Artist in Each of Us. Craftsbury Common, Vermont: Art Therapy Publications.

Cocquiot, Gustave. (1923). Vincent van Gogh. Ollendorf: Paris. p.194. 
Collins, Bradley. (2001) Van Gogh and Gauguin: electric arguments and utopian dreams. Boulder, Colorado: Westview Press.

Cooper, David. (1997) God is a Verb, Kabbalah and the Practice of Mystical Judaism. New York, NY: Riverhead Books.

Creativity and Madness Conference Brochure, Aug 2003. Tarzania, CA: The American Institute of Medical Education (AIMED).

Dawe, Frederick. (1977) Understanding Vincent van Gogh. London, England: Trewin Copplestone Publishing, Ltd.

Dobrin, Arnold. (1975) I Am a Stranger on the Earth: The Story of Vincent van Gogh. New York, NY: Frederick Warne \& Co.

Freud, S. (1900). Interpretation of Dreams. New York, NY: Avon Books.

Freud, S. (1953). A General Introduction to Psychoanalysis. Garden City, NY: Doubleday \& Co.

Gantt, Linda and Tabone, Carmello (1998) Formal Elements Art Therapy Scale, The Rating Manual. Morgantown, West Virginia: Gargoyle Press.

Gilbert, Rita. (1995). Living with Art, $4^{\text {th }}$ ed. New York, NY: McGraw-Hill, Inc.

Gogh, Vincent van. (1958). The Complete Letters of Vincent van Gogh (V. 1-3), Greenwich, CT: New York Graphic Society.

Graetz, H. R. (1963). The Symbolic Language of Vincent van Gogh. New York: McGraw Hill.

Harmon, Melissa Burdick (2003). "Vincent van Gogh: Blazing Genius, Tormented Soul.” Biography Magazine. 7 (2) Feb. 2003. 84, (6 pgs).

Hays, Edward. (1986) St. George and the Dragon and the Quest for the Holy Grail. Leavenworth, KS: Forest of Peace Publishing.

Huyghe, Rene. (undated). Van Gogh. Italy: Flammarion. Warner Books.

Jacq, Christian. (1995). Ramses, Vol. 1, The Son of Light. New York, NY:

Jamison, Kay Redfield. (1993) Touched with Fire: Manic-Depressive Illness and the Artistic Temperament. New York, NY: Simon \& Schuster. 
Jamison, Kay Redfield. (2004) Exuberance: The Passion for Life. New York, NY: Random House, Inc.

Jung, Carl G. (1964) Man and His Symbols. New York, NY: Dell Publishing Co.

Jung, C.G. (1970). Four Archetypes, Mother/Rebirth/Spirit/Trickster. Princeton, NJ: Princeton University Press.

Kernberg, Otto. (1985) Borderline Conditions and Pathological Narcissism. Northvale, NJ: Jason Aronson Inc.

Kristeva, Julia. (1980). Desire in Language, A Semiotic Approach to Literature and Art. New York, NY: Columbia University Press.

Kristeva, Julia. (1984) Revolution in Poetic Language. New York, NY: Columbia University Press.

Kristeva, Julia. (1987) In the Beginning Was Love: Psychoanalysis and Faith. New York, NY: Columbia University Press.

Lacan, Jacques. (1968) The Language of the Self, The Function of Language in Psychoanalysis. Baltimore, MD: Johns Hopkins University Press.

Leon, Emilia Gabriela. (2000) I Confess: Vincent van Gogh Confessional Writer and Congressional Hero. Dominquez Hill 0582: California State University

Loran, Erle.(1947). Cezanne’s Composition. Berkley \& Los Angeles, CA: University of California Press.

Lubin, Albert J. (1972) Stranger on the Earth: A Psychological Biography of Vincent van Gogh. New York, NY: Holt, Rinehart and Winston.

Lusebrink, V. (1990). Imagery and Visual Expression in Therapy. New York, NY: Plenum Press.

Takei, Michelle. (2006) Manual: MARI Color Symbolism. MARI Creative Resources, Inc.: Raleigh, NC.

McQuillen, Melissa. (1989) Van Gogh. New York, NY: Thames and Hudson.

Meier-Graefe, Julius. (1987) Vincent van Gogh, A Biography. New York, NY: Dover Publications, Inc.

Nagera, Humberto. (1967) Vincent van Gogh: A Psychological Study. New York, NY: New York, NY: International Universities Press. 

Collins.

Peters, Elizabeth, (2000). He Shall Thunder in the Sky. New York, NY: Harper

Piaget, J. (1962). Play, Dreams and Imitation in Childhood. New York, NY: W. W. Norton \& Co.

Pickvance, Ronald. (1984). Van Gogh in Arles. New York, NY: Harry N. Abrams, Inc. Publishers.

Pickvance, Roland (1987). Van Gogh in Saint-Remy and Auvers. New York, NY: The Metropolitan Museum of Art, Harry N. Abrams, Inc. Publishers.

Reid, William H. and Wise, Michael G. (1995) DSM-IV Training Guide. New York, NY: Brunner Mazel Publishers.

Ryckman, Richard. (1985). Theories of Personality, 3 rd Ed. Monterey CA: Brooks/Cole Publishing Company.

Seton-Williams, M.V. (1988). Egyptian Legends and Stories. New York, NY: Barnes \& Noble, Inc.

Sarup, Madan. (1993) Introductory Guide to Post-Structuralism and PostModernism. Athens, GA: University of Georgia Press.

Schlain, Leonard. (1993) Art and Physics. New York, NY: Penguin Press.

Schlain, L. (1998). The Alphabet versus the Goddess: The Conflict Between Word and Image. New York, NY: Penguin Putnam, Inc.

Seton-Williams, M.V. (1988) Egyptian Legends and Stories. New York, NY: Barnes \& Noble, Inc.

Soth, Lauren (1986). “Van Gogh’s Agony.” Art Bulletin, 68 (2), 83-84, 303-313.

Stein, Susan Alyson, (Ed.). (1986) Van Gogh, A Retrospective. Beaux Arts Edition. The Metropolitan Museum of Art. New York, NY: Hugh Lauter Levin Associates, Inc.

The Jerusalem Bible. (1966). “Ecclesiastes 3: 1-9” Garden City, NY: Doubleday \& Co., Inc.

Turco, Ronald. (1998) The Architecture of Creativity, Profiles behind the Mask. Chatas, OR: Dancing Moon Press.

Wilson, Colin. (1999) From Atlantis to the Sphinx: Recovering the Lost Wisdom of the Ancient World. New York, NY: Fromm International Publishing Corporation. 
Zemel, Carol. (1997) Van Gogh’s Progress. Berkley, CA: University of California Press. 


\section{APPENDIX MATERIALS}

APPENDIX 1. Formal Elements Rating Scale........................ 355

APPENDIX 2. Formal Elements Guide. .............................357

APPENDIX 3. Expected Tendencies for Formal Elements Rating Scale...362

APPENDIX 4. FERS scored by the author (for Artworks 1 to 64).........365

APPENDIX 5. Graphs for each Artwork............................. 430

APPENDIX 6. Graphs for each Formal Element.......................453

APPENDIX 7. Comparison of Percent Scores (by period and element)... 464

APPENDIX 8. Comparison of Raw Scores (by period and element).......469 


\section{APPENDIX 1. Formal Elements Rating Scale.}

Appendix 1 contains a blank (unscored) copy of the Formal Elements Rating Scale (FERS). The FERS is an original research document developed by Suzy Grey, ATR-BC, LPAT, who is the author of this pilot study. The FERS is designed to spread ratings for twenty formal elements of art over a continuum from a score of 1 (less of that formal element) to 5 (more of that formal element). It is important to note that the scores do not imply that a score of 1 is either less good or more good than a higher score, it is simply a spread of scores. 


\section{Formal Elements}

Rating Scale (FERS)

\begin{tabular}{|c|c|c|c|c|c|c|c|}
\hline & Figure & & \begin{tabular}{|ll}
5 & 4
\end{tabular} & 3 & 2 & 1 & Total \\
\hline I & Line Quality & $\begin{array}{l}\text { 5. Fluid and Flowing } \\
\text { 1. Jagged, and Broken }\end{array}$ & & & & & \\
\hline II & Perseveration & $\begin{array}{l}\text { 5. Freedom of Expression } \\
\text { 1. Excessive Repetition }\end{array}$ & & & & & \\
\hline III & Shape and Mass & $\begin{array}{r}\text { 5. Organic } \\
\text { 1. Geometric }\end{array}$ & & & & & \\
\hline IV & Abstraction vs Realism & $\begin{array}{l}\text { 5. Realistic } \\
\text { 1. Abstract }\end{array}$ & & & & & \\
\hline $\mathrm{V}$ & Figure Ground Relationship & $\begin{array}{r}\text { 5. Subject Dominant } \\
\text { 1. Background Dominant }\end{array}$ & & & & & \\
\hline VI & Value (Dark and Light) & $\begin{array}{l}\text { 5. Light Colors } \\
\text { 1. Dark Colors }\end{array}$ & & & & & \\
\hline VII & Intensity of Color & $\begin{array}{l}\text { 5. Pure and Saturated } \\
\text { 1. Greyed and Softened }\end{array}$ & & & & & \\
\hline VIII & Variety of Color & $\begin{array}{r}\text { 5. Polychromatic } \\
\text { 1. Monochromatic }\end{array}$ & & & & & \\
\hline IX & Texture & $\begin{array}{l}\text { 5. Impasto } \\
\text { 1. Smooth }\end{array}$ & & & & & \\
\hline $\mathrm{X}$ & Pattern & $\begin{array}{l}\text { 5. Highly Repeated Motifs } \\
\text { 1. No Repeated Motifs }\end{array}$ & & & & & \\
\hline XI & $\begin{array}{l}\text { Spatial Organization } \\
\text { (Evenness of Space) }\end{array}$ & $\begin{array}{l}\text { 5. Evenly Dispersed } \\
\text { 1. Irregularly Dispersed }\end{array}$ & & & & & \\
\hline XII & $\begin{array}{l}\text { Spatial Organization } \\
\text { (Denseness) }\end{array}$ & $\begin{array}{r}\text { 5. Densely packed } \\
\text { 1. Open Space }\end{array}$ & & & & & \\
\hline XIII & Illusion of Depth & $\begin{array}{r}\text { 5. Deep } \\
\text { 1. Flat }\end{array}$ & & & & & \\
\hline XIV & Time and Motion & $\begin{array}{l}\text { 5. In Motion } \\
\text { 1.No Motion }\end{array}$ & & & & & \\
\hline $\mathrm{XV}$ & Unity and Variety & $\begin{array}{l}\text { 5. Varied } \\
\text { 1. Unified }\end{array}$ & & & & & \\
\hline $\mathrm{XVI}$ & Emphasis and Focal Point & $\begin{array}{l}\text { 5. Definate Focal Point } \\
\text { 1. No Focal Point }\end{array}$ & & & & & \\
\hline XVII & Proportion & $\begin{array}{l}\text { 5. Elements in Proportion } \\
\text { 1. Elements out of Proportion }\end{array}$ & & & & & \\
\hline XVIII & Scale (Small to Large) & $\begin{array}{l}\text { 5. Large Scale } \\
\text { 1. Small Scale }\end{array}$ & & & & & \\
\hline XIX & Rhythm & $\begin{array}{c}\text { 5. Rhythmic } \\
\text { 1. Static }\end{array}$ & & & & & \\
\hline $\mathrm{XX}$ & Centric or Eccentric & $\begin{array}{l}\text { 5. Internal Vectors } \\
\text { 1. External Vectors }\end{array}$ & & & & & \\
\hline \multicolumn{3}{|c|}{ Totals } & & & & & \\
\hline
\end{tabular}




\section{APPENDIX 2. Formal Elements Guide.}

Appendix 2 is composed of a Formal Elements Guide that will assist the person rating the FERS. Specific descriptions are given to assist the rater in assigning scores of 1 to 5 on each formal element. A suggestion for further research would be to develop a bank of thumbnail sketches to demonstrate each score 1 through 5 for each formal

element. This would greatly assist the rater and would likely provide more reliability and validity in the results.

\section{Formal Elements Guide}

\section{Line Quality}


1. All lines are jagged, diagonal or broken.

2. Most lines are jagged, diagonal or broken.

3. There are equally balanced amounts of jagged, diagonal or broken lines and fluid flowing lines.

4. Most lines are fluid and flowing.

5. All lines are fluid and flowing.

\section{Expressive Style}

1. One or more graphic elements is repeated unnecessarily and excessively (perseveration) to the detriment of freedom of expression.

2. One or more graphic elements is repeated somewhat excessively.

3. There are equally balanced amounts of freedom of expression and repetition of graphic elements.

4. There is a considerable amount of freedom of expression without unnecessary repetition of graphic elements.

5. There is a great deal of freedom of expression, and repetition of graphic elements is in the service of artistic expression.

\section{Shape and Mass}

1. The picture is composed entirely of geometric shapes and masses.

2. The picture is composed mostly of geometric shapes and masses.

3. There is an equal balance of geometric and organic shapes and masses.

4. The picture is composed mostly of organic shapes and masses.

5. The picture is composed entirely of organic shapes and masses.

\section{Abstraction or Realism}

1. The picture is abstract.

2. The picture is mostly abstract.

3. There is an equal balance between abstraction and realism.

4. The picture is mostly realistic.

5. The picture is realistic.

\section{Figure Ground Relationship}

1. The picture is background dominant (negative space).

2. There is more background dominant space than subject dominant space.

3. There is an equal balance between background dominant space and subject dominant space.

4. There is more subject dominant space than background dominant space.

5. The picture is subject dominant (positive space).

\section{Value ((Dark and Light)}

1. Most of the picture is made up of dark colors.

2. There are more dark colors than light colors.

3. There is an equal balance of dark and light colors.

4. There are more light colors than dark colors.

5. Most of the picture is made up of light colors. 


\section{Intensity of Color}

1. Most of the colors are low intensity (greyed and softened).

2. There are more low intensity colors than high intensity colors.

3. There is an equal balance of low and high intensity colors.

4. There are more high intensity colors than low intensity colors.

5. Most of the colors are high intensity (pure and saturated).

\section{Variety of Color}

1. Monochromatic, only one color is used.

2. Mostly one color is used.

3. Several colors are used.

4. Quite a few colors are used.

5. Polychromatic, many colors are used.

\section{Texture}

1. Fine texture, surface is perceived as smooth and flat.

2. Surface is mostly smooth and flat.

3. Surface has an equal balance of smoothness and impasto.

4. Surface is mostly rough and bumpy.

5. Impasto, surface is rough or bumpy.

\section{Pattern}

1. Surface is plain and simple with no repeated motifs.

2. Surface is mostly plain and simple with few repeated motifs.

3. Surface is equally balanced between plain and simple (without repeated motifs) and highly decorative (with many repeated motifs).

4. Surface is highly decorative with several repeated motifs.

5. Surface is highly decorative, covered with many repeated motifs.

\section{Spatial Organization (Evenness of Space)}

1. Forms are irregularly dispersed to create a very unusual division of space.

2. Forms are organized to create a somewhat unusual division of space.

3. Forms are organized in the way one might expect.

4. Forms are organized somewhat evenly throughout the space.

5. Forms are evenly dispersed throughout the space.

\section{Spatial Denseness}

1. Most of the surface is open space.

2. There is more open space than filled space.

3. There is an equal balance between open space and filled space.

4. There is more filled space than open space.

5. Most of the surface is filled with forms densely packed.

XIII. Illusion of Depth 
1. The picture seems flat, on the surface, has a shallow depth.

2. The picture seems mostly flat, but has some depth.

3. The picture is equally balanced between flatness and depth.

4. The picture seems mostly deep, but is somewhat shallow.

5. The picture seems deep; forms seem to recede in space.

XIV. Time and Motion (may be implied)

1. The picture seems statue still, no motion, implies stopped time.

2. The picture seems to be mostly still, but has a little bit of motion.

3. The picture is equally balanced between stillness and motion.

4. The picture is mostly active, seems in motion.

5. The picture seems active and lively, in motion, implies elapsed time.

XV. Unity and Variety

1. The picture seems highly unified and coherent; elements go together.

2. The picture seems mostly unified and coherent.

3. There is an equal balance between unified, coherent elements and varied elements.

4. The picture seems mostly varied so as to be somewhat discordant.

5. The picture seems excessively varied with elements that may not seem to go together.

\section{Emphasis and Focal Point}

1. The picture does not have a definite emphasis or focal point.

2. The picture has an element that might be the emphasis or focal point.

3. The picture has more than one element that might be an emphasis or focal point.

4. The picture has a primary and a secondary emphasis or focal point.

5. The picture has a definite emphasis or focal point.

\section{Proportion}

1. Size relationships between the elements of the picture appear exceedingly out of proportion.

2. Size relationships between the elements of the picture appear fairly out of proportion.

3. Some elements of the picture appear out of proportion, other parts appear in proportion.

4. Size relationships between elements of the picture appear mostly in proportion. 
5. Size relationships between elements of the picture appear in proportion.

XVIII. Scale (Small to Large)

1. All elements in the picture seem small in scale.

2. Most elements in the picture seem small in scale.

3. The elements in the picture seem normal in scale, neither small nor large.

4. Some elements in the picture seem large in scale.

5. All elements in the picture seem large in scale.

\section{Rhythm (Visual)}

1. The picture seems completely still or static.

2. The picture seems mostly still or static.

3. The picture has a balance of stillness and elements of visual rhythm.

4. The picture seems mostly rhythmic visually.

5. The picture seems to pulse and throb with visual rhythmic movement.

\section{Centric or Eccentric}

1. The composition of the picture is eccentric, i.e. is grid-like, has vectors that are responses to external centers of attraction or repulsion.

2. The composition of the picture is mostly eccentric.

3. The composition of the picture combines elements of both centric and eccentric (the squaring of the circle).

4. The composition of the picture is mostly centric.

5. The composition of the picture is centric, i.e. organized around an internal center.

APPENDIX 3. Expected Tendencies for Formal Elements Rating Scale. 
Appendix 3 contains the Expected Tendencies for each formal element in the artwork of Vincent van Gogh that is included in this pilot study. Expected tendencies were determined by this author at the beginning of this pilot study. The discussion of the expected tendencies is found in chapters 8 and 9. This author recognizes that many other expected tendencies could be stated and that the expected tendencies would be different if stated for the study of a different artist than Vincent van Gogh, the artist studied in this dissertation. As to the heuristic value of this pilot study and suggestions for further research, this author is hopeful that a statement of expected tendencies for use with psychiatric patients could be developed and that the FERS might be shown to be in useful in the evaluation of treatment and evaluation of psychiatric patients.

\section{Expected Tendencies for Formal Elements Rating Scale}

I. Line Quality: A predominance of jagged, diagonal or broken lines in the artwork of Vincent van Gogh is expected to correlate with artworks done near the time of a crisis.

II. Expressive Style: Excessive repetition of graphic elements in the artwork of Vincent van Gogh will correlate with art works done near the time of a crisis. 
III. Shape and Mass: The artwork of Vincent van Gogh is expected to be composed primarily of organic shapes and masses at all times.

IV. Abstraction or Realism: A high degree of abstraction in the artwork of Vincent van Gogh will correlate with artworks done near the time of a crisis.

V. Figure Ground Relationship: The amount of positive and negative space in the artwork of Vincent van Gogh is expected to be balanced at all times.

VI. Value (Dark and Light): An unbalanced use of very light or very dark colors, such as a predominance of very light or very dark colors is expected to correlate with depressed mental status.

VII. Intensity of Color: A predominant use of low intensity colors is expected to correlate with depressed mental status while a predominance of high intensity color is expected to correlate with an elevated or manic mental status.

VIII. Variety of Color: A limited variety of color, monochromatic or primarily monochromatic artworks are expected to correlate with depressed mental status, while polychromy is expected to correlate with elevated or manic mental status.

IX. Texture: In most instances, an impasto surface and a high score as to texture is expected in the artwork of Vincent van Gogh; a fine textured surface may correlate with exaggerated attempts to establish control and may therefore correlate with times of emotional and mental distress.

X. Pattern: A high incidence of surface pattern formed by many repeated motifs in the artwork of Vincent van Gogh is expected to correlate to times of emotional and mental distress.

XI. Spatial Organization (Evenness of Space): Forms are expected to be evenly placed within the available space of the artwork of Vincent van Gogh at all times.

XII. Spatial Denseness: The amount of open space in the artwork of Vincent van Gogh is expected to be greater during times of depressed mood.

XIII. Illusion of Depth: Flatness and shallow depth in the art work of Vincent van Gogh are expected to correlate with times of depressed mood.

XIV. Time and Motion: A balance between a sense of stillness and a sense of motion is expected at all times in the art work of Vincent van Gogh. 
$\mathrm{XV}$. Unity and Variety: The artwork of Vincent van Gogh is expected to be highly unified, coherent and composed of elements that go together at all times. Excessively varied and disordered artworks are not expected at any time regardless of emotional state.

XVI. Emphasis and Focal Point: The artwork of Vincent van Gogh is expected to have an element that might be the focal point at all times.

XVII. Proportion: The size relationships between parts in the artwork of Vincent van Gogh are expected to be in proportion at all times.

XVIII. Scale (Small to Large): Elements in the artwork of Vincent van Gogh are expected to seem normal size with the exception that depictions of persons are expected to seem small in scale at times in the artwork of Vincent van Gogh.

XIX. Rhythm: Artworks of Vincent van Gogh that were done near the time of a crisis are expected to pulse and throb with rhythmic movement.

XX. Centric or Eccentric: It is expected that the composition of Vincent van Gogh will vary between centric and eccentric without correlating to his mental status. 
APPENDIX 4. FERS scored by the author (for Artworks 1 to 64)

Appendix 4 has the 64 copies of the FERS, one for each artwork that is included in this pilot study, as scored by the author. This author recognizes the need for further research, and suggests a study with a sufficiently high number of raters, perhaps with demographics to group raters as to whether they have specific art background, (i.e. art historians, art therapists, artists, or art majors), and a control group of the general public. Reliability and validity of the FERS as an evaluative tool has not been established, and the need for much further research is noted. It is the hope of this researcher that the FERS will be a springboard for much further research. 


\begin{tabular}{|c|c|c|c|c|c|c|c|c|}
\hline & \multicolumn{2}{|c|}{ Figure 1: Wheatfield with a Lark, 1887} & 5 & 4 & 3 & 2 & 1 & Total \\
\hline $\mathrm{I}$ & Line Quality & $\begin{array}{l}\text { 5. Fluid and Flowing } \\
\text { 1. Jagged and Broken }\end{array}$ & $\mathrm{X}$ & & & & & 5 \\
\hline II & Expressive Style & $\begin{array}{l}\text { 5. Freedom of Expression } \\
\text { 1. Excessive Repetition }\end{array}$ & $\mathrm{X}$ & & & & & 5 \\
\hline III & Shape and Mass & $\begin{array}{l}\text { 5. Organic } \\
\text { 1. Geometric }\end{array}$ & $\mathrm{X}$ & & & & & 5 \\
\hline IV & Abstraction or Realism & $\begin{array}{l}\text { 5. Realistic } \\
\text { 1. Abstract }\end{array}$ & $\mathrm{X}$ & & & & & 5 \\
\hline $\mathrm{V}$ & Figure Ground Relationship & $\begin{array}{r}\text { 5. Subject Dominant } \\
\text { 1. Background Dominant }\end{array}$ & & & $\mathrm{X}$ & & & 3 \\
\hline VI & Value (Dark and Light) & $\begin{array}{l}\text { 5. Light Colors } \\
\text { 1. Dark Colors }\end{array}$ & & & $\mathrm{X}$ & & & 3 \\
\hline VII & Intensity of Color & $\begin{array}{l}\text { 5. Pure and Saturated } \\
\text { 1. Greyed and Softened }\end{array}$ & & & & $\mathrm{X}$ & & 2 \\
\hline VIII & Variety of Color & $\begin{array}{r}\text { 5. Polychromatic } \\
\text { 1. Monochromatic }\end{array}$ & & $\mathrm{X}$ & & & & 4 \\
\hline IX & Texture & $\begin{array}{l}\text { 5. Impasto } \\
\text { 1. Smooth }\end{array}$ & & $\mathrm{X}$ & & & & 4 \\
\hline $\mathrm{X}$ & Pattern & $\begin{array}{r}\text { 5. Highly Repeated Motifs } \\
\text { 1. No Repeated Motifs }\end{array}$ & & $\mathrm{X}$ & & & & 4 \\
\hline XI & $\begin{array}{l}\text { Spatial Organization } \\
\text { (Evenness of Space) }\end{array}$ & $\begin{array}{l}\text { 5. Evenly Dispersed } \\
\text { 1. Irregularly Dispersed }\end{array}$ & $\mathrm{X}$ & & & & & 5 \\
\hline XII & Spatial Denseness & $\begin{array}{r}\text { 5. Densely packed } \\
\text { 1. Open Space }\end{array}$ & & & & $\mathrm{X}$ & & 2 \\
\hline XIII & Illusion of Depth & $\begin{array}{l}\text { 5. Deep } \\
\text { 1. Flat }\end{array}$ & $\mathrm{X}$ & & & & & 5 \\
\hline XIV & Time and Motion & $\begin{array}{l}\text { 5. In Motion } \\
\text { 1.No Motion }\end{array}$ & & $\mathrm{X}$ & & & & 4 \\
\hline $\mathrm{XV}$ & Unity and Variety & $\begin{array}{l}\text { 5. Varied } \\
\text { 1. Unified }\end{array}$ & & & & & $\mathrm{X}$ & 1 \\
\hline XVI & Emphasis and Focal Point & $\begin{array}{r}\text { 5. Definite Focal Point } \\
\text { 1. No Focal Point } \\
\end{array}$ & $\mathrm{X}$ & & & & & 5 \\
\hline XVII & Proportion & $\begin{array}{l}\text { 5. Elements in Proportion } \\
\text { 1. Elements out of Proportion }\end{array}$ & $\mathrm{X}$ & & & & & 5 \\
\hline XVIII & Scale (Small to Large) & $\begin{array}{l}\text { 5. Large Scale } \\
\text { 1. Small Scale }\end{array}$ & & & $\mathrm{X}$ & & & 3 \\
\hline XIX & Rhythm & $\begin{array}{r}\text { 5. Rhythmic } \\
\text { 1. Static } \\
\end{array}$ & & $\mathrm{X}$ & & & & 4 \\
\hline
\end{tabular}




\begin{tabular}{|c|c|c|c|c|c|c|c|c|}
\hline $\mathrm{XX}$ & Centric or Eccentric & $\begin{array}{l}\text { 5. Internal Vectors } \\
\text { 1. External Vectors }\end{array}$ & & & $\mathbf{X}$ & & & 3 \\
\hline \multicolumn{3}{|c|}{ Totals } & 8 & 5 & 4 & 2 & 1 & 77 \\
\hline
\end{tabular}

Formal Elements

Rating Scale (FERS)

\begin{tabular}{|c|c|c|c|c|c|c|c|c|}
\hline & \multicolumn{2}{|c|}{$\begin{array}{l}\text { Figure 2: Lemons, Pears, Apples, Grapes } \\
\text { and an Orange } 1887\end{array}$} & 5 & 4 & 3 & 2 & 1 & Total \\
\hline $\mathrm{I}$ & Line Quality & $\begin{array}{l}\text { 5. Fluid and Flowing } \\
\text { 1. Jagged and Broken }\end{array}$ & & $\mathrm{X}$ & & & & 4 \\
\hline II & Expressive Style & $\begin{array}{r}\text { 5. Freedom of Expression } \\
\text { 1. Excessive Repetition }\end{array}$ & & $\mathrm{X}$ & & & & 4 \\
\hline III & Shape and Mass & $\begin{array}{r}\text { 5. Organic } \\
\text { 1. Geometric }\end{array}$ & $\mathrm{X}$ & & & & & 5 \\
\hline IV & Abstraction or Realism & $\begin{array}{l}\text { 5. Realistic } \\
\text { 1. Abstract }\end{array}$ & & & & $\mathrm{X}$ & & 2 \\
\hline $\mathrm{V}$ & Figure Ground Relationship & $\begin{array}{r}\text { 5. Subject Dominant } \\
\text { 1. Background Dominant }\end{array}$ & & & $\mathrm{X}$ & & & 3 \\
\hline VI & Value (Dark and Light) & $\begin{array}{l}\text { 5. Light Colors } \\
\text { 1. Dark Colors }\end{array}$ & $\mathrm{X}$ & & & & & 5 \\
\hline VII & Intensity of Color & $\begin{array}{l}\text { 5. Pure and Saturated } \\
\text { 1. Greyed and Softened }\end{array}$ & $\mathrm{X}$ & & & & & 5 \\
\hline VIII & Variety of Color & $\begin{array}{r}\text { 5. Polychromatic } \\
\text { 1. Monochromatic }\end{array}$ & & & & $\mathrm{X}$ & & 2 \\
\hline IX & Texture & $\begin{array}{l}\text { 5. Impasto } \\
\text { 1. Smooth }\end{array}$ & & $\mathrm{X}$ & & & & 4 \\
\hline $\mathrm{X}$ & Pattern & $\begin{array}{l}\text { 5. Highly Repeated Motifs } \\
\text { 1. No Repeated Motifs }\end{array}$ & & $\mathrm{X}$ & & & & 4 \\
\hline XI & $\begin{array}{l}\text { Spatial Organization } \\
\text { (Evenness of Space) }\end{array}$ & $\begin{array}{l}\text { 5. Evenly Dispersed } \\
\text { 1. Irregularly Dispersed }\end{array}$ & & $\mathrm{X}$ & & & & 4 \\
\hline XII & Spatial Denseness & $\begin{array}{l}\text { 5. Densely packed } \\
\text { 1. Open Space }\end{array}$ & & & $\mathrm{X}$ & & & 3 \\
\hline XIII & Illusion of Depth & $\begin{array}{r}\text { 5. Deep } \\
\text { 1. Flat }\end{array}$ & & & & $\mathrm{X}$ & & 2 \\
\hline XIV & Time and Motion & $\begin{array}{l}\text { 5. In Motion } \\
\text { 1.No Motion }\end{array}$ & & & & & $\mathrm{X}$ & 1 \\
\hline XV & Unity and Variety & $\begin{array}{l}\text { 5. Varied } \\
\text { 1. Unified }\end{array}$ & & & & & $X$ & 1 \\
\hline XVI & Emphasis and Focal Point & $\begin{array}{r}\text { 5. Definite Focal Point } \\
\text { 1. No Focal Point } \\
\end{array}$ & & & $\mathrm{X}$ & & & 3 \\
\hline XVII & Proportion & $\begin{array}{l}\text { 5. Elements in Proportion } \\
\text { 1. Elements out of Proportion }\end{array}$ & $\mathrm{X}$ & & & & & 5 \\
\hline
\end{tabular}




\begin{tabular}{|c|c|c|c|c|c|c|c|c|}
\hline XVIII & Scale (Small to Large) & $\begin{array}{l}\text { 5. Large Scale } \\
\text { 1. Small Scale }\end{array}$ & & & $\mathrm{X}$ & & & 3 \\
\hline XIX & Rhythm & $\begin{array}{c}\text { 5. Rhythmic } \\
\text { 1. Static }\end{array}$ & & & $X$ & & & 3 \\
\hline $\mathrm{XX}$ & Centric or Eccentric & $\begin{array}{l}\text { 5. Internal Vectors } \\
\text { 1. External Vectors }\end{array}$ & $\mathrm{X}$ & & & & & 5 \\
\hline \multicolumn{3}{|c|}{ Totals } & 5 & 5 & 5 & 3 & 2 & 68 \\
\hline
\end{tabular}

Formal Elements

Rating Scale (FERS)

\begin{tabular}{|c|c|c|c|c|c|c|c|c|}
\hline & \multicolumn{2}{|c|}{ Figure 3: Portrait of Pere Tanguy 1887-88 } & \multirow[t]{2}{*}{5} & \multirow{2}{*}{$\begin{array}{l}4 \\
X\end{array}$} & \multirow[t]{2}{*}{3} & \multicolumn{2}{|c|}{21} & Total \\
\hline I & Line Quality & $\begin{array}{l}\text { 5. Fluid and Flowing } \\
\text { 1. Jagged, and Broken }\end{array}$ & & & & & & 4 \\
\hline II & Perseveration & $\begin{array}{l}\text { 5. Freedom of Expression } \\
\text { 1. Excessive Repetition }\end{array}$ & & $\mathrm{X}$ & & & & 4 \\
\hline III & Shape and Mass & $\begin{array}{r}\text { 5. Organic } \\
\text { 1. Geometric }\end{array}$ & $\mathrm{X}$ & & & & & 5 \\
\hline IV & Abstraction vs Realism & $\begin{array}{l}\text { 5. Realistic } \\
\text { 1. Abstract }\end{array}$ & & $\mathrm{X}$ & & & & 4 \\
\hline $\mathrm{V}$ & Figure Ground Relationship & $\begin{array}{r}\text { 5. Subject Dominant } \\
\text { 1. Background Dominant }\end{array}$ & & & $\mathrm{X}$ & & & 3 \\
\hline VI & Value (Dark and Light) & $\begin{array}{l}\text { 5. Light Colors } \\
\text { 1. Dark Colors }\end{array}$ & & & $\mathrm{X}$ & & & 3 \\
\hline VII & Intensity of Color & $\begin{array}{l}\text { 5. Pure and Saturated } \\
\text { 1. Greyed and Softened }\end{array}$ & & & $\mathrm{X}$ & & & 3 \\
\hline VIII & Variety of Color & $\begin{array}{r}\text { 5. Polychromatic } \\
\text { 1. Monochromatic }\end{array}$ & $\mathrm{X}$ & & & & & 5 \\
\hline IX & Texture & $\begin{array}{l}\text { 5. Impasto } \\
\text { 1. Smooth }\end{array}$ & & $\mathrm{X}$ & & & & 4 \\
\hline $\mathrm{X}$ & Pattern & $\begin{array}{l}\text { 5. Highly Repeated Motifs } \\
\text { 1. No Repeated Motifs }\end{array}$ & $\mathrm{X}$ & & & & & 5 \\
\hline XI & $\begin{array}{l}\text { Spatial Organization } \\
\text { (Evenness of Space) }\end{array}$ & $\begin{array}{l}\text { 5. Evenly Dispersed } \\
\text { 1. Irregularly Dispersed }\end{array}$ & & & & & $\mathrm{X}$ & 1 \\
\hline$\overline{\mathrm{XII}}$ & $\begin{array}{l}\text { Spatial Organization } \\
\text { (Denseness) }\end{array}$ & $\begin{array}{r}\text { 5. Densely packed } \\
\text { 1. Open Space }\end{array}$ & $\mathrm{X}$ & & & & & 5 \\
\hline XIII & Illusion of Depth & $\begin{array}{r}\text { 5. Deep } \\
\text { 1. Flat }\end{array}$ & & & & $\mathrm{X}$ & & 2 \\
\hline XIV & Time and Motion & $\begin{array}{l}\text { 5. In Motion } \\
\text { 1.No Motion }\end{array}$ & & & & & $\mathrm{X}$ & 1 \\
\hline
\end{tabular}




\begin{tabular}{|c|c|c|c|c|c|c|c|c|}
\hline $\mathrm{XV}$ & Unity and Variety & $\begin{array}{l}\text { 5. Varied } \\
\text { 1. Unified }\end{array}$ & & & & & $\mathrm{X}$ & 1 \\
\hline$\overline{\mathrm{XVI}}$ & Emphasis and Focal Point & $\begin{array}{r}\text { 5. .Definate Focal Point } \\
\text { 1. No Focal Point }\end{array}$ & $\mathrm{X}$ & & & & & 5 \\
\hline XVII & Proportion & $\begin{array}{l}\text { 5. Elements in Proportion } \\
\text { 1. Elements out of Proportion }\end{array}$ & $\mathrm{X}$ & & & & & 5 \\
\hline XVIII & Scale (Small to Large) & $\begin{array}{l}\text { 5. Large Scale } \\
\text { 1. Small Scale }\end{array}$ & & & $\mathrm{X}$ & & & 3 \\
\hline XIX & Rhythm & $\begin{array}{r}\text { 5. Rhythmic } \\
\text { 1. Static }\end{array}$ & & & & & $\mathrm{X}$ & 1 \\
\hline XX & Centric or Eccentric & $\begin{array}{l}\text { 5. Internal Vectors } \\
\text { 1. External Vectors }\end{array}$ & & & & $\mathbf{X}$ & & 3 \\
\hline \multicolumn{3}{|c|}{ Totals } & 5 & 6 & 4 & 3 & 1 & 67 \\
\hline
\end{tabular}

Formal Elements

Rating Scale (FERS)

\begin{tabular}{|c|c|c|c|c|c|c|c|c|}
\hline & \multicolumn{2}{|c|}{ Figure 4: Self Portrait, Paris 1886} & \multirow{2}{*}{\multicolumn{2}{|c|}{\begin{tabular}{l|l}
\multicolumn{1}{l|}{4} & 4 \\
$X$ &
\end{tabular}}} & \multirow[t]{2}{*}{3} & \multicolumn{2}{|c|}{21} & \multirow{2}{*}{$\begin{array}{c}\text { Total } \\
5\end{array}$} \\
\hline $\mathrm{I}$ & Line Quality & $\begin{array}{l}\text { 5. Fluid and Flowing } \\
\text { 1. Jagged, and Broken }\end{array}$ & & & & & & \\
\hline II & Perseveration & $\begin{array}{l}\text { 5. Freedom of Expression } \\
\text { 1. Excessive Repetition }\end{array}$ & & $\mathrm{X}$ & & & & 4 \\
\hline III & Shape and Mass & $\begin{array}{r}\text { 5. Organic } \\
\text { 1. Geometric }\end{array}$ & $\mathrm{X}$ & & & & & 5 \\
\hline IV & Abstraction vs Realism & $\begin{array}{l}\text { 5. Realistic } \\
\text { 1. Abstract }\end{array}$ & $\mathrm{X}$ & & & & & 5 \\
\hline $\mathrm{V}$ & Figure Ground Relationship & $\begin{array}{r}\text { 5. Subject Dominant } \\
\text { 1. Background Dominant }\end{array}$ & & & $\mathrm{X}$ & & & 3 \\
\hline VI & Value (Dark and Light) & $\begin{array}{l}\text { 5. Light Colors } \\
\text { 1. Dark Colors }\end{array}$ & & & & & $\mathrm{X}$ & 1 \\
\hline VII & Intensity of Color & $\begin{array}{l}\text { 5. Pure and Saturated } \\
\text { 1. Greyed and Softened }\end{array}$ & & & & $\mathrm{X}$ & & 2 \\
\hline VIII & Variety of Color & $\begin{array}{r}\text { 5. Polychromatic } \\
\text { 1. Monochromatic }\end{array}$ & & & & $\mathrm{X}$ & & 2 \\
\hline IX & Texture & $\begin{array}{l}\text { 5. Impasto } \\
\text { 1. Smooth } \\
\end{array}$ & & & & & $\mathrm{X}$ & 1 \\
\hline $\mathrm{X}$ & Pattern & $\begin{array}{l}\text { 5. Highly Repeated Motifs } \\
\text { 1. No Repeated Motifs }\end{array}$ & & & & & $\mathrm{X}$ & 1 \\
\hline $\mathrm{XI}$ & $\begin{array}{l}\text { Spatial Organization } \\
\text { (Evenness of Space) }\end{array}$ & $\begin{array}{r}\text { 5. Evenly Dispersed } \\
\text { 1. Irregularly Dispersed }\end{array}$ & $\mathrm{X}$ & & & & & 5 \\
\hline
\end{tabular}




\begin{tabular}{|c|c|c|c|c|c|c|c|c|}
\hline XII & $\begin{array}{l}\text { Spatial Organization } \\
\text { (Denseness) }\end{array}$ & $\begin{array}{r}\text { 5. Densely packed } \\
\text { 1. Open Space }\end{array}$ & & & $\mathrm{X}$ & & & 3 \\
\hline$\overline{\mathrm{XIII}}$ & Illusion of Depth & $\begin{array}{r}\text { 5. Deep } \\
\text { 1. Flat } \\
\end{array}$ & & & & & $\mathrm{X}$ & 1 \\
\hline XIV & Time and Motion & $\begin{array}{l}\text { 5. In Motion } \\
\text { 1.No Motion }\end{array}$ & & & & & $\mathrm{X}$ & 1 \\
\hline $\mathrm{XV}$ & Unity and Variety & $\begin{array}{l}\text { 5. Varied } \\
\text { 1. Unified }\end{array}$ & & & & & $\mathrm{X}$ & 1 \\
\hline XVI & Emphasis and Focal Point & $\begin{array}{r}\text { 5. .Definate Focal Point } \\
\text { 1. No Focal Point } \\
\end{array}$ & $\mathrm{X}$ & & & & & 5 \\
\hline XVII & Proportion & $\begin{array}{l}\text { 5. Elements in Proportion } \\
\text { 1. Elements out of Proportion }\end{array}$ & $\mathrm{X}$ & & & & & 5 \\
\hline XVIII & Scale (Small to Large) & $\begin{array}{l}\text { 5. Large Scale } \\
\text { 1. Small Scale }\end{array}$ & & & $\mathrm{X}$ & & & 3 \\
\hline XIX & Rhythm & $\begin{array}{r}\text { 5. Rhythmic } \\
\text { 1. Static } \\
\end{array}$ & & & & & $\mathrm{X}$ & 1 \\
\hline $\mathrm{XX}$ & Centric or Eccentric & $\begin{array}{r}\text { 5. Internal Vectors } \\
\text { 1. External Vectors }\end{array}$ & $\mathbf{X}$ & & & & & 5 \\
\hline \multicolumn{3}{|c|}{ Totals } & 7 & 1 & 3 & 2 & 7 & 60 \\
\hline
\end{tabular}

Formal Elements

Rating Scale (FERS)

\begin{tabular}{|c|c|c|c|c|c|c|c|c|}
\hline & \multicolumn{2}{|c|}{ Figure 5: Self-Portrait, Paris 1887} & 5 & 4 & 3 & 2 & 1 & Total \\
\hline $\mathrm{I}$ & Line Quality & $\begin{array}{l}\text { 5. Fluid and Flowing } \\
\text { 1. Jagged and Broken }\end{array}$ & & & & $\mathrm{X}$ & & 2 \\
\hline II & Expressive Style & $\begin{array}{l}\text { 5. Freedom of Expression } \\
\text { 1. Excessive Repetition }\end{array}$ & & & & & $\mathrm{X}$ & 1 \\
\hline III & Shape and Mass & $\begin{array}{r}\text { 5. Organic } \\
\text { 1. Geometric } \\
\end{array}$ & & & $\mathrm{X}$ & & & 3 \\
\hline IV & Abstraction or Realism & $\begin{array}{l}\text { 5. Realistic } \\
\text { 1. Abstract }\end{array}$ & & & $\mathrm{X}$ & & & 3 \\
\hline $\mathrm{V}$ & Figure Ground Relationship & $\begin{array}{r}\text { 5. Subject Dominant } \\
\text { 1. Background Dominant }\end{array}$ & & & $\mathrm{X}$ & & & 3 \\
\hline VI & Value (Dark and Light) & $\begin{array}{l}\text { 5. Light Colors } \\
\text { 1. Dark Colors }\end{array}$ & & & & $\mathrm{X}$ & & 2 \\
\hline VII & Intensity of Color & $\begin{array}{l}\text { 5. Pure and Saturated } \\
\text { 1. Greyed and Softened }\end{array}$ & & & & $\mathrm{X}$ & & 2 \\
\hline VIII & Variety of Color & $\begin{array}{r}\text { 5. Polychromatic } \\
\text { 1. Monochromatic }\end{array}$ & & & $\mathrm{X}$ & & & 3 \\
\hline
\end{tabular}




\begin{tabular}{|c|c|c|c|c|c|c|c|c|}
\hline IX & Texture & $\begin{array}{l}\text { 5. Impasto } \\
\text { 1. Smooth }\end{array}$ & & $\mathrm{X}$ & & & & 4 \\
\hline $\mathrm{X}$ & Pattern & $\begin{array}{l}\text { 5. Highly Repeated Motifs } \\
\text { 1. No Repeated Motifs }\end{array}$ & $\mathrm{X}$ & & & & & 5 \\
\hline $\mathrm{XI}$ & $\begin{array}{l}\text { Spatial Organization } \\
\text { (Evenness of Space) }\end{array}$ & $\begin{array}{r}\text { 5. Evenly Dispersed } \\
\text { 1. Irregularly Dispersed }\end{array}$ & $\mathrm{X}$ & & & & & 5 \\
\hline XII & Spatial Denseness & $\begin{array}{r}\text { 5. Densely packed } \\
\text { 1. Open Space } \\
\end{array}$ & & $\mathrm{X}$ & & & & 4 \\
\hline XIII & Illusion of Depth & $\begin{array}{l}\text { 5. Deep } \\
\text { 1. Flat } \\
\end{array}$ & & & & & $\mathrm{X}$ & 1 \\
\hline XIV & Time and Motion & $\begin{array}{l}\text { 5. In Motion } \\
\text { 1.No Motion }\end{array}$ & & & & & $\mathrm{X}$ & 1 \\
\hline $\mathrm{XV}$ & Unity and Variety & $\begin{array}{l}\text { 5. Varied } \\
\text { 1. Unified }\end{array}$ & & $\mathrm{X}$ & & & & 4 \\
\hline$\overline{\mathrm{XVI}}$ & Emphasis and Focal Point & $\begin{array}{r}\text { 5. Definite Focal Point } \\
1 . \text { No Focal Point }\end{array}$ & $\mathrm{X}$ & & & & & 5 \\
\hline XVII & Proportion & $\begin{array}{l}\text { 5. Elements in Proportion } \\
\text { 1. Elements out of Proportion }\end{array}$ & $\mathrm{X}$ & & & & & 5 \\
\hline XVIII & Scale (Small to Large) & $\begin{array}{l}\text { 5. Large Scale } \\
\text { 1. Small Scale }\end{array}$ & & & $\mathrm{X}$ & & & 3 \\
\hline XIX & Rhythm & $\begin{array}{c}\text { 5. Rhythmic } \\
\text { 1. Static }\end{array}$ & $\mathrm{X}$ & & & & & 5 \\
\hline XX & Centric or Eccentric & $\begin{array}{l}\text { 5. Internal Vectors } \\
\text { 1. External Vectors }\end{array}$ & $X$ & & & & & 5 \\
\hline \multicolumn{3}{|c|}{ Totals } & 6 & 3 & 5 & 3 & 3 & 66 \\
\hline
\end{tabular}

Formal Elements

Rating Scale (FERS)

\begin{tabular}{|c|c|c|c|c|c|c|c|c|}
\hline & \multicolumn{2}{|c|}{$\begin{array}{l}\text { Figure 6: Self-Portrait, Paris } 1887 \text { (in pale } \\
\text { tones) }\end{array}$} & \multirow[t]{2}{*}{5} & \multirow[t]{2}{*}{4} & \multirow[t]{2}{*}{3} & \multirow[t]{2}{*}{2} & \multirow[t]{2}{*}{1} & \multirow{2}{*}{$\begin{array}{c}\text { Total } \\
2\end{array}$} \\
\hline $\bar{I}$ & Line Quality & $\begin{array}{l}\text { 5. Fluid and Flowing } \\
\text { 1. Jagged and Broken }\end{array}$ & & & & & & \\
\hline II & Expressive Style & $\begin{array}{l}\text { 5. Freedom of Expression } \\
\text { 1. Excessive Repetition }\end{array}$ & $\mathrm{X}$ & & & & & 5 \\
\hline III & Shape and Mass & $\begin{array}{r}\text { 5. Organic } \\
\text { 1. Geometric }\end{array}$ & & $\mathrm{X}$ & & & & 4 \\
\hline IV & Abstraction or Realism & $\begin{array}{l}\text { 5. Realistic } \\
\text { 1. Abstract }\end{array}$ & & & $\mathrm{X}$ & & & 3 \\
\hline
\end{tabular}




\begin{tabular}{|c|c|c|c|c|c|c|c|c|}
\hline $\mathrm{V}$ & Figure Ground Relationship & $\begin{array}{r}\text { 5. Subject Dominant } \\
\text { 1. Background Dominant } \\
\end{array}$ & & & $\mathrm{X}$ & & & 3 \\
\hline VI & Value (Dark and Light) & $\begin{array}{l}\text { 5. Light Colors } \\
\text { 1. Dark Colors }\end{array}$ & & $\mathrm{X}$ & & & & 4 \\
\hline VII & Intensity of Color & $\begin{array}{l}\text { 5. Pure and Saturated } \\
\text { 1. Greyed and Softened }\end{array}$ & & & & $\mathrm{X}$ & & 2 \\
\hline VIII & Variety of Color & $\begin{array}{r}\text { 5. Polychromatic } \\
\text { 1. Monochromatic }\end{array}$ & & & & $\bar{X}$ & & 2 \\
\hline IX & Texture & $\begin{array}{l}\text { 5. Impasto } \\
\text { 1. Smooth } \\
\end{array}$ & & & $\mathrm{X}$ & & & 3 \\
\hline $\bar{X}$ & Pattern & $\begin{array}{l}\text { 5. Highly Repeated Motifs } \\
\text { 1. No Repeated Motifs }\end{array}$ & $\mathrm{X}$ & & & & & 5 \\
\hline XI & $\begin{array}{l}\text { Spatial Organization } \\
\text { (Evenness of Space) }\end{array}$ & $\begin{array}{l}\text { 5. Evenly Dispersed } \\
\text { 1. Irregularly Dispersed }\end{array}$ & $\mathrm{X}$ & & & & & 5 \\
\hline XII & Spatial Denseness & $\begin{array}{r}\text { 5. Densely packed } \\
\text { 1. Open Space }\end{array}$ & & $\mathrm{X}$ & & & & 4 \\
\hline XIII & Illusion of Depth & $\begin{array}{l}\text { 5. Deep } \\
\text { 1. Flat }\end{array}$ & & & & & $\mathrm{X}$ & 1 \\
\hline$\overline{\mathrm{XIV}}$ & Time and Motion & $\begin{array}{l}\text { 5. In Motion } \\
\text { 1.No Motion }\end{array}$ & & & & & $\mathrm{X}$ & 1 \\
\hline $\mathrm{XV}$ & Unity and Variety & $\begin{array}{l}\text { 5. Varied } \\
\text { 1. Unified }\end{array}$ & & & $\mathrm{X}$ & & & 3 \\
\hline XVI & Emphasis and Focal Point & $\begin{array}{r}\text { 5. Definite Focal Point } \\
\text { 1. No Focal Point }\end{array}$ & $\mathrm{X}$ & & & & & 5 \\
\hline XVII & Proportion & $\begin{array}{l}\text { 5. Elements in Proportion } \\
\text { 1. Elements out of Proportion }\end{array}$ & $\mathrm{X}$ & & & & & 5 \\
\hline XVIII & Scale (Small to Large) & $\begin{array}{l}\text { 5. Large Scale } \\
\text { 1. Small Scale }\end{array}$ & & & $\mathrm{X}$ & & & 3 \\
\hline XIX & Rhythm & $\begin{array}{c}\text { 5. Rhythmic } \\
\text { 1. Static }\end{array}$ & & & $\mathrm{X}$ & & & 3 \\
\hline XX & Centric or Eccentric & $\begin{array}{l}\text { 5. Internal Vectors } \\
\text { 1. External Vectors }\end{array}$ & $X$ & & & & & 5 \\
\hline \multicolumn{3}{|c|}{ Totals } & 6 & 3 & 6 & 3 & 2 & 68 \\
\hline
\end{tabular}

Formal Elements

Rating Scale (FERS)

\begin{tabular}{|c|c|c|c|c|c|c|c|c|}
\hline & $\begin{array}{l}\text { Figure } 7: \text { Se } \\
\text { Paris } 1887\end{array}$ & Grey Felt Hat, & 5 & 4 & 3 & 2 & 1 & Total \\
\hline I & Line Quality & $\begin{array}{l}\text { 5. Fluid and Flowing } \\
\text { 1. Jagged and Broken }\end{array}$ & & $\mathrm{X}$ & & & & 4 \\
\hline II & Expressive Style & $\begin{array}{l}\text { 5. Freedom of Expression } \\
\text { 1. Excessive Repetition }\end{array}$ & & $\mathrm{X}$ & & & & 4 \\
\hline
\end{tabular}




\begin{tabular}{|c|c|c|c|c|c|c|c|c|}
\hline III & Shape and Mass & $\begin{array}{r}\text { 5. Organic } \\
\text { 1. Geometric }\end{array}$ & $\mathrm{X}$ & & & & & 5 \\
\hline IV & Abstraction or Realism & $\begin{array}{l}\text { 5. Realistic } \\
\text { 1. Abstract }\end{array}$ & & $\mathrm{X}$ & & & & 4 \\
\hline $\mathrm{V}$ & Figure Ground Relationship & $\begin{array}{r}\text { 5. Subject Dominant } \\
\text { 1. Background Dominant }\end{array}$ & & & $\mathrm{X}$ & & & 3 \\
\hline VI & Value (Dark and Light) & $\begin{array}{l}\text { 5. Light Colors } \\
\text { 1. Dark Colors }\end{array}$ & & $\mathrm{X}$ & & & & 4 \\
\hline VII & Intensity of Color & $\begin{array}{l}\text { 5. Pure and Saturated } \\
\text { 1. Greyed and Softened }\end{array}$ & & & & $\mathrm{X}$ & & 2 \\
\hline VIII & Variety of Color & $\begin{array}{r}\text { 5. Polychromatic } \\
\text { 1. Monochromatic }\end{array}$ & & $\mathrm{X}$ & & & & 4 \\
\hline IX & Texture & $\begin{array}{l}\text { 5. Impasto } \\
\text { 1. Smooth }\end{array}$ & & $\mathrm{X}$ & & & & 4 \\
\hline $\mathrm{X}$ & Pattern & $\begin{array}{l}\text { 5. Highly Repeated Motifs } \\
\text { 1. No Repeated Motifs }\end{array}$ & & & & $\mathrm{X}$ & & 2 \\
\hline $\mathrm{XI}$ & $\begin{array}{l}\text { Spatial Organization } \\
\text { (Evenness of Space) }\end{array}$ & $\begin{array}{l}\text { 5. Evenly Dispersed } \\
\text { 1. Irregularly Dispersed }\end{array}$ & & & $\mathrm{X}$ & & & 3 \\
\hline XII & Spatial Denseness & $\begin{array}{r}\text { 5. Densely packed } \\
\text { 1. Open Space }\end{array}$ & & & $\mathrm{X}$ & & & 3 \\
\hline XIII & Illusion of Depth & $\begin{array}{r}\text { 5. Deep } \\
\text { 1. Flat }\end{array}$ & & & & $\mathrm{X}$ & & 2 \\
\hline XIV & Time and Motion & $\begin{array}{l}\text { 5. In Motion } \\
\text { 1.No Motion }\end{array}$ & & & & & $\mathrm{X}$ & 1 \\
\hline $\mathrm{XV}$ & Unity and Variety & $\begin{array}{l}\text { 5. Varied } \\
\text { 1. Unified }\end{array}$ & & & $\mathrm{X}$ & & & 3 \\
\hline XVI & Emphasis and Focal Point & $\begin{array}{r}\text { 5. Definite Focal Point } \\
1 . \text { No Focal Point }\end{array}$ & $\mathrm{X}$ & & & & & 5 \\
\hline XVII & Proportion & $\begin{array}{l}\text { 5. Elements in Proportion } \\
\text { 1. Elements out of Proportion }\end{array}$ & $\mathrm{X}$ & & & & & 5 \\
\hline XVIII & Scale (Small to Large) & $\begin{array}{l}\text { 5. Large Scale } \\
\text { 1. Small Scale }\end{array}$ & & & $\mathrm{X}$ & & & 3 \\
\hline XIX & Rhythm & $\begin{array}{c}\text { 5. Rhythmic } \\
\text { 1. Static }\end{array}$ & & & & & $\mathrm{X}$ & 1 \\
\hline $\mathrm{XX}$ & Centric or Eccentric & $\begin{array}{l}\text { 5. Internal Vectors } \\
\text { 1. External Vectors }\end{array}$ & & $\mathbf{X}$ & & & & 4 \\
\hline \multicolumn{3}{|c|}{ Totals } & 3 & 7 & 5 & 3 & 2 & 66 \\
\hline
\end{tabular}

Formal Elements

Rating Scale (FERS) 


\begin{tabular}{|c|c|c|c|c|c|c|c|c|}
\hline & 1888 & & & & & & & \\
\hline $\mathrm{I}$ & Line Quality & $\begin{array}{l}\text { 5. Fluid and Flowing } \\
\text { 1. Jagged and Broken }\end{array}$ & & & $\mathrm{X}$ & & & 3 \\
\hline II & Expressive Style & $\begin{array}{l}\text { 5. Freedom of Expression } \\
\text { 1. Excessive Repetition } \\
\end{array}$ & & & & & $\mathrm{X}$ & 1 \\
\hline III & Shape and Mass & $\begin{array}{r}\text { 5. Organic } \\
\text { 1. Geometric }\end{array}$ & $\mathrm{X}$ & & & & & 5 \\
\hline IV & Abstraction or Realism & $\begin{array}{l}\text { 5. Realistic } \\
\text { 1. Abstract }\end{array}$ & & $\mathrm{X}$ & & & & 4 \\
\hline $\mathrm{V}$ & Figure Ground Relationship & $\begin{array}{r}\text { 5. Subject Dominant } \\
\text { 1. Background Dominant }\end{array}$ & & $\mathrm{X}$ & & & & 4 \\
\hline VI & Value (Dark and Light) & $\begin{array}{l}\text { 5. Light Colors } \\
\text { 1. Dark Colors } \\
\end{array}$ & & $\mathrm{X}$ & & & & 4 \\
\hline VII & Intensity of Color & $\begin{array}{l}\text { 5. Pure and Saturated } \\
\text { 1. Greyed and Softened }\end{array}$ & & & & $\mathrm{X}$ & & 2 \\
\hline VIII & Variety of Color & $\begin{array}{r}\text { 5. Polychromatic } \\
\text { 1. Monochromatic }\end{array}$ & & & $\mathrm{X}$ & & & 3 \\
\hline IX & Texture & $\begin{array}{l}\text { 5. Impasto } \\
\text { 1. Smooth }\end{array}$ & & $\mathrm{X}$ & & & & 4 \\
\hline $\mathrm{X}$ & Pattern & $\begin{array}{l}\text { 5. Highly Repeated Motifs } \\
\text { 1. No Repeated Motifs }\end{array}$ & $\mathrm{X}$ & & & & & 5 \\
\hline $\mathrm{XI}$ & $\begin{array}{l}\text { Spatial Organization } \\
\text { (Evenness of Space) }\end{array}$ & $\begin{array}{r}\text { 5. Evenly Dispersed } \\
\text { 1. Irregularly Dispersed }\end{array}$ & & & & $\mathrm{X}$ & & 2 \\
\hline XII & Spatial Denseness & $\begin{array}{r}\text { 5. Densely packed } \\
\text { 1. Open Space } \\
\end{array}$ & $\mathrm{X}$ & & & & & 5 \\
\hline XIII & Illusion of Depth & $\begin{array}{r}\text { 5. Deep } \\
\text { 1. Flat } \\
\end{array}$ & & & & & $\mathrm{X}$ & 1 \\
\hline XIV & Time and Motion & $\begin{array}{l}\text { 5. In Motion } \\
\text { 1.No Motion }\end{array}$ & & & & & $\mathrm{X}$ & 1 \\
\hline $\mathrm{XV}$ & Unity and Variety & $\begin{array}{l}\text { 5. Varied } \\
\text { 1. Unified }\end{array}$ & & $\mathrm{X}$ & & & & 4 \\
\hline XVI & Emphasis and Focal Point & $\begin{array}{r}\text { 5. Definite Focal Point } \\
\text { 1. No Focal Point } \\
\end{array}$ & $\mathrm{X}$ & & & & & 5 \\
\hline XVII & Proportion & $\begin{array}{l}\text { 5. Elements in Proportion } \\
\text { 1. Elements out of Proportion }\end{array}$ & $\mathrm{X}$ & & & & & 5 \\
\hline XVIII & Scale (Small to Large) & $\begin{array}{l}\text { 5. Large Scale } \\
\text { 1. Small Scale }\end{array}$ & & & $\mathrm{X}$ & & & 3 \\
\hline XIX & Rhythm & $\begin{array}{c}\text { 5. Rhythmic } \\
\text { 1. Static }\end{array}$ & $\mathrm{X}$ & & & & & 5 \\
\hline $\mathrm{XX}$ & Centric or Eccentric & $\begin{array}{l}\text { 5. Internal Vectors } \\
\text { 1. External Vectors }\end{array}$ & $\mathbf{X}$ & & & & & 5 \\
\hline \multicolumn{3}{|c|}{ Totals } & 7 & 5 & 3 & 2 & 3 & 71 \\
\hline
\end{tabular}

Formal Elements

Rating Scale (FERS) 


\begin{tabular}{|c|c|c|c|c|c|c|c|c|}
\hline $\mathrm{I}$ & Line Quality & $\begin{array}{l}\text { 5. Fluid and Flowing } \\
\text { 1. Jagged and Broken } \\
\end{array}$ & & & $\mathrm{X}$ & & & 3 \\
\hline II & Expressive Style & $\begin{array}{l}\text { 5. Freedom of Expression } \\
\text { 1. Excessive Repetition }\end{array}$ & & $\mathrm{X}$ & & & & 4 \\
\hline III & Shape and Mass & $\begin{array}{r}\text { 5. Organic } \\
\text { 1. Geometric }\end{array}$ & & $\mathrm{X}$ & & & & 4 \\
\hline IV & Abstraction or Realism & $\begin{array}{l}\text { 5. Realistic } \\
\text { 1. Abstract }\end{array}$ & $\mathrm{X}$ & & & & & 5 \\
\hline $\mathrm{V}$ & Figure Ground Relationship & $\begin{array}{r}\text { 5. Subject Dominant } \\
\text { 1. Background Dominant }\end{array}$ & & & $\mathrm{X}$ & & & 3 \\
\hline VI & Value (Dark and Light) & $\begin{array}{l}\text { 5. Light Colors } \\
\text { 1. Dark Colors } \\
\end{array}$ & & $\mathrm{X}$ & & & & 4 \\
\hline VII & Intensity of Color & $\begin{array}{l}\text { 5. Pure and Saturated } \\
\text { 1. Greyed and Softened }\end{array}$ & & $\mathrm{X}$ & & & & 4 \\
\hline VIII & Variety of Color & $\begin{array}{r}\text { 5. Polychromatic } \\
\text { 1. Monochromatic }\end{array}$ & & $\mathrm{X}$ & & & & 4 \\
\hline IX & Texture & $\begin{array}{l}\text { 5. Impasto } \\
\text { 1. Smooth }\end{array}$ & & & & $\mathrm{X}$ & & 2 \\
\hline $\mathrm{X}$ & Pattern & $\begin{array}{l}\text { 5. Highly Repeated Motifs } \\
\text { 1. No Repeated Motifs }\end{array}$ & & & $\mathrm{X}$ & & & 3 \\
\hline XI & $\begin{array}{l}\text { Spatial Organization } \\
\text { (Evenness of Space) }\end{array}$ & $\begin{array}{l}\text { 5. Evenly Dispersed } \\
\text { 1. Irregularly Dispersed }\end{array}$ & & & & $\mathrm{X}$ & & 2 \\
\hline XII & Spatial Denseness & $\begin{array}{r}\text { 5. Densely packed } \\
\text { 1. Open Space }\end{array}$ & & & & $\mathrm{X}$ & & 2 \\
\hline XIII & Illusion of Depth & $\begin{array}{r}\text { 5. Deep } \\
\text { 1. Flat }\end{array}$ & $\mathrm{X}$ & & & & & 5 \\
\hline XIV & Time and Motion & $\begin{array}{l}\text { 5. In Motion } \\
\text { 1.No Motion }\end{array}$ & & & & & $\mathrm{X}$ & 1 \\
\hline $\mathrm{XV}$ & Unity and Variety & $\begin{array}{l}\text { 5. Varied } \\
\text { 1. Unified }\end{array}$ & & & $\mathrm{X}$ & & & 3 \\
\hline XVI & Emphasis and Focal Point & $\begin{array}{r}\text { 5. Definite Focal Point } \\
1 . \text { No Focal Point } \\
\end{array}$ & & & $\mathrm{X}$ & & & 3 \\
\hline XVII & Proportion & $\begin{array}{r}\text { 5. Elements in Proportion } \\
\text { 1. Elements out of Proportion }\end{array}$ & $\mathrm{X}$ & & & & & 5 \\
\hline XVIII & Scale (Small to Large) & $\begin{array}{l}\text { 5. Large Scale } \\
\text { 1. Small Scale }\end{array}$ & & & $\mathrm{X}$ & & & 3 \\
\hline XIX & Rhythm & $\begin{array}{r}\text { 5. Rhythmic } \\
\text { 1. Static } \\
\end{array}$ & & & & & $\mathrm{X}$ & 1 \\
\hline $\mathrm{XX}$ & Centric or Eccentric & $\begin{array}{l}\text { 5. Internal Vectors } \\
\text { 1. External Vectors }\end{array}$ & & & & $\mathrm{X}$ & & 2 \\
\hline \multicolumn{3}{|c|}{$\begin{array}{ll}\text { Totals } \\
\end{array}$} & 3 & 5 & 7 & 3 & 2 & 63 \\
\hline
\end{tabular}

Formal Elements

Rating Scale (FERS) 


\begin{tabular}{|c|c|c|c|c|c|c|c|c|}
\hline $\mathrm{I}$ & Line Quality & $\begin{array}{l}\text { 5. Fluid and Flowing } \\
\text { 1. Jagged and Broken }\end{array}$ & & $\mathrm{X}$ & & & & 4 \\
\hline II & Expressive Style & $\begin{array}{l}\text { 5. Freedom of Expression } \\
\text { 1. Excessive Repetition }\end{array}$ & & $\mathrm{X}$ & & & & 4 \\
\hline III & Shape and Mass & $\begin{array}{r}\text { 5. Organic } \\
\text { 1. Geometric }\end{array}$ & & $\mathrm{X}$ & & & & 4 \\
\hline IV & Abstraction or Realism & $\begin{array}{l}\text { 5. Realistic } \\
\text { 1. Abstract }\end{array}$ & & $X$ & & & & 4 \\
\hline $\mathrm{V}$ & Figure Ground Relationship & $\begin{array}{r}\text { 5. Subject Dominant } \\
\text { 1. Background Dominant }\end{array}$ & & $\mathrm{X}$ & & & & 4 \\
\hline VI & Value (Dark and Light) & $\begin{array}{l}\text { 5. Light Colors } \\
\text { 1. Dark Colors }\end{array}$ & & & $\mathrm{X}$ & & & 3 \\
\hline VII & Intensity of Color & $\begin{array}{l}\text { 5. Pure and Saturated } \\
\text { 1. Greyed and Softened }\end{array}$ & $\mathrm{X}$ & & & & & 5 \\
\hline VIII & Variety of Color & $\begin{array}{r}\text { 5. Polychromatic } \\
\text { 1. Monochromatic } \\
\end{array}$ & $\mathrm{X}$ & & & & & 5 \\
\hline IX & Texture & $\begin{array}{l}\text { 5. Impasto } \\
\text { 1. Smooth }\end{array}$ & & & $\mathrm{X}$ & & & 3 \\
\hline $\mathrm{X}$ & Pattern & $\begin{array}{l}\text { 5. Highly Repeated Motifs } \\
\text { 1. No Repeated Motifs }\end{array}$ & & & $\mathrm{X}$ & & & 3 \\
\hline XI & $\begin{array}{l}\text { Spatial Organization } \\
\text { (Evenness of Space) }\end{array}$ & $\begin{array}{l}\text { 5. Evenly Dispersed } \\
\text { 1. Irregularly Dispersed }\end{array}$ & $\mathrm{X}$ & & & & & 5 \\
\hline XII & Spatial Denseness & $\begin{array}{r}\text { 5. Densely packed } \\
\text { 1. Open Space } \\
\end{array}$ & & $\mathrm{X}$ & & & & 4 \\
\hline XIII & Illusion of Depth & $\begin{array}{l}\text { 5. Deep } \\
\text { 1. Flat }\end{array}$ & $\mathrm{X}$ & & & & & 5 \\
\hline XIV & Time and Motion & $\begin{array}{l}\text { 5. In Motion } \\
\text { 1.No Motion }\end{array}$ & $\mathrm{X}$ & & & & & 5 \\
\hline $\mathrm{XV}$ & Unity and Variety & $\begin{array}{l}\text { 5. Varied } \\
\text { 1. Unified }\end{array}$ & & & & & $\mathrm{X}$ & 1 \\
\hline XVI & Emphasis and Focal Point & $\begin{array}{r}\text { 5. Definite Focal Point } \\
\text { 1. No Focal Point } \\
\end{array}$ & $X$ & & & & & 5 \\
\hline XVII & Proportion & $\begin{array}{l}\text { 5. Elements in Proportion } \\
\text { 1. Elements out of Proportion }\end{array}$ & $X$ & & & & & 5 \\
\hline XVIII & Scale (Small to Large) & $\begin{array}{l}\text { 5. Large Scale } \\
\text { 1. Small Scale }\end{array}$ & & & $X$ & & & 3 \\
\hline XIX & Rhythm & $\begin{array}{c}\text { 5. Rhythmic } \\
\text { 1. Static }\end{array}$ & & & $X$ & & & 3 \\
\hline XX & Centric or Eccentric & $\begin{array}{l}\text { 5. Internal Vectors } \\
\text { 1. External Vectors }\end{array}$ & & & $\mathrm{X}$ & & & 3 \\
\hline \multicolumn{3}{|c|}{$\begin{array}{ll} & \text { Totals } \\
\end{array}$} & 7 & 6 & 6 & 0 & 1 & 78 \\
\hline
\end{tabular}

Formal Elements

Rating Scale (FERS) 


\begin{tabular}{|c|c|c|c|c|c|c|c|c|}
\hline I & Line Quality & $\begin{array}{l}\text { 5. Fluid and Flowing } \\
\text { 1. Jagged and Broken }\end{array}$ & & & $\mathrm{X}$ & & & 3 \\
\hline II & Expressive Style & $\begin{array}{l}\text { 5. Freedom of Expression } \\
\text { 1. Excessive Repetition }\end{array}$ & & & & $\mathrm{X}$ & & 2 \\
\hline III & Shape and Mass & $\begin{array}{r}\text { 5. Organic } \\
\text { 1. Geometric } \\
\end{array}$ & & $\mathrm{X}$ & & & & 4 \\
\hline IV & Abstraction or Realism & $\begin{array}{l}\text { 5. Realistic } \\
\text { 1. Abstract }\end{array}$ & & X & & & & 4 \\
\hline $\mathrm{V}$ & Figure Ground Relationship & $\begin{array}{r}\text { 5. Subject Dominant } \\
\text { 1. Background Dominant }\end{array}$ & & & $\mathrm{X}$ & & & 3 \\
\hline VI & Value (Dark and Light) & $\begin{array}{l}\text { 5. Light Colors } \\
\text { 1. Dark Colors }\end{array}$ & & $\mathrm{X}$ & & & & 4 \\
\hline VII & Intensity of Color & $\begin{array}{l}\text { 5. Pure and Saturated } \\
\text { 1. Greyed and Softened }\end{array}$ & & $\mathrm{X}$ & & & & 4 \\
\hline VIII & Variety of Color & $\begin{array}{r}\text { 5. Polychromatic } \\
\text { 1. Monochromatic }\end{array}$ & $\mathrm{X}$ & & & & & 5 \\
\hline IX & Texture & $\begin{array}{l}\text { 5. Impasto } \\
\text { 1. Smooth }\end{array}$ & & $\mathrm{X}$ & & & & 4 \\
\hline $\mathrm{X}$ & Pattern & $\begin{array}{l}\text { 5. Highly Repeated Motifs } \\
\text { 1. No Repeated Motifs }\end{array}$ & $\mathrm{X}$ & & & & & 5 \\
\hline XI & $\begin{array}{l}\text { Spatial Denseness } \\
\text { (Evenness of Space) }\end{array}$ & $\begin{array}{l}\text { 5. Evenly Dispersed } \\
\text { 1. Irregularly Dispersed }\end{array}$ & & & & $\mathrm{X}$ & & 2 \\
\hline XII & Spatial Denseness & $\begin{array}{r}\text { 5. Densely packed } \\
\text { 1. Open Space } \\
\end{array}$ & & $\mathrm{X}$ & & & & 4 \\
\hline XIII & Illusion of Depth & $\begin{array}{r}\text { 5. Deep } \\
\text { 1. Flat }\end{array}$ & $\mathrm{X}$ & & & & & 5 \\
\hline XIV & Time and Motion & $\begin{array}{l}\text { 5. In Motion } \\
\text { 1.No Motion }\end{array}$ & & & & & $\mathrm{X}$ & 1 \\
\hline $\mathrm{XV}$ & Unity and Variety & $\begin{array}{l}\text { 5. Varied } \\
\text { 1. Unified }\end{array}$ & & $\mathrm{X}$ & & & & 4 \\
\hline XVI & Emphasis and Focal Point & $\begin{array}{r}\text { 5. Definite Focal Point } \\
\text { 1. No Focal Point } \\
\end{array}$ & & & & $\mathrm{X}$ & & 2 \\
\hline XVII & Proportion & $\begin{array}{l}\text { 5. Elements in Proportion } \\
\text { 1. Elements out of Proportion }\end{array}$ & $\mathrm{X}$ & & & & & 5 \\
\hline XVIII & Scale (Small to Large) & $\begin{array}{l}\text { 5. Large Scale } \\
\text { 1. Small Scale }\end{array}$ & & & $\mathrm{X}$ & & & 3 \\
\hline XIX & Rhythm & $\begin{array}{c}\text { 5. Rhythmic } \\
\text { 1. Static } \\
\end{array}$ & & & $\mathrm{X}$ & & & 3 \\
\hline XX & Centric or Eccentric & $\begin{array}{l}\text { 5. Internal Vectors } \\
\text { 1. External Vectors }\end{array}$ & & X & & & & 4 \\
\hline \multicolumn{3}{|c|}{ Totals } & 4 & 8 & 4 & 3 & 1 & 71 \\
\hline
\end{tabular}

Formal Elements

Rating Scale (FERS) 


\begin{tabular}{|c|c|c|c|c|c|c|c|c|}
\hline $\mathrm{I}$ & Line Quality & $\begin{array}{l}\text { 5. Fluid and Flowing } \\
\text { 1. Jagged and Broken }\end{array}$ & & $\mathrm{X}$ & & & & 4 \\
\hline II & Expressive Style & $\begin{array}{l}\text { 5. Freedom of Expression } \\
\text { 1. Excessive Repetition }\end{array}$ & & $\mathrm{X}$ & & & & 4 \\
\hline III & Shape and Mass & $\begin{array}{r}\text { 5. Organic } \\
\text { 1. Geometric }\end{array}$ & & & $\mathrm{X}$ & & & 3 \\
\hline IV & Abstraction or Realism & $\begin{array}{l}\text { 5. Realistic } \\
\text { 1. Abstract }\end{array}$ & & $X$ & & & & 4 \\
\hline $\mathrm{V}$ & Figure Ground Relationship & $\begin{array}{r}\text { 5. Subject Dominant } \\
\text { 1. Background Dominant }\end{array}$ & & & & $\mathrm{X}$ & & 2 \\
\hline VI & Value (Dark and Light) & $\begin{array}{l}\text { 5. Light Colors } \\
\text { 1. Dark Colors }\end{array}$ & & & $\mathrm{X}$ & & & 3 \\
\hline VII & Intensity of Color & $\begin{array}{l}\text { 5. Pure and Saturated } \\
\text { 1. Greyed and Softened }\end{array}$ & & $\mathrm{X}$ & & & & 4 \\
\hline VIII & Variety of Color & $\begin{array}{r}\text { 5. Polychromatic } \\
\text { 1. Monochromatic }\end{array}$ & $\mathrm{X}$ & & & & & 5 \\
\hline IX & Texture & $\begin{array}{l}\text { 5. Impasto } \\
\text { 1. Smooth }\end{array}$ & & $\mathrm{X}$ & & & & 4 \\
\hline $\mathrm{X}$ & Pattern & $\begin{array}{l}\text { 5. Highly Repeated Motifs } \\
\text { 1. No Repeated Motifs }\end{array}$ & & $\mathrm{X}$ & & & & 4 \\
\hline XI & $\begin{array}{l}\text { Spatial Organization } \\
\text { (Evenness of Space) }\end{array}$ & $\begin{array}{l}\text { 5. Evenly Dispersed } \\
\text { 1. Irregularly Dispersed }\end{array}$ & & & & $\mathrm{X}$ & & 2 \\
\hline XII & Spatial Denseness & $\begin{array}{r}\text { 5. Densely packed } \\
\text { 1. Open Space }\end{array}$ & & & & $\mathrm{X}$ & & 2 \\
\hline XIII & Illusion of Depth & $\begin{array}{r}\text { 5. Deep } \\
\text { 1. Flat }\end{array}$ & $\mathrm{X}$ & & & & & 5 \\
\hline XIV & Time and Motion & $\begin{array}{l}\text { 5. In Motion } \\
\text { 1.No Motion }\end{array}$ & & & & $\mathrm{X}$ & & 2 \\
\hline $\mathrm{XV}$ & Unity and Variety & $\begin{array}{l}\text { 5. Varied } \\
\text { 1. Unified } \\
\end{array}$ & & & & & $\mathrm{X}$ & 1 \\
\hline XVI & Emphasis and Focal Point & $\begin{array}{r}\text { 5. Definite Focal Point } \\
1 . \text { No Focal Point } \\
\end{array}$ & & $\mathrm{X}$ & & & & 4 \\
\hline XVII & Proportion & $\begin{array}{l}\text { 5. Elements in Proportion } \\
\text { 1. Elements out of Proportion }\end{array}$ & $\mathrm{X}$ & & & & & 5 \\
\hline XVIII & Scale (Small to Large) & $\begin{array}{l}\text { 5. Large Scale } \\
\text { 1. Small Scale }\end{array}$ & & & $\mathrm{X}$ & & & 3 \\
\hline XIX & Rhythm & $\begin{array}{c}\text { 5. Rhythmic } \\
\text { 1. Static }\end{array}$ & & & & $\mathrm{X}$ & & 2 \\
\hline $\mathrm{XX}$ & Centric or Eccentric & $\begin{array}{l}\text { 5. Internal Vectors } \\
\text { 1. External Vectors }\end{array}$ & & $\mathrm{X}$ & & & & 4 \\
\hline \multicolumn{3}{|c|}{\begin{tabular}{|l} 
Totals \\
\end{tabular}} & 3 & 8 & 3 & 5 & 1 & 67 \\
\hline
\end{tabular}

Formal Elements

Rating Scale (FERS) 


\begin{tabular}{|c|c|c|c|c|c|c|c|c|}
\hline $\mathrm{I}$ & Line Quality & $\begin{array}{l}\text { 5. Fluid and Flowing } \\
\text { 1. Jagged and Broken }\end{array}$ & $\mathrm{X}$ & & & & & 5 \\
\hline II & Expressive Style & $\begin{array}{l}\text { 5. Freedom of Expression } \\
\text { 1. Excessive Repetition } \\
\end{array}$ & & & $\mathrm{X}$ & & & 3 \\
\hline III & Shape and Mass & $\begin{array}{r}\text { 5. Organic } \\
\text { 1. Geometric }\end{array}$ & & $\mathrm{X}$ & & & & 4 \\
\hline IV & Abstraction or Realism & $\begin{array}{l}\text { 5. Realistic } \\
\text { 1. Abstract }\end{array}$ & $\mathrm{X}$ & & & & & 5 \\
\hline $\mathrm{V}$ & Figure Ground Relationship & $\begin{array}{r}\text { 5. Subject Dominant } \\
\text { 1. Background Dominant }\end{array}$ & & & $\mathrm{X}$ & & & 3 \\
\hline VI & Value (Dark and Light) & $\begin{array}{r}\text { 5. Light Colors } \\
\text { 1. Dark Colors } \\
\end{array}$ & & & $\mathrm{X}$ & & & 3 \\
\hline VII & Intensity of Color & $\begin{array}{l}\text { 5. Pure and Saturated } \\
\text { 1. Greyed and Softened }\end{array}$ & & $\mathrm{X}$ & & & & 4 \\
\hline VIII & Variety of Color & $\begin{array}{r}\text { 5. Polychromatic } \\
\text { 1. Monochromatic }\end{array}$ & $\mathrm{X}$ & & & & & 5 \\
\hline IX & Texture & $\begin{array}{l}\text { 5. Impasto } \\
\text { 1. Smooth }\end{array}$ & & $\mathrm{X}$ & & & & 4 \\
\hline $\mathrm{X}$ & Pattern & $\begin{array}{l}\text { 5. Highly Repeated Motifs } \\
\text { 1. No Repeated Motifs }\end{array}$ & $\mathrm{X}$ & & & & & 5 \\
\hline $\mathrm{XI}$ & $\begin{array}{l}\text { Spatial Organization } \\
\text { (Evenness of Space) }\end{array}$ & $\begin{array}{l}\text { 5. Evenly Dispersed } \\
\text { 1. Irregularly Dispersed }\end{array}$ & & & $\mathrm{X}$ & & & 3 \\
\hline XII & Spatial Denseness & $\begin{array}{r}\text { 5. Densely packed } \\
\text { 1. Open Space }\end{array}$ & & & $\mathrm{X}$ & & & 3 \\
\hline XIII & Illusion of Depth & $\begin{array}{r}\text { 5. Deep } \\
\text { 1. Flat } \\
\end{array}$ & $\mathrm{X}$ & & & & & 5 \\
\hline XIV & Time and Motion & $\begin{array}{l}\text { 5. In Motion } \\
\text { 1.No Motion }\end{array}$ & & & & & $\mathrm{X}$ & 1 \\
\hline $\mathrm{XV}$ & Unity and Variety & $\begin{array}{l}\text { 5. Varied } \\
\text { 1. Unified } \\
\end{array}$ & & & & & $\mathrm{X}$ & 1 \\
\hline XVI & Emphasis and Focal Point & $\begin{array}{r}\text { 5. Definite Focal Point } \\
1 . \text { No Focal Point } \\
\end{array}$ & & & & $\mathrm{X}$ & & 2 \\
\hline XVII & Proportion & $\begin{array}{l}\text { 5. Elements in Proportion } \\
\text { 1. Elements out of Proportion }\end{array}$ & $\mathrm{X}$ & & & & & 5 \\
\hline XVIII & Scale (Small to Large) & $\begin{array}{l}\text { 5. Large Scale } \\
\text { 1. Small Scale }\end{array}$ & & & $\mathrm{X}$ & & & 3 \\
\hline XIX & Rhythm & $\begin{array}{c}\text { 5. Rhythmic } \\
\text { 1. Static }\end{array}$ & & & $\mathrm{X}$ & & & 3 \\
\hline $\mathrm{XX}$ & Centric or Eccentric & $\begin{array}{l}\text { 5. Internal Vectors } \\
\text { 1. External Vectors }\end{array}$ & & & & $\mathrm{X}$ & & 2 \\
\hline \multicolumn{3}{|c|}{$\begin{array}{ll}\text { Totals } \\
\end{array}$} & 6 & 3 & 7 & 2 & 2 & 69 \\
\hline
\end{tabular}

Formal Elements

Rating Scale (FERS) 
Formal Elements

Rating Scale (FERS)

\begin{tabular}{|c|c|c|c|c|c|c|c|c|}
\hline & \multicolumn{2}{|c|}{$\begin{array}{l}\text { Figure 14: Still Life with Blue Enamel } \\
\text { Coffeepot, } 1888\end{array}$} & \multirow[t]{2}{*}{5} & \multirow{2}{*}{$\begin{array}{l}4 \\
X\end{array}$} & \multirow[t]{2}{*}{3} & \multirow[t]{2}{*}{2} & \multirow[t]{2}{*}{1} & \multirow{2}{*}{$\begin{array}{c}\text { Total } \\
4\end{array}$} \\
\hline $\mathrm{I}$ & Line Quality & $\begin{array}{l}\text { 5. Fluid and Flowing } \\
\text { 1. Jagged and Broken }\end{array}$ & & & & & & \\
\hline II & Expressive Style & $\begin{array}{l}\text { 5. Freedom of Expression } \\
\text { 1. Excessive Repetition }\end{array}$ & $\mathrm{X}$ & & & & & 5 \\
\hline III & Shape and Mass & $\begin{array}{r}\text { 5. Organic } \\
\text { 1. Geometric }\end{array}$ & & & & $\mathrm{X}$ & & 2 \\
\hline IV & Abstraction or Realism & $\begin{array}{l}\text { 5. Realistic } \\
\text { 1. Abstract }\end{array}$ & & $X$ & & & & 4 \\
\hline $\mathrm{V}$ & Figure Ground Relationship & $\begin{array}{r}\text { 5. Subject Dominant } \\
\text { 1. Background Dominant } \\
\end{array}$ & & $\mathrm{X}$ & & & & 4 \\
\hline VI & Value (Dark and Light) & $\begin{array}{l}\text { 5. Light Colors } \\
\text { 1. Dark Colors }\end{array}$ & & & $\mathrm{X}$ & & & 3 \\
\hline VII & Intensity of Color & $\begin{array}{l}\text { 5. Pure and Saturated } \\
\text { 1. Greyed and Softened }\end{array}$ & & $\mathrm{X}$ & & & & 4 \\
\hline VIII & Variety of Color & $\begin{array}{r}\text { 5. Polychromatic } \\
\text { 1. Monochromatic }\end{array}$ & $\mathrm{X}$ & & & & & 5 \\
\hline IX & Texture & $\begin{array}{l}\text { 5. Impasto } \\
\text { 1. Smooth } \\
\end{array}$ & & & $\mathrm{X}$ & & & 3 \\
\hline $\bar{X}$ & Pattern & $\begin{array}{l}\text { 5. Highly Repeated Motifs } \\
\text { 1. No Repeated Motifs }\end{array}$ & & & $\mathrm{X}$ & & & 3 \\
\hline XI & $\begin{array}{l}\text { Spatial Organization } \\
\text { (Evenness of Space) }\end{array}$ & $\begin{array}{l}\text { 5. Evenly Dispersed } \\
\text { 1. Irregularly Dispersed }\end{array}$ & & & $\mathrm{X}$ & & & 3 \\
\hline XII & Spatial Denseness & $\begin{array}{r}\text { 5. Densely packed } \\
\text { 1. Open Space }\end{array}$ & & & & $\mathrm{X}$ & & 2 \\
\hline XIII & Illusion of Depth & $\begin{array}{l}\text { 5. Deep } \\
\text { 1. Flat }\end{array}$ & & & $\mathrm{X}$ & & & 3 \\
\hline XIV & Time and Motion & $\begin{array}{l}\text { 5. In Motion } \\
\text { 1.No Motion }\end{array}$ & & & & & $\mathrm{X}$ & 1 \\
\hline $\mathrm{XV}$ & Unity and Variety & $\begin{array}{l}\text { 5. Varied } \\
\text { 1. Unified }\end{array}$ & & & $\mathrm{X}$ & & & 3 \\
\hline XVI & Emphasis and Focal Point & $\begin{array}{r}\text { 5. Definite Focal Point } \\
1 . \text { No Focal Point } \\
\end{array}$ & $\mathrm{X}$ & & & & & 5 \\
\hline XVII & Proportion & $\begin{array}{l}\text { 5. Elements in Proportion } \\
\text { 1. Elements out of Proportion }\end{array}$ & $X$ & & & & & 5 \\
\hline XVIII & Scale (Small to Large) & $\begin{array}{l}\text { 5. Large Scale } \\
\text { 1. Small Scale }\end{array}$ & & & $\mathrm{X}$ & & & 3 \\
\hline XIX & Rhythm & $\begin{array}{c}\text { 5. Rhythmic } \\
\text { 1. Static }\end{array}$ & & & & $X$ & & 2 \\
\hline $\mathrm{XX}$ & Centric or Eccentric & $\begin{array}{l}\text { 5. Internal Vectors } \\
\text { 1. External Vectors }\end{array}$ & & & $\mathrm{X}$ & & & 3 \\
\hline & Totals & & 4 & 4 & 8 & 3 & 1 & 67 \\
\hline
\end{tabular}


Formal Elements

Rating Scale (FERS)

\begin{tabular}{|c|c|c|c|c|c|c|c|c|}
\hline & \multicolumn{2}{|c|}{$\begin{array}{l}\text { Figure 15: Fishing Boats on the Beach at } \\
\text { Saintes-Maries-de-la Mer, } 1888\end{array}$} & \multirow[t]{2}{*}{5} & \multirow[t]{2}{*}{4} & \multirow{2}{*}{\begin{tabular}{|l|}
3 \\
$X$
\end{tabular}} & \multirow[t]{2}{*}{2} & \multirow[t]{2}{*}{1} & \multirow{2}{*}{$\begin{array}{c}\text { Total } \\
3\end{array}$} \\
\hline $\mathrm{I}$ & Line Quality & $\begin{array}{l}\text { 5. Fluid and Flowing } \\
\text { 1. Jagged and Broken }\end{array}$ & & & & & & \\
\hline II & Expressive Style & $\begin{array}{l}\text { 5. Freedom of Expression } \\
\text { 1. Excessive Repetition }\end{array}$ & & & $\mathrm{X}$ & & & 3 \\
\hline III & Shape and Mass & $\begin{array}{r}\text { 5. Organic } \\
\text { 1. Geometric }\end{array}$ & & & $\mathrm{X}$ & & & 3 \\
\hline IV & Abstraction or Realism & $\begin{array}{l}\text { 5. Realistic } \\
\text { 1. Abstract }\end{array}$ & $\mathrm{X}$ & & & & & 5 \\
\hline $\mathrm{V}$ & Figure Ground Relationship & $\begin{array}{l}\text { 5. Subject Dominant } \\
\text { 1. Background Dominant }\end{array}$ & & & & $\mathrm{X}$ & & 2 \\
\hline VI & Value (Dark and Light) & $\begin{array}{l}\text { 5. Light Colors } \\
\text { 1. Dark Colors }\end{array}$ & & $\mathrm{X}$ & & & & 4 \\
\hline VII & Intensity of Color & $\begin{array}{l}\text { 5. Pure and Saturated } \\
\text { 1. Greyed and Softened }\end{array}$ & & & & $\mathrm{X}$ & & 2 \\
\hline VIII & Variety of Color & $\begin{array}{l}\text { 5. Polychromatic } \\
\text { 1. Monochromatic }\end{array}$ & & & $\mathrm{X}$ & & & 3 \\
\hline IX & Texture & $\begin{array}{l}\text { 5. Impasto } \\
\text { 1. Smooth }\end{array}$ & & & $\mathrm{X}$ & & & 3 \\
\hline $\bar{X}$ & Pattern & $\begin{array}{l}\text { 5. Highly Repeated Motifs } \\
\text { 1. No Repeated Motifs }\end{array}$ & & $\mathrm{X}$ & & & & 4 \\
\hline $\mathrm{XI}$ & $\begin{array}{l}\text { Spatial Organization } \\
\text { (Evenness of Space) }\end{array}$ & $\begin{array}{r}\text { 5. Evenly Dispersed } \\
\text { 1. Irregularly Dispersed } \\
\end{array}$ & & & $\mathrm{X}$ & & & 3 \\
\hline$\overline{\mathrm{XII}}$ & Spatial Denseness & $\begin{array}{r}\text { 5. Densely packed } \\
\text { 1. Open Space }\end{array}$ & & & & $\mathrm{X}$ & & 2 \\
\hline XIII & Illusion of Depth & $\begin{array}{r}\text { 5. Deep } \\
\text { 1. Flat }\end{array}$ & $\mathrm{X}$ & & & & & 5 \\
\hline XIV & Time and Motion & $\begin{array}{l}\text { 5. In Motion } \\
\text { 1.No Motion }\end{array}$ & & & & & $\mathrm{X}$ & 1 \\
\hline $\mathrm{XV}$ & Unity and Variety & $\begin{array}{l}\text { 5. Varied } \\
\text { 1. Unified }\end{array}$ & & & & & $\mathrm{X}$ & 1 \\
\hline$\overline{\mathrm{XVI}}$ & Emphasis and Focal Point & $\begin{array}{r}\text { 5. Definite Focal Point } \\
\text { 1. No Focal Point }\end{array}$ & & $\mathrm{X}$ & & & & 4 \\
\hline XVII & Proportion & $\begin{array}{l}\text { 5. Elements in Proportion } \\
\text { 1. Elements out of Proportion }\end{array}$ & $\mathrm{X}$ & & & & & 5 \\
\hline XVIII & Scale (Small to Large) & $\begin{array}{l}\text { 5. Large Scale } \\
\text { 1. Small Scale }\end{array}$ & & & $\mathrm{X}$ & & & 3 \\
\hline XIX & Rhythm & $\begin{array}{r}\text { 5. Rhythmic } \\
\text { 1. Static } \\
\end{array}$ & & & $\mathrm{X}$ & & & 3 \\
\hline $\mathrm{XX}$ & Centric or Eccentric & $\begin{array}{l}\text { 5. Internal Vectors } \\
\text { 1. External Vectors }\end{array}$ & & & $\mathrm{X}$ & & & 3 \\
\hline & Totals & & 3 & 3 & 9 & 3 & 2 & 62 \\
\hline
\end{tabular}


Formal Elements

Rating Scale (FERS)

\begin{tabular}{|c|c|c|c|c|c|c|c|c|}
\hline & \multicolumn{2}{|c|}{ Figure 16: Portrait of a Zouave, 1888} & \multirow[t]{2}{*}{5} & \multirow{2}{*}{$\begin{array}{l}4 \\
X\end{array}$} & \multirow[t]{2}{*}{3} & \multirow[t]{2}{*}{2} & \multirow[t]{2}{*}{1} & \multirow{2}{*}{$\frac{\text { Total }}{4}$} \\
\hline $\mathrm{I}$ & Line Quality & $\begin{array}{l}\text { 5. Fluid and Flowing } \\
\text { 1. Jagged and Broken }\end{array}$ & & & & & & \\
\hline II & Expressive Style & $\begin{array}{l}\text { 5. Freedom of Expression } \\
\text { 1. Excessive Repetition }\end{array}$ & & $\mathrm{X}$ & & & & 4 \\
\hline III & Shape and Mass & $\begin{array}{r}\text { 5. Organic } \\
\text { 1. Geometric }\end{array}$ & & & $\mathrm{X}$ & & & 3 \\
\hline IV & Abstraction or Realism & $\begin{array}{l}\text { 5. Realistic } \\
\text { 1. Abstract }\end{array}$ & & $\mathrm{X}$ & & & & 4 \\
\hline $\mathrm{V}$ & Figure Ground Relationship & $\begin{array}{l}\text { 5. Subject Dominant } \\
\text { 1. Background Dominant }\end{array}$ & & $\mathrm{X}$ & & & & 4 \\
\hline VI & Value (Dark and Light) & $\begin{array}{l}\text { 5. Light Colors } \\
\text { 1. Dark Colors }\end{array}$ & & & & $\mathrm{X}$ & & 2 \\
\hline VII & Intensity of Color & $\begin{array}{l}\text { 5. Pure and Saturated } \\
\text { 1. Greyed and Softened }\end{array}$ & $\mathrm{X}$ & & & & & 5 \\
\hline VIII & Variety of Color & $\begin{array}{l}\text { 5. Polychromatic } \\
\text { 1. Monochromatic }\end{array}$ & $\mathrm{X}$ & & & & & 5 \\
\hline IX & Texture & $\begin{array}{l}\text { 5. Impasto } \\
\text { 1. Smooth }\end{array}$ & & & & $\mathrm{X}$ & & 2 \\
\hline $\mathrm{X}$ & Pattern & $\begin{array}{l}\text { 5. Highly Repeated Motifs } \\
\text { 1. No Repeated Motifs }\end{array}$ & & & $\mathrm{X}$ & & & 3 \\
\hline $\mathrm{XI}$ & $\begin{array}{l}\text { Spatial Organization } \\
\text { (Evenness of Space) }\end{array}$ & $\begin{array}{l}\text { 5. Evenly Dispersed } \\
\text { 1. Irregularly Dispersed }\end{array}$ & & & & $\mathrm{X}$ & & 2 \\
\hline XII & Spatial Denseness & $\begin{array}{r}\text { 5. Densely packed } \\
\text { 1. Open Space }\end{array}$ & $\mathrm{X}$ & & & & & 5 \\
\hline XIII & Illusion of Depth & $\begin{array}{l}\text { 5. Deep } \\
\text { 1. Flat }\end{array}$ & & & & & $\mathrm{X}$ & 1 \\
\hline XIV & Time and Motion & $\begin{array}{l}\text { 5. In Motion } \\
\text { 1.No Motion }\end{array}$ & & & & & $\mathrm{X}$ & 1 \\
\hline $\mathrm{XV}$ & Unity and Variety & $\begin{array}{l}\text { 5. Varied } \\
\text { 1. Unified }\end{array}$ & & & & $\mathrm{X}$ & & 2 \\
\hline XVI & Emphasis and Focal Point & $\begin{array}{r}\text { 5. Definite Focal Point } \\
\text { 1. No Focal Point }\end{array}$ & $\mathrm{X}$ & & & & & 5 \\
\hline XVII & Proportion & $\begin{array}{l}\text { 5. Elements in Proportion } \\
\text { 1. Elements out of Proportion }\end{array}$ & & & $\mathrm{X}$ & & & 3 \\
\hline XVIII & Scale (Small to Large) & $\begin{array}{l}\text { 5. Large Scale } \\
\text { 1. Small Scale }\end{array}$ & & $\mathrm{X}$ & & & & 4 \\
\hline XIX & Rhythm & $\begin{array}{r}\text { 5. Rhythmic } \\
\text { 1. Static } \\
\end{array}$ & & & & $\mathrm{X}$ & & 2 \\
\hline XX & Centric or Eccentric & $\begin{array}{l}\text { 5. Internal Vectors } \\
\text { 1. External Vectors }\end{array}$ & & & $\mathrm{X}$ & & & 3 \\
\hline & Totals & & 4 & 5 & 4 & 5 & 2 & 64 \\
\hline
\end{tabular}


Formal Elements

Rating Scale (FERS)

\begin{tabular}{|c|c|c|c|c|c|c|c|c|}
\hline & \multicolumn{2}{|c|}{ Figure 17: La Mousmé, 1888} & \multirow[t]{2}{*}{5} & \multirow{2}{*}{$\begin{array}{l}4 \\
X\end{array}$} & \multirow[t]{2}{*}{3} & \multirow[t]{2}{*}{2} & \multirow[t]{2}{*}{1} & \multirow{2}{*}{$\frac{\text { Total }}{4}$} \\
\hline $\mathrm{I}$ & Line Quality & $\begin{array}{l}\text { 5. Fluid and Flowing } \\
\text { 1. Jagged and Broken }\end{array}$ & & & & & & \\
\hline II & Expressive Style & $\begin{array}{l}\text { 5. Freedom of Expression } \\
\text { 1. Excessive Repetition }\end{array}$ & $\mathrm{X}$ & & & & & 5 \\
\hline III & Shape and Mass & $\begin{array}{r}\text { 5. Organic } \\
\text { 1. Geometric }\end{array}$ & & $\mathrm{X}$ & & & & 4 \\
\hline IV & Abstraction or Realism & $\begin{array}{l}\text { 5. Realistic } \\
\text { 1. Abstract }\end{array}$ & $\mathrm{X}$ & & & & & 5 \\
\hline $\mathrm{V}$ & Figure Ground Relationship & $\begin{array}{r}\text { 5. Subject Dominant } \\
\text { 1. Background Dominant }\end{array}$ & & $\mathrm{X}$ & & & & 4 \\
\hline VI & Value (Dark and Light) & $\begin{array}{l}\text { 5. Light Colors } \\
\text { 1. Dark Colors }\end{array}$ & & & $\mathrm{X}$ & & & 3 \\
\hline VII & Intensity of Color & $\begin{array}{l}\text { 5. Pure and Saturated } \\
\text { 1. Greyed and Softened }\end{array}$ & & & $\mathrm{X}$ & & & 3 \\
\hline VIII & Variety of Color & $\begin{array}{l}\text { 5. Polychromatic } \\
\text { 1. Monochromatic }\end{array}$ & & $\mathrm{X}$ & & & & 4 \\
\hline IX & Texture & $\begin{array}{l}\text { 5. Impasto } \\
\text { 1. Smooth } \\
\end{array}$ & & & & $\mathrm{X}$ & & 2 \\
\hline $\mathrm{X}$ & Pattern & $\begin{array}{l}\text { 5. Highly Repeated Motifs } \\
\text { 1. No Repeated Motifs }\end{array}$ & & $\mathrm{X}$ & & & & 4 \\
\hline $\mathrm{XI}$ & $\begin{array}{l}\text { Spatial Organization } \\
\text { (Evenness of Space) }\end{array}$ & $\begin{array}{l}\text { 5. Evenly Dispersed } \\
\text { 1. Irregularly Dispersed }\end{array}$ & & & $\mathrm{X}$ & & & 3 \\
\hline XII & Spatial Denseness & $\begin{array}{l}\text { 5. Densely packed } \\
\text { 1. Open Space }\end{array}$ & & & $\mathrm{X}$ & & & 3 \\
\hline XIII & Illusion of Depth & $\begin{array}{r}\text { 5. Deep } \\
\text { 1. Flat }\end{array}$ & & & & & $\mathrm{X}$ & 1 \\
\hline XIV & Time and Motion & $\begin{array}{l}\text { 5. In Motion } \\
\text { 1.No Motion }\end{array}$ & & & & & $\mathrm{X}$ & 1 \\
\hline $\mathrm{XV}$ & Unity and Variety & $\begin{array}{l}\text { 5. Varied } \\
\text { 1. Unified }\end{array}$ & & & & & $\mathrm{X}$ & 1 \\
\hline XVI & Emphasis and Focal Point & $\begin{array}{r}\text { 5. Definite Focal Point } \\
1 . \text { No Focal Point }\end{array}$ & $\mathrm{X}$ & & & & & 5 \\
\hline XVII & Proportion & $\begin{array}{l}\text { 5. Elements in Proportion } \\
\text { 1. Elements out of Proportion }\end{array}$ & & $\mathrm{X}$ & & & & 4 \\
\hline XVIII & Scale (Small to Large) & $\begin{array}{l}\text { 5. Large Scale } \\
\text { 1. Small Scale }\end{array}$ & & & $\mathrm{X}$ & & & 3 \\
\hline XIX & Rhythm & $\begin{array}{r}\text { 5. Rhythmic } \\
\text { 1. Static }\end{array}$ & & & & $\mathrm{X}$ & & 2 \\
\hline XX & Centric or Eccentric & $\begin{array}{l}\text { 5. Internal Vectors } \\
\text { 1. External Vectors }\end{array}$ & & & $\mathrm{X}$ & & & 3 \\
\hline & Totals & & 3 & 6 & 6 & 2 & 3 & 64 \\
\hline
\end{tabular}


Formal Elements

Rating Scale (FERS)

\begin{tabular}{|c|c|c|c|c|c|c|c|c|}
\hline & \multicolumn{2}{|c|}{ Figure 18: Portrait of Joseph Roulin, 1888} & \multirow[t]{2}{*}{5} & \multirow{2}{*}{$\begin{array}{l}4 \\
X\end{array}$} & \multirow[t]{2}{*}{3} & \multirow[t]{2}{*}{2} & \multirow[t]{2}{*}{1} & \multirow{2}{*}{$\frac{\text { Total }}{4}$} \\
\hline $\mathrm{I}$ & Line Quality & $\begin{array}{l}\text { 5. Fluid and Flowing } \\
\text { 1. Jagged and Broken }\end{array}$ & & & & & & \\
\hline II & Expressive Style & $\begin{array}{l}\text { 5. Freedom of Expression } \\
\text { 1. Excessive Repetition }\end{array}$ & & $\mathrm{X}$ & & & & 4 \\
\hline III & Shape and Mass & $\begin{array}{r}\text { 5. Organic } \\
\text { 1. Geometric }\end{array}$ & & $\mathrm{X}$ & & & & 4 \\
\hline IV & Abstraction or Realism & $\begin{array}{r}\text { 5. Realistic } \\
\text { 1. Abstract }\end{array}$ & $\mathrm{X}$ & & & & & 5 \\
\hline $\mathrm{V}$ & Figure Ground Relationship & $\begin{array}{r}\text { 5. Subject Dominant } \\
\text { 1. Background Dominant } \\
\end{array}$ & & $\mathrm{X}$ & & & & 4 \\
\hline VI & Value (Dark and Light) & $\begin{array}{l}\text { 5. Light Colors } \\
\text { 1. Dark Colors }\end{array}$ & & & $\mathrm{X}$ & & & 3 \\
\hline VII & Intensity of Color & $\begin{array}{l}\text { 5. Pure and Saturated } \\
\text { 1. Greyed and Softened }\end{array}$ & & $\mathrm{X}$ & & & & 4 \\
\hline VIII & Variety of Color & $\begin{array}{r}\text { 5. Polychromatic } \\
\text { 1. Monochromatic }\end{array}$ & & $\mathrm{X}$ & & & & 4 \\
\hline IX & Texture & $\begin{array}{l}\text { 5. Impasto } \\
\text { 1. Smooth }\end{array}$ & & & & $\mathrm{X}$ & & 2 \\
\hline $\mathrm{X}$ & Pattern & $\begin{array}{l}\text { 5. Highly Repeated Motifs } \\
\text { 1. No Repeated Motifs }\end{array}$ & & & & $\mathrm{X}$ & & 2 \\
\hline $\mathrm{XI}$ & $\begin{array}{l}\text { Spatial Organization } \\
\text { (Evenness of Space) }\end{array}$ & $\begin{array}{l}\text { 5. Evenly Dispersed } \\
\text { 1. Irregularly Dispersed }\end{array}$ & & & & $\mathrm{X}$ & & 2 \\
\hline XII & Spatial Denseness & $\begin{array}{r}\text { 5. Densely packed } \\
\text { 1. Open Space }\end{array}$ & & $\mathrm{X}$ & & & & 4 \\
\hline XIII & Illusion of Depth & $\begin{array}{r}\text { 5. Deep } \\
\text { 1. Flat }\end{array}$ & & & & & $\mathrm{X}$ & 1 \\
\hline XIV & Time and Motion & $\begin{array}{l}\text { 5. In Motion } \\
\text { 1.No Motion }\end{array}$ & & & & & $\mathrm{X}$ & 1 \\
\hline $\mathrm{XV}$ & Unity and Variety & $\begin{array}{l}\text { 5. Varied } \\
\text { 1. Unified }\end{array}$ & & & & & $\mathrm{X}$ & 1 \\
\hline $\mathrm{XVI}$ & Emphasis and Focal Point & $\begin{array}{r}\text { 5. Definite Focal Point } \\
\text { 1. No Focal Point }\end{array}$ & $\mathrm{X}$ & & & & & 5 \\
\hline XVII & Proportion & $\begin{array}{l}\text { 5. Elements in Proportion } \\
\text { 1. Elements out of Proportion }\end{array}$ & & $\mathrm{X}$ & & & & 4 \\
\hline XVIII & Scale (Small to Large) & $\begin{array}{l}\text { 5. Large Scale } \\
\text { 1. Small Scale }\end{array}$ & & $\mathrm{X}$ & & & & 4 \\
\hline XIX & Rhythm & $\begin{array}{r}\text { 5. Rhythmic } \\
\text { 1. Static } \\
\end{array}$ & & & & & $\mathrm{X}$ & 1 \\
\hline $\mathrm{XX}$ & Centric or Eccentric & $\begin{array}{l}\text { 5. Internal Vectors } \\
\text { 1. External Vectors }\end{array}$ & & $\mathrm{X}$ & & & & 4 \\
\hline & Totals & & 2 & 10 & 1 & 3 & 4 & 63 \\
\hline
\end{tabular}


Formal Elements

Rating Scale (FERS)

\begin{tabular}{|c|c|c|c|c|c|c|c|c|}
\hline & \multicolumn{2}{|c|}{$\begin{array}{l}\text { Figure 19: Portrait of Eugene Boch } \\
\text { (The Poet), } 1888\end{array}$} & \multirow[t]{2}{*}{5} & \multirow{2}{*}{$\begin{array}{l}4 \\
X\end{array}$} & \multirow[t]{2}{*}{3} & \multirow[t]{2}{*}{2} & \multirow[t]{2}{*}{1} & \multirow{2}{*}{$\begin{array}{c}\text { Total } \\
4\end{array}$} \\
\hline $\mathrm{I}$ & Line Quality & $\begin{array}{l}\text { 5. Fluid and Flowing } \\
\text { 1. Jagged and Broken }\end{array}$ & & & & & & \\
\hline II & Expressive Style & $\begin{array}{l}\text { 5. Freedom of Expression } \\
\text { 1. Excessive Repetition }\end{array}$ & $\mathrm{X}$ & & & & & 5 \\
\hline III & Shape and Mass & $\begin{array}{r}\text { 5. Organic } \\
\text { 1. Geometric }\end{array}$ & & $\mathrm{X}$ & & & & 4 \\
\hline IV & Abstraction or Realism & $\begin{array}{l}\text { 5. Realistic } \\
\text { 1. Abstract }\end{array}$ & & $\mathrm{X}$ & & & & 4 \\
\hline $\mathrm{V}$ & Figure Ground Relationship & $\begin{array}{r}\text { 5. Subject Dominant } \\
\text { 1. Background Dominant }\end{array}$ & & $\mathrm{X}$ & & & & 4 \\
\hline VI & Value (Dark and Light) & $\begin{array}{l}\text { 5. Light Colors } \\
\text { 1. Dark Colors }\end{array}$ & & & $\mathrm{X}$ & & & 3 \\
\hline VII & Intensity of Color & $\begin{array}{l}\text { 5. Pure and Saturated } \\
\text { 1. Greyed and Softened }\end{array}$ & $\mathrm{X}$ & & & & & 5 \\
\hline VIII & Variety of Color & $\begin{array}{r}\text { 5. Polychromatic } \\
\text { 1. Monochromatic } \\
\end{array}$ & & $\mathrm{X}$ & & & & 4 \\
\hline IX & Texture & $\begin{array}{l}\text { 5. Impasto } \\
\text { 1. Smooth }\end{array}$ & & $\mathrm{X}$ & & & & 4 \\
\hline $\bar{X}$ & Pattern & $\begin{array}{l}\text { 5. Highly Repeated Motifs } \\
\text { 1. No Repeated Motifs }\end{array}$ & & & $\mathrm{X}$ & & & 3 \\
\hline XI & $\begin{array}{l}\begin{array}{l}\text { Spatial Organization } \\
\text { (Evenness of Space) }\end{array} \\
\end{array}$ & $\begin{array}{r}\text { 5. Evenly Dispersed } \\
\text { 1. Irregularly Dispersed }\end{array}$ & & $\mathrm{X}$ & & & & 4 \\
\hline$\overline{\mathrm{XII}}$ & Spatial Denseness & $\begin{array}{r}\text { 5. Densely packed } \\
\text { 1. Open Space } \\
\end{array}$ & & $\mathrm{X}$ & & & & 4 \\
\hline XIII & Illusion of Depth & $\begin{array}{r}\text { 5. Deep } \\
\text { 1. Flat } \\
\end{array}$ & $\mathrm{X}$ & & & & & 5 \\
\hline XIV & Time and Motion & $\begin{array}{l}\text { 5. In Motion } \\
\text { 1.No Motion }\end{array}$ & & & & & $\mathrm{X}$ & 1 \\
\hline $\mathrm{XV}$ & Unity and Variety & $\begin{array}{l}\text { 5. Varied } \\
\text { 1. Unified }\end{array}$ & & & & $\mathrm{X}$ & & 2 \\
\hline$\overline{\mathrm{XVI}}$ & Emphasis and Focal Point & $\begin{array}{r}\text { 5. Definite Focal Point } \\
1 . \text { No Focal Point }\end{array}$ & $\mathrm{X}$ & & & & & 5 \\
\hline XVII & Proportion & $\begin{array}{l}\text { 5. Elements in Proportion } \\
\text { 1. Elements out of Proportion }\end{array}$ & & $\mathrm{X}$ & & & & 4 \\
\hline XVIII & Scale (Small to Large) & $\begin{array}{l}\text { 5. Large Scale } \\
\text { 1. Small Scale }\end{array}$ & & $\mathrm{X}$ & & & & 4 \\
\hline XIX & Rhythm & $\begin{array}{r}\text { 5. Rhythmic } \\
\text { 1. Static } \\
\end{array}$ & & & & & $X$ & 1 \\
\hline $\mathrm{XX}$ & Centric or Eccentric & $\begin{array}{l}\text { 5. Internal Vectors } \\
\text { 1. External Vectors }\end{array}$ & $\mathbf{X}$ & & & & & 5 \\
\hline & Total & & 5 & 10 & 2 & 1 & 2 & 75 \\
\hline
\end{tabular}


Formal Elements

Rating Scale (FERS)

\begin{tabular}{|c|c|c|c|c|c|c|c|c|}
\hline & \multicolumn{2}{|c|}{ Figure 20: Portrait of Patience Escalier } & \multirow[t]{2}{*}{5} & \multirow{2}{*}{$\begin{array}{l}4 \\
X\end{array}$} & \multirow[t]{2}{*}{3} & \multirow[t]{2}{*}{2} & \multirow[t]{2}{*}{1} & \multirow{2}{*}{$\frac{\text { Total }}{4}$} \\
\hline $\mathrm{I}$ & Line Quality & $\begin{array}{l}\text { 5. Fluid and Flowing } \\
\text { 1. Jagged and Broken }\end{array}$ & & & & & & \\
\hline II & Expressive Style & $\begin{array}{r}\text { 5. Freedom of Expression } \\
\text { 1. Excessive Repetition }\end{array}$ & $\mathrm{X}$ & & & & & 5 \\
\hline III & Shape and Mass & $\begin{array}{r}\text { 5. Organic } \\
\text { 1. Geometric }\end{array}$ & & $\mathrm{X}$ & & & & 4 \\
\hline IV & Abstraction or Realism & $\begin{array}{l}\text { 5. Realistic } \\
\text { 1. Abstract }\end{array}$ & & $X$ & & & & 4 \\
\hline V & Figure Ground Relationship & $\begin{array}{r}\text { 5. Subject Dominant } \\
\text { 1. Background Dominant }\end{array}$ & & $\mathrm{X}$ & & & & 4 \\
\hline VI & Value (Dark and Light) & $\begin{array}{l}\text { 5. Light Colors } \\
\text { 1. Dark Colors }\end{array}$ & & & & $\mathrm{X}$ & & 2 \\
\hline VII & Intensity of Color & $\begin{array}{l}\text { 5. Pure and Saturated } \\
\text { 1. Greyed and Softened }\end{array}$ & $\mathrm{X}$ & & & & & 5 \\
\hline VIII & Variety of Color & $\begin{array}{r}\text { 5. Polychromatic } \\
\text { 1. Monochromatic }\end{array}$ & $\mathrm{X}$ & & & & & 5 \\
\hline IX & Texture & $\begin{array}{l}\text { 5. Impasto } \\
\text { 1. Smooth }\end{array}$ & & $\mathrm{X}$ & & & & 4 \\
\hline $\bar{X}$ & Pattern & $\begin{array}{l}\text { 5. Highly Repeated Motifs } \\
\text { 1. No Repeated Motifs }\end{array}$ & & & & & $\mathrm{X}$ & 1 \\
\hline XI & $\begin{array}{l}\text { Spatial Organization } \\
\text { (Evenness of Space) }\end{array}$ & $\begin{array}{l}\text { 5. Evenly Dispersed } \\
\text { 1. Irregularly Dispersed }\end{array}$ & & & $\mathrm{X}$ & & & 3 \\
\hline XII & Spatial Denseness & $\begin{array}{r}\text { 5. Densely packed } \\
\text { 1. Open Space }\end{array}$ & & $\mathrm{X}$ & & & & 4 \\
\hline XIII & Illusion of Depth & $\begin{array}{l}\text { 5. Deep } \\
\text { 1. Flat }\end{array}$ & & & & & $\mathrm{X}$ & 1 \\
\hline XIV & Time and Motion & $\begin{array}{l}\text { 5. In Motion } \\
\text { 1.No Motion }\end{array}$ & & & & & $\mathrm{X}$ & 1 \\
\hline $\mathrm{XV}$ & Unity and Variety & $\begin{array}{l}\text { 5. Varied } \\
\text { 1. Unified }\end{array}$ & & & & & $\mathrm{X}$ & 1 \\
\hline XVI & Emphasis and Focal Point & $\begin{array}{r}\text { 5. Definite Focal Point } \\
\text { 1. No Focal Point } \\
\end{array}$ & $\mathrm{X}$ & & & & & 5 \\
\hline XVII & Proportion & $\begin{array}{l}\text { 5. Elements in Proportion } \\
\text { 1. Elements out of Proportion }\end{array}$ & $\mathrm{X}$ & & & & & 5 \\
\hline XVIII & Scale (Small to Large) & $\begin{array}{l}\text { 5. Large Scale } \\
\text { 1. Small Scale }\end{array}$ & & & $X$ & & & 3 \\
\hline XIX & Rhythm & $\begin{array}{r}\text { 5. Rhythmic } \\
\text { 1. Static }\end{array}$ & & & & & $X$ & 1 \\
\hline XX & Centric or Eccentric & $\begin{array}{r}\text { 5. Internal Vectors } \\
\text { 1. External Vectors }\end{array}$ & $X$ & & & & & 5 \\
\hline & Totals & & 6 & 6 & 2 & 1 & 5 & 67 \\
\hline
\end{tabular}


Formal Elements

Rating Scale (FERS)

\begin{tabular}{|c|c|c|c|c|c|c|c|c|}
\hline & \multicolumn{2}{|c|}{ Figure 21: The Sower, 1888 (After Millet) } & \multirow[t]{2}{*}{5} & \multirow{2}{*}{\begin{tabular}{|l|}
4 \\
$X$
\end{tabular}} & \multirow[t]{2}{*}{3} & \multirow[t]{2}{*}{2} & \multirow[t]{2}{*}{1} & \multirow{2}{*}{$\frac{\text { Total }}{4}$} \\
\hline I & Line Quality & $\begin{array}{l}\text { 5. Fluid and Flowing } \\
\text { 1. Jagged and Broken }\end{array}$ & & & & & & \\
\hline II & Expressive Style & $\begin{array}{l}\text { 5. Freedom of Expression } \\
\text { 1. Excessive Repetition }\end{array}$ & $\mathrm{X}$ & & & & & 5 \\
\hline III & Shape and Mass & $\begin{array}{r}\text { 5. Organic } \\
\text { 1. Geometric } \\
\end{array}$ & & $\mathrm{X}$ & & & & 4 \\
\hline IV & Abstraction or Realism & $\begin{array}{l}\text { 5. Realistic } \\
\text { 1. Abstract }\end{array}$ & & $X$ & & & & 4 \\
\hline $\mathrm{V}$ & Figure Ground Relationship & $\begin{array}{l}\text { 5. Subject Dominant } \\
\text { 1. Background Dominant }\end{array}$ & & & & $\mathrm{X}$ & & 2 \\
\hline VI & Value (Dark and Light) & $\begin{array}{l}\text { 5. Light Colors } \\
\text { 1. Dark Colors }\end{array}$ & & $\mathrm{X}$ & & & & 4 \\
\hline VII & Intensity of Color & $\begin{array}{l}\text { 5. Pure and Saturated } \\
\text { 1. Greyed and Softened }\end{array}$ & & $\mathrm{X}$ & & & & 4 \\
\hline VIII & Variety of Color & $\begin{array}{r}\text { 5. Polychromatic } \\
\text { 1. Monochromatic }\end{array}$ & & $\mathrm{X}$ & & & & 4 \\
\hline IX & Texture & $\begin{array}{l}\text { 5. Impasto } \\
\text { 1. Smooth }\end{array}$ & $\mathrm{X}$ & & & & & 5 \\
\hline $\mathrm{X}$ & Pattern & $\begin{array}{l}\text { 5. Highly Repeated Motifs } \\
\text { 1. No Repeated Motifs }\end{array}$ & $\mathrm{X}$ & & & & & 5 \\
\hline XI & $\begin{array}{l}\text { Spatial Organization } \\
\text { (Evenness of Space) }\end{array}$ & $\begin{array}{l}\text { 5. Evenly Dispersed } \\
\text { 1. Irregularly Dispersed }\end{array}$ & & $\mathrm{X}$ & & & & 4 \\
\hline XII & Spatial Denseness & $\begin{array}{r}\text { 5. Densely packed } \\
\text { 1. Open Space } \\
\end{array}$ & $\mathrm{X}$ & & & & & 5 \\
\hline XIII & Illusion of Depth & $\begin{array}{r}\text { 5. Deep } \\
\text { 1. Flat } \\
\end{array}$ & $\mathrm{X}$ & & & & & 5 \\
\hline XIV & Time and Motion & $\begin{array}{l}\text { 5. In Motion } \\
\text { 1.No Motion }\end{array}$ & & & $\mathrm{X}$ & & & 3 \\
\hline $\mathrm{XV}$ & Unity and Variety & $\begin{array}{l}\text { 5. Varied } \\
\text { 1. Unified } \\
\end{array}$ & & & $\mathrm{X}$ & & & 3 \\
\hline XVI & Emphasis and Focal Point & $\begin{array}{r}\text { 5. Definite Focal Point } \\
\text { 1. No Focal Point }\end{array}$ & & $\mathrm{X}$ & & & & 4 \\
\hline XVII & Proportion & $\begin{array}{l}\text { 5. Elements in Proportion } \\
\text { 1. Elements out of Proportion }\end{array}$ & $\mathrm{X}$ & & & & & 5 \\
\hline XVIII & Scale (Small to Large) & $\begin{array}{l}\text { 5. Large Scale } \\
\text { 1. Small Scale } \\
\end{array}$ & & & $\mathrm{X}$ & & & 3 \\
\hline XIX & Rhythm & $\begin{array}{r}\text { 5. Rhythmic } \\
\text { 1. Static } \\
\end{array}$ & $\mathrm{X}$ & & & & & 5 \\
\hline $\mathrm{XX}$ & Centric or Eccentric & $\begin{array}{l}\text { 5. Internal Vectors } \\
\text { 1. External Vectors }\end{array}$ & & $\mathrm{X}$ & & & & 4 \\
\hline & Totals & & 7 & 9 & 3 & 1 & 0 & 82 \\
\hline
\end{tabular}


Formal Elements

Rating Scale (FERS)

\begin{tabular}{|c|c|c|c|c|c|c|c|c|}
\hline & \multicolumn{2}{|c|}{$\begin{array}{l}\text { Figure 22: Still-Life Vase with Sunflowers, } \\
1888\end{array}$} & 5 & 4 & 3 & 2 & 1 & Total \\
\hline $\mathrm{I}$ & Line Quality & $\begin{array}{l}\text { 5. Fluid and Flowing } \\
\text { 1. Jagged and Broken }\end{array}$ & & $\mathrm{X}$ & & & & 4 \\
\hline II & Expressive Style & $\begin{array}{l}\text { 5. Freedom of Expression } \\
\text { 1. Excessive Repetition }\end{array}$ & & & $\mathrm{X}$ & & & 3 \\
\hline III & Shape and Mass & $\begin{array}{r}\text { 5. Organic } \\
\text { 1. Geometric }\end{array}$ & & $\mathrm{X}$ & & & & 4 \\
\hline IV & Abstraction or Realism & $\begin{array}{l}\text { 5. Realistic } \\
\text { 1. Abstract }\end{array}$ & & $\mathrm{X}$ & & & & 4 \\
\hline $\mathrm{V}$ & Figure Ground Relationship & $\begin{array}{r}\text { 5. Subject Dominant } \\
\text { 1. Background Dominant }\end{array}$ & & $\mathrm{X}$ & & & & 4 \\
\hline VI & Value (Dark and Light) & $\begin{array}{l}\text { 5. Light Colors } \\
\text { 1. Dark Colors } \\
\end{array}$ & $\mathrm{X}$ & & & & & 5 \\
\hline VII & Intensity of Color & $\begin{array}{l}\text { 5. Pure and Saturated } \\
\text { 1. Greyed and Softened }\end{array}$ & $\mathrm{X}$ & & & & & 5 \\
\hline VIII & Variety of Color & $\begin{array}{r}\text { 5. Polychromatic } \\
\text { 1. Monochromatic }\end{array}$ & & & $\mathrm{X}$ & & & 3 \\
\hline IX & Texture & $\begin{array}{l}\text { 5. Impasto } \\
\text { 1. Smooth }\end{array}$ & & & $\mathrm{X}$ & & & 3 \\
\hline $\bar{X}$ & Pattern & $\begin{array}{l}\text { 5. Highly Repeated Motifs } \\
\text { 1. No Repeated Motifs }\end{array}$ & $\mathrm{X}$ & & & & & 5 \\
\hline XI & $\begin{array}{l}\text { Spatial Organization } \\
\text { (Evenness of Space) }\end{array}$ & $\begin{array}{l}\text { 5. Evenly Dispersed } \\
\text { 1. Irregularly Dispersed }\end{array}$ & & $\mathrm{X}$ & & & & 4 \\
\hline XII & Spatial Denseness & $\begin{array}{r}\text { 5. Densely packed } \\
\text { 1. Open Space }\end{array}$ & & $\mathrm{X}$ & & & & 4 \\
\hline XIII & Illusion of Depth & $\begin{array}{l}\text { 5. Deep } \\
\text { 1. Flat }\end{array}$ & & & & & $\mathrm{X}$ & 1 \\
\hline XIV & Time and Motion & $\begin{array}{l}\text { 5. In Motion } \\
\text { 1.No Motion }\end{array}$ & & & & & $\bar{X}$ & 1 \\
\hline $\mathrm{XV}$ & Unity and Variety & $\begin{array}{l}\text { 5. Varied } \\
\text { 1. Unified }\end{array}$ & & & & & $\mathrm{X}$ & 1 \\
\hline$\overline{\mathrm{XVI}}$ & Emphasis and Focal Point & $\begin{array}{r}\text { 5. Definite Focal Point } \\
1 . \text { No Focal Point }\end{array}$ & & & $\mathrm{X}$ & & & 3 \\
\hline XVII & Proportion & $\begin{array}{l}\text { 5. Elements in Proportion } \\
\text { 1. Elements out of Proportion }\end{array}$ & $\mathrm{X}$ & & & & & 5 \\
\hline XVIII & Scale (Small to Large) & $\begin{array}{l}\text { 5. Large Scale } \\
\text { 1. Small Scale }\end{array}$ & & & $\mathrm{X}$ & & & 3 \\
\hline XIX & Rhythm & $\begin{array}{c}\text { 5. Rhythmic } \\
\text { 1. Static }\end{array}$ & & & $\mathrm{X}$ & & & 3 \\
\hline $\mathrm{XX}$ & Centric or Eccentric & $\begin{array}{l}\text { 5. Internal Vectors } \\
\text { 1. External Vectors }\end{array}$ & $\mathrm{X}$ & & & & & 5 \\
\hline & Totals & & 5 & 6 & 6 & 0 & 3 & 70 \\
\hline
\end{tabular}


Formal Elements

Rating Scale (FERS)

\begin{tabular}{|c|c|c|c|c|c|c|c|c|}
\hline & \multicolumn{2}{|c|}{ Figure 23: The Night Café, 1888} & \multirow[t]{2}{*}{5} & \multirow[t]{2}{*}{4} & \multirow{2}{*}{\begin{tabular}{l|}
3 \\
$X$
\end{tabular}} & \multirow[t]{2}{*}{2} & \multirow[t]{2}{*}{1} & \multirow{2}{*}{$\frac{\text { Total }}{3}$} \\
\hline I & Line Quality & $\begin{array}{l}\text { 5. Fluid and Flowing } \\
\text { 1. Jagged and Broken }\end{array}$ & & & & & & \\
\hline II & Expressive Style & $\begin{array}{l}\text { 5. Freedom of Expression } \\
\text { 1. Excessive Repetition }\end{array}$ & & & & $\mathrm{X}$ & & 2 \\
\hline III & Shape and Mass & $\begin{array}{r}\text { 5. Organic } \\
\text { 1. Geometric }\end{array}$ & & & & $\mathrm{X}$ & & 2 \\
\hline IV & Abstraction or Realism & $\begin{array}{l}\text { 5. Realistic } \\
\text { 1. Abstract }\end{array}$ & & $\mathrm{X}$ & & & & 4 \\
\hline $\mathrm{V}$ & Figure Ground Relationship & $\begin{array}{r}\text { 5. Subject Dominant } \\
\text { 1. Background Dominant }\end{array}$ & $\mathrm{X}$ & & & & & 5 \\
\hline VI & Value (Dark and Light) & $\begin{array}{r}\text { 5. Light Colors } \\
\text { 1. Dark Colors } \\
\end{array}$ & & & $\mathrm{X}$ & & & 3 \\
\hline VII & Intensity of Color & $\begin{array}{l}\text { 5. Pure and Saturated } \\
\text { 1. Greyed and Softened }\end{array}$ & $\mathrm{X}$ & & & & & 5 \\
\hline VIII & Variety of Color & $\begin{array}{r}\text { 5. Polychromatic } \\
\text { 1. Monochromatic }\end{array}$ & & $\mathrm{X}$ & & & & 4 \\
\hline IX & Texture & $\begin{array}{l}\text { 5. Impasto } \\
\text { 1. Smooth }\end{array}$ & & $\mathrm{X}$ & & & & 4 \\
\hline $\mathrm{X}$ & Pattern & $\begin{array}{l}\text { 5. Highly Repeated Motifs } \\
\text { 1. No Repeated Motifs }\end{array}$ & & $\mathrm{X}$ & & & & 4 \\
\hline $\mathrm{XI}$ & $\begin{array}{l}\text { Spatial Organization } \\
\text { (Evenness of Space) }\end{array}$ & $\begin{array}{l}\text { 5. Evenly Dispersed } \\
\text { 1. Irregularly Dispersed }\end{array}$ & & & & $\mathrm{X}$ & & 2 \\
\hline XII & Spatial Denseness & $\begin{array}{r}\text { 5. Densely packed } \\
\text { 1. Open Space }\end{array}$ & & $\mathrm{X}$ & & & & 4 \\
\hline XIII & Illusion of Depth & $\begin{array}{r}\text { 5. Deep } \\
\text { 1. Flat } \\
\end{array}$ & $\mathrm{X}$ & & & & & 5 \\
\hline XIV & Time and Motion & $\begin{array}{l}\text { 5. In Motion } \\
\text { 1.No Motion }\end{array}$ & & & & & $\mathrm{X}$ & 1 \\
\hline $\mathrm{XV}$ & Unity and Variety & $\begin{array}{l}\text { 5. Varied } \\
\text { 1. Unified }\end{array}$ & & & $\mathrm{X}$ & & & 3 \\
\hline XVI & Emphasis and Focal Point & $\begin{array}{r}\text { 5. Definite Focal Point } \\
1 . \text { No Focal Point } \\
\end{array}$ & & $\mathrm{X}$ & & & & 4 \\
\hline XVII & Proportion & $\begin{array}{l}\text { 5. Elements in Proportion } \\
\text { 1. Elements out of Proportion }\end{array}$ & $\mathrm{X}$ & & & & & 5 \\
\hline XVIII & Scale (Small to Large) & $\begin{array}{l}\text { 5. Large Scale } \\
\text { 1. Small Scale } \\
\end{array}$ & & & $\mathrm{X}$ & & & 3 \\
\hline XIX & Rhythm & $\begin{array}{c}\text { 5. Rhythmic } \\
\text { 1. Static }\end{array}$ & & & & $\mathrm{X}$ & & 2 \\
\hline $\mathrm{XX}$ & Centric or Eccentric & $\begin{array}{l}\text { 5. Internal Vectors } \\
\text { 1. External Vectors }\end{array}$ & & & & $\mathbf{X}$ & & 2 \\
\hline & Totals & & 4 & 6 & 4 & 5 & 1 & 67 \\
\hline
\end{tabular}


Formal Elements

Rating Scale (FERS)

\begin{tabular}{|c|c|c|c|c|c|c|c|c|}
\hline & \multicolumn{2}{|c|}{ Figure 24: Portait of Milliet, 1888} & \multirow[t]{2}{*}{5} & \multirow{2}{*}{\begin{tabular}{|l|}
4 \\
$X$ \\
\end{tabular}} & \multirow[t]{2}{*}{3} & \multirow[t]{2}{*}{2} & \multirow[t]{2}{*}{1} & \multirow{2}{*}{$\begin{array}{c}\text { Total } \\
4\end{array}$} \\
\hline $\mathrm{I}$ & Line Quality & $\begin{array}{l}\text { 5. Fluid and Flowing } \\
\text { 1. Jagged and Broken }\end{array}$ & & & & & & \\
\hline II & Expressive Style & $\begin{array}{l}\text { 5. Freedom of Expression } \\
\text { 1. Excessive Repetition }\end{array}$ & $\mathrm{X}$ & & & & & 5 \\
\hline III & Shape and Mass & $\begin{array}{r}\text { 5. Organic } \\
\text { 1. Geometric }\end{array}$ & & $\mathrm{X}$ & & & & 4 \\
\hline IV & Abstraction or Realism & $\begin{array}{l}\text { 5. Realistic } \\
\text { 1. Abstract }\end{array}$ & & $\mathrm{X}$ & & & & 4 \\
\hline V & Figure Ground Relationship & $\begin{array}{r}\text { 5. Subject Dominant } \\
\text { 1. Background Dominant }\end{array}$ & & $\mathrm{X}$ & & & & 4 \\
\hline VI & Value (Dark and Light) & $\begin{array}{l}\text { 5. Light Colors } \\
\text { 1. Dark Colors } \\
\end{array}$ & & & & & $\mathrm{X}$ & 1 \\
\hline VII & Intensity of Color & $\begin{array}{l}\text { 5. Pure and Saturated } \\
\text { 1. Greyed and Softened }\end{array}$ & $\mathrm{X}$ & & & & & 5 \\
\hline VIII & Variety of Color & $\begin{array}{r}\text { 5. Polychromatic } \\
\text { 1. Monochromatic }\end{array}$ & $\mathrm{X}$ & & & & & 5 \\
\hline IX & Texture & $\begin{array}{l}\text { 5. Impasto } \\
\text { 1. Smooth } \\
\end{array}$ & & $\mathrm{X}$ & & & & 4 \\
\hline $\mathrm{X}$ & Pattern & $\begin{array}{r}\text { 5. Highly Repeated Motifs } \\
\text { 1. No Repeated Motifs } \\
\end{array}$ & & $\mathrm{X}$ & & & & 4 \\
\hline $\mathrm{XI}$ & $\begin{array}{l}\text { Spatial Organization } \\
\text { (Evenness of Space) }\end{array}$ & $\begin{array}{r}\text { 5. Evenly Dispersed } \\
\text { 1. Irregularly Dispersed } \\
\end{array}$ & & & $\mathrm{X}$ & & & 3 \\
\hline XII & Spatial Denseness & $\begin{array}{r}\text { 5. Densely packed } \\
\text { 1. Open Space }\end{array}$ & & $\mathrm{X}$ & & & & 4 \\
\hline XIII & Illusion of Depth & $\begin{array}{r}\text { 5. Deep } \\
\text { 1. Flat } \\
\end{array}$ & & & & $\mathrm{X}$ & & 2 \\
\hline XIV & Time and Motion & $\begin{array}{l}\text { 5. In Motion } \\
\text { 1.No Motion }\end{array}$ & & & & & $\mathrm{X}$ & 1 \\
\hline $\mathrm{XV}$ & Unity and Variety & $\begin{array}{l}\text { 5. Varied } \\
\text { 1. Unified } \\
\end{array}$ & & & & $\mathrm{X}$ & & 2 \\
\hline XVI & Emphasis and Focal Point & $\begin{array}{r}\text { 5. Definite Focal Point } \\
\text { 1. No Focal Point }\end{array}$ & & & & $\mathrm{X}$ & & 2 \\
\hline XVII & Proportion & $\begin{array}{r}\text { 5. Elements in Proportion } \\
\text { 1. Elements out of Proportion }\end{array}$ & $\mathrm{X}$ & & & & & 5 \\
\hline XVIII & Scale (Small to Large) & $\begin{array}{l}\text { 5. Large Scale } \\
\text { 1. Small Scale }\end{array}$ & & & $\mathrm{X}$ & & & 3 \\
\hline XIX & Rhythm & $\begin{array}{l}\text { 5. Rhythmic } \\
\text { 1. Static }\end{array}$ & & & & & $\mathrm{X}$ & 1 \\
\hline $\mathrm{XX}$ & Centric or Eccentric & $\begin{array}{r}\text { 5. Internal Vectors } \\
\text { 1. External Vectors }\end{array}$ & $\mathrm{X}$ & & & & & 5 \\
\hline & Totals & & 5 & 7 & 2 & 3 & 3 & 68 \\
\hline
\end{tabular}


Formal Elements

Rating Scale (FERS)

\begin{tabular}{|c|c|c|c|c|c|c|c|c|}
\hline & \multicolumn{2}{|c|}{ Figure 25: Starry Night on the Rhône, 1888} & \multirow[t]{2}{*}{5} & \multirow[t]{2}{*}{4} & \multirow{2}{*}{$\begin{array}{l}3 \\
X\end{array}$} & \multirow[t]{2}{*}{2} & \multirow[t]{2}{*}{1} & \multirow{2}{*}{$\frac{\text { Total }}{3}$} \\
\hline $\mathrm{I}$ & Line Quality & $\begin{array}{l}\text { 5. Fluid and Flowing } \\
\text { 1. Jagged and Broken }\end{array}$ & & & & & & \\
\hline II & Expressive Style & $\begin{array}{l}\text { 5. Freedom of Expression } \\
\text { 1. Excessive Repetition }\end{array}$ & & & $\mathrm{X}$ & & & 3 \\
\hline III & Shape and Mass & $\begin{array}{r}\text { 5. Organic } \\
\text { 1. Geometric }\end{array}$ & & $\mathrm{X}$ & & & & 4 \\
\hline IV & Abstraction or Realism & $\begin{array}{l}\text { 5. Realistic } \\
\text { 1. Abstract }\end{array}$ & & & $\mathrm{X}$ & & & 3 \\
\hline $\mathrm{V}$ & Figure Ground Relationship & $\begin{array}{r}\text { 5. Subject Dominant } \\
\text { 1. Background Dominant }\end{array}$ & & $\mathrm{X}$ & & & & 4 \\
\hline VI & Value (Dark and Light) & $\begin{array}{l}\text { 5. Light Colors } \\
\text { 1. Dark Colors }\end{array}$ & & & & $\mathrm{X}$ & & 2 \\
\hline VII & Intensity of Color & $\begin{array}{l}\text { 5. Pure and Saturated } \\
\text { 1. Greyed and Softened }\end{array}$ & & $\mathrm{X}$ & & & & 4 \\
\hline VIII & Variety of Color & $\begin{array}{l}\text { 5. Polychromatic } \\
\text { 1. Monochromatic }\end{array}$ & & & $\mathrm{X}$ & & & 3 \\
\hline IX & Texture & $\begin{array}{l}\text { 5. Impasto } \\
\text { 1. Smooth } \\
\end{array}$ & & $\mathrm{X}$ & & & & 4 \\
\hline $\mathrm{X}$ & Pattern & $\begin{array}{r}\text { 5. Highly Repeated Motifs } \\
\text { 1. No Repeated Motifs } \\
\end{array}$ & & $\mathrm{X}$ & & & & 4 \\
\hline $\mathrm{XI}$ & $\begin{array}{l}\text { Spatial Organization } \\
\text { (Evenness of Space) }\end{array}$ & $\begin{array}{r}\text { 5. Evenly Dispersed } \\
\text { 1. Irregularly Dispersed } \\
\end{array}$ & & & & $\mathrm{X}$ & & 2 \\
\hline XII & Spatial Denseness & $\begin{array}{r}\text { 5. Densely packed } \\
\text { 1. Open Space }\end{array}$ & & & & $\mathrm{X}$ & & 2 \\
\hline XIII & Illusion of Depth & $\begin{array}{l}\text { 5. Deep } \\
\text { 1. Flat }\end{array}$ & $\mathrm{X}$ & & & & & 5 \\
\hline XIV & Time and Motion & $\begin{array}{l}\text { 5. In Motion } \\
\text { 1.No Motion }\end{array}$ & & & & $\mathrm{X}$ & & 2 \\
\hline $\mathrm{XV}$ & Unity and Variety & $\begin{array}{l}\text { 5. Varied } \\
\text { 1. Unified } \\
\end{array}$ & & & & & $\mathrm{X}$ & 1 \\
\hline XVI & Emphasis and Focal Point & $\begin{array}{r}\text { 5. Definite Focal Point } \\
\text { 1. No Focal Point }\end{array}$ & & & & $\mathrm{X}$ & & 2 \\
\hline XVII & Proportion & $\begin{array}{l}\text { 5. Elements in Proportion } \\
\text { 1. Elements out of Proportion }\end{array}$ & $\mathrm{X}$ & & & & & 5 \\
\hline XVIII & Scale (Small to Large) & $\begin{array}{l}\text { 5. Large Scale } \\
\text { 1. Small Scale }\end{array}$ & & & $\mathrm{X}$ & & & 3 \\
\hline XIX & Rhythm & $\begin{array}{r}\text { 5. Rhythmic } \\
\text { 1. Static }\end{array}$ & & & $X$ & & & 3 \\
\hline $\mathrm{XX}$ & Centric or Eccentric & $\begin{array}{l}\text { 5. Internal Vectors } \\
\text { 1. External Vectors }\end{array}$ & & & & $\mathrm{X}$ & & 2 \\
\hline & Totals & & 2 & 5 & 6 & 6 & 1 & 61 \\
\hline
\end{tabular}


Formal Elements

Rating Scale (FERS)

\begin{tabular}{|c|c|c|c|c|c|c|c|c|}
\hline & \multicolumn{2}{|c|}{ Figure 26: The Café Terrace at Night, 1888} & \multirow[t]{2}{*}{5} & \multirow{2}{*}{\begin{tabular}{|l|}
4 \\
$X$
\end{tabular}} & \multirow[t]{2}{*}{3} & \multirow[t]{2}{*}{2} & \multirow[t]{2}{*}{1} & \multirow{2}{*}{$\frac{\text { Total }}{4}$} \\
\hline $\mathrm{I}$ & Line Quality & $\begin{array}{l}\text { 5. Fluid and Flowing } \\
\text { 1. Jagged and Broken }\end{array}$ & & & & & & \\
\hline II & Expressive Style & $\begin{array}{l}\text { 5. Freedom of Expression } \\
\text { 1. Excessive Repetition }\end{array}$ & $\mathrm{X}$ & & & & & 5 \\
\hline III & Shape and Mass & $\begin{array}{r}\text { 5. Organic } \\
\text { 1. Geometric }\end{array}$ & & & $\mathrm{X}$ & & & 3 \\
\hline IV & Abstraction or Realism & $\begin{array}{l}\text { 5. Realistic } \\
\text { 1. Abstract }\end{array}$ & & $X$ & & & & 4 \\
\hline $\mathrm{V}$ & Figure Ground Relationship & $\begin{array}{r}\text { 5. Subject Dominant } \\
\text { 1. Background Dominant } \\
\end{array}$ & & $\mathrm{X}$ & & & & 4 \\
\hline VI & Value (Dark and Light) & $\begin{array}{l}\text { 5. Light Colors } \\
\text { 1. Dark Colors } \\
\end{array}$ & & & $\mathrm{X}$ & & & 3 \\
\hline VII & Intensity of Color & $\begin{array}{l}\text { 5. Pure and Saturated } \\
\text { 1. Greyed and Softened }\end{array}$ & $\mathrm{X}$ & & & & & 5 \\
\hline VIII & Variety of Color & $\begin{array}{r}\text { 5. Polychromatic } \\
\text { 1. Monochromatic }\end{array}$ & $\mathrm{X}$ & & & & & 5 \\
\hline IX & Texture & $\begin{array}{l}\text { 5. Impasto } \\
\text { 1. Smooth } \\
\end{array}$ & & & & $\mathrm{X}$ & & 2 \\
\hline $\mathrm{X}$ & Pattern & $\begin{array}{l}\text { 5. Highly Repeated Motifs } \\
\text { 1. No Repeated Motifs }\end{array}$ & & $\mathrm{X}$ & & & & 4 \\
\hline $\mathrm{XI}$ & $\begin{array}{l}\text { Spatial Organization } \\
\text { (Evenness of Space) }\end{array}$ & $\begin{array}{l}\text { 5. Evenly Dispersed } \\
\text { 1. Irregularly Dispersed }\end{array}$ & & & $\mathrm{X}$ & & & 3 \\
\hline XII & Spatial Denseness & $\begin{array}{r}\text { 5. Densely packed } \\
\text { 1. Open Space }\end{array}$ & & $\mathrm{X}$ & & & & 4 \\
\hline XIII & Illusion of Depth & $\begin{array}{r}\text { 5. Deep } \\
\text { 1. Flat } \\
\end{array}$ & $\mathrm{X}$ & & & & & 5 \\
\hline XIV & Time and Motion & $\begin{array}{l}\text { 5. In Motion } \\
\text { 1.No Motion }\end{array}$ & & & $\mathrm{X}$ & & & 3 \\
\hline $\mathrm{XV}$ & Unity and Variety & $\begin{array}{l}\text { 5. Varied } \\
\text { 1. Unified } \\
\end{array}$ & & & & & $\mathrm{X}$ & 1 \\
\hline $\mathrm{XVI}$ & Emphasis and Focal Point & $\begin{array}{r}\text { 5. Definite Focal Point } \\
1 . \text { No Focal Point } \\
\end{array}$ & & $\mathrm{X}$ & & & & 4 \\
\hline XVII & Proportion & $\begin{array}{l}\text { 5. Elements in Proportion } \\
\text { 1. Elements out of Proportion }\end{array}$ & $\mathrm{X}$ & & & & & 5 \\
\hline XVIII & Scale (Small to Large) & $\begin{array}{l}\text { 5. Large Scale } \\
\text { 1. Small Scale } \\
\end{array}$ & & & $\mathrm{X}$ & & & 3 \\
\hline XIX & Rhythm & $\begin{array}{r}\text { 5. Rhythmic } \\
\text { 1. Static } \\
\end{array}$ & & & $\mathrm{X}$ & & & 3 \\
\hline $\mathrm{XX}$ & Centric or Eccentric & $\begin{array}{l}\text { 5. Internal Vectors } \\
\text { 1. External Vectors }\end{array}$ & & & $\mathrm{X}$ & & & 3 \\
\hline & Totals & & 5 & 6 & 7 & 1 & 1 & 73 \\
\hline
\end{tabular}


Formal Elements

Rating Scale (FERS)

\begin{tabular}{|c|c|c|c|c|c|c|c|c|}
\hline & \multicolumn{2}{|c|}{ Figure 27: The Yellow House, 1888} & \multirow[t]{2}{*}{5} & \multirow[t]{2}{*}{4} & \multirow{2}{*}{$\begin{array}{l}3 \\
X\end{array}$} & \multirow[t]{2}{*}{2} & \multirow[t]{2}{*}{1} & \multirow{2}{*}{$\frac{\text { Total }}{3}$} \\
\hline I & Line Quality & $\begin{array}{l}\text { 5. Fluid and Flowing } \\
\text { 1. Jagged and Broken }\end{array}$ & & & & & & \\
\hline II & Expressive Style & $\begin{array}{l}\text { 5. Freedom of Expression } \\
\text { 1. Excessive Repetition }\end{array}$ & $\mathrm{X}$ & & & & & 5 \\
\hline III & Shape and Mass & $\begin{array}{r}\text { 5. Organic } \\
\text { 1. Geometric } \\
\end{array}$ & & & $\mathrm{X}$ & & & 3 \\
\hline IV & Abstraction or Realism & $\begin{array}{l}\text { 5. Realistic } \\
\text { 1. Abstract }\end{array}$ & $\mathrm{X}$ & & & & & 5 \\
\hline $\mathrm{V}$ & Figure Ground Relationship & $\begin{array}{l}\text { 5. Subject Dominant } \\
\text { 1. Background Dominant }\end{array}$ & & & $\mathrm{X}$ & & & 3 \\
\hline VI & Value (Dark and Light) & $\begin{array}{l}\text { 5. Light Colors } \\
\text { 1. Dark Colors }\end{array}$ & & & $\mathrm{X}$ & & & 3 \\
\hline VII & Intensity of Color & $\begin{array}{l}\text { 5. Pure and Saturated } \\
\text { 1. Greyed and Softened }\end{array}$ & $\mathrm{X}$ & & & & & 5 \\
\hline VIII & Variety of Color & $\begin{array}{l}\text { 5. Polychromatic } \\
\text { 1. Monochromatic }\end{array}$ & $\mathrm{X}$ & & & & & 5 \\
\hline IX & Texture & $\begin{array}{l}\text { 5. Impasto } \\
\text { 1. Smooth }\end{array}$ & & & $\mathrm{X}$ & & & 3 \\
\hline $\mathrm{X}$ & Pattern & $\begin{array}{l}\text { 5. Highly Repeated Motifs } \\
\text { 1. No Repeated Motifs }\end{array}$ & & & & $\mathrm{X}$ & & 2 \\
\hline XI & $\begin{array}{l}\text { Spatial Organization } \\
\text { (Evenness of Space) }\end{array}$ & $\begin{array}{l}\text { 5. Evenly Dispersed } \\
\text { 1. Irregularly Dispersed }\end{array}$ & & & $\mathrm{X}$ & & & 3 \\
\hline XII & Spatial Denseness & $\begin{array}{r}\text { 5. Densely packed } \\
\text { 1. Open Space } \\
\end{array}$ & & & $\mathrm{X}$ & & & 3 \\
\hline XIII & Illusion of Depth & $\begin{array}{r}\text { 5. Deep } \\
\text { 1. Flat }\end{array}$ & $\mathrm{X}$ & & & & & 5 \\
\hline XIV & Time and Motion & $\begin{array}{l}\text { 5. In Motion } \\
\text { 1.No Motion }\end{array}$ & & & $\mathrm{X}$ & & & 3 \\
\hline $\mathrm{XV}$ & Unity and Variety & $\begin{array}{l}\text { 5. Varied } \\
\text { 1. Unified }\end{array}$ & & & & & $\mathrm{X}$ & 1 \\
\hline XVI & Emphasis and Focal Point & $\begin{array}{r}\text { 5. Definite Focal Point } \\
\text { 1. No Focal Point }\end{array}$ & $\mathrm{X}$ & & & & & 5 \\
\hline XVII & Proportion & $\begin{array}{l}\text { 5. Elements in Proportion } \\
\text { 1. Elements out of Proportion }\end{array}$ & $\mathrm{X}$ & & & & & 5 \\
\hline XVIII & Scale (Small to Large) & $\begin{array}{l}\text { 5. Large Scale } \\
\text { 1. Small Scale } \\
\end{array}$ & & & $\mathrm{X}$ & & & 3 \\
\hline XIX & Rhythm & $\begin{array}{r}\text { 5. Rhythmic } \\
\text { 1. Static } \\
\end{array}$ & & & $\mathrm{X}$ & & & 3 \\
\hline $\mathrm{XX}$ & Centric or Eccentric & $\begin{array}{l}\text { 5. Internal Vectors } \\
\text { 1. External Vectors }\end{array}$ & & & & $\mathrm{X}$ & & 2 \\
\hline & Totals & & 7 & 0 & 10 & 2 & 1 & 70 \\
\hline
\end{tabular}


Formal Elements

Rating Scale (FERS)

\begin{tabular}{|c|c|c|c|c|c|c|c|c|}
\hline & \multicolumn{2}{|c|}{ Figure 28: Self-Portrait ( as a Bonze), 1888} & \multirow{2}{*}{$\begin{array}{l}5 \\
X\end{array}$} & \multirow[t]{2}{*}{4} & \multirow[t]{2}{*}{3} & \multirow[t]{2}{*}{2} & \multirow[t]{2}{*}{1} & \multirow{2}{*}{$\frac{\text { Total }}{5}$} \\
\hline $\mathrm{I}$ & Line Quality & $\begin{array}{l}\text { 5. Fluid and Flowing } \\
\text { 1. Jagged and Broken }\end{array}$ & & & & & & \\
\hline II & Expressive Style & $\begin{array}{l}\text { 5. Freedom of Expression } \\
\text { 1. Excessive Repetition }\end{array}$ & $\mathrm{X}$ & & & & & 5 \\
\hline III & Shape and Mass & $\begin{array}{r}\text { 5. Organic } \\
\text { 1. Geometric }\end{array}$ & & $\mathrm{X}$ & & & & 4 \\
\hline IV & Abstraction or Realism & $\begin{array}{l}\text { 5. Realistic } \\
\text { 1. Abstract }\end{array}$ & & $\mathrm{X}$ & & & & 4 \\
\hline V & Figure Ground Relationship & $\begin{array}{r}\text { 5. Subject Dominant } \\
\text { 1. Background Dominant }\end{array}$ & & & $\mathrm{X}$ & & & 3 \\
\hline VI & Value (Dark and Light) & $\begin{array}{l}\text { 5. Light Colors } \\
\text { 1. Dark Colors }\end{array}$ & & & $\mathrm{X}$ & & & 3 \\
\hline VII & Intensity of Color & $\begin{array}{l}\text { 5. Pure and Saturated } \\
\text { 1. Greyed and Softened }\end{array}$ & & $\mathrm{X}$ & & & & 4 \\
\hline VIII & Variety of Color & $\begin{array}{l}\text { 5. Polychromatic } \\
\text { 1. Monochromatic }\end{array}$ & & & $\mathrm{X}$ & & & 3 \\
\hline IX & Texture & $\begin{array}{l}\text { 5. Impasto } \\
\text { 1. Smooth }\end{array}$ & & & & $\mathrm{X}$ & & 2 \\
\hline $\mathrm{X}$ & Pattern & $\begin{array}{l}\text { 5. Highly Repeated Motifs } \\
\text { 1. No Repeated Motifs }\end{array}$ & & & & $\mathrm{X}$ & & 2 \\
\hline $\mathrm{XI}$ & $\begin{array}{l}\text { Spatial Organization } \\
\text { (Evenness of Space) }\end{array}$ & $\begin{array}{r}\text { 5. Evenly Dispersed } \\
\text { 1. Irregularly Dispersed }\end{array}$ & & & $\mathrm{X}$ & & & 3 \\
\hline XII & Spatial Denseness & $\begin{array}{r}\text { 5. Densely packed } \\
\text { 1. Open Space }\end{array}$ & & & $\mathrm{X}$ & & & 3 \\
\hline XIII & Illusion of Depth & $\begin{array}{r}\text { 5. Deep } \\
\text { 1. Flat }\end{array}$ & & & & $\mathrm{X}$ & & 2 \\
\hline XIV & Time and Motion & $\begin{array}{l}\text { 5. In Motion } \\
\text { 1.No Motion }\end{array}$ & & & & & $\mathrm{X}$ & 1 \\
\hline $\mathrm{XV}$ & Unity and Variety & $\begin{array}{l}\text { 5. Varied } \\
\text { 1. Unified }\end{array}$ & & & & $\mathrm{X}$ & & 2 \\
\hline XVI & Emphasis and Focal Point & $\begin{array}{r}\text { 5. Definite Focal Point } \\
\text { 1. No Focal Point }\end{array}$ & $\mathrm{X}$ & & & & & 5 \\
\hline XVII & Proportion & $\begin{array}{l}\text { 5. Elements in Proportion } \\
\text { 1. Elements out of Proportion }\end{array}$ & $\mathrm{X}$ & & & & & 5 \\
\hline XVIII & Scale (Small to Large) & $\begin{array}{l}\text { 5. Large Scale } \\
\text { 1. Small Scale }\end{array}$ & & & $\mathrm{X}$ & & & 3 \\
\hline XIX & Rhythm & $\begin{array}{r}\text { 5. Rhythmic } \\
\text { 1. Static }\end{array}$ & & & & $\mathrm{X}$ & & 2 \\
\hline XX & Centric or Eccentric & $\begin{array}{l}\text { 5. Internal Vectors } \\
\text { 1. External Vectors }\end{array}$ & $X$ & & & & & 5 \\
\hline & Total & & 5 & 3 & 6 & 5 & 1 & 66 \\
\hline
\end{tabular}


Formal Elements

Rating Scale (FERS)

\begin{tabular}{|c|c|c|c|c|c|c|c|c|}
\hline & \multicolumn{2}{|c|}{$\begin{array}{l}\text { Figure 29: Self-Portrait with Straw Hat and } \\
\text { Pipe, } 1888\end{array}$} & \multirow[t]{2}{*}{5} & \multirow[t]{2}{*}{4} & \multirow[t]{2}{*}{3} & \multirow[t]{2}{*}{2} & \multirow{2}{*}{$\begin{array}{l}1 \\
X\end{array}$} & \multirow{2}{*}{\begin{tabular}{|c|} 
Total \\
1
\end{tabular}} \\
\hline $\mathrm{I}$ & Line Quality & $\begin{array}{l}\text { 5. Fluid and Flowing } \\
\text { 1. Jagged and Broken }\end{array}$ & & & & & & \\
\hline II & Expressive Style & $\begin{array}{r}\text { 5. Freedom of Expression } \\
\text { 1. Excessive Repetition }\end{array}$ & & & & & $\mathrm{X}$ & 1 \\
\hline III & Shape and Mass & $\begin{array}{r}\text { 5. Organic } \\
\text { 1. Geometric }\end{array}$ & $\mathrm{X}$ & & & & & 5 \\
\hline IV & Abstraction or Realism & $\begin{array}{l}\text { 5. Realistic } \\
\text { 1. Abstract }\end{array}$ & & & $\mathrm{X}$ & & & 3 \\
\hline $\mathrm{V}$ & Figure Ground Relationship & $\begin{array}{r}\text { 5. Subject Dominant } \\
\text { 1. Background Dominant }\end{array}$ & & $\mathrm{X}$ & & & & 4 \\
\hline VI & Value (Dark and Light) & $\begin{array}{l}\text { 5. Light Colors } \\
\text { 1. Dark Colors }\end{array}$ & & & $\mathrm{X}$ & & & 3 \\
\hline VII & Intensity of Color & $\begin{array}{l}\text { 5. Pure and Saturated } \\
\text { 1. Greyed and Softened }\end{array}$ & & & $\mathrm{X}$ & & & 3 \\
\hline VIII & Variety of Color & $\begin{array}{r}\text { 5. Polychromatic } \\
\text { 1. Monochromatic } \\
\end{array}$ & & & $\mathrm{X}$ & & & 3 \\
\hline IX & Texture & $\begin{array}{l}\text { 5. Impasto } \\
\text { 1. Smooth }\end{array}$ & $\mathrm{X}$ & & & & & 5 \\
\hline $\mathrm{X}$ & Pattern & $\begin{array}{l}\text { 5. Highly Repeated Motifs } \\
\text { 1. No Repeated Motifs }\end{array}$ & $\mathrm{X}$ & & & & & 5 \\
\hline XI & $\begin{array}{l}\text { Spatial Organization } \\
\text { (Evenness of Space) }\end{array}$ & $\begin{array}{r}\text { 5. Evenly Dispersed } \\
\text { 1. Irregularly Dispersed }\end{array}$ & & & & $\mathrm{X}$ & & 2 \\
\hline XII & Spatial Denseness & $\begin{array}{r}\text { 5. Densely packed } \\
\text { 1. Open Space }\end{array}$ & $\mathrm{X}$ & & & & & 5 \\
\hline XIII & Illusion of Depth & $\begin{array}{r}\text { 5. Deep } \\
\text { 1. Flat }\end{array}$ & & & & $\mathrm{X}$ & & 2 \\
\hline XIV & Time and Motion & $\begin{array}{l}\text { 5. In Motion } \\
\text { 1.No Motion }\end{array}$ & & & & & $\mathrm{X}$ & 1 \\
\hline $\mathrm{XV}$ & Unity and Variety & $\begin{array}{l}\text { 5. Varied } \\
\text { 1. Unified }\end{array}$ & & $\mathrm{X}$ & & & & 4 \\
\hline $\mathrm{XVI}$ & Emphasis and Focal Point & $\begin{array}{r}\text { 5. Definite Focal Point } \\
1 . \text { No Focal Point }\end{array}$ & $\mathrm{X}$ & & & & & 5 \\
\hline XVII & Proportion & $\begin{array}{l}\text { 5. Elements in Proportion } \\
\text { 1. Elements out of Proportion }\end{array}$ & $\mathrm{X}$ & & & & & 5 \\
\hline XVIII & Scale (Small to Large) & $\begin{array}{l}\text { 5. Large Scale } \\
\text { 1. Small Scale }\end{array}$ & & & $\mathrm{X}$ & & & 3 \\
\hline XIX & Rhythm & $\begin{array}{r}\text { 5. Rhythmic } \\
\text { 1. Static }\end{array}$ & & & $\mathrm{X}$ & & & 3 \\
\hline $\mathrm{XX}$ & Centric or Eccentric & $\begin{array}{l}\text { 5. Internal Vectors } \\
\text { 1. External Vectors }\end{array}$ & $\mathrm{X}$ & & & & & 5 \\
\hline & Total & & 7 & 2 & 6 & 2 & 3 & 68 \\
\hline
\end{tabular}


Formal Elements

Rating Scale (FERS)

\begin{tabular}{|c|c|c|c|c|c|c|c|c|}
\hline & \multicolumn{2}{|c|}{ Figure 30: Tarasçon Diligence, 1888} & \multirow[t]{2}{*}{5} & \multirow{2}{*}{\begin{tabular}{|l|}
4 \\
$X$
\end{tabular}} & \multirow[t]{2}{*}{3} & \multirow[t]{2}{*}{2} & \multirow[t]{2}{*}{1} & \multirow{2}{*}{$\frac{\text { Total }}{4}$} \\
\hline $\mathrm{I}$ & Line Quality & $\begin{array}{l}\text { 5. Fluid and Flowing } \\
\text { 1. Jagged and Broken }\end{array}$ & & & & & & \\
\hline II & Expressive Style & $\begin{array}{l}\text { 5. Freedom of Expression } \\
\text { 1. Excessive Repetition }\end{array}$ & $\mathrm{X}$ & & & & & 5 \\
\hline III & Shape and Mass & $\begin{array}{r}\text { 5. Organic } \\
\text { 1. Geometric }\end{array}$ & & & & $\mathrm{X}$ & & 2 \\
\hline IV & Abstraction or Realism & $\begin{array}{l}\text { 5. Realistic } \\
\text { 1. Abstract }\end{array}$ & & $\mathrm{X}$ & & & & 4 \\
\hline $\mathrm{V}$ & Figure Ground Relationship & $\begin{array}{r}\text { 5. Subject Dominant } \\
\text { 1. Background Dominant }\end{array}$ & & $\mathrm{X}$ & & & & 4 \\
\hline VI & Value (Dark and Light) & $\begin{array}{c}\text { 5. Light Colors } \\
\text { 1. Dark Colors }\end{array}$ & & $\mathrm{X}$ & & & & 4 \\
\hline VII & Intensity of Color & $\begin{array}{l}\text { 5. Pure and Saturated } \\
\text { 1. Greyed and Softened }\end{array}$ & & & $\mathrm{X}$ & & & 3 \\
\hline VIII & Variety of Color & $\begin{array}{r}\text { 5. Polychromatic } \\
\text { 1. Monochromatic }\end{array}$ & & $\mathrm{X}$ & & & & 4 \\
\hline IX & Texture & $\begin{array}{l}\text { 5. Impasto } \\
\text { 1. Smooth } \\
\end{array}$ & & $\mathrm{X}$ & & & & 4 \\
\hline $\mathrm{X}$ & Pattern & $\begin{array}{r}\text { 5. Highly Repeated Motifs } \\
\text { 1. No Repeated Motifs } \\
\end{array}$ & & & $\mathrm{X}$ & & & 3 \\
\hline XI & $\begin{array}{l}\text { Spatial Organization } \\
\text { (Evenness of Space) }\end{array}$ & $\begin{array}{r}\text { 5. Evenly Dispersed } \\
\text { 1. Irregularly Dispersed } \\
\end{array}$ & & & & $\mathrm{X}$ & & 2 \\
\hline XII & Spatial Denseness & $\begin{array}{r}\text { 5. Densely packed } \\
\text { 1. Open Space }\end{array}$ & & & $\mathrm{X}$ & & & 3 \\
\hline XIII & Illusion of Depth & $\begin{array}{r}\text { 5. Deep } \\
\text { 1. Flat } \\
\end{array}$ & & $\mathrm{X}$ & & & & 4 \\
\hline XIV & Time and Motion & $\begin{array}{l}\text { 5. In Motion } \\
\text { 1.No Motion }\end{array}$ & & & & & $\mathrm{X}$ & 1 \\
\hline $\mathrm{XV}$ & Unity and Variety & $\begin{array}{l}\text { 5. Varied } \\
\text { 1. Unified } \\
\end{array}$ & & & & & $\mathrm{X}$ & 1 \\
\hline XVI & Emphasis and Focal Point & $\begin{array}{r}\text { 5. Definite Focal Point } \\
\text { 1. No Focal Point }\end{array}$ & $\mathrm{X}$ & & & & & 5 \\
\hline XVII & Proportion & $\begin{array}{r}\text { 5. Elements in Proportion } \\
\text { 1. Elements out of Proportion }\end{array}$ & $\mathrm{X}$ & & & & & 5 \\
\hline XVIII & Scale (Small to Large) & $\begin{array}{l}\text { 5. Large Scale } \\
\text { 1. Small Scale }\end{array}$ & & & $\mathrm{X}$ & & & 3 \\
\hline XIX & Rhythm & $\begin{array}{l}\text { 5. Rhythmic } \\
\text { 1. Static }\end{array}$ & & & & $\mathrm{X}$ & & 2 \\
\hline $\mathrm{XX}$ & Centric or Eccentric & $\begin{array}{r}\text { 5. Internal Vectors } \\
\text { 1. External Vectors }\end{array}$ & & & $X$ & & & 3 \\
\hline & Totals & & 3 & 7 & 5 & 3 & 2 & 66 \\
\hline
\end{tabular}


Formal Elements

Rating Scale (FERS)

\begin{tabular}{|c|c|c|c|c|c|c|c|c|}
\hline & \multicolumn{2}{|c|}{ Figure 31: Van Gogh's Bedroom, 1888} & \multirow[t]{2}{*}{5} & \multirow{2}{*}{$\begin{array}{l}4 \\
X\end{array}$} & \multirow[t]{2}{*}{3} & \multirow[t]{2}{*}{2} & \multirow[t]{2}{*}{1} & \multirow{2}{*}{$\frac{\text { Total }}{4}$} \\
\hline I & Line Quality & $\begin{array}{l}\text { 5. Fluid and Flowing } \\
\text { 1. Jagged and Broken }\end{array}$ & & & & & & \\
\hline II & Expressive Style & $\begin{array}{l}\text { 5. Freedom of Expression } \\
\text { 1. Excessive Repetition }\end{array}$ & & & $\mathrm{X}$ & & & 3 \\
\hline III & Shape and Mass & $\begin{array}{r}\text { 5. Organic } \\
\text { 1. Geometric } \\
\end{array}$ & & & & $\mathrm{X}$ & & 2 \\
\hline IV & Abstraction or Realism & $\begin{array}{l}\text { 5. Realistic } \\
\text { 1. Abstract }\end{array}$ & $\mathrm{X}$ & & & & & 5 \\
\hline $\mathrm{V}$ & Figure Ground Relationship & $\begin{array}{r}\text { 5. Subject Dominant } \\
\text { 1. Background Dominant }\end{array}$ & & & $\mathrm{X}$ & & & 3 \\
\hline VI & Value (Dark and Light) & $\begin{array}{l}\text { 5. Light Colors } \\
\text { 1. Dark Colors }\end{array}$ & & & $\mathrm{X}$ & & & 3 \\
\hline VII & Intensity of Color & $\begin{array}{l}\text { 5. Pure and Saturated } \\
\text { 1. Greyed and Softened }\end{array}$ & & & $\mathrm{X}$ & & & 3 \\
\hline VIII & Variety of Color & $\begin{array}{r}\text { 5. Polychromatic } \\
\text { 1. Monochromatic }\end{array}$ & $\mathrm{X}$ & & & & & 5 \\
\hline IX & Texture & $\begin{array}{l}\text { 5. Impasto } \\
\text { 1. Smooth }\end{array}$ & & $\mathrm{X}$ & & & & 4 \\
\hline $\mathrm{X}$ & Pattern & $\begin{array}{l}\text { 5. Highly Repeated Motifs } \\
\text { 1. No Repeated Motifs }\end{array}$ & $\mathrm{X}$ & & & & & 5 \\
\hline XI & $\begin{array}{l}\text { Spatial Organization } \\
\text { (Evenness of Space) }\end{array}$ & $\begin{array}{l}\text { 5. Evenly Dispersed } \\
\text { 1. Irregularly Dispersed }\end{array}$ & & & & $\mathrm{X}$ & & 2 \\
\hline XII & Spatial Denseness & $\begin{array}{r}\text { 5. Densely packed } \\
\text { 1. Open Space } \\
\end{array}$ & & & $\mathrm{X}$ & & & 3 \\
\hline XIII & Illusion of Depth & $\begin{array}{r}\text { 5. Deep } \\
\text { 1. Flat } \\
\end{array}$ & $\mathrm{X}$ & & & & & 5 \\
\hline XIV & Time and Motion & $\begin{array}{l}\text { 5. In Motion } \\
\text { 1.No Motion }\end{array}$ & & & & & $\mathrm{X}$ & 1 \\
\hline $\mathrm{XV}$ & Unity and Variety & $\begin{array}{l}\text { 5. Varied } \\
\text { 1. Unified }\end{array}$ & & & & & $\mathrm{X}$ & 1 \\
\hline XVI & Emphasis and Focal Point & $\begin{array}{r}\text { 5. Definite Focal Point } \\
\text { 1. No Focal Point }\end{array}$ & $\mathrm{X}$ & & & & & 5 \\
\hline XVII & Proportion & $\begin{array}{l}\text { 5. Elements in Proportion } \\
\text { 1. Elements out of Proportion }\end{array}$ & & & $\mathrm{X}$ & & & 3 \\
\hline XVIII & Scale (Small to Large) & $\begin{array}{l}\text { 5. Large Scale } \\
\text { 1. Small Scale } \\
\end{array}$ & & $\mathrm{X}$ & & & & 4 \\
\hline XIX & Rhythm & $\begin{array}{r}\text { 5. Rhythmic } \\
\text { 1. Static } \\
\end{array}$ & & & & & $\mathrm{X}$ & 1 \\
\hline $\mathrm{XX}$ & Centric or Eccentric & $\begin{array}{l}\text { 5. Internal Vectors } \\
\text { 1. External Vectors }\end{array}$ & & & & $\mathrm{X}$ & & 2 \\
\hline & Total & & 5 & 3 & 6 & 3 & 3 & 64 \\
\hline
\end{tabular}


Formal Elements

Rating Scale (FERS)

\begin{tabular}{|c|c|c|c|c|c|c|c|c|}
\hline & \multicolumn{2}{|c|}{ Figure 32: The Sower, October 1888} & \multirow[t]{2}{*}{5} & \multirow[t]{2}{*}{4} & \multirow[t]{2}{*}{3} & \multirow{2}{*}{$\begin{array}{l}2 \\
X\end{array}$} & \multirow[t]{2}{*}{1} & \multirow{2}{*}{$\frac{\text { Total }}{2}$} \\
\hline $\mathrm{I}$ & Line Quality & $\begin{array}{l}\text { 5. Fluid and Flowing } \\
\text { 1. Jagged and Broken }\end{array}$ & & & & & & \\
\hline II & Expressive Style & $\begin{array}{r}\text { 5. Freedom of Expression } \\
\text { 1. Excessive Repetition }\end{array}$ & & & & $\mathrm{X}$ & & 2 \\
\hline III & Shape and Mass & $\begin{array}{r}\text { 5. Organic } \\
\text { 1. Geometric }\end{array}$ & & $\mathrm{X}$ & & & & 4 \\
\hline IV & $\begin{array}{l}\text { Aureigbstraction or Realism } \\
\text { Realistic }\end{array}$ & $\begin{array}{c}5 . \\
\text { 1. Abstract }\end{array}$ & $\mathrm{X}$ & & & & & 5 \\
\hline V & Figure Ground Relationship & $\begin{array}{r}\text { 5. Subject Dominant } \\
\text { 1. Background Dominant }\end{array}$ & & & & & $\mathrm{X}$ & 1 \\
\hline VI & Value (Dark and Light) & $\begin{array}{l}\text { 5. Light Colors } \\
\text { 1. Dark Colors }\end{array}$ & $\mathrm{X}$ & & & & & 5 \\
\hline VII & Intensity of Color & $\begin{array}{l}\text { 5. Pure and Saturated } \\
\text { 1. Greyed and Softened }\end{array}$ & & & $\mathrm{X}$ & & & 3 \\
\hline VIII & Variety of Color & $\begin{array}{r}\text { 5. Polychromatic } \\
\text { 1. Monochromatic } \\
\end{array}$ & & & $\mathrm{X}$ & & & 3 \\
\hline IX & Texture & $\begin{array}{l}\text { 5. Impasto } \\
\text { 1. Smooth }\end{array}$ & $\mathrm{X}$ & & & & & 5 \\
\hline $\bar{X}$ & Pattern & $\begin{array}{r}\text { 5. Highly Repeated Motifs } \\
\text { 1. No Repeated Motifs } \\
\end{array}$ & $\mathrm{X}$ & & & & & 5 \\
\hline XI & $\begin{array}{l}\text { Spatial Organization } \\
\text { (Evenness of Space) }\end{array}$ & $\begin{array}{r}\text { 5. Evenly Dispersed } \\
\text { 1. Irregularly Dispersed } \\
\end{array}$ & & & $\mathrm{X}$ & & & 3 \\
\hline XII & Spatial Denseness & $\begin{array}{r}\text { 5. Densely packed } \\
\text { 1. Open Space } \\
\end{array}$ & & & & & $X$ & 1 \\
\hline XIII & Illusion of Depth & $\begin{array}{r}\text { 5. Deep } \\
\text { 1. Flat }\end{array}$ & $\mathrm{X}$ & & & & & 5 \\
\hline XIV & Time and Motion & $\begin{array}{l}\text { 5. In Motion } \\
\text { 1.No Motion }\end{array}$ & & & & $\mathrm{X}$ & & 2 \\
\hline $\mathrm{XV}$ & Unity and Variety & $\begin{array}{l}\text { 5. Varied } \\
\text { 1. Unified } \\
\end{array}$ & & & & & $\mathrm{X}$ & 1 \\
\hline XVI & Emphasis and Focal Point & $\begin{array}{r}\text { 5. Definite Focal Point } \\
\text { 1. No Focal Point } \\
\end{array}$ & $\mathrm{X}$ & & & & & 5 \\
\hline XVII & Proportion & $\begin{array}{r}\text { 5. Elements in Proportion } \\
\text { 1. Elements out of Proportion }\end{array}$ & $X$ & & & & & 5 \\
\hline XVIII & Scale (Small to Large) & $\begin{array}{l}\text { 5. Large Scale } \\
\text { 1. Small Scale }\end{array}$ & & & & $X$ & & 2 \\
\hline XIX & Rhythm & $\begin{array}{l}\text { 5. Rhythmic } \\
\text { 1. Static }\end{array}$ & & $\mathrm{X}$ & & & & 4 \\
\hline $\mathrm{XX}$ & Centric or Eccentric & $\begin{array}{r}\text { 5. Internal Vectors } \\
\text { 1. External Vectors } \\
\end{array}$ & & $\mathrm{X}$ & & & & 4 \\
\hline & Totals & & 7 & 3 & 3 & 4 & 3 & 67 \\
\hline
\end{tabular}


Formal Elements

Rating Scale (FERS)

\begin{tabular}{|c|c|c|c|c|c|c|c|c|}
\hline & \multicolumn{2}{|c|}{ Figure 33: The Sower, November 1888} & \multirow[t]{2}{*}{5} & \multirow[t]{2}{*}{4} & \multirow[t]{2}{*}{3} & \multirow{2}{*}{$\begin{array}{l}2 \\
X\end{array}$} & \multirow[t]{2}{*}{1} & \multirow{2}{*}{$\frac{\text { Total }}{2}$} \\
\hline $\mathrm{I}$ & Line Quality & $\begin{array}{l}\text { 5. Fluid and Flowing } \\
\text { 1. Jagged and Broken }\end{array}$ & & & & & & \\
\hline II & Expressive Style & $\begin{array}{l}\text { 5. Freedom of Expression } \\
\text { 1. Excessive Repetition }\end{array}$ & & & $\mathrm{X}$ & & & 3 \\
\hline III & Shape and Mass & $\begin{array}{r}\text { 5. Organic } \\
\text { 1. Geometric }\end{array}$ & $\mathrm{X}$ & & & & & 5 \\
\hline IV & Abstraction or Realism & $\begin{array}{l}\text { 5. Realistic } \\
\text { 1. Abstract }\end{array}$ & & & $\mathrm{X}$ & & & 3 \\
\hline V & Figure Ground Relationship & $\begin{array}{r}\text { 5. Subject Dominant } \\
\text { 1. Background Dominant }\end{array}$ & & & & $\mathrm{X}$ & & 2 \\
\hline VI & Value (Dark and Light) & $\begin{array}{l}\text { 5. Light Colors } \\
\text { 1. Dark Colors }\end{array}$ & & & & $\mathrm{X}$ & & 2 \\
\hline VII & Intensity of Color & $\begin{array}{l}\text { 5. Pure and Saturated } \\
\text { 1. Greyed and Softened }\end{array}$ & & & & $\mathrm{X}$ & & 2 \\
\hline VIII & Variety of Color & $\begin{array}{r}\text { 5. Polychromatic } \\
\text { 1. Monochromatic }\end{array}$ & $\mathrm{X}$ & & & & & 5 \\
\hline IX & Texture & $\begin{array}{l}\text { 5. Impasto } \\
\text { 1. Smooth }\end{array}$ & & $\mathrm{X}$ & & & & 4 \\
\hline $\bar{X}$ & Pattern & $\begin{array}{l}\text { 5. Highly Repeated Motifs } \\
\text { 1. No Repeated Motifs }\end{array}$ & & $\mathrm{X}$ & & & & 4 \\
\hline XI & $\begin{array}{l}\text { Spatial Organization } \\
\text { (Evenness of Space) }\end{array}$ & $\begin{array}{l}\text { 5. Evenly Dispersed } \\
\text { 1. Irregularly Dispersed }\end{array}$ & & & & $\mathrm{X}$ & & 2 \\
\hline XII & Spatial Denseness & $\begin{array}{r}\text { 5. Densely packed } \\
\text { 1. Open Space }\end{array}$ & & & & $\mathrm{X}$ & & 2 \\
\hline XIII & Illusion of Depth & $\begin{array}{l}\text { 5. Deep } \\
\text { 1. Flat }\end{array}$ & $\mathrm{X}$ & & & & & 5 \\
\hline XIV & Time and Motion & $\begin{array}{l}\text { 5. In Motion } \\
\text { 1.No Motion }\end{array}$ & & & $\mathrm{X}$ & & & 3 \\
\hline $\mathrm{XV}$ & Unity and Variety & $\begin{array}{l}\text { 5. Varied } \\
\text { 1. Unified }\end{array}$ & & & & $\mathrm{X}$ & & 2 \\
\hline XVI & Emphasis and Focal Point & $\begin{array}{r}\text { 5. Definite Focal Point } \\
1 . \text { No Focal Point } \\
\end{array}$ & & $\mathrm{X}$ & & & & 4 \\
\hline XVII & Proportion & $\begin{array}{l}\text { 5. Elements in Proportion } \\
\text { 1. Elements out of Proportion }\end{array}$ & $\mathrm{X}$ & & & & & 5 \\
\hline XVIII & Scale (Small to Large) & $\begin{array}{l}\text { 5. Large Scale } \\
\text { 1. Small Scale }\end{array}$ & & $\mathrm{X}$ & & & & 4 \\
\hline XIX & Rhythm & $\begin{array}{r}\text { 5. Rhythmic } \\
\text { 1. Static }\end{array}$ & & & $\mathrm{X}$ & & & 3 \\
\hline XX & Centric or Eccentric & $\begin{array}{l}\text { 5. Internal Vectors } \\
\text { 1. External Vectors }\end{array}$ & & $\mathbf{X}$ & & & & 4 \\
\hline & Totals & & 4 & 5 & 4 & 7 & 0 & 66 \\
\hline
\end{tabular}


Formal Elements

Rating Scale (FERS)

\begin{tabular}{|c|c|c|c|c|c|c|c|c|}
\hline & \multicolumn{2}{|c|}{ Figure 34: L’ Arlésienne, 1888} & \multirow[t]{2}{*}{5} & \multirow[t]{2}{*}{4} & \multirow{2}{*}{\begin{tabular}{l|}
3 \\
$X$
\end{tabular}} & \multirow[t]{2}{*}{2} & \multirow[t]{2}{*}{1} & \multirow{2}{*}{$\frac{\text { Total }}{3}$} \\
\hline $\mathrm{I}$ & Line Quality & $\begin{array}{l}\text { 5. Fluid and Flowing } \\
\text { 1. Jagged and Broken }\end{array}$ & & & & & & \\
\hline II & Expressive Style & $\begin{array}{l}\text { 5. Freedom of Expression } \\
\text { 1. Excessive Repetition }\end{array}$ & $\mathrm{X}$ & & & & & 5 \\
\hline III & Shape and Mass & $\begin{array}{r}\text { 5. Organic } \\
\text { 1. Geometric } \\
\end{array}$ & & & $\mathrm{X}$ & & & 3 \\
\hline IV & Abstraction or Realism & $\begin{array}{l}\text { 5. Realistic } \\
\text { 1. Abstract }\end{array}$ & & $\mathrm{X}$ & & & & 4 \\
\hline $\mathrm{V}$ & Figure Ground Relationship & $\begin{array}{r}\text { 5. Subject Dominant } \\
\text { 1. Background Dominant } \\
\end{array}$ & & $\mathrm{X}$ & & & & 4 \\
\hline VI & Value (Dark and Light) & $\begin{array}{l}\text { 5. Light Colors } \\
\text { 1. Dark Colors }\end{array}$ & & & $\mathrm{X}$ & & & 3 \\
\hline VII & Intensity of Color & $\begin{array}{l}\text { 5. Pure and Saturated } \\
\text { 1. Greyed and Softened }\end{array}$ & $\mathrm{X}$ & & & & & 5 \\
\hline VIII & Variety of Color & $\begin{array}{r}\text { 5. Polychromatic } \\
\text { 1. Monochromatic }\end{array}$ & $\mathrm{X}$ & & & & & 5 \\
\hline IX & Texture & $\begin{array}{l}\text { 5. Impasto } \\
\text { 1. Smooth }\end{array}$ & & $\mathrm{X}$ & & & & 4 \\
\hline $\mathrm{X}$ & Pattern & $\begin{array}{l}\text { 5. Highly Repeated Motifs } \\
\text { 1. No Repeated Motifs }\end{array}$ & & & & $\mathrm{X}$ & & 2 \\
\hline XI & $\begin{array}{l}\text { Spatial Organization } \\
\text { (Evenness of Space) }\end{array}$ & $\begin{array}{l}\text { 5. Evenly Dispersed } \\
\text { 1. Irregularly Dispersed }\end{array}$ & & & $\mathrm{X}$ & & & 3 \\
\hline XII & Spatial Denseness & $\begin{array}{r}\text { 5. Densely packed } \\
\text { 1. Open Space } \\
\end{array}$ & & & $\mathrm{X}$ & & & 3 \\
\hline XIII & Illusion of Depth & $\begin{array}{r}\text { 5. Deep } \\
\text { 1. Flat } \\
\end{array}$ & & & & $\mathrm{X}$ & & 2 \\
\hline XIV & Time and Motion & $\begin{array}{l}\text { 5. In Motion } \\
\text { 1.No Motion }\end{array}$ & & & & & $\mathrm{X}$ & 1 \\
\hline $\mathrm{XV}$ & Unity and Variety & $\begin{array}{l}\text { 5. Varied } \\
\text { 1. Unified }\end{array}$ & & & & & $\mathrm{X}$ & 1 \\
\hline XVI & Emphasis and Focal Point & $\begin{array}{r}\text { 5. Definite Focal Point } \\
1 . \text { No Focal Point }\end{array}$ & $\mathrm{X}$ & & & & & 5 \\
\hline XVII & Proportion & $\begin{array}{l}\text { 5. Elements in Proportion } \\
\text { 1. Elements out of Proportion }\end{array}$ & $\mathrm{X}$ & & & & & 5 \\
\hline XVIII & Scale (Small to Large) & $\begin{array}{l}\text { 5. Large Scale } \\
\text { 1. Small Scale }\end{array}$ & & & $\mathrm{X}$ & & & 3 \\
\hline XIX & Rhythm & $\begin{array}{r}\text { 5. Rhythmic } \\
\text { 1. Static }\end{array}$ & & & & & $\mathrm{X}$ & 1 \\
\hline $\mathrm{XX}$ & Centric or Eccentric & $\begin{array}{l}\text { 5. Internal Vectors } \\
\text { 1. External Vectors }\end{array}$ & & $\mathrm{X}$ & & & & 4 \\
\hline & Total & & 5 & 4 & 6 & 2 & 3 & 66 \\
\hline
\end{tabular}


Formal Elements

Rating Scale (FERS)

\begin{tabular}{|c|c|c|c|c|c|c|c|c|}
\hline & \multicolumn{2}{|c|}{ Figure 35: Les Alyscamps } & \multirow[t]{2}{*}{5} & \multirow{2}{*}{$\begin{array}{l}4 \\
X\end{array}$} & \multirow[t]{2}{*}{3} & \multirow[t]{2}{*}{2} & \multirow[t]{2}{*}{1} & \multirow{2}{*}{$\frac{\text { Total }}{4}$} \\
\hline $\mathrm{I}$ & Line Quality & $\begin{array}{l}\text { 5. Fluid and Flowing } \\
\text { 1. Jagged and Broken }\end{array}$ & & & & & & \\
\hline II & Expressive Style & $\begin{array}{r}\text { 5. Freedom of Expression } \\
\text { 1. Excessive Repetition }\end{array}$ & & & & $\mathrm{X}$ & & 2 \\
\hline III & Shape and Mass & $\begin{array}{r}\text { 5. Organic } \\
\text { 1. Geometric } \\
\end{array}$ & & & & $\mathrm{X}$ & & 2 \\
\hline IV & Abstraction or Realism & $\begin{array}{l}\text { 5. Realistic } \\
\text { 1. Abstract }\end{array}$ & & & $\mathrm{X}$ & & & 3 \\
\hline $\mathrm{V}$ & Figure Ground Relationship & $\begin{array}{r}\text { 5. Subject Dominant } \\
\text { 1. Background Dominant }\end{array}$ & & & $\mathrm{X}$ & & & 3 \\
\hline VI & Value (Dark and Light) & $\begin{array}{c}\text { 5. Light Colors } \\
\text { 1. Dark Colors } \\
\end{array}$ & & & & $\mathrm{X}$ & & 2 \\
\hline VII & Intensity of Color & $\begin{array}{l}\text { 5. Pure and Saturated } \\
\text { 1. Greyed and Softened }\end{array}$ & & & & $\mathrm{X}$ & & 2 \\
\hline VIII & Variety of Color & $\begin{array}{r}\text { 5. Polychromatic } \\
\text { 1. Monochromatic }\end{array}$ & & $\mathrm{X}$ & & & & 4 \\
\hline IX & Texture & $\begin{array}{l}\text { 5. Impasto } \\
\text { 1. Smooth } \\
\end{array}$ & & & $\mathrm{X}$ & & & 3 \\
\hline $\mathrm{X}$ & Pattern & $\begin{array}{r}\text { 5. Highly Repeated Motifs } \\
\text { 1. No Repeated Motifs } \\
\end{array}$ & $\mathrm{X}$ & & & & & 5 \\
\hline XI & $\begin{array}{l}\text { Spatial Organization } \\
\text { (Evenness of Space) }\end{array}$ & $\begin{array}{r}\text { 5. Evenly Dispersed } \\
\text { 1. Irregularly Dispersed } \\
\end{array}$ & & & & & $\mathrm{X}$ & 1 \\
\hline XII & Spatial Denseness & $\begin{array}{r}\text { 5. Densely packed } \\
\text { 1. Open Space }\end{array}$ & & & $\mathrm{X}$ & & & 3 \\
\hline XIII & Illusion of Depth & $\begin{array}{r}\text { 5. Deep } \\
\text { 1. Flat } \\
\end{array}$ & $\mathrm{X}$ & & & & & 5 \\
\hline XIV & Time and Motion & $\begin{array}{l}\text { 5. In Motion } \\
\text { 1.No Motion } \\
\end{array}$ & & & $\mathrm{X}$ & & & 3 \\
\hline $\mathrm{XV}$ & Unity and Variety & $\begin{array}{l}\text { 5. Varied } \\
\text { 1. Unified } \\
\end{array}$ & & & & & $\mathrm{X}$ & 1 \\
\hline XVI & Emphasis and Focal Point & $\begin{array}{r}\text { 5. Definite Focal Point } \\
\text { 1. No Focal Point }\end{array}$ & $\mathrm{X}$ & & & & & 5 \\
\hline XVII & Proportion & $\begin{array}{l}\text { 5. Elements in Proportion } \\
\text { 1. Elements out of Proportion }\end{array}$ & $\mathrm{X}$ & & & & & 5 \\
\hline XVIII & Scale (Small to Large) & $\begin{array}{l}\text { 5. Large Scale } \\
\text { 1. Small Scale }\end{array}$ & & & $\mathrm{X}$ & & & 3 \\
\hline XIX & Rhythm & $\begin{array}{r}\text { 5. Rhythmic } \\
\text { 1. Static }\end{array}$ & & $\mathrm{X}$ & & & & 4 \\
\hline $\mathrm{XX}$ & Centric or Eccentric & $\begin{array}{r}\text { 5. Internal Vectors } \\
\text { 1. External Vectors }\end{array}$ & & & & & $\mathrm{X}$ & 1 \\
\hline & Total & & 4 & 3 & 6 & 4 & 3 & 61 \\
\hline
\end{tabular}


Formal Elements

Rating Scale (FERS)

\begin{tabular}{|c|c|c|c|c|c|c|c|c|}
\hline & \multicolumn{2}{|c|}{ Figure 36: The Red Vineyard } & \multirow[t]{2}{*}{5} & \multirow[t]{2}{*}{4} & \multirow{2}{*}{\begin{tabular}{l|}
3 \\
$X$
\end{tabular}} & \multirow[t]{2}{*}{2} & \multirow[t]{2}{*}{1} & \multirow{2}{*}{$\frac{\text { Total }}{3}$} \\
\hline $\mathrm{I}$ & Line Quality & $\begin{array}{l}\text { 5. Fluid and Flowing } \\
\text { 1. Jagged and Broken }\end{array}$ & & & & & & \\
\hline II & Expressive Style & $\begin{array}{l}\text { 5. Freedom of Expression } \\
\text { 1. Excessive Repetition }\end{array}$ & & & $\mathrm{X}$ & & & 3 \\
\hline III & Shape and Mass & $\begin{array}{r}\text { 5. Organic } \\
\text { 1. Geometric }\end{array}$ & & $\mathrm{X}$ & & & & 4 \\
\hline IV & Abstraction or Realism & $\begin{array}{l}\text { 5. Realistic } \\
\text { 1. Abstract }\end{array}$ & & $\mathrm{X}$ & & & & 4 \\
\hline $\mathrm{V}$ & Figure Ground Relationship & $\begin{array}{r}\text { 5. Subject Dominant } \\
\text { 1. Background Dominant }\end{array}$ & & $\mathrm{X}$ & & & & 4 \\
\hline VI & Value (Dark and Light) & $\begin{array}{c}\text { 5. Light Colors } \\
\text { 1. Dark Colors } \\
\end{array}$ & & & $\mathrm{X}$ & & & 3 \\
\hline VII & Intensity of Color & $\begin{array}{l}\text { 5. Pure and Saturated } \\
\text { 1. Greyed and Softened }\end{array}$ & $\mathrm{X}$ & & & & & 5 \\
\hline VIII & Variety of Color & $\begin{array}{r}\text { 5. Polychromatic } \\
\text { 1. Monochromatic }\end{array}$ & $\mathrm{X}$ & & & & & 5 \\
\hline IX & Texture & $\begin{array}{l}\text { 5. Impasto } \\
\text { 1. Smooth } \\
\end{array}$ & & $\mathrm{X}$ & & & & 4 \\
\hline $\mathrm{X}$ & Pattern & $\begin{array}{l}\text { 5. Highly Repeated Motifs } \\
\text { 1. No Repeated Motifs } \\
\end{array}$ & $\mathrm{X}$ & & & & & 5 \\
\hline $\mathrm{XI}$ & $\begin{array}{l}\text { Spatial Organization } \\
\text { (Evenness of Space) }\end{array}$ & $\begin{array}{r}\text { 5. Evenly Dispersed } \\
\text { 1. Irregularly Dispersed } \\
\end{array}$ & & & $\mathrm{X}$ & & & 3 \\
\hline XII & Spatial Denseness & $\begin{array}{r}\text { 5. Densely packed } \\
\text { 1. Open Space }\end{array}$ & & $\mathrm{X}$ & & & & 4 \\
\hline XIII & Illusion of Depth & $\begin{array}{r}\text { 5. Deep } \\
\text { 1. Flat } \\
\end{array}$ & $\mathrm{X}$ & & & & & 5 \\
\hline XIV & Time and Motion & $\begin{array}{l}\text { 5. In Motion } \\
\text { 1.No Motion } \\
\end{array}$ & & $\mathrm{X}$ & & & & 4 \\
\hline $\mathrm{XV}$ & Unity and Variety & $\begin{array}{l}\text { 5. Varied } \\
\text { 1. Unified } \\
\end{array}$ & & & $\mathrm{X}$ & & & 3 \\
\hline $\mathrm{XVI}$ & Emphasis and Focal Point & $\begin{array}{r}\text { 5. Definite Focal Point } \\
1 . \text { No Focal Point } \\
\end{array}$ & & & $\mathrm{X}$ & & & 3 \\
\hline XVII & Proportion & $\begin{array}{l}\text { 5. Elements in Proportion } \\
\text { 1. Elements out of Proportion }\end{array}$ & $\mathrm{X}$ & & & & & 5 \\
\hline XVIII & Scale (Small to Large) & $\begin{array}{l}\text { 5. Large Scale } \\
\text { 1. Small Scale } \\
\end{array}$ & & & $\mathrm{X}$ & & & 3 \\
\hline XIX & Rhythm & $\begin{array}{r}\text { 5. Rhythmic } \\
\text { 1. Static }\end{array}$ & $\mathrm{X}$ & & & & & 5 \\
\hline $\mathrm{XX}$ & Centric or Eccentric & $\begin{array}{r}\text { 5. Internal Vectors } \\
\text { 1. External Vectors }\end{array}$ & & & $\mathrm{X}$ & & & 3 \\
\hline & Total & & 6 & 6 & 8 & 0 & 0 & 78 \\
\hline
\end{tabular}


Formal Elements

Rating Scale (FERS)

\begin{tabular}{|c|c|c|c|c|c|c|c|c|}
\hline & \multicolumn{2}{|c|}{ Figure 37: Van Gogh's Chair } & \multirow[t]{2}{*}{5} & \multirow{2}{*}{\begin{tabular}{|l|}
4 \\
$X$
\end{tabular}} & \multirow[t]{2}{*}{3} & \multirow[t]{2}{*}{2} & \multirow[t]{2}{*}{1} & \multirow{2}{*}{$\frac{\text { Total }}{4}$} \\
\hline $\mathrm{I}$ & Line Quality & $\begin{array}{l}\text { 5. Fluid and Flowing } \\
\text { 1. Jagged and Broken }\end{array}$ & & & & & & \\
\hline II & Expressive Style & $\begin{array}{l}\text { 5. Freedom of Expression } \\
\text { 1. Excessive Repetition }\end{array}$ & & $\mathrm{X}$ & & & & 4 \\
\hline III & Shape and Mass & $\begin{array}{r}\text { 5. Organic } \\
\text { 1. Geometric } \\
\end{array}$ & & & & $\mathrm{X}$ & & 2 \\
\hline IV & Abstraction or Realism & $\begin{array}{l}\text { 5. Realistic } \\
\text { 1. Abstract }\end{array}$ & $\mathrm{X}$ & & & & & 5 \\
\hline $\mathrm{V}$ & Figure Ground Relationship & $\begin{array}{r}\text { 5. Subject Dominant } \\
\text { 1. Background Dominant } \\
\end{array}$ & & $\mathrm{X}$ & & & & 4 \\
\hline VI & Value (Dark and Light) & $\begin{array}{l}\text { 5. Light Colors } \\
\text { 1. Dark Colors }\end{array}$ & & & $\mathrm{X}$ & & & 3 \\
\hline VII & Intensity of Color & $\begin{array}{l}\text { 5. Pure and Saturated } \\
\text { 1. Greyed and Softened }\end{array}$ & & & $\mathrm{X}$ & & & 3 \\
\hline VIII & Variety of Color & $\begin{array}{r}\text { 5. Polychromatic } \\
\text { 1. Monochromatic }\end{array}$ & & $\mathrm{X}$ & & & & 4 \\
\hline IX & Texture & $\begin{array}{l}\text { 5. Impasto } \\
\text { 1. Smooth }\end{array}$ & & $\mathrm{X}$ & & & & 4 \\
\hline $\mathrm{X}$ & Pattern & $\begin{array}{l}\text { 5. Highly Repeated Motifs } \\
\text { 1. No Repeated Motifs }\end{array}$ & & $\mathrm{X}$ & & & & 4 \\
\hline XI & $\begin{array}{l}\text { Spatial Organization } \\
\text { (Evenness of Space) }\end{array}$ & $\begin{array}{l}\text { 5. Evenly Dispersed } \\
\text { 1. Irregularly Dispersed }\end{array}$ & & & & $\mathrm{X}$ & & 2 \\
\hline XII & Spatial Denseness & $\begin{array}{r}\text { 5. Densely packed } \\
\text { 1. Open Space } \\
\end{array}$ & & & $\mathrm{X}$ & & & 3 \\
\hline XIII & Illusion of Depth & $\begin{array}{l}\text { 5. Deep } \\
\text { 1. Flat }\end{array}$ & & & & $\mathrm{X}$ & & 2 \\
\hline XIV & Time and Motion & $\begin{array}{l}\text { 5. In Motion } \\
\text { 1.No Motion }\end{array}$ & & & & & $\mathrm{X}$ & 1 \\
\hline $\mathrm{XV}$ & Unity and Variety & $\begin{array}{l}\text { 5. Varied } \\
\text { 1. Unified }\end{array}$ & & & & & $\mathrm{X}$ & 1 \\
\hline XVI & Emphasis and Focal Point & $\begin{array}{r}\text { 5. Definite Focal Point } \\
1 . \text { No Focal Point }\end{array}$ & & $\mathrm{X}$ & & & & 4 \\
\hline XVII & Proportion & $\begin{array}{l}\text { 5. Elements in Proportion } \\
\text { 1. Elements out of Proportion }\end{array}$ & & $\mathrm{X}$ & & & & 4 \\
\hline XVIII & Scale (Small to Large) & $\begin{array}{l}\text { 5. Large Scale } \\
\text { 1. Small Scale }\end{array}$ & & & $\mathrm{X}$ & & & 3 \\
\hline XIX & Rhythm & $\begin{array}{r}\text { 5. Rhythmic } \\
\text { 1. Static }\end{array}$ & & & $\mathrm{X}$ & & & 3 \\
\hline $\mathrm{XX}$ & Centric or Eccentric & $\begin{array}{l}\text { 5. Internal Vectors } \\
\text { 1. External Vectors }\end{array}$ & & & $\mathrm{X}$ & & & 3 \\
\hline & Total & & 1 & 8 & 6 & 3 & 2 & 63 \\
\hline
\end{tabular}


Formal Elements

Rating Scale (FERS)

\begin{tabular}{|c|c|c|c|c|c|c|c|c|}
\hline & \multicolumn{2}{|c|}{ Figure 38: Gauguin's Chair } & \multirow[t]{2}{*}{5} & \multirow[t]{2}{*}{4} & \multirow{2}{*}{\begin{tabular}{l|}
3 \\
$X$
\end{tabular}} & \multirow[t]{2}{*}{2} & \multirow[t]{2}{*}{1} & \multirow{2}{*}{$\frac{\text { Total }}{3}$} \\
\hline I & Line Quality & $\begin{array}{l}\text { 5. Fluid and Flowing } \\
\text { 1. Jagged and Broken }\end{array}$ & & & & & & \\
\hline II & Expressive Style & $\begin{array}{l}\text { 5. Freedom of Expression } \\
\text { 1. Excessive Repetition }\end{array}$ & & $\mathrm{X}$ & & & & 4 \\
\hline III & Shape and Mass & $\begin{array}{r}\text { 5. Organic } \\
\text { 1. Geometric } \\
\end{array}$ & & & & $\mathrm{X}$ & & 2 \\
\hline IV & Abstraction or Realism & $\begin{array}{l}\text { 5. Realistic } \\
\text { 1. Abstract }\end{array}$ & & $\mathrm{X}$ & & & & 4 \\
\hline $\mathrm{V}$ & Figure Ground Relationship & $\begin{array}{r}\text { 5. Subject Dominant } \\
\text { 1. Background Dominant } \\
\end{array}$ & & & & $\mathrm{X}$ & & 2 \\
\hline VI & Value (Dark and Light) & $\begin{array}{l}\text { 5. Light Colors } \\
\text { 1. Dark Colors }\end{array}$ & & & & $\mathrm{X}$ & & 2 \\
\hline VII & Intensity of Color & $\begin{array}{l}\text { 5. Pure and Saturated } \\
\text { 1. Greyed and Softened }\end{array}$ & & $\mathrm{X}$ & & & & 4 \\
\hline VIII & Variety of Color & $\begin{array}{r}\text { 5. Polychromatic } \\
\text { 1. Monochromatic }\end{array}$ & & $\mathrm{X}$ & & & & 4 \\
\hline IX & Texture & $\begin{array}{l}\text { 5. Impasto } \\
\text { 1. Smooth }\end{array}$ & & & $\mathrm{X}$ & & & 3 \\
\hline $\bar{X}$ & Pattern & $\begin{array}{l}\text { 5. Highly Repeated Motifs } \\
\text { 1. No Repeated Motifs }\end{array}$ & & $\mathrm{X}$ & & & & 4 \\
\hline $\mathrm{XI}$ & $\begin{array}{l}\text { Spatial Organization } \\
\text { (Evenness of Space) }\end{array}$ & $\begin{array}{l}\text { 5. Evenly Dispersed } \\
\text { 1. Irregularly Dispersed }\end{array}$ & & & $\mathrm{X}$ & & & 3 \\
\hline XII & Spatial Denseness & $\begin{array}{r}\text { 5. Densely packed } \\
\text { 1. Open Space } \\
\end{array}$ & & & & $\mathrm{X}$ & & 2 \\
\hline XIII & Illusion of Depth & $\begin{array}{r}\text { 5. Deep } \\
\text { 1. Flat } \\
\end{array}$ & & & $\mathrm{X}$ & & & 3 \\
\hline XIV & Time and Motion & $\begin{array}{l}\text { 5. In Motion } \\
\text { 1.No Motion }\end{array}$ & & & & & $\mathrm{X}$ & 1 \\
\hline $\mathrm{XV}$ & Unity and Variety & $\begin{array}{l}\text { 5. Varied } \\
\text { 1. Unified }\end{array}$ & & & $\mathrm{X}$ & & & 3 \\
\hline XVI & Emphasis and Focal Point & $\begin{array}{r}\text { 5. Definite Focal Point } \\
1 . \text { No Focal Point }\end{array}$ & $\mathrm{X}$ & & & & & 5 \\
\hline XVII & Proportion & $\begin{array}{l}\text { 5. Elements in Proportion } \\
\text { 1. Elements out of Proportion }\end{array}$ & $\mathrm{X}$ & & & & & 5 \\
\hline XVIII & Scale (Small to Large) & $\begin{array}{l}\text { 5. Large Scale } \\
\text { 1. Small Scale } \\
\end{array}$ & & & $\mathrm{X}$ & & & 3 \\
\hline XIX & Rhythm & $\begin{array}{c}\text { 5. Rhythmic } \\
\text { 1. Static } \\
\end{array}$ & & & $\mathrm{X}$ & & & 3 \\
\hline $\mathrm{XX}$ & Centric or Eccentric & $\begin{array}{l}\text { 5. Internal Vectors } \\
\text { 1. External Vectors }\end{array}$ & $\mathrm{X}$ & & & & & 5 \\
\hline & Totals & & 3 & 5 & 7 & 4 & 1 & 65 \\
\hline
\end{tabular}


Formal Elements

Rating Scale (FERS)

\begin{tabular}{|c|c|c|c|c|c|c|c|c|}
\hline & \multicolumn{2}{|c|}{$\begin{array}{l}\text { Figure 39: Self-Portrait with Bandaged Ear } \\
\text { and Pipe }\end{array}$} & \multirow[t]{2}{*}{5} & \multirow{2}{*}{\begin{tabular}{|c|}
4 \\
$X$ \\
\end{tabular}} & \multirow[t]{2}{*}{3} & \multirow[t]{2}{*}{2} & \multirow[t]{2}{*}{1} & \multirow{2}{*}{$\begin{array}{c}\text { Total } \\
4\end{array}$} \\
\hline $\mathrm{I}$ & Line Quality & $\begin{array}{l}\text { 5. Fluid and Flowing } \\
\text { 1. Jagged and Broken }\end{array}$ & & & & & & \\
\hline II & Expressive Style & $\begin{array}{l}\text { 5. Freedom of Expression } \\
\text { 1. Excessive Repetition }\end{array}$ & $\mathrm{X}$ & & & & & 5 \\
\hline III & Shape and Mass & $\begin{array}{r}\text { 5. Organic } \\
\text { 1. Geometric }\end{array}$ & & $\mathrm{X}$ & & & & 4 \\
\hline IV & Abstraction or Realism & $\begin{array}{l}\text { 5. Realistic } \\
\text { 1. Abstract }\end{array}$ & $\mathrm{X}$ & & & & & 5 \\
\hline $\mathrm{V}$ & Figure Ground Relationship & $\begin{array}{r}\text { 5. Subject Dominant } \\
\text { 1. Background Dominant }\end{array}$ & & & $\mathrm{X}$ & & & 3 \\
\hline VI & Value (Dark and Light) & $\begin{array}{r}\text { 5. Light Colors } \\
\text { 1. Dark Colors } \\
\end{array}$ & & & $\mathrm{X}$ & & & 3 \\
\hline VII & Intensity of Color & $\begin{array}{l}\text { 5. Pure and Saturated } \\
\text { 1. Greyed and Softened }\end{array}$ & $\mathrm{X}$ & & & & & 5 \\
\hline VIII & Variety of Color & $\begin{array}{r}\text { 5. Polychromatic } \\
\text { 1. Monochromatic }\end{array}$ & & $\mathrm{X}$ & & & & 4 \\
\hline IX & Texture & $\begin{array}{l}\text { 5. Impasto } \\
\text { 1. Smooth }\end{array}$ & & & $\mathrm{X}$ & & & 3 \\
\hline $\bar{X}$ & Pattern & $\begin{array}{l}\text { 5. Highly Repeated Motifs } \\
\text { 1. No Repeated Motifs }\end{array}$ & & & $\mathrm{X}$ & & & 3 \\
\hline XI & $\begin{array}{l}\begin{array}{l}\text { Spatial Organization } \\
\text { (Evenness of Space) }\end{array} \\
\end{array}$ & $\begin{array}{r}\text { 5. Evenly Dispersed } \\
\text { 1. Irregularly Dispersed }\end{array}$ & & & $\mathrm{X}$ & & & 3 \\
\hline XII & Spatial Denseness & $\begin{array}{r}\text { 5. Densely packed } \\
\text { 1. Open Space } \\
\end{array}$ & & & $\mathrm{X}$ & & & 3 \\
\hline XIII & Illusion of Depth & $\begin{array}{r}\text { 5. Deep } \\
\text { 1. Flat }\end{array}$ & & & & & $\mathrm{X}$ & 1 \\
\hline XIV & Time and Motion & $\begin{array}{l}\text { 5. In Motion } \\
\text { 1.No Motion }\end{array}$ & & & & $\mathrm{X}$ & & 2 \\
\hline $\mathrm{XV}$ & Unity and Variety & $\begin{array}{l}\text { 5. Varied } \\
\text { 1. Unified }\end{array}$ & & & & & $\mathrm{X}$ & 1 \\
\hline $\mathrm{XVI}$ & Emphasis and Focal Point & $\begin{array}{r}\text { 5. Definite Focal Point } \\
1 . \text { No Focal Point } \\
\end{array}$ & $\mathrm{X}$ & & & & & 5 \\
\hline XVII & Proportion & $\begin{array}{l}\text { 5. Elements in Proportion } \\
\text { 1. Elements out of Proportion }\end{array}$ & $\mathrm{X}$ & & & & & 5 \\
\hline XVIII & Scale (Small to Large) & $\begin{array}{l}\text { 5. Large Scale } \\
\text { 1. Small Scale }\end{array}$ & & & $\mathrm{X}$ & & & 3 \\
\hline XIX & Rhythm & $\begin{array}{c}\text { 5. Rhythmic } \\
\text { 1. Static }\end{array}$ & & & $\mathrm{X}$ & & & 3 \\
\hline $\mathrm{XX}$ & Centric or Eccentric & $\begin{array}{l}\text { 5. Internal Vectors } \\
\text { 1. External Vectors }\end{array}$ & $\mathrm{X}$ & & & & & 5 \\
\hline & Totals & & 6 & 3 & 8 & 1 & 2 & 70 \\
\hline
\end{tabular}


Formal Elements

Rating Scale (FERS)

\begin{tabular}{|c|c|c|c|c|c|c|c|c|}
\hline & \multicolumn{2}{|c|}{ Figure 40: Portrait of Dr. Félix Rey } & \multirow[t]{2}{*}{5} & \multirow{2}{*}{$\begin{array}{l}4 \\
X\end{array}$} & \multirow[t]{2}{*}{3} & \multirow[t]{2}{*}{2} & \multirow[t]{2}{*}{1} & \multirow{2}{*}{$\frac{\text { Total }}{4}$} \\
\hline $\mathrm{I}$ & Line Quality & $\begin{array}{l}\text { 5. Fluid and Flowing } \\
\text { 1. Jagged and Broken }\end{array}$ & & & & & & \\
\hline II & Expressive Style & $\begin{array}{l}\text { 5. Freedom of Expression } \\
\text { 1. Excessive Repetition }\end{array}$ & & & & $\mathrm{X}$ & & 2 \\
\hline III & Shape and Mass & $\begin{array}{r}\text { 5. Organic } \\
\text { 1. Geometric } \\
\end{array}$ & & & $\mathrm{X}$ & & & 3 \\
\hline IV & Abstraction or Realism & $\begin{array}{l}\text { 5. Realistic } \\
\text { 1. Abstract }\end{array}$ & & & $\mathrm{X}$ & & & 3 \\
\hline $\mathrm{V}$ & Figure Ground Relationship & $\begin{array}{r}\text { 5. Subject Dominant } \\
\text { 1. Background Dominant }\end{array}$ & & $\mathrm{X}$ & & & & 4 \\
\hline VI & Value (Dark and Light) & $\begin{array}{r}\text { 5. Light Colors } \\
\text { 1. Dark Colors }\end{array}$ & & & & $\mathrm{X}$ & & 2 \\
\hline VII & Intensity of Color & $\begin{array}{l}\text { 5. Pure and Saturated } \\
\text { 1. Greyed and Softened }\end{array}$ & & $\mathrm{X}$ & & & & 4 \\
\hline VIII & Variety of Color & $\begin{array}{r}\text { 5. Polychromatic } \\
\text { 1. Monochromatic }\end{array}$ & & $\mathrm{X}$ & & & & 4 \\
\hline IX & Texture & $\begin{array}{l}\text { 5. Impasto } \\
\text { 1. Smooth }\end{array}$ & & & & $\mathrm{X}$ & & 2 \\
\hline $\mathrm{X}$ & Pattern & $\begin{array}{l}\text { 5. Highly Repeated Motifs } \\
\text { 1. No Repeated Motifs }\end{array}$ & $\mathrm{X}$ & & & & & 5 \\
\hline XI & $\begin{array}{l}\text { Spatial Organization } \\
\text { (Evenness of Space) }\end{array}$ & $\begin{array}{l}\text { 5. Evenly Dispersed } \\
\text { 1. Irregularly Dispersed }\end{array}$ & & $\mathrm{X}$ & & & & 4 \\
\hline XII & Spatial Denseness & $\begin{array}{r}\text { 5. Densely packed } \\
\text { 1. Open Space }\end{array}$ & $\mathrm{X}$ & & & & & 5 \\
\hline XIII & Illusion of Depth & $\begin{array}{r}\text { 5. Deep } \\
\text { 1. Flat }\end{array}$ & & & & & $\mathrm{X}$ & 1 \\
\hline XIV & Time and Motion & $\begin{array}{l}\text { 5. In Motion } \\
\text { 1.No Motion }\end{array}$ & & & & & $\mathrm{X}$ & 1 \\
\hline $\mathrm{XV}$ & Unity and Variety & $\begin{array}{l}\text { 5. Varied } \\
\text { 1. Unified }\end{array}$ & & & $\mathrm{X}$ & & & 3 \\
\hline $\mathrm{XVI}$ & Emphasis and Focal Point & $\begin{array}{r}\text { 5. Definite Focal Point } \\
\text { 1. No Focal Point }\end{array}$ & $\mathrm{X}$ & & & & & 5 \\
\hline XVII & Proportion & $\begin{array}{l}\text { 5. Elements in Proportion } \\
\text { 1. Elements out of Proportion }\end{array}$ & & $\mathrm{X}$ & & & & 4 \\
\hline XVIII & Scale (Small to Large) & $\begin{array}{l}\text { 5. Large Scale } \\
\text { 1. Small Scale }\end{array}$ & & & $\mathrm{X}$ & & & 3 \\
\hline XIX & Rhythm & $\begin{array}{r}\text { 5. Rhythmic } \\
\text { 1. Static }\end{array}$ & & $\mathrm{X}$ & & & & 4 \\
\hline $\mathrm{XX}$ & Centric or Eccentric & $\begin{array}{l}\text { 5. Internal Vectors } \\
\text { 1. External Vectors }\end{array}$ & $\mathrm{X}$ & & & & & 5 \\
\hline & Totals & & 4 & 7 & 4 & 3 & 2 & 68 \\
\hline
\end{tabular}


Formal Elements

Rating Scale (FERS)

\begin{tabular}{|c|c|c|c|c|c|c|c|c|}
\hline & Figure 41: La Berceus & & 5 & 4 & 3 & 2 & 1 & Total \\
\hline $\mathrm{I}$ & Line Quality & $\begin{array}{l}\text { 5. Fluid and Flowing } \\
\text { 1. Jagged and Broken }\end{array}$ & & $\mathrm{X}$ & & & & 4 \\
\hline II & Expressive Style & $\begin{array}{l}\text { 5. Freedom of Expression } \\
\text { 1. Excessive Repetition }\end{array}$ & & & $\mathrm{X}$ & & & 3 \\
\hline III & Shape and Mass & $\begin{array}{r}\text { 5. Organic } \\
\text { 1. Geometric }\end{array}$ & & & $\mathrm{X}$ & & & 3 \\
\hline IV & Abstraction or Realism & $\begin{array}{l}\text { 5. Realistic } \\
\text { 1. Abstract }\end{array}$ & & $\mathrm{X}$ & & & & 4 \\
\hline $\mathrm{V}$ & Figure Ground Relationship & $\begin{array}{r}\text { 5. Subject Dominant } \\
\text { 1. Background Dominant }\end{array}$ & & & $\mathrm{X}$ & & & 3 \\
\hline VI & Value (Dark and Light) & $\begin{array}{c}\text { 5. Light Colors } \\
\text { 1. Dark Colors } \\
\end{array}$ & & & & $\mathrm{X}$ & & 2 \\
\hline VII & Intensity of Color & $\begin{array}{l}\text { 5. Pure and Saturated } \\
\text { 1. Greyed and Softened }\end{array}$ & $\mathrm{X}$ & & & & & 5 \\
\hline VIII & Variety of Color & $\begin{array}{r}\text { 5. Polychromatic } \\
\text { 1. Monochromatic } \\
\end{array}$ & $\mathrm{X}$ & & & & & 5 \\
\hline IX & Texture & $\begin{array}{l}\text { 5. Impasto } \\
\text { 1. Smooth } \\
\end{array}$ & & & & $\mathrm{X}$ & & 2 \\
\hline $\mathrm{X}$ & Pattern & $\begin{array}{r}\text { 5. Highly Repeated Motifs } \\
\text { 1. No Repeated Motifs } \\
\end{array}$ & $\mathrm{X}$ & & & & & 5 \\
\hline XI & $\begin{array}{l}\text { Spatial Organization } \\
\text { (Evenness of Space) }\end{array}$ & $\begin{array}{r}\text { 5. Evenly Dispersed } \\
\text { 1. Irregularly Dispersed } \\
\end{array}$ & & $\mathrm{X}$ & & & & 4 \\
\hline XII & Spatial Denseness & $\begin{array}{r}\text { 5. Densely packed } \\
\text { 1. Open Space }\end{array}$ & $\mathrm{X}$ & & & & & 5 \\
\hline XIII & Illusion of Depth & $\begin{array}{r}\text { 5. Deep } \\
\text { 1. Flat } \\
\end{array}$ & & & & $\mathrm{X}$ & & 2 \\
\hline XIV & Time and Motion & $\begin{array}{l}\text { 5. In Motion } \\
\text { 1.No Motion }\end{array}$ & & & & & $\mathrm{X}$ & 1 \\
\hline $\mathrm{XV}$ & Unity and Variety & $\begin{array}{l}\text { 5. Varied } \\
\text { 1. Unified } \\
\end{array}$ & & & $\mathrm{X}$ & & & 3 \\
\hline $\mathrm{XVI}$ & Emphasis and Focal Point & $\begin{array}{r}\text { 5. Definite Focal Point } \\
1 . \text { No Focal Point } \\
\end{array}$ & $\mathrm{X}$ & & & & & 5 \\
\hline XVII & Proportion & $\begin{array}{l}\text { 5. Elements in Proportion } \\
\text { 1. Elements out of Proportion }\end{array}$ & & & & $\mathrm{X}$ & & 2 \\
\hline XVIII & Scale (Small to Large) & $\begin{array}{l}\text { 5. Large Scale } \\
\text { 1. Small Scale } \\
\end{array}$ & & $\mathrm{X}$ & & & & 4 \\
\hline XIX & Rhythm & $\begin{array}{r}\text { 5. Rhythmic } \\
\text { 1. Static } \\
\end{array}$ & & $\mathrm{X}$ & & & & 4 \\
\hline $\mathrm{XX}$ & Centric or Eccentric & $\begin{array}{l}\text { 5. Internal Vectors } \\
\text { 1. External Vectors } \\
\end{array}$ & $\mathrm{X}$ & & & & & 5 \\
\hline \multicolumn{3}{|c|}{ Totals } & 6 & 5 & 4 & 4 & 1 & 71 \\
\hline
\end{tabular}


Formal Elements

Rating Scale (FERS)

\begin{tabular}{|c|c|c|c|c|c|c|c|c|}
\hline & Figure 42: Irises, 188 & & 5 & 4 & 3 & 2 & 1 & Total \\
\hline I & Line Quality & $\begin{array}{l}\text { 5. Fluid and Flowing } \\
\text { 1. Jagged and Broken }\end{array}$ & $\mathrm{X}$ & & & & & 5 \\
\hline II & Expressive Style & $\begin{array}{r}\text { 5. Freedom of Expression } \\
\text { 1. Excessive Repetition }\end{array}$ & $\mathrm{X}$ & & & & & 5 \\
\hline III & Shape and Mass & $\begin{array}{r}\text { 5. Organic } \\
\text { 1. Geometric } \\
\end{array}$ & $\mathrm{X}$ & & & & & 5 \\
\hline IV & Abstraction or Realism & $\begin{array}{l}\text { 5. Realistic } \\
\text { 1. Abstract }\end{array}$ & $\mathrm{X}$ & & & & & 5 \\
\hline V & Figure Ground Relationship & $\begin{array}{r}\text { 5. Subject Dominant } \\
\text { 1. Background Dominant }\end{array}$ & $\mathrm{X}$ & & & & & 5 \\
\hline VI & Value (Dark and Light) & $\begin{array}{l}\text { 5. Light Colors } \\
\text { 1. Dark Colors } \\
\end{array}$ & & & $\mathrm{X}$ & & & 3 \\
\hline VII & Intensity of Color & $\begin{array}{l}\text { 5. Pure and Saturated } \\
\text { 1. Greyed and Softened }\end{array}$ & & $\mathrm{X}$ & & & & 4 \\
\hline VIII & Variety of Color & $\begin{array}{r}\text { 5. Polychromatic } \\
\text { 1. Monochromatic }\end{array}$ & & $\mathrm{X}$ & & & & 4 \\
\hline IX & Texture & $\begin{array}{l}\text { 5. Impasto } \\
\text { 1. Smooth } \\
\end{array}$ & & & $\mathrm{X}$ & & & 3 \\
\hline $\mathrm{X}$ & Pattern & $\begin{array}{l}\text { 5. Highly Repeated Motifs } \\
\text { 1. No Repeated Motifs }\end{array}$ & & $\mathrm{X}$ & & & & 4 \\
\hline XI & $\begin{array}{l}\text { Spatial Organization } \\
\text { (Evenness of Space) }\end{array}$ & $\begin{array}{r}\text { 5. Evenly Dispersed } \\
\text { 1. Irregularly Dispersed } \\
\end{array}$ & & & & $\mathrm{X}$ & & 2 \\
\hline XII & Spatial Denseness & $\begin{array}{r}\text { 5. Densely packed } \\
\text { 1. Open Space } \\
\end{array}$ & $\mathrm{X}$ & & & & & 5 \\
\hline XIII & Illusion of Depth & $\begin{array}{r}\text { 5. Deep } \\
\text { 1. Flat } \\
\end{array}$ & & $\mathrm{X}$ & & & & 4 \\
\hline XIV & Time and Motion & $\begin{array}{l}\text { 5. In Motion } \\
\text { 1.No Motion }\end{array}$ & & & $\mathrm{X}$ & & & 3 \\
\hline $\mathrm{XV}$ & Unity and Variety & $\begin{array}{l}\text { 5. Varied } \\
\text { 1. Unified }\end{array}$ & & & & & $\mathrm{X}$ & 1 \\
\hline XVI & Emphasis and Focal Point & $\begin{array}{r}\text { 5. Definite Focal Point } \\
1 . \text { No Focal Point }\end{array}$ & & & & $\mathrm{X}$ & & 2 \\
\hline XVII & Proportion & $\begin{array}{l}\text { 5. Elements in Proportion } \\
\text { 1. Elements out of Proportion }\end{array}$ & $\mathrm{X}$ & & & & & 5 \\
\hline XVIII & Scale (Small to Large) & $\begin{array}{l}\text { 5. Large Scale } \\
\text { 1. Small Scale }\end{array}$ & & & $\mathrm{X}$ & & & 3 \\
\hline XIX & Rhythm & $\begin{array}{r}\text { 5. Rhythmic } \\
\text { 1. Static }\end{array}$ & & $\mathrm{X}$ & & & & 4 \\
\hline $\mathrm{XX}$ & Centric or Eccentric & $\begin{array}{r}\text { 5. Internal Vectors } \\
\text { 1. External Vectors } \\
\end{array}$ & & $\mathrm{X}$ & & & & 4 \\
\hline \multicolumn{3}{|c|}{ Totals } & 7 & 6 & 4 & 2 & 1 & 76 \\
\hline
\end{tabular}


Formal Elements

Rating Scale (FERS)

\begin{tabular}{|c|c|c|c|c|c|c|c|c|}
\hline & \multicolumn{2}{|c|}{ Figure 43: Irises (Amsterdam Still-Life) } & \multirow[t]{2}{*}{5} & \multirow{2}{*}{\begin{tabular}{|l|}
4 \\
$X$
\end{tabular}} & \multirow[t]{2}{*}{3} & \multirow[t]{2}{*}{2} & \multirow[t]{2}{*}{1} & \multirow{2}{*}{$\frac{\text { Total }}{4}$} \\
\hline I & Line Quality & $\begin{array}{l}\text { 5. Fluid and Flowing } \\
\text { 1. Jagged and Broken }\end{array}$ & & & & & & \\
\hline II & Expressive Style & $\begin{array}{l}\text { 5. Freedom of Expression } \\
\text { 1. Excessive Repetition }\end{array}$ & $\mathrm{X}$ & & & & & 5 \\
\hline III & Shape and Mass & $\begin{array}{r}\text { 5. Organic } \\
\text { 1. Geometric }\end{array}$ & & $\mathrm{X}$ & & & & 4 \\
\hline IV & Abstraction or Realism & $\begin{array}{l}\text { 5. Realistic } \\
\text { 1. Abstract }\end{array}$ & & $\mathrm{X}$ & & & & 4 \\
\hline $\mathrm{V}$ & Figure Ground Relationship & $\begin{array}{r}\text { 5. Subject Dominant } \\
\text { 1. Background Dominant }\end{array}$ & & & $\mathrm{X}$ & & & 3 \\
\hline VI & Value (Dark and Light) & $\begin{array}{c}\text { 5. Light Colors } \\
\text { 1. Dark Colors }\end{array}$ & & & $\mathrm{X}$ & & & 3 \\
\hline VII & Intensity of Color & $\begin{array}{l}\text { 5. Pure and Saturated } \\
\text { 1. Greyed and Softened }\end{array}$ & $\mathrm{X}$ & & & & & 5 \\
\hline VIII & Variety of Color & $\begin{array}{r}\text { 5. Polychromatic } \\
\text { 1. Monochromatic }\end{array}$ & & $\mathrm{X}$ & & & & 4 \\
\hline IX & Texture & $\begin{array}{l}\text { 5. Impasto } \\
\text { 1. Smooth } \\
\end{array}$ & & $\mathrm{X}$ & & & & 4 \\
\hline $\mathrm{X}$ & Pattern & $\begin{array}{r}\text { 5. Highly Repeated Motifs } \\
\text { 1. No Repeated Motifs } \\
\end{array}$ & & & $\mathrm{X}$ & & & 3 \\
\hline $\mathrm{XI}$ & $\begin{array}{l}\text { Spatial Organization } \\
\text { (Evenness of Space) }\end{array}$ & $\begin{array}{r}\text { 5. Evenly Dispersed } \\
\text { 1. Irregularly Dispersed } \\
\end{array}$ & & & & $\mathrm{X}$ & & 2 \\
\hline XII & Spatial Denseness & $\begin{array}{r}\text { 5. Densely packed } \\
\text { 1. Open Space }\end{array}$ & & $\mathrm{X}$ & & & & 4 \\
\hline XIII & Illusion of Depth & $\begin{array}{r}\text { 5. Deep } \\
\text { 1. Flat } \\
\end{array}$ & & & & & $\mathrm{X}$ & 1 \\
\hline XIV & Time and Motion & $\begin{array}{l}\text { 5. In Motion } \\
\text { 1.No Motion } \\
\end{array}$ & & & & & $\mathrm{X}$ & 1 \\
\hline $\mathrm{XV}$ & Unity and Variety & $\begin{array}{l}\text { 5. Varied } \\
\text { 1. Unified } \\
\end{array}$ & & & & & $\mathrm{X}$ & 1 \\
\hline XVI & Emphasis and Focal Point & $\begin{array}{r}\text { 5. Definite Focal Point } \\
\text { 1. No Focal Point }\end{array}$ & & & & & $\mathrm{X}$ & 1 \\
\hline XVII & Proportion & $\begin{array}{r}\text { 5. Elements in Proportion } \\
\text { 1. Elements out of Proportion }\end{array}$ & $\mathrm{X}$ & & & & & 5 \\
\hline XVIII & Scale (Small to Large) & $\begin{array}{l}\text { 5. Large Scale } \\
\text { 1. Small Scale }\end{array}$ & & & $\mathrm{X}$ & & & 3 \\
\hline XIX & Rhythm & $\begin{array}{l}\text { 5. Rhythmic } \\
\text { 1. Static }\end{array}$ & & & $\mathrm{X}$ & & & 3 \\
\hline $\mathrm{XX}$ & Centric or Eccentric & $\begin{array}{r}\text { 5. Internal Vectors } \\
\text { 1. External Vectors }\end{array}$ & $\mathrm{X}$ & & & & & 5 \\
\hline & Total & & 4 & 6 & 5 & 1 & 4 & 65 \\
\hline
\end{tabular}


Formal Elements

Rating Scale (FERS)

\begin{tabular}{|c|c|c|c|c|c|c|c|c|}
\hline & \multicolumn{2}{|c|}{ Figure 44: Irises (Metropolitan Still-Life) } & \multirow[t]{2}{*}{5} & \multirow{2}{*}{\begin{tabular}{|l|}
4 \\
$X$
\end{tabular}} & \multirow[t]{2}{*}{3} & \multirow[t]{2}{*}{2} & \multirow[t]{2}{*}{1} & \multirow{2}{*}{$\frac{\text { Total }}{4}$} \\
\hline I & Line Quality & $\begin{array}{l}\text { 5. Fluid and Flowing } \\
\text { 1. Jagged and Broken }\end{array}$ & & & & & & \\
\hline II & Expressive Style & $\begin{array}{l}\text { 5. Freedom of Expression } \\
\text { 1. Excessive Repetition }\end{array}$ & $\mathrm{X}$ & & & & & 5 \\
\hline III & Shape and Mass & $\begin{array}{r}\text { 5. Organic } \\
\text { 1. Geometric } \\
\end{array}$ & & $\mathrm{X}$ & & & & 4 \\
\hline IV & Abstraction or Realism & $\begin{array}{l}\text { 5. Realistic } \\
\text { 1. Abstract }\end{array}$ & $\mathrm{X}$ & & & & & 5 \\
\hline $\mathrm{V}$ & Figure Ground Relationship & $\begin{array}{r}\text { 5. Subject Dominant } \\
\text { 1. Background Dominant } \\
\end{array}$ & & $\mathrm{X}$ & & & & 4 \\
\hline VI & Value (Dark and Light) & $\begin{array}{c}\text { 5. Light Colors } \\
\text { 1. Dark Colors } \\
\end{array}$ & & & $\mathrm{X}$ & & & 3 \\
\hline VII & Intensity of Color & $\begin{array}{l}\text { 5. Pure and Saturated } \\
\text { 1. Greyed and Softened }\end{array}$ & $\mathrm{X}$ & & & & & 5 \\
\hline VIII & Variety of Color & $\begin{array}{r}\text { 5. Polychromatic } \\
\text { 1. Monochromatic }\end{array}$ & & $\mathrm{X}$ & & & & 4 \\
\hline IX & Texture & $\begin{array}{l}\text { 5. Impasto } \\
\text { 1. Smooth }\end{array}$ & & & & $\mathrm{X}$ & & 2 \\
\hline $\mathrm{X}$ & Pattern & $\begin{array}{l}\text { 5. Highly Repeated Motifs } \\
\text { 1. No Repeated Motifs }\end{array}$ & & & $\mathrm{X}$ & & & 3 \\
\hline $\mathrm{XI}$ & $\begin{array}{l}\text { Spatial Organization } \\
\text { (Evenness of Space) }\end{array}$ & $\begin{array}{r}\text { 5. Evenly Dispersed } \\
\text { 1. Irregularly Dispersed } \\
\end{array}$ & & & & $\mathrm{X}$ & & 2 \\
\hline XII & Spatial Denseness & $\begin{array}{r}\text { 5. Densely packed } \\
\text { 1. Open Space }\end{array}$ & & $\mathrm{X}$ & & & & 4 \\
\hline XIII & Illusion of Depth & $\begin{array}{r}\text { 5. Deep } \\
\text { 1. Flat } \\
\end{array}$ & & & & & $\mathrm{X}$ & 1 \\
\hline XIV & Time and Motion & $\begin{array}{l}\text { 5. In Motion } \\
\text { 1.No Motion } \\
\end{array}$ & & & & & $\mathrm{X}$ & 1 \\
\hline $\mathrm{XV}$ & Unity and Variety & $\begin{array}{l}\text { 5. Varied } \\
\text { 1. Unified } \\
\end{array}$ & & & & & $\mathrm{X}$ & 1 \\
\hline XVI & Emphasis and Focal Point & $\begin{array}{r}\text { 5. Definite Focal Point } \\
\text { 1. No Focal Point }\end{array}$ & & & & & $\mathrm{X}$ & 1 \\
\hline XVII & Proportion & $\begin{array}{l}\text { 5. Elements in Proportion } \\
\text { 1. Elements out of Proportion }\end{array}$ & $\mathrm{X}$ & & & & & 5 \\
\hline XVIII & Scale (Small to Large) & $\begin{array}{l}\text { 5. Large Scale } \\
\text { 1. Small Scale }\end{array}$ & & & $\mathrm{X}$ & & & 3 \\
\hline XIX & Rhythm & $\begin{array}{r}\text { 5. Rhythmic } \\
\text { 1. Static }\end{array}$ & & & $\mathrm{X}$ & & & 3 \\
\hline $\mathrm{XX}$ & Centric or Eccentric & $\begin{array}{r}\text { 5. Internal Vectors } \\
\text { 1. External Vectors }\end{array}$ & $\mathrm{X}$ & & & & & 5 \\
\hline & Total & & 5 & 5 & 4 & 2 & 4 & 65 \\
\hline
\end{tabular}


Formal Elements

Rating Scale (FERS)

\begin{tabular}{|c|c|c|c|c|c|c|c|c|}
\hline & \multicolumn{2}{|c|}{ Figure 45: Pink Roses in a Vase } & \multirow{2}{*}{$\begin{array}{l}5 \\
X\end{array}$} & \multirow[t]{2}{*}{4} & \multirow[t]{2}{*}{3} & \multirow[t]{2}{*}{2} & \multirow[t]{2}{*}{1} & \multirow{2}{*}{$\frac{\text { Total }}{5}$} \\
\hline I & Line Quality & $\begin{array}{l}\text { 5. Fluid and Flowing } \\
\text { 1. Jagged and Broken }\end{array}$ & & & & & & \\
\hline II & Expressive Style & $\begin{array}{l}\text { 5. Freedom of Expression } \\
\text { 1. Excessive Repetition }\end{array}$ & $\mathrm{X}$ & & & & & 5 \\
\hline III & Shape and Mass & $\begin{array}{r}\text { 5. Organic } \\
\text { 1. Geometric } \\
\end{array}$ & $\mathrm{X}$ & & & & & 5 \\
\hline IV & Abstraction or Realism & $\begin{array}{l}\text { 5. Realistic } \\
\text { 1. Abstract }\end{array}$ & $\mathrm{X}$ & & & & & 5 \\
\hline $\mathrm{V}$ & Figure Ground Relationship & $\begin{array}{r}\text { 5. Subject Dominant } \\
\text { 1. Background Dominant } \\
\end{array}$ & $\mathrm{X}$ & & & & & 5 \\
\hline VI & Value (Dark and Light) & $\begin{array}{l}\text { 5. Light Colors } \\
\text { 1. Dark Colors } \\
\end{array}$ & & & $\mathrm{X}$ & & & 3 \\
\hline VII & Intensity of Color & $\begin{array}{l}\text { 5. Pure and Saturated } \\
\text { 1. Greyed and Softened }\end{array}$ & & & $\mathrm{X}$ & & & 3 \\
\hline VIII & Variety of Color & $\begin{array}{r}\text { 5. Polychromatic } \\
\text { 1. Monochromatic }\end{array}$ & & & $\mathrm{X}$ & & & 3 \\
\hline IX & Texture & $\begin{array}{l}\text { 5. Impasto } \\
\text { 1. Smooth }\end{array}$ & & $\mathrm{X}$ & & & & 4 \\
\hline $\mathrm{X}$ & Pattern & $\begin{array}{l}\text { 5. Highly Repeated Motifs } \\
\text { 1. No Repeated Motifs }\end{array}$ & & $\mathrm{X}$ & & & & 4 \\
\hline $\mathrm{XI}$ & $\begin{array}{l}\text { Spatial Organization } \\
\text { (Evenness of Space) }\end{array}$ & $\begin{array}{l}\text { 5. Evenly Dispersed } \\
\text { 1. Irregularly Dispersed }\end{array}$ & & $\mathrm{X}$ & & & & 4 \\
\hline XII & Spatial Denseness & $\begin{array}{r}\text { 5. Densely packed } \\
\text { 1. Open Space }\end{array}$ & & $\mathrm{X}$ & & & & 4 \\
\hline XIII & Illusion of Depth & $\begin{array}{r}\text { 5. Deep } \\
\text { 1. Flat }\end{array}$ & & & & & $\mathrm{X}$ & 1 \\
\hline XIV & Time and Motion & $\begin{array}{l}\text { 5. In Motion } \\
\text { 1.No Motion }\end{array}$ & & & & & $\mathrm{X}$ & 1 \\
\hline $\mathrm{XV}$ & Unity and Variety & $\begin{array}{l}\text { 5. Varied } \\
\text { 1. Unified }\end{array}$ & & & & & $\mathrm{X}$ & 1 \\
\hline $\mathrm{XVI}$ & Emphasis and Focal Point & $\begin{array}{r}\text { 5. Definite Focal Point } \\
1 . \text { No Focal Point }\end{array}$ & & & & & $\mathrm{X}$ & 1 \\
\hline XVII & Proportion & $\begin{array}{l}\text { 5. Elements in Proportion } \\
\text { 1. Elements out of Proportion }\end{array}$ & 5 & & & & & 5 \\
\hline XVIII & Scale (Small to Large) & $\begin{array}{l}\text { 5. Large Scale } \\
\text { 1. Small Scale }\end{array}$ & & & $\mathrm{X}$ & & & 3 \\
\hline XIX & Rhythm & $\begin{array}{c}\text { 5. Rhythmic } \\
\text { 1. Static }\end{array}$ & & & $\mathrm{X}$ & & & 3 \\
\hline $\mathrm{XX}$ & Centric or Eccentric & $\begin{array}{l}\text { 5. Internal Vectors } \\
\text { 1. External Vectors }\end{array}$ & $\mathrm{X}$ & & & & & 5 \\
\hline & Totals & & 7 & 4 & 5 & 0 & 4 & 70 \\
\hline
\end{tabular}


Formal Elements

Rating Scale (FERS)

\begin{tabular}{|c|c|c|c|c|c|c|c|c|}
\hline & \multicolumn{2}{|c|}{ Figure 46: The Prisoner's Round } & \multirow[t]{2}{*}{5} & \multirow[t]{2}{*}{4} & \multirow{2}{*}{\begin{tabular}{l|}
3 \\
$X$
\end{tabular}} & \multirow[t]{2}{*}{2} & \multirow[t]{2}{*}{1} & \multirow{2}{*}{$\frac{\text { Total }}{3}$} \\
\hline I & Line Quality & $\begin{array}{l}\text { 5. Fluid and Flowing } \\
\text { 1. Jagged and Broken }\end{array}$ & & & & & & \\
\hline II & Expressive Style & $\begin{array}{r}\text { 5. Freedom of Expression } \\
\text { 1. Excessive Repetition }\end{array}$ & & & & $\mathrm{X}$ & & 2 \\
\hline III & Shape and Mass & $\begin{array}{r}\text { 5. Organic } \\
\text { 1. Geometric } \\
\end{array}$ & & & $\mathrm{X}$ & & & 3 \\
\hline IV & Abstraction or Realism & $\begin{array}{l}\text { 5. Realistic } \\
\text { 1. Abstract }\end{array}$ & & $\mathrm{X}$ & & & & 4 \\
\hline $\mathrm{V}$ & Figure Ground Relationship & $\begin{array}{r}\text { 5. Subject Dominant } \\
\text { 1. Background Dominant }\end{array}$ & & & & $\mathrm{X}$ & & 2 \\
\hline VI & Value (Dark and Light) & $\begin{array}{l}\text { 5. Light Colors } \\
\text { 1. Dark Colors }\end{array}$ & & & $\mathrm{X}$ & & & 3 \\
\hline VII & Intensity of Color & $\begin{array}{l}\text { 5. Pure and Saturated } \\
\text { 1. Greyed and Softened }\end{array}$ & & $\mathrm{X}$ & & & & 4 \\
\hline VIII & Variety of Color & $\begin{array}{r}\text { 5. Polychromatic } \\
\text { 1. Monochromatic } \\
\end{array}$ & $\mathrm{X}$ & & & & & 5 \\
\hline IX & Texture & $\begin{array}{l}\text { 5. Impasto } \\
\text { 1. Smooth }\end{array}$ & & & $\mathrm{X}$ & & & 3 \\
\hline $\bar{X}$ & Pattern & $\begin{array}{l}\text { 5. Highly Repeated Motifs } \\
\text { 1. No Repeated Motifs }\end{array}$ & $\mathrm{X}$ & & & & & 5 \\
\hline $\mathrm{XI}$ & $\begin{array}{l}\text { Spatial Organization } \\
\text { (Evenness of Space) }\end{array}$ & $\begin{array}{r}\text { 5. Evenly Dispersed } \\
\text { 1. Irregularly Dispersed }\end{array}$ & $\mathrm{X}$ & & & & & 5 \\
\hline XII & Spatial Denseness & $\begin{array}{r}\text { 5. Densely packed } \\
\text { 1. Open Space } \\
\end{array}$ & & & $\mathrm{X}$ & & & 3 \\
\hline XIII & Illusion of Depth & $\begin{array}{r}\text { 5. Deep } \\
\text { 1. Flat }\end{array}$ & $\mathrm{X}$ & & & & & 5 \\
\hline XIV & Time and Motion & $\begin{array}{l}\text { 5. In Motion } \\
\text { 1.No Motion }\end{array}$ & & $\mathrm{X}$ & & & & 4 \\
\hline $\mathrm{XV}$ & Unity and Variety & $\begin{array}{l}\text { 5. Varied } \\
\text { 1. Unified }\end{array}$ & & & & & $\mathrm{X}$ & 1 \\
\hline XVI & Emphasis and Focal Point & $\begin{array}{r}\text { 5. Definite Focal Point } \\
1 . \text { No Focal Point }\end{array}$ & $\mathrm{X}$ & & & & & 5 \\
\hline XVII & Proportion & $\begin{array}{l}\text { 5. Elements in Proportion } \\
\text { 1. Elements out of Proportion }\end{array}$ & & $\mathrm{X}$ & & & & 4 \\
\hline XVIII & Scale (Small to Large) & $\begin{array}{l}\text { 5. Large Scale } \\
\text { 1. Small Scale }\end{array}$ & & & $\mathrm{X}$ & & & 3 \\
\hline XIX & Rhythm & $\begin{array}{r}\text { 5. Rhythmic } \\
\text { 1. Static }\end{array}$ & & $\mathrm{X}$ & & & & 4 \\
\hline $\mathrm{XX}$ & Centric or Eccentric & $\begin{array}{l}\text { 5. Internal Vectors } \\
\text { 1. External Vectors }\end{array}$ & & & $\mathrm{X}$ & & & 3 \\
\hline & Totals & & 5 & 5 & 7 & 2 & 1 & 71 \\
\hline
\end{tabular}


Formal Elements

Rating Scale (FERS)

\begin{tabular}{|c|c|c|c|c|c|c|c|c|}
\hline & Figure 47: Cypresses & & 5 & 4 & 3 & 2 & 1 & Total \\
\hline $\mathrm{I}$ & Line Quality & $\begin{array}{l}\text { 5. Fluid and Flowing } \\
\text { 1. Jagged and Broken }\end{array}$ & $\mathrm{X}$ & & & & & 5 \\
\hline II & Expressive Style & $\begin{array}{r}\text { 5. Freedom of Expression } \\
\text { 1. Excessive Repetition }\end{array}$ & & & $\mathrm{X}$ & & & 3 \\
\hline III & Shape and Mass & $\begin{array}{r}\text { 5. Organic } \\
\text { 1. Geometric } \\
\end{array}$ & $\mathrm{X}$ & & & & & 5 \\
\hline IV & Abstraction or Realism & $\begin{array}{l}\text { 5. Realistic } \\
\text { 1. Abstract }\end{array}$ & & $\mathrm{X}$ & & & & 4 \\
\hline $\mathrm{V}$ & Figure Ground Relationship & $\begin{array}{r}\text { 5. Subject Dominant } \\
\text { 1. Background Dominant }\end{array}$ & & & $\mathrm{X}$ & & & 3 \\
\hline VI & Value (Dark and Light) & $\begin{array}{l}\text { 5. Light Colors } \\
\text { 1. Dark Colors } \\
\end{array}$ & & & $\mathrm{X}$ & & & 3 \\
\hline VII & Intensity of Color & $\begin{array}{l}\text { 5. Pure and Saturated } \\
\text { 1. Greyed and Softened }\end{array}$ & & $\mathrm{X}$ & & & & 4 \\
\hline VIII & Variety of Color & $\begin{array}{r}\text { 5. Polychromatic } \\
\text { 1. Monochromatic }\end{array}$ & & $\mathrm{X}$ & & & & 4 \\
\hline IX & Texture & $\begin{array}{l}\text { 5. Impasto } \\
\text { 1. Smooth } \\
\end{array}$ & $\mathrm{X}$ & & & & & 5 \\
\hline $\mathrm{X}$ & Pattern & $\begin{array}{l}\text { 5. Highly Repeated Motifs } \\
\text { 1. No Repeated Motifs }\end{array}$ & & $\mathrm{X}$ & & & & 4 \\
\hline XI & $\begin{array}{l}\text { Spatial Organization } \\
\text { (Evenness of Space) }\end{array}$ & $\begin{array}{r}\text { 5. Evenly Dispersed } \\
\text { 1. Irregularly Dispersed } \\
\end{array}$ & & & $\mathrm{X}$ & & & 3 \\
\hline XII & Spatial Denseness & $\begin{array}{r}\text { 5. Densely packed } \\
\text { 1. Open Space }\end{array}$ & & $\mathrm{X}$ & & & & 4 \\
\hline XIII & Illusion of Depth & $\begin{array}{r}\text { 5. Deep } \\
\text { 1. Flat } \\
\end{array}$ & $\mathrm{X}$ & & & & & 5 \\
\hline XIV & Time and Motion & $\begin{array}{l}\text { 5. In Motion } \\
\text { 1.No Motion }\end{array}$ & & & & & $\mathrm{X}$ & 1 \\
\hline $\mathrm{XV}$ & Unity and Variety & $\begin{array}{l}\text { 5. Varied } \\
\text { 1. Unified }\end{array}$ & & & & & $\mathrm{X}$ & 1 \\
\hline $\mathrm{XVI}$ & Emphasis and Focal Point & $\begin{array}{r}\text { 5. Definite Focal Point } \\
\text { 1. No Focal Point }\end{array}$ & & & $\mathrm{X}$ & & & 3 \\
\hline XVII & Proportion & $\begin{array}{l}\text { 5. Elements in Proportion } \\
\text { 1. Elements out of Proportion }\end{array}$ & $\mathrm{X}$ & & & & & 5 \\
\hline XVIII & Scale (Small to Large) & $\begin{array}{l}\text { 5. Large Scale } \\
\text { 1. Small Scale }\end{array}$ & & $\mathrm{X}$ & & & & 4 \\
\hline XIX & Rhythm & $\begin{array}{r}\text { 5. Rhythmic } \\
\text { 1. Static }\end{array}$ & & $\mathrm{X}$ & & & & 4 \\
\hline $\mathrm{XX}$ & Centric or Eccentric & $\begin{array}{r}\text { 5. Internal Vectors } \\
\text { 1. External Vectors } \\
\end{array}$ & $\mathrm{X}$ & & & & & 5 \\
\hline \multicolumn{3}{|c|}{ Totals } & 6 & 7 & 5 & 0 & 2 & 75 \\
\hline
\end{tabular}


Formal Elements

Rating Scale (FERS)

\begin{tabular}{|c|c|c|c|c|c|c|c|c|}
\hline & \multicolumn{2}{|c|}{ Figure 48: The Starry Night } & \multirow[t]{2}{*}{5} & \multirow{2}{*}{\begin{tabular}{|l|}
4 \\
$X$
\end{tabular}} & \multirow[t]{2}{*}{3} & \multirow[t]{2}{*}{2} & \multirow[t]{2}{*}{1} & \multirow{2}{*}{$\frac{\text { Total }}{4}$} \\
\hline I & Line Quality & $\begin{array}{l}\text { 5. Fluid and Flowing } \\
\text { 1. Jagged and Broken }\end{array}$ & & & & & & \\
\hline II & Expressive Style & $\begin{array}{l}\text { 5. Freedom of Expression } \\
\text { 1. Excessive Repetition }\end{array}$ & $\mathrm{X}$ & & & & & 5 \\
\hline III & Shape and Mass & $\begin{array}{r}\text { 5. Organic } \\
\text { 1. Geometric }\end{array}$ & & $\mathrm{X}$ & & & & 4 \\
\hline IV & Abstraction or Realism & $\begin{array}{l}\text { 5. Realistic } \\
\text { 1. Abstract }\end{array}$ & & & $\mathrm{X}$ & & & 3 \\
\hline $\mathrm{V}$ & Figure Ground Relationship & $\begin{array}{r}\text { 5. Subject Dominant } \\
\text { 1. Background Dominant } \\
\end{array}$ & & & & & $\mathrm{X}$ & 1 \\
\hline VI & Value (Dark and Light) & $\begin{array}{l}\text { 5. Light Colors } \\
\text { 1. Dark Colors }\end{array}$ & & $\mathrm{X}$ & & & & 4 \\
\hline VII & Intensity of Color & $\begin{array}{l}\text { 5. Pure and Saturated } \\
\text { 1. Greyed and Softened }\end{array}$ & & & $\mathrm{X}$ & & & 3 \\
\hline VIII & Variety of Color & $\begin{array}{r}\text { 5. Polychromatic } \\
\text { 1. Monochromatic }\end{array}$ & & $\mathrm{X}$ & & & & 4 \\
\hline IX & Texture & $\begin{array}{l}\text { 5. Impasto } \\
\text { 1. Smooth } \\
\end{array}$ & $\mathrm{X}$ & & & & & 5 \\
\hline $\mathrm{X}$ & Pattern & $\begin{array}{l}\text { 5. Highly Repeated Motifs } \\
\text { 1. No Repeated Motifs } \\
\end{array}$ & $\mathrm{X}$ & & & & & 5 \\
\hline XI & $\begin{array}{l}\text { Spatial Organization } \\
\text { (Evenness of Space) }\end{array}$ & $\begin{array}{r}\text { 5. Evenly Dispersed } \\
\text { 1. Irregularly Dispersed }\end{array}$ & & & & & $\mathrm{X}$ & 1 \\
\hline XII & Spatial Denseness & $\begin{array}{r}\text { 5. Densely packed } \\
\text { 1. Open Space }\end{array}$ & & $\mathrm{X}$ & & & & 4 \\
\hline XIII & Illusion of Depth & $\begin{array}{r}\text { 5. Deep } \\
\text { 1. Flat } \\
\end{array}$ & $\mathrm{X}$ & & & & & 5 \\
\hline XIV & Time and Motion & $\begin{array}{l}\text { 5. In Motion } \\
\text { 1.No Motion }\end{array}$ & & & $\mathrm{X}$ & & & 3 \\
\hline $\mathrm{XV}$ & Unity and Variety & $\begin{array}{l}\text { 5. Varied } \\
\text { 1. Unified } \\
\end{array}$ & & & $\mathrm{X}$ & & & 3 \\
\hline XVI & Emphasis and Focal Point & $\begin{array}{r}\text { 5. Definite Focal Point } \\
1 . \text { No Focal Point } \\
\end{array}$ & & & $\mathrm{X}$ & & & 3 \\
\hline XVII & Proportion & $\begin{array}{l}\text { 5. Elements in Proportion } \\
\text { 1. Elements out of Proportion }\end{array}$ & $\mathrm{X}$ & & & & & 5 \\
\hline XVIII & Scale (Small to Large) & $\begin{array}{l}\text { 5. Large Scale } \\
\text { 1. Small Scale } \\
\end{array}$ & & & $\mathrm{X}$ & & & 2 \\
\hline XIX & Rhythm & $\begin{array}{r}\text { 5. Rhythmic } \\
\text { 1. Static } \\
\end{array}$ & & & $\mathrm{X}$ & & & 3 \\
\hline $\mathrm{XX}$ & Centric or Eccentric & $\begin{array}{l}\text { 5. Internal Vectors } \\
\text { 1. External Vectors }\end{array}$ & & $\mathrm{X}$ & & & & 4 \\
\hline & Totals & & 5 & 6 & 7 & 0 & 2 & 72 \\
\hline
\end{tabular}


Formal Elements

Rating Scale (FERS)

\begin{tabular}{|c|c|c|c|c|c|c|c|c|}
\hline & \multicolumn{2}{|c|}{ Figure 49: Self-Portrait (Saint-Rémy \#1) } & \multirow{2}{*}{$\begin{array}{l}5 \\
X\end{array}$} & \multirow[t]{2}{*}{4} & \multirow[t]{2}{*}{3} & \multirow[t]{2}{*}{2} & \multirow[t]{2}{*}{1} & \multirow{2}{*}{$\frac{\text { Total }}{5}$} \\
\hline $\mathrm{I}$ & Line Quality & $\begin{array}{l}\text { 5. Fluid and Flowing } \\
\text { 1. Jagged and Broken }\end{array}$ & & & & & & \\
\hline II & Expressive Style & $\begin{array}{l}\text { 5. Freedom of Expression } \\
\text { 1. Excessive Repetition }\end{array}$ & & & & $\mathrm{X}$ & & 2 \\
\hline III & Shape and Mass & $\begin{array}{r}\text { 5. Organic } \\
\text { 1. Geometric }\end{array}$ & & $\mathrm{X}$ & & & & 4 \\
\hline IV & Abstraction or Realism & $\begin{array}{l}\text { 5. Realistic } \\
\text { 1. Abstract }\end{array}$ & $\mathrm{X}$ & & & & & 5 \\
\hline V & Figure Ground Relationship & $\begin{array}{r}\text { 5. Subject Dominant } \\
\text { 1. Background Dominant }\end{array}$ & $\mathrm{X}$ & & & & & 5 \\
\hline VI & Value (Dark and Light) & $\begin{array}{l}\text { 5. Light Colors } \\
\text { 1. Dark Colors }\end{array}$ & & & & $\mathrm{X}$ & & 2 \\
\hline VII & Intensity of Color & $\begin{array}{l}\text { 5. Pure and Saturated } \\
\text { 1. Greyed and Softened }\end{array}$ & & $\mathrm{X}$ & & & & 4 \\
\hline VIII & Variety of Color & $\begin{array}{r}\text { 5. Polychromatic } \\
\text { 1. Monochromatic }\end{array}$ & & $\mathrm{X}$ & & & & 4 \\
\hline IX & Texture & $\begin{array}{l}\text { 5. Impasto } \\
\text { 1. Smooth }\end{array}$ & $\mathrm{X}$ & & & & & 5 \\
\hline $\bar{X}$ & Pattern & $\begin{array}{l}\text { 5. Highly Repeated Motifs } \\
\text { 1. No Repeated Motifs }\end{array}$ & & $\mathrm{X}$ & & & & 4 \\
\hline XI & $\begin{array}{l}\text { Spatial Organization } \\
\text { (Evenness of Space) }\end{array}$ & $\begin{array}{l}\text { 5. Evenly Dispersed } \\
\text { 1. Irregularly Dispersed }\end{array}$ & & $\mathrm{X}$ & & & & 4 \\
\hline XII & Spatial Denseness & $\begin{array}{l}\text { 5. Densely packed } \\
\text { 1. Open Space }\end{array}$ & & $\mathrm{X}$ & & & & 4 \\
\hline XIII & Illusion of Depth & $\begin{array}{r}\text { 5. Deep } \\
\text { 1. Flat }\end{array}$ & & & & & $\mathrm{X}$ & 1 \\
\hline XIV & Time and Motion & $\begin{array}{l}\text { 5. In Motion } \\
\text { 1.No Motion }\end{array}$ & & & & & $\mathrm{X}$ & 1 \\
\hline $\mathrm{XV}$ & Unity and Variety & $\begin{array}{l}\text { 5. Varied } \\
\text { 1. Unified }\end{array}$ & & & & & $\mathrm{X}$ & 1 \\
\hline XVI & Emphasis and Focal Point & $\begin{array}{r}\text { 5. Definite Focal Point } \\
\text { 1. No Focal Point } \\
\end{array}$ & $\mathrm{X}$ & & & & & 5 \\
\hline XVII & Proportion & $\begin{array}{l}\text { 5. Elements in Proportion } \\
\text { 1. Elements out of Proportion }\end{array}$ & $\mathrm{X}$ & & & & & 5 \\
\hline XVIII & Scale (Small to Large) & $\begin{array}{l}\text { 5. Large Scale } \\
\text { 1. Small Scale }\end{array}$ & & & $\mathrm{X}$ & & & 3 \\
\hline XIX & Rhythm & $\begin{array}{c}\text { 5. Rhythmic } \\
\text { 1. Static }\end{array}$ & & & & & $X$ & 1 \\
\hline XX & Centric or Eccentric & $\begin{array}{l}\text { 5. Internal Vectors } \\
\text { 1. External Vectors }\end{array}$ & $X$ & & & & & 5 \\
\hline & Totals & & 7 & 6 & 1 & 2 & 4 & 70 \\
\hline
\end{tabular}


Formal Elements

Rating Scale (FERS)

\begin{tabular}{|c|c|c|c|c|c|c|c|c|}
\hline & \multicolumn{2}{|c|}{ Figure 50: Self-Portrait (Saint-Rémy \#2) } & \multirow{2}{*}{$\begin{array}{l}5 \\
X\end{array}$} & \multirow[t]{2}{*}{4} & \multirow[t]{2}{*}{3} & \multirow[t]{2}{*}{2} & \multirow[t]{2}{*}{1} & \multirow{2}{*}{$\frac{\text { Total }}{5}$} \\
\hline $\mathrm{I}$ & Line Quality & $\begin{array}{l}\text { 5. Fluid and Flowing } \\
\text { 1. Jagged and Broken }\end{array}$ & & & & & & \\
\hline II & Expressive Style & $\begin{array}{l}\text { 5. Freedom of Expression } \\
\text { 1. Excessive Repetition }\end{array}$ & & & $\mathrm{X}$ & & & 3 \\
\hline III & Shape and Mass & $\begin{array}{r}\text { 5. Organic } \\
\text { 1. Geometric } \\
\end{array}$ & $\mathrm{X}$ & & & & & 5 \\
\hline IV & Abstraction or Realism & $\begin{array}{l}\text { 5. Realistic } \\
\text { 1. Abstract }\end{array}$ & $\mathrm{X}$ & & & & & 5 \\
\hline $\mathrm{V}$ & Figure Ground Relationship & $\begin{array}{r}\text { 5. Subject Dominant } \\
\text { 1. Background Dominant }\end{array}$ & & & $\mathrm{X}$ & & & 3 \\
\hline$\overline{\mathrm{VI}}$ & Value (Dark and Light) & $\begin{array}{l}\text { 5. Light Colors } \\
\text { 1. Dark Colors }\end{array}$ & $\mathrm{X}$ & & & & & 5 \\
\hline VII & Intensity of Color & $\begin{array}{l}\text { 5. Pure and Saturated } \\
\text { 1. Greyed and Softened }\end{array}$ & & $\mathrm{X}$ & & & & 4 \\
\hline VIII & Variety of Color & $\begin{array}{r}\text { 5. Polychromatic } \\
\text { 1. Monochromatic }\end{array}$ & & & & $\mathrm{X}$ & & 2 \\
\hline IX & Texture & $\begin{array}{l}\text { 5. Impasto } \\
\text { 1. Smooth }\end{array}$ & $\mathrm{X}$ & & & & & 5 \\
\hline $\mathrm{X}$ & Pattern & $\begin{array}{l}\text { 5. Highly Repeated Motifs } \\
\text { 1. No Repeated Motifs }\end{array}$ & $\mathrm{X}$ & & & & & 5 \\
\hline $\mathrm{XI}$ & $\begin{array}{l}\text { Spatial Organization } \\
\text { (Evenness of Space) }\end{array}$ & $\begin{array}{l}\text { 5. Evenly Dispersed } \\
\text { 1. Irregularly Dispersed }\end{array}$ & & & $\mathrm{X}$ & & & 3 \\
\hline XII & Spatial Denseness & $\begin{array}{r}\text { 5. Densely packed } \\
\text { 1. Open Space }\end{array}$ & & & $\mathrm{X}$ & & & 3 \\
\hline XIII & Illusion of Depth & $\begin{array}{r}\text { 5. Deep } \\
\text { 1. Flat }\end{array}$ & & & & & $\mathrm{X}$ & 1 \\
\hline XIV & Time and Motion & $\begin{array}{l}\text { 5. In Motion } \\
\text { 1.No Motion }\end{array}$ & & & & & $\mathrm{X}$ & 1 \\
\hline $\mathrm{XV}$ & Unity and Variety & $\begin{array}{l}\text { 5. Varied } \\
\text { 1. Unified }\end{array}$ & & & & & $\mathrm{X}$ & 1 \\
\hline XVI & Emphasis and Focal Point & $\begin{array}{r}\text { 5. Definite Focal Point } \\
1 . \text { No Focal Point }\end{array}$ & $\mathrm{X}$ & & & & & 5 \\
\hline XVII & Proportion & $\begin{array}{l}\text { 5. Elements in Proportion } \\
\text { 1. Elements out of Proportion }\end{array}$ & $\mathrm{X}$ & & & & & 5 \\
\hline XVIII & Scale (Small to Large) & $\begin{array}{l}\text { 5. Large Scale } \\
\text { 1. Small Scale }\end{array}$ & & & $\mathrm{X}$ & & & 3 \\
\hline XIX & Rhythm & $\begin{array}{r}\text { 5. Rhythmic } \\
\text { 1. Static } \\
\end{array}$ & $\mathrm{X}$ & & & & & 5 \\
\hline XX & Centric or Eccentric & $\begin{array}{l}\text { 5. Internal Vectors } \\
\text { 1. External Vectors }\end{array}$ & $\mathrm{X}$ & & & & & 5 \\
\hline & Totals & & 10 & 1 & 5 & 1 & 3 & 74 \\
\hline
\end{tabular}




\begin{tabular}{|c|c|c|c|c|c|c|c|c|}
\hline $\mathrm{I}$ & Line Quality & $\begin{array}{l}\text { 5. Fluid and Flowing } \\
\text { 1. Jagged and Broken }\end{array}$ & $\mathrm{X}$ & & & & & 5 \\
\hline II & Expressive Style & $\begin{array}{l}\text { 5. Freedom of Expression } \\
\text { 1. Excessive Repetition }\end{array}$ & $\mathrm{X}$ & & & & & 5 \\
\hline III & Shape and Mass & $\begin{array}{r}\text { 5. Organic } \\
\text { 1. Geometric } \\
\end{array}$ & $\mathrm{X}$ & & & & & 5 \\
\hline IV & Abstraction or Realism & $\begin{array}{l}\text { 5. Realistic } \\
\text { 1. Abstract }\end{array}$ & $\mathrm{X}$ & & & & & 5 \\
\hline $\mathrm{V}$ & Figure Ground Relationship & $\begin{array}{r}\text { 5. Subject Dominant } \\
\text { 1. Background Dominant } \\
\end{array}$ & $\mathrm{X}$ & & & & & 5 \\
\hline VI & Value (Dark and Light) & $\begin{array}{l}\text { 5. Light Colors } \\
\text { 1. Dark Colors }\end{array}$ & & $\mathrm{X}$ & & & & 4 \\
\hline VII & Intensity of Color & $\begin{array}{l}\text { 5. Pure and Saturated } \\
\text { 1. Greyed and Softened }\end{array}$ & & $\mathrm{X}$ & & & & 4 \\
\hline VIII & Variety of Color & $\begin{array}{r}\text { 5. Polychromatic } \\
\text { 1. Monochromatic } \\
\end{array}$ & & & $\mathrm{X}$ & & & 3 \\
\hline IX & Texture & $\begin{array}{l}\text { 5. Impasto } \\
\text { 1. Smooth } \\
\end{array}$ & & $\mathrm{X}$ & & & & 4 \\
\hline $\mathrm{X}$ & Pattern & $\begin{array}{l}\text { 5. Highly Repeated Motifs } \\
\text { 1. No Repeated Motifs }\end{array}$ & & & & $\mathrm{X}$ & & 2 \\
\hline XI & $\begin{array}{l}\text { Spatial Organization } \\
\text { (Evenness of Space) }\end{array}$ & $\begin{array}{l}\text { 5. Evenly Dispersed } \\
\text { 1. Irregularly Dispersed }\end{array}$ & & & $\mathrm{X}$ & & & 3 \\
\hline XII & Spatial Denseness & $\begin{array}{r}\text { 5. Densely packed } \\
\text { 1. Open Space } \\
\end{array}$ & & $\mathrm{X}$ & & & & 4 \\
\hline XIII & Illusion of Depth & $\begin{array}{r}\text { 5. Deep } \\
\text { 1. Flat }\end{array}$ & & & & & $\mathrm{X}$ & 1 \\
\hline XIV & Time and Motion & $\begin{array}{l}\text { 5. In Motion } \\
\text { 1.No Motion }\end{array}$ & & & & & $\mathrm{X}$ & 1 \\
\hline $\mathrm{XV}$ & Unity and Variety & $\begin{array}{l}\text { 5. Varied } \\
\text { 1. Unified }\end{array}$ & & & & & $\mathrm{X}$ & 1 \\
\hline XVI & Emphasis and Focal Point & $\begin{array}{r}\text { 5. Definite Focal Point } \\
\text { 1. No Focal Point } \\
\end{array}$ & $\mathrm{X}$ & & & & & 5 \\
\hline XVII & Proportion & $\begin{array}{l}\text { 5. Elements in Proportion } \\
\text { 1. Elements out of Proportion }\end{array}$ & $\mathrm{X}$ & & & & & 5 \\
\hline XVIII & Scale (Small to Large) & $\begin{array}{l}\text { 5. Large Scale } \\
\text { 1. Small Scale }\end{array}$ & & & $X$ & & & 3 \\
\hline XIX & Rhythm & $\begin{array}{c}\text { 5. Rhythmic } \\
\text { 1. Static } \\
\end{array}$ & & & & $\mathrm{X}$ & & 2 \\
\hline XX & Centric or Eccentric & $\begin{array}{l}\text { 5. Internal Vectors } \\
\text { 1. External Vectors }\end{array}$ & $X$ & & & & & 5 \\
\hline \multicolumn{3}{|c|}{ Totals } & 8 & 4 & 3 & 2 & 3 & 72 \\
\hline
\end{tabular}

Formal Elements

Rating Scale (FERS) 
Formal Elements

Rating Scale (FERS)

\begin{tabular}{|c|c|c|c|c|c|c|c|c|}
\hline & \multicolumn{2}{|c|}{ Figure 52: Self-Portrait (Saint-Rémy \#4) } & \multirow[t]{2}{*}{5} & \multirow[t]{2}{*}{4} & \multirow[t]{2}{*}{3} & \multirow{2}{*}{$\begin{array}{l}2 \\
X\end{array}$} & \multirow[t]{2}{*}{1} & \multirow{2}{*}{$\frac{\text { Total }}{2}$} \\
\hline $\mathrm{I}$ & Line Quality & $\begin{array}{l}\text { 5. Fluid and Flowing } \\
\text { 1. Jagged and Broken }\end{array}$ & & & & & & \\
\hline II & Expressive Style & $\begin{array}{l}\text { 5. Freedom of Expression } \\
\text { 1. Excessive Repetition }\end{array}$ & & & & $\mathrm{X}$ & & 2 \\
\hline III & Shape and Mass & $\begin{array}{r}\text { 5. Organic } \\
\text { 1. Geometric } \\
\end{array}$ & $\mathrm{X}$ & & & & & 5 \\
\hline IV & Abstraction or Realism & $\begin{array}{l}\text { 5. Realistic } \\
\text { 1. Abstract }\end{array}$ & & $\mathrm{X}$ & & & & 4 \\
\hline $\mathrm{V}$ & Figure Ground Relationship & $\begin{array}{r}\text { 5. Subject Dominant } \\
\text { 1. Background Dominant }\end{array}$ & & $\mathrm{X}$ & & & & 4 \\
\hline VI & Value (Dark and Light) & $\begin{array}{l}\text { 5. Light Colors } \\
\text { 1. Dark Colors }\end{array}$ & & & & $\mathrm{X}$ & & 2 \\
\hline VII & Intensity of Color & $\begin{array}{l}\text { 5. Pure and Saturated } \\
\text { 1. Greyed and Softened }\end{array}$ & & & $\mathrm{X}$ & & & 3 \\
\hline VIII & Variety of Color & $\begin{array}{r}\text { 5. Polychromatic } \\
\text { 1. Monochromatic }\end{array}$ & & $\mathrm{X}$ & & & & 4 \\
\hline IX & Texture & $\begin{array}{l}\text { 5. Impasto } \\
\text { 1. Smooth }\end{array}$ & & $\mathrm{X}$ & & & & 4 \\
\hline $\mathrm{X}$ & Pattern & $\begin{array}{l}\text { 5. Highly Repeated Motifs } \\
\text { 1. No Repeated Motifs }\end{array}$ & $\mathrm{X}$ & & & & & 5 \\
\hline $\mathrm{XI}$ & $\begin{array}{l}\text { Spatial Organization } \\
\text { (Evenness of Space) }\end{array}$ & $\begin{array}{r}\text { 5. Evenly Dispersed } \\
\text { 1. Irregularly Dispersed }\end{array}$ & & & $\mathrm{X}$ & & & 3 \\
\hline XII & Spatial Denseness & $\begin{array}{l}\text { 5. Densely packed } \\
\text { 1. Open Space }\end{array}$ & & $\mathrm{X}$ & & & & 4 \\
\hline XIII & Illusion of Depth & $\begin{array}{r}\text { 5. Deep } \\
\text { 1. Flat }\end{array}$ & & & & & $\mathrm{X}$ & 1 \\
\hline XIV & Time and Motion & $\begin{array}{l}\text { 5. In Motion } \\
\text { 1.No Motion }\end{array}$ & & & & & $\mathrm{X}$ & 1 \\
\hline $\mathrm{XV}$ & Unity and Variety & $\begin{array}{l}\text { 5. Varied } \\
\text { 1. Unified }\end{array}$ & & $\mathrm{X}$ & & & & 4 \\
\hline $\mathrm{XVI}$ & Emphasis and Focal Point & $\begin{array}{r}\text { 5. Definite Focal Point } \\
\text { 1. No Focal Point }\end{array}$ & $\mathrm{X}$ & & & & & 5 \\
\hline XVII & Proportion & $\begin{array}{l}\text { 5. Elements in Proportion } \\
\text { 1. Elements out of Proportion }\end{array}$ & $\mathrm{X}$ & & & & & 5 \\
\hline XVIII & Scale (Small to Large) & $\begin{array}{l}\text { 5. Large Scale } \\
\text { 1. Small Scale }\end{array}$ & & & $\mathrm{X}$ & & & 3 \\
\hline XIX & Rhythm & $\begin{array}{r}\text { 5. Rhythmic } \\
\text { 1. Static }\end{array}$ & $\mathrm{X}$ & & & & & 5 \\
\hline $\mathrm{XX}$ & Centric or Eccentric & $\begin{array}{l}\text { 5. Internal Vectors } \\
\text { 1. External Vectors }\end{array}$ & $\mathrm{X}$ & & & & & 5 \\
\hline & Total & & 6 & 6 & 3 & 3 & 2 & 71 \\
\hline
\end{tabular}


Formal Elements

Rating Scale (FERS)

\begin{tabular}{|c|c|c|c|c|c|c|c|c|}
\hline & \multicolumn{2}{|c|}{ Figure 53: Cottages with Thatched Roofs } & \multirow[t]{2}{*}{5} & \multirow{2}{*}{\begin{tabular}{|l|}
4 \\
$X$
\end{tabular}} & \multirow[t]{2}{*}{3} & \multirow[t]{2}{*}{2} & \multirow[t]{2}{*}{1} & \multirow{2}{*}{$\frac{\text { Total }}{4}$} \\
\hline $\mathrm{I}$ & Line Quality & $\begin{array}{l}\text { 5. Fluid and Flowing } \\
\text { 1. Jagged and Broken }\end{array}$ & & & & & & \\
\hline II & Expressive Style & $\begin{array}{l}\text { 5. Freedom of Expression } \\
\text { 1. Excessive Repetition }\end{array}$ & & & & $\mathrm{X}$ & & 2 \\
\hline III & Shape and Mass & $\begin{array}{r}\text { 5. Organic } \\
\text { 1. Geometric }\end{array}$ & & $\mathrm{X}$ & & & & 4 \\
\hline IV & Abstraction or Realism & $\begin{array}{l}\text { 5. Realistic } \\
\text { 1. Abstract }\end{array}$ & & & $\mathrm{X}$ & & & 3 \\
\hline $\mathrm{V}$ & Figure Ground Relationship & $\begin{array}{r}\text { 5. Subject Dominant } \\
\text { 1. Background Dominant }\end{array}$ & & $\mathrm{X}$ & & & & 4 \\
\hline VI & Value (Dark and Light) & $\begin{array}{c}\text { 5. Light Colors } \\
\text { 1. Dark Colors } \\
\end{array}$ & & $\mathrm{X}$ & & & & 4 \\
\hline VII & Intensity of Color & $\begin{array}{l}\text { 5. Pure and Saturated } \\
\text { 1. Greyed and Softened }\end{array}$ & & & & $\mathrm{X}$ & & 2 \\
\hline VIII & Variety of Color & $\begin{array}{r}\text { 5. Polychromatic } \\
\text { 1. Monochromatic }\end{array}$ & & & & $\mathrm{X}$ & & 2 \\
\hline IX & Texture & $\begin{array}{l}\text { 5. Impasto } \\
\text { 1. Smooth } \\
\end{array}$ & & & & & $\mathrm{X}$ & 1 \\
\hline $\mathrm{X}$ & Pattern & $\begin{array}{l}\text { 5. Highly Repeated Motifs } \\
\text { 1. No Repeated Motifs }\end{array}$ & & $\mathrm{X}$ & & & & 4 \\
\hline $\mathrm{XI}$ & $\begin{array}{l}\text { Spatial Organization } \\
\text { (Evenness of Space) }\end{array}$ & $\begin{array}{r}\text { 5. Evenly Dispersed } \\
\text { 1. Irregularly Dispersed } \\
\end{array}$ & & & & $\mathrm{X}$ & & 2 \\
\hline XII & Spatial Denseness & $\begin{array}{r}\text { 5. Densely packed } \\
\text { 1. Open Space }\end{array}$ & & $\mathrm{X}$ & & & & 4 \\
\hline XIII & Illusion of Depth & $\begin{array}{r}\text { 5. Deep } \\
\text { 1. Flat } \\
\end{array}$ & $\mathrm{X}$ & & & & & 5 \\
\hline XIV & Time and Motion & $\begin{array}{l}\text { 5. In Motion } \\
\text { 1.No Motion } \\
\end{array}$ & & & & & $\mathrm{X}$ & 1 \\
\hline $\mathrm{XV}$ & Unity and Variety & $\begin{array}{l}\text { 5. Varied } \\
\text { 1. Unified } \\
\end{array}$ & & $\mathrm{X}$ & & & & 4 \\
\hline $\mathrm{XVI}$ & Emphasis and Focal Point & $\begin{array}{r}\text { 5. Definite Focal Point } \\
1 . \text { No Focal Point } \\
\end{array}$ & & & & & $\mathrm{X}$ & 1 \\
\hline XVII & Proportion & $\begin{array}{l}\text { 5. Elements in Proportion } \\
\text { 1. Elements out of Proportion }\end{array}$ & & $\mathrm{X}$ & & & & 4 \\
\hline XVIII & Scale (Small to Large) & $\begin{array}{l}\text { 5. Large Scale } \\
\text { 1. Small Scale } \\
\end{array}$ & & & $\mathrm{X}$ & & & 3 \\
\hline XIX & Rhythm & $\begin{array}{r}\text { 5. Rhythmic } \\
\text { 1. Static }\end{array}$ & $\mathrm{X}$ & & & & & 5 \\
\hline $\mathrm{XX}$ & Centric or Eccentric & $\begin{array}{r}\text { 5. Internal Vectors } \\
\text { 1. External Vectors }\end{array}$ & & & $\mathrm{X}$ & & & 3 \\
\hline & Totals & & 2 & 8 & 3 & 4 & 3 & 62 \\
\hline
\end{tabular}


Formal Elements

Rating Scale (FERS)

\begin{tabular}{|c|c|c|c|c|c|c|c|c|}
\hline & \multicolumn{2}{|c|}{$\begin{array}{l}\text { Figure 54: Old Vineyard with Peasant } \\
\text { Woman }\end{array}$} & 5 & 4 & 3 & 2 & 1 & Total \\
\hline $\mathrm{I}$ & Line Quality & $\begin{array}{l}\text { 5. Fluid and Flowing } \\
\text { 1. Jagged and Broken }\end{array}$ & & $\mathrm{X}$ & & & & 4 \\
\hline II & Expressive Style & $\begin{array}{r}\text { 5. Freedom of Expression } \\
\text { 1. Excessive Repetition }\end{array}$ & & & & $\mathrm{X}$ & & 2 \\
\hline III & Shape and Mass & $\begin{array}{r}\text { 5. Organic } \\
\text { 1. Geometric }\end{array}$ & & $\mathrm{X}$ & & & & 4 \\
\hline IV & Abstraction or Realism & $\begin{array}{l}\text { 5. Realistic } \\
\text { 1. Abstract }\end{array}$ & & $\mathrm{X}$ & & & & 4 \\
\hline $\mathrm{V}$ & Figure Ground Relationship & $\begin{array}{r}\text { 5. Subject Dominant } \\
\text { 1. Background Dominant }\end{array}$ & & $\mathrm{X}$ & & & & 4 \\
\hline VI & Value (Dark and Light) & $\begin{array}{l}\text { 5. Light Colors } \\
\text { 1. Dark Colors }\end{array}$ & & $\mathrm{X}$ & & & & 4 \\
\hline VII & Intensity of Color & $\begin{array}{l}\text { 5. Pure and Saturated } \\
\text { 1. Greyed and Softened }\end{array}$ & & & & $\mathrm{X}$ & & 2 \\
\hline VIII & Variety of Color & $\begin{array}{r}\text { 5. Polychromatic } \\
\text { 1. Monochromatic } \\
\end{array}$ & & & & $\mathrm{X}$ & & 2 \\
\hline IX & Texture & $\begin{array}{l}\text { 5. Impasto } \\
\text { 1. Smooth }\end{array}$ & & & & & $\mathrm{X}$ & 1 \\
\hline $\mathrm{X}$ & Pattern & $\begin{array}{r}\text { 5. Highly Repeated Motifs } \\
\text { 1. No Repeated Motifs } \\
\end{array}$ & & $\mathrm{X}$ & & & & 4 \\
\hline XI & $\begin{array}{l}\text { Spatial Organization } \\
\text { (Evenness of Space) }\end{array}$ & $\begin{array}{l}\text { 5. Evenly Dispersed } \\
\text { 1. Irregularly Dispersed }\end{array}$ & & & & $\mathrm{X}$ & & 2 \\
\hline XII & Spatial Denseness & $\begin{array}{r}\text { 5. Densely packed } \\
\text { 1. Open Space } \\
\end{array}$ & & $\mathrm{X}$ & & & & 4 \\
\hline XIII & Illusion of Depth & $\begin{array}{r}\text { 5. Deep } \\
\text { 1. Flat } \\
\end{array}$ & $\mathrm{X}$ & & & & & 5 \\
\hline XIV & Time and Motion & $\begin{array}{l}\text { 5. In Motion } \\
\text { 1.No Motion }\end{array}$ & & & & & $\mathrm{X}$ & 1 \\
\hline $\mathrm{XV}$ & Unity and Variety & $\begin{array}{l}\text { 5. Varied } \\
\text { 1. Unified }\end{array}$ & & $\mathrm{X}$ & & & & 4 \\
\hline XVI & Emphasis and Focal Point & $\begin{array}{r}\text { 5. Definite Focal Point } \\
\text { 1. No Focal Point }\end{array}$ & & & & $\mathrm{X}$ & & 2 \\
\hline XVII & Proportion & $\begin{array}{l}\text { 5. Elements in Proportion } \\
\text { 1. Elements out of Proportion }\end{array}$ & $\mathrm{X}$ & & & & & 5 \\
\hline XVIII & Scale (Small to Large) & $\begin{array}{l}\text { 5. Large Scale } \\
\text { 1. Small Scale }\end{array}$ & & & $\mathrm{X}$ & & & 3 \\
\hline XIX & Rhythm & $\begin{array}{r}\text { 5. Rhythmic } \\
\text { 1. Static }\end{array}$ & $\mathrm{X}$ & & & & & 5 \\
\hline $\mathrm{XX}$ & Centric or Eccentric & $\begin{array}{r}\text { 5. Internal Vectors } \\
\text { 1. External Vectors }\end{array}$ & & & & $\mathrm{X}$ & & 2 \\
\hline & Total & & 3 & 8 & 1 & 6 & 2 & 64 \\
\hline
\end{tabular}


Formal Elements

Rating Scale (FERS)

\begin{tabular}{|c|c|c|c|c|c|c|c|c|}
\hline & \multicolumn{2}{|c|}{ Figure 55: House of Père Pilon } & \multirow[t]{2}{*}{5} & \multirow[t]{2}{*}{4} & \multirow{2}{*}{$\begin{array}{l}3 \\
X\end{array}$} & \multirow[t]{2}{*}{2} & \multirow[t]{2}{*}{1} & \multirow{2}{*}{$\frac{\text { Total }}{3}$} \\
\hline $\mathrm{I}$ & Line Quality & $\begin{array}{l}\text { 5. Fluid and Flowing } \\
\text { 1. Jagged and Broken }\end{array}$ & & & & & & \\
\hline II & Expressive Style & $\begin{array}{l}\text { 5. Freedom of Expression } \\
\text { 1. Excessive Repetition }\end{array}$ & & & $\mathrm{X}$ & & & 3 \\
\hline III & Shape and Mass & $\begin{array}{r}\text { 5. Organic } \\
\text { 1. Geometric }\end{array}$ & & & $\mathrm{X}$ & & & 3 \\
\hline IV & Abstraction or Realism & $\begin{array}{l}\text { 5. Realistic } \\
\text { 1. Abstract }\end{array}$ & & & $\mathrm{X}$ & & & 3 \\
\hline $\mathrm{V}$ & Figure Ground Relationship & $\begin{array}{r}\text { 5. Subject Dominant } \\
\text { 1. Background Dominant }\end{array}$ & & & $\mathrm{X}$ & & & 3 \\
\hline VI & Value (Dark and Light) & $\begin{array}{l}\text { 5. Light Colors } \\
\text { 1. Dark Colors } \\
\end{array}$ & & & $\mathrm{X}$ & & & 3 \\
\hline VII & Intensity of Color & $\begin{array}{l}\text { 5. Pure and Saturated } \\
\text { 1. Greyed and Softened }\end{array}$ & & & & $\mathrm{X}$ & & 2 \\
\hline VIII & Variety of Color & $\begin{array}{r}\text { 5. Polychromatic } \\
\text { 1. Monochromatic }\end{array}$ & & & $\mathrm{X}$ & & & 3 \\
\hline IX & Texture & $\begin{array}{l}\text { 5. Impasto } \\
\text { 1. Smooth } \\
\end{array}$ & & $\mathrm{X}$ & & & & 4 \\
\hline $\mathrm{X}$ & Pattern & $\begin{array}{r}\text { 5. Highly Repeated Motifs } \\
\text { 1. No Repeated Motifs } \\
\end{array}$ & & & $\mathrm{X}$ & & & 3 \\
\hline XI & $\begin{array}{l}\text { Spatial Organization } \\
\text { (Evenness of Space) }\end{array}$ & $\begin{array}{r}\text { 5. Evenly Dispersed } \\
\text { 1. Irregularly Dispersed } \\
\end{array}$ & & & $\mathrm{X}$ & & & 3 \\
\hline XII & Spatial Denseness & $\begin{array}{r}\text { 5. Densely packed } \\
\text { 1. Open Space }\end{array}$ & & $\mathrm{X}$ & & & & 4 \\
\hline XIII & Illusion of Depth & $\begin{array}{r}\text { 5. Deep } \\
\text { 1. Flat } \\
\end{array}$ & $\mathrm{X}$ & & & & & 5 \\
\hline XIV & Time and Motion & $\begin{array}{l}\text { 5. In Motion } \\
\text { 1.No Motion } \\
\end{array}$ & & & & & $\mathrm{X}$ & 1 \\
\hline $\mathrm{XV}$ & Unity and Variety & $\begin{array}{l}\text { 5. Varied } \\
\text { 1. Unified } \\
\end{array}$ & & & & & $\mathrm{X}$ & 1 \\
\hline XVI & Emphasis and Focal Point & $\begin{array}{r}\text { 5. Definite Focal Point } \\
\text { 1. No Focal Point }\end{array}$ & & & & $\mathrm{X}$ & & 2 \\
\hline XVII & Proportion & $\begin{array}{r}\text { 5. Elements in Proportion } \\
\text { 1. Elements out of Proportion }\end{array}$ & $\mathrm{X}$ & & & & & 5 \\
\hline XVIII & Scale (Small to Large) & $\begin{array}{l}\text { 5. Large Scale } \\
\text { 1. Small Scale }\end{array}$ & & & $\mathrm{X}$ & & & 3 \\
\hline XIX & Rhythm & $\begin{array}{r}\text { 5. Rhythmic } \\
\text { 1. Static }\end{array}$ & & & $\mathrm{X}$ & & & 3 \\
\hline $\mathrm{XX}$ & Centric or Eccentric & $\begin{array}{l}\text { 5. Internal Vectors } \\
\text { 1. External Vectors }\end{array}$ & & & & & $\mathrm{X}$ & 1 \\
\hline & Totals & & 2 & 2 & 11 & 2 & 3 & 58 \\
\hline
\end{tabular}


Formal Elements

Rating Scale (FERS)

\begin{tabular}{|c|c|c|c|c|c|c|c|c|}
\hline & \multicolumn{2}{|c|}{$\begin{array}{l}\text { Figure 56: Village Street and Stairs with } \\
\text { Figures }\end{array}$} & 5 & 4 & & & & \\
\hline $\mathrm{I}$ & Line Quality & $\begin{array}{l}\text { 5. Fluid and Flowing } \\
\text { 1. Jagged and Broken }\end{array}$ & & $\mathrm{X}$ & & & & 4 \\
\hline II & Expressive Style & $\begin{array}{r}\text { 5. Freedom of Expression } \\
\text { 1. Excessive Repetition }\end{array}$ & & $\mathrm{X}$ & & & & 4 \\
\hline III & Shape and Mass & $\begin{array}{r}\text { 5. Organic } \\
\text { 1. Geometric } \\
\end{array}$ & & $\mathrm{X}$ & & & & 4 \\
\hline IV & Abstraction or Realism & $\begin{array}{l}\text { 5. Realistic } \\
\text { 1. Abstract }\end{array}$ & & & $\mathrm{X}$ & & & 3 \\
\hline $\mathrm{V}$ & Figure Ground Relationship & $\begin{array}{r}\text { 5. Subject Dominant } \\
\text { 1. Background Dominant } \\
\end{array}$ & $\mathrm{X}$ & & & & & 5 \\
\hline VI & Value (Dark and Light) & $\begin{array}{l}\text { 5. Light Colors } \\
\text { 1. Dark Colors }\end{array}$ & & $\mathrm{X}$ & & & & 4 \\
\hline VII & Intensity of Color & $\begin{array}{l}\text { 5. Pure and Saturated } \\
\text { 1. Greyed and Softened }\end{array}$ & & $\mathrm{X}$ & & & & 4 \\
\hline VIII & Variety of Color & $\begin{array}{r}\text { 5. Polychromatic } \\
\text { 1. Monochromatic }\end{array}$ & $\mathrm{X}$ & & & & & 5 \\
\hline IX & Texture & $\begin{array}{l}\text { 5. Impasto } \\
\text { 1. Smooth }\end{array}$ & & $\mathrm{X}$ & & & & 4 \\
\hline $\mathrm{X}$ & Pattern & $\begin{array}{l}\text { 5. Highly Repeated Motifs } \\
\text { 1. No Repeated Motifs }\end{array}$ & $\mathrm{X}$ & & & & & 5 \\
\hline $\mathrm{XI}$ & $\begin{array}{l}\begin{array}{l}\text { Spatial Organization } \\
\text { (Evenness of Space) }\end{array} \\
\end{array}$ & $\begin{array}{r}\text { 5. Evenly Dispersed } \\
\text { 1. Irregularly Dispersed }\end{array}$ & & & & $\mathrm{X}$ & & 2 \\
\hline XII & Spatial Denseness & $\begin{array}{r}\text { 5. Densely packed } \\
\text { 1. Open Space }\end{array}$ & & & & $\mathrm{X}$ & & 2 \\
\hline XIII & Illusion of Depth & $\begin{array}{l}\text { 5. Deep } \\
\text { 1. Flat }\end{array}$ & $\mathrm{X}$ & & & & & 5 \\
\hline XIV & Time and Motion & $\begin{array}{l}\text { 5. In Motion } \\
\text { 1.No Motion }\end{array}$ & & & $\mathrm{X}$ & & & 3 \\
\hline $\mathrm{XV}$ & Unity and Variety & $\begin{array}{l}\text { 5. Varied } \\
\text { 1. Unified }\end{array}$ & & $\mathrm{X}$ & & & & 4 \\
\hline XVI & Emphasis and Focal Point & $\begin{array}{r}\text { 5. Definite Focal Point } \\
1 . \text { No Focal Point } \\
\end{array}$ & & & $\mathrm{X}$ & & & 3 \\
\hline XVII & Proportion & $\begin{array}{l}\text { 5. Elements in Proportion } \\
\text { 1. Elements out of Proportion }\end{array}$ & $\mathrm{X}$ & & & & & 5 \\
\hline XVIII & Scale (Small to Large) & $\begin{array}{l}\text { 5. Large Scale } \\
\text { 1. Small Scale }\end{array}$ & & & $X$ & & & 3 \\
\hline XIX & Rhythm & $\begin{array}{r}\text { 5. Rhythmic } \\
\text { 1. Static } \\
\end{array}$ & $\mathrm{X}$ & & & & & 5 \\
\hline XX & Centric or Eccentric & $\begin{array}{l}\text { 5. Internal Vectors } \\
\text { 1. External Vectors }\end{array}$ & & & $\mathbf{X}$ & & & 3 \\
\hline & Total & & 6 & 7 & 5 & 2 & 0 & 77 \\
\hline
\end{tabular}


Formal Elements

Rating Scale (FERS)

\begin{tabular}{|c|c|c|c|c|c|c|c|c|}
\hline & \multicolumn{2}{|c|}{ Figure 57: Church at Auvers } & \multirow[t]{2}{*}{5} & \multirow[t]{2}{*}{4} & \multirow{2}{*}{$\begin{array}{l}3 \\
x\end{array}$} & \multirow[t]{2}{*}{2} & \multirow[t]{2}{*}{1} & \multirow{2}{*}{$\frac{\text { Total }}{3}$} \\
\hline I & Line Quality & $\begin{array}{l}\text { 5. Fluid and Flowing } \\
\text { 1. Jagged and Broken }\end{array}$ & & & & & & \\
\hline II & Expressive Style & $\begin{array}{l}\text { 5. Freedom of Expression } \\
\text { 1. Excessive Repetition }\end{array}$ & $\mathrm{X}$ & & & & & 5 \\
\hline III & Shape and Mass & $\begin{array}{r}\text { 5. Organic } \\
\text { 1. Geometric } \\
\end{array}$ & & & & $\mathrm{X}$ & & 2 \\
\hline IV & Abstraction or Realism & $\begin{array}{l}\text { 5. Realistic } \\
\text { 1. Abstract }\end{array}$ & & $\mathrm{X}$ & & & & 4 \\
\hline $\mathrm{V}$ & Figure Ground Relationship & $\begin{array}{r}\text { 5. Subject Dominant } \\
\text { 1. Background Dominant }\end{array}$ & & & $\mathrm{X}$ & & & 3 \\
\hline VI & Value (Dark and Light) & $\begin{array}{l}\text { 5. Light Colors } \\
\text { 1. Dark Colors }\end{array}$ & & & & $\mathrm{X}$ & & 2 \\
\hline VII & Intensity of Color & $\begin{array}{l}\text { 5. Pure and Saturated } \\
\text { 1. Greyed and Softened }\end{array}$ & & & & $\mathrm{X}$ & & 2 \\
\hline VIII & Variety of Color & $\begin{array}{r}\text { 5. Polychromatic } \\
\text { 1. Monochromatic }\end{array}$ & & $\mathrm{X}$ & & & & 4 \\
\hline IX & Texture & $\begin{array}{l}\text { 5. Impasto } \\
\text { 1. Smooth }\end{array}$ & & $\mathrm{X}$ & & & & 4 \\
\hline $\mathrm{X}$ & Pattern & $\begin{array}{l}\text { 5. Highly Repeated Motifs } \\
\text { 1. No Repeated Motifs }\end{array}$ & & $\mathrm{X}$ & & & & 4 \\
\hline $\mathrm{XI}$ & $\begin{array}{l}\text { Spatial Organization } \\
\text { (Evenness of Space) }\end{array}$ & $\begin{array}{r}\text { 5. Evenly Dispersed } \\
\text { 1. Irregularly Dispersed }\end{array}$ & & & $\mathrm{X}$ & & & 3 \\
\hline XII & Spatial Denseness & $\begin{array}{r}\text { 5. Densely packed } \\
\text { 1. Open Space }\end{array}$ & & & $\mathrm{X}$ & & & 3 \\
\hline XIII & Illusion of Depth & $\begin{array}{r}\text { 5. Deep } \\
\text { 1. Flat }\end{array}$ & $\mathrm{X}$ & & & & & 5 \\
\hline XIV & Time and Motion & $\begin{array}{l}\text { 5. In Motion } \\
\text { 1.No Motion }\end{array}$ & & & & $\mathrm{X}$ & & 2 \\
\hline $\mathrm{XV}$ & Unity and Variety & $\begin{array}{l}\text { 5. Varied } \\
\text { 1. Unified }\end{array}$ & & & & & $\mathrm{X}$ & 1 \\
\hline $\mathrm{XVI}$ & Emphasis and Focal Point & $\begin{array}{r}\text { 5. Definite Focal Point } \\
\text { 1. No Focal Point }\end{array}$ & & $\mathrm{X}$ & & & & 4 \\
\hline XVII & Proportion & $\begin{array}{l}\text { 5. Elements in Proportion } \\
\text { 1. Elements out of Proportion }\end{array}$ & & $\mathrm{X}$ & & & & 4 \\
\hline XVIII & Scale (Small to Large) & $\begin{array}{l}\text { 5. Large Scale } \\
\text { 1. Small Scale }\end{array}$ & & & $\mathrm{X}$ & & & 3 \\
\hline XIX & Rhythm & $\begin{array}{r}\text { 5. Rhythmic } \\
\text { 1. Static }\end{array}$ & & & $\mathrm{X}$ & & & 3 \\
\hline $\mathrm{XX}$ & Centric or Eccentric & $\begin{array}{l}\text { 5. Internal Vectors } \\
\text { 1. External Vectors }\end{array}$ & & & & & $\mathrm{X}$ & 1 \\
\hline & Totals & & 2 & 6 & 6 & 4 & 2 & 62 \\
\hline
\end{tabular}


Formal Elements

Rating Scale (FERS)

\begin{tabular}{|c|c|c|c|c|c|c|c|c|}
\hline & \multicolumn{2}{|c|}{ Figure 58: Portrait of Dr. Gachet } & \multirow[t]{2}{*}{5} & \multirow{2}{*}{\begin{tabular}{|l|}
4 \\
$X$ \\
\end{tabular}} & \multirow[t]{2}{*}{3} & \multirow[t]{2}{*}{2} & \multirow[t]{2}{*}{1} & \multirow{2}{*}{$\frac{\text { Total }}{4}$} \\
\hline $\mathrm{I}$ & Line Quality & $\begin{array}{l}\text { 5. Fluid and Flowing } \\
\text { 1. Jagged and Broken }\end{array}$ & & & & & & \\
\hline II & P Expressive Style & $\begin{array}{r}\text { 5. Freedom of Expression } \\
\text { 1. Excessive Repetition }\end{array}$ & & $\mathrm{X}$ & & & & 4 \\
\hline III & Shape and Mass & $\begin{array}{r}\text { 5. Organic } \\
\text { 1. Geometric } \\
\end{array}$ & & $\mathrm{X}$ & & & & 4 \\
\hline IV & Abstraction or Realism & $\begin{array}{l}\text { 5. Realistic } \\
\text { 1. Abstract }\end{array}$ & & $\mathrm{X}$ & & & & 4 \\
\hline $\mathrm{V}$ & Figure Ground Relationship & $\begin{array}{r}\text { 5. Subject Dominant } \\
\text { 1. Background Dominant }\end{array}$ & $\mathrm{X}$ & & & & & 5 \\
\hline VI & Value (Dark and Light) & $\begin{array}{r}\text { 5. Light Colors } \\
\text { 1. Dark Colors } \\
\end{array}$ & & & & $\mathrm{X}$ & & 2 \\
\hline VII & Intensity of Color & $\begin{array}{l}\text { 5. Pure and Saturated } \\
\text { 1. Greyed and Softened }\end{array}$ & & $\mathrm{X}$ & & & & 4 \\
\hline VIII & Variety of Color & $\begin{array}{r}\text { 5. Polychromatic } \\
\text { 1. Monochromatic }\end{array}$ & & $\mathrm{X}$ & & & & 4 \\
\hline IX & Texture & $\begin{array}{l}\text { 5. Impasto } \\
\text { 1. Smooth } \\
\end{array}$ & & $\mathrm{X}$ & & & & 4 \\
\hline $\mathrm{X}$ & Pattern & $\begin{array}{r}\text { 5. Highly Repeated Motifs } \\
\text { 1. No Repeated Motifs } \\
\end{array}$ & $\mathrm{X}$ & & & & & 5 \\
\hline $\mathrm{XI}$ & $\begin{array}{l}\text { Spatial Organization } \\
\text { (Evenness of Space) }\end{array}$ & $\begin{array}{r}\text { 5. Evenly Dispersed } \\
\text { 1. Irregularly Dispersed } \\
\end{array}$ & & & & $\mathrm{X}$ & & 2 \\
\hline XII & Spatial Denseness & $\begin{array}{r}\text { 5. Densely packed } \\
\text { 1. Open Space }\end{array}$ & & $\mathrm{X}$ & & & & 4 \\
\hline XIII & Illusion of Depth & $\begin{array}{r}\text { 5. Deep } \\
\text { 1. Flat } \\
\end{array}$ & $\mathrm{X}$ & & & & & 5 \\
\hline XIV & Time and Motion & $\begin{array}{l}\text { 5. In Motion } \\
\text { 1.No Motion } \\
\end{array}$ & & & & & $\mathrm{X}$ & 1 \\
\hline $\mathrm{XV}$ & Unity and Variety & $\begin{array}{l}\text { 5. Varied } \\
\text { 1. Unified } \\
\end{array}$ & & & & $\mathrm{X}$ & & 2 \\
\hline XVI & Emphasis and Focal Point & $\begin{array}{r}\text { 5. Definite Focal Point } \\
1 . \text { No Focal Point }\end{array}$ & $\mathrm{X}$ & & & & & 5 \\
\hline XVII & Proportion & $\begin{array}{r}\text { 5. Elements in Proportion } \\
\text { 1. Elements out of Proportion }\end{array}$ & $\mathrm{X}$ & & & & & 5 \\
\hline XVIII & Scale (Small to Large) & $\begin{array}{l}\text { 5. Large Scale } \\
\text { 1. Small Scale }\end{array}$ & & & $\mathrm{X}$ & & & 3 \\
\hline XIX & Rhythm & $\begin{array}{r}\text { 5. Rhythmic } \\
\text { 1. Static }\end{array}$ & & & & $\mathrm{X}$ & & 2 \\
\hline $\mathrm{XX}$ & Centric or Eccentric & $\begin{array}{r}\text { 5. Internal Vectors } \\
\text { 1. External Vectors }\end{array}$ & $\mathrm{X}$ & & & & & 5 \\
\hline & Totals & & 6 & 8 & 1 & 4 & 1 & 74 \\
\hline
\end{tabular}


Formal Elements

Rating Scale (FERS)

\begin{tabular}{|c|c|c|c|c|c|c|c|c|}
\hline & \multicolumn{2}{|c|}{$\begin{array}{l}\text { Figure 59: Wild Flowers and Thistles in a } \\
\text { Vase }\end{array}$} & \multirow[t]{2}{*}{5} & \multirow[t]{2}{*}{4} & \multirow[t]{2}{*}{3} & \multirow{2}{*}{$\begin{array}{l}2 \\
X\end{array}$} & \multirow[t]{2}{*}{1} & Total \\
\hline $\mathrm{I}$ & Line Quality & $\begin{array}{l}\text { 5. Fluid and Flowing } \\
\text { 1. Jagged and Broken }\end{array}$ & & & & & & 2 \\
\hline II & Expressive Style & $\begin{array}{l}\text { 5. Freedom of Expression } \\
\text { 1. Excessive Repetition }\end{array}$ & & $\mathrm{X}$ & & & & 4 \\
\hline III & Shape and Mass & $\begin{array}{r}\text { 5. Organic } \\
\text { 1. Geometric }\end{array}$ & & $\mathrm{X}$ & & & & 4 \\
\hline IV & Abstraction or Realism & $\begin{array}{l}\text { 5. Realistic } \\
\text { 1. Abstract }\end{array}$ & & $\mathrm{X}$ & & & & 4 \\
\hline$\overline{\mathrm{V}}$ & Figure Ground Relationship & $\begin{array}{r}\text { 5. Subject Dominant } \\
\text { 1. Background Dominant }\end{array}$ & $\mathrm{X}$ & & & & & 5 \\
\hline VI & Value (Dark and Light) & $\begin{array}{l}\text { 5. Light Colors } \\
\text { 1. Dark Colors }\end{array}$ & & & $\mathrm{X}$ & & & 3 \\
\hline VII & Intensity of Color & $\begin{array}{l}\text { 5. Pure and Saturated } \\
\text { 1. Greyed and Softened }\end{array}$ & & $\mathrm{X}$ & & & & 4 \\
\hline VIII & Variety of Color & $\begin{array}{r}\text { 5. Polychromatic } \\
\text { 1. Monochromatic }\end{array}$ & $\mathrm{X}$ & & & & & 5 \\
\hline IX & Texture & $\begin{array}{l}\text { 5. Impasto } \\
\text { 1. Smooth }\end{array}$ & & $\mathrm{X}$ & & & & 4 \\
\hline $\bar{X}$ & Pattern & $\begin{array}{l}\text { 5. Highly Repeated Motifs } \\
\text { 1. No Repeated Motifs }\end{array}$ & & $\mathrm{X}$ & & & & 4 \\
\hline XI & $\begin{array}{l}\text { Spatial Organization } \\
\text { (Evenness of Space) }\end{array}$ & $\begin{array}{r}\text { 5. Evenly Dispersed } \\
\text { 1. Irregularly Dispersed }\end{array}$ & & & & $\mathrm{X}$ & & 2 \\
\hline XII & Spatial Denseness & $\begin{array}{r}\text { 5. Densely packed } \\
\text { 1. Open Space }\end{array}$ & & $\mathrm{X}$ & & & & 4 \\
\hline XIII & Illusion of Depth & $\begin{array}{r}\text { 5. Deep } \\
\text { 1. Flat }\end{array}$ & & & & $\mathrm{X}$ & & 2 \\
\hline XIV & Time and Motion & $\begin{array}{l}\text { 5. In Motion } \\
\text { 1.No Motion }\end{array}$ & & & & & $\mathrm{X}$ & 1 \\
\hline $\mathrm{XV}$ & Unity and Variety & $\begin{array}{l}\text { 5. Varied } \\
\text { 1. Unified }\end{array}$ & $\mathrm{X}$ & & & & & 5 \\
\hline$\overline{X V I}$ & Emphasis and Focal Point & $\begin{array}{r}\text { 5. Definite Focal Point } \\
\text { 1. No Focal Point }\end{array}$ & $\mathrm{X}$ & & & & & 5 \\
\hline XVII & Proportion & $\begin{array}{l}\text { 5. Elements in Proportion } \\
\text { 1. Elements out of Proportion }\end{array}$ & $\mathrm{X}$ & & & & & 5 \\
\hline XVIII & Scale (Small to Large) & $\begin{array}{l}\text { 5. Large Scale } \\
\text { 1. Small Scale }\end{array}$ & & & $\mathrm{X}$ & & & 3 \\
\hline XIX & Rhythm & $\begin{array}{c}\text { 5. Rhythmic } \\
\text { 1. Static }\end{array}$ & & & $\mathrm{X}$ & & & 3 \\
\hline $\mathrm{XX}$ & Centric or Eccentric & $\begin{array}{l}\text { 5. Internal Vectors } \\
\text { 1. External Vectors }\end{array}$ & $\mathrm{X}$ & & & & & 5 \\
\hline & Totals & & 6 & 7 & 3 & 3 & 1 & 74 \\
\hline
\end{tabular}


Formal Elements

Rating Scale (FERS)

\begin{tabular}{|c|c|c|c|c|c|c|c|c|}
\hline & \multicolumn{2}{|c|}{ Figure 60: Marguerite Gachet at the Piano } & \multirow[t]{2}{*}{5} & \multirow{2}{*}{$\begin{array}{l}4 \\
X\end{array}$} & \multirow[t]{2}{*}{3} & \multirow[t]{2}{*}{2} & \multirow[t]{2}{*}{1} & \multirow{2}{*}{$\frac{\text { Total }}{4}$} \\
\hline $\mathrm{I}$ & Line Quality & $\begin{array}{l}\text { 5. Fluid and Flowing } \\
\text { 1. Jagged and Broken }\end{array}$ & & & & & & \\
\hline II & Expressive Style & $\begin{array}{l}\text { 5. Freedom of Expression } \\
\text { 1. Excessive Repetition }\end{array}$ & & & $\mathrm{X}$ & & & 3 \\
\hline III & Shape and Mass & $\begin{array}{r}\text { 5. Organic } \\
\text { 1. Geometric }\end{array}$ & & $\mathrm{X}$ & & & & 4 \\
\hline IV & Abstraction or Realism & $\begin{array}{l}\text { 5. Realistic } \\
\text { 1. Abstract }\end{array}$ & & $\mathrm{X}$ & & & & 4 \\
\hline $\mathrm{V}$ & Figure Ground Relationship & $\begin{array}{r}\text { 5. Subject Dominant } \\
\text { 1. Background Dominant } \\
\end{array}$ & & $\mathrm{X}$ & & & & 4 \\
\hline VI & Value (Dark and Light) & $\begin{array}{l}\text { 5. Light Colors } \\
\text { 1. Dark Colors }\end{array}$ & & & $\mathrm{X}$ & & & 3 \\
\hline VII & Intensity of Color & $\begin{array}{l}\text { 5. Pure and Saturated } \\
\text { 1. Greyed and Softened }\end{array}$ & & $\mathrm{X}$ & & & & 4 \\
\hline VIII & Variety of Color & $\begin{array}{r}\text { 5. Polychromatic } \\
\text { 1. Monochromatic }\end{array}$ & & $\mathrm{X}$ & & & & 4 \\
\hline IX & Texture & $\begin{array}{r}\text { 5. Impasto } \\
\text { 1. Smooth } \\
\end{array}$ & & $\mathrm{X}$ & & & & 4 \\
\hline $\mathrm{X}$ & Pattern & $\begin{array}{r}\text { 5. Highly Repeated Motifs } \\
\text { 1. No Repeated Motifs } \\
\end{array}$ & $\mathrm{X}$ & & & & & 5 \\
\hline XI & $\begin{array}{l}\text { Spatial Organization } \\
\text { (Evenness of Space) }\end{array}$ & $\begin{array}{r}\text { 5. Evenly Dispersed } \\
\text { 1. Irregularly Dispersed } \\
\end{array}$ & & $\mathrm{X}$ & & & & 4 \\
\hline XII & Spatial Denseness & $\begin{array}{r}\text { 5. Densely packed } \\
\text { 1. Open Space }\end{array}$ & & $\mathrm{X}$ & & & & 4 \\
\hline XIII & Illusion of Depth & $\begin{array}{l}\text { 5. Deep } \\
\text { 1. Flat }\end{array}$ & & & $\mathrm{X}$ & & & 3 \\
\hline XIV & Time and Motion & $\begin{array}{l}\text { 5. In Motion } \\
\text { 1.No Motion }\end{array}$ & & $\mathrm{X}$ & & & & 4 \\
\hline $\mathrm{XV}$ & Unity and Variety & $\begin{array}{l}\text { 5. Varied } \\
\text { 1. Unified } \\
\end{array}$ & & & $\mathrm{X}$ & & & 3 \\
\hline $\mathrm{XVI}$ & Emphasis and Focal Point & $\begin{array}{r}\text { 5. Definite Focal Point } \\
\text { 1. No Focal Point }\end{array}$ & $\mathrm{X}$ & & & & & 5 \\
\hline XVII & Proportion & $\begin{array}{r}\text { 5. Elements in Proportion } \\
\text { 1. Elements out of Proportion }\end{array}$ & $\mathrm{X}$ & & & & & 5 \\
\hline XVIII & Scale (Small to Large) & $\begin{array}{l}\text { 5. Large Scale } \\
\text { 1. Small Scale }\end{array}$ & & $\mathrm{X}$ & & & & 4 \\
\hline XIX & Rhythm & $\begin{array}{r}\text { 5. Rhythmic } \\
\text { 1. Static }\end{array}$ & & $\mathrm{X}$ & & & & 4 \\
\hline $\mathrm{XX}$ & Centric or Eccentric & $\begin{array}{l}\text { 5. Internal Vectors } \\
\text { 1. External Vectors }\end{array}$ & & $\mathbf{X}$ & & & & 4 \\
\hline & Totals & & 3 & 13 & 4 & 0 & 0 & 79 \\
\hline
\end{tabular}


Formal Elements

Rating Scale (FERS)

\begin{tabular}{|c|c|c|c|c|c|c|c|c|}
\hline & Figure 61: Wheatfields & & 5 & 4 & 3 & 2 & 1 & Total \\
\hline $\mathrm{I}$ & Line Quality & $\begin{array}{l}\text { 5. Fluid and Flowing } \\
\text { 1. Jagged and Broken }\end{array}$ & $\mathrm{X}$ & & & & & 5 \\
\hline II & Expressive Style & $\begin{array}{l}\text { 5. Freedom of Expression } \\
\text { 1. Excessive Repetition }\end{array}$ & $\mathrm{X}$ & & & & & 5 \\
\hline III & Shape and Mass & $\begin{array}{r}\text { 5. Organic } \\
\text { 1. Geometric }\end{array}$ & $\mathrm{X}$ & & & & & 5 \\
\hline IV & Abstraction or Realism & $\begin{array}{l}\text { 5. Realistic } \\
\text { 1. Abstract }\end{array}$ & & & $\mathrm{X}$ & & & 3 \\
\hline $\mathrm{V}$ & Figure Ground Relationship & $\begin{array}{r}\text { 5. Subject Dominant } \\
\text { 1. Background Dominant }\end{array}$ & & $\mathrm{X}$ & & & & 4 \\
\hline VI & Value (Dark and Light) & $\begin{array}{c}\text { 5. Light Colors } \\
\text { 1. Dark Colors } \\
\end{array}$ & & & $\mathrm{X}$ & & & 3 \\
\hline VII & Intensity of Color & $\begin{array}{l}\text { 5. Pure and Saturated } \\
\text { 1. Greyed and Softened }\end{array}$ & & $\mathrm{X}$ & & & & 4 \\
\hline VIII & Variety of Color & $\begin{array}{r}\text { 5. Polychromatic } \\
\text { 1. Monochromatic } \\
\end{array}$ & & $\mathrm{X}$ & & & & 4 \\
\hline IX & Texture & $\begin{array}{l}\text { 5. Impasto } \\
\text { 1. Smooth } \\
\end{array}$ & $\mathrm{X}$ & & & & & 5 \\
\hline $\mathrm{X}$ & Pattern & $\begin{array}{r}\text { 5. Highly Repeated Motifs } \\
\text { 1. No Repeated Motifs } \\
\end{array}$ & & $\mathrm{X}$ & & & & 4 \\
\hline XI & $\begin{array}{l}\text { Spatial Organization } \\
\text { (Evenness of Space) }\end{array}$ & $\begin{array}{r}\text { 5. Evenly Dispersed } \\
\text { 1. Irregularly Dispersed } \\
\end{array}$ & & $\mathrm{X}$ & & & & 4 \\
\hline XII & Spatial Denseness & $\begin{array}{r}\text { 5. Densely packed } \\
\text { 1. Open Space }\end{array}$ & & & $\mathrm{X}$ & & & 3 \\
\hline XIII & Illusion of Depth & $\begin{array}{r}\text { 5. Deep } \\
\text { 1. Flat } \\
\end{array}$ & $\mathrm{X}$ & & & & & 5 \\
\hline XIV & Time and Motion & $\begin{array}{l}\text { 5. In Motion } \\
\text { 1.No Motion }\end{array}$ & & & & & $\mathrm{X}$ & 1 \\
\hline $\mathrm{XV}$ & Unity and Variety & $\begin{array}{l}\text { 5. Varied } \\
\text { 1. Unified } \\
\end{array}$ & & & $\mathrm{X}$ & & & 3 \\
\hline $\mathrm{XVI}$ & Emphasis and Focal Point & $\begin{array}{r}\text { 5. Definite Focal Point } \\
1 . \text { No Focal Point }\end{array}$ & & & $\mathrm{X}$ & & & 3 \\
\hline XVII & Proportion & $\begin{array}{l}\text { 5. Elements in Proportion } \\
\text { 1. Elements out of Proportion }\end{array}$ & $\mathrm{X}$ & & & & & 5 \\
\hline XVIII & Scale (Small to Large) & $\begin{array}{l}\text { 5. Large Scale } \\
\text { 1. Small Scale }\end{array}$ & & & $\mathrm{X}$ & & & 3 \\
\hline XIX & Rhythm & $\begin{array}{r}\text { 5. Rhythmic } \\
\text { 1. Static }\end{array}$ & & $\mathrm{X}$ & & & & 4 \\
\hline $\mathrm{XX}$ & Centric or Eccentric & $\begin{array}{r}\text { 5. Internal Vectors } \\
\text { 1. External Vectors }\end{array}$ & & & & $\mathrm{X}$ & & 2 \\
\hline \multicolumn{3}{|c|}{ Totals } & 6 & 6 & 6 & 1 & 1 & 75 \\
\hline
\end{tabular}


Formal Elements

Rating Scale (FERS)

\begin{tabular}{|c|c|c|c|c|c|c|c|c|}
\hline & \multicolumn{2}{|c|}{ Figure 62: Bank of the Ôise at Auvers } & \multirow[t]{2}{*}{5} & \multirow[t]{2}{*}{4} & \multirow[t]{2}{*}{3} & \multirow{2}{*}{\begin{tabular}{|l|}
2 \\
$X$
\end{tabular}} & \multirow[t]{2}{*}{1} & \multirow{2}{*}{$\frac{\text { Total }}{2}$} \\
\hline I & Line Quality & $\begin{array}{l}\text { 5. Fluid and Flowing } \\
\text { 1. Jagged and Broken }\end{array}$ & & & & & & \\
\hline II & Expressive Style & $\begin{array}{l}\text { 5. Freedom of Expression } \\
\text { 1. Excessive Repetition }\end{array}$ & & & & $\mathrm{X}$ & & 2 \\
\hline III & Shape and Mass & $\begin{array}{r}\text { 5. Organic } \\
\text { 1. Geometric } \\
\end{array}$ & & & $\mathrm{X}$ & & & 3 \\
\hline IV & Abstraction or Realism & $\begin{array}{l}\text { 5. Realistic } \\
\text { 1. Abstract }\end{array}$ & & $\mathrm{X}$ & & & & 4 \\
\hline $\mathrm{V}$ & Figure Ground Relationship & $\begin{array}{r}\text { 5. Subject Dominant } \\
\text { 1. Background Dominant }\end{array}$ & $\mathrm{X}$ & & & & & 5 \\
\hline $\begin{array}{l}\mathrm{VI} \\
\end{array}$ & Value (Dark and Light) & $\begin{array}{l}\text { 5. Light Colors } \\
\text { 1. Dark Colors }\end{array}$ & & & $\mathrm{X}$ & & & 3 \\
\hline VII & Intensity of Color & $\begin{array}{l}\text { 5. Pure and Saturated } \\
\text { 1. Greyed and Softened }\end{array}$ & & $\mathrm{X}$ & & & & 4 \\
\hline VIII & Variety of Color & $\begin{array}{r}\text { 5. Polychromatic } \\
\text { 1. Monochromatic }\end{array}$ & & $\mathrm{X}$ & & & & 4 \\
\hline IX & Texture & $\begin{array}{l}\text { 5. Impasto } \\
\text { 1. Smooth }\end{array}$ & $\mathrm{X}$ & & & & & 5 \\
\hline $\mathrm{X}$ & Pattern & $\begin{array}{l}\text { 5. Highly Repeated Motifs } \\
\text { 1. No Repeated Motifs }\end{array}$ & & $\mathrm{X}$ & & & & 4 \\
\hline XI & $\begin{array}{l}\text { Spatial Organization } \\
\text { (Evenness of Space) }\end{array}$ & $\begin{array}{r}\text { 5. Evenly Dispersed } \\
\text { 1. Irregularly Dispersed }\end{array}$ & & & & $\mathrm{X}$ & & 2 \\
\hline XII & Spatial Denseness & $\begin{array}{r}\text { 5. Densely packed } \\
\text { 1. Open Space }\end{array}$ & & $\mathrm{X}$ & & & & 4 \\
\hline XIII & Illusion of Depth & $\begin{array}{l}\text { 5. Deep } \\
\text { 1. Flat }\end{array}$ & $\mathrm{X}$ & & & & & 5 \\
\hline XIV & Time and Motion & $\begin{array}{l}\text { 5. In Motion } \\
\text { 1.No Motion }\end{array}$ & & & & $\mathrm{X}$ & & 2 \\
\hline $\mathrm{XV}$ & Unity and Variety & $\begin{array}{l}\text { 5. Varied } \\
\text { 1. Unified }\end{array}$ & & $\mathrm{X}$ & & & & 4 \\
\hline $\mathrm{XVI}$ & Emphasis and Focal Point & $\begin{array}{r}\text { 5. Definite Focal Point } \\
1 . \text { No Focal Point }\end{array}$ & & $\mathrm{X}$ & & & & 4 \\
\hline XVII & Proportion & $\begin{array}{r}\text { 5. Elements in Proportion } \\
\text { 1. Elements out of Proportion }\end{array}$ & & $\mathrm{X}$ & & & & 4 \\
\hline XVIII & Scale (Small to Large) & $\begin{array}{l}\text { 5. Large Scale } \\
\text { 1. Small Scale }\end{array}$ & & $\mathrm{X}$ & & & & 4 \\
\hline XIX & Rhythm & $\begin{array}{r}\text { 5. Rhythmic } \\
\text { 1. Static } \\
\end{array}$ & & $\mathrm{X}$ & & & & 4 \\
\hline $\mathrm{XX}$ & Centric or Eccentric & $\begin{array}{l}\text { 5. Internal Vectors } \\
\text { 1. External Vectors }\end{array}$ & & $\mathrm{X}$ & & & & 4 \\
\hline & Totals & & 3 & 11 & 2 & 4 & 0 & 73 \\
\hline
\end{tabular}


Formal Elements

Rating Scale (FERS)

\begin{tabular}{|c|c|c|c|c|c|c|c|c|}
\hline & \multicolumn{2}{|c|}{ Figure 63: Wheatfield Under Clouded Sky } & \multirow[t]{2}{*}{5} & \multirow{2}{*}{$\begin{array}{l}4 \\
X\end{array}$} & \multirow[t]{2}{*}{3} & \multirow[t]{2}{*}{2} & \multirow[t]{2}{*}{1} & \multirow{2}{*}{$\frac{\text { Total }}{4}$} \\
\hline $\mathrm{I}$ & Line Quality & $\begin{array}{l}\text { 5. Fluid and Flowing } \\
\text { 1. Jagged and Broken }\end{array}$ & & & & & & \\
\hline II & Expressive Style & $\begin{array}{l}\text { 5. Freedom of Expression } \\
\text { 1. Excessive Repetition }\end{array}$ & & $\mathrm{X}$ & & & & 4 \\
\hline III & Shape and Mass & $\begin{array}{r}\text { 5. Organic } \\
\text { 1. Geometric }\end{array}$ & $\mathrm{X}$ & & & & & 5 \\
\hline IV & Abstraction or Realism & $\begin{array}{l}\text { 5. Realistic } \\
\text { 1. Abstract }\end{array}$ & & & $\mathrm{X}$ & & & 3 \\
\hline $\mathrm{V}$ & Figure Ground Relationship & $\begin{array}{r}\text { 5. Subject Dominant } \\
\text { 1. Background Dominant }\end{array}$ & $\mathrm{X}$ & & & & & 5 \\
\hline VI & Value (Dark and Light) & $\begin{array}{l}\text { 5. Light Colors } \\
\text { 1. Dark Colors } \\
\end{array}$ & & & $\mathrm{X}$ & & & 3 \\
\hline VII & Intensity of Color & $\begin{array}{l}\text { 5. Pure and Saturated } \\
\text { 1. Greyed and Softened }\end{array}$ & & $\mathrm{X}$ & & & & 4 \\
\hline VIII & Variety of Color & $\begin{array}{r}\text { 5. Polychromatic } \\
\text { 1. Monochromatic }\end{array}$ & & $\mathrm{X}$ & & & & 4 \\
\hline IX & Texture & $\begin{array}{l}\text { 5. Impasto } \\
\text { 1. Smooth } \\
\end{array}$ & & $\mathrm{X}$ & & & & 4 \\
\hline $\mathrm{X}$ & Pattern & $\begin{array}{r}\text { 5. Highly Repeated Motifs } \\
\text { 1. No Repeated Motifs } \\
\end{array}$ & & $\mathrm{X}$ & & & & 4 \\
\hline $\mathrm{XI}$ & $\begin{array}{l}\text { Spatial Organization } \\
\text { (Evenness of Space) }\end{array}$ & $\begin{array}{r}\text { 5. Evenly Dispersed } \\
\text { 1. Irregularly Dispersed } \\
\end{array}$ & & $\mathrm{X}$ & & & & 4 \\
\hline XII & Spatial Denseness & $\begin{array}{r}\text { 5. Densely packed } \\
\text { 1. Open Space }\end{array}$ & & & & & $\mathrm{X}$ & 1 \\
\hline XIII & Illusion of Depth & $\begin{array}{r}\text { 5. Deep } \\
\text { 1. Flat } \\
\end{array}$ & $\mathrm{X}$ & & & & & 5 \\
\hline XIV & Time and Motion & $\begin{array}{l}\text { 5. In Motion } \\
\text { 1.No Motion } \\
\end{array}$ & & & & & $\mathrm{X}$ & 1 \\
\hline $\mathrm{XV}$ & Unity and Variety & $\begin{array}{l}\text { 5. Varied } \\
\text { 1. Unified } \\
\end{array}$ & & & $\mathrm{X}$ & & & 3 \\
\hline XVI & Emphasis and Focal Point & $\begin{array}{r}\text { 5. Definite Focal Point } \\
\text { 1. No Focal Point }\end{array}$ & & & & & $\mathrm{X}$ & 1 \\
\hline XVII & Proportion & $\begin{array}{r}\text { 5. Elements in Proportion } \\
\text { 1. Elements out of Proportion }\end{array}$ & $\mathrm{X}$ & & & & & 5 \\
\hline XVIII & Scale (Small to Large) & $\begin{array}{l}\text { 5. Large Scale } \\
\text { 1. Small Scale }\end{array}$ & & & $\mathrm{X}$ & & & 3 \\
\hline XIX & Rhythm & $\begin{array}{l}\text { 5. Rhythmic } \\
\text { 1. Static }\end{array}$ & & $\mathrm{X}$ & & & & 4 \\
\hline $\mathrm{XX}$ & Centric or Eccentric & $\begin{array}{r}\text { 5. Internal Vectors } \\
\text { 1. External Vectors }\end{array}$ & & & & & $\mathrm{X}$ & 1 \\
\hline & Totals & & 4 & 8 & 4 & 0 & 4 & 68 \\
\hline
\end{tabular}


Formal Elements

Rating Scale (FERS)

\begin{tabular}{|c|c|c|c|c|c|c|c|c|}
\hline & \multicolumn{2}{|c|}{ Figure 64: Crows over the Wheatfield } & \multirow[t]{2}{*}{5} & \multirow[t]{2}{*}{4} & \multirow[t]{2}{*}{3} & \multirow{2}{*}{$\begin{array}{l}2 \\
X\end{array}$} & \multirow[t]{2}{*}{1} & \multirow{2}{*}{$\frac{\text { Total }}{2}$} \\
\hline $\mathrm{I}$ & Line Quality & $\begin{array}{l}\text { 5. Fluid and Flowing } \\
\text { 1. Jagged and Broken }\end{array}$ & & & & & & \\
\hline II & Expressive Style & $\begin{array}{l}\text { 5. Freedom of Expression } \\
\text { 1. Excessive Repetition }\end{array}$ & & & & $\mathrm{X}$ & & 2 \\
\hline III & Shape and Mass & $\begin{array}{r}\text { 5. Organic } \\
\text { 1. Geometric }\end{array}$ & $\mathrm{X}$ & & & & & 5 \\
\hline IV & Abstraction or Realism & $\begin{array}{l}\text { 5. Realistic } \\
\text { 1. Abstract }\end{array}$ & & $\mathrm{X}$ & & & & 4 \\
\hline V & Figure Ground Relationship & $\begin{array}{r}\text { 5. Subject Dominant } \\
\text { 1. Background Dominant }\end{array}$ & & & & $\mathrm{X}$ & & 2 \\
\hline VI & Value (Dark and Light) & $\begin{array}{l}\text { 5. Light Colors } \\
\text { 1. Dark Colors }\end{array}$ & & & $\mathrm{X}$ & & & 3 \\
\hline VII & Intensity of Color & $\begin{array}{l}\text { 5. Pure and Saturated } \\
\text { 1. Greyed and Softened }\end{array}$ & & $\mathrm{X}$ & & & & 4 \\
\hline VIII & Variety of Color & $\begin{array}{r}\text { 5. Polychromatic } \\
\text { 1. Monochromatic }\end{array}$ & & $\mathrm{X}$ & & & & 4 \\
\hline IX & Texture & $\begin{array}{l}\text { 5. Impasto } \\
\text { 1. Smooth }\end{array}$ & $\mathrm{X}$ & & & & & 5 \\
\hline $\bar{X}$ & Pattern & $\begin{array}{l}\text { 5. Highly Repeated Motifs } \\
\text { 1. No Repeated Motifs }\end{array}$ & $\mathrm{X}$ & & & & & 5 \\
\hline XI & $\begin{array}{l}\text { Spatial Organization } \\
\text { (Evenness of Space) }\end{array}$ & $\begin{array}{l}\text { 5. Evenly Dispersed } \\
\text { 1. Irregularly Dispersed }\end{array}$ & & & & $\mathrm{X}$ & & 2 \\
\hline XII & Spatial Denseness & $\begin{array}{r}\text { 5. Densely packed } \\
\text { 1. Open Space }\end{array}$ & & $\mathrm{X}$ & & & & 4 \\
\hline XIII & Illusion of Depth & $\begin{array}{l}\text { 5. Deep } \\
\text { 1. Flat }\end{array}$ & $\mathrm{X}$ & & & & & 5 \\
\hline XIV & Time and Motion & $\begin{array}{l}\text { 5. In Motion } \\
\text { 1.No Motion }\end{array}$ & $\mathrm{X}$ & & & & & 5 \\
\hline $\mathrm{XV}$ & Unity and Variety & $\begin{array}{l}\text { 5. Varied } \\
\text { 1. Unified }\end{array}$ & & $\mathrm{X}$ & & & & 4 \\
\hline XVI & Emphasis and Focal Point & $\begin{array}{r}\text { 5. Definite Focal Point } \\
1 . \text { No Focal Point } \\
\end{array}$ & $\mathrm{X}$ & & & & & 5 \\
\hline XVII & Proportion & $\begin{array}{l}\text { 5. Elements in Proportion } \\
\text { 1. Elements out of Proportion }\end{array}$ & & $\mathrm{X}$ & & & & 4 \\
\hline XVIII & Scale (Small to Large) & $\begin{array}{l}\text { 5. Large Scale } \\
\text { 1. Small Scale }\end{array}$ & & & $\mathrm{X}$ & & & 3 \\
\hline XIX & Rhythm & $\begin{array}{c}\text { 5. Rhythmic } \\
\text { 1. Static }\end{array}$ & $\mathrm{X}$ & & & & & 5 \\
\hline XX & Centric or Eccentric & $\begin{array}{l}\text { 5. Internal Vectors } \\
\text { 1. External Vectors }\end{array}$ & $X$ & & & & & 5 \\
\hline & Totals & & 8 & 6 & 2 & 4 & 0 & 78 \\
\hline
\end{tabular}


APPENDIX 5. Graphs for each Artwork.

Appendix 5 contains 64 graphs, one for each artwork included, and provides a visual format for understanding the spread of the formal elements by a score of from 1 (least) to 5 (more). It is noted by the author that this information may be gained from the scored FERS as well, by establishing a line graph through the scores, but it was felt that for purposes of this pilot study that a separate graph for each artwork would present the information in a clearer manner. 

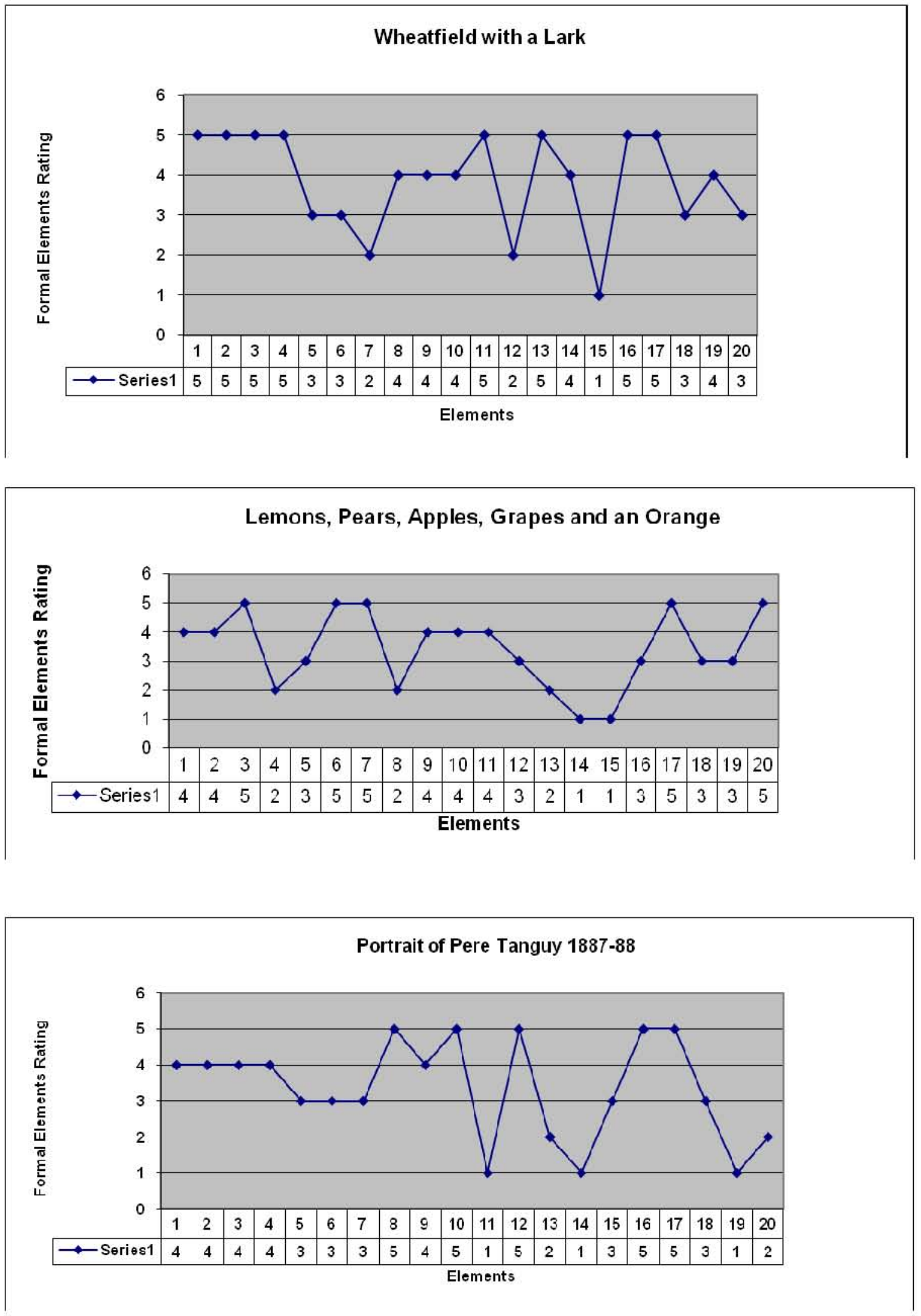

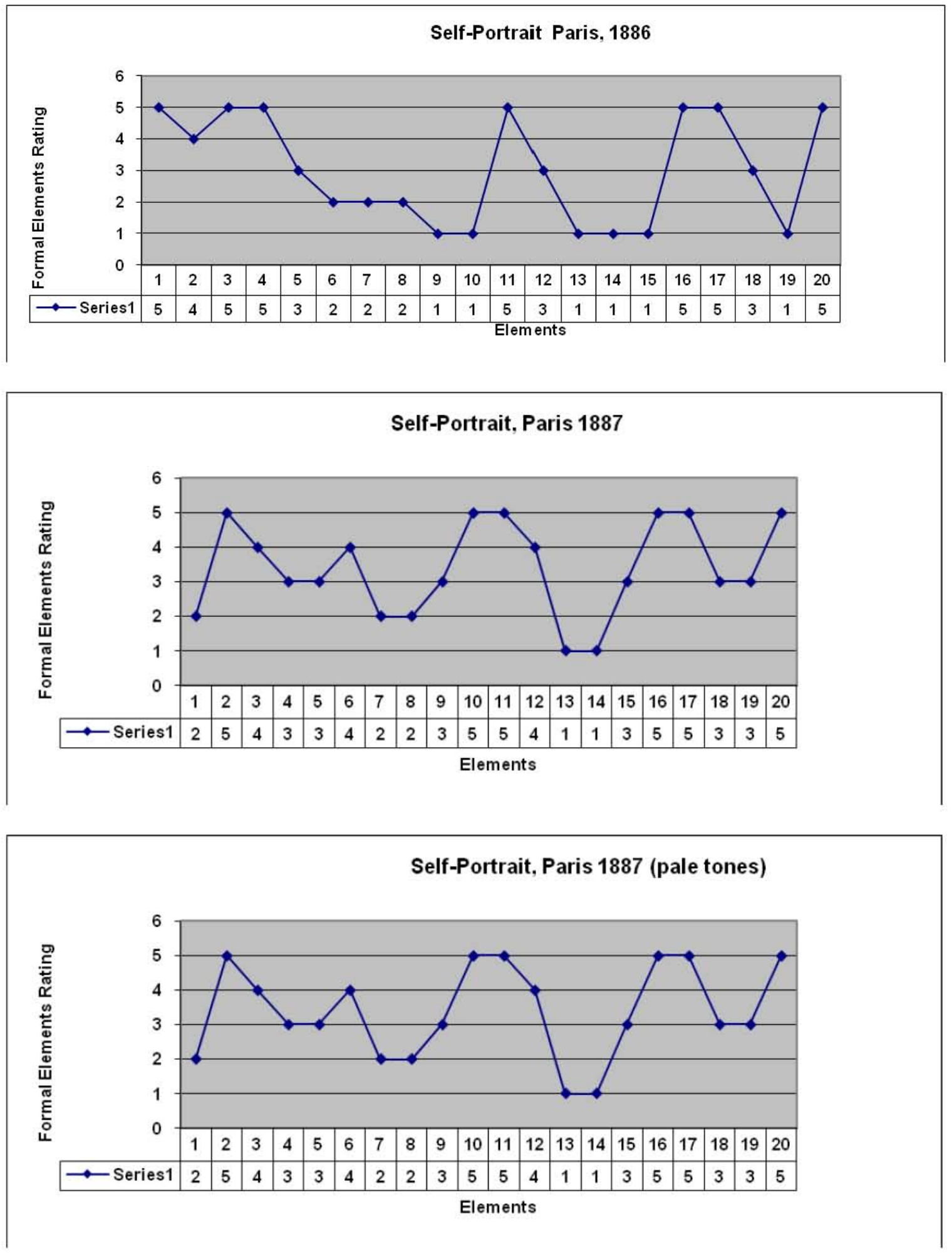

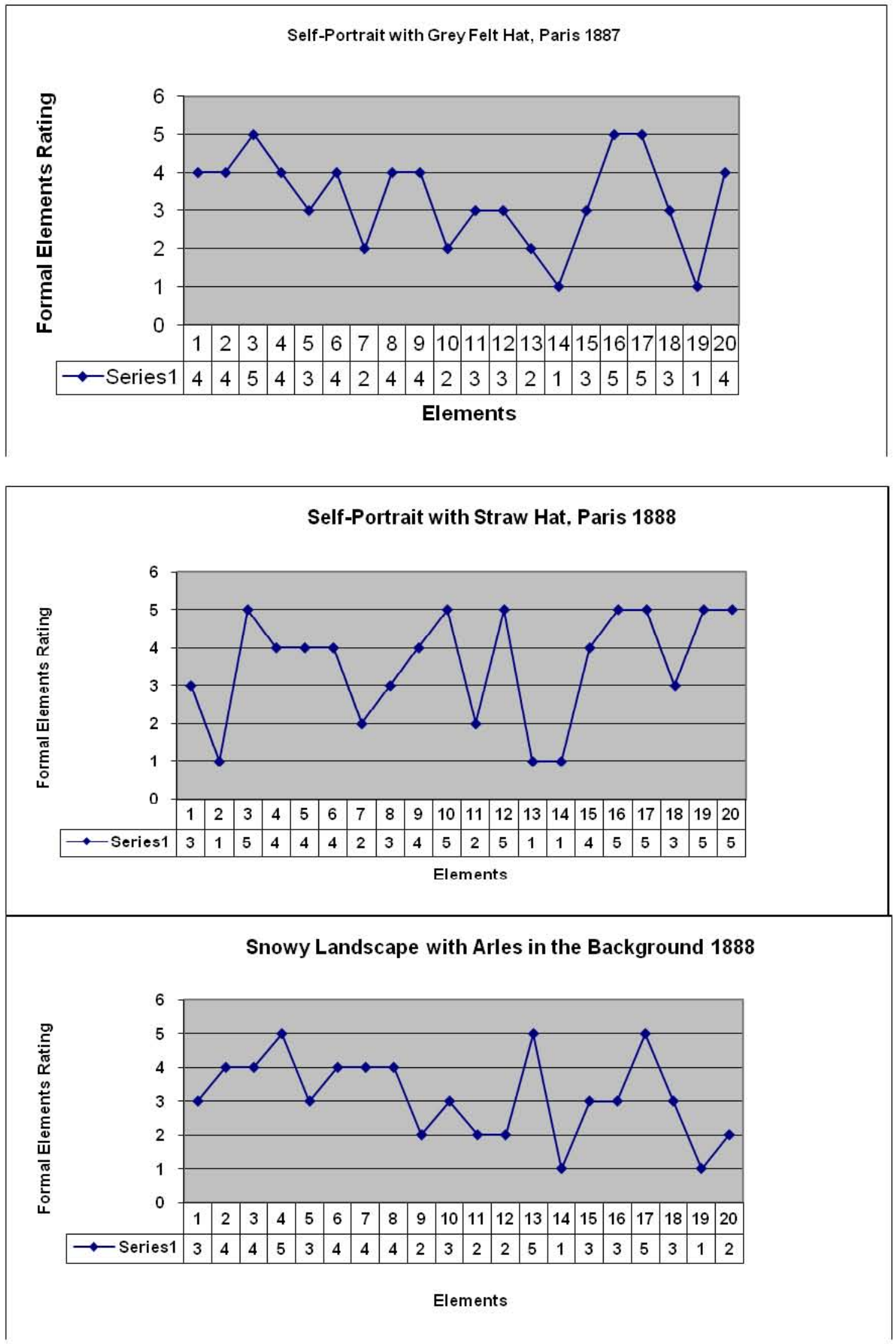
The Painter on the Road to Tarascon, 1887

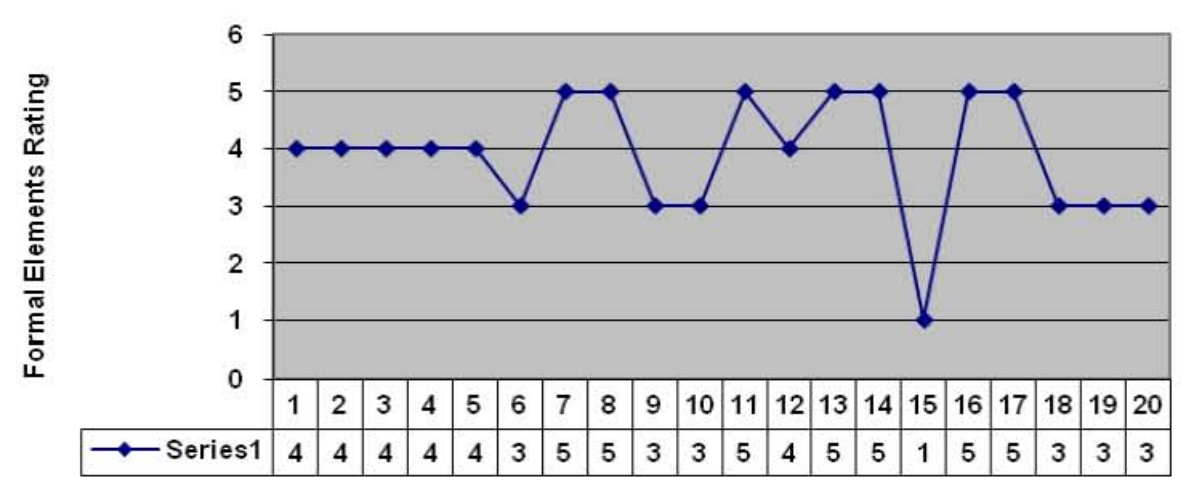

Elements

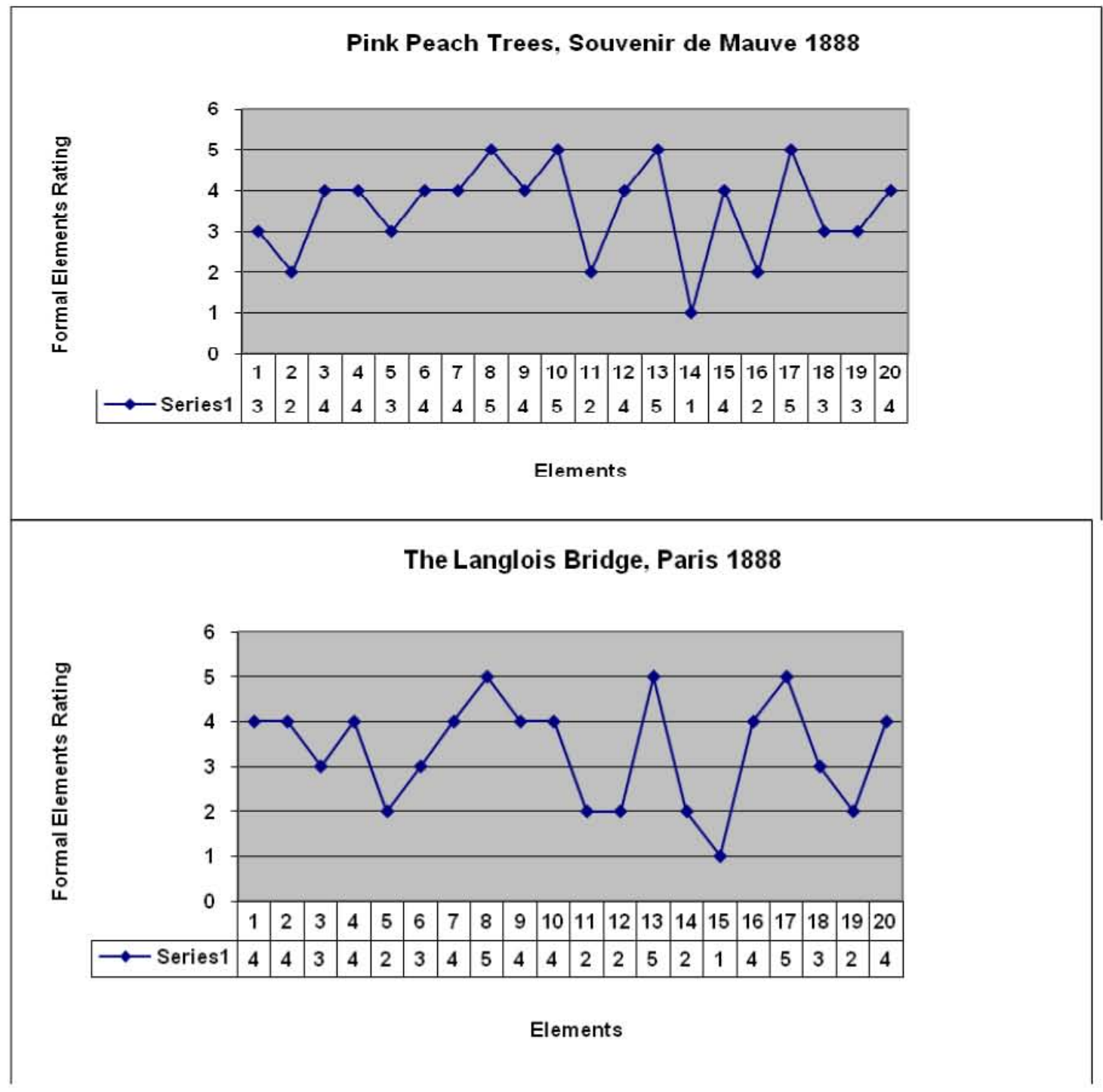



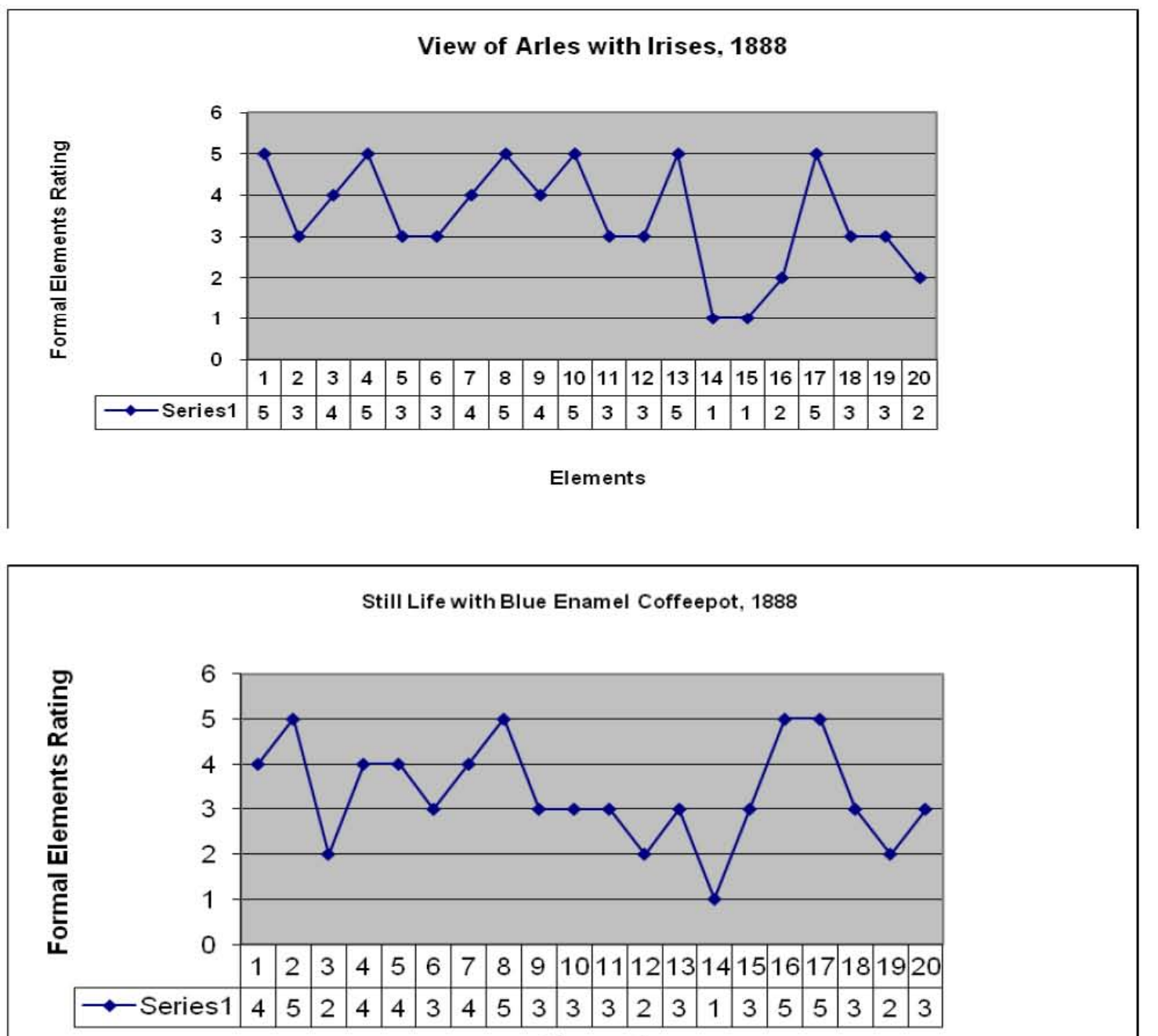

Elements

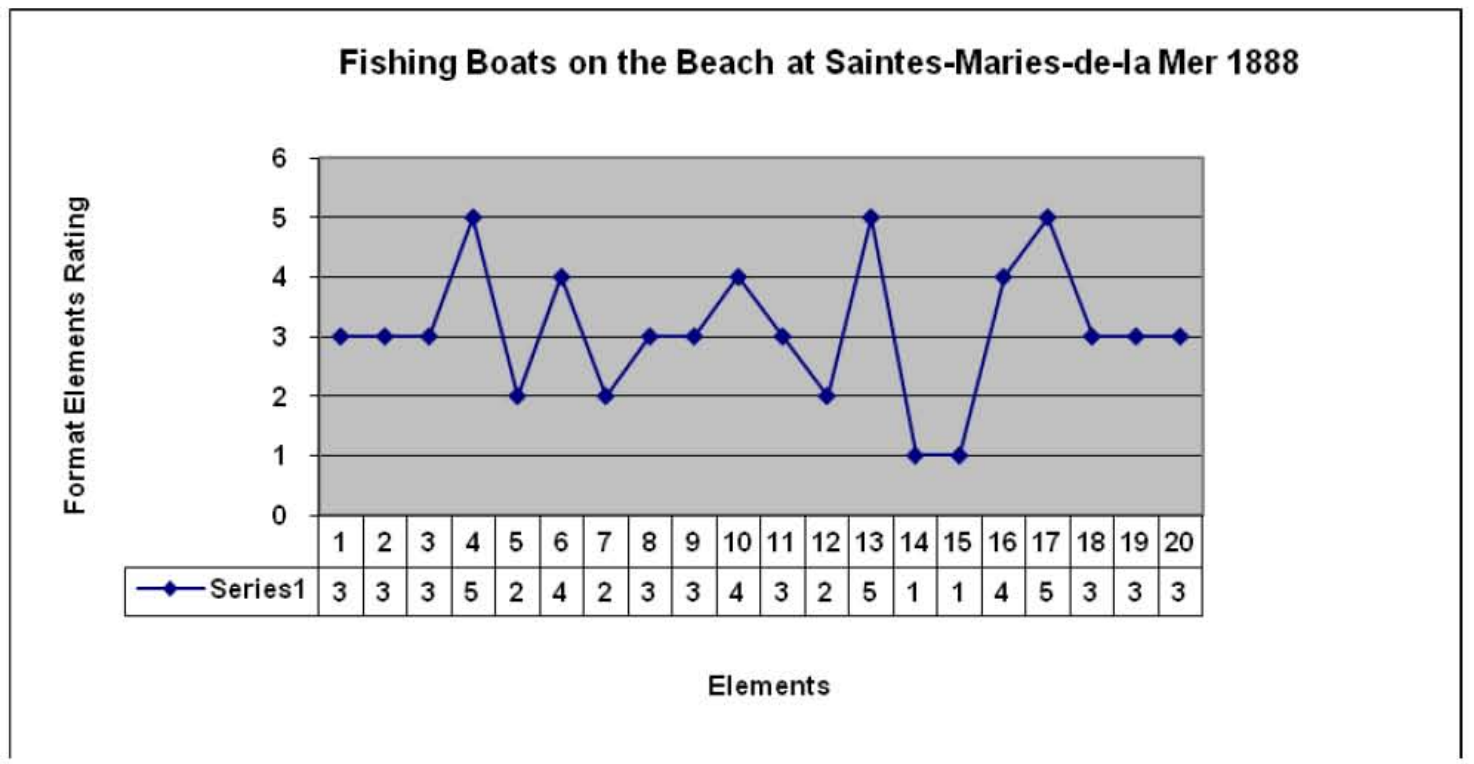



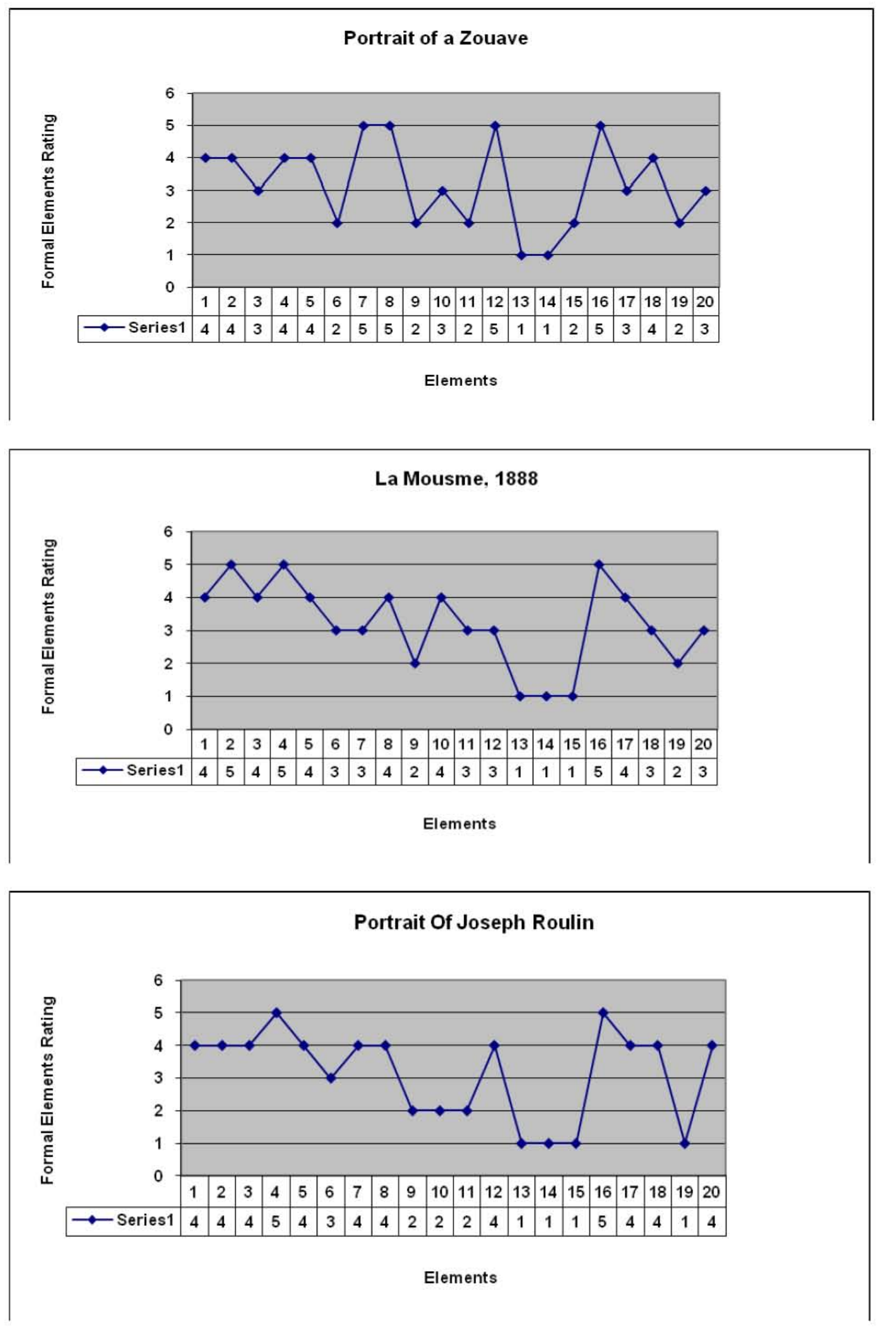

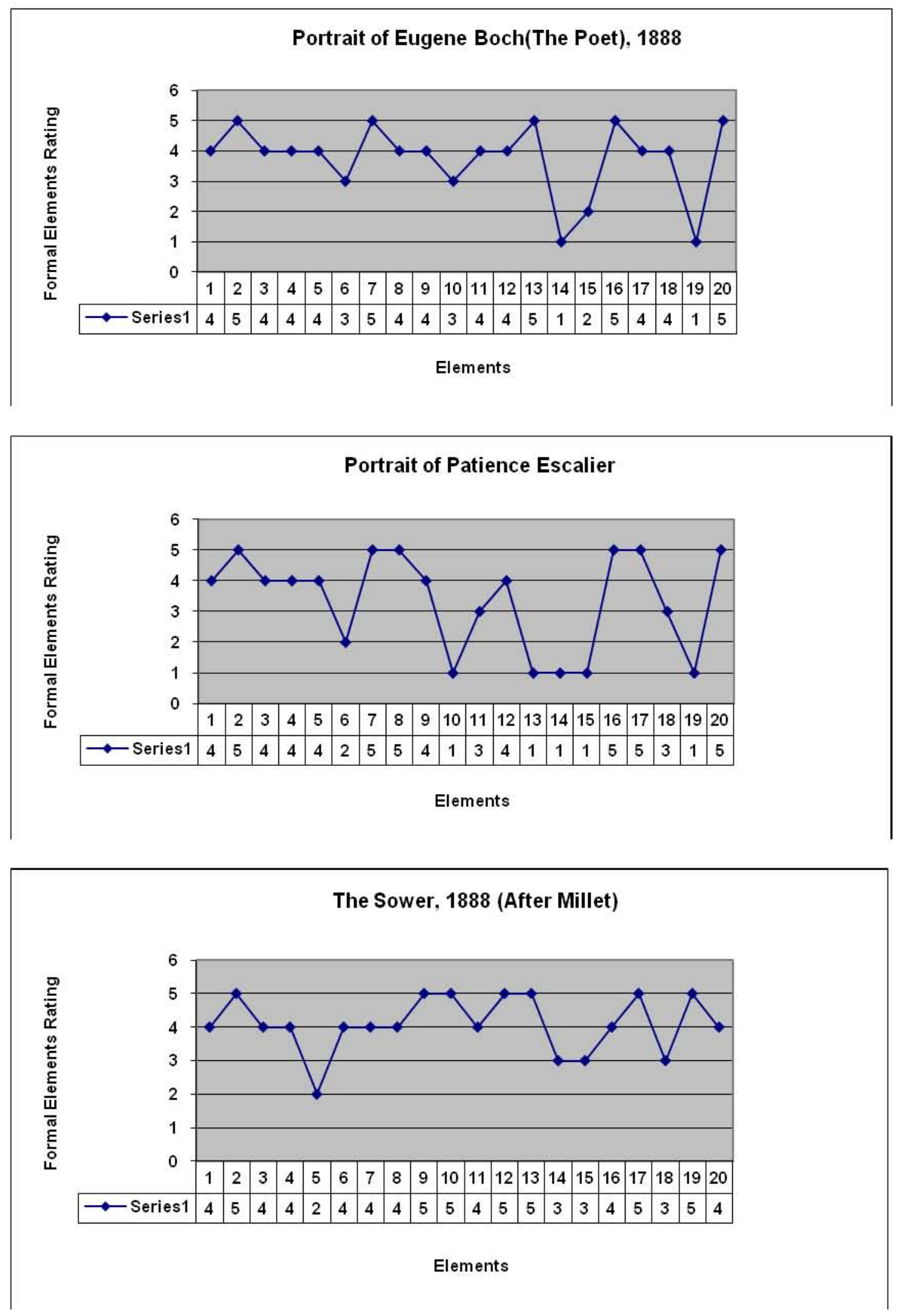

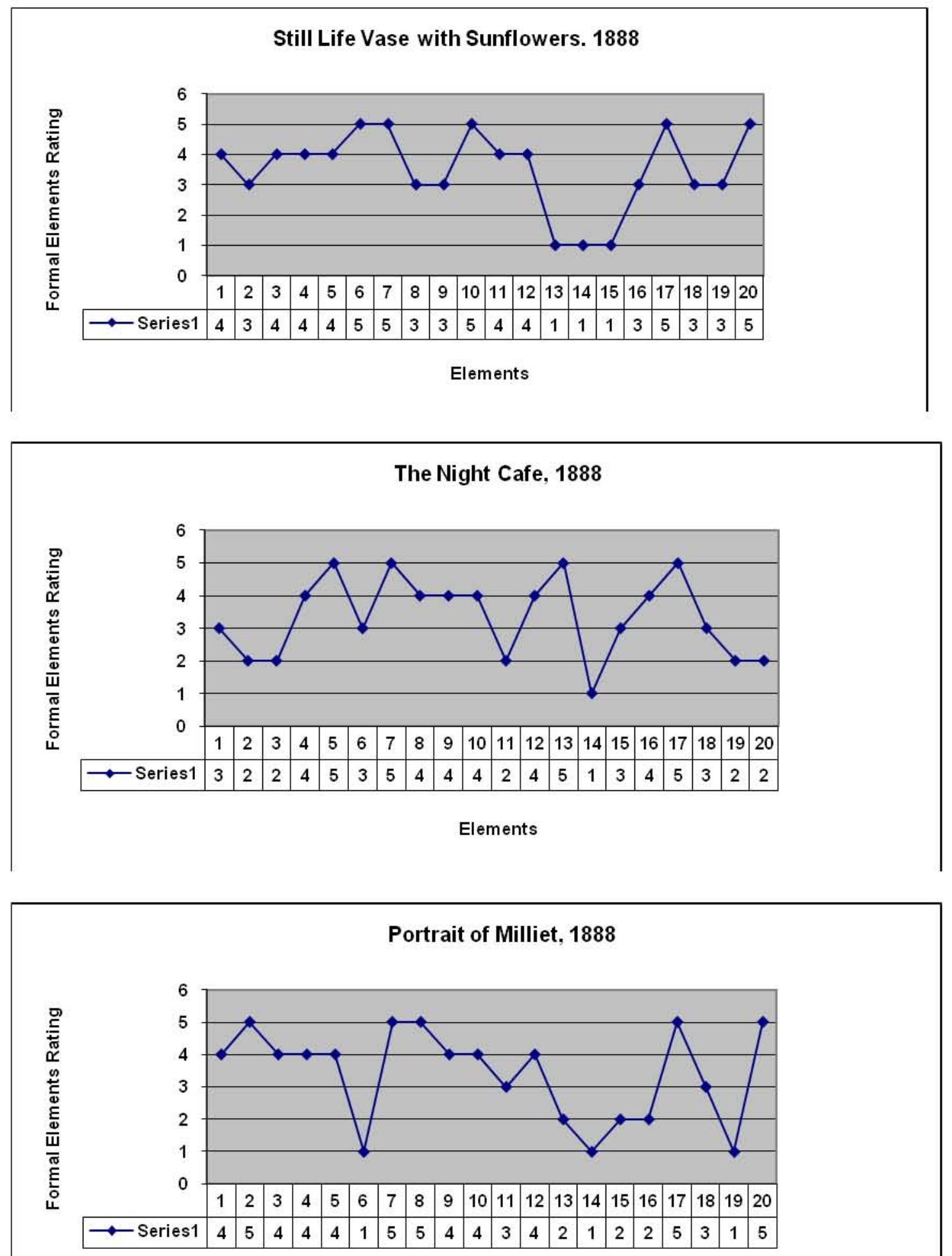

Elements 


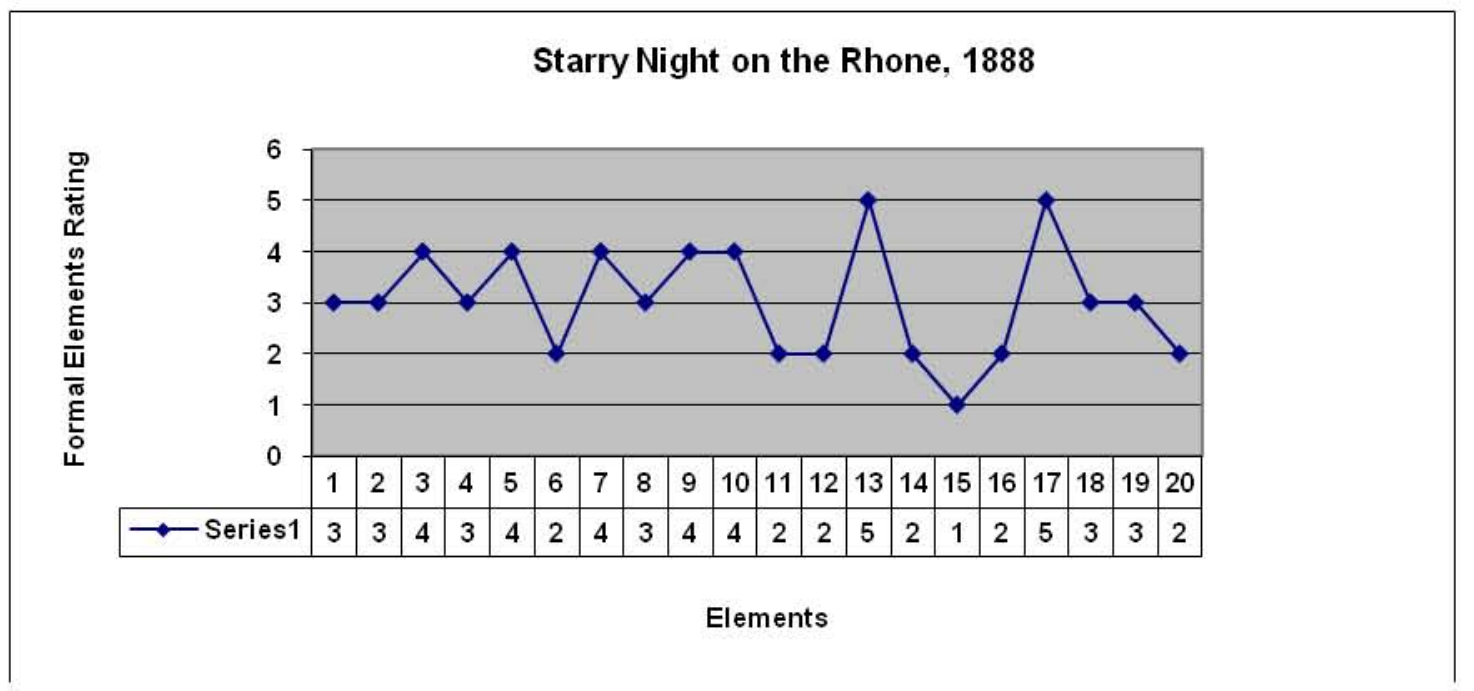

The Cafe Terrace at Night. 1888

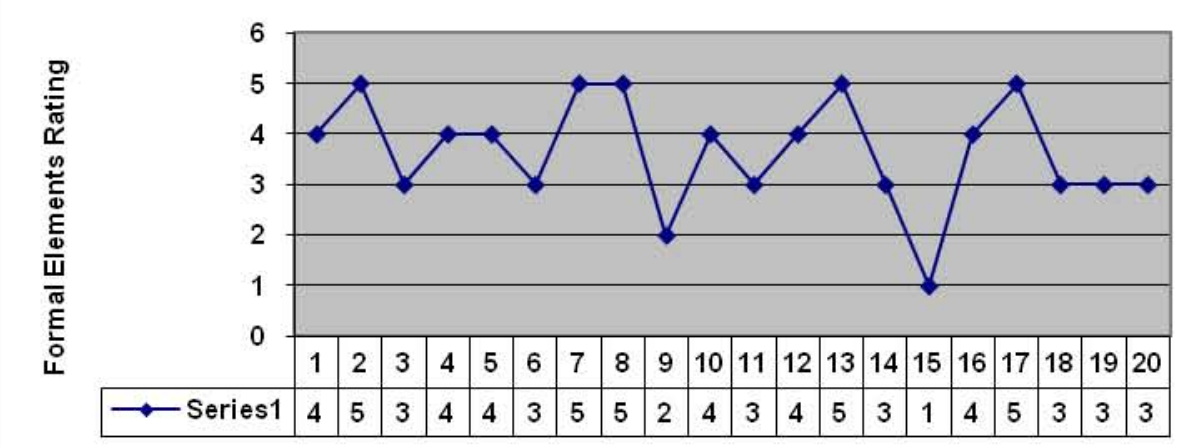

Elements

The Yellow House, 1888

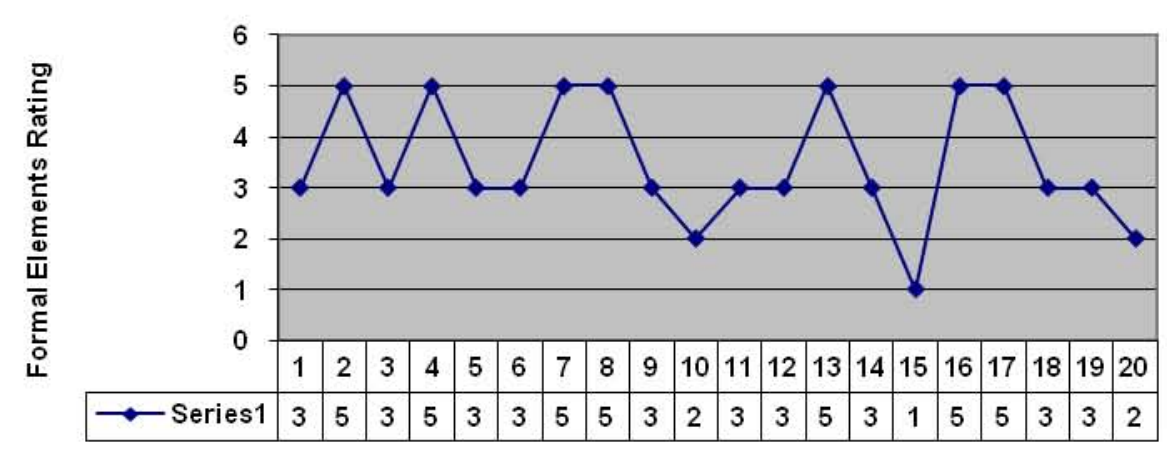

Elements 

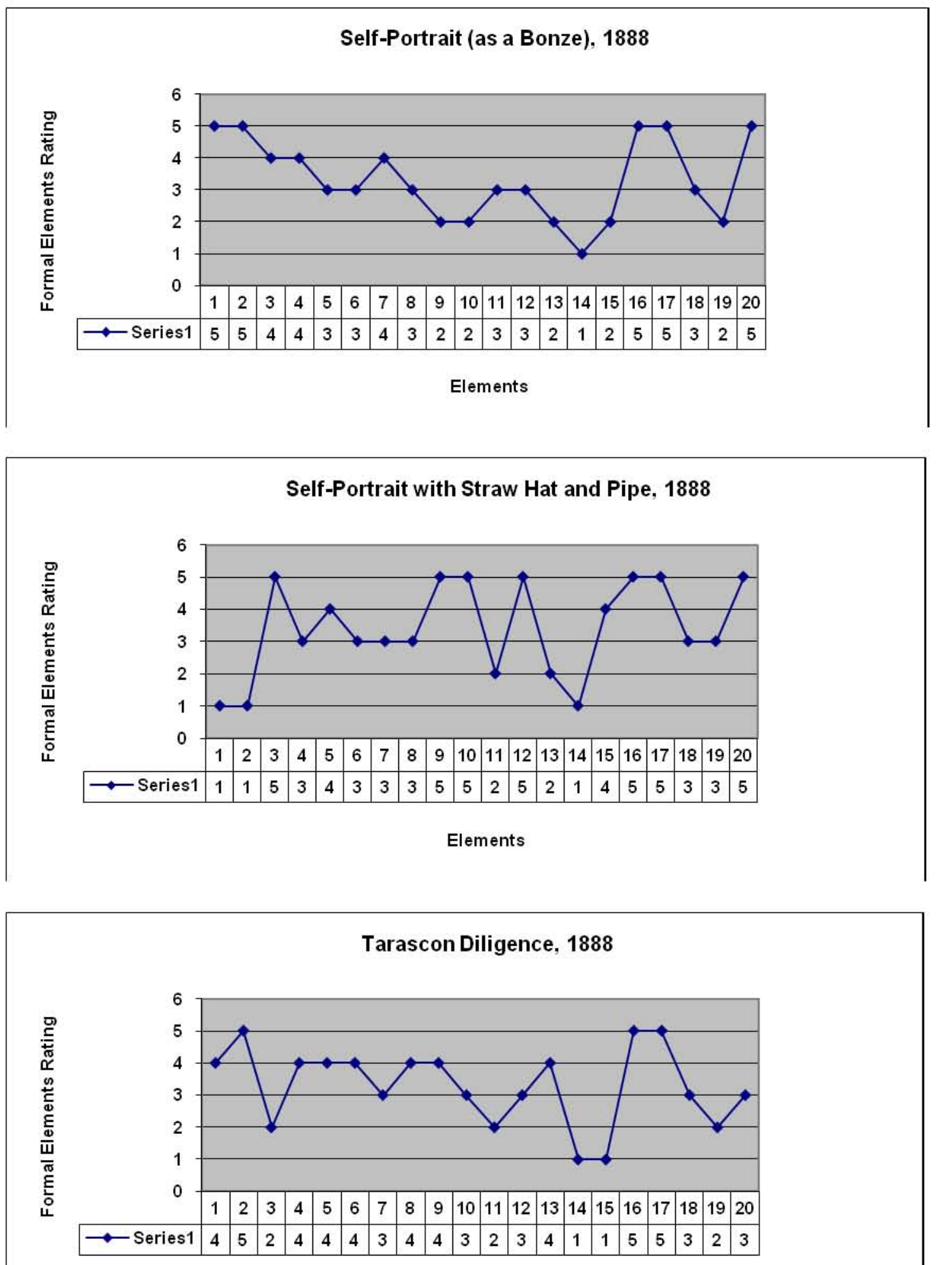

Elements 

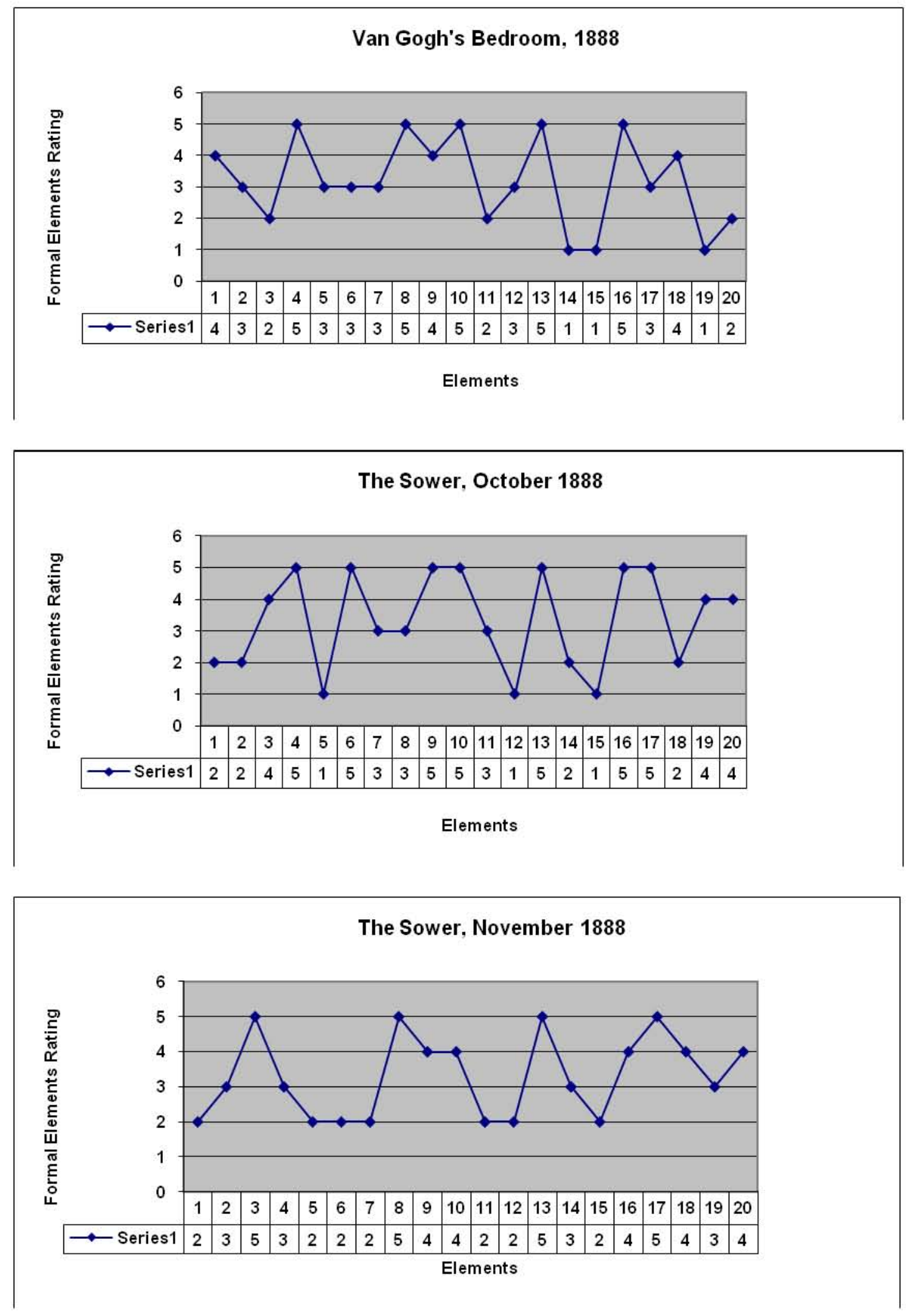

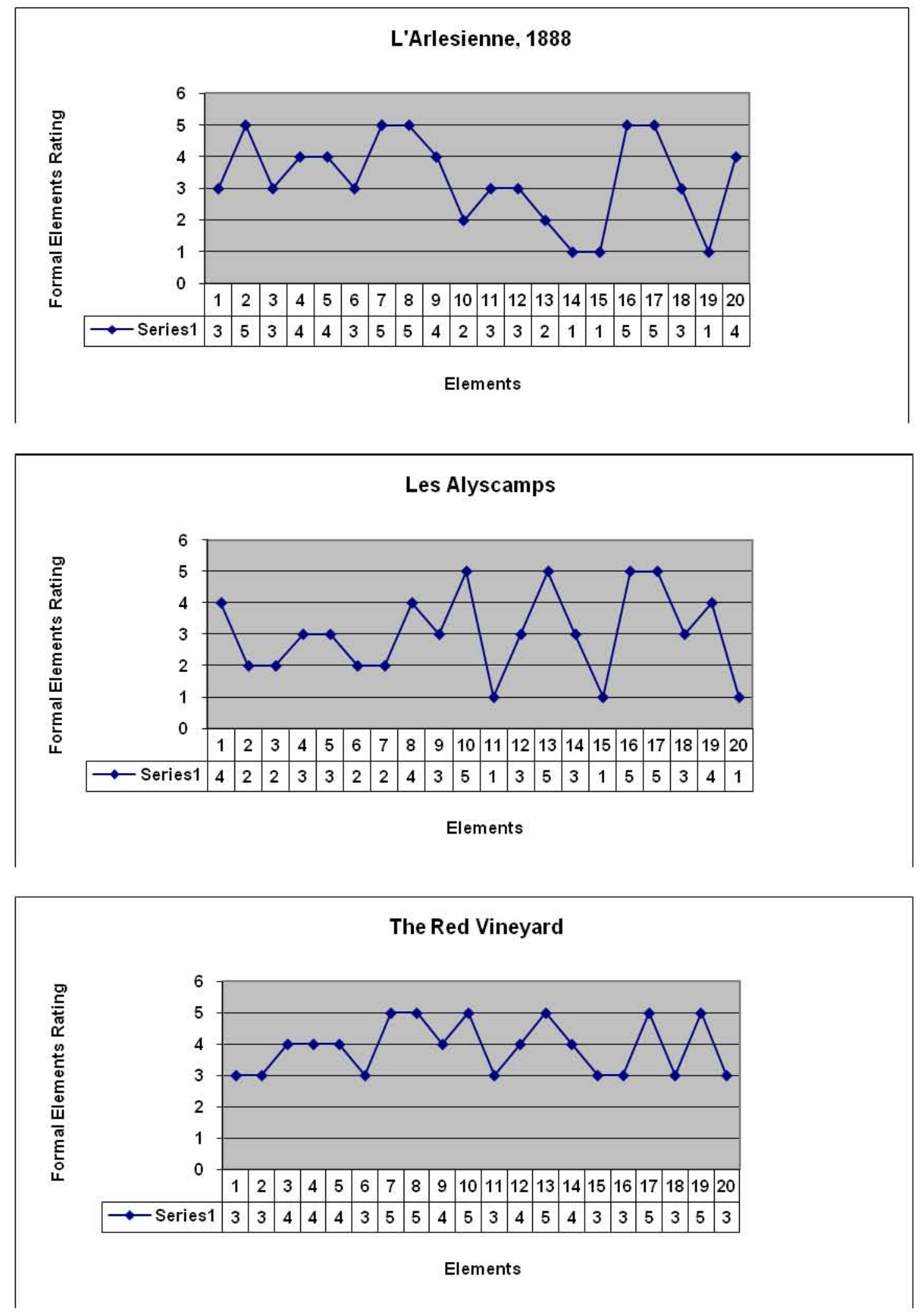

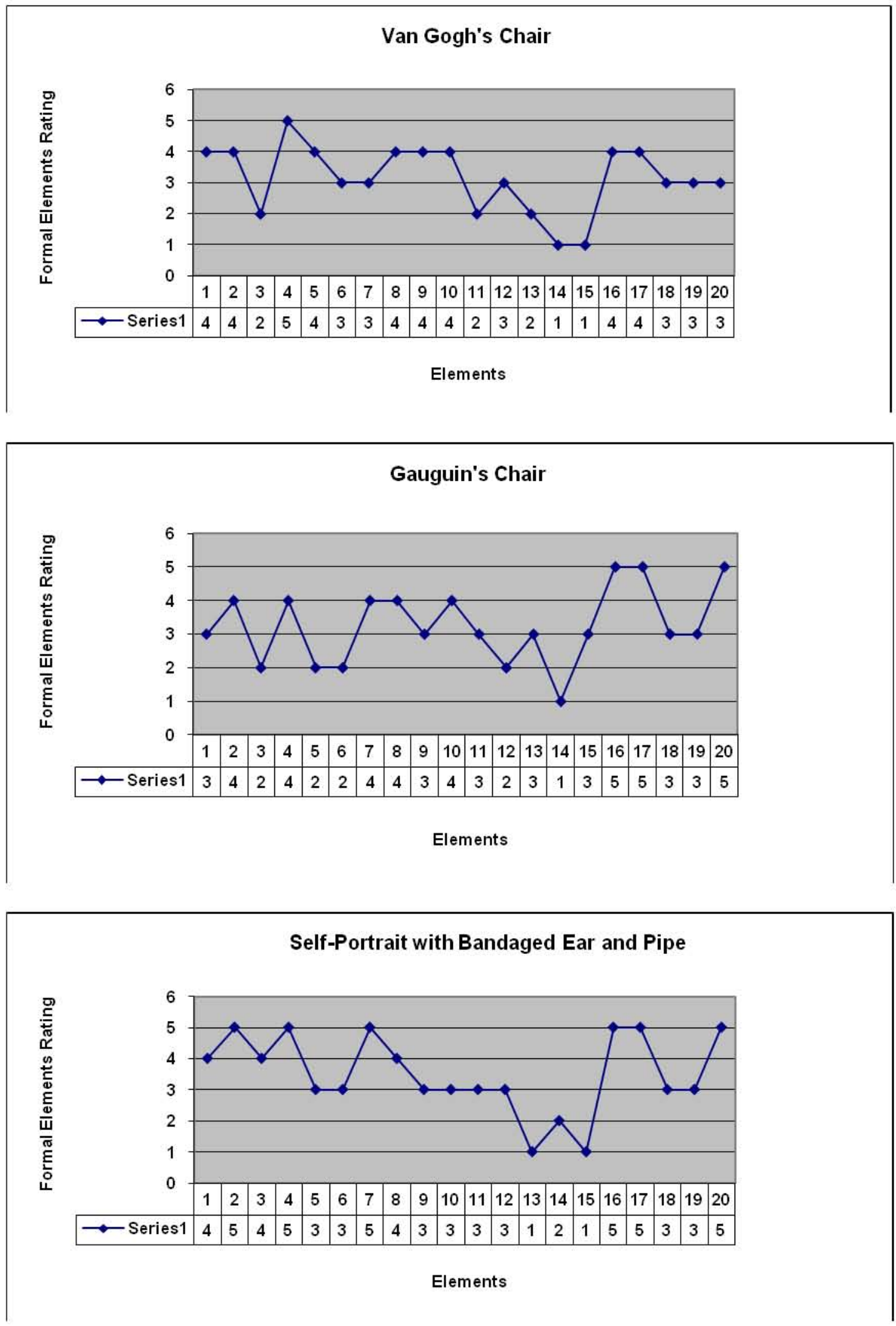

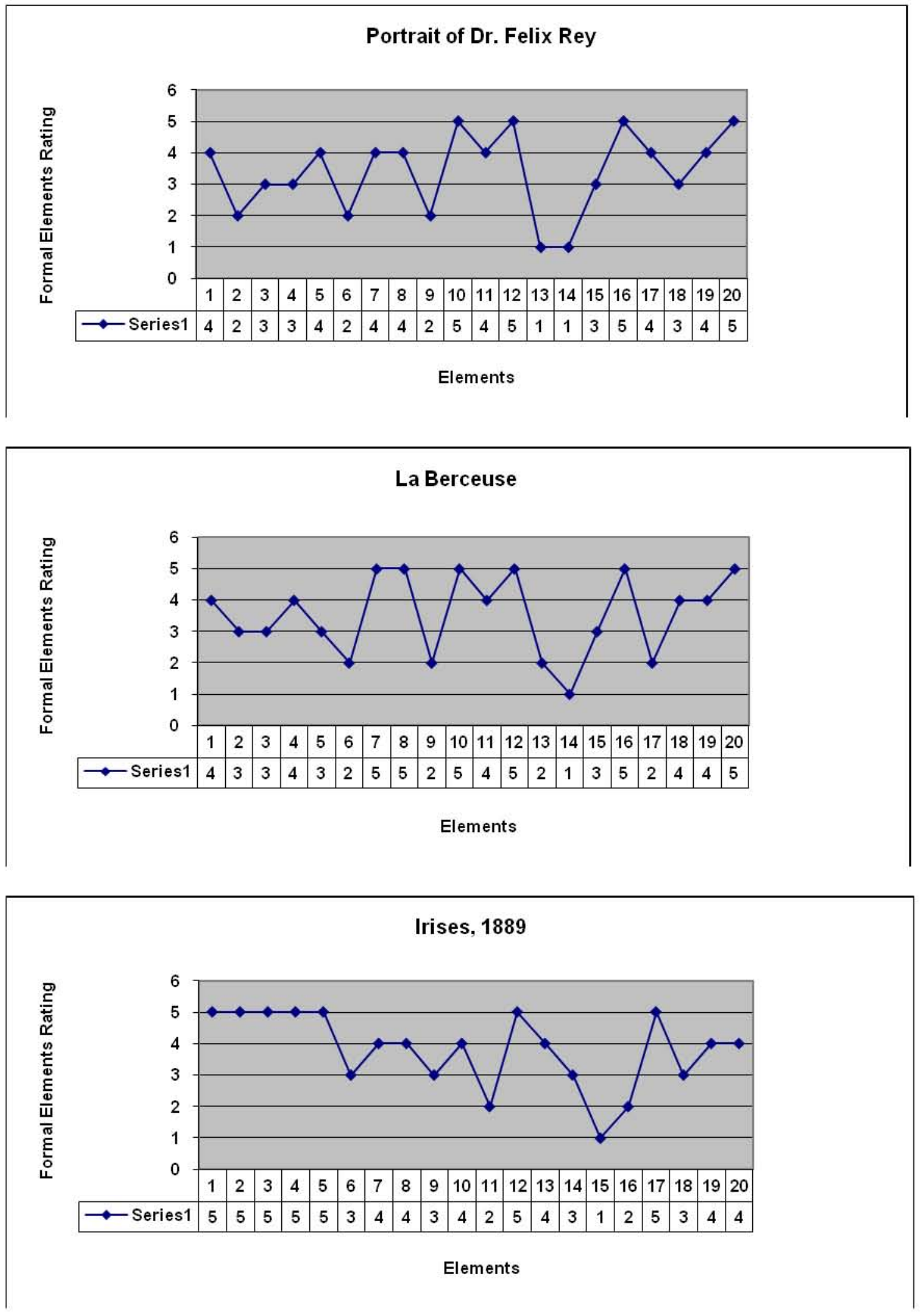

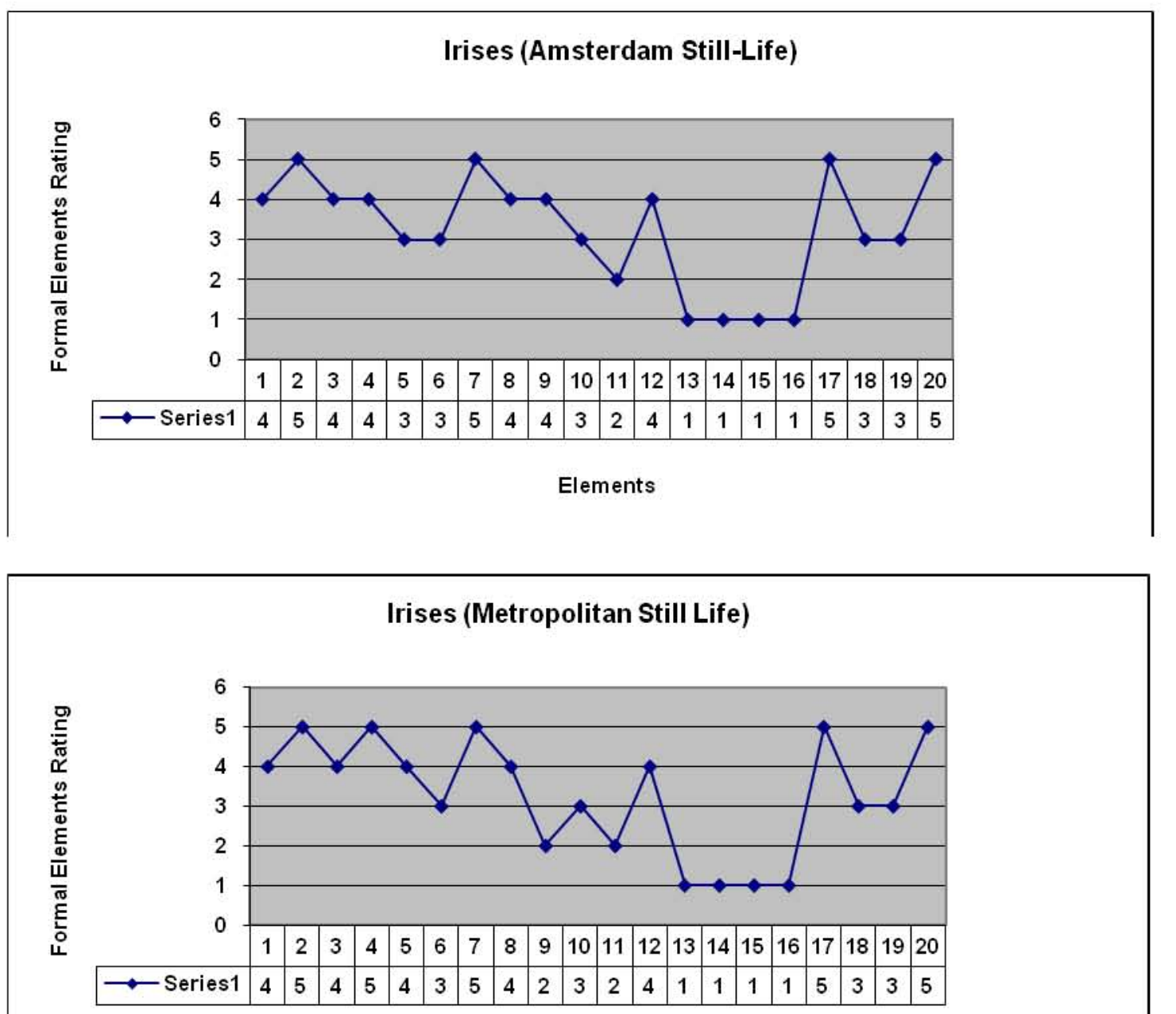

Elements

\section{Pink Roses in a Vase}

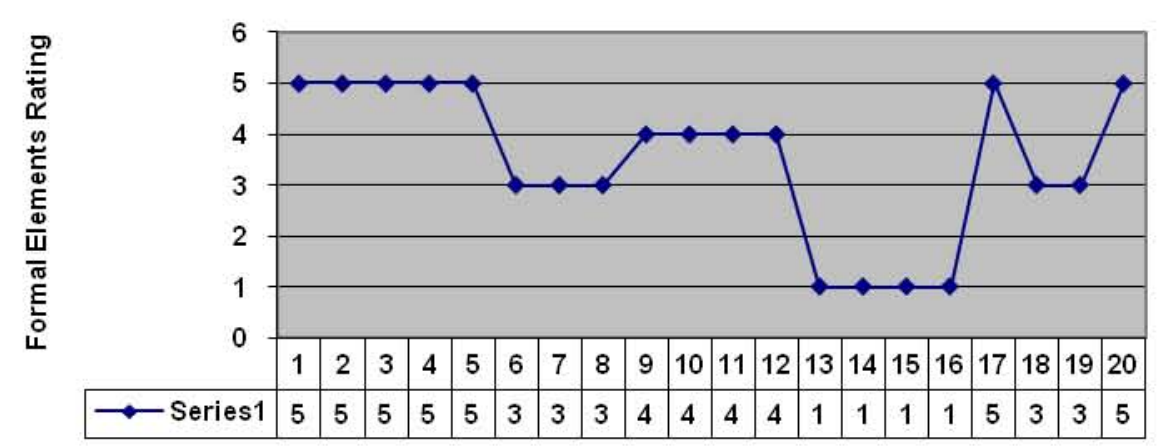

Elements 


\section{The Prisoner's Round}

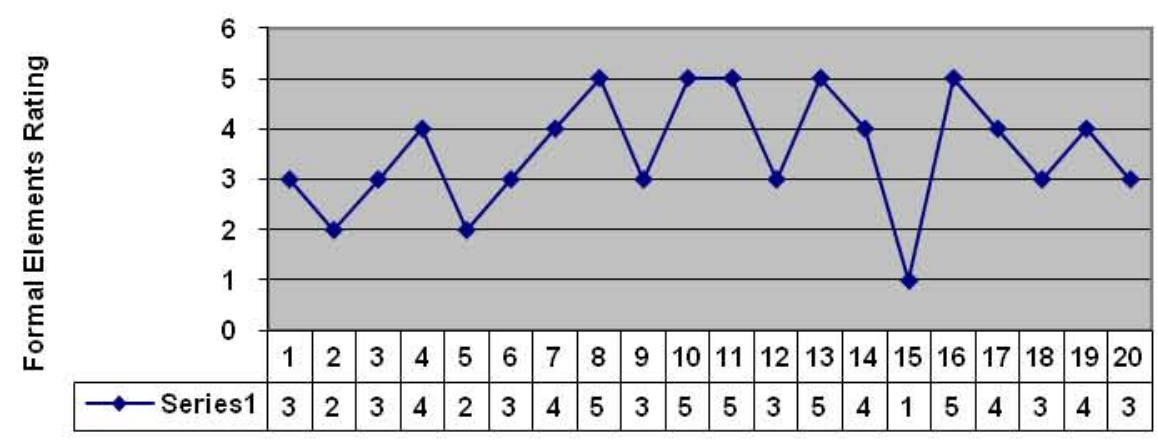

Elements

\section{Cypresses (Metropolitan)}

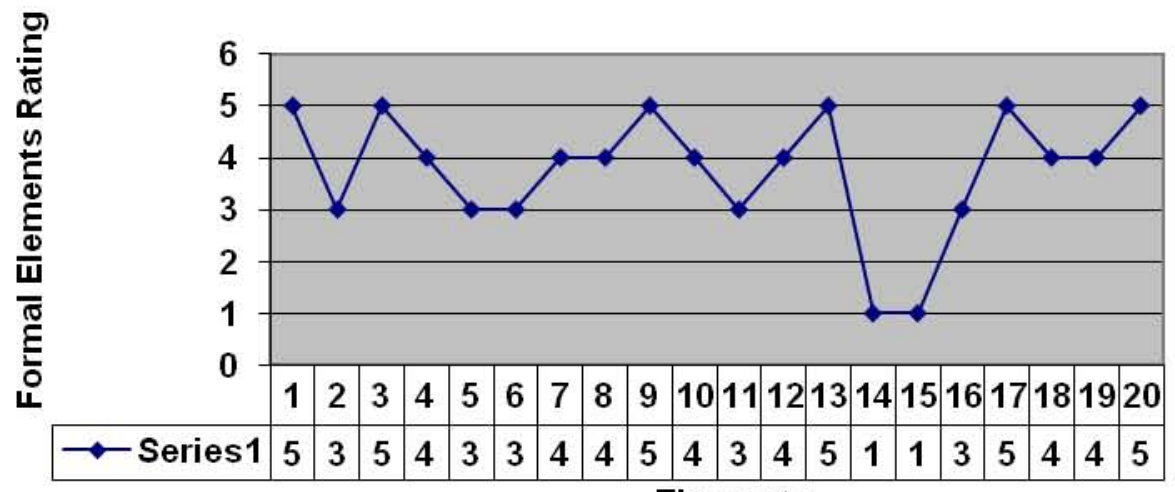

Elements

The Starry Night

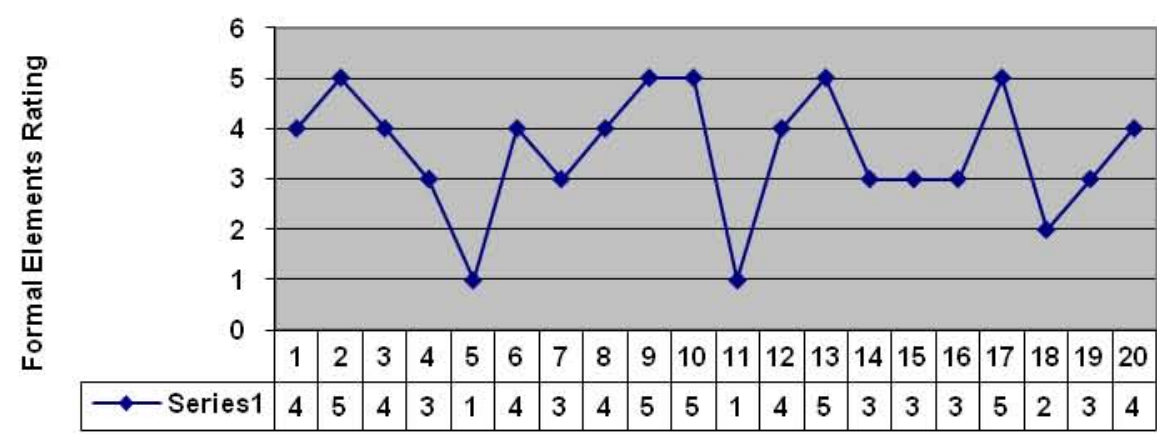

Elements 

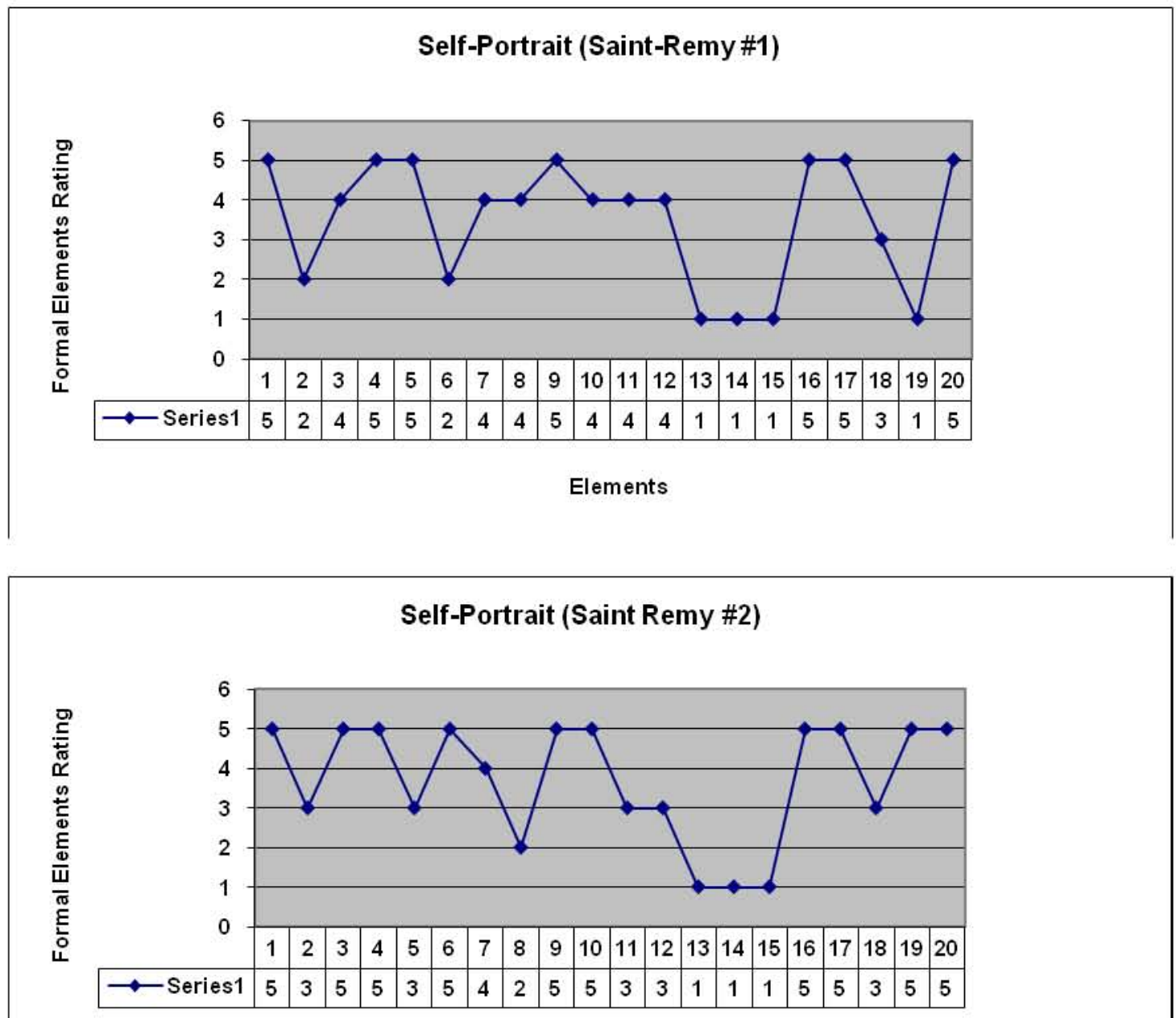

Elements

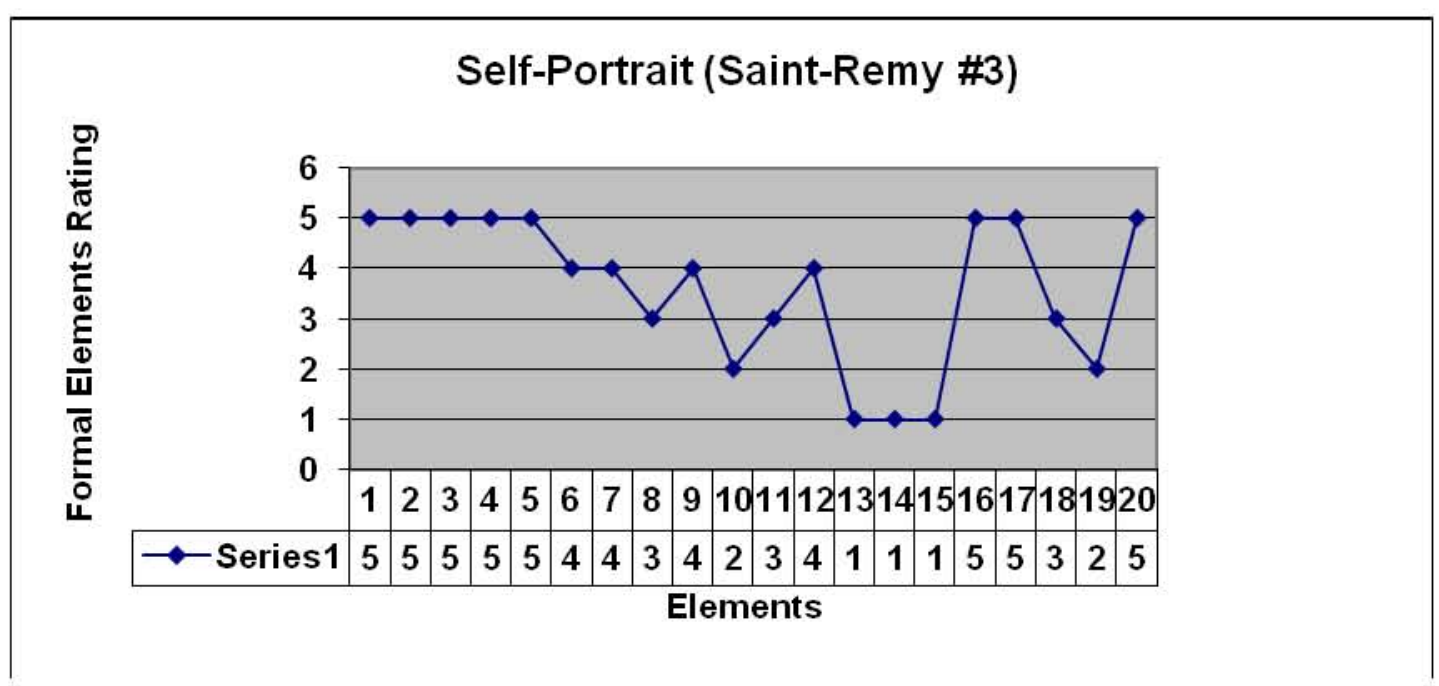




\section{Self-Portrait (Saint Remy \#4)}

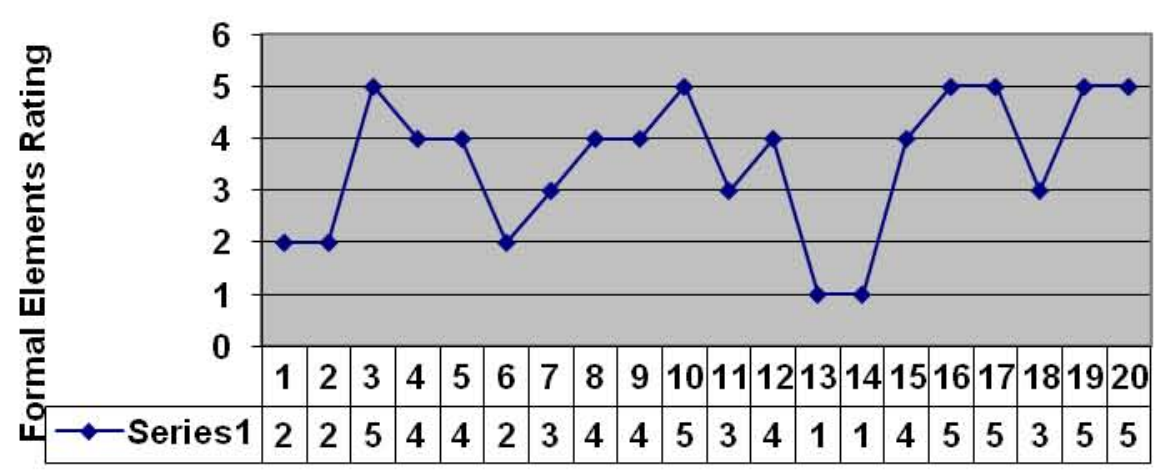

Elements

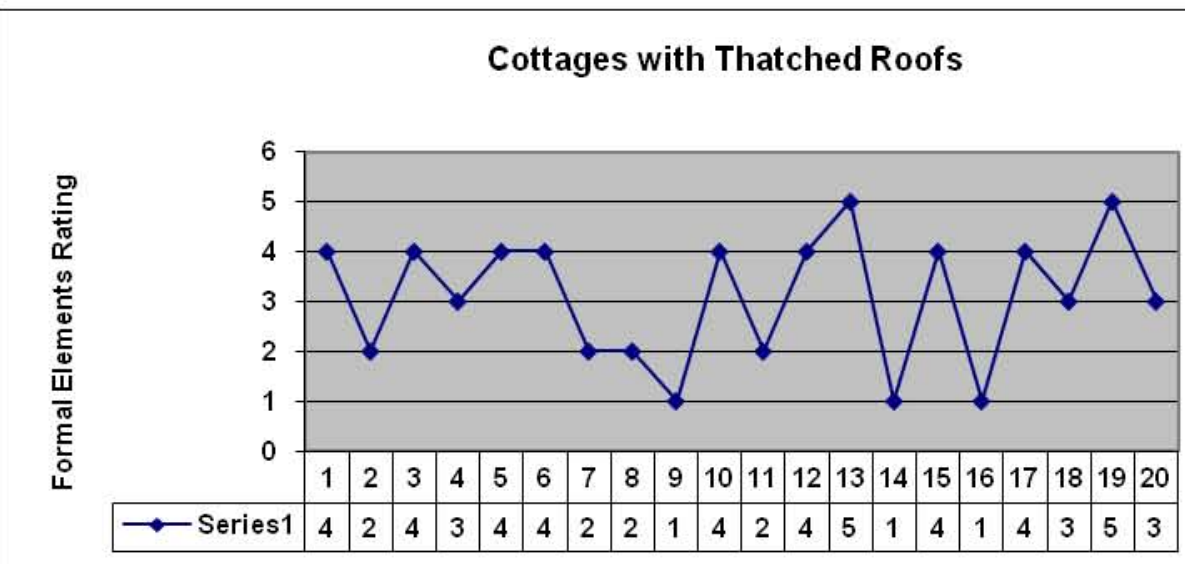

Elements

\section{Old Vineyard with Peasant Woman}

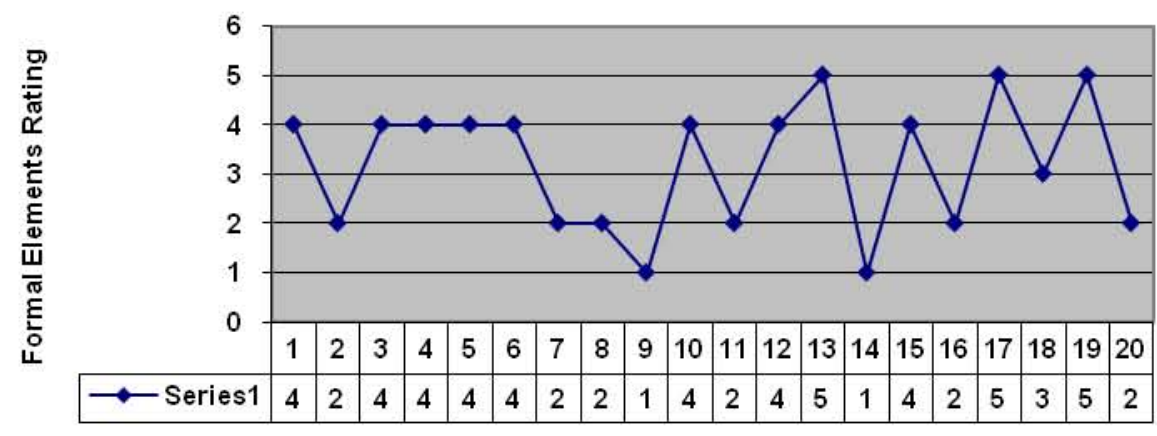

Elements 


\section{House of Pere Pilon}

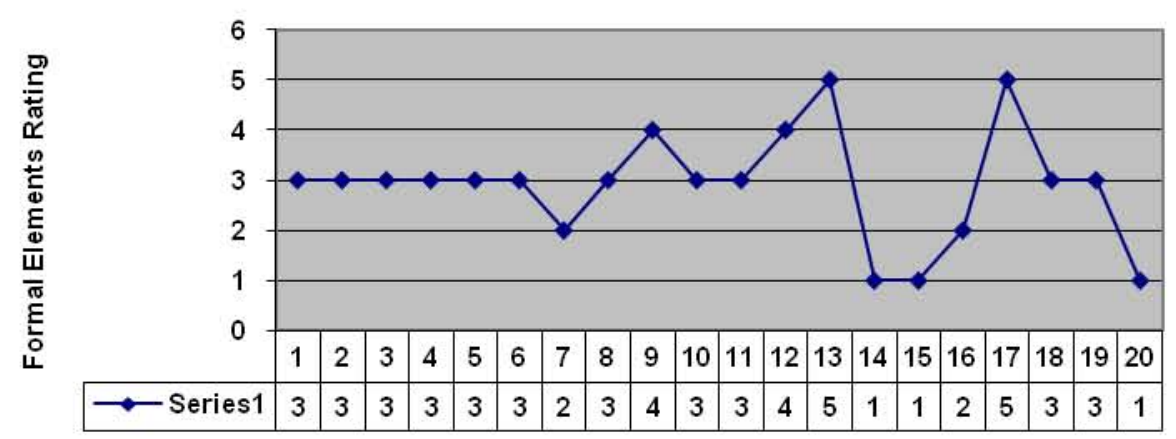

Elements

\section{Village Street and Stairs with Figures}

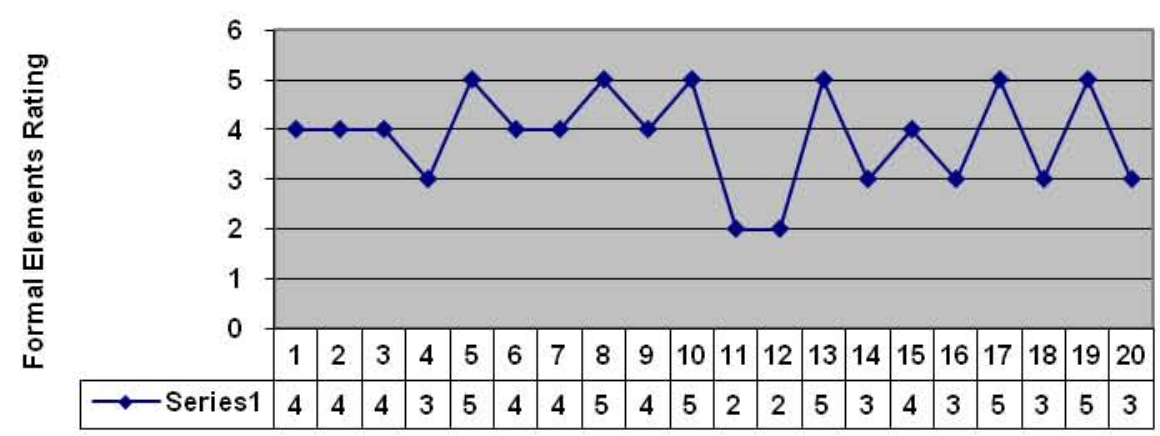

Elements

\section{The Church at Auvers}

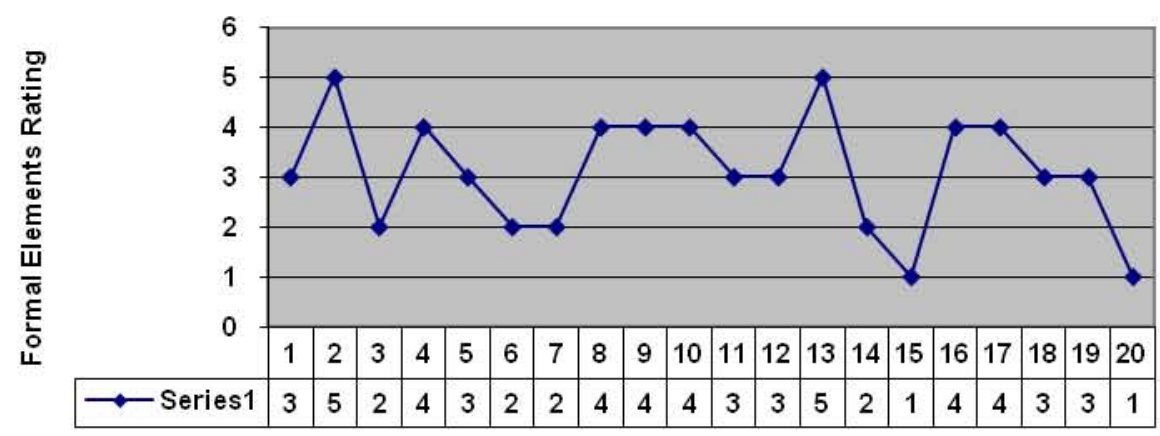

Elements 

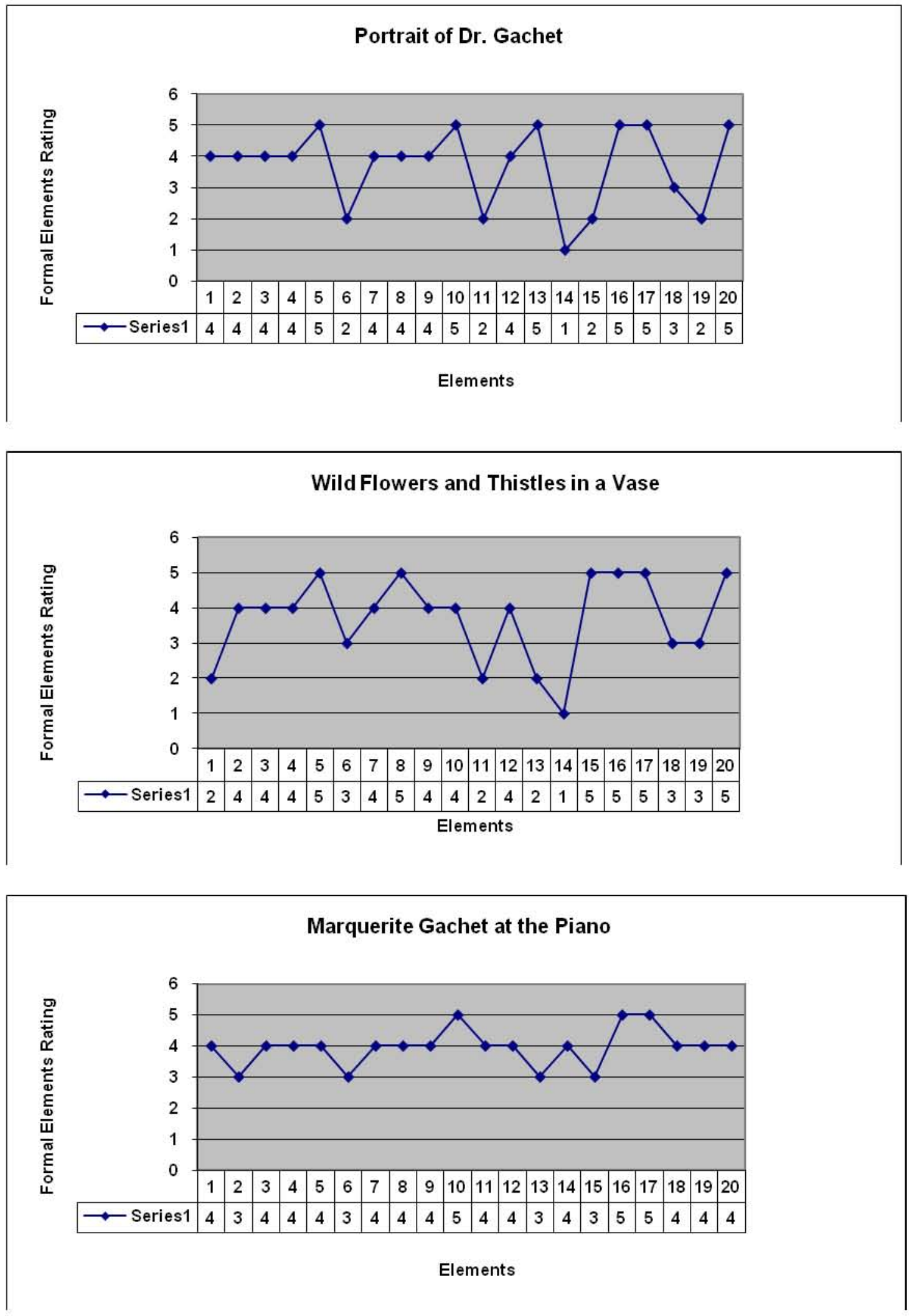


\section{Wheatfields}

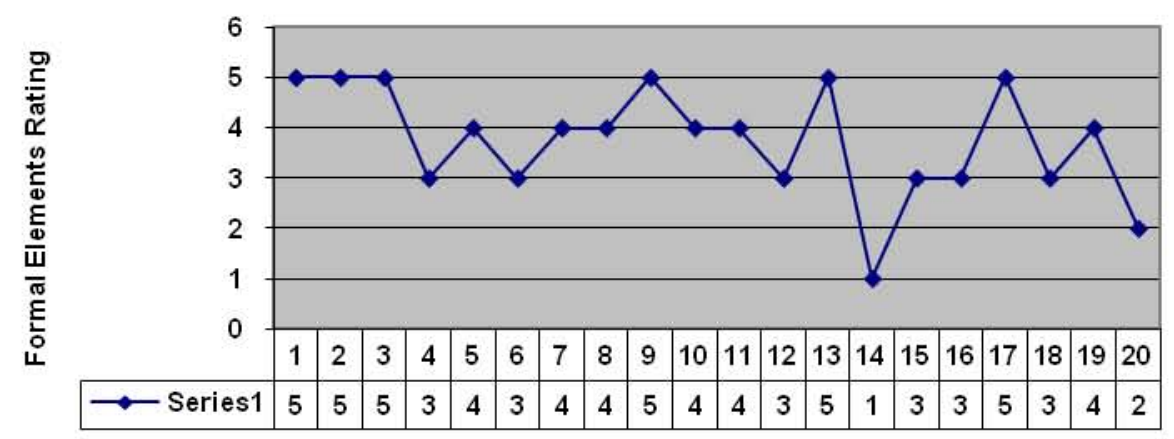

Elements

\section{Bank of the Oise at Auvers}

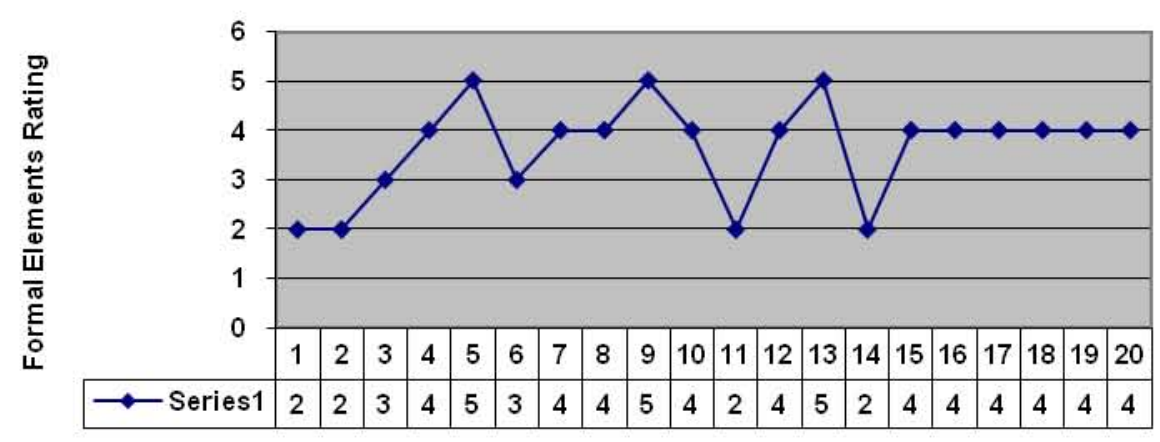

Elements

\section{Wheatfield under Clouded Sky}

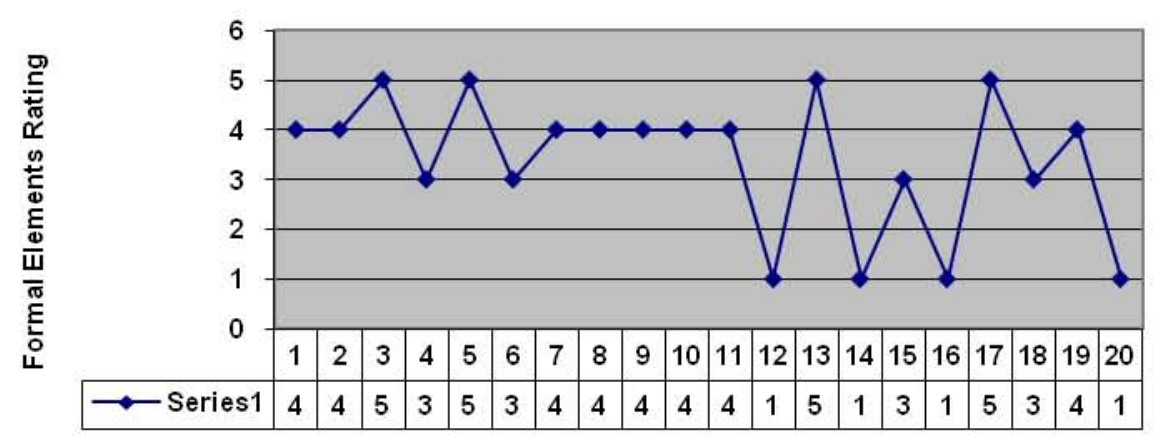

Elements 


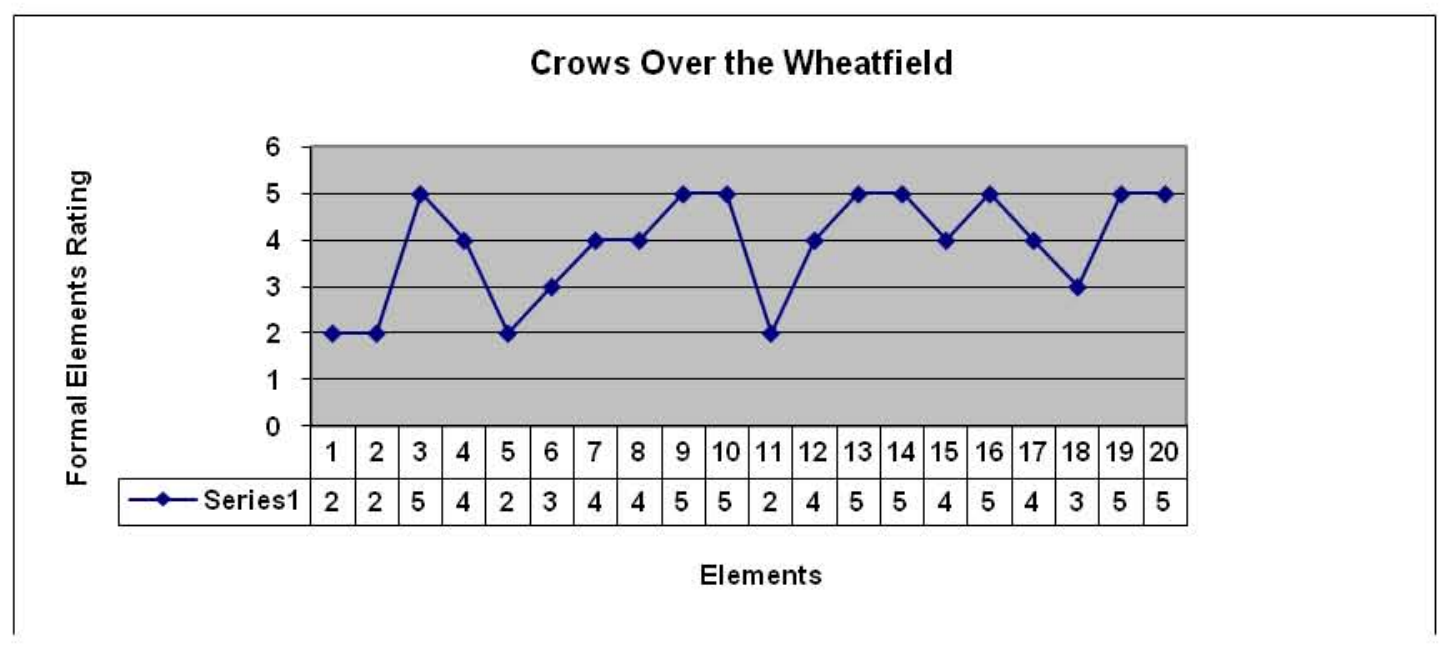


APPENDIX 6. Graphs for each Formal Element.

Appendix 6 has 20 graphs, one for each formal element that was included in this study. The sixty-four artworks that were used in this study are included in each formal element graph, and a spread over time is shown as the artworks are arranged by period:

1. Paris (March 1886 to Feb 1888) a time prior to the onset of the major pathology of Vincent van Gogh

2. Arles, the first period (Feb 1888 to mid-July 1888), from his arrival to the formulation of his plan for a studio of the South

3. Arles, the second period ( mid-July 1888 to Oct 20, 1888) waiting for Gauguin

4. Arles, the third period (Oct 20, 1888 to May 8, 1889) from companionship to confinement, a time of increasing mental instability

5. Saint-Rémy (May 8, 1889 to May 16, 1890) a time of confinement

6. Auvers, (May 16,1890 to July 29, 1890) a time of decline and death This series of graphs is intended to show change in formal elements in the artworks of Vincent van Gogh over time. 
APPENDIX 7. Comparison of Percent Scores (by period and element)

Appendix 7 has the formal elements scores for each time period as described in the introduction to Appendix 6. The formal elements scores for each time period have been converted to percentages. It is noted that the incidence of higher scores (4's and 5's) becomes more as time passes in the life of Vincent van Gogh. This indicates a greater amount of the formal elements and a movement toward less balance in the scores. It appears that as Vincent became more unstable mentally, that his artwork reflected variability toward more extreme expression of the visual elements. 
APPENDIX 8. Comparison of Raw Scores (by period and element)

Appendix 8 has a raw score for each artwork included in this pilot study. The raw score was determined by adding together the scores for each of the twenty formal elements as rated on the FERS. Possible scores range from 20 to 100. The lowest possible score for each element was 1 and the highest possible score for each element was 5. In actuality the scores ranged from 58 (lowest) to 82 (highest).

The raw scores were color coded by period in accordance with a recognized art therapy research study called MARI Creative Resources (2006). White was selected for the color coding for Paris (March 1886 to Feb 1888) and according to MARI research, (2006, 74) the colors gray, white and black bear the quality "I detach.” Paris is seen as a time of both detachment and attachment. While there is attachment to his brother Theo, there is an even greater detachment in preparing for his move to Arles, away from family and homeland.

All of the artworks from Arles are color coded with shades of yellow due to the familiar concept of the "high yellow note" that Vincent van Gogh achieved at Arles. For the first period at Arles, from his arrival to the formulation of his plan for a studio of the South, (Feb 1888 to mid-July 1888), the artworks are color-coded with a light yellow. The second period from Arles, (mid-July 1888 to Oct 20, 1888), while Vincent was waiting for Gauguin, is color coded with a clear bright medium intensity yellow. And ochre is used for the third period from Arles, (Oct 20, 1888 to May 8, 1889), a time of increasing mental instability when van Gogh went from companionship with his friend Gauguin to confinement due to mental health issues. According to MARI color 
symbolism $(2006,66)$ yellow presents the message, "I know" and yellow has the qualities of being active and out-going, developing autonomy and self-consciousness, appearance of ego, and cognition and thinking. Arles was a very active time for Vincent and it was the time period when he was likely the most active and out-going in his life, meeting new people, going new places, and carrying his art materials to plein-air painting sites. The MARI color symbolism for light yellow includes flexibility of thought and tolerance of new ideas and approaches. This could represent the new style of impressionism that Vincent was working out in his painting. According to the Mari resources, light yellow also includes the quality of no defenses and Vincent, in his new environs was likely open and not very defended in his emotional responses.

Bright yellow, used to color code artworks from the second period at Arles is active, relates to the good father figure, and to clarity and communication (MARI, 66). Vincent was very active during this timeframe and he sublimated his feelings about a father figure into Gauguin who became both a substitute for a father figure and for a female companion. The psychosexual elements in Vincent's mental makeup are convoluted at best and perhaps could be considered "completely twisted." Ochre was used to color code the artworks from the third period at Arles. The MARI research (2006, 66) states that ochre speaks of a confused or tarnished relationship, ambivalence with father, and negative aspects of patriarchy and judgmentalism. The relationship with Gauguin was certainly tarnished, if not destroyed, and Gauguin took on the aspect of the judgmental and abandoning father figure.

The artworks from Saint-Rémy (May 8, 1889 to May 16, 1890) were color coded green in accordance with the MARI (2006, 72 and 68). Green may be symbolic of growth, healing and regeneration, but some shades of green also have the connotation of 
sickness, and toxicity. Saint-Rémy was a time of confinement and the hoped for healing did not manifest itself. Vincent's life had become toxic.

Vincent's short time at Auvers , (May 16,1890 to July 29, 1890) was a time of decline and death and this author color coded the artworks blue. It is noteworthy to mention the increasing amount of dark blue that was used in the artworks of Vincent van Gogh from the time of Saint-Rémy onward through the time at Auvers. The MARI (2006, $64,65,71$ ) symbolism for dark blue deals with deep intuition, negative aspects of Mother, womb-tomb nature of Mother Earth, mystery, cold, and fear of engulfment and oblivion. The blue seems to show that Vincent had a dark intuition of a deep reality that his life might not be for much longer.

The results of the color symbolism analysis by period are striking. The reader is directed to the graph for appendix 8. It is readily apparent that the artworks from SaintRémy clearly cluster in the third $1 / 4^{\text {th }}$ of the scores and the scores from Auvers occupy much of the fourth quadrant in this spread of scores. 
APPENDIX 7. Comparison of Percent Scores (by period and element)

Appendix 7 has the formal elements scores for each time period as described in the introduction to Appendix 6. The formal elements scores for each time period have been converted to percentages. It is noted that the incidence of higher scores (4's and 5's) becomes more as time passes in the life of Vincent van Gogh. This indicates a greater amount of the formal elements and a movement toward less balance in the scores. It appears that as Vincent became more unstable mentally, that his artwork reflected variability toward more extreme expression of the visual elements. 

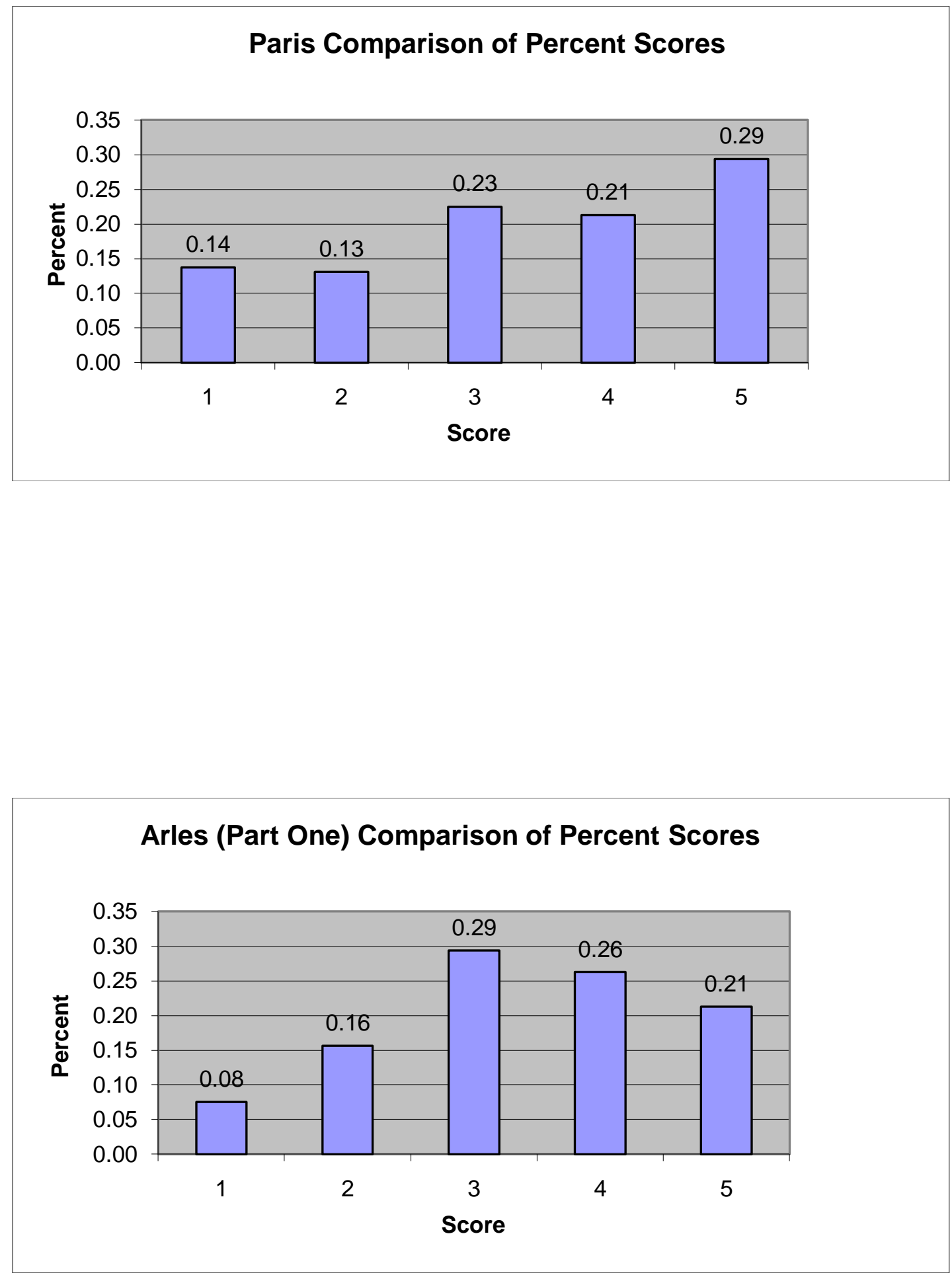

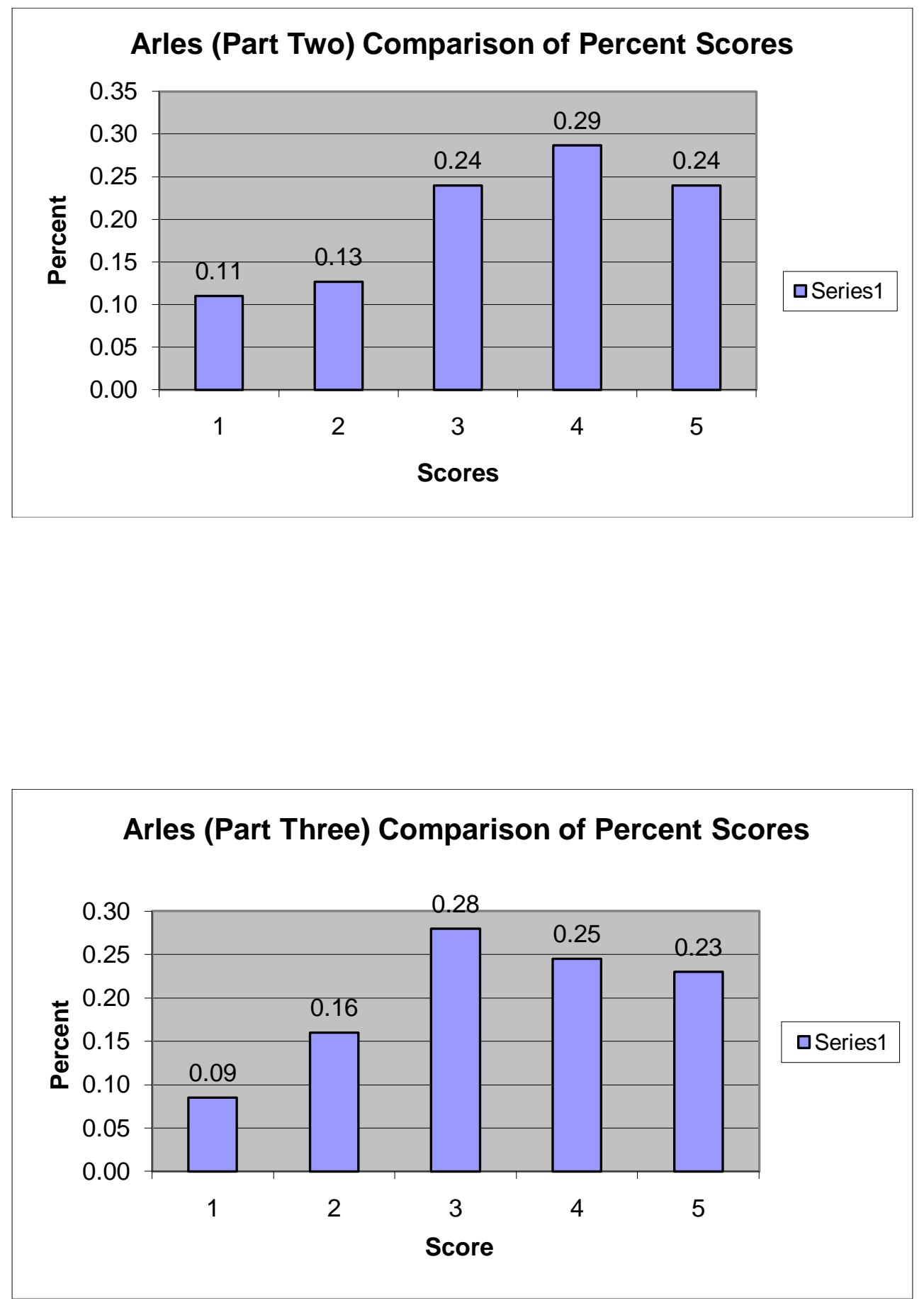

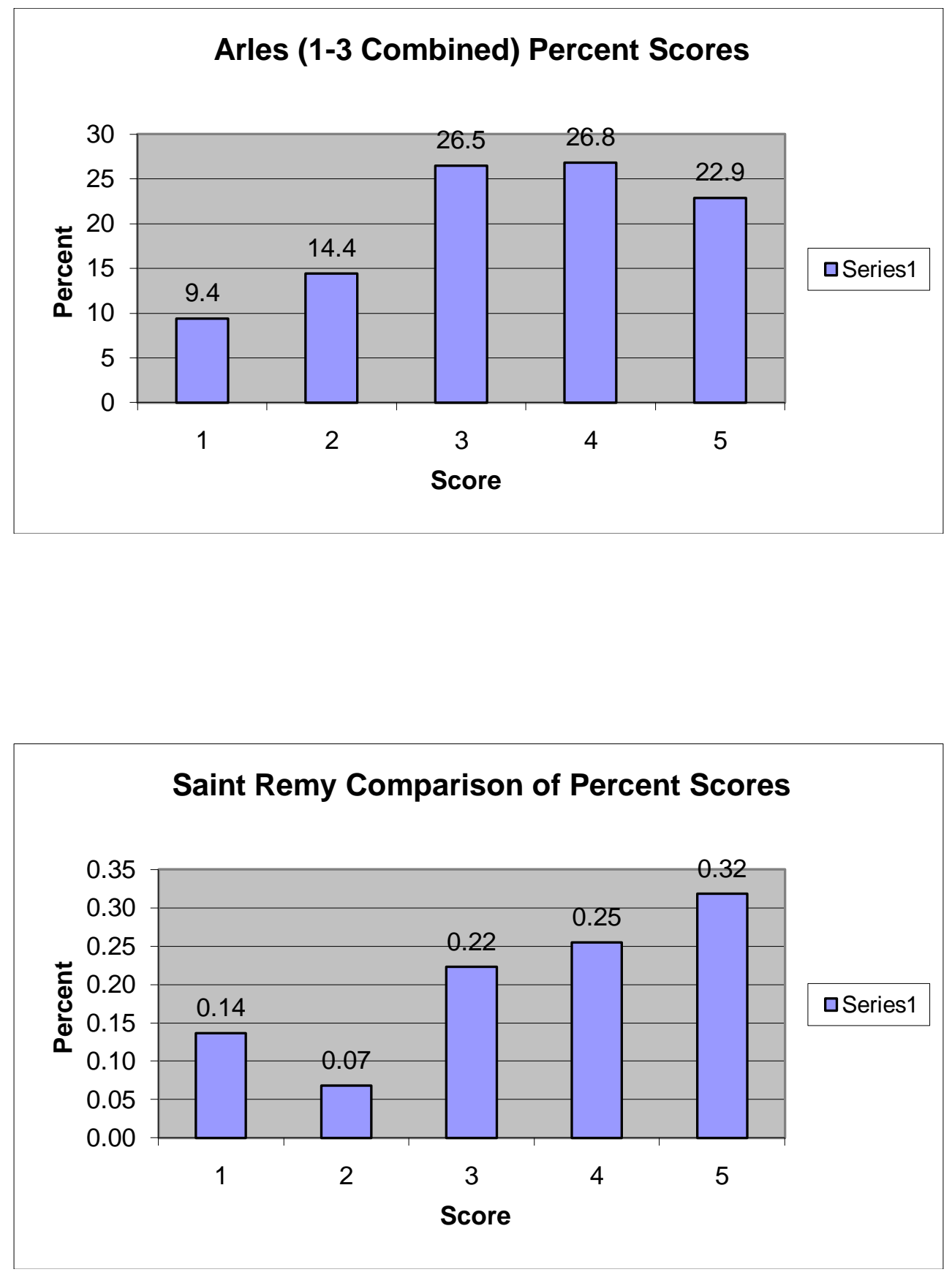


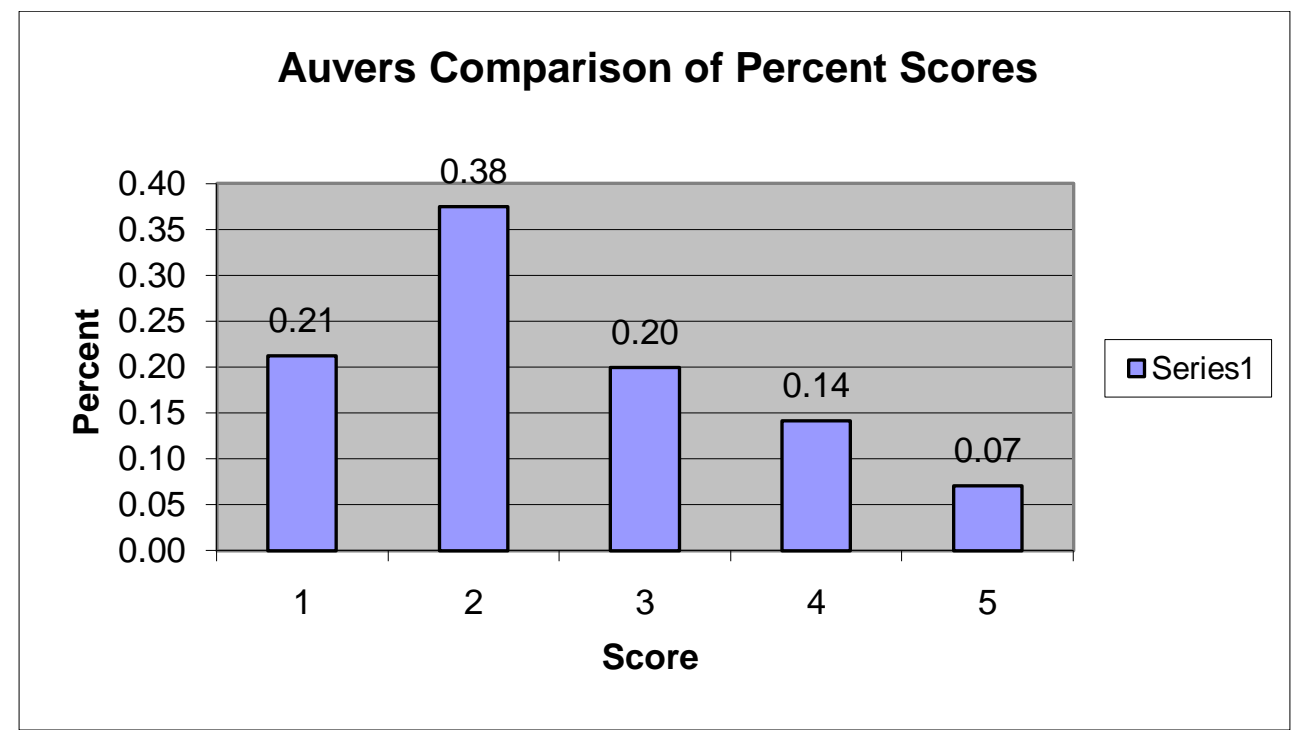


APPENDIX 8. Comparison of Raw Scores (by period and element)

Appendix 8 has a raw score for each artwork included in this pilot study. The raw score was determined by adding together the scores for each of the twenty formal elements as rated on the FERS. Possible scores range from 20 to 100. The lowest possible score for each element was 1 and the highest possible score for each element was 5. In actuality the scores ranged from 58 (lowest) to 82 (highest).

The raw scores were color coded by period in accordance with a recognized art therapy research study called MARI Creative Resources (2006). White was selected for the color coding for Paris (March 1886 to Feb 1888) and according to MARI research, (2006, 74) the colors gray, white and black bear the quality "I detach.” Paris is seen as a time of both detachment and attachment. While there is attachment to his brother Theo, there is an even greater detachment in preparing for his move to Arles, away from family and homeland.

All of the artworks from Arles are color coded with shades of yellow due to the familiar concept of the "high yellow note” that Vincent van Gogh achieved at Arles. For the first period at Arles, from his arrival to the formulation of his plan for a studio of the South, (Feb 1888 to mid-July 1888), the artworks are color-coded with a light yellow. The second period from Arles, (mid-July 1888 to Oct 20, 1888), while Vincent was waiting for Gauguin, is color coded with a clear bright medium intensity yellow. And 
ochre is used for the third period from Arles, (Oct 20, 1888 to May 8, 1889), a time of increasing mental instability when van Gogh went from companionship with his friend Gauguin to confinement due to mental health issues. According to MARI color symbolism $(2006,66)$ yellow presents the message, "I know” and yellow has the qualities of being active and out-going, developing autonomy and self-consciousness, appearance of ego, and cognition and thinking. Arles was a very active time for Vincent and it was the time period when he was likely the most active and out-going in his life, meeting new people, going new places, and carrying his art materials to plein-air painting sites. The MARI color symbolism for light yellow includes flexibility of thought and tolerance of new ideas and approaches. This could represent the new style of impressionism that Vincent was working out in his painting. According to the Mari resources, light yellow also includes the quality of no defenses and Vincent, in his new environs was likely open and not very defended in his emotional responses.

Bright yellow, used to color code artworks from the second period at Arles is active, relates to the good father figure, and to clarity and communication (MARI, 66). Vincent was very active during this timeframe and he sublimated his feelings about a father figure into Gauguin who became both a substitute for a father figure and for a female companion. The psychosexual elements in Vincent's mental makeup are convoluted at best and perhaps could be considered "completely twisted.” Ochre was used to color code the artworks from the third period at Arles. The MARI research (2006, 66) states that ochre speaks of a confused or tarnished relationship, ambivalence with father, and negative aspects of patriarchy and judgmentalism. The relationship with 
Gauguin was certainly tarnished, if not destroyed, and Gauguin took on the aspect of the judgmental and abandoning father figure.

The artworks from Saint-Rémy (May 8, 1889 to May 16, 1890) were color coded green in accordance with the MARI (2006, 72 and 68). Green may be symbolic of growth, healing and regeneration, but some shades of green also have the connotation of sickness, and toxicity. Saint-Rémy was a time of confinement and the hoped for healing did not manifest itself. Vincent's life had become toxic.

Vincent's short time at Auvers , (May 16,1890 to July 29, 1890) was a time of decline and death and this author color coded the artworks blue. It is noteworthy to mention the increasing amount of dark blue that was used in the artworks of Vincent van Gogh from the time of Saint-Rémy onward through the time at Auvers. The MARI (2006, 64, 65, 71) symbolism for dark blue deals with deep intuition, negative aspects of Mother, womb-tomb nature of Mother Earth, mystery, cold, and fear of engulfment and oblivion. The blue seems to show that Vincent had a dark intuition of a deep reality that his life might not be for much longer.

The results of the color symbolism analysis by period are striking. The reader is directed to the graph for appendix 8. It is readily apparent that the artworks from SaintRémy clearly cluster in the third $1 / 4^{\text {th }}$ of the scores and the scores from Auvers occupy much of the fourth quadrant in this spread of scores. 
This is a summary of the artworks by period in the same order as the sort by

totals.

Quadrant 1:

1. \#55 The House of Père Pilon

58

2. \# 4 Self-Portrait, Paris, 1886

3. \#25 Starry Night on the Rhone

4. \#35 Les Alyscamps

5. \#15 Fishing Boats on the Beach at Saintes-Maries

6. \#53 Cottages with Thatched Roofs

7. \#57 The Church at Auvers

8. \# 9 Snowy Landscape with Arles in the Background

9. \#18 Portrait of Joseph Roulin

10. \#37 Van Gogh's Chair

11. \#16 Portrait of a Zouave

12. \# 17 La Mousmé

13. \# 31 Van Gogh's Bedroom

14. \# 54 Old Vineyard with Peasant Woman

15. \# 38 Gauguin's Chair

16. \# 43 Irises (Amsterdam Still-Life)

Quadrant 2:

17. \#44 Irises (Metropolitan Still-Life)

18. \# 5 Self-Portrait, Paris, 1887

19. \# 7 Self-Portrait with Grey Felt Hat, Paris, 1887

20. \# 28 Self-Portrait (as a Bonze)

21. \#30 The Tarasçon Diligence

22. \#33 The Sower (November 1888)

23. \# 34 The Sower (October 1888)

24. \# 3 Portrait of Pere Tanguy

25. \#12 The Langlois Bridge

26. \#14 Still-Life with Blue Enamel Coffeepot

27. \# 20 Portrait of Patience Escalier

28. \# 23 The Night Café

29. \# 32 The Sower October 1888

30. \# 2 Lemons, Pears, Apples, Grapes and an Orange

31. \#6 Self-Portrait, Paris, 1887 (pale tones)

32. \#24 Portrait of Milliet
Auvers Raw Score

Paris $\quad$ Raw Score 60

Arles, 2 Raw Score 61

Arles, $3 \quad$ Raw Score 61

Arles, 1 Raw Score 62

Auvers Raw Score 62

Auvers Raw Score 62

Arles, $1 \quad$ Raw Score 63

Arles, 2 Raw Score 63

Arles, 3 Raw Score 63

Arles, 1 Raw Score 64

Arles, 2 Raw Score 64

Arles, 2 Raw Score 64

Auvers Raw Score 64

Arles, 3 Raw Score 65

Saint-Rémy Raw Score 65

Saint-Rémy Raw Score 65

Paris Raw Score 66

Paris Raw Score 66

Arles, 2 Raw Score 66

Arles, 2 Raw Score 66

Arles, 3 Raw Score 66

Arles, 3 Raw Score 66

Paris Raw Score 67

Arles, $1 \quad$ Raw Score 67

Arles , $1 \quad$ Raw Score 67

Arles, 2 Raw Score 67

Arles, 2 Raw Score 67

Arles, 3 Raw Score 67

Paris $\quad$ Raw Score 68

Paris Raw Score 68

Arles, 2 Raw Score 68 
Quadrant 3:

33. \# 29 Self-Portrait with Straw Hat and Pipe

34. \# 40 Portrait of Dr. Félix Rey

35. \# 63 Wheatfield Under Clouded Sky

36. \# 13 View of Arles with Irises

37. \# 22 Still-Life: Vase with Sunflowers

38. \# 27 The Yellow House

39. \# 39 Self-Portrait with Bandaged Ear and Pipe

40. \# 45 Pink Roses in a Vase

41. \# 49 Self-Portrait (Saint-Rémy \# 1)

42. \# 8 Self-Portrait with Straw Hat, Paris, 1888

43. \# 11 Pink Peach Trees (Souvenir of Mauve)

44. \# 41 La Berceuse

45. \# 46 The Prisoner's Round

46. \# 52 Self-Portrait (Saint-Rémy \# 4)

47. \# 48 The Starry Night

48. \# 51 Self-Portrait (Saint-Rémy \# 3)

Arles 2

Arles 3

Auvers

Arles, 1

Arles, 2

Arles, 2

Arles, 3

Saint-Rémy

Saint-Rémy

Paris

Arles, 1

Arles, 3

Saint-Rémy

Saint-Rémy

Saint-Rémy

Saint-Rémy
Raw Score 68

Raw Score 68

Raw Score 68

Raw Score 69

Raw Score 70

Raw Score 70

Raw Score 70

Raw Score 70

Raw Score 70

Raw Score 71

Raw Score 71

Raw Score 71

Raw Score 71

Raw Score 71

Raw Score 72

Raw Score 72

Arles, 2

Auvers

Saint-Rémy

Auvers

Auvers

Arles, 2

Saint-Rémy

Auvers

Saint-Rémy

Paris

Auvers

Arles, 1

Arles, 3

Auvers

Auvers

Arles, 2
Raw Score 73

Raw Score 73

Raw Score 74

Raw Score 74

Raw Score 74

Raw Score 75

Raw Score 75

Raw Score 75

Raw Score 76

Raw Score 77

Raw Score 77

Raw Score 78

Raw Score 78

Raw Score 78

Raw Score 79

Raw Score 82 
VITA

Sue Ann Grey was born in Salisbury, Maryland on March 28, 1943. She attended elementary school and junior high in Snow Hill, Maryland, and graduated from Snow Hill High School with honors in June 1961. With a full academic scholarship, the following September she entered the University of Maryland and in June 1965 received a Bachelor of Science in Home Economics Education. She re-entered the University of Maryland in 1968 and received a Master of Science in 1972 in Textiles and Apparel with specialization in Historical Technologies. While at University of Maryland she was elected to the honor societies of Omicron Nu and Phi Kappa Phi. In 1976, she completed a Certificate of Advanced Studies at Johns Hopkins University in Liberal Studies with focus in art history. After teaching in junior high, high school and college, in 1989 Ms. Grey returned to school to study art therapy at the University of Louisville, and completed a Master of Arts in Expressive Therapy in 1993. At the University of Louisville she was inducted into the Golden Key Honor Society.

Ms. Grey is in private practice as a Psychotherapist specializing in Art Therapy. Ms. Grey has been elected to membership in Cambridge Who’s Who, and National Register's Who's Who among Executives and Professionals. 